National Institute of Standards and Technology

NIST Special Publication 806, 1996 Edition

\title{
Standards Activities of Organizations in the United States
}


he National Institute of Standards and Technology was established in 1988 by Congress
to "assist industry in the development of technology . . . needed to improve product quality, to modernize manufacturing processes, to ensure product reliability . . . and to facilitate rapid commercialization ... of products based on new scientific discoveries."

NIST, originally founded as the National Bureau of Standards in 1901, works to strengthen U.S. industry's competitiveness; advance science and engineering; and improve public health, safety, and the environment. One of the agency's basic functions is to develop, maintain, and retain custody of the national standards of measurement, and provide the means and methods for comparing standards used in science, engineering, manufacturing, commerce, industry, and education with the standards adopted or recognized by the Federal Government.

As an agency of the U.S. Commerce Department's Technology Administration, NIST conducts basic and applied research in the physical sciences and engineering, and develops measurement techniques, test methods, standards, and related services. The Institute does generic and precompetitive work on new and advanced technologies. NIST's research facilities are located at Gaithersburg, MD 20899, and at Boulder, CO 80303. For more information contact the Public Inquiries Desk, 301-975-3058. 


\section{NIST Special Publication 806, 1996 Edition}

\section{Standards Activities of Organizations in the United States}

Robert B. Toth, Editor

Office of Standards Services

National Institute of Standards and Technology

Gaithersburg, MD 20899-0001

(Supersedes NIST Spec. Publ. 806)

September 1996

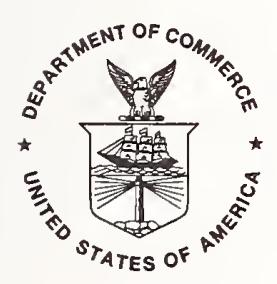

U.S. Department of Commerce Michael Kantor, Secretary

Technology Administration

Mary L. Good, Under Secretary for Technology

National Institute of Standards and Technology Arati Prabhakar, Director 
National Institute of Standards and Technology

Special Publication 806, 1996 Edition (Supersedes NIST Spec. Publ. 806)

Natl. Inst. Stand. Technol.

Spec. Publ. 806, 1996 Ed.

775 pages (Sep. 1996)

CODEN: NSPUE2
U.S. Government Printing Office

Washington: 1996
For sale by the Superintendent of Documents

U.S. Government Printing Office

Washington, DC 20402 
The U.S. National Institute of Standards and Technology (NIST) assists the private sector and other agencies of government through research and development of better methods of measurement, determination of physical constants and properties of materials, and design of practical test procedures. We consider standards essential media for disseminating the results of the Institute's research, hence the working of the national standardization system is of vital concern to NIST. The Institute's Technology Services and its office of Standards Services coordinate within the Federal Government and with the private sector in policy, procedural, and informational matters concerning standards and activities related to their application.

This directory is one of NIST's most popular publications. It is widely distributed in the United States and abroad. It identifies and describes U.S. public and private sector organizations that develop, publish, and revise standards, participate in those processes, identify standards, or make standards available through information centers or distribution channels. These organizations are the foundation for the U.S. standardization system, which has grown steadily since the first volume in this series was issued in 1941. Most of the standards developed by the organizations listed in this directory are included in NIST's National Center for Standards and Certification Information, and are available for reference at the Center's facility. For further information on the Center, see page 718 of this directory.

We believe that this directory will be a useful reference for all who need and use U.S. standards. 
Every entry in this directory was carefully prepared by representatives of the participating organizations. Obviously, this directory could not have been issued without the contributions and cooperation of hundreds of staff persons in the trade associations, professional societies, government agencies, and other organizations that constitute the "standardization community." They deserve the thanks of those who worked on this project and all who use the directory.

Maureen Breitenberg ably coordinated and monitored this project for NIST's Office of standards Services. Special thanks are due the staff of R. B. Toth Associates, who compiled this directory under contract to NIST. In particular, Mary Ellen Hinkley managed all aspects of information gathering and processing.

Robert B. Toth Editor 


\section{ABSTRACT}

This directory is a guide to mandatory and voluntary standards activities in the United States at the Federal level and by nongovernmental (trade associations, technical and other professional societies)organizations. It excludes proprietary (company) standards and those of state and local levels of government. Superseding the 1991 edition (NBS SP 806, "Standards Activities of Organizations in the United States"), it includes standards distributors, libraries, and information centers. It also lists organizations that no longer develop standards or have become defunct since the previous directory was issued.

More than 700 current descriptive commentaries are formatted, with subject headings to facilitate access to specific information. The main sections cover developers of formal and informal nongovernment standards; Federal agencies which develop standards; sources of standards documents and information; a subject index and related listings covering acronyms and initials, defunct bodies, and those organizations with name changes. Organizations have been included if they develop standards or contribute to the standardization process, whether voluntary or mandatory, or are sources of standards documents or information. An introductory section provides general information on Federal (including military) standards activities, a list of 20 major nongovernment standards developers, and an overview of U.S. (national) standardization activities.

Keywords :

codes; government standardization activities; nongovernment standardization activities; overview of U.S. standardization activities; recommended practices; sources of standards; specifications; standardization; formal standards; informal standards; test methods 

Foreword

Acknowledgments

Abstract

1. Introduction

1.I Scope and Criteria . . . . . . . . . . . . . . . . . . 1

1.2 An Overview . . . . . . . . . . . . . . . . . 2

1.3 Applications of standards . . . . . . . . . . . . . . 5

1.4 Changes Since 1991 . . . . . . . . . . . . . . . . 7

1.5 Compilation of Information . . . . . . . . . . . . . . 8

1.6 Future Updates . . . . . . . . . . . . . . . . . . . 9

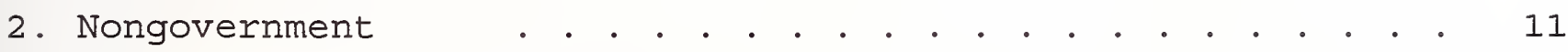

2.1 Developers of Formal and Informal Standards . . . . . . 11

2.2 Other Organizations Developing Informal Standards . . . 573

3. Federal Government . . . . . . . . . . . . . . . . . . 581

3.1 Federal Voluntary Standards Policy

(OMB Circular A-119) . . . . . . . . . . . . . . . 581

3.2 Role of Interagency Committee on Standards Policy . . 582

3.3 Federal Government Organizations . . . . . . . . . . . . 582

4. Sources of Standards and

Information About Standards . . . . . . . . . . . 701

5. Subject Index and Related Listings . . . . . . . . . . . . 723

5.1 Subject Index (Organizations by Major Subjects) • • . 723

5.2 Acronyms and Initials . . . . . . . . . . . . . . 759

5.3 Former Names of Listed Organizations . . . . . . . . . . 773

5.4 Organizations No Longer Involved in Standardization • . 777 

Standardization activities in the United states are broad, complex, and decentralized. This directory is intended to provide perspective and to serve as a source of information about the U.S. standardization system; the inputs are based on material provided by the principals.

This directory is the seventh in a series started in 1941. The first edition, NBS Miscellaneous Publication (MP) 169, "Standardization Activities of National Technical and Trade Organizations," was edited by Robert A. Martino and covered 450 organizations. The second edition, NBS MP 230, was edited by sherman Booth and issued in 1960. The third edition, "Directory of United States Standardization Activities, NBS MP 288, was edited by Joan Hartman and issued in 1967, and the 1975 edition, NBS Special Publication 417, was edited by Sophie Chumas. This publication supersedes the 1984 and 1991 editions (SP 681 and SP 806 respectively), both of which were compiled and edited by Robert Toth.

\subsection{SCOPE AND CRITERIA}

This edition summarizes standardization activities of more than 700 organizations which, in the aggregate, comprise the U.S. standardization system. In the broadest sense, "standards" include specifications, codes, guidelines, recommended practices, grading rules, and similar documents. This directory also refers to regulatory standards developed by government agencies, but not to laws or regulations per se. However, many federal, state, and local regulations and codes are based on the voluntary standards of organizations listed in this directory.

The directory includes organizations that develop standards and also those that work with others to develop and use standards or that regularly comment on draft standards. Activities that develop only ethical/ professional standards, or that set standards for judging animals, are not included.

This profile of U.S. standardization activities is necessarily a snapshot of a moving target. Although extensive efforts were made to be comprehensive, some organizations that conduct standardization activities may not be represented. New standards developing organizations spring up, and there are standards known only to specialists in a narrow field. The information summarized here has been derived from numerous sources. However, it may not be all-encompassing and inclusive.

In response to increasing interest and application of standards throughout the world, the directory also lists some major sources of U.S. standards outside the United States and major U.S. sources of foreign and international standards. Self-designated regional and international organizations are covered separately in a companion NIST Special Publication 767, "Directory of International and Regional Organizations Conducting Standards-Related Activities," which has 338 entries, and NIST 
SP 795, "Directory of European Regional Standards-Related Organizations," which has 154 entries.

\subsection{AN OVERVIEW}

The U.S. standardization community includes: (1) government and nongovernment standards developing organizations; (2) affected interests that participate in the development and approval of standards; and (3) organizations which disseminate standards and information about standards. At the national level, the United States currently maintains about 93000 standards in an active status. Figure 1 shows the various categories of standards developers and their output.

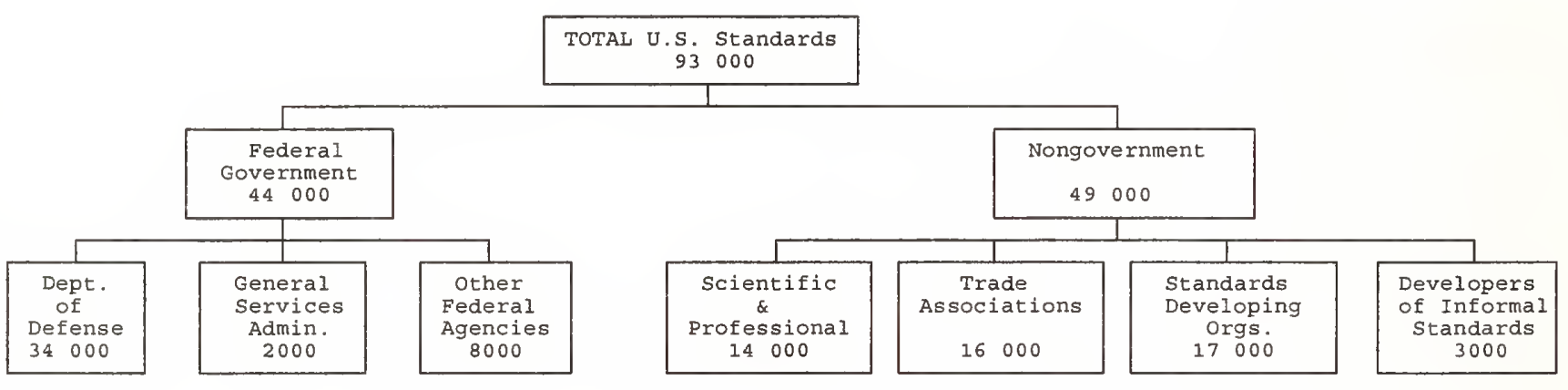

Figure 1. The estimated number of U.S. standards and their developers in 1996. *In addition, the Federal Government has adopted 9500 nongovernmental standards.

In the past 5-year period, the total number of U.S. standards has not increased; and, for the first time, the private sector maintains more national standards than the government. Federal agencies are canceling more standards than they develop, and are also adopting nongovernment standards instead of preparing their own. The total number of Federal Government standards has decreased by 8000 in the past 5 years, and the number of adopted nongovernment standards has increased by 4600 . Nongovernment standards developing organizations are adding to the overall 
body of standards at a net rate averaging 3.4 percent per year. Very few voluntary standards are being canceled or inactivated.

20 MAJOR NONGOVERNMENT STANDARDS DEVELOPERS

Aerospace Industries Association

3000

American Association of Blood Banks

500

Am. Assoc. of State Highway and Trans. Officials

1100

Am. Conference of Govt. Industrial Hygienists

750

American National standards Institute

$1500 *$

American Oil Chemists Society

410

American Petroleum Institute

500

American Railway Engineers Association

400

American Society for Testing and Materials

9900

American Society of Mechanical Engineers

Association of American Railroads

1400

AOAC International

2100

Cosmetic, Toiletry \& Fragrance Association

Electronic Industries Association

1300

Institute of Electrical \& Electronics Engineers

Natl. Association of Photographic Manufacturers

Semiconductor Equipt. and Materials Intl.

Society of Automotive Engineers International

Underwriters Laboratories

U.S. Pharmacopeial Convention

* These standards were developed by organizations other than ANSI and then published and copyrighted by ANSI as American National standards.

Table 1 
Significantly, this increased output can be attributed primarily to midsized standards developers. In 1996 the standards of the 19 major nongovernment standards developers (excluding ANSI), shown in Table 1 , constitute 71 percent of the nongovernment standards database. In 1984, their standards constituted 81 percent of the total.

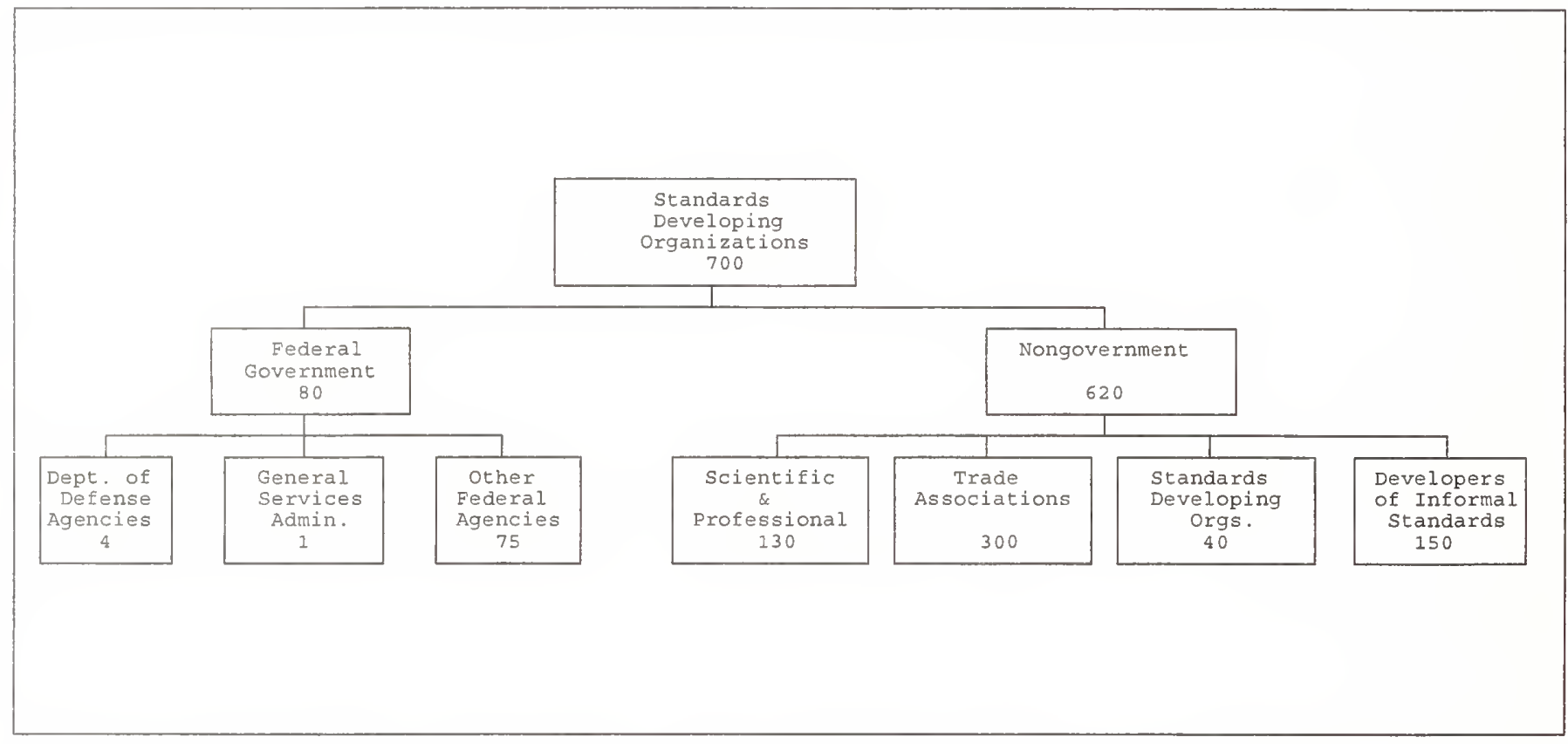

Figure 2. Number of U.S. standards developing organizations. *Approximately 130 of the 620 nongovernmental organizations have prepared a few standards in the past and occasionally update them, but are not actively engaged in ongoing standards development.

The number of Federal agencies developing standards has remained relatively constant. The number of private sector standards developing organizations with active, ongoing standards development programs has increased by about 50 organizations developing formal standards, and a whole new category of standards developers has emerged. These private sector organizations, for the most part, work outside the traditional standards development

framework. Figure 2 depicts the types of nongovernmental organizations that develop national standards. These can be categorized into four groups, the first three of which prepare formal standards.

1. Scientific and Professional Societies. Some of the more than 2000 societies in this group, in addition to their professional and educational roles, also develop standards. Examples are the American Society of Mechanical Engineers, American Association of Cereal Chemists, and the Acoustical Society of America.

2. Trade Associations. These associations deal with mutual business problems in a particular industry, and promote the industry and its products. To address their objectives, many trade associations 
develop standards for the products manufactured by their members, although a few concentrate on developing standards for products used by their industries. The Aerospace Industries Association and the American Petroleum Institute are two trade associations that develop standards for items used by their member companies.

3. Standards Developing Organizations. Organizations founded specifically to develop standards are often designated "standards developing organizations" (SDOs). Some confusion occurs when the four types of organizations are collectively called SDOs. The oldest SDO in the United States is the U.S. Pharmacopeial Convention. It published standards for 219 drugs in 1820. The American Society for Testing and Materials can be classified as an SDO, as can many of the organizations that serve as secretariats for ANSI accredited committees (e.g., the Alliance for Telecommunications solutions).

4. Developers of Informal Standards. This category, listed in section 2.2 on page 573, could be considered a subset of the group of SDOs founded specifically to develop standards, but these sDos operate outside the traditional standards development framework. They develop or promote standards which are described as ad hoc, de facto, or consortia standards. Within Europe, and for some regional and international SDOs, the informal standards of these organizations are designated Publicly Available Specifications (PAS) if their developers made them available for public comment. The X/Open consortium has been designated as a Recognized Submitter of PASs by ISO/IEC Joint Technical Committee 1 which enables the committee to adopt or "transpose" X/Open standards. Examples of developers of informal standards with entries in this edition are the ATM Forum, Bellcore, the Process Industry Practices Initiative (PIP), United States Council for Automotive Research (USCAR), and the Internet Engineering Task Force. Additional information and a list of more than 80 developers of informal standards is included in section 2.2 of this directory. It is estimated that there may be as many as 150 such organizations in the United States and 50 to 70 others in the rest of the world.

\subsection{APPLICATIONS OF STANDARDS}

The number of published standards is not necessarily an absolute indicator of overall activity level or significance. Although counted as a single standard, the 12000 page Boiler Code of the American Society of Mechanical Engineers, and any of the model building codes are not comparable to 95 percent of the standards published in the United states.

The number of available standards may not be indicative of their value to industry and commerce. Real value is realized only when standards are used. Methods have yet to be developed to measure how often, or how widely, individual standards are implemented. Standards developers report that 80 percent of their orders for individual standards are for 15 or 20 percent of the total number of published standards. Many standards are seldom used. We also know that, in spite of 5 -year reviews, a substantial 
portion of our standards refer to and document obsolescent technology that, while appropriate for spares and maintenance of older equipment, is no longer appropriate for new designs. Some believe that 25 to 30 percent of our national standards - both government and industry - fall into this category. Finally, some U.S. standards are redundant or overlapping. In a few areas, particularly building and construction, we often find five or six standards that, while not identical, define the functional requirements for the same type of product or material. More than 11000 standards ( $12 \%$ ) are applicable to building and construction. More than half of the nongovernment developers of formal standards prepare standards used in building and construction. Two hundred of the 300 trade associations which prepare standards do so exclusively for building products.

The increasing role of organizations that develop standards outside the traditional framework is not the only trend that has affected the overall number of standards and their application. Harmonization of standards used in Canada and the United states is resulting in consolidation and simplification. The outcome of these efforts is one or two standards replacing an earlier three or four Canadian and half a dozen U.S. standards. The national adoption of international standards is increasing. Ten years ago fewer than ten national adoptions (indicated by the designation ANSI/ISO) were listed in the ANSI Catalog. Today the number of adopted ISO and IEC standards is approaching 150. Many of these are based on U.S. standards which can be canceled. Others preclude the need to develop U.S. standards. National adoptions, however, are not a true indication of the extent that U.S. manufacturers and service providers are implementing international standards. Unlike many other countries, U.S. standards developers and users, particularly in high-technology industries and global markets, do not wait for the ANSI imprimatur before citing an international standard. It is estimated that more than half of ISO's and IEC's standards are implemented directly by U.S. standards developers and users.

As Figure 1 indicates, the Department of Defense (DoD) is, by far, the largest developer of standards in the United states. Moreover, the 5650 Federal specifications and Standards and Commercial Item Descriptions (procurement specifications for off-the-self products) prepared by DoD and the General Services Administration (GSA) are widely used by federal and state agencies to procure many common products, and federal test methods are used in many industries. It is estimated that another 8000 standards are developed by such federal agencies as the Occupational safety and Health Administration (OSHA), the Environmental Protection Agency (EPA), the Food and Drug Administration (FDA), National Institute of Standards and Technology (NIST), and others. Many of these are in a gray area where it is difficult to differentiate between standards and regulations.

Recent trends in DoD standards development have been toward the elimination of detailed military specifications and standards in favor of adopting nongovernment standards or developing Commercial Item Descriptions and defense performance specifications. From 1990 to 1995, DoD canceled over 6700 military specifications and standards, while adopting 2400 nongovernment standards and issuing nearly 1900 Commercial Item Descriptions for procurement of off-the-shelf products. The DoD has now adopted over 7400 nongovernment standards and published more than 4200 
Commercial Item Descriptions. Other agencies are also using nongovernment standards extensively. GSA has adopted more than 800 nongovernment

standards. The Department of Energy's Technical standards Program has adopted 60 DOE standards and 800 from the private sector. It is probable that a number of federal agencies have adopted the same nongovernment standard, so the total number adopted by all federal agencies may be overstated.

\subsection{CHANGES SINCE 1991}

The U.S. standardization community is in a period of change and, within some industrial sectors, redirection. Government contractors, particularly within the defense industry, are learning to cope as the Department of Defense implements policies that promote the use of performance specifications and nongovernment standards, canceling thousands of military standards and specifications. Private sector standards developers are stepping in to fill apparent voids. Equipment suppliers and users are working in many forums to develop standards to promote interconnectivity for telecommunications and information technology systems. A number of trade associations have instituted standardization initiatives to accommodate their members' needs for electronic data interchange (EDI) capabilities.

Nearly 50 federal and private sector organizations are included in this directory for the first time. Seventy have been deleted because they no longer have standardization programs or have merged or disbanded, and the total number of entries has dropped from approximately 750 to approximately 700. This may be because more organizations now prefer to describe their publications as guidelines or recommended practices rather than as standards, and a new class of standards is being published for general use: Interim or Draft standards. Many organizations are responding to the needs of new technologies by developing standards that can be implemented on a trial basis prior to publication of a fully definitive, final standard.

Many organizations have added "international" to their name, and a dozen use only an acronym, so that their fields of specialization are not evident to the uninitiated. Examples include AIM USA, AOAC International, NACE International, NSF International, and SFI Foundation. A more positive trend is the increasing availability of e-mail addresses that can be used to communicate with standards developers in government and the private sector. More than 50 World-Wide Web sites are Iisted and each week more organizations announce that their WWW sites are on the Internet providing access to information about their standardization programs. Many make it easier to order standards by putting their catalogs on-line. The Defense Information Systems Agency and the Department of Defense Single stock Point enable some users to download standards from the Internet. A few standards committees are developing standards on-line, but the most extensive user of the Internet for standards development and delivery is, appropriately, the Internet Engineering Task Force. Thousands of experts develop consensus positions on a range of technical issues in the transparent, open forum of the Internet. 


\subsection{COMPILATION OF INFORMATION}

More than 1200 nongovernment organizations and 100 government agencies were invited to provide entries for the current directory. They included all those cited in the previous edition; organizational members of ANSI; those represented in on-line databases of standards; and organizations listed in directories of trade associations and professional societies. Information for the entries was voluntarily provided by the submitting organizations, but it was sometimes necessary to reformat or edit for uniformity. Wherever possible, information on secretariats, designations, quantities, and the availability of standards was verified by consulting ISO, IEC, and ANSI publications, as well as electronic databases of standards developers and their distributors. In some instances organizations chose not to submit entries although they are known to be standards developers. Identifying authoritative spokespersons for organizations which develop informal standards proved to be especially difficult. Follow-up mailings and telephone calls were made primarily to confirm information. Corrections were sought only in the event of obviously erroneous entries.

The major sections on nongovernment organizations and federal agencies are each preceded by a short description of mechanisms for policy development and coordination. Entries are organized in the various sections of the directory under subheadings to permit information to be found easily. Naturally, organizations with limited standards activities have fewer subheadings.

Each responding organization has determined for itself whether or not it is a "Standards Developer." A few organizations (less than 30) self-identify as Standards Developers although they neither develop nor publish standards, but in fact work within the structure of another organization. Similarly, a few organizations, many of them focal points for standards activities in their field, insist that they not be cited as standards Developers, but as working with other organizations to develop standards. A perusal of the information included in the standardization Activities subheading will usually clarify the actual role. 
1.6 FUTURE UPDATES

Organizations that are not included in this directory are invited to send pertinent information to:

National Institute of Standards and Technology

Office of Standards Services

Bldg. 820, Room 280

Gaithersburg, Maryland 20899

Fax: (301) 926-2871

e-mail: maureen.breitenberg@nist.gov

WWW: http://wWw.nist.gov

Listed organizations are encouraged to keep NIST informed of changes in organizational name or address.

In the near future this directory will be available on the Internet. The Web site will include forms so that listed organizations can update their entries, and new entries can be submitted by those not yet listed. This may well be the last edition in paper of a publication that has served the standardization community for more than half a century.

9 



\subsection{DEVELOPERS OF FORMAL AND INFORMAL STANDARDS}

This section lists in alphabetical order 605 entries for trade associations, professional and technical societies, and other U.S. private sector organizations that develop standards or work with other organizations to develop standards. The information presented is intended to provide basic data, not only on the type of standards that are prepared, but some indications of the level of activity. Organizations were asked to provide information on the number of members involved in standardization, the number of staff personnel devoted to standardization programs, and secretariats that they sponsor. The individual named is directly responsible for the organization's standardization activities and should be contacted if additional information is required.

Organizations were asked whether or not they had any certification, qualification, or accreditation programs for products, laboratories, or services. In many cases it was considered just as important to indicate when there was no qualification program. Many standards developers provided information on the prefixes or other designations which identify their publications.

The keywords were provided by the listed organization, supplemented by the editor. These keywords simplify on-line search and for that reason are separated by semicolons the convention that is utilized in most search software. Keywords synopsize the areas in which the organization's standardization activities are directed and, as such, assist the directory user to find pertinent, responsible organizations more quickly. 

Type of

Organization

\section{standards}

Development

\section{Standards}

Designation

Scope

Standardization Activities

Availability

Keywords
J. Jeffrey Wherry, Manager

3020 Detroit Road

Cleveland, Ohio 44145

(216) 899-0010

FAX: (216) 892-1404

Founded: 1933

Standards Staff: 1

Trade Association

Standards Developer

Standards developer since 1933.

Ten standards published.

Processed through ANSI.

ANSI B74.x.

Manufacturers of natural and manufactured abrasives, i.e., silicon carbide, aluminum oxide, corundum, emery, garnet, etc., used in grinding wheels, coated abrasives and other products.

Administered by Standards committee and several subcommittees; participates in international standardization work, cooperating with the International organization for Standardization (ISO), the Federation of European Producers of Abrasives (FEPA), and ANSI. Publishes ten standards including standards on density, capillarity, friability, and chemical analysis of abrasive grains. Promulgates its documents through the Grinding wheel Institute Accredited Standards Committee B74. The Technical and Administrative Directors provide technical advice and answer queries related to the committee's standards activities.

Distributed directly and through ANSI.

abrasives; manufacturing; materials;

\section{ACCREDITED STANDARDS COMMITTEE X9 - FINANCIAL SERVICES}

Cynthia L. Fuller, Associate Director

C/O American Bankers Association

1120 Connecticut Avenue, NW.

Washington, DC 20036

(202) 663-5284

FAX: (202) 663-7554

e-mail: cfuller@aba.com 
Type of

Organization

Standards

Development

Standards

Designation

Secretariats

Scope

Standardization

Activities

Availability

Keywords

ACCREDITING BUREAU OF HEALTH EDUCATION SCHOOLS Trial Use. and Related Services ANSI.
33 active standards, all processed through ANSI.

5 published technical guidelines; 1 published Draft standard for

X9. $x x-199 x$ (ex. X9.37-1995); ANSI X9.xx-199x.

Accredited Standards Committee X9 - Financial Services Administrator, U.S. Technical Advisory Group IS/TO 68, Banking

Standardization for facilitating financial services operations.

More than 200 committee members participate in development of standards which cover PIN management, wholesale financial transactions, authentication and encryption, check processing specification including electronic check exchange and imaging, magnetic stripe cards, retail electronic transactions, and securities processing. Numerous standards are under development, in such areas as public key cryptography and secure remote access to financial databases. $x 9$ members also vote on international financial industry standards developed under the International organization for standardization.

Distributed through publisher (phone (216)974-7650) and through

banking; financial services; standards; retail financial; wholesale financial; computers; security;
Type of

organization
Carol A. Moneymaker, Executive Director

2700 South Quincy street

Suite 210

Arlington, Virginia 22206

(703) 998-1200

FAX: (703) 998-2550

Founded: 1964

Standards staff: 9

Accrediting Agency 
Certification

scope

Standardization Activities

Availability

Formerly

Reywords

ACIL

Type of

Organization
Accredited program graduates are eligible for professional registration with American Medical Technologists Registry as medical laboratory technician (MLT) and registered medical assistants (RMA) .

Recognized by U.S. Department of Education to accredit medical laboratory technician education programs in the private and public sector through junior college level and medical assistant programs in the private sector and allied health institutions in the private sector. Recognized by Commission on Recognition of Post Secondary Accreditation to accredit medical laboratory technician and medical assistant education programs in the private sector and institutions of allied health in the private sector.

Establishes criteria and standards for the administration and operation of health education institutions and specialized programs for medical laboratory technician and medical assistant education; enhances the profession through the improvement of schools, programs, and quality of graduates; provides sound business and ethical standards in the fields of health education; maintains standards and procedures consistent with the philosophies and best-known practices of other educational accrediting agencies.

Distributed directly.

Accrediting Bureau of Medical Technology Schools (1964-78) Accrediting Bureau of Medical Laboratory Schools (1968-78)

accreditation; medical laboratory; dental; medical; health education; public health;

Joseph F. O'Neil, Executive Director

$1629 \mathrm{~K}$ Street NW.

Washington, DC 20006

(202) 887-5872 FAX: (202) 887-0021

e-mail: acil@dce2.com

Founded: 1937 Standards Staff: 3

Trade Association

Works through other organizations to develop standards 
Representation

Secretariat

scope

Standardization

Activities

Availability

Formerly

Keywords

ACOUSTICAL SOCIETY OF AMERICA

Avril Brenig, Standards Manager

120 Wall street, 32nd Floor

New York, New York 10005-3993

(212) 248-0373

FAX: (212) 248-0146

Founded: 1929

Standards staff: 3
Type of

organization
Technical Society

Standards Developer 
Standards

Development

\section{Standards \\ Designation}

Government

Adoption

Secretariats

scope

Standardization Activities

Availability
Standards development since 1932 .

Organizer of 85 working groups and 700 participants active in standards development.

Over 100 active standards.

Processed through ANSI.

Draft standards available for review.

ANSI SX.X.

Some referenced by FDA

Four ANSI accredited standards committees:

S1, Acoustics

S2, Mechanical Vibration and Shock

S3, Bioacoustics

S12, Noise

ISO/TC 108, Mechanical Vibration and shock

ISO/TC $108 \mathrm{SC} 1$, Balancing

A national society of physicists and engineers involved in the fields of electroacoustics, ultrasonics, architectural acoustics, psychological and physiological acoustics, music, noise and vibration control.

Coordinates development of standards, specifications, methods of measurement and test, and terminology in the fields of physical acoustics, including architectural acoustics, electroacoustics, sonics and ultrasonics, underwater sound, mechanical shock and vibration, psychological and physiological acoustics, including aspects of general acoustics, shock and vibration which pertain to biological safety, tolerance and comfort; and acoustical, environmental, and occupational noise. Each of the accredited standards committees (operating in accordance with procedures approved by ANSI) is responsible for developing, voting upon, and maintaining or revising its own standards. The ASA standards secretariat administers committee organization and activity, and provides liaison between the accredited standards committees and ANSI. After the standards have been produced and adopted by the accredited standards committees, and approved as American National Standards by ANSI, the ASA Standards Secretariat arranges for their publication and distribution.

These four Accredited Standards Committees also provide the United states input to various international committees (IEC and IS).

sold directly and through ANSI. 
Type of

Organization

Representation

Scope

Standardization

Activities

Keywords
Christine Norris, Executive Director

401 N. Michigan Avenue

Chicago, Illinois 60611

(312) 644-6610

FAX : (312) 321-6869

Founded: 1933

Standards staff: 8 part-time

Trade Association

works through other organizations to develop standards

ANSI

Twenty member companies represent the major packaging adhesive manufacturing firms in the United states and twenty associate members represent supplier companies. Provides a forum for members to meet and exchange ideas for the advancement of the industry and its members, including research and development of better adhesives and applications. Sales and marketing techniques, employee health and safety, statistical analyses, and regular updates on the economic climate are other important functions.

The Adhesives Manufacturing Association is not a standards developing organization; it works within the voluntary standards system to coordinate adhesive standards activities and act as the industry voice. Also monitors proposed regulations and standards at the federal, state, and local levels.

adhesives; packaging; manufacturing;

ADVANCED TELEVISION SYSTEMS COMMITTEE

\author{
Robert Hopkins, Executive Director \\ $1750 \mathrm{~K}$ Street, NW. \\ Suite 800 \\ Washington, DC 20006 \\ (202) 828-3130 \\ FAX: (202) 828-3131 \\ e-mail: atsc@atsc.org \\ WWW: //Www.atsc.org \\ Founded : 1982 \\ Standards Staff: 2
}


Type of

Organization

Standards

Development

\section{Standards}

Designation

Government

Adoption

Certification

scope

Availability

Formerly

Keywords
Standards Developing Organization

Develops voluntary national standards for advanced television systems in the United States, including generation, distribution, reception, and display of improved NTSC television systems, enhanced television systems, and high definition television (HDTV) systems.

ATSC currently has three standards:

A/49 Ghost Canceling Reference Signal standard.

A/52 Digital Audio Compression standard (AC-3).

A/53 ATSC Digital Television standard.

ATSC standard A/49 has been adopted by the Federal

Communications Commission (FCC). ATSC Standard A/53 has been proposed for adoption by the FCC.

ATSC does not have a program to certify, qualify, or accredit.

Created by the Joint Committee for Intersociety Coordination (JCIC). Coordinates the development of voluntary national technical standards for advanced television. Makes recommendations to the United States Department of state for its use in developing positions on various standards issues that are considered by international standards organizations. Membership includes television equipment manufacturers, broadcasters, cable companies, and associated trade and professional societies.

ATSC standards are available on the Internet using a Web browser at http://www.atsc.org or by anonymous ftp to ftp.atsc.org.

National Television System Committee (NTSC)

advanced television; ATV; communications; digital television; electronics; high definition television; HDTV; television;

ADVISORY COMMISSION ON TEXTBOOK SPECIFICATIONS

Stephen P. Snyder, Administrative Director

45 William street

Suite 245

Wellesley, Massachusetts 02181

(617) 239-0103 
Type of

Organization

Government

Adoption

scope

Standardization

Activities

Availability

Keywords

AERONAUTICAI RADIO, INC.
Advisory Commission

Standards Developer

ACTS standards are applied by most states for textbook purchases.

A federation of three organizations comprised of representation from the Association of American Publishers, Book Manufacturers Institute, and the National Association of state Textbook Administrators.

Developed the Manufacturing Standards and Specifications for Textbooks, which establish quality standards for paper, printing, binding, and related details. These standards are intended as a guide to aid manufacturers, publishers, textbook administrators, and the general public. The Technical-Administrative Director profiles technical advice and answers queries related to the Commission's standards activities.

Distributed directly.

publishing; textbooks; education;

\author{
Daniel A. Martine, Director Avionics Engineering \\ 2551 Rica Road \\ Annapolis, Maryland 21401 \\ (301) 266-4111 \\ FAX: (410) $266-4040$ \\ Founded: 1929 \\ Standards Staff: 6 \\ Service Provider \\ Standards Developer
}

250 Form, Fit, and Function (performance) standards describe airborne electronic equipment for transport aircraft. Draft standards and related reports available upon request. None processed through ANSI.

ARINC Equipment Characteristics (specific equipment). ARINC standards (basic system elements). ARINC Reports (guidance material).

No certification, qualification, or accreditation programs.

Airlines Electronic Engineering Committee (AEEC).

A wholly owned subsidiary of ARINC Incorporated, which is owned by major air transport operators. Provides telecommunications ser- 
Standardization

Activities

Availability

Keywords vices without discrimination to all users of the airspace within the United states. Provides planning and coordination of the users' telecommunications needs with participation by all elements of aviation.

ARINC's voluntary standardization activities are conducted by the EEC, chaired by D.A. Martinec, Director of ARINC Avionics Engineering Department. AEEC comprises user specialists from United States, European and Pacific basin airlines, general aviation, U.S. Air Force and airline associations. The voluntary standards are generally drafted by a subcommittee comprised of users, equipment and airframe manufacturers, regulatory agencies and other interested parties. AEEC supervises the subcommittee work and adopts completed documents when appropriate.

Paper copies are available directly; microfilm from IS.

avionics; navigation; surveillance; air-traffic-control; aviation; transportation; electronics; communication;

\section{AEROSPACE INDUSTRIES ASSOCIATION OF AMERICA}

Bruce I. Mahone, Manager, Standards Programs

1250 Eye Street, NW

Washington, DC 20005

(202) 371-8462 FAX: (202) 371-8470

e-mail: aia@millkern.com

Founded: 1919 Standards Staff: 2

Type of

Organization

Standards

Development

\section{Standards \\ Designation}

Government Adoption
Trade Association

Standards Developer

Standards developer since 1938.

130 members participating in standards activities.

3000 standards, including 140 metric.

None processed through ANSI.

Draft standards available for review.

NAS, National Aerospace Standard.

NA, Metric NAS.

The Department of Defense has adopted nearly 700

National Aerospace Standards (NAS's). 
scope

\section{Standardization Activities}

No certification, qualification, or accreditation programs.

ISO/TC 20 Aircraft and space Vehicles.

International Coordinating Council of Aerospace Industries Associations, industry interface with the International Civil Aviation Organization.

American National Metric Council, Aerospace Sector Committee.

A national trade association representing United States companies engaged in research, development, and manufacture of such aerospace systems as aircraft, missiles, spacecraft, and space launch vehicles; propulsion, guidance, and control systems for flight vehicles; and a variety of airborne and ground-based equipment essential to the operation of flight vehicles. Functions on national and international levels, representing its membership in a wide range of technological and other relationships with government agencies and the public.

Standardization activities are directed toward fulfilling user-defined requirements of the industry and its customers. A close working alliance exists with the Department of Defense, National Aeronautics and Space Administration, and other agencies and industry organizations. This liaison involves direct participation of government representatives in meetings and activities of the association's primary standards developing body, the National Aerospace Standards Committee. Technical input is solicited from all affected interests. Committees also review and make recommendations on government standards documents and participate in standards programs of ANSI, SAE, ASME, DOD, DOC, and FAA.

NAS's are used worldwide in high stress environments. They are applied on all types of aerospace and other high-technology systems, as well as critical non-aerospace applications, such as rapid transit rail cars, amusement park rides, high speed diesel engines, and racing cars. The NAS series is best known for its high strength, precision fasteners, which include bolts, screws, nuts, and rivets of all types in inch (NAS) and metric (NA) series. Other NAS's define high pressure hose, electrical connectors, splices and terminations, rod end bearings, and many other types of hardware and components.

Nearly 100 of NAS's specify requirements for manufacturing equipment used by aerospace and other industries, including numerically controlled (NC) and computer aided manufacturing (CAM) machine tools, NC welding and fabrication equipment. One of the first 
Availability

Formerly

Keywords

AGRICULTURAI RETAILERS ASSOCIATION

Paul E. Kindinger, Executive Vice President

11701 Borman Drive

St. Louis, Missouri 63146

(314) 567-6655

Founded: 1955

Type of

Organization

standards

Development

scope

Standardization

Activities

Availability
Trade Association

Standards Developer

Standards developer since 1974.

4 active standards, all processed through ANSI.

A national trade association representing the fluid fertilizer industry worldwide. Consists of 950 member companies in the United States and 16 foreign countries including retail fertilizer dealerships, fertilizer manufacturers, equipment manufacturers, and distributor/jobbers. Serves its membership through support programs in research, technical services, education, legislative action, public relations, and publication services.

Develops guidelines for regulatory authorities writing their own regulations. Assists individuals working with equipment and materials covered by the standards.

Sold directly and through ANSI. 
Formerly

Keywords

AIM USA

Type of

Organization

Standards

Development

Standards

Designation

Government

Adoption

Certification

scope

Standardization

Activities

Availability
National Fertilizer Solutions Association (1992)

fertilizer; nitrogen; phosphoric acid; storage; safety; agriculture;

Larry $W$. Roberts, President and CEO

634 Alpha Drive

Pittsburgh, Pennsylvania 15238-2802

(412) 963-8588 FAX: (412) 963-8753

e-mail: adc@aimusa.org

Founded: 1972 Standards Staff: 4

Trade Association

Standards Developer

Since 1987 has developed standards for automatic data

collection including bar coding, and magnetic strip. 160 Member Companies; participate in AIM, ANSI, government, industry trade association, and inter-industry standards activities. AIM is approved to use the ANSI canvass review method.

AIM.

All nine Uniform Symbology Specifications.

Film Masters Manufacturer Certification (manufacturers of bar code film masters for mass printing).

A national trade association of companies involved in the manufacture or integration of automatic data and collection and identification hardware, software, supplies, services and systems for industrial, commercial, and government applications. Technologies represented include bar code, radio frequency identification, wireless data communications, magnetic stripe, vision systems, biometrics, and OCR.

Current activities include standardization of bar code symbols, some aspects of magnetic stripe media measurements (magnetic properties) and specification of immunity to magnetic interference, and creation of a standard for radio frequency identification of companion animals.

Distributed directly. 
automatic data collection; automatic identification; bar codes; magnetic stripe; RFID; wireless; data communication; biometrics; OCR;

\section{AIR AND WASTE MANAGEMENT ASSOCIATION}

John A. Thorner, Executive Director

P.O. Box 2861

Pittsburgh, Pennsylvania 15230

(412) 232-3444 FAX: (412) 232-3450

Founded: 1907

Type of

Organization

Representation

Scope

Standardization

Activities

Keywords
Technical Society

Works through other organizations to develop standards

ANSI Committee Z-21, Subcommittee on Standards for Domestic GasFired Incinerators; ANSI Z-105, Air Cleaning Equipment Committee; ANSI Z-91, Committee of Installation Standards for Oil Burners and Oil Burning Equipment; ANSI 2-228, Incinerator Committee; International Organization for Standardization; Technical Committee ISO/TC 146; and Air Purity Intersociety Committee (Manual of Methods of Ambient Air Sampling Analysis).

A voluntary, cooperative, nonprofit, technical organization devoted to air pollution control and waste management. Membership of over 16000 is composed of engineers, scientists, enforcement officials, industrial organizations, manufacturers of control equipment and instrumentation, scientific and educational institutions, and consultants.

Contributes to standards development through representation on various committees of standards setting organizations.

air pollution; environment; waste management;

AIR CONDITIONING AND REFRIGERATION INSTITUTE

Mark Menzer, Vice President of Engineering and Research

4301 N. Fairfax Drive, Suite 425

Arlington, Virginia 22203

(703) $524-8800$

FAX: (703)528-3816

WNW: http://www.ari.org

Founded: 1953

Standards Staff: 10 
Type of

Organization

Standards

Development

Standards

Designation

Government

Adoption

Certification

Secretariats

Scope

Standardization

Activities
Trade Association

Standards Developer

Standards developer since its formation in 1953. 150 members participate in standards activities. Over 50 active standards processed through ANSI. Draft standards available for review; interested parties are invited to participate in standards development.

ARI prefix.

Some government agencies recommend purchase of protested according to specific ARI standards and/or ARI certified products.

Seventeen certification programs. Product performance certified by manufacturer, verified by $A R I$ through an independent laboratory.

Chairmanship U.S. TAG ISO/TC 86, Refrigeration; Chairman, IEC/TC 61D Secretariat, ISO TC $86 / \mathrm{SC} 6$, Air-conditioning and heat pump units.

Trade association of manufacturers of air conditioning, heating, commercial and industrial refrigeration, excluding room air conditioners, household refrigerators and freezers, portable humidifiers and dehumidifiers.

Activities of ARI include: Equipment standards pertaining to physical and operating characteristics of items and equipment; Testing standards procedures for testing equipment in order to determine performance and operating characteristics; Rating standards containing provisions for converting data into general statements of capacity and performance which can be applied to a series of production items; Application standards specifying acceptable installation criteria, including initial selection of equipment.

Standards issued cover: unitary air-conditioning equipment and heat pumps, air-cooling and air-heating coils, forced circulation, free-delivery air-coolers for refrigeration, central station airhandling units, room air-induction units, centrifugal liquidchilling packages, reciprocation chilling packages, liquid line driers, self-contained mechanically-refrigerated drinking water coolers, transport refrigeration units, and sound rating and application standards. ARI also has an International standards Engineer to handle international standards activities. 
Availability

Formerly

Keywords
Distributed directly and through IHS and Global.

Refrigeration Equipment Manufacturers Association (REMA)

Air-Conditioning and Refrigeration Machinery Association (ACRMA)

air-conditioning; refrigeration; heat pumps; water coolers; sound; cooling coils; heating coils; air handling; building;

\section{AIR CONDITIONING CONTRACTORS OF AMERICA}

James P. Norris, Executive Vice President

1712 New Hampshire Avenue, NW

washington, DC 20036

(202) 483-9370 FAX: (202) 234-4721

e-mail: accaadmn@acca.org

Founded: 1969 Standards Staff: 2

Type of

organization

Standards

Development

Government

Adoption

scope

Standardization Activities
Trade Association

Standards Developer

Standards developer since 1960.

50 members involved in standards development.

Five standards published.

None processed through ANSI.

HUD, FHA, EPA

An organization of heating, air conditioning, and refrigeration contractors, representing such contractors throughout the United States and in a limited number of foreign countries. Provides management training, TQM training, HVAC system design training, industry relations and government relations services for its members.

Develops procedures and standards for residential and commercial heating and air conditioning system design, load calculation, and equipment selection. Standards specifically prepared for use by non-engineering design personnel, although used by others. Participates in ANSI Committee $\mathrm{z} 21$ and various ASHRAE committees. Provides EPA-approved certification programs relating to recovery, recycling, and reclamation of CPCs. 
Availability

Formerly

Keywords sold directly.

Air conditioning and Refrigeration Contractors of America

National Warm Air Heating and Air Conditioning Association (Merged in 1969)

National Environmental Systems Contractors Association (formed by Merger, 1969)

Current name adopted 1978

air-conditioning; heating; refrigeration; air handling; building;

AIR DISTRIBUTION INSTITUTE

Type of

Organization

Standards

Development

scope

Standardization Activities

Availability

Keywords
Patricia H. Keating, General Manager

4415 West Harrison street

Suite $242-C$

Hillside, Illinois 60162

(708) 449-2933

FAX: (708) 449-0837

Founded: 1947

Standards Staff: 3

Trade Association

Standards Developer

Participated in the development and updating of

Simplified Practice Recommendation R207 since 1947.

A national trade association representing United states companies engaged in research, development, and manufacture of air distribution equipment, such as pipe, duct, and fittings for warm air heating and air conditioning, for use in residential single and multi-family dwellings.

Develops production, distribution, and use standards for pipe, duct, and fitting for warm-air heating and air conditioning. Produces a numerical data system for identification of products as manufactured by its members, in concert with North American Heating and Air Conditioning wholesalers. Currently updating simplified practices and recommendations.

Distributed directly.

air handling; 
Peter N. Hanly, Executive Vice President

30 West University Drive

Arlington Heights, Illinois 60004

(708) 394-0150

FAX: (708) 253-0088

e-mail: amca@delphi.com.

Founded: 1917 Standards Staff: 22

Type of

organization

standards

Development

standards

Designation

Certification

secretariats

scope

Standardization Activities
Trade Association

Standards Developer

Standards developer since 1960 .

236 members participating in standards activities.

29 active standards.

2 processed through ANSI.

Draft standards available for review.

ANSI accredited standard setting body.

AMCA prefix.

Products which have been performance rated in accordance with AMCA standards are eligible to be licensed under the Certified Rating Program and are identified by the display of the AMCA Certified Ratings seal.

ANSI/TAG for ISO/TC 117 since 1988.

An international trade association of manufacturers of fans, louver, and dampers used in industrial, commercial, residential, and institutional air handling systems. Includes more than 236 manufacturers in the USA and Canada and some 50 countries overseas. Promotes and furthers the interests of the public and manufacturers of air moving and control devices throughout the world. Promotes the use of voluntary standards and technical documents to help purchasers, specifiers, and users with selection, application, and safe and efficient use of those products.

Aims at the development of accurate and reliable testing procedures which are adopted as standards and used as a basis for rating the industry's products. Adopts standards to measure the performance of all air moving devices and the sound power of this equipment, in addition to air curtains and industrial ceiling fans. These include relating pressure drop and/or water penetration to the air flow rate of louvers, dampers, and shutters; leakage rate of dampers at a given pressure difference. Other technical standards cover a wide variety of subjects including nomenclature, drive arrangements, sizes, classification for spark resistant construction, operating limits for centrifugal fans, and inlet box positions for centrifugal fans. 
Availability

Formerly

Keywords
Works closely with ASHRAE. Developed "Laboratory Methods of Testing Fans for Rating," a joint standard with ASHRAE. Works with ISO/TC 117 to develop an international standard for air performance testing. Review and makes recommendations on standards and documents of ASHRAE, ASME, ISO, NFPA, and UL.

Sold directly. Joint ASHRAE standards also available through ASHRAE .

National Association of Fan Manufacturers (1955)

The Power Fan Manufacturers' Association (1955)

Industrial Unit Heater Association (1955)

Home Ventilation Institute (Merged 1984)

air curtain; blower; damper; fan; louver; shutters; noise control; air handling; building; residential fans;

\section{AIR TRANSPORT ASSOCIATION OF AMERICA}

\author{
Type of \\ Organization \\ standards \\ Development \\ Standards \\ Designation
}

Secretariats
James Landry, President

1709 New York Avenue, NW.

Washington, DC 20005

(202) 626-4000 FAX: (202) 862-0570

Founded: 1936 Standards Staff: 2

Trade Association

Standards Developer

32 members participate in standards development.

ATA prefix.

MSG-3 Airline Manufacturers Maintenance Program Planning Document. WATOG World Airline Technical Operations Glossary.

ATA/IATA Interline Communications Manual.

S2000 Specification.

ATA provides the secretariat for all of the above standards except the ATA/IATA Interline Communications Manual, which is provided by the IATA. 
scope

standardization

Activities

Availability

Keywords
A national trade association for 30 United states scheduled air carriers and two Canadian scheduled air carriers which are associate members. Provides services in operations, technical, traffic, government affairs, and finance fields. Functions on national and international levels, representing its membership before government bodies, the public, and associated industries.

Develops and maintains specifications and guidelines for use by airlines and suppliers in maintenance, supply, communications, and other programs. Primarily directed toward meeting the needs of airlines and those organizations, both public and commercial, which interface with the scheduled air carriers. Standards development requires national and international coordination between user airlines and suppliers through the ATA committee structure.

Distributed directly.

transportation; communications; maintenance; aviation;

\section{AIRCRAFT OWNERS AND PILOTS ASSOCIATION}

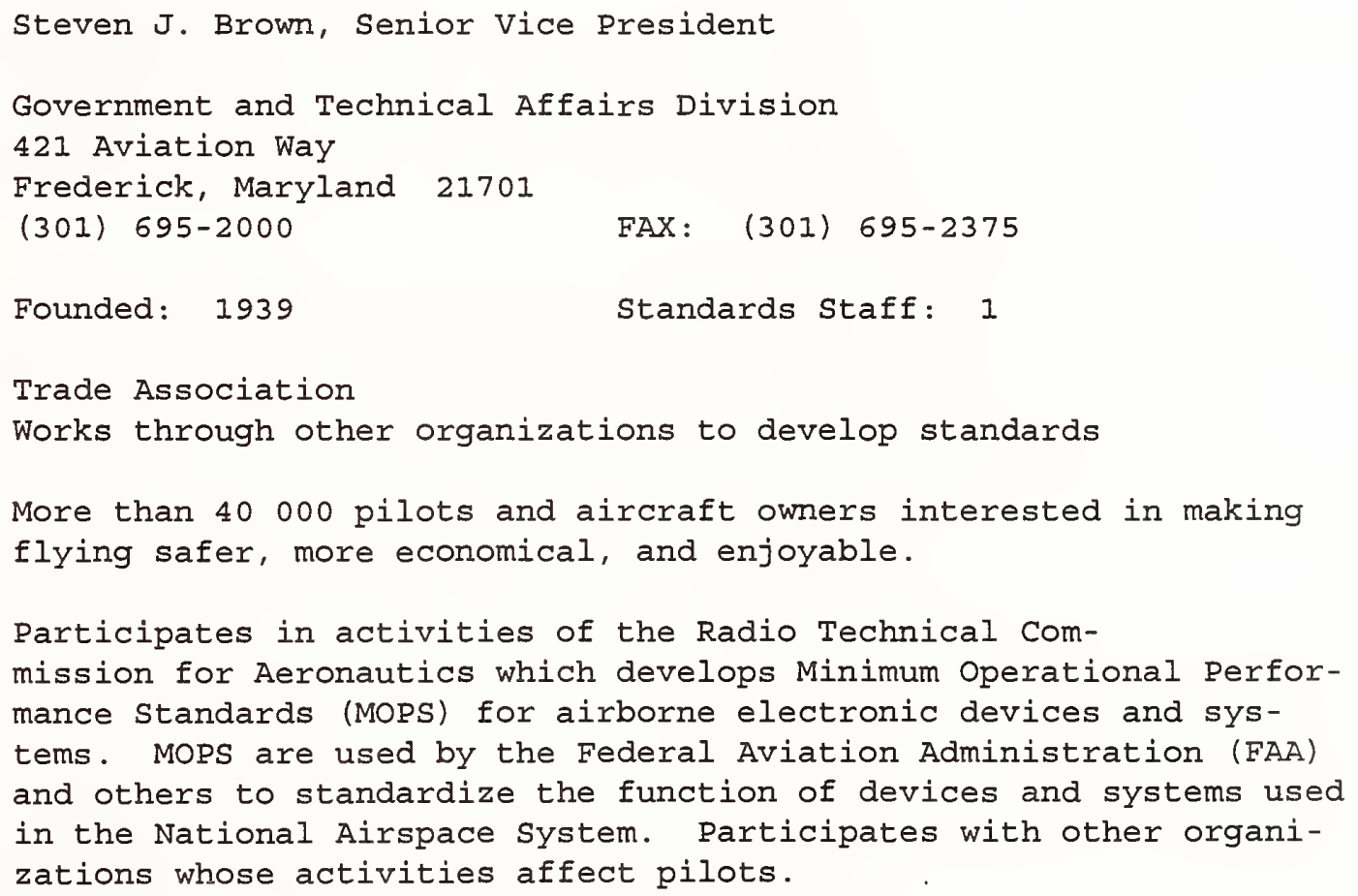




\section{ALIIANCE FOR TELECOMMUNICATIONS INDUSTRY SOLUTIONS}

Type of

Organization

Representation

Standards

Development

Standards

Designation

Government

Adoption
O.J. Gusella, Executive Director

1200 G Street, NW

Suite 500

washington, DC 20005

(202) 434-8830

FAX: (202) 393-5453

e-mail: gus.gusella@l.org

WNW: http://www.t1.org

Founded: 1983

Standards staff: 23

Sponsoring organization for accredited standards developing committees

The Alliance for Telecommunications Industry Solutions represents the member companies on American National Standards Boards, Councils and committees such as the construction standards, Information Systems Standards, and Electrical Equipment Standards Boards. ATIS also represents the member companies to American National standards Institute accredited organizations that use the canvass method of approval.

Committee T1 - Telecommunications first started developing Standards in 1984. Over 1000 representatives from various interest categories comprise the membership. Included are exchange and interexchange carriers, manufacturers, enhanced service providers, user groups, professional associations and government agencies.

Committee T1 - Telecommunications has 265 active standards and is completing new standards at the rate of approximately six per month. All of Committee $\mathrm{Tl}$ 's standards output are processed through ANSI for designation as American National standards.

Draft standards are available for review during the ANSI BSR-8 process through the Committee $\mathrm{T} 1$ secretariat of the Alliance for Telecommunications Industry solutions.

Committee T1 - Telecommunications standards are designated ANSI $\mathrm{T} 1 . \mathrm{x} \times \mathrm{x}$

Committee T1 - Telecommunications standards are

voluntary. To date none has been adopted by regulatory or administrative agencies. Many of Tl's standards have been referenced in Procurement Documents, however, with wording such as "--values must meet or exceed those specified in ANSI T1.xxx." 


\section{secretariats}

scope

Standardization

Activities

Availability

Formerly

Keywords
ATIS does not sponsor programs certifying products or personnel.

ATIS provides secretariat support to its sponsored accredited committees TI - Telecommunications, 05, Wood Poles and Wood Products, and its other sponsored forums and committees. These include the: SONET Inter-operability Forum (joined ATIS 8/95), Carrier Liaison Committee (CLC), Electronic Communications Service Provider Committee (ECSPC), Information Industry Liaison Committee (IILC), Network Reliability Steering Committee (NRSC), Protection Engineers Group (PEG), Telecommunications Industry Forum (TCIF).

ATIS actively promotes the timely resolution of national and international issues involving telecommunications standards and operations guidelines. Further, ATIS initiates and maintains open industry forums to address technical and operational issues affecting the nation's telecommunications facilities and services and the development of innovative technologies. ATIS is also an information resource to its members, the forum participants, federal and state agencies and other interested parties.

Committee T1 - Telecommunications develops American National standards regarding interconnection and interoperability of telecommunications networks at interfaces with end user systems, carriers, information and enhanced services providers and customer premises equipment. Additionally, Tl is responsible for contributing a large quantity of technical material to the Department of State's U.S. National process for adoption as official U.S. contribution's to the International Telecommunica tions Union.

Committee 05, Wood Poles and Wood Products, develop American National standards regarding wood poles, cross-arms, and laminated wood products used in outside plant applications in the telecommu nications industry.

Distributed through ANSI.

Exchange Carriers Standards Association (ECSA), 1993

telecommunications; interfaces; poles; 
Type of

Organization

Representation

Scope

Standardization

Activities

Formerly

Keywords

ALUMINUM ASSOCIATION

Type of

Organization
Rodger S. Lawson, Ph.D., President

1501 Woodfield Road

Suite 400 West

Schaumburg, Illinois 60173-4980

(708) $330-8500$

FAX: (708) $330-8602$

Founded: 1922

Standards staff: 1

Trade Association

Works through other organizations to support standards development

50 Representatives serving on 100 standards committees of ANSI, NFPA, ASTM, and ASME.

A membership organization of 244 property/casualty insurers addressing the spectrum of insurance related issues.

Financially supports, through ANSI and NFPA, the consensus development of safety and health standards, as well as provides technical representatives to assist in formulating standards. To maximize the usefulness of the standards alliance, representatives urge performance standards where practicable. Standards are used in training seminars and in evaluating hazards and risks.

American Mutual Insurance Alliance National Association of Mutual Casualty Companies and Alliance of American Insurers

insurance; loss control; fire protection; safety; industrial hygiene;

David N. Parker, President

900 19th Street, NW.

Washington, DC 20006

(202) 862-5138

FAX: (202) 862-5164

Founded: 1933

Standards staff: 2

Trade Association

Standards Developer 
standards

Development

Certification

secretariats

Scope

Standardization

Activities

Availability

Keywords
7 active standards.

Processed through ANSI.

No certification, qualification, or accreditation programs.

ANSI Standards Committee $\mathrm{H3} 5$ on Aluminum and Aluminum Alloys.

Serves the public as a source of noncommercial, industry wide information on aluminum and the aluminum industry. Membership embraces producers of primary ingot, sheet, and plate; and leading extruders, foundries, secondary smelters, forging firms, and producers of aluminum electrical conductors. Represents virtually all United states primary aluminum production and 85 percent of semifabricated aluminum product shipments.

Functions include developing, publishing, and distributing technical data, collecting and publishing industry statistics, and conducting school programs and industry seminars.

Standards of the association are the basis for aluminum and aluminum alloy products for the majority of government, American Society for Testing and Materials, company, and other specifications. Specific publications include: Aluminum standards and Data (published biennially), Drafting standards Aluminum Extruded and Tubular Products, Designation System for Aluminum Finishes, Welding Aluminum: Theory and Practice; Aluminum Design Manual, and Standards for Aluminum standard Permanent Mold Castings.

Directly through ANSI.

aluminum; alloys; metallurgy; materials;

\section{AMERICAN ACADEMY OF PEDIATRICS}

Joe M. Sanders, Jr., M.D., Executive Director

141 Northwest Point Boulevard

Elk Grove Village, Illinois 60007

(708) 228-5005 FAX: (708) 228-5097

Founded: $1930 \quad$ Standards Staff: 4

Type of

Organization
Professional society

Health Care Guidelines Development 
The American Academy of Pediatrics is committed to the attainment of optimal physical, mental, and social health for all infants, children, adolescents, and young adults. To this end, the 49000 members of the Academy dedicate their efforts and resources.

Standardization Activities

Availability

Keywords
The AAP publishes statements and manuals to help health professionals in their treatment of children. These recommendations have been used by regulatory agencies to establish guidelines for pediatric care. These pertain to perinatal care, pediatric nutrition, out-of-home day care, and treatment of infectious diseases, guidelines for health supervision, accident and poison prevention, school health, sports medicine, drug therapies and toxicities, and environmental hazards.

Distributed directly.

children; guidelines; perinatal care; general health care;

AMERICAN ALIIANCE FOR HEAITH, PHYSICAL EDUCATION, RECREATION AND DANCE

Type of

Organization

Certification

Scope

Standardization

Activities
A. Gilson Brown, Executive Vice President

1900 Association Drive

Reston, Virginia 22091

(703) $476-3400$

FAX: (703) 476-9527

e-mail: evp@aahperd.org.

Founded: 1885

Standards staff: 5

Professional Society

Standards Developer

Certification programs are implemented at the state level through activities of AAHPERD members. Professional preparation programs in colleges are developed using AAHPERD standards.

A voluntary professional organization for education in the field of recreation and dance. Promotes the improvement of education through such professional services as consultation, periodicals and special publications, leadership development, determination of standards, public information, and research.

Standards are national in scope and are promoted through the education of teachers and professionals in allied fields. Publishes over 30 books and pamphlets containing guideIines and standards. With funding from the Department of Health, Education and Welfare, prepared Guideline for Professional Preparation for Personnel Involved in Physical Education and Recreation 
Keywords

for the Handicapped. Cooperates with other organizations such as the Association for the Advancement of Health Education, National Association for sport and Physical Education, and the American Association for Leisure and Recreation.

AMERICAN ARCHITECTURAL MANUFACTURERS ASSOCIATION

Carl Wagus, Technical Director

1540 E. Dundee Road, suite 310

Suite 118

Palatine, IL 60067-8321

(708) 202-1350

FAX: (708) 202-1480

Founded: 1936

Standards Staff: 4

Type of

Organization

Standards

Designation

Standards

Designation

Government

Adoption

Certification

Secretariats

scope
Trade Association

Standards Developer

Standards developer since 1936. Over 200 member companies participate internally in standards creation. ANSI standards are canvassed to hundreds of nonmember organizations, companies and individuals. AAMA currently has 43 standards, four of which are ANSI/AAMA standards.

ANSI/AAMA prefix (e.g., ANSI/AAMA 101-93), or AAMA prefix (e.g., AAMA 1701.2-1995).

ANSI/AAMA standards referenced by HUD for both conventional construction and for mobile home/manufactured housing. ANSI/AAMA standards are also referenced in the ICBO Uniform Building Code, BoCA National code, SBCCI standard Building code and CABO one and Two Family Dwelling Code.

Certification programs for: aluminum and vinyl windows and doors; storm windows; storm doors; windows, egress windows and swing doors used in manufactured housing; vinyl extrusions used in windows and doors.

None

AAMA is a trade association of approximately 200 firms engaged in the manufacture and sale of architectural building components. 
Standardization

Activities

Availability

Keywords
These include windows, sliding glass doors, storm windows and doors, curtain walls, store fronts, skylights, residential siding, and related products. AAMA activities include developing standards, certification programs, specifications and guidelines for architects and specifiers; encouraging research and develop ment of new or improved products; and representing the interests of the architectural building products industry to code and regulatory bodies.

AAMA standards are developed by committees and approved by consensus ballot to the entire membership. ANSI/AAMA standards are created by the same process, but are then canvassed to outside companies and individuals following ANSI procedures. AANA certifies products to the AAMA and ANSI/AAMA standards, requiring testing conducted by independent laboratories accredited by AAMA and validated through periodic in-plant inspection of production. AAMA's certification programs are monitored and accredited by ANSI.

AAMA standards are available only directly through AAMA. ANSI/AAMA standards are available from AAMA or from ANSI.

aluminum; vinyl; windows; doors; curtain walls; store fronts; skylights; siding; building; mobile home; manufactured housing;

AMERICAN ASSOCIATION FOR CLINICAL CHEMISTRY

Richard G. Flaherty, Executive Vice President

2101 L Street, NW

Suite 202

washington, DC 20037

(202) 857-0717 FAX: (202) 887-5093

Founded: 1948

Type of

Organization

Scope

Standardization Activities
Scientific/Professional society

Works through other organizations to develop standards

A nonprofit organization of professional chemists who specialize in clinical chemistry.

The Standards Committee carries out background development of standard methodology and materials, and collaborates closely with the International Federation of Clinical Chemistry and the National Committee on Clinical Laboratory standards and the National Institutes of Health. Maintains close alliance with the clinical laboratory programs of the U.S. National Institute of standards and Technology in developing specifications for new standard reference materials, and with the Centers for Disease 
Formerly

Keywords
Control and Prevention and with the Food and Drug Administration in evaluating methods and performance in the field. Methods and recommendations are published in the journal, Clinical Chemistry, or in the book series, Standard Methods in Clinical Chemistry.

The American Association of Clinical Chemists (1975)

clinical chemistry; laboratory testing;

AMERICAN ASSOCIATION FOR LABORATORY ACCREDITATION

Peter Unger, President

656 Quince Orchard Road, Suite 620

Gaithersburg, Maryland 20878-1409

(301) 670-1377 FAX: (301) 869-1495

Founded: 1978

Type of

organization

Certification

Scope

Standardization Activities
Scientific Organization

Accreditation, Registration, Certification Body

Accredits laboratories on a voluntary basis to ISO Guide 25 . Accreditation is renewed on a two-year interval, with annual review documentation. Registers reference material supplies and laboratories to ISO 9000 and certifies reference materials. 729 accreditation actions in 41 states, Korea, Italy, Mexico, Switzerland, Taiwan and Canada in 11 fields of testing.

Accreditation for testing laboratories and/or inspection agencies on the basis of technical competence. Membership available to individuals, educational, scientific, engineering or technical society, governmental, corporations or trade associations. Currently, 390 active members. Fields of testing include acoustical, biological, chemical, construction materials, electrical, environmental, geotechnical, mechanical, metrology, nondestructive, and thermal. Special programs include asbestos, automotive, coal, metals, metal fasteners, paint, radon, thermal (insulation materials and fire testing), thermal (wood heaters), and windows and doors.

Employs ISO Guide 25 for general criteria. Specific criteria for each field of testing are developed with the use of national standards. Participates in United States delegation to the International Laboratory Accreditation Conferences. 


\title{
AMERICAN ASSOCIATION FOR RESPIRATORY CARE
}

\author{
Sam P. Giordano, Executive Director
}

11030 Ables Lane

Dallas, Texas 75229

(214) 243-2272

FAX: (214) 484-2720

Founded: 1947

Standards Staff: 5

Type of

Organization

Standards

Development

standards

Designation

Scope

Standardization Activities

Availability
Professional Society

Standards Developer

Develops standards concerning administrative, clinical, and technical aspects of respiratory care. Standards available for review.

AARC prefix.

The sole developer of clinical standards for respiratory care practices. Cooperates to develop administrative standards with such organizations as the Joint Commission of Accreditation of Hospitals. Develops technical standards in cooperation with the American National Standards Institute (ANSI), the Association for the Advancement of Medical Instrumentation (AAMI), and the $\mathrm{Na}-$ tional Fire Protection Association (NFPA). Also develops clinical standards in cooperation with appropriate regulatory agencies and sponsoring organizations.

Maintains a standards Committee which responds to requests for standard development from various groups. The standards committee also reviews existing data and develops documents without outside requests for such activity. Standards developed in cooperation with other organizations and approved by AARC directors are officially endorsed and published. All standards developed are reviewed every five years. Amends documents prior to mandatory review period if significant changes have occurred to warrant such amendments.

Distributed directly. 
Formerly

Keywords
American Association for Respiratory Therapy

respiratory care; respiratory therapy; clinical practice; health care;

\section{AMERICAN ASSOCIATION OF ADVERTISING AGENCIES}

o. Burtch Drake, President

405 Lexington Avenue

New York, New York 10174

(212) $682-2500$

FAX: (212) 682-8391

Founded: 1917

Standards Staff: 2

Type of

organization

standards

Development

Scope

Standardization Activities
Trade Association

Standards Developer

Standards developer since 1948.

5 active standards.

Fosters, strengthens and improves the advertising agency business; advances the cause of advertising; and aids member agencies to operate more efficiently and profitably.

Cooperates with other industry organizations to develop standards or specifications for the graphic arts industry ensuring quality control for the preparation and distribution of advertising materials for current and future print-related media. This includes involvement with the changes occurring to the offset, rotogravure, and other digitally driven printing processes. Through its involvement in industry initiatives the AAAA assures successful implementation of standards that aid its members. Helping achieve this is an ongoing dialogue with the Magazine Publishers of America, the International Prepress Association (IPA), the National Association of Printing Ink Manufacturers, the Gravure Association of America, the Printing Industries of America (PIA) as well as the N.A.A. (Newspaper Association of America). All of these organizations have the common purpose of improving the reproduction of advertisements in either magazines or newspapers.

As the transition continues to link advertising digitally with current and alternative media (e.g., CD-ROM, multimedia, Web Sites, HDTV, etc.) Both domestically and abroad, standards will be necessary for the entire evolution. The AAAA Print Committee, along with industry organizations and associations like the DDAP (Digital Distribution of Advertising for Publication), the Committee for Graphic Arts Technology Standards (CGATS), the National 
integration.

Printing Equipment and Supply Association, and the Research and Engineering Council, moves to unite a global economy through the development of accredited standards driven by open process

Availability

Keywords
Distributed directly.

magazines; publishing; advertising; communications; printing;

AMERICAN ASSOCIATION OF BLOOD BANKS

Karen Shoos, Chief Executive officer

8101 Glenbrook Road

Bethesda, Maryland 20814

(301) 907-6977

FAX: (301) 970-6895

Founded: $\quad 1947$

Standards Staff: 5

Type of

Organization

standards

Development

Standards

Designation

Government

Adoption

Certification

Scope
Professional society

Standards Developer

Standards developer since 1958.

All proposed standards are published for comment prior to final adoption.

Over 500 active standards.

None processed through ANSI.

AABB prefix.

The Department of Defense has adopted AABB Standards and provides them to their hospital and blood collecting facilities. Several state health departments have adopted AABB Standards as the basis for regulation.

Inspection and Accreditation Program which, through inspecting and accrediting facilities, strives to improve the quality and safety of transfusions and assists the medical director of a blood bank or transfusion service in determining whether methods, procedures, and personnel meet established $A A B B$ standards. Several states accept $A A B B$ inspections as equivalent to their state inspections for 1 icensing requirements.

A professional, not-for-profit scientific and administrative association for those individuals and institutions engaged in the many facets of blood banking. Membership includes physicians, 


\section{Standardization Activities}

Availability

Keywords scientists, medical technologists, administrators, nurses and other involved in the field of blood banking. The AABB serves as the focus for the advancement of the professional practice of blood collection, transfusion therapy, and related fields. 9200 individual and 2400 institutional members

Develops and publishes standards of minimum acceptable practice applicable to relevant aspects of blood banking; maintains liaison with other organizations, including the College of American Pathologists, Health Care Financing Administration, and the Food and Drug Administration.

Distributed directly.

blood banks; transfusion; public health;

AMERICAN ASSOCIATION OF CEREAL CHEMISTS

Type of

Organization

\section{standards} Development

\section{Standards \\ Designation}

Government Adoption

Certification
Steven C. Nelson, Executive Vice President

3340 Pilot Knob Road

St. Paul, Minnesota 55121

(612) $454-7250$

FAX: (612) 454-0766

Founded: 1915

Standards staff: 4

Scientific Society

Standards Developer

Standards developer since 1924.

250 members active in standards development.

32 technical committees assist in standards work.

350 standard methods and procedures.

AACC Approved Methods 00-00.

Largely used by the Federal Grain Inspection Service of the USDA and FDA in the area of cereals.

Provides certification program for "Sanitation Analyst." Specialized area for quantitative and qualitative analysis of food products for possible contamination by insects, rodents, or other foreign matter of animal origin.

Scope

An international society which develops and standardizes analytical methods used in the milling and baking industries. Expanded in latter years to cover entire cereal processing industry and to 
standardization

Activities

Availability

Keywords advance and encourage research on all cereal grains and related materials. Methodology is related to all needs of the cereal

scientist, from sampling, inorganic and organic ingredients, and microbiology, to chemical residues, additives, and sanitation.

Develops methodology rather than standards per se.

Cooperates with the Association of official Analytical Chemists, American Oil Chemists Society and ASTM. Subjects include analytical methods and apparatus for flours and doughs, flour specifications, and sanitation methods.

Sold directly or through bookstores.

cereals; cereal chemistry; grain; grain storage; nutrition; food; agriculture; sanitation;

\section{AMERICAN ASSOCIATION OF MOTOR VEHICLE ADMINISTRATORS}

Type of

Organization

Representation

Scope

Standardization Activities
John Strandquist, President and CEO

4200 Wilson Boulevard

Suite 600

Arlington, VA 22203

(703) $522-4200$

FAX: (703) 522-1553

Founded: 1933

Standards Staff: 25

Voluntary Nonprofit Association of state and Provincial officials.

Works through other organizations to develop standards.

Members and staff representatives active in standards setting committees of SAE, ANSI, ASTM, Canadian Standards Association, National Highway Traffic Safety Administration (NHTSA), CPSC, Economic Commission for Europe (ECE), and Federal Highway Administration (FHWA).

An organization responsible for the administration and enforcement of motor vehicle and traffic laws in the United states and Canada. Provides the principal forum where state and provincial officials exchange information on developments in the industry and maintain liaison between industry and Federal Government.

Activities are directed toward promoting uniform laws and regulations for motor vehicle administration, traffic law enforcement, highway safety, and the standardization and uniform enforcement of these laws. Principal functions are in the areas of: model program development in disciplines relating to motor 
vehicle administration, police traffic services, and highway safety; an information clearinghouse; and the industry spokesman.

Services include advice and counsel in various facets of driver services, vehicle services, commercial motor carrier activities, including interstate and provincial reciprocity, and program planning and systems development.

Keywords motor vehicle; automobile; safety; traffic laws; transportation; government officials;

AMERICAN ASSOCIATION OF NEUROLOGICAL SURGEONS

SEe JOINT NEUROSURGICAL COMMITTEE ON DEVICES AND DRUGS

\section{AMERICAN ASSOCIATION OF NURSERYMEN}

Robert J. Dolibois, CAE, Executive Vice President

1250 Eye street, NW.

Washington, DC 20005

(202) 789-2900 FAX: (202) 789-1893

Founded: 1876

Type of

Trade Association

Organization

Standards Developer

Standards

American Standards for Nursery Stock ANSI-Z60.1 - 1990.

Designation

Scope

Enables the nursery industry to work on those projects and activities which foster the general welfare of the industry and their customers.

Standardization Activities
Develops grades and standards for the use of the nursery industry, landscape architects, landscape contractors, governmental agencies, and others preparing lists and specifications for trading in trees, shrubs, roses, vines, fruit trees, small fruit, bulbs, tubers, and forest tree seedlings through its Horticulture Standards Committee. Standards contain height, caliper, root size, root ball, container size and various other standardized means of describing nursery plants. 
Availability

Keywords

AMERICAN ASSOCIATION OF

POISON CONTROL CENTERS

Type of

Organization

Scope

Standardization

Activities

Availability

Keywords
Distributed directly and through ANSI.

horticulture; nursery plants; agriculture;

3201 New Mexico Avenue, NW

suite 310

Washington, DC 20016

(202) 362-7217

FAX: (202) 362-8377

Founded: 1957

Trade Association

Standards Developer

The American Association of Poison Control Centers is the professional association for poison centers and those interested in the prevention and treatment of poison exposures. Activities include compilation of national statistics about poison exposures; extended data searches for detailed information about exposures to specific products; sponsorship of an annual scientific meeting; certification of regional poison centers; and certification of specialists in poison information.

A committee on Regional Poison Control Center Certification prepares standard recommended practices for poison control and poison information centers. Since 1979 these have been accepted as standard recommended practices for the establishment and operation of properly qualified centers.

A Committee on Personnel Proficiency is responsible for preparing and administering a certification examination for specialists in poison information, since 1983.

Distributed directly.

poison control; education; medical certification;

AMERICAN ASSOCIATION OF PSYCHIATRIC SERVICES FOR CHILDREN

Sydney Koret, Ph.D., Executive Director

1200-C Scottsville Road, Suite 225

Rochester, New York 14624

(716) 235-6910 
Founded: 1948

Type of

Organization

Certification

scope

Standardization

Activities

Keywords
Professional Society

Standards Developer

AAPSC provides accreditation to organizations providing children's mental health service and/or training.

Membership consists of 160 child psychiatric services that foster prevention of mental and emotional disorders and further the development and application of clinical knowledge dealing with child mental health as well as individual practitioners (child psychiatrists, psychologists, social workers, nurses, etc.) Provides for individual or organizational extraordinary achievement and in study and treatment of schizophrenia.

Provides leadership in defining and maintaining standards of clinical practice, organization of treatment, and specialized training. To be eligible for accreditation, a child psychiatric facility must provide proof of its continuity of service, together with background of its key staff members. The AAPSC Division of Accreditation reviews treatment approaches, staff competence and quality, quality care and physical plant in a site visit, conducted by trained visitors. The Division, organized by mental health disciplines, reviews and determines eligibility for accreditation.

mental health; psychiatric services; children; health care;

\section{AMERICAN ASSOCIATION OF STATE HIGHWAY AND TRANSPORTATION OFFICIALS}

Francis B. Francois, Executive Director

444 North Capitol Street NW

Suite 249

Washington, DC 20001

(202) 624-5800

FAX: (202) 624-5806

Founded: $1914 \quad$ Standards Staff: 5

Type of

Organization

Standards

Designation
State Government Association

Standards Developer

Materials Specifications: M-XXX.

Test Methods: T-XXX.

Recommended Practices: R-XXX. 
Government

Adoption

Certification

Scope

Standardization

Activities

Availability

Formerly

Keywords
The Federal Highway Administration has adopted AAsHTO standards by reference in the Code of Federal Regulations. State transportation agencies either adopt or reference AAsHTO to standards.

Operates a laboratory accreditation program on behalf of state highway and transportation officials. The AASHTO Materials Reference Laboratory (AMRL), established at the National Institute of Standards and Technology, promotes uniformity in the testing of construction materials by public or private sector laboratories serving the construction field.

Fosters development, operation, and maintenance of a nation-wide integrated transportation system and cooperates with other appropriate agencies in considering matters of mutual interest in serving the public need.

Develops and publishes The standard specifications for Transportation Materials and Methods of Sampling and Testing, containing 176 specifications and 9 recommended practices. Maintains a subcommittee on Material which has members representing each of the 50 states, the Commonwealths of Puerto Rico and the Northern Mariana Islands, the District of Columbia, the United States Department of Transportation, the New Jersey Turnpike Authority, 6 Canadian Provinces and 2 territories.

Develops and Publishes Interim specifications which have the same status as standards of the American Association of state Highway and Transportation officials, but are tentative revisions to be approved by the subcommittee prior to issuance as standards of the Association.

Develops and publishes: Standard Specifications for Highway Bridges; A Policy on Geometric Design of Rural Highways; A Policy on Design of Urban Highways and Arterial streets; Guide to Metric Conversion' Guide for Design of Pavement Structures; Guide for the Design of Park-and-Ride Facilities; Highway Drainage Guidelines; A Policy on Geometric Design of Highways and Streets; and Roadside Design Guide.

sold directly and through IS.

American Association of State Highway Officials (1973)

transportation; highways; construction materials; government officials; 
William R. Martin, Executive Director

P.O. Box 12215

Research Triangle Park, North Carolina 27709

(919) 549-8141 FAX: (919) 549-8933

Founded: 1921 Standards Staff: 2

Type of

Organization

standards

Development

standards

Designation

Government

Adoption

Certification

Secretariats

scope

Standardization

Activities
Technical Society

Standards Developer

Standards Developer since 1921.

1100 members participating in standards activities.

138 active standards.

Most AATCC Test Methods become American National.

Standards through ANSI.

Drafts of proposed or revised test methods available for review.

AATCC prefix.

Various government agencies have either adopted or adapted a number of AATCC test methods.

No certification, qualification, or accreditation programs.

ISO/TC $38 / \mathrm{SC} 1$, Tests for colored textiles and colorants ISO/TC $38 / \mathrm{SC} 2$, Cleansing, finishing and water resistance tests USA TAG for ISO/TC 38-Textiles

Promotes increased knowledge of the application of dyes and chemicals in the textile industry; encourages, in a practical way, research on chemical processes and materials of importance to the textile industry; and promotes the exchange of professional knowledge.

Membership includes many leading textile chemists and colorists in nearly every state and 50 countries. Some 300 companies support the association as corporate members.

Internationally recognized for its standard methods of testing dyed and chemically treated fibers and fabrics to measure such performance characteristics as colorfastness to light and washing, crease resistance, shrinkage, wash-and-wear, water resistance, flammability, and other conditions to which textiles may be subjected. Ensures textile quality and performance by controlled AATCC test methods. 
Availability

Keywords
Maintains cooperative relationships with other associations and agencies of the federal government. Participates in the International Organization for Standardization (ISO) in an effort to bring about worldwide uniformity in testing procedures.

Publishes Textile Chemist and Colorist, issued monthly, and an annual Technical Manual containing the association's test methods. Collaborates with the British society of Dyers and colorists on numerous projects.

Distributed directly and through IHS and Global.

textiles; chemistry; dyes; finished; colorfastness; flammability; laboratory testing;

\section{AMERICAN AUTOMOBILE ASSOCIATION}

Robert I. Darbelnet, President and CEO

1000 AAA Drive

Heathrow, Florida 32746-5064

(407) 444-7000

FAX: (407) 444-8030

Founded: 1902

Type of

organization

Scope

Standardization

Activities
Trade Association

Works through other organizations to develop standards

Federation of 113 motor clubs serving more than 37 million members throughout the United states and Canada. A nonprofit, tax-paying organization, which provides auto and travel-related services to its members, and works on behalf of the best interests of the motoring and traveling public to promote safer and more enjoyable travel.

Participates in the development of proposed standards of various types relating to increasing the safety and convenience of pedestrians in traffic. Develops detailed methods and standards for training new drivers and improving the skills of older drivers. Represented on committees of the Transportation Research Board, National Safety Council, and National Committee on Uniform Traffic Control Devices.

Cooperates with other organizations to develop standards for the operation of school safety patrols and adult crossing guards, and in standards activities in the fields of pedestrian protection, and automotive engineering. 


\section{AMERICAN AUTOMOBILE MANUFACTURERS ASSOCIATION OF THE UNITED STATES}

Richard L. Klimisch, Ph.D., Vice President

Engineering Affairs Division

7430 Second Avenue

Suite 300

Detroit, Michigan 48202

(313) $872-4312$

FAX : (313) $872-5405$

Founded: 1913

Type of

Organization

Scope

Standardization

Activities

Formerly

Keywords
Trade Association

Works through other organizations to develop standards and develops standards unique to auto industry.

Manufacturers of passenger and commercial cars and light trucks. Conducts research projects; collects historical facts and figures; compiles statistics; monitors, evaluates and responds to federal and state legislation and regulatory activity dealing with motor vehicles and their use; and coordinates actions on occupational safety and health.

The Association is a member of ANSI and participates in standards development related to motor vehicles, workplace health and safety, motor vehicle systems and traffic accident reporting. The Association participates in the Organization Internationale des Constructeurs d'Automobiles related to vehicle regulations.

Motor Vehicle Manufacturers Association (1992)

Automobile Manufacturers Association (1972)

National Automobile Chamber of Commerce

automobiles; automotive; light trucks; cars; transportation; workplace; accident reporting; 
Type of

Organization

Standards

Development

standards

Designation

Certification

secretariats

scope

standardization

Activities

Availability

Formerly

Keywords
Brian T. Borders, President

120019 th street, NW

Suite 300

Washington, DC 20036

(202) 429-5155

Founded: 1933

FAX: (202) 663-7543

Standards staff: 3

Trade Association

Standards Developer

30 active standards.

ANSI/ABMA prefix.

No certification, qualification, or accreditation programs

Accredited standards Committee B3 operating under ANSI procedures. U.S. TAG for IS/TO 4 and subcommittees SC 3, SC 6, SC 9, SC 10, SC 11 .

International Secretariat for IS/TO 20/SC 15, Airframe. Bearings.

Membership comprised of manufacturers of ball bearings, roller bearings, balls, rollers, spherical plain bearings, and major components.

Develops ANSI/ABMA standards.

Directly and through ANSI, IS, and Global.

Anti-Friction Bearing Manufacturers Association (1993)

ball bearings; roller bearings; machinery;

AMERICAN BOAT AND YACHT COUNCIL

C. T. "Skip" Moyer, III, Executive Director

3069 Solomon's Island Road

Edgewater, Maryland 21037-1416

(410) $956-1050$

FAX: (410) 956-2737 


\section{Type of}

Organization

\section{Standards}

Development

\section{standards}

Designation

Government

Adoption

scope

standardization

Activities

Availability

Reywords
Technical Society

Standards Developer

70 standards currently active.

8 processed through ANSI.

25 project technical committees.

220 committee members are active in standards development.

ABYC prefix, e.g., ABYC E-9 Direct Current

(DC) Electrical systems on Boats.

U.S. Coast Guard references ABYC standards.

An independent, nonprofit, membership organization representative of recreational boating including members from industry, insur ance, Government, and the boating public. Membership consists of 3100 individuals, corporations and associations.

Develops safety standards and recommended practices for the design, construction, equipage, and maintenance of boats and their related accessories. Standards are generated by project technical committees and reviewed by the ABYC Technical Board and Board of Directors prior to publication. Standards provide a basis for certification programs of other organizations and are used as source material by the U.S. Coast Guard in their development of safety regulations under the Boating Safety Act of 1971. ABYC standards have served as the basis for 30 ISO standards.

Individual members work voluntarily through committees and boards to implement the boating safety standards program. In addition, liaison is maintained with other organizations by means of memberships on NFPA 302, Subcommittee on Motor Craft; SAE Marine Technical Committee; UL Marine Engineering Council; National Safe Boating Council; National Boating Safety Advisory Council; Rules of the Road Advisory Council; ASTM F-15.10, Gasoline Containers for Consumer Use; and ISO/TC 188 Small Craft.

Distributed directly.

boats; boating safety; transportation; recreation; 
Type of

Organization

Scope

Standardization

Activities

Availability

Formerly

Keywords
Russell N. Mosher, President

950 North Glebe Road, Suite 160

Arlington, Virginia 22209

(703) 522-7350 FAX: (703) 522-2665

e-mail: 76041,2623@compuserv.com

Founded: $1888 \quad$ Standards staff: 1

Trade Association

Manufacturers of boilers and allied equipment; compiles statistics and conducts training programs.

Maintains a Technical Committee. Publishes a lexicon of industry terminology, water quality, steam quality and accessory product definitions.

Distributed directly.

American Boiler Manufacturers Association and Affiliated Industries (1960)

boilers; heating; industrial equipment; steam generators;

AMERICAN BOWLING CONGRESS/WOMEN'S INTERNATIONAL BOWLING CONGRESS

Dan Speranza, Manager

Equipment Specification Department

5301 South 76 th street

Greendale, Wisconsin 53129-1127

(414) 421-6400

FAX: (414) 421-1194

Founded: 1895

Standards staff: 7

Type of

Organization

Certification
Trade Association

Standards Developer

All bowling lanes under the jurisdiction of the ABC/WIBC are certified annually by representative of local bowling associations chartered by $\mathrm{ABC} / \mathrm{WIBC}$. Lanes are measured and checked to ensure that physical properties and dimensions correspond to ABC/WIBC specifications. When found to meet all specifications, an A$\mathrm{BC} /$ WIBC decal is issued for posting in the establishment. 
A nonprofit, noncommercial, membership service organization for male bowlers ( $A B C$ ) and female bowlers (WIBC). Sponsors competitions; provides standard rules and tests. Approves material and equipment.

\section{Standardization Activities}

Availability

Formerly

Keywords
Instrumental in developing specifications for playing equipment worldwide. Maintains an equipment testing and research department that works with new products brought to it for consideration, and also maintains a constant check on products already in use. Publishes equipment specifications annually in the ABC constitution, Rules and specifications. Standard developed for lanes, bowling balls, pins, pinsetting machines, automatic scorers, and foul detectors. Equipment specifications are printed annually in the ABC Constitution, Rules and specifications book.

Distributed directly.

Absorbed the United States Seniors Bowling Association (1964)

bowling; recreation;

\section{AMERICAN BRUSH MANUFACTURERS ASSOCIATION}

Taylor Fernley, Managing Director

1900 Arch Street

Philadelphia, Pennsylvania 19103

(215) 564-3484

FAX : (215) 564-2175

Founded: 1918

Trade Association

Standards Developer

ANSI B165.1 and B165.2.

The national trade association representing manufacturers of brushes, brooms, and mops, together with suppliers of parts, materials, machinery, and services. ABMA maintains several divisions organized by type of product including paint applicator, personal, household maintenance, broom and mop, and industrial.

All current standard activities are conducted by the safety and standards Committee of the Industrial Division, which works closely with ANSI. The main thrust of two standards developed to date is concern with safe operation of power driven rotary wheeltype brushes. ANSI B165.1 (1979) defines safety requirements for the design, care and use of power driven brushing tools; and ANSI B165.2 (1982) covers safety requirements with wood, plastic, or composition hubs and cores. 
Type of

Organization

Standards

Development

Standards

Designation

Government

Adoption

Certification

\author{
Frank J. Iarossi, Chairman \\ Two World Trade Center, \\ 106th Floor \\ New York, NY 10048 \\ (212) 839-5000
}

FAX: (201) 839-5130

Founded: 1862

Standards Staff: 12

Technical Society

Standards Developer

Established and administers standards called "Rules" for the design, construction, and periodic survey of merchant ships and other marine structures; publishes 15 volumes of Rules and 31 guides; and publishes the Record, a registry of merchant vessels.

ABS prefix.

Over 100 governments recognize ABS to act on their behalf by conducting surveys and issuing certificates relating to various international maritime conventions. ABS is authorized by USCG to act on their behalf in reviewing plans and inspecting United States flag vessels which are certified by the USCG. USCG also recognizes $A B S$ to perform admeasurement of vessels and issue tonnage certificates on their behalf. Under the Merchant Marine Act of 1920, ABS is recognized as a United States Government agency for classification of merchant vessels that it may own.

ABS has separate volumes of Rules and Requirement for the Certification of Cargo Containers and for Cargo Gear. Also, classification involves various certifications to provide assurance that the ABS Rules are met, such as those for design plans, machinery components, welders, etc. ABS also provides certification services according to other recognized standards or client-specified standards. 
An international ship classification society and nonprofit corporation. Objectives include: preparation of standards, known as "Rules" and "Guides", for the construction of hulls and machinery of ships and other marine structures, including material specifications and regulations for periodic surveys. Standards published annually and modified to keep pace with developments in shipbuilding and marine engineering; analysis of plans for vessels projected to be built or reconversions of existing vessels to verify that they meet the standards set by the rules; verification of the building to approved plans of the new hull and its main machinery, boilers and vital auxiliaries, and the construction for hull and machinery as required by the Rules; carrying out periodic and damage surveys as called for by the Rules; annual publication of the Record of the American Bureau of Shipping, which contains essential details of hull and machinery and survey status of bureau-classed vessels; issuance of certificates of character for bureau-classed vessels, i.e., classification certificates, seaworthy certificates, confirmation of class certificates, etc.

standardization Activities

Availability

Formerly

Keywords
Promulgates and annually updates its Rules through committees composed of individuals internationally eminent in their marine field.

standards distributed directly through all offices of ABS.

American Shipmaster's Association (1862-1898)

merchant ships; vessels; marine engineering; transportation; containers; safety;

AMERICAN BUS ASSOCIATION

George T. Snyder, Jr., President and CEO

1100 New York Avenue, NW, Suite 1050

Washington, DC 20005-3934

(202) 842-1645

FAX: (202) 842-0850

Founded: $1926 \quad$ Standards Staff: 3

Type of

Organization

Representation
Trade Association

Works through other organizations to develop standards

Department of Transportation, Interstate Commerce Commission 
A trade organization of the intercity bus industry with more than 700 motor coach owner and tour company members in the United states, Canada and Mexico. Its members operate charter, tour, regular route, airport express, special operations and contract services. Another 2300 members are travel and tourism organizations and suppliers of bus products and services who work in partnership with the North American motor coach industry.

Standardization Activities
Formerly

Keywords
Concerned with the development of standards and requirements in matters affecting motor carrier and motor vehicle safety and occupational safety and health. Included are operation, maintenance, and inspection of vehicles, safety-related parts and accessories such as brakes, tires, lights, windows, seats, etc.; control of noise and pollutant emissions; and accident reporting. Cooperates with the U.S. Department of Transportation, and participates in the work of voluntary groups. Works with federal and state legislative groups in connection with standardization of vehicle sizes and weights.

Also works with the Interstate Commerce Commission and other interested Government agencies, and industry groups in connection with standards and requirements relative to such matters as accounting, reporting of financial and operating data, certification of operating authorities, and vehicle registration.

Association committees and staff representatives are primarily responsible for its standardization activities. Included are committees on safety and Ethics.

Motor Bus Division of American Automobile Association National Motor Bus Division of American Automobile Association National Association of Motor Bus Operators (1960)

bus transportation; transportation; vehicles; motorcoach tours; charters; intercity bus;

Robert A. Reinfried, Executive Secretary

9384-D Forestwood Lane

Manassas, VA 22110

(703) $330-7079$

FAX : (703) 330-7984

Founded: 1981 
Type of

Organization

Representation

scope

Standardization

Activities

Formerly

Keywords
Trade Association

Works through other organizations to develop standards

7 members active in ACA standardization serving on ASME, ANSI, and ISO standards committees

Manufacturers of sprocket-driven chain and sprockets for power transmission and the conveyance of materials.

Active in standardization of dimensions of roller, silent, engineering steel and malleable iron chains, sprockets and wheels for the purpose of securing interchangeability, and also in recommendations for standards for power capacity and speed for these chains. Does not publish standards, preferring to sponsor standards for adoption through the procedures of the American National Standards Institute (ANSI). Cooperates with the American Society of Mechanical Engineers, Society of Automotive Engineers, American Petroleum Institute, Conveyor Equipment Manufacturers Association, and the American Gear Manufacturers Association in standardization matters of mutual interest. ANSI standards covering chain include B29.1 through B29.25M. Participates in the work of Technical Committee 100 of the International Organization for Standardization.

Association of Roller and Silent Chain Manufacturers and Malleable Chain Manufacturers Institute

American Chain Sprocket Chain Manufacturers Association

chain; sprockets; power transmission; machinery;

\section{AMERICAN CHEMICAL SOCIETY}

COMMITTEE ON ANALYTICAL REAGENTS

Clarence Lowery, Chairman

c/o Books Department

American Chemical Society

1155 Sixteenth Street NW.

Washington, DC 20036

(202) 872-4600 FAX: (202) 872-4600

WWW: http//www.acs.org/

Founded: $1876 \quad$ Standards Staff: 3

Type of

Organization

Standards

Development
Scientific Society

Standards Developer

63 existing standards for reagents; 15-30 under development or revision. None processed through ANSI. 
Standards

Designation

Scope

Standardization

Activities

Availability

Formerly

Keywords
ACS prefix.

Sets standards by which manufacturers can classify their reagents for sale as ACS Grade. Reagents labeled as such are known to purchasers to be of a certain purity and to meet certain maximum and minimum requirements.

Develops and publishes standards for reagent chemicals that have utility in analytical chemistry work. Revises existing standards with new and improved methods. Considers new standards for additional useful reagents. Standards and revisions are available for review by nonmembers. Publishes specifications in a volume titled "Reagent Chemicals" at approximately 5-year intervals.

Distributed directly.

Committee on the Purity of Chemical Reagents (1903-27)

chemicals; reagents; analysis; testing; materials;

AMERICAN COLLEGE OF SURGEONS

Paul A. Ebert, MD, Director

55 East Erie Street

Chicago, Illinois 60611

(312) 664-4050

FAX: (312) 440-7014

Founded: 1913

Type of

Organization

standards

Development

Scope

Standardization

Activities
Professional Medical Society Standards Developer

The national organization responsible for the standardization and approval of hospital cancer programs in the United states.

An association of 54000 surgeons organized for the primary purpose of improving the quality of care for the surgical patient by elevating the standards of surgical education and practice.

Cooperates with other recognized national medical organizations in the accreditation of hospitals and in the approval of graduate training programs in general surgery and the surgical specialties. Active in the establishment of medical instrumentation standards through its representative who serves on a committee of AAMI. 
Availability

Keywords
Distributed directly.

medical care; surgery; medical training; cancer; medical treatments; trauma;

\section{AMERICAN CONCRETE INSTITUTE}

Paul C. Breeze, Director of Engineering

22400 West Seven Mile Road

Detroit, Michigan 48219

(313) 532-2600

Founded: 1905

FAX: (313) 538-0655

Standards Staff: 6
Type of

Organization

Standards

Development

Standards

Designation

Government

Adoption

Certification
Technical Society

Standards Developer

Standards Developer since 1906; 30 active standards, including 3 metric, plus 130 committee reports; 3000 members participate in standards activities; most standards processed through ANSI; draft standards available for review.

ACI prefix.

The Department of Defense has adopted a number of ACI standards.

ACI administers the following certification programs: Concrete Field Testing Technician, Grade I; Concrete Laboratory Testing Technician, Grades I and II; Concrete Construction Inspector-inTraining; Concrete Construction Inspector, Concrete Transportation Inspector In-Training; Concrete Transportation Construction Inspector, Concrete Flatwork Finisher, and Concrete Flatwork Technician.

ACI accredits equivalent certification programs administered by other organizations.

Devotes its efforts to the solution of technical requirements related to the design, construction, and maintenance of concrete and reinforced concrete structures, and to the dissemination of information in this field. 
standardization Activities

Availability

Formerly

Keywords
One hundred and ten technical committees study specialized problems through the evaluation of published information, research reports, and majority opinion based on field practices, leading to the development of committee reports. Many committee reports evolve into standards after technical review and discussion by the membership and letter ballot of the members.

Standards are confined to codes, specifications, and standards practices related to structures as a whole. Basic materials and "over-the-counter" components are deliberately excluded from the scope of its standardization procedures.

Distributed directly and through Global and IHS.

National Association of Cement Users (1913)

concrete; reinforced concrete; prestressed concrete; structural design; construction; restoration; repair;

\section{AMERICAN CONCRETE PAVEMENT ASSOCIATION}

\begin{tabular}{|c|c|}
\hline & $\begin{array}{l}3800 \text { North wilke Road } \\
\text { Suite } 490 \\
\text { Arlington Heights, Illinois } 60004 \\
\text { (708) } 966-2272 \\
\text { FAX: (708) } 394-5610\end{array}$ \\
\hline & Standards staff: 2 \\
\hline Type of & Trade Association \\
\hline Organization & Standards Developer \\
\hline scope & $\begin{array}{l}\text { Represents } 500 \text { construction firms, material suppliers and equip- } \\
\text { ment manufacturers on matters affecting the industry's relations } \\
\text { with the public and public agencies. Seeks to improve the quality } \\
\text { of concrete pavement and create new markets for members. }\end{array}$ \\
\hline $\begin{array}{l}\text { Standardization } \\
\text { Activities }\end{array}$ & $\begin{array}{l}\text { Prepares guide specifications on concrete pavement } \\
\text { construction, fast track concrete paving, rehabilitation, resur- } \\
\text { facing, and restoration. Cooperates with state, federal and local } \\
\text { agencies in reviewing their specifications. provides upon request } \\
\text { recommendations regarding concrete pavement design and construc- } \\
\text { tion. }\end{array}$ \\
\hline Reywords & concrete; pavement; construction; materials; \\
\hline
\end{tabular}


Jeffrey I. Enyart, President

8618 Westwood Center Drive, Suite 105

Vienna, Virginia 22182

(703) 821-1990 FAX: (703) 821-3054

e-mail: jenyart@ix.netcom.com

Founded: $1907 \quad$ Standards Staff: 2

Type of

Organization

Representation

scope

Standardization Activities
Trade Association

Works through other organizations to develop standards

An international trade association representing the precast concrete pipe industry. Activities include research, technical services, promotion, advertising, education, safety, and the publication of technical and industry information. Members produce concrete pipe, box sections, and related products for storm sewers, sanitary sewers, and culverts; drain tile; irrigation systems; and low-head pressure systems.

Not a standards developing organization, but works within the voluntary standards system to coordinate concrete pipe industry standards activities and acts as the industry voice.

Industry-related products are covered by national consensus standards developed by ASTM, AASHTO, and AREA. Manufacturing standards cover precast concrete products, such as non-reinforced pipe for sewers, culverts, drain tile, and irrigation; reinforced circular, arch and elliptical pipe, box sections, and manholes for sewers and culverts; reinforced circular pipe for low-head pressure systems; and perforated pipe. Other manufacturing standards cover joints, jointing materials, and resilient connectors for pipe to structure connections. Proof of design and quality assurance are covered by plant test methods standards. Acceptance of installed products is covered in standards practices for various field tests. Design standards for pipe and box sections cover determination of loads, stresses, and required structural strength.

sewer; culvert; irrigation; drain tile; construction; 
Type of

Organization

Representation

scope

Standardization

Activities

Keywords

David P. Posser, President

8618 Westwood Center Drive, Suite 105

Vienna, Virginia 22182

(703) $839-4350$

FAX: (703) $821-3054$

Founded: 1949

Standards staff: 2

Trade Association

Works through other organizations to develop standards

Primarily ASTM and AWWA

An international trade association representing the concrete pressure pipe industry. Activities include research, technical services promotion, public relations, advertising, education, and liaison with technical societies and government agencies. Its members produce precast concrete pressure pipe for transmission lines in irrigation, industrial and domestic water-supply systems, as well as distribution feeder mains, pressure siphons, sewer force mains, and sewer outfall lines.

Not a standards developing organization, but works within the voluntary standards system to coordinate concrete pressure pipe industry standards activities and acts as the industry voice.

Products of the industry are covered by national consensus standards developed by the American society for Testing and Materials (ASTM) and the American Water Works Association (AWWA). Manufacturing standards cover reinforced concrete pressure pipe, reinforced concrete cylinder pipe, pretensioned concrete cylinder pipe, and prestressed concrete cylinder pipe.

water-supply; sewage; construction;

AMERICAN CONFERENCE OF GOVERNMENTAL INDUSTRIAL HYGIENISTS

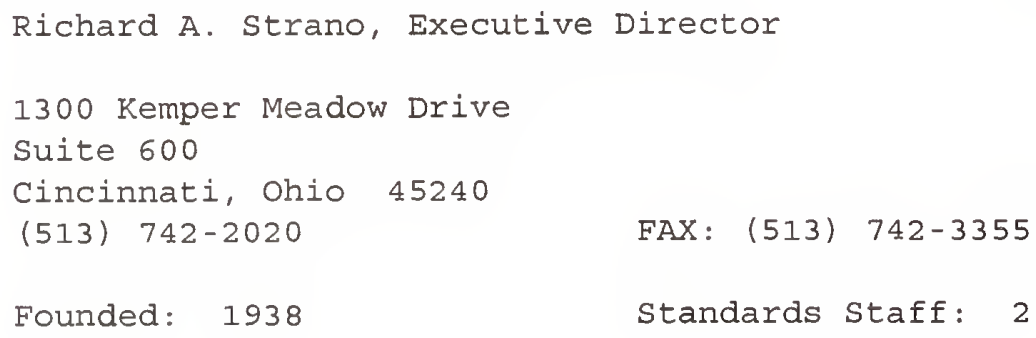


Type of

Organization

Standards

Development

Government

Adoption

Secretariats

Scope

Standardization

Activities

Availability

Keywords

AMERICAN CONGRESS ON SURVEYING AND MAPPING

Type of

organization

Certification

Scope
Professional Society

Standards Developer

Standards developer since 1940's.

750 Documentations defining Threshold Limit Values and Bio-Indices.

Various federal agencies, including OSHA, Department of Labor.

Threshold Limit Values for Chemical Substances Committee.

Threshold Limit Values for Physical Agents Committee.

Industrial ventilation Committee.

A national professional association of practicing industrial hygiene and occupational and environmental safety and health personnel. Assembles guides, recommends practices, and develops technical background for the evaluation and control of the occupational environment.

Develops and annually revises the Threshold Limit Values which are recommended on airborne contaminants and physical agents in workplaces. Used by professionals with direct responsibilities for worker health protection. Publishes the Industrial Ventilation Manual of Recommended Practices.

Sold directly in paper and CD-ROM.

industrial hygiene; airborne contaminants; occupational safety; Threshold Limit Values; Bio-Indices; industrial ventilation; public health; government officials;
John Lisack, Executive Director

5410 Grosvenor Lane

Bethesda, Maryland 20814

(301) 493-0200 FAX: (301) 493-8245

Founded: 1941

Professional society

Works through other organizations to develop standards

Hydrographic Surveyor Certification Program since 1984.

A national professional association representing 11000 members in the fields of surveying and mapping; composed of three member organizations: National Society of Professional Surveyors (NSPS), 
American Association for Geodetic Surveying (AAGS), and American Cartographic Association (ACA).

Standardization Activities

Keywords
Cooperates with ASCE, ANMC, International Cartographic Association (ICA) and International Federation of surveyors (FIG) to promote standards in the fields of land and geodetic surveying and cartography.

Developed 1989 Digital Cartographic Data Standards. Works voluntarily through committees.

surveying; mapping; cartography; data processing;

AMERICAN CRYSTALLOGRAPHIC ASSOCIATION

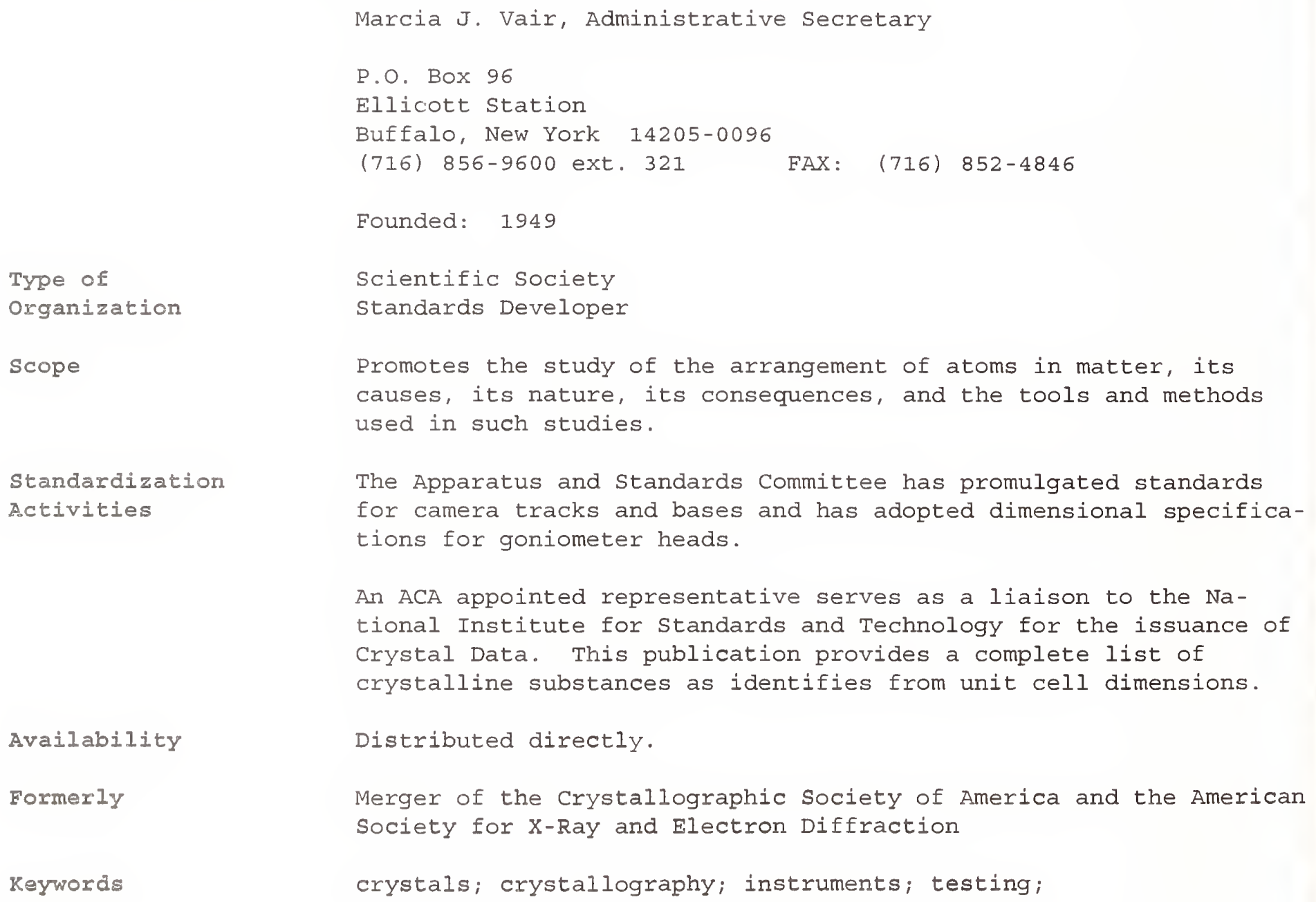

Standardization Activities

Availability

Formerly

Keywords

The Apparatus and Standards Committee has promulgated standards for camera tracks and bases and has adopted dimensional specifications for goniometer heads.

An ACA appointed representative serves as a liaison to the $\mathrm{Na}-$ tional Institute for standards and Technology for the issuance of Crystal Data. This publication provides a complete list of crystalline substances as identifies from unit cell dimensions.

Distributed directly.

Merger of the Crystallographic Society of America and the American Society for $\mathrm{X}$-Ray and Electron Diffraction

crystals; crystallography; instruments; testing; 
Dr. Warren S. Clark, Jr., Chief Executive Officer

130 North Franklin Street Chicago, Illinois 60606

(312) $782-4888$

Founded: 1923

Trade Association

Standards Developer

Standards developer since 1923 for evaporated milk products, testing, and sanitation, since 1925 for dry milk products, and since 1971 for whey products.

The U.S. Department of Agriculture has adopted industry-recommended

standards for grades of nonfat dry milk, instant nonfat dry milk, dry whole milk and dry buttermilk. Developed common and usual names for whey and whey products that have been accepted by the FDA and were published as a Regulation in the Federal Register of September 4, 1981 (Vol. 46, No. 172, pp. 44434-42).

No certification, qualification, or accreditation programs.

A national trade association for the processed dairy products industry. Scope of activity includes evaporated and dry milk products, as well as whey and modified whey products, including lactose (milk sugar). Serves and promotes the interests of its members; enhances the acceptance and utilization of processed dairy products, maintains liaison and represents the industry in dealings with governmental agencies and legislative bodies; supports technical and marketing research; and assembles and disseminates statistics and other information.

Activities coordinated through Standards/Research Committee. Develops standards in the areas of product definitions/nomenclature; specifications and grade classifications; and sanitation for processed dairy products including evaporated milk, evaporated lowfat milk, evaporated skim milk, and evaporated filled milk; nonfat dry milk, instant nonfat dry milk, dry whole milk and dry buttermilk; whey, reduced lactose whey, reduced minerals whey, whey protein concentrate, and lactose. Accepted by the industry nationally and internationally. Cooperates with the Food and Drug Administration and the Department of Agriculture. Participates in the Codex Alimentarius program. 


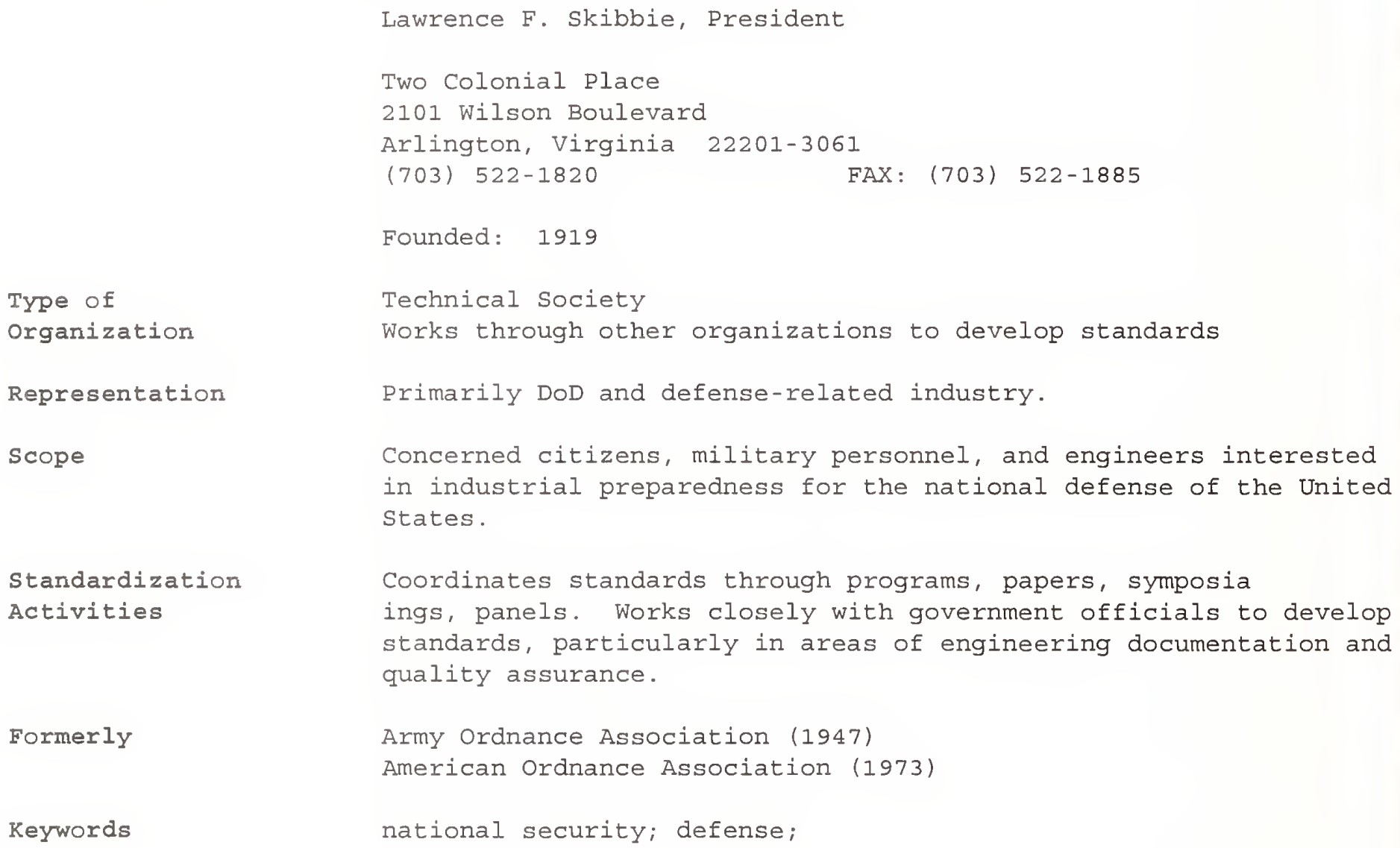

Keywords

national security; defense;

\section{AMERICAN DENTAL ASSOCIATION}

Sharon Stanford, Assistant Director, Dental Standards and Guidelines, Council on Scientific Affairs

211 East Chicago Avenue Chicago, Illinois 60611

(312) 440-2509

FAX: (312) 440-2536

e-mail: stanfors@ada.org

Founded: 1859

Standards Staff: 4 


\section{Type of}

Organization

Standards

Development

\section{Standards}

Designation

Government

Adoption

Certification

Secretariats

Scope (ASC MD156)

Standardization

Activities

Availability

Formerly

Keywords
Professional Society

Standards Developer

Specifications and certification program since 1928.

53 active standards - all American National Standards.

Working projects underway for 85 specifications.

Draft standards available for comment.

ANSI/ADA prefix.

The Department of Defense has adopted 3 standards.

Acceptance program based upon physical standards or guidelines; proof of biological, and clinical safety and effectiveness.

U.S. TAG for ISO/TC 106 Dentistry.

Working Group 2, Prosthodontic Materials of ISO/TC 106.

Accredited standards Committee MDI56 (ASC MDI56).

Nomenclature, standards and specifications for dental materials, except those recognized as drugs. Nomenclature, standards and specifications for dental instruments, equipment and accessories used in dental practice, dental technology and oral hygiene which are offered to the public or profession. Orthodontic, prosthetic, and restorative appliances designed or developed by the dentist for an individual patient are excluded.

Council on Scientific Affairs, acts as administrative secretariat and sponsor activities of ASC MD 156. The ADA also sponsors participation in ANSI activities of the International Organization for Standardization Technical Committee 106 on Dentistry. The ADA works both nationally and internationally in the formulation of standards for dental materials, instruments and equipment.

Distributed through ANSI.

National Dental Association (1897-1922)

Absorbed: Southern Dental Association (1897)

dentistry; dental materials, instruments and equipment; medical devices; health care; 
Rachel Howard, Executive Director

P O BOX 799

Rockville, Maryland 20848-0799

(301) 460-6875

FAX: (301) 460-8591

Incorporated: 1959

Type of

Organization

Scope

Standardization

Activities

Keywords
Professional Association

Works through other organizations to develop standards

Conducts educational programs relating to management, administration, performance, and instruction of design/drafting; sponsors councils; conducts an annual convention/exposition. Over 2000 members engaged in the manual and/or automated design and drafting fields.

Maintains a Standards Committee which reviews ANSI proposed standards relating to the design/drafting fields. Submits comments to ANSI relating to proposed and existing standards. Informs the membership of the release, cost, and availability of new standards.

design; drafting; interactive graphics; documentation; configuration management; change control; metric; data processing;

\section{AMERICAN ELECTROENCEPHALOGRAPHIC SOCIETY}

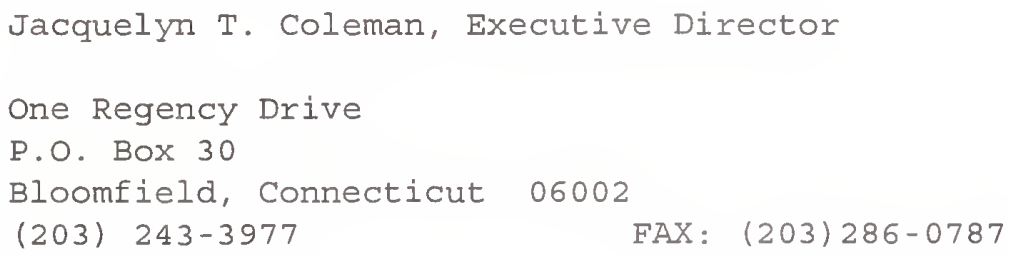

Furthers the knowledge of electroencephalography and related sciences, and promotes the exchange of scientific and professional information and opinions throughout the world.

Works to establish uniform standards, techniques, and procedures; assists in setting up standards for training, examination, and qualification of clinical electroencephalographers and techni- 
cians; draws up minimum specifications for apparatus and equipment to maintain high clinical standards.

Availability

Reywords

Distributed directly.

medical instruments; electroencephalography; neurology; health care :

\section{AMERICAN ELECTROPLATERS AND SURFACE FINISHERS SOCIETY}

Ted Witt, CEF, Executive Director

12644 Research Parkway

Orlando, Florida 32826

(407) 281-6441 FAX: (407) 281-6446

Founded: 1909

Type of

Organization

Representation

scope

Standardization Activities

Formerly

Keywords
Scientific Society

Works through other organizations to develop standards

ASTM, ANSI, ISO

Promotes all aspects of electroplating and surface finishing.

Participates in standards development pertaining to electroplated coatings. Relies on work of American Society for Testing and Materials (ASTM), Committee B-8 on Electrodeposited Metallic Coatings, and endorses the standards prepared by Committee B- 8 whose members are members of the American Electroplaters and Surface Finishers Society. Maintains formal representation on ASTM Committees A-5 on Corrosion of Iron and Steel, D-19 on Industrial Water, and B-7 on the Anodic Oxidation of Aluminum and Magnesium Alloys, as well as American National Standards Institute Committee $\mathrm{zg}$ on Safety Codes for Exhaust Systems. Holds Secretariat of ISO/TC 107.

National Electro-Platers Association of the United States and Canada (1913)

American Electroplaters Society

electroplating; metallic coating; materials; surface finishing; 


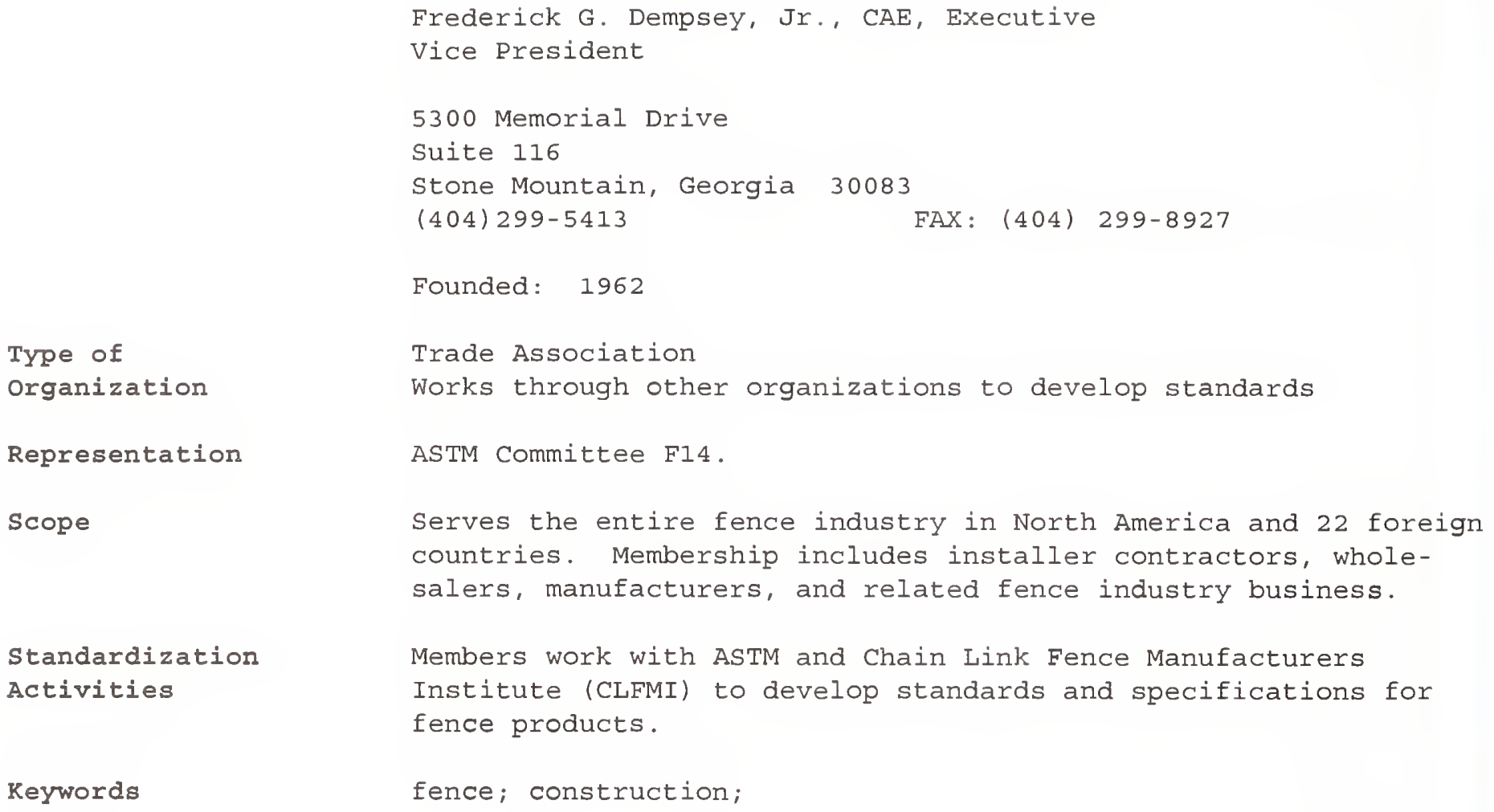

AMERICAN FIBER MANUFACTURERS ASSOCIATION

Type of

Organization

Representation

scope
Paul T. O'Day, President

115017 th street NW.

Washington, DC 20036

(202) 296-6508 FAX: (202) 296-3052

Founded: $1933 \quad$ Standards Staff: 1

Trade Association

Works through other organizations to develop standards

Fifteen member companies of MMFPA are represented by the Association's Technical Committee on committees and task groups of ASTM, ANSI, ANMC, and NFPA.

Membership represents 90 percent of the United states producers of manmade fibers and yarns. Functions on a national scale to present the industry's position before voluntary standards groups and those government agencies that develop or reference standards applicable to the overall textile industry. 
standardization Activities

Keywords
Not a standards developing organization. The association represents the industry before standards groups, such as ASTM, ANSI, and NFPA, concerned with flammability standards for textile products, including apparel and home furnishing items, such as carpets, draperies, and upholstered furniture. Cooperates with NIST, including the NIST Research Associate program, to develop meaningful and relevant flammability test procedures, such as the Carpet Flooring Radiant panel Test Method. Represents the industry before those groups which develop or reference methods and standards for other fiber/textile properties, performance and metrication. Monitors and develops appropriate actions of those government agencies which develop or reference standards impacting the man-made fiber/textile industry.

fiber; yarn; textiles; clothing; carpet; draperies; bedding; fire protection;

AMERICAN FOREST AND PAPER ASSOCIATION

Dr. Patricia Layton, Director, Energy and Materials Policy

Standards and Metrics Department

1111 19th street, NW

Suite 800

washington, DC 20036

(202) 463-2700

FAX: (202) 463-5180

Founded : 1993

Standards staff: 3

Type of

Organization

Representation

secretariats
Trade Association

Standards Developer

AASHTO, ACI, ANSI, ASHRAE, ASAE, ASCE, ASTM, NFPA, ISO, TAPPI.

ANSI NDS Committee.

ASCE LRFD Committee.

U.S. TAG to ISO/TC 6 (Paper, Board and Pulps).

The American Forest and Paper Association (AF\&PA) represents approximately 500 member companies and related trade associations (whose memberships are in the thousands) which grow, harvest, and process wood and wood fiber, manufacture pulp, paper and paperboard products from both virgin and recovered fiber, and produce solid wood products. As a single national association, AF\&PA represents a vital national industry which accounts for over 7 percent of the total U. S. Manufacturing output. 
standardization

Activities

Availability

Formerly

Keywords

\section{AMERICAN FOUNDRYMEN'S SOCIETY}

Type of

Organization

Standards

Development

Certification

Secretariats

Scope
AF\&PA develops design and construction guidelines and standards tc ensure the broadest acceptance of wood and wood products in construction and other uses. In addition, AF\&PA participates in number of standards developing committees related to the forest products industry as a whole. These committees include: ASTM D06 Paper and Paperboard; ASTM D07, Wood Products; ASTM E50, Environ mental Assessment; ISO/TC 6, Paper, Board, and Pulps; and ISO/TC 207, Environmental Management systems. Through its participation in these committees, AF\&PA contributes to the development of test methods used throughout the forest products industry and ensures that the interests of the forest products industry are fully represented in the evolving area of environmental performance standards.

Standards are available directly from AF\&PA.

The American Paper Institute (API - founded 1966) and the National Forest Products Association (NFPA - founded 1902) merged in 1993 to form the American Forest and Paper Association (AF\&PA).

wood; wood products; construction; building; paper; pulp;
Charles H. Jones, Executive Vice President

505 state Drive

Des Plaines, Illinois 60016

(708) 824-0181

FAX: (708) $824-7848$

Founded: 1896

Standards Staff: 1

Technical Society

Standards Developer

Standards developer since 1936.

Three active standards developed under ANSI.

No certification, qualification, or accreditation programs.

ANSI $2241 . x$

An international technical society for the metalcasting industry in North America. Develops and disseminates technical information regarding metallurgy, melting, coremaking, molding, sand practice, 


\section{Standardization Activities}

Availability

Formerly

Keywords

and control of both the internal and external environment. Sponsors research concerning all facets of the metalcasting process and environment. Through its Cast Metals Institute (CMI), prepares and presents short courses and seminars on various subjects of interest.

Participates on a number of standards writing committees of both ANSI and ASTM.

Available directly or through ANSI.

American Foundrymen's Association

casting; foundry; metallurgy; materials;

\section{AMERICAN FURNITURE MANUFACTURERS ASSOCIATION}

Joseph Ziolkowski, Technical Director

Post Office Box HP-7

223 Wrenn Street

High Point, North Carolina 27261

(919) $884-5000$

FAX : (919) 884-5303

Founded: 1984

Type of

Organization

Representation

Scope

Trade Association

Works through other organizations to develop standards

ASTM, ANSI, NFPA, UFAC.

A voluntary organization of furniture manufacturers dedicated to fostering the growth and development of the furniture industry and improving the effectiveness and efficiency of the furniture manufacturers.

Develops voluntary guidelines for woven and knit upholstery fabrics through the Joint Industry Upholstered Fabric Committee.

Works with the Upholstered Furniture Action Council (UFAC) to conduct research into more cigarette resistant furniture.

Established a Joint Industry Foam Standards Committee to develop guidelines and standards for the performance and use of urethane foam.

Developed voluntary guidelines for bunk beds through the Joint Industry Bunk Bed Committee which has now been turned over to Committee F-15 in ASTM. 
Formerly

Keywords
National Association of Furniture Manufacturers; Southern Furniture Manufactures Association

upholstery; textiles; furniture; consumer products ;

AMERICAN GALVANIZERS ASSOCIATION

Dr. Tom Langill, Technical Director

$12200 \mathrm{E}$. Iliff Avenue

Aurora, CO 80014

(800) 468-7732

FAX: (303) 750-2909

(303) $750-2900$

Founded: 1935

Type of

Organization

Representation

scope

Standardization

Activities

Reywords
Trade Association

works through other organizations to develop standards

Active on more than 15 standards committees of ASTM and NACE.

Members supply over 60 percent of the galvanizing after fabrication done in North America. Aims to improve the efficiency of the industry, to encourage the application of the latest advances in technology, and to promote the wider use of hot dip galvanized products. Activities include advertising and promotion, technical services and development management advisory services, and marketing.

Works within the voluntary standards system to coordinate industry standards activities and acts as the industry voice. Areas of involvement include coating standards for hot dip galvanized (zinc-coated) steel products such as: fasteners, castings, forgings, structural shapes, tanks, fencing, piping, grating, reinforcing bars, and structural plate. Represented on American Society for Testing and Materials subcommittees concerned with development and review of specifications for galvanizing and corrosion protection.

galvanizing; metallic coating; corrosion protection; materials; 
Allen J. Callahan, Manager, Standards

International Approval Services

8501 E. Pleasant Valley Road

Cleveland, Ohio 44131

(216) 524-4990

FAX: (216) 642-3463

e-mail: jcairns@apk.net

American Gas Association

1515 Wilson Boulevard

Arlington, Virginia 22209

(703) 841-8400

FAX: (703) 841-8406

e-mail: lingels@aga.com

Founded: 1918

Standards staff: 12

Type of

Organization

\section{Standards}

Development

Standards

Designation

Secretariats

Trade Association

Standards Sponsor

360 individuals active in standards development.

68 active standards.

ANSI Accredited Standards Programs.

Draft standards available for review.

International Approval services (IAS) is a joint venture of the American Gas Association (A.G.A.) Laboratories, and CGA Approvals, Inc. in Canada. IAS-U.S. is a wholly owned subsidiary of A.G.A. IAS provides standards secretariat services on behalf of A.G.A. for ANSI Accredited $\mathrm{Z} 21, \mathrm{Z} 83$ and $\mathrm{z} 223$ projects, and is an ANSI accredited standards developer for LC and NGV projects. ANSI Accredited $\mathrm{Z} 380$ and B109 projects are managed directly by A.G.A.

ANSI $\mathrm{Z21.x}$.

ANSI $Z 83 . x$.

ANSI $2223 . x$.

ANSI $B 380 . x$.

ANSI B109. $\mathrm{x}$.

ANSI LC $\mathrm{x}$.

ANSI NGV $x$.

Accredited Standards Committee Z21, Performance and Installation of Gas-Burning Appliances and Related Accessories, and its 19 technical subcommittees.

Accredited Standards Committee 283, Industrial Gas Equipment Installation and Utilization, and its five technical subcommittees.

Accredited Standards Committee Z223, National Fuel Gas Code, and its four advisory groups. 
Accredited Standards Committee B109, Gas Displacement Meters and Service Regulators

Accredited Standards Committee z380, Gas Piping Technology.

Certification

Scope

Standardization

Activities
IAS maintains testing facilities in Cleveland, Ohio, Irvine, California, and Toronto, Ontario, Canada. Engineering Centers provide regional testing and follow-up inspection services and are located in North Carolina, Tennessee, Texas, and British Columbia, Canada. IAS is a nationally recognized third party certification agency. Gas, electric and oil equipment, and natural gas vehicle (NGV) equipment submitted voluntarily by manufacturers are tested for compliance with the applicable national standards. In the absence of a national standard, IAS develops IAS Requirements for one-of-a-kind products. Products complying with these requirements also receive design certification. Products found in compliance with the standards/requirements can display the A.G.A. and CGA seals of design approval or listing symbol, and are included in the IAS Directory of Certified Appliances and Accessories. The production of certified equipment is monitored by regular follow-up factory inspections.

IAS also provides services in accordance with ISO 9000, and environmental management system registration in accordance with the ISO 14000 series standards.

A trade association composed of about 300 natural gas distribution, transmission, gathering and marketing companies in North America, which together account for more than 90 percent of the natural gas delivered in the United states. In addition, 30 natural gas organizations from countries around the world participate in A.G.A.'s international program.

Works within the voluntary standards system to coordinate activities relative to national standards of interest to the gas industry. While not a standards developing organization, the Association actively participates in national standards development, including appointment of Association representation in the areas of gas utilization equipment and its installation, and gas operating equipment and supplies.

Functions as the Administrative Secretariat to five Committees whose operating procedures are accredited by ANSI as demonstrating the principles of due process and consensus. These five committees have 30 technical subgroups; supervise 49 standards covering residential gas appliances and accessories, 14 standards covering commercial and industrial gas equipment, three standards on gas displacement meters, one pending standard on service regulators, a standard covering the installation of gas piping, appliances and appliance venting, and a standard guide for Gas Transmission and Distribution Piping Systems. 
Availability

Formerly

Keywords
In addition, IAS supervises one "LC" standard for corrugated stainless steel house piping, one pending "LC" standard For agricultural heaters, three "NGV" (natural gas vehicle) equipment standards, and eight pending "NGV" standards.

80 A.G.A. members and 26 staff participate in standardization activities of 62 standards developing committees of other organizations, including ASTM, ASME, NFPA, API and a number of American National standards Committees.

Standards distributed by A.G.A. and through ANSI, IHS and Global.

A.G.A. was formed by merger of the Gas Institute and National Commercial Gas Institute.

IAS is a joint venture of the A.G.A. laboratories and CGA Approval, Inc.

fuel gas; natural gas; energy; building; consumer products; appliances;

AMERICAN GEAR MANUFACTURERS ASSOCIATION

Joe T. Franklin, Jr., Executive Director

1500 King street

Suite 201

Alexandria, Virginia 22314

(703) 684-0211

FAX: (703) 684-0242

e-mail: agma@clark.net

Founded : 1916

Standards Staff: 2

Type of

Organization

Standards

Development
Trade Association

Standards Developer

35 committees, and 200 members participate in standards.

60 active standards; 37 processed through ANSI.

Draft standards and revisions available for review by interested parties. 
Standards

Designation

Secretariats

Scope

Standardization

Activities

Availability

Keywords
AGMA prefix.

Secretariat to ISO/TC 60 .

U.S. Technical Advisory Group to Iso/TC 60.

Membership includes a majority of the principal manufacturers of gears, speed reducers and increasers in the United States and Canada. Develops standards to promote a common language for the industry. Scope has increased to developing a wide variety of public and economic programs which assist member companies to compete more effectively. Through the Administrative Division supports 6 Councils concerning itself with marketing programs, public and government affairs as well as statistical information services.

Standards cover such areas as: gear industry nomenclature; gear specification drawings; hobs and shaper-cutters; application classification of gear motors and other types of speed reducers; standards on tooth form geometry; strength and durability formulas; inspection methods and practices; gear blank materials; lubrication of open or enclosed gearing; design and rating of speed reducers; spur, helical, herringbone, worm, bevel, fine pitch, aerospace gears. Standards committees are listed in the Annual AGMA Directory.

Maintains liaison with the American National Standards Institute, American Society of Mechanical Engineers, Society of Automotive Engineers, Metal Cutting Tool Institute, Cooling Tower Institute, Machinery and Allied Products institute, National Machine Tool Builders Association, American Petroleum Institute, and other technical organizations. Participates in the International Organization for standardization (ISO), through the facilities of ANSI. Also cooperates with the Federal Government in standardization activities.

Sold directly and through IHS and Global.

gears; gearing; speed reducers; gearmotors; lubrication; gear design; machinery; 
C. Curtis Peterson, Executive Vice President

1210 W. Northwest Highway

Palatine, Illinois 60067

(708) $934-8800$

Founded: 1976

Trade Organization

Standards Developer

Standards developed through ANSI.

ANSI/AHA prefix.

Government references ANSI/AHA standards in Government standards and guide specifications.

Quality Conformance Programs for Hardboard Siding based upon ANSI 135.6 .

Represents manufacturers of hardboard products used for exterior siding, interior wall paneling, household and commercial furniture, and industrial and commercial products. Serves as the central clearing house on industry and technical information for architects, builders, contractors, distributors, dealers, government agencies, and the general public. Coordinates industry effort for statistical reports, standard/specification programs, research activities, building codes, environmental affairs, educational publications, manufacturing and safety activities, and governmental relations.

Develops standards for hardboard, hardboard prefinished paneling, hardboard siding, and fiberboard products. Works with building code organization for effective utilization of these products. Administers a quality conformance program for hardboard siding.

Sold directly and through ANSI.

hardboard; fiberboard; building; materials; 
M. E. Rhett Flater, Executive Director

217 North Washington street

Alexandria, Virginia 22314

Organization

Representation

scope

standardization

Activities

Keywords
(703) 684-6777

Founded: 1943

Professional Society

Works through other organizations to develop standards

FAX: (703) 739-9279

Standards staff: 1

DoD, FAA, NASA, SAE, International Civil Aviation Organization (ICAO), JAA and other organizations.

A technical professional organization dedicated to the advancement of all types of vertical flight technologies. Membership includes all the major helicopter air frame, engine, and systems manufacturers worldwide. Provides the principal forum for the exchange of technical information pertaining to the realm of vertical flight. Representation includes military and civil, governmental and educational institutions and activities. Maintains a specialized technical reference library.

Maintains 13 technical committees with interests in acoustics, aerodynamics, aircraft design, avionics and systems, crash safety, commercial aerodynamics, operators, dynamics, handling qualities, icing manufacturing and product assurance, propulsion, structures and materials, test and evaluation, crew stations and human factors, flight simulation, military operations, and product support.

vertical flight; helicopter; rotorcraft; aerodynamics; aeronautics; propulsion; avionics; acoustics; defense; aerospace; transportation;

AMERICAN HOSPITAL ASSOCIATION

Douglas S. Erickson, Director Design and Construction

Office of Health Facilities Management

One North Franklin Avenue

Chicago, Illinois 60606

(312) 422-3858

FAX: (312) 422-4571

Founded: 1898 
Keywords
Trade/Professional Association

Works through other organizations to develop standards

National Institute of Standards and Technology, Agencies within the Department of Health and Human Services and the Department of Labor, ANSI, NFPA, ASTM, EPA, OSHA and others.

Provides education, research, and representation services for 5000 hospitals, health care systems, networks and other providers.

The Office of Health Facilities Management has the primary responsibility for codes and standards advocacy activities related to hospital planning, design, engineering, equipment, supplies and facilities management. Maintains liaison with national organizations and government agencies concerned with the development of standards. Major goal is the development of standards which are based on knowledge, cost/benefit analysis and a statistical profile establishing need.

Liaison activities include recommendation, review, revision and testimony on standards. Actively participates in the development of standards for: fire and life safety; hospital engineering; equipment and facilities; infection control; hospital supplies; and environmental issues.

hospital; life safety; material management; hospital equipment; health care; facilities management;

\section{AMERICAN HOTEL AND MOTEL ASSOCIATION}

Kenneth F. Hine, Executive Vice President and Chief Executive Officer

1201 New York Avenue, NW

washington, DC 20005-3917

(202) 289-3100

FAX: (202) 289-3104

Founded: 1910

Standards staff: 2

\section{Type of}

Organization

Representation

Scope
Trade Association

Works through other organizations to develop standards

ANSI, ASTM, UL.

An international trade association representing the hotel and motel industry with primary efforts directed to the United states. 
Standardization Activities

Formerly

Keywords
Cooperates with other organizations in standards development. Adoption of any standards by an individual hotel/motel property is solely on a voluntary basis. Maintains liaison with the National Fire Protection Association, the National Institute of Standards and Technology, the National Institute of Building sciences and the U.S. Fire Administration and the American Society for Testing and Materials. Works with the National Legislative Conference on Arson to support arson control.

Involved in code activities of Building officials and Code Administrators International, International Conference of Building officials, National Conference of states on Building Codes and Standards, Southern Building Code Congress International, and Western Fire Chiefs Association.

Active in ASME's development of USA Standards Safety Code for Elevators, Dumbwaiters, and Escalators; and USA Recommended Practice for the Inspection of Elevators. Represented on various committees of ANSI, ASTM, and UL.

American Hotel Protective Association (1917)

American Hotel Association (1962)

hotels; motels; safety; fire protection;

\section{AMERICAN INDUSTRIAL HYGIENE ASSOCIATION}

O. Gordon Banks, Executive Director

2700 Prosperity Avenue

Suite 250

Fairfax, Virginia 22031-4311

(703) 849-8888

FAX: (703) 207-3561

Founded: 1939 Standards Staff: 2

Professional Society

Standards Developer

ANSI 29 committee.

Objectives are to increase the knowledge of industrial hygiene through interchange and dissemination of information; promote the study and control of environmental factors affecting the health and well-being of workers in the workplace; correlate such activities as are conducted by individuals and agencies throughout industrial, educational, and governmental groups; and bring together persons interested in all aspects of the profession. Acts as clearinghouse for information on occupational health and safety. Brings together members of the profession through the 
formation of technical committees, local chapters and the conducting of continuing education course work and an annual meeting.

standardization

Activities

Keywords
This association operates as a standards developer, acting as secretariat for ANSI's 79 committee and through comments by the association's 44 technical committees on public policy.

industrial hygiene; environmental; occupational safety; public health;

\section{AMERICAN INSTITUTE OF AERONAUTICS AND ASTRONAUTICS}

James E. French, Director of Standards

1801 Alexander Bell Drive

3 rd Floor

Reston, Virginia 22091

(703) $264-7570$

FAX: (703) 264-7551

e-mail: standards@aiaa.org

Founded: 1963

Standards Staff: 2
Type of

organization

Standards

Development

Standards

Designation

Government

Adoption

Certification

Secretariats

Scope
Professional Society

Standards Developer

Standards developer since 1980; accredited by ANSI in 1987. Approximately 300 participants.

30 active standards; five distinctly metric.

66 percent American National standards.

Draft standards available for review directly.

Standard: ANSI/AIAA S-017-1991.

Recommended Practice: ANSI/AIAA R-004-1992.

Guide: ANSI/AIAA G-057-1994.

Special Report: A SP-069-1995.

Four adopted or referenced by DoD; one by DoT.

No certification, qualification, or accreditation programs.

ISO TC 20/SC 14, Space Systems and Operations.

Advances the arts, sciences, and technology of aeronautics and astronautics, and nurtures and promotes the professionalism of those engaged in these pursuits. Serves the needs and professional interests of members, and improves public understanding of the profession and its contributions. 
Standardization

Activities

Availability

Formerly

Keywords

AMERICAN INSTITUTE OF ARCHITECTS

Type of

Organization

scope

Standardization

Activities
Directs activities toward achieving technical understanding in advance of new aerospace hardware and software designs and development. Works closely with the Department of Defense and National Aeronautics and Space Administration, encouraging direct participation of industry, academia and Government representatives in meetings and activities of the standards committees.

Distributed directly.

American Rocket Society (1930)

Institute for Aeronautical Sciences (1932)

Institute for Aerospace Science (1960)

aerospace; aeronautics; astronautics; spacecraft; launch vehicles; spacecraft; space systems;

Founded: 1857

Professional society

Works through other organizations to develop standards

Serves the needs and improves the capability of architects; conducts public relations and educational programs. Encourages the utilization of national consensus codes and standards.

Maintains liaison with model building code organizations and standards writing groups within the industry. Several hundred AIA members work within the framework of the AIA Codes and standards committee.

Issues a variety of contract forms and formulates recommendations concerning size and character of building product literature directed to the architect. Active in development of a uniform system for correlation of a specifications outline, a filing system for product data, and project cost accounting guide. 
Availability

Keywords
Directly and through IHS.

architecture; building ;

\section{AMERICAN INSTITUTE OF PHYSICS}

Marc H. Brodsky, Executive Director

One Physics Ellipse

College Park, Maryland 20740

(301) 209-3131

FAX: (301) 209-3133

Founded: 1931

Type of

Organization

scope

Standardization

Activities

Availability

Reywords
Scientific Society

standards Developer

A nonprofit membership corporation which promotes the advancement of physics and its application to human welfare.

Standards, including secretariats or Committees, are provided by the Acoustical society of America and the optical society of America. Both are Member Societies of AIP. AIP publishes and distributes standards for the Acoustical Society of America.

Distributed directly.

optics; acoustics;

\section{AMERICAN INSTITUTE OF STEEL CONSTRUCTION}

Neil w. Zundel, President

One East Wacker Drive

Suite 3100

Chicago, Illinois 60601-2001

(312) $670-2400$

Founded: $1921 \quad$ Standards Staff: 3

Type of

organization

Government

Adoption
Trade Association

Standards Developer

Specifications for structural steel for Buildings has been widely adopted by building code bodies and Government agencies. 
A nonprofit trade association representing and serving the fabricated structural steel industry in the United states. Improves and advances the use of fabricated structural steel through marketing and technical research aimed at developing the most efficient, safe, and economical design and fabrication of steel framed structures.

Provides a variety of services to the construction industry, design profession, and steel fabricating companies including specifications, technical publications, design aids, research and development programs, plus informational and educational services conducted nationally, plus quality certification programs.

Standardization

Activities

Availability

Keywords
Publishes the AISC Specification for the Design, Fabrication and Erection of structural steel for Buildings, and the Manual of steel Construction. Also publishes the AISC Code of standard Practice and a number of specifications for materials, products, and assemblies which may be used in steel framed structures. The specifications and the manual are accepted and used universally by architects, engineers, building code bodies and government agencies.

Distributed directly and through IHS and Global.

steel; structural; construction; building;

\section{AMERICAN INSTITUTE OF TIMBER CONSTRUCTION}

Matthew C. Mathias, Executive Vice President

7012 S. Revere Parkway

Suite 140

Englewood, Colorado 80112

(303) $792-7557$

FAX: (303) 792-0669

Founded: $1952 \quad$ Standards Staff: 3

Trade Association

Standards Developer

Standards developer since 1952.

200 members have opportunity to participate in standards activities.

15 active standards.

one processed through ANSI.

AITC prefix.
Standards

Designation 
Government

Adoption

Certification

secretariats

scope

standardization

Activities

Availability

Keywords
Adopted by local, regional, and state building codes and federal government agencies.

Licenses qualified timber lamination plants to mark and certify products as being in conformance with ANSI/AITC A190.I.

ANSI/AITC A190.1.

The American Institute of Timber Construction is the national technical trade association of the structural glued laminated timber (glulam) industry.

AITC's standardization activities are administered by the Institute's staff with the advice and assistance of the AITC Technical Advisory Committee. In addition to industry standards related to structural glued laminated timber and heavy timber construction, AITC has used the ANSI canvass procedure to develop ANSI/AITC A190.1, "Structural Glued Laminated Timber", which is the basis for the Institute's quality control certification program. ANSI and industry standards are adopted by building code agencies to govern the use of structural glued laminated timber. standards specify design and manufacturing requirements.

Sold directly.

wood; glulam; structural; laminated timber; construction; building ;

AMERICAN INSURANCE SERVICES GROUP

Gerald E. Lingenfelter, Vice President

Engineering and Safety Service

85 John Street

New York, New York 10038

(212) 669-0475

FAX: (212)669-0550

Founded: 1984

Standards Staff: 12

Type of

Organization

Representation

scope
Trade Association

Works through other organizations to develop standards.

ANSI, ASTM, NFPA, UL, etc.

This subsidiary of the American Insurance Association represents 325 companies providing commercial property casualty and liability insurance. Endeavors to reduce and control life and property losses as well as injuries, and damage to health and the environment thereby enhancing the general public's safety, health, and welfare. Publishes technical information reports on industrial safety and hygiene, fire protection, construction, crime preven- 
Standardization

Activities

Formerly

Reywords

AMERICAN IRON AND STEEL INSTITUTE

Andrew G. Sharkey, III, President

1101 17th street, NW.

Washington, DC 20036

(202) $452-7100$

FAX: (202) 463-6573

Founded: 1855

Standards staff: 2
Type of

Organization

Standards

Development

Standards

Designation tion, special hazards, workers' compensation, motor vehicle

Engineering and Safety service administers standardization

activities. Participates in nearly 100 standards writing committees of the American National standards Institute, National Fire Protection Association, American society for Testing Materials, Underwriters Laboratories Incorporated, and others that deal with vehicles, safety of personnel in the workplace, crime, and con-

Created by the merger of National Board of Fire Underwriters, Association of Casualty and surety Companies, and American Insuroccupational safety; crime prevention; motor vehicle safety; fire protection; industrial hygiene; product safety; insurance; environmental science; safety; construction; less control;

Trade Association

Standards Developer

Three design specifications.

As a result of early standardization efforts of the Automobile Manufacturers Association at the beginning of this century and present work by the society of Automotive Engineers and AISI, numerical designations of steels which only refer to chemical composition ranges and limits are often identified as AISI/SAE "Standard Steels." 
Government Adoption

secretariats

Scope

standardization

Activities

Availability

Formerly

Keywords
The design specifications are referred to in building codes and state and federal specifications for construction.

U.S. Technical Advisory Group for Iso Technical Committee 167 on Steel and Aluminum structures.

Activities include research, technology, and engineering, collection and dissemination of statistics, public distribution of information about the industry and its products, public affairs, and discussion of industrial relations, including health, safety, and hygiene.

Developed and published design specifications for cold-formed steel structural members and for light-gage cold-formed stainless steel structural members.

Actively supports standardization activities through participation in the work of standards boards and committees of American $\mathrm{Na-}$ tional standards Institute, American Society of Civil Engineers, American Society for Testing and Materials, National Fire Protection Association, and others.

Distributed directly and through IHS and Global.

American Iron and Steel Association (1912)

steel; stainless steel; structural members; construction; materials;

AMERICAN LADDER INSTITUTE

Joseph E. Ziemba, Executive Director

c/o Smith, Bucklin and Associates

401 North Michigan Avenue

Suite 2400

Chicago, Illinois 60611

(312) 644-6610

FAX: (312) 321-6869

Founded: 1935

Standards Staff: 1

Type of

organization

standards

Development

standards

Designation
Trade Association

Standards Developer

Standards Developer since late $1930 \mathrm{~s}$.

5 active standards.

All processed through ANSI.

ANSI $14 . x$. 
Scope

Standardization Activities

Availability

Keywords

AMERICAN LAMINATORS ASSOCIATION

Type of

Organization

Standards

Development

Standards

Designation

Certification

Scope

Standardization

Activities Panels.
Accredited Standards Committee, A14 Ladder Safety Committee.

A national trade association representing United states companies engaged in the research, development, manufacture, and safety of ladders. Represents its membership in industry matters.

Promotes uniform design and manufacturer specifications and ladder safety. Works with government bodies, particularly NIOSH, OSHA and CPSC, in addressing design questions. Participates in activities related to production equipment used in making ladders.

Current standards include: Al4.1 Portable Wood Ladder; A14.2 Portable Metal Ladder; Al4.3 Fixed Ladder; Al4.5 Portable Reinforced Plastic; A14.7 Rolling Ladders; A14.8 Ladder Accessories.

Sold directly through ANSI.

ladders; wood; metal; fiberglass; reinforced plastic; rolling ladder stands; industrial equipment; consumer products; safety; portable; fixed; accessories; step;

\author{
Arthur s. Langlie, Executive Director \\ P. O. Box 2209 \\ Seattle, Washington 98111-2209 \\ (206) 382-1671
}

Founded : 1984

Standards Staff: 1

Trade Association

Standards Developer

1 active standard.

ALA-1992: The Performance Standard For Thermoset Decorative

Self-certification by each manufacturing member.

A national trade association of the thermoset decorative panel industry with members throughout the United states and Canada.

American Laminators Association promotes thermoset decorative panels meeting the performance standard ALA 1992 under its registered trademark PERMALAM. Those panels are produced by ALA manufacturing members throughout the United States and Canada, and the panels are for decorative uses primarily in cabinetry, fixtures, furniture, and other interior uses. 


\section{AMERICAN LEATHER CHEMISTS ASSOCIATION}

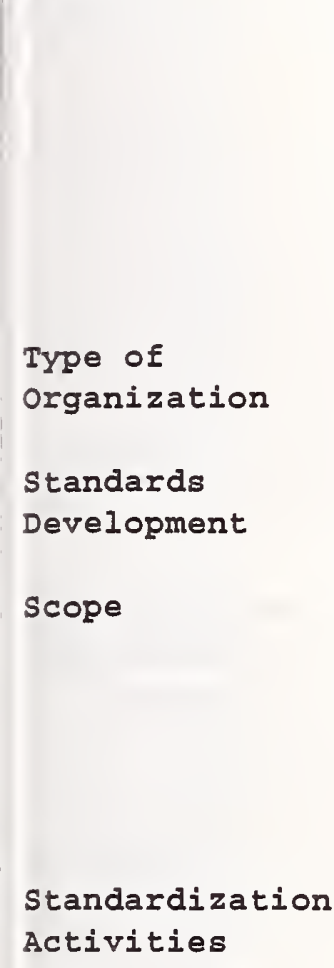

Velma Becker, Executive Secretary

c/o University of Cincinnati

P. O. Box 210014

Cincinnati, Ohio 45221-0014

(513) 556-1197

FAX: (513) 556-2377

Technical Society

Standards Developer

150 standard test methods.

Chemists, leather technologists, and educators concerned with the tanning and leather industry. Objectives are to devise and perfect methods for the analysis and testing of leathers and materials used in leather manufacture; to promote advancement of chemistry and other sciences in their application to leather related problems.

Maintains technical committees which develop methods of analysis and testing. Final methods published as the official methods of the association. Works with the American Society for Testing of Materials to coordinate physical test methods. Member of the International Union of Leather Chemists Society and participates in the development of methods for international use.

ALCA methods are incorporated in industry specifications. Members include representatives from government concerned with leather or leather products. Closely affiliated with the Leather Industries of America, formerly the Tanners Council of America. 


\begin{tabular}{|c|c|}
\hline & Elizabeth Martinez, Executive Director \\
\hline & 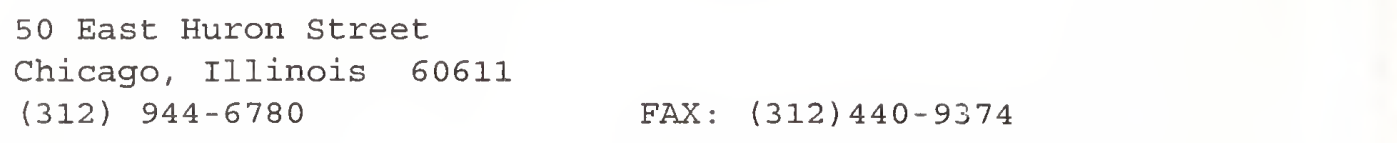 \\
\hline & standards staff: \\
\hline Type of & Professional Association \\
\hline Organization & standards Developer \\
\hline Representation & National Information standards Organization (NISO). \\
\hline Scope & $\begin{array}{l}\text { Promotes libraries and librarianship to assure the delivery of } \\
\text { user-oriented information service to all. Establishes standards } \\
\text { of service, support, education, and welfare for libraries and } \\
\text { library personnel; safeguards the professional status of librari- } \\
\text { ans; promotes popular understanding and public acceptance of the } \\
\text { value of the library service. }\end{array}$ \\
\hline $\begin{array}{l}\text { Standardization } \\
\text { Activities }\end{array}$ & $\begin{array}{l}\text { Develops standards and guidelines both quantitative and } \\
\text { qualitative for library service and Iibrarianship. Standards and } \\
\text { guidelines adopted by ALA or its units include College Library } \\
\text { Standards; standards for Faculty status for College and University } \\
\text { Libraries; standards for University Libraries; statement of } \\
\text { Quantitative Standards for Two-Year Learning Resources Programs; } \\
\text { Library standards for Adult Correctional Institutions; Library } \\
\text { standards for Jails and Detention Facilities; Library standards } \\
\text { for Juvenile Correctional Institutions; Standards for Accredita- } \\
\text { tion; standards for Libraries at Institutions for the Mentally } \\
\text { Retarded; standards of Service for the Library of Congress Na- } \\
\text { tional Library service Network of Libraries Serving the BIind and } \\
\text { Physically Handicapped. }\end{array}$ \\
\hline & $\begin{array}{l}\text { Also works through committees and assists in the development of } \\
\text { uniform codes for analyzing and cataloging information. }\end{array}$ \\
\hline Availability & Sold directly. \\
\hline Keywords & library; librarianship; physically handicapped; education; \\
\hline
\end{tabular}


Type of

Organization

Representation

scope

Standardization

Activities

Formerly

Reywords
Richard D. Upton, CCE, President

P. O. Box 420288

2050 Stemmons Freeway

Dallas, Texas 75342-0288

(214) 698-9898

FAX: (214) 698-9899

Founded: 1943

Standards Staff: 1

Trade Association

Works with other organizations to develop standards

UL; Luminaire Harmonization.

Represents manufacturers of lighting fixtures, portable lamps, lamps (bulbs) and lighting accessories. Also represents lighting showrooms and manufacturers' representatives. Monitors and reacts to issues that affect UL listing of products and to regulatory changes that affect the industry. Conducts educational programs.

Actively involved with Underwriters Laboratories with matters affecting the UL standards for all lighting fixtures and portable lamps. Works with CSA to provide harmonization of standards between Canada and the United States. Works with NOM to enable importation of lighting products from Mexico.

American Home Lighting Institute

lighting; fixtures; track lighting; recessed; landscape lighting; low voltage;

AMERICAN LUMBER STANDARDS COMMITTEE

Thomas D. Searles, Executive Vice President

P.O. Box 210

Germantown, Maryland 20875

(301) 972-1700

FAX: (301) 540-8004

Founded: $1922 \quad$ Standards Staff: 5

Type of

Organization

Standards

Development
Standards Developing Organization

Standards Developer

Sets the standards under which virtually all of the lumber in the United states and Canada is produced. 
Government Adoption

Scope

Standardization

Activities widely used by federal and local government agencies.

This committee serves in the Department of Commerce's Voluntary Product standards Program. It maintains PS 20, which provides terminology, classification of American standard Lumber, measurement and tally (sizes) requirements for grading rules, grade marking (labeling), inspection and reinspection (upon complaint), Committee functions, Board of Review (accreditation board) functions, the National Grading Rule Committee membership and functions, commercial names of principal softwood species, definitions of terms and lumber abbreviations. It is implemented through an internationally recognized consensus accreditation and certification program, the purpose of which is to provide for uniform, industry-wide grade marking and inspection of softwood lumber and the preservative pressure treatment of certain wood products. Its Board of Review accredits four grading agencies and six ruleswriting agencies in the United states and 15 grading agencies and one rules-writing agencies in the Canada to grade mark untreated lumber. It also accredits 4 laboratories and 8 agencies that supervise the labeling of the preservative pressure treatment of certain wood products using AWPA standards. The committee consists of 22 representatives and 22 alternate groups of lumber manufacturers, lumber inspection agencies, engineers, architects, home builders, wholesalers, retailers, millwork manufacturers, wood using industries and other consumers, as well as four ex officio nonvoting government agency representatives appointed by the secretary of Commerce.

Acts to consider revisions or amendments to the PS 20 . Elects a Board of Review and adopts policies used by the Board in carrying out its accreditation functions. Principal functions of the Board are to review and approve lumber grading rules submitted by agencies to assure they conform to the American Lumber standards requirements; reviews and approves grading agencies; and continuously reviews adequacy, competency and reliability of approved agencies. Elects a Board of Review and adopts policies used by the Board in carrying out its functions.

Principal functions of the Board are to review and approve rules submitted by agencies to ensure that they conform to the American Lumber standards requirements; review and approve grading agencies; and to continuously review adequacy, competency and reliability of approved agencies. 


\section{AMERICAN MEDICAL ASSOCIATION}

Aprac
Type of
Organiz

organization

\section{Standards}

Development

scope

\section{Standardization}

Activities

Availability

Reywords
James S. Todd, M.D., Executive Vice President

515 North state street

Chicago, Illinois 60610
(312) 464-5000

Founded: 1846

Professional society

Standards Developer

Develops advisory standards.

None processed through ANSI.
FAX: (312) $464-4184$

Standards Staff: 7
A national organization of physicians whose objective is to foster the advancement of medical science, medical practice, and the public health.

Develops advisory standards dealing with drug evaluation, diagnostic and the therapeutic technology assessment, guides to the evaluation of physical impairment, physical fitness standards for industry, undergraduate medical education, hospital residency training programs, and continuing medical education. Maintains close liaison with the Federal Government in matters of drug nomenclature (through the United States Adopted Names Council), medical and device evaluation at the post-marketing level of surveillance, and other issues of a scientific nature that arise in the practice of medicine.

Issues reports relating to guidelines for the determination of permanent impairment, and many other issues relative to the medical diagnosis and management of patient problems.

Distributed directly.

medicine; medical; drugs; health care; 
Type of

Organization

Scope

Standardization

Activities

Availability

Keywords
4330 East West Highway

Suite 1117

Bethesda, Maryland 20814

(301) 718-6508

FAX: (301) 656-0989

e-mail: anmcmetric@aol.com

Founded: 1973

Standards Staff: 1

Trade Association

Works through other organizations to develop standards

A private, nonprofit organization dedicated to planning, coordinating, and facilitating voluntary metric transition activities in various sectors of the United states economy. A focal point for private sector metric transition planning activity and information.

Distributes information about metric activities in the United States, Canada, and around the world. Publishes a newsletter and special issue papers. Conducts conferences, seminars, and educational workshops. Supplier of metric training and assistance publications and products.

Assists standards making bodies by identifying needs for standards in SI units, evaluating priorities, and making recommendations for standards development.

Distributed directly.

metric; measurement; international trade; manufacturing; business; general;

AMERICAN NATIONAL STANDARDS INSTITUTE

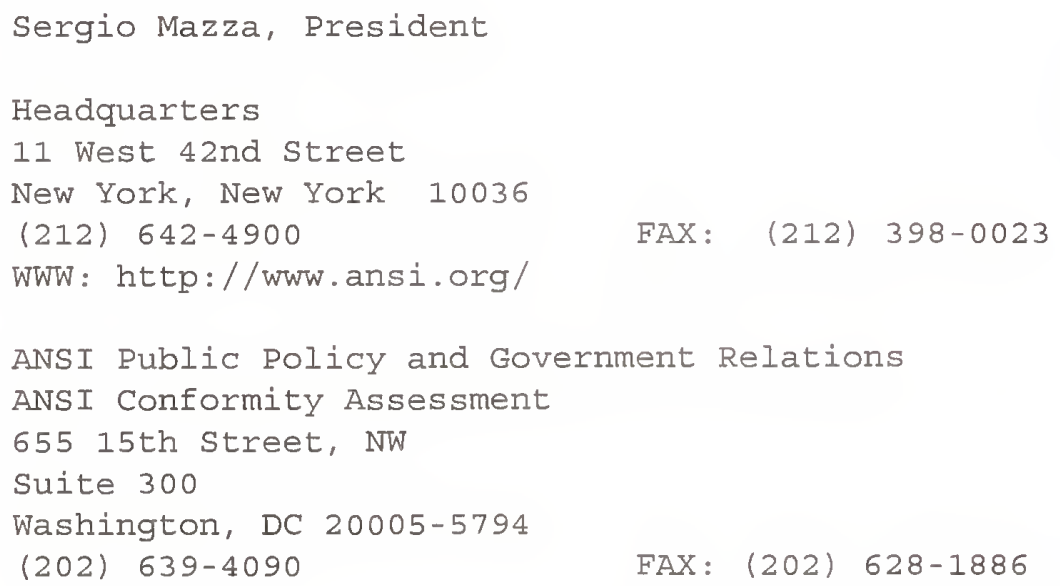


Type of

organization

Standards

Designation

Government

Adoption

Certification
Standards coordinating and approval organization. Does not develop standards.

11180 standards approved by ANSI are designated American National Standards.

American National Standards and ANSI's third party product accreditation programs are adopted and referenced by government at the federal, state, and local levels.

ANSI accredits third party product certification programs in accordance with ANSI $z 34.1$ and ISO/CASCO Guides. ANSI's program is nationally and internationally recognized. ANSI has established Memoranda of Understanding with several international accreditation organizations. Oversight of ANSI's accreditation programs is provided by the Accreditation Committee, which is comprised of government, certifier and industry representatives and operates under due process and consensus procedures. A list of accredited third party certification programs is available upon request.

ANSI jointly operates with the Registrar Accreditation Board, the American National Accreditation Program for Registrars of Quality Systems. Registrars are accredited to perform registrations/ certifications of organizations in accordance with ISO 9000 series standards. The ANSI/RAB program is nationally and internationally recognized. ANSI has established Memoranda of Understanding with several international accreditation organizations. The program is operated under due process and consensus procedures. A list of accredited registrars is available upon request.

ANSI is establishing a national program to accredit ISO 14000 Environmental Management systems (EMS) registrars, auditors, certifiers, and auditor training providers. Registrars already accredited to the ANSI/RAB ISO 9000 program will only be required to demonstrate compliance with any additional requirements that apply specifically to EMS activities.

The ANSI federation is a partnership of standards developers, trade associations, labor unions, professional societies, industry, consumers, academia and government agencies. ANSI does not write standards; it serves as a catalyst for standards development by its diverse membership. ANSI is a nonprofit privately funded membership organization that coordinates the United States volunary standards system to develop voluntary standards. 265 professional and technical societies, and trade associations that develop standards in the United States are members of ANSI; 1100 companies are members. 
Standardization Activities
ANSI performs the following major functions:

- coordinates the development of voluntary national standards in the United States;

- approves standards as American National Standards;

- enables United States participation in non-treaty international standards developing organizations, such as the International Organization for Standardization (ISO), the International Electrotechnical Commission (IEC), and the European Telecommunications Standards Institute (ETSI);

- serves as the United States source and information center for strategic standardization and for all American National

Standards and those issued by ISO, IEC, and their members;

- maintains interface with government at all levels on standards related matters.

National Coordination -

Coordinates and harmonizes private sector standards activity in the United States and accreditation of standards developers. It assists participants in the voluntary standards system to reach agreement on the needs for standards, encourages qualified organizations to develop them, and follows up on progress. It provides standards developers with procedures and services to use their resources effectively, avoid duplication of effort, and resolve conflicts.

Approval of American National Standards -

Standards are approved by ANSI as American National Standards when ANSI finds that its criteria for due process have been met and that a consensus for approval exists among those directly and materially affected.

International Management and Coordination -

ANSI is the United States member of the International Organization for Standardization (ISO) and, through the U.S. National Committee, the International Electrotechnical Commission (IEC). The Institute manages, coordinates, and provides financial and administrative support for United States participation in these two major nongovernmental standards developing bodies. With the support of its members and other cooperating bodies, the Institute participates in some 2000 ISO technical committees and subgroups. It administers the secretariats of 30 Iso technical committees, 88 subcommittees, and 392 working groups. It helps govern Iso through membership on its Council and Executive and Planning committees. 
The U.S. National Committee of IEC, which is a committee of ANSI, participates in 90 percent of the International Electrotechnical Commission's technical programs and is represented on IEC's policy-making council and committees. It holds the secretariat of 13 IEC technical committees and 20 subcommittees.

Clearinghouse and Information Center -

Serving as the clearinghouse and information center for national, international, regional, and foreign national standards is another of ANSI's functions. The following are available from ANSI:

All 11180 approved American National Standards.

ISO and IEC International Standards.

ISO and IEC Draft International Standards.

CEN Proposals - Draft European Standards developed and issued for preliminary vote by the European Committee for Standardization (CEN).

Draft specifications of the Electronic Components Committee of CENELEC - the European Committee for Electrotechnical Standardization.

Standards of 106 other national standards organizations that belong to ISO.

Latest catalogs issued by ISO, IEC, and their members.

Interface with Government -

Furnishes advice, counsel, and testimony to congressional committees and state and local legislative bodies. It encourages government agencies to participate in voluntary standards activities and to use voluntary standards, where appropriate. Close cooperative ties exist between ANSI and individual federal agencies. For example: The Department of Defense, General Services Administration, and National Institute of Standards and Technology are ANSI members. An ANSI-Consumer Products Safety Commission Coordinating Committee works to enhance overall cooperation between CPSC and private sector organizations that develop standards for consumer products and services. An ANSI-OSHA (Occupational Safety and Health Administration) Coordinating Committee performs a similar function in the area of standards for industrial safety.

American Engineering Standards Committee (1918);

American Standards Association (1928);

United States of America Standards Institute (1968); 
Type of

Organization

standards

Development

Standards

Designation

Government

Adoption

Secretariats

Scope

Standardization

Activities
Marilyn D. Weber, Manager, Standards Department

555 North Kensington Avenue

La Grange Park, Illinois

(708) 352-6611 FAX: (708) 352-6464

e-mail: mweber@ans.org

Founded: 1954 Standards Staff: 2

Scientific and Professional Society

Standards Developer

125 active projects.

103 approved standards.

All processed through ANSI.

Draft standards available for review.

ANS prefix.

A number of NRC Regulatory Guides reference ANS standards; several standards are referenced in the Code of Federal Regulations.

N16, Nuclear Criticality Safety.

N17, Research Reactors, Reactor Physics, and Radiation Shielding. N48, Radioactive Waste Management.

American Nuclear Society Nuclear Power Plant standards Committee (NUPPSCO).

A nonprofit, international, scientific, engineering and education organization. Aims to advance science and engineering related to the atomic nucleus and allied sciences and arts and to integrate the disciplines constituting nuclear science and technology.

Maintains a standards committee which ascertains the need for standards in the nuclear field, develops such standards, and cooperates with other organizations to develop standards. Maintains 16 subcommittees in the areas of nuclear design criteria, reactor operations, performance criteria, radiation protection, nuclear criticality safety, research reactors, reactor physics, computational methods, fuel and waste management, and environmental remediation of radioactively contaminated sites. 
Sold directly and through ANSI and Global. Microform and CD-ROM copies are available through Information Handling Services.

reactor; radioactive waste; nuclear; nuclear power plant; radiation shielding; energy; safety; criticality safety; research reactor; and environmental remediation;

\section{AMERICAN OCCUPATIONAL MEDICAL ASSOCIATION}

Donald L. Hoops, Ph.D., Executive Vice President

55 West Seegers Road

Arlington Heights, Illinois 60070

(708) $228-6850$

Founded: 1916

Standards Staff: 1

Type of

organization

Certification

Scope

Standardization

Activities

Availability

Keywords
Professional Society

standards Developer

Provides recognition of achievement and studies in Occupational Medical Practice via the Association's Basic Curriculum Program in occupational Medicine.

Represents the profession in matters pertaining to Occupational and Environmental Medical Practice.

Actively participates in various standards developing committees. Sets forth acceptable medical practices in the form of recommended guidelines. Comments on and suggests modifications to all related federal legislation.

Distributed directly.

occupational medicine; public health; health care; environmental; 
Type of

Organization

Standards

Development

Certification

scope

Standardization Activities

Availability

Formerly

Keywords

\author{
J. Lyon, Executive Director \\ P.O. Box 3489 \\ Champaign, Illinois 61826-3489
}

(217) 359-2344

FAX: (217) 351-8091

Founded: 1909 Standards Staff: 4

Scientific society

Standards Developer

Standards Developer since 1909.

300 committee members participate in standards activities.

410 active standards.

None processed through ANSI

The Society certifies Approved Chemists and Certified Laboratories through its Examination Board.

A scientific organization concerned with basic research on animal marine, and vegetable oils and fats, including their extraction, refining, use in consumer and industrial products, safety, packag. ing, and quality control.

Publishes the official Methods and Recommended Practices of the American oil Chemists society, a result of the work of various technical committees. Offers accurately tested and graded natura: bleaching earth, activated bleaching earth, refining cups and other materials, all designed for use with specific methodology.

Sponsors joint committees with the American society for Testing and Materials, Association of official Agricultural Chemists, and American Association of Cereal Chemists. Representation maintained on committees of the American Association for the Advancement of Science, National Fire Protection Association, National Research Council, U.S. Technical Advisory Group for ISO/TC 34, anc the Codex Alimentarius Committee on Fats and Oils.

sold directly.

Society of Cotton Products Analysts (1922)

fats; vegetable oil; fish oil; analysis; oil extraction; oil refining; food; laboratory testing; 
Earle L. Hunter, O.D., Executive Director

243 North Lindbergh Boulevard

St. Louis, Missouri 63141

(314) 991-4100 FAX: (314) 991-4101

Founded: $1898 \quad$ Standards Staff: 2

Professional society

Works through other organizations to develop standards

ANSI, ISO, IEC.

Council on optometric Education accredits and certifies schools and colleges of optometry in United States and Canada. The Commission on ophthalmic standards conducts a seal of Certification and Acceptance program for ophthalmic related products. Manufacturers can voluntarily submit products for evaluation. Those products that meet recognized standards or specifications adopted by the Commission are awarded the AOA seal of Certification or Acceptance for use in product labeling and advertising.

A nonprofit corporation representing doctors of optometry and students of optometry. A federation of associations representing each of the 50 states, the District of Columbia, and doctors of optometry in the armed forces. Objectives are to improve the vision care and health of the pubic and to promote the art and science of the profession of optometry.

The Commission on Ophthalmic standards serves as the coordinating body for AOA's activities with private and governmental groups in the development of standards and policies related to the quality of ophthalmic materials, instrumentation and procedures.

The Council on Optometric Education is the accrediting body for schools and colleges of optometry, as recognized by the U. S. Department of Education and the Council on Postsecondary Accreditation.

American Association of Opticians (1919)

education; optometry; ophthalmic products; vision; public health; 
Type of

Organization

Standards

Development

Standards

Designation

Representation

Government Adoption

Certification
R. L. Jones, Vice President, Industry Operations

1220 L Street, NW.

Washington, DC 20005

(202) 682-8000 FAX: (202) 682-8029

WWW: http://Www.api.org

Founded: $1919 \quad$ Standards Staff: 30

Trade Association

Standards Developer

Standards developer since 1919.

500 active standards.

100 industry committees and 1500 people active in standards work.

45 percent of API standards processed through ANSI.

5 percent published jointly with ASTM.

23 percent are adopted or being processed by ISO.

API standards are called standards, recommended

practices, publications, bulletins, guidelines, and specifications.

Members serve on committees of other organizations including the American Society for Testing and Materials, Society of Automotive Engineers, the American Society of Mechanical Engineers, the Institute of Electrical and Electronics Engineers, Instrument Society of America, National Fire Protection Association, Scientific Apparatus Manufacturers Association, American National Standards Institute, American Gear Manufacturers Association, National Association of Corrosion Engineers, Society for NonDestructive Testing, American Welding Society, Association of Drilling Constructors, American Gas Association, American Iron and Steel Institute, and the Association of Well-Head Equipment Manufacturers.

Department of Transportation, Department of Defense, Occupational Safety and Health Administration, U.S. Customs Service, the Environmental protection Agency, U.S. Geological Survey.

API issues a monogram to those field equipment manufacturers who produce equipment according to API standards. API also licenses companies to use API registered quality marks on their motor oils if they meet API specifications. API certifies inspectors of pressure vessels, above-ground storage tanks, and piping. API also administers a testing laboratory accreditation program. 
ISO/TC $67 / \mathrm{SC} 9$, Wellhead Equipment and Pipeline Valves. API/ASTM, Joint Committee on static Petroleum Measurement.

A national association encompassing all branches of the petroleum industry and composed of over 300 companies.

Activities directed toward fulfilling user-defined requirements of the industry and its customers. The Industry Operations group produces standards in the area of transportation, marketing, production, refining, measurement, safety and fire protection. Maintains liaison with other standardization bodies. Standards are primarily performance oriented, with some design and process specifications where appropriate. Standards used worldwide and offered for adoption to the International Organization of Legal Metrology and the International Organization for standardization.

Distributed directly and through IHS and Global.

petroleum; petroleum equipment; petroleum measurement; petroleum transportation; materials;

\section{AMERICAN PHARMACEUTICAL ASSOCIATION}

John A. Gans, Pharm. D., Executive Vice President

2215 Constitution Avenue, NW.

Washington, DC 20037

(202) 628-4410 FAX: (202) 638-3793

Founded: 1852 Standards staff: 2

Type of

Organization

scope

standardization Activities
Professional Society

Standards Developer

A national professional society with 45000 individual pharmacists and pharmaceutical scientists in the United states. Concerns itself with matters affecting the professional, technical, legal, and scientific aspects of the practice of pharmacy.

Primary standardization programs pertain to standards of practice for the profession of pharmacy. Responsible for the pharmacy profession's code of ethics. Through its Board of pharmaceutical Specialties, establishes criteria for specialization and certification of specialists within pharmacy. Participates jointly with other organizations in sponsoring and conducting a program known as the United states Adopted Names Council (USAN), for the establishment of standardized nonproprietary nomenclature for drugs. Through USAN, APhA is involved with the world Health Organization in developing international nomenclature for the naming of drugs. Also participates in programs of the Pan-American Health Organization and the Federation International Pharmaceutique. Maintains 
Availability

Keywords

AMERICAN PIPE FITTINGS ASSOCIATION

Type of

Organization

Representation

Scope

Standardization

Activities

Formerly

Keywords

suite N contact with the Food and Drug Administration; the Treasury Department, Alcohol and Tobacco Division; the Social Security Administration, Medicare Division; and the Justice Department, Drug Enforcement Administration. Co-found-er of the Pharmacy Technician Certification Board, developed to administer voluntary national certification of pharmacy technicians.

Distributed directly.

pharmaceutical; drugs; drug purity; nomenclature; health care; pharmacist; pharmaco therapy; pharmacy ethics; practice standards; pharmacy technician;

Clay D. Tyeryar, CAE, Executive Director

7297 Lee Highway

Falls Church, Virginia 22042

(703) 533-1321

FAX: (703) 241-5603

Founded: 1938

Trade Association

Works through other organizations to develop standards

Represented on the standards committees of MSSVFI and ANSI B16.

An association of American pipe fittings manufacturers and producers of pipe hangers and suppliers.

Although not a standards developing organization, encourages, contributes to, and cooperates in the development of standards for products within the scope of the association which will benefit the industry, its customers and the public.

Pipe Fittings Manufacturers Association (1964)

pipe hangers; pipe supports; building; construction; 
Melvin Sabshin, Medical Director

$1400 \mathrm{~K}$ street, NW.

Washington, DC 20005

(202) 682-6000 FAX: (202) 682-6114

Founded 1844

Type of

Organization

Scope

Standardization Activities

Availability

Formerly

Keywords
Professional Society

Works through other standards developer

A medical specialty organization which furthers the study of the nature, treatment, and prevention of mental disorders; contributes to the development of standards for psychiatric facilities; disseminates information and promotes psychiatric education.

Actively participates in development of standard classification for mental illness and the Diagnostic and statistical Manual for Mental Disorders. This is published by the APA and used throughout the world. Serves as consultant to the World Health Organization on the publication, International Classification of Diseases. Also, develops practice guidelines for treatments of psychiatric disorders.

Joins with the Accreditation Council for Graduate Medical Education and the Residency Review Committee for Psychiatry to establish standards for accreditation of residency training programs in psychiatry and serves as a member organization of the American Board of Psychiatry and Neurology, which administers an oral and written examination to certify physicians in psychiatry. Is represented on the Hospital Accreditation and Mental Health Professional and Technical Advisory Committees of the Joint Commission on Accreditation of Healthcare Organizations.

Activities are conducted through the APA Council on Medical Education and Career Development; the Council on Economic Affairs and its Committees on standards and Survey Procedures; and the Council on Research and its Task Force on Diagnostic and Statistical Manual IV, and its steering Committee on Practice Guidelines.

Distributed directly.

Association of Medical Superintendents of American Institutions for the Insane (1892)

American Medico-Psychological Association (1921)

psychiatry; health care; education; 
Type of

Organization

standards

Development

Certification

scope

Standardization

Activities

Availability

Keywords

\section{AMERICAN PUBLIC HEALTH ASSOCIATION}

Fernando M. Treviño, PhD., M.P.H., Executive Director

1015 15th street NW.

Washington, DC 20005

(202) 789-5600 FAX: (202) 789-5681

Founded: 1872 Standards staff: 2

Professional society

Standards Developer
Type of

Organization
Maintains Board of Professional standards with eight standards setting committees. Conducts site visits in conjunction with ceditation activities of new training facilities. Certifies

Distributed directly.

psychoanalysis; psychology; psychiatry; education;
FAX: (212) 593-0571

Standards staff: 4 
Professional organization of public health officials and practitioners which seeks to protect and promote personal and environmental health. Promulgates standards, establishes uniform practices and procedures, and publishes peer reviewed public health research.

standardization Activities

Availability

Keywords
Develops standards of procedures, personnel qualifications, and practice. Publishes and updates standard Methods for the Examination of Dairy Products; Standard Methods for the Examination of Water and Wastewater; and Standards for Healthful Housing. Publishes other works where standards are included, for example, Suggested Ordinance and Recommendations Covering Public Swimming Pools. Also publishes standard methods for the Microbiological Examination of Ambient Air.

Represented on various boards of the American National Standards Institute (ANSI) and cosponsors sectional Committee A40 on Minimum Requirements for Plumbing. APHA is involved in standards of accreditation for schools of public health. APHA develops policies and publications on such subjects as TB control, radiological health and chronic disease which serve as guides for practitioners, scientists, technologists, administrators, and others concerned with public health problems.

Distributed directly.

public health; sanitation; education;

\section{AMERICAN RAILWAY ENGINEERING ASSOCIATION}

David E. Staplin, Executive Director

50 F street, NW.

Washington, DC 20001

(202) 639-2190 FAX: (202) 639-2183

Founded: $1899 \quad$ Standards Staff: 4

Type of

organization

\section{Standards}

Development

Standards

Designation
Professional Society

Standards Developer since 1905

400 recommended practices developed.

None processed through ANSI.

23 Committees active in developing recommended practices.

AREA prefix; some rail specifications carry only RE prefix. 
Government

Adoption

Scope

Standardization

Activities

Availability

Formerly

Keywords
Recommended practices are used as specifications in government contracts.

An international (the United States, Canada, and Mexico) professional association whose purpose is the advancement of knowledge pertaining to the scientific and economic location, construction, operation, and maintenance of railways.

Directed toward the principles, specifications, plans, and economics pertaining to the fixed-plant engineering, design, and construction of railways (except signals and communications), and allied services and facilities. Recommended practices are published in the AREA Bulletin for comment. Once approved for publication by the Association's Board of Directors, they appear in the Manual for Railway Engineering. Works closely with the Department of Transportation's Federal Railroad administration and Transportation Systems Center.

Distributed directly and through IHS.

American Railway Engineering and Maintenance of Way Association

transportation; construction; railroads; track; railway; rails;

\section{AMERICAN ROAD AND TRANSPORTATION BUILDERS ASSOCIATION}

T. Peter Ruane, President and CEO

The ARTBA Building

1010 Massachusetts Avenue, NW

Washington, DC 20001

(202) 289-4434

Founded : 1902

FAX :

(202) 289-4435

Standards Staff: I
Type of

organization

scope
Trade Association

Standards Developer

Fosters and encourages the full utilization of scientific and educational measures toward the accomplishment of an integrated national highway, airport, and urban public transportation system adequate to accommodate the growth and advancement of transportation necessary for the civil economy and the national defense. 


\section{standardization} Activities

Availability

Formerly

Keywords
Membership includes federal, state, county and city highway engineers and administrators, as well as consulting engineers, highway contractors, producers of highway materials, manufacturers and distributors of highway machinery, and educators in civil engineering colleges and universities.

Committees study problems relating to highway legislation, finance, design, construction, maintenance, equipment, and operation. Efforts are directed toward development of improved standards to bring about utilization of new materials and eliminate waste and improper methods.

Cooperates with other associations in joint activities. Publishes bulletins dealing with practical application of technical and semitechnical developments.

Distributed directly.

American Road Makers (1910)

highways; road construction; construction; transportation;

AMERICAN SOCIETY FOR ARTIFICIAL INTERNAL ORGANS

Karen Burke, Executive Director

Headquarter office

P.O. Box C

Boca Raton, Florida 33429

(407) 391-8589

FAX : (407) 368-9153

e-mail: 74761.404@compuserve.com

Founded : 1955

Type of

Organization

Representation
Scientific society

works through other organizations to develop standards

The ASAIO Renal Disease and Detoxification Committee works in collaboration with its counterpart in AAMI. The society is also represented on the Medical Devices standards Board of ANSI. Members and policies are called upon to contribute to the FDA activities in medical device regulation, such as the Cardiovascular and Gastroenterology-Urology Medical Device Classification Panels. Internationally, members represent the United states on ISO/TC 150 SC 2: Surgical Implants and Artificial Organs (Cardiac Valves, Pacemakers, Vascular Prostheses, Blood Gas Exchangers and Hemodialysis). Additionally, members contribute to the development of IEC document TC 62D: Hemodialysis Equipment. 
An organization which promotes the development and safe usage of artificial internal organs, with 1400 members from both medical and engineering specialties. At the present time approximately two-thirds of the activities are in the fields of artificial kidneys and artificial hearts/circulatory assist. The remainder are devoted to innovations in other areas, such as plasmapheresis tissue engineering, biohybrid organs and artificial organs for liver failure, diabetes mellitus, vascular disease and disorders of the genitourinary tract.

Standardization Activities

Keywords
Members are active in the development of voluntary medical device standards and guidelines for the user through a variety of mechanisms, including consensus symposia, investigation into the risks and hazards of medical devices, and contributions to the efforts of standards making organizations. Standards committees of the Society are appointed by the President. The Renal Diseases and Detoxification Committee meets annually; members of this committee are also members of the AAMI Committee in this field. Resulting standards are subjected to the review of processes of AAMI and ANSI.

artificial organs; health care; medical devices;

\title{
AMERICAN SOCIETY FOR CLINICAL LABORATORY SCIENCE
}

\author{
Elissa Passiment, Executive Director \\ 7910 Woodmont Avenue \\ suite 530 \\ Bethesda, Maryland 20814 \\ (301) 657-2768 \\ FAX: (301) 657-2909 \\ Founded: 1932 \\ Standards staff: 2
}

Type of

Organization

scope
Professional society

Standards Developer

A national professional organization composed of 20000 members committed to providing efficient health care, quality service and accurate information/test results cost effectively to the public. Also committed to providing proper educational training to future clinicians as well as continuing education to clinical laboratory professionals/educators. 


\section{Availability}

Formerly

Keywords
Standards for day-to-day practice are covered in ASCLS's competence assurance documents, which undergo regular review for continued relevancy; LS's position papers; and National Committee for Clinical Laboratory Standards (NCCLS) specifications for biology and chemistry reagents or reference materials, controls for equipment, etc.

Works with the Food and Drug Administration in conducting a pilot project for surveillance of products used in clinical laboratories.

A member of the Medical Device Technical Advisory Board of the American National Standards Institute.

Cooperates with NCCLS and the International Association of Medical Laboratory Technologists in the development of international standards.

Distributed directly.

American Society of Medical Technologists (prior to 1972)

American Society of Chemical Laboratory Technicians (1936)

medical; medical technology; testing; laboratory equipment;

\section{AMERICAN SOCIETY FOR ENOLOGY AND VITICULTURE}

Dr. Steven Fike, Technical Projects Committee Director

P.O. Box 1855

Davis, California 95617

(916) 753-3142

FAX: (916) $753-3318$

e-mail: ASEVDavis@aol.com

Founded: 1950

Professional Society

Works through other organizations to develop standards

A nonprofit corporation comprised of enologists, viticulturists and suppliers to the wine and grape industry, exclusively for scientific and literary purposes in enology and viticulture. Publishes the American Journal of Enology and Viticulture which contains original research papers, short abstracts, and reviews. Sponsors scholarship awards and an annual meeting. 
Standardization

Activities

Formerly

Keywords
The Technical Projects Committee develops technical projects of interest to the society's membership.

American Society of Enologists (1984)

enology; viticulture; wine; winemaking; beverages;

\section{AMERICAN SOCIETY FOR NONDESTRUCTIVE TESTING}

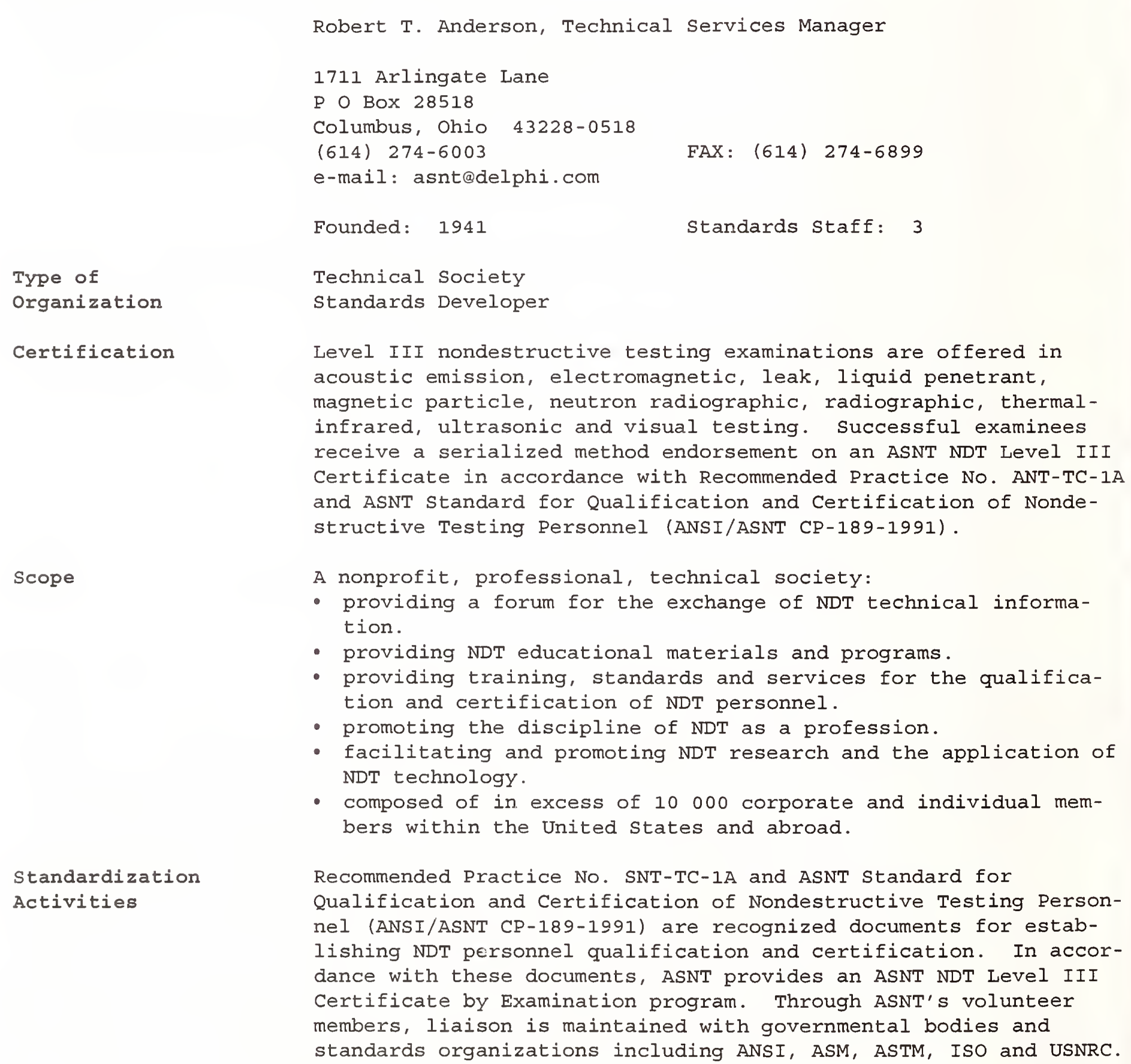


Availability

Formerly

Keywords
Publications are sold directly and through ASNT's Publications Department.

The American Industrial Radium and X-Ray Society (1941-1946)

The Society for Nondestructive Testing (1946-1967)

nondestructive testing; inspection; laboratory; testing; quality assurance; acoustic emission; electromagnetic; leak; liquid penetrant; magnetic particle; neutron radiographic; radiographic; thermal-infrared; ultrasonic; visual;

\section{AMERICAN SOCIETY FOR PHOTOGRAMMETRY AND REMOTE SENSING}

Sype of
Organization
Standards
Designation
Government
Adoption
Certification
Scope

\section{standardization Activities}

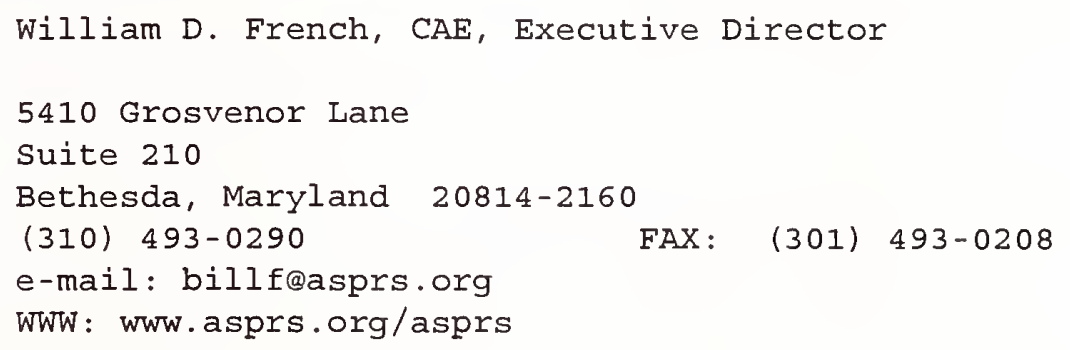
Budget for use by government agencies such as Geological survey, National Ocean Survey, Defense Mapping Agency, Forest Service, Federal Highway Administration.

Active Voluntary program awarding qualified individuals title of "ertified Photogrammetrist."

Primarily concerned with the art, science, and technology of measuring and interpreting photographic and remote-sensor images. scope of interest includes the fields of aerial photography, photogrammetric surveys, photographic interpretation, remote sensing, and Geographic Information systems (GIS). Publishes a monthly journal devoted to new developments, equipment, techniques, and applications in these areas.

Developed nomenclature for photogrammetry and remote sensing standards. Developing standards for large scale photogrammetric mapping. Publishes manuals which are generally accepted as standards of reference including the Manual of Photogrammetry, the Manual of Photographic Interpretation, the Manual of Color Aerial 


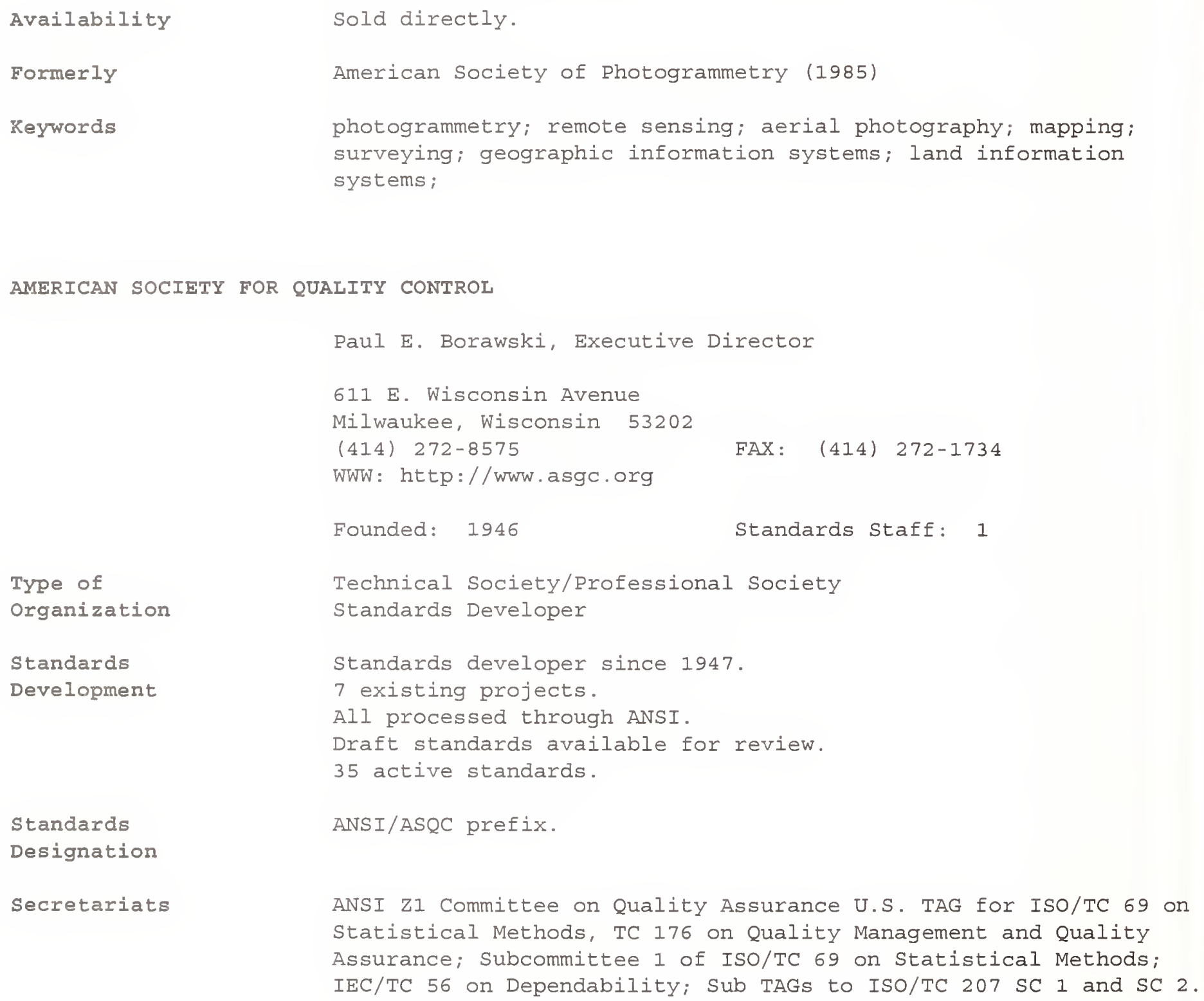


Scope

Standardization

Activities

Availability

Reywords
Advances the theory and practice of quality. Creates, promotes, and stimulates interest in the advancement and diffusion of knowledge of the science of quality and of its application to manufacturing and service industries.

Maintains a standards council which directs and coordinates national and international standards activities.

Distributed directly and through IHS, Global, and ANSI.

quality control; quality assurance; sampling; inspection; quality systems; quality management; quality auditing; environmental management;

\section{AMERICAN SOCIETY FOR TESTING AND MATERIALS}

James A. Thomas, President

100 Barr Harbor Drive

West Conshohocken, Pennsylvania 19428-2959

(610) 832-9500

FAX: (610) 832-9555

WWW: http://Www.astm.org

Founded: 1898 Standards Staff: 200

Type of

Organization

Standards

Development

Standards

Designation

Government Adoption

Certification
Technical Society

Standards Developer

9900 active standards.

Metric equivalency required.

32000 members, including 4000 international.

132 Technical Committees.

Any interested party may participate.

ASTM.

The Department of Defense has adopted 2000 ASTM standards. Local building codes reference 600. The following agencies also have adopted ASTM Standards: General Services Administration, Public Building Service, Veterans Administration, Environmental Protection Agency, Food and Drug Administration occupational safety and Health Administration, National Institute of Occupational Health and Safety, Department of Energy, Department of Housing and Urban Development, Department of Agriculture, and Department of Transportation.

No certification, qualification, or accreditation programs. 
A nonprofit organization formed to develop standards on characteristics and performance of materials, products, systems, and services; and to promote related knowledge. Standards include classifications, guides, practices, specifications, terminology, and test methods.

Standardization Activities

Availability

Reywords
Standards cover iron and steel products; nonferrous metal product; metal test methods and analytical procedures; construction; petroleum products; lubricants and fossil fuels; paints; related coatings, and aromatics; textiles; plastics; rubber; electrical insulation and electronics; water and environmental technology; nuclear, solar, and geothermal energy; medical devices; general methods and instrumentation, general products, chemical specialties, environmental assessment and end use products.

Standards developed by the Society's committees are published in the 70 volume Annual Book of ASTM standards. Hundreds of technical papers and reports presented at ASTM symposia and meetings are published in special Technical publications, the society's monthly magazine "Standardization News," and in quarterly publications. All are distributed worldwide.

ASTM standards are developed by those having expertise in the specific areas who choose, voluntarily, to work with the ASTM system-producers, users, ultimate consumers, and representatives of government and academia. ASTM provides a forum in which these people can meet on a common ground to write standards that will best meet the needs of all the interested parties. The ASTM system adheres to the principles of due process, assuring equal access to and equal voice in the standards forum.

Draft standards undergo a balloting process from the subcommittee, to main committee, and to the entire society -- with careful attention paid to minority opinions at each balloting level -before they are published as official ASTM standards.

Distributed directly and through IHS, and Global.

materials; products; systems; services; testing; concrete; building; textiles; machinery; office products; electrical equipment; safety; defense environment; public health; medical devices; laboratory equipment; consumer products; industrial equipment; general; 
Type of

organization

Standards

Development

Standards

Designation

Government

Adoption

Certification

Scope

Standardization Activities
Russell H. Hahn, P.E. Director of Standards

and Technical Services

2950 Niles Road

St. Joseph, Michigan 49085

(616) 429-0300

FAX: (616) 429-3852

e-mail: hahn@asae.org

WWW: http://asae.org/

Founded: $1907 \quad$ Standards Staff: 3

Professional Society

Standards Developing Organization

Standards developer since 1909.

145 technical committees and subcommittees active or potentially active in standards development.

210 standards, engineering practices, and data, most with SImetric units.

Accredited by ANSI; 25 percent standards approved by ANSI.

Drafts available for review.

S, Standard; EP, Engineering Practice; D, Data.

Examples: S318.11 Mar 95; EP364.1 Aug 93; D309.1 Dec 92.

OSHA 4 ; EPA-1; USDA-5; other government agencies-1.

No certification, qualification, or accreditation programs.

Professional and technical organization of 8000 members worldwide who are interested in engineering knowledge and technology for agricultural, food, and biological systems. Develops engineering standards used in agriculture. Sponsors international technical meetings and continuing education programs. Publishes peer reviewed technical journals.

Develops voluntary standards for agricultural equipment systems, facilities and processes. Standards cover technical areas within the six ASAE technical divisions/institutes: Emerging Technologies, Information and Electrical Systems, Food and Process Engineering, Power and Machinery, Soil and Water, and structures and Environment. Standards considered national in scope and used for numerous international standardization proposals. ASAE's Cooperative Standards Program encompasses the development, adoption, publication, distribution, and maintenance of needed voluntary standards for industry and the consumer in agriculture and in related industries such as turf and landscape. 
Maintains liaison with other technical societies such as ASME, ASHRAE, ASTM, IEEE, SAE, and ANSI. ASAE participates in United States Technical Advisory Groups for ISO/TC 23, Agricultural Tractors and Machinery; ISO/TC 31 Tires, Rims, and Valves; and ISO/TC 131 Fluid Power Systems and Components.

Availability

Keywords
Hardcopy available directly. CD-ROM and microfiche through IHS. Index on Internet at http://asae.org/.

agriculture; irrigation; structures; drainage; livestock; grain; machinery; safety; food processing; electronic; environmental; electric; tractors; turf; and landscape; erosion;

\section{AMERICAN SOCIETY OF ANESTHESIOLOGISTS}

Type of

Organization

Representation

Scope

Standardization Activities
Glenn W. Johnson, Executive Director

520 N. Northwest Highway

Park Ridge, Illinois 60068

(708) $825-5586$

FAX: (708) 825-1692

Founded: 1905

Professional society

Works through other organizations to develop standards

Individual members participate in standardization activities of ANSI, ASTM, ISO, and NFPA.

A national medical society composed of over 26000 members, most of whom are physicians specializing in the practice of the medical specialty of anesthesiology. Among its purposes is to "raise the standards of the specialty by fostering and encouraging education, research and scientific progress in anesthesiology" and to disseminate information concerning the specialty.

The society works within the voluntary standards system to prevent the views of anesthesiologists on matters relating to the agents, devices, and facilities they use in their practices. Its Committee on Equipment and Standards deals with mechanical, electrical, and structural matters as they relate to anesthesiology. This committee is charged with the duties of representing the society in activities related to standards development and supervising and coordinating liaison activities to organizations such as ANSI, ASTM, ISO, NFPA, and other professional and technical bodies in the medical field. 
Formerly

Reywords
The committee on Equipment and Standards maintains liaison with the standardization work of other professional and technical bodies in the medical field. While previously active in ANSI Committee Z79, Standards for Anesthesia and Respiratory Equipment, ASA currently participates in ASTM F29.

Long Island Society of Anesthetists (1911)

New York Society of Anesthetists (1936)

American Society of Anesthetists (1945)

anesthesia; respiratory equipment; medical; medical devices;

\section{AMERICAN SOCIETY OF BAKERY ENGINEERS}

Thomas L. Kuk, President

2 North Riverside Plaza

Suite 1733

Chicago, Illinois 60606

(312) 332-2264

FAX: (312) 332-6560

Founded: 1924

Standard Staff: 1

Professional society

Standards Developer

Association of baking industry production professionals, equipment manufacturers, ingredient suppliers and related baking services organizations. The ASBE mission is to promote the advancement of baking science technology.

Develop standards for bakery equipment particularly safety requirements.

Standards are developed in accordance with ANSI procedures in conjunction with the American Bakers Association, The Bakery Equipment Manufacturers Association, The Biscuit and Cracker Manufacturers Association, and the Retail Bakers of America.

Distributed through ANSI.

bakery equipment; equipment safety; 
Type of

Organization

standards

Development

standards

Designation

Certification

scope

Standardization

Activities

Availability

Keywords
Steven C. Nelson, Executive Officer

3340 Pilot Knob Road

St. Paul, Minnesota 55121

(612) $454-7250$

FAX: (612) $454-0766$

Founded: 1934 Standards Staff: 3

Professional Society

Standards Developer

200 standard methods of analysis.

ASBC Method.

Check Sample services provide the opportunity for subscribing laboratories to check their analytical accuracy on a periodic basis. For each service, a statistical summary of the analytical data is provided for use as an internal check. Check Sample services include Malt Analysis, Cereal Adjunct, Beer Analysis, and Hop Analysis. Another available service is Malt for standardizing mills. Standard malt is used to insure reliable milling and grinding samples for industry-wide analysis. The soluble starch service provides a special starch product available only to ASBC members, and is lot-checked by ASBC.

750 members worldwide engaged in all aspects of brewing. Maintains high professional standards; conducts, promotes, and encourages scientific research in brewing and related industries; studies, develops, and adopts uniform methods for the analysis of raw materials, supplies, and products; holds meetings and disseminates technical knowledge.

Publishes ASBC Methods of Analysis which contain 200 official ASBC methods relating to brewing chemistry. Also has available Tables for Extract in Malt and Cereals, and Tables related to Wort, Beer, Brewing sugars and syrups.

Sold directly.

beer; beverages; testing; 
James Rossberg, Manager, Building Standards

1015 15th Street, NW

Suite 600

Washington, D.C, 20005

(202) 789-2200

FAX: (202) 289-6797

Founded: 1852

Standards Staff: 2

Type of

Organization

standards

Development

Standards

Designation

Scope

Standardization

Activities

Availability

Keywords
Technical Society

Standards Developer

Standards developer from 1875-1895 and 1974-present.

2000 members and nonmembers participating in standards activities. ASCE is an ANSI accredited standards developing organization.

ASCE prefix.

A 120000 member organization for civil engineers in the United States dedicated to the civil engineering profession, offering opportunities for individual professional development and providing a forum for communication between individuals and groups involved in the practice of civil engineering.

Maintains activities in these and related areas: Composite Deck Slab, Steel Deck, Pile Foundation, Drilled Shafts, Temporary Excavations, Nuclear Safety Related Earth Structures, Seismic Analysis, Steel Cables for Buildings, Minimum Design Loads for Buildings and Other Structures, Masonry structures (joint with American Concrete Institute), Air Supported Structures, Engineered Wood Construction, Tensioned Fabric Structures, wind Tunnel

Testing, steel Transmission Towers and Poles, Water Regulatory Standards; Rehabilitation of Buildings, Structural Composites and Plastics, Testing of Seismic Isolation Systems, and Fiberglass Reinforced stacks. Technical and task committees seek to advance knowledge in specific engineering areas, focusing on relevant problems and concerns, by publishing standards, manuals, guides, reports, proceedings, and by conducting conferences and workshops.

Available directly.

civil engineering; decks; slabs; structures; environment; foundations; nuclear safety; building; construction; loads; masonry; wood; seismic; 
Type of

Organization

Standards

Development

Standards

Designation

scope

Standardization

Activities

Availability

Keywords
David W. Barrack, Executive Director

1767 Business Center Drive

Suite 302

Reston, VA 22090

(703) 438-8292

FAX: (703) 438-3113

Founded: 1966

Standards staff: 1

Trade Association

Standards Developer

Standards Developer since 1967.

ASTM approved.

ASEP prefix.

A nonprofit organization devoted to improving the efficiency of its industry and to promoting the use of printing on plastics, with a domestic and foreign membership of 45 companies.

Cooperates with ASTM in developing specifications which include parts design; mold design; substrate fabrication requisites; plastic product qualification; test procedures and standards (including standard test panel, adhesion, corrosion, thermal cycling, and appearance); performance capabilities (including substrate, plate construction, and proven applications); handling of molded parts for plating; and industry terms. Publishes standards and Guidelines which include these standards.

Distributed directly.

plastics; electroplated plastics; manufacturing; materials; EMI/RFI shielding;

AMERICAN SOCIETY OF HEATING, REFRIGERATING AND AIR-CONDITIONING ENGINEERS

Jim I. Heldenbrand, Manager of Standards

1791 Tullie Circle NE.

Atlanta, Georgia 30329

(404) 636-8400

FAX: (404) 321-5478

e-mail: jheldenb@ashrae.org

WWW: http://WWW.ashrae.org

Founded: 1894

Standards Staff: 8 
Type of

Organization

Standards

Development

Standards

Designation

Government

Adoption

Certification

Secretariats

Scope

Standardization

Activities
Technical Society

Standards Developer

Standards developer since 1959.

Over 400 members and nonmembers participating in standards activities.

Most standard processed through ANSI.

Draft standards available for review.

69 active standards.

ASHRAE prefix.

ASHRAE/IESNA Standard 90.1, Energy Efficient Design of New Buildings Except Low-Rise Residential Buildings is referenced in the Energy Policy Act and it, or earlier editions, serves as the basis for building code provisions in all 50 states. ASHRAE Standard 15, Safety Code for Mechanical Refrigeration and ASHRAE Standard 62, Ventilation for Acceptable Indoor Air Quality are used in whole or in part by the three model code organizations.

No certification, qualification, or accreditation programs.

U.S. Technical Advisory Group for ISO/TC 86, Refrigeration. ISO/TC 86, Subcommittees 1, Safety; 6, Factory Assembled Units; and 8 , Refrigerants and Lubricants.

ISO/TC 117, Subcommittee 2, Industrial Fans.

ISO/TC 144, Subcommittee 1, Air Distribution and Diffusion.

An international membership organization operated for the exclusive purpose of advancing the arts and sciences of heating, refrigeration, air conditioning and ventilation, the allied arts and sciences, and related human factors for the benefit of the public.

Assists industry and the public by offering a uniform method of testing for rating purposes, and by suggesting safe practices in designating and installing equipment, by providing proper definitions of this equipment and by providing other information which may serve to guide the industry. Creation of standards is determined by need, and conformance to them is completely voluntary.

Maintains approximately 80 active standards committees, supported by a staff organization administered by the Manager of standards. Continuously promulgates new standards and reviews current standards to reflect technical advances in the field. 
Availability

Formerly

Keywords
A series of standards relates to energy conservation in new and existing building. Other standards specify methods of testing for rating equipment, ventilation levels for indoor air quality, conditions for indoor comfort, mechanical refrigeration safety, and guidelines for reducing CFC emissions and commissioning buildings.

Sold directly and through ANSI, IHS, and Global.

Merger of American Society of Heating and Air-Conditioning Engineers and the American Society of Refrigerating Engineers (1959)

heating; refrigeration; air conditioning; ventilation; energy conservation; environmental quality; construction; building; commissioning ;

\section{AMERICAN SOCIETY OF MECHANICAL ENGINEERS}

\author{
Type of \\ Organization \\ standards \\ Development \\ Government \\ Adoption
}

Certification

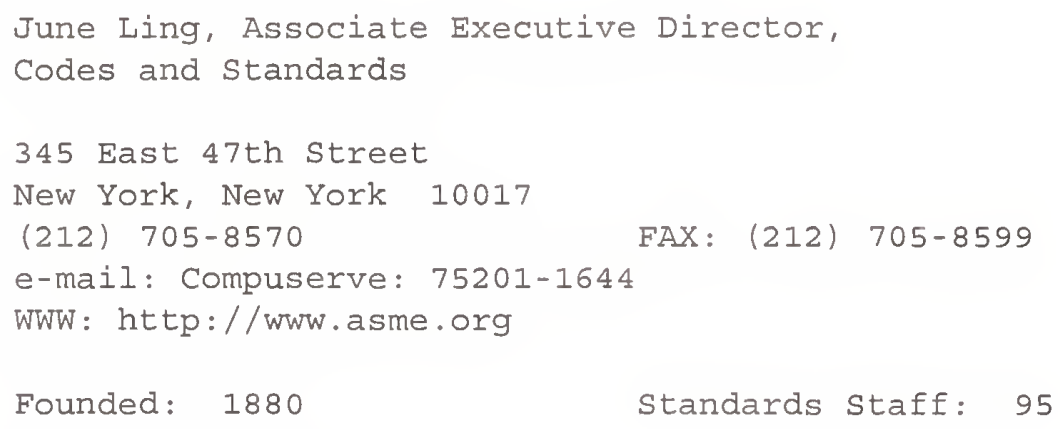

120 standards have been adopted by the Department of Defense. Many others have been adopted by the coast Guard and the Nuclear Regulatory Commission. The Boiler and Pressure Vessel code has been widely adopted by responsible state and provincial agencies in the United states and Canada.

ASME operates accreditation programs in connection with its activity for boilers and pressure vessels, for nuclear plant components, and safety and pollution prevention equipment used in offshore oil and gas operations. The society authorizes manufacturers to apply ASME Code symbol stamps to their product, indicating compliance with the respective code or standard. The society 
also administers Certification Programs relating to Elevator Inspections and Resource Recovery Facility Operators, Medical and Industrial Waste Facilities.

Scope

Standardization Activities
An educational and scientific society organized to promote the art and science of mechanical engineering and the allied arts and sciences; encourage original research; foster engineering; promote the exchange of information of engineers among themselves and with allied technologists; broaden the usefulness of the engineering profession in cooperation with other engineering and technical societies; and promote a high level of ethical practice.

Standards development is an important part of the society's activity to promote the art and science of mechanical engineering. The ASME Council on Codes and Standards supervises the standardization activities of the society under the authority delegated to it by the ASME Board of Governors. Standards are developed under ANSI Accredited Organization Procedures. Documents presented to the Society under the ANSI Canvass Method, where ASME has a Standards Committee whose scope covers that of the proposed standard, are reviewed by the appropriate committee.

Participates actively in international standardization through its sponsorship of ASME Committees which serve as the USA Technical Advisory Groups for the International organization for Standardization (ISO) and International Electrotechnical Committee (IEC).

The Boiler and Pressure Vessel Code is ASME's most widely recognized standards publication. It is a definitive compilation of safety and performance requirements for power and heating boilers, nuclear reactors and power plants, as well as pressure vessels. The Performance Test Codes define accepted methods of determining performance and efficiency for a wide range of equipment and systems, from safety valves and gas turbines to fuels, incinerators, and centrifugal pumps. Many other fields have benefitted from ASME standards and codes. These include drafting practices and symbols, screw threads, bolts, nuts, rivets, and other fasteners in conventional and metric measure; machine tools, cutters and accessories; valves, pipe fittings, and plumbing fixtures; cranes, conveyors, and related equipment; and safety codes for elevators and escalators. 
Availability

Keywords

AMERICAN SOCIETY OF PLUMBING ENGINEERS

Type of

Organization

Representation

Scope

Standardization Activities sellers.

\#210

(805) 495-7120

Founded: 1964 ties. the field of engineering.
Distributed directly and through ANSI, IHS, Global, and other book

abbreviations; accreditation; boiler code; cranes; drafting practices; elevators; fasteners; freight containers; hand tools; industrial trucks; machine tools; machinery; nuclear; mechanical; plumbing; pollution prevention; pressure piping; pressure vessels; qualification; quality assurance; safety; solar energy; industrial equipment; valves;

Kenneth G. Wentink, PE, CIPE, President

3617 Thousand Oaks Boulevard

Westlake, California 91362

FAX: (805) $495-4861$

Technical Society

Works through other organizations to develop standards

National standards Plumbing Code Committee of the National Association of Plumbing-Heating-Cooling Contractors, the American National standards Institute (ANSI), the American National Standards Committee A40, International Association of Plumbing and Mechanical Officials (IAPMO), Southern Building Code Congress, International (SBCCI), and the American Society of Sanitary Engineers (ASSE), and on local code and administrative authori-

A nonprofit professional technical society organized to elevate

plumbing to professional status. The only international organization devoted exclusively to the interests and concerns of plumbing

Although ASPE does not publish standards, it is engaged in the important work of advising builders, architects, and property owners in the value, to them and to their projects, of well conceived, carefully prepared plumbing drawings and clear, concise specifications.

ASPE's code committee examines all regulatory codes pertaining to the plumbing industry; submits proposed revisions or clarifications of codes to code-writing authorities in an effort to simplify, standardize, and modernize all codes; and offers advisory services to other organizations or to governmental agencies involved in writing or enacting codes. 


\section{AMERICAN SOCIETY OF SAFETY ENGINEERS}

Thomas F. Bresnahan, Director, Technical Services

1800 East Oakton Street

Des Plaines, Illinois 60018-2187

(708) 629-4121 x224 FAX: (708) 296-9221

Founded: 1911

Type of

Organization

Secretariats

Scope

Standardization Activities
Professional society

Standards Developer and works through other organizations to develop standards

ANSI 287, Eye Protection.

Z117, Confined Spaces.

z359, Fall Protection Equipment.

A1264, Workplace, Floor and Wall Openings, Railings and Stairways. z390 Hydrogen Sulfide Safety Training.

Composed of 32000 career safety specialists organized to enhance the status and promote the advancement of all safety disciplines; foster the technical, scientific and managerial knowledge and skills of all safety and health professionals; and support the technical, social, and economic well-being of all safety practitioners.

The ASSE currently serves as secretariat to five ASSE accredited national standards committees for ANSI 287, Eye Protection; Z117, Confined Spaces; Z259, Fall Protection Equipment; A1264, Workplace, Floor and Wall Openings, Railings and Stairways; z390, Hydrogen Sulfide Safety Training. In addition, the Society appoints its safety professionals to various ANSI, NFPA, and other national standards writing organizations. It also participates on other standards making committees of other organizations where representation of the profession is appropriate. Recommendations of society members are offered to various governmental agencies when establishing advisory standards committees. 
Formerly

Keywords
Absorbed the United Association of Casualty Inspectors

safety; safety engineering;

\section{AMERICAN SOCIETY OF SANITARY ENGINEERING}

Type of

organization

Standards

Development

Standards

Designation

Government

Adoption

Certification

Scope

Standardization

Activities

Availability

Formerly

Keywords
Gael H. Dunn, Executive Secretary

P.O. Box 40362

Bay Village, Ohio 44140

(216) 835-3040

Founded : 1906

FAX: (216) 835-3488

Standards staff: 2

Technical society

standards Developer

34 active standards.

Standards submitted for ANSI approval.

ASSE prefix.

Standards are referenced by a large number of government agencies.

ASSE Seal Program

Plumbers, contractors, apprentices, journeymen, inspectors, engineers, health officials, and manufacturers interested in promoting public health and sanitation. Conducts research on plumbing and sanitation.

Develops performance standards for plumbing system components. standards provide a tool for measuring quality and effectiveness of a product. Products meeting these standards are identified by the ASSE Seal. Components of plumbing systems include backflow prevention devices, pressure regulators, water hammer arresters, water mixing and shower control valves, anti-siphon hydrants, and other devices which directly affect public health and safety.

Distributed directly and through IHS.

American Society of Inspectors of Plumbing and Sanitary Engineering

plumbing; construction; sanitation; public health; 
Leonard Guarraia, Chief Executive officer

540 Maryville Centre Drive

St. Louis, Missouri 63141

(314) $576-1770$

FAX: (314) 576-2786

Founded: 1920

Type of

Organization

Representation

scope

Standardization

Activities

Keywords
Trade Association

Works through other organizations to develop standards

Grain Standards Division, Foreign Agricultural Service, and Federal Grain Inspection service of USDA

A nonprofit, soybean producer-owned trade association organized to expand markets for soybeans and soybean products overseas.

Works with NOPA, AFMA, AAFCO, and AOCS in monitoring standards, specifications and trading rules for soybeans, soybean meal, and soybean oil, both for domestic sale and sale into the export markets.

soybean; agriculture;

\section{AMERICAN SPEECH-LANGUAGE AND HEARING ASSOCIATION}

Sharon Goldsmith, Ph.D., Director Professional Affairs Department

10801 Rockville Pike

Rockville, Maryland 20852

(301) 897-5700 FAX: (301) 571-0457

e-mail: sgoldsmith@asha.org

Founded: $1925 \quad$ Standards Staff: 22

Type of

Organization

Certification

Scope
Professional Society

Standards Developer

ASHA is the accrediting agency for college and university programs offering graduate degrees in speech-language pathology and audiology and for programs offering clinical services in speech-language pathology and audiology to the public. ASHA is the only national certifying agency for professionals who are speech language pathologists and audiologists.

A national professional and scientific association representing over 81000 speech-language pathologists and audiologists engaged in research, teaching, and clinical activities concerned with communication behavior and disorders. Maintains high standards of 
Standardization Activities

Availability

Formerly

Keywords clinical competence for professionals providing services to the public; certifies audiologists and speech language pathologists for entry level independent practice; encourages the development of comprehensive clinical service programs; promotes investigation of human communication and its disorders; and stimulates exchange of information about human communication.

Directed toward assuring quality of the speech-language pathology and audiology services provided to communicatively impaired persons. Develops standards for appropriate education and training of speech-language pathologists and audiologists. Accredits professional clinical service programs in speech-language pathology and audiology which meet criteria on organizational structure, quality service with functional, measurable outcomes, personnel, records, physical plant and equipment, community relations, and program evaluation. Incorporates ANSI standards on electroacoustic measurements of hearing aids; on permissible ambient noise during audiometric testing; and on calibration of audiometric equipment into Professional Services Board (PSB) clinical accreditation standards.

Maintains Council on Professional standards which establishes and monitors all standards programs related to certification, continuing education, education and training, and professional services. Reviews and comments on standards proposed by ANSI that pertain to electro- and bioacoustic characteristics of audiometric equipment, hearing aids, and environments for hearing testing.

Standards are recognized by the Council of Postsecondary Accreditation, U.S. Department of Education, Joint Commission on Accreditation of Health Organizations, National Easter seal Society, Council of state Administrators of Vocational Rehabilitation and Commission on Accreditation of Rehabilitation Facilities.

Distributed directly from the Association.

American Speech \& Hearing Association (1978)

speech; language; audiology; hearing; acoustics; communication disorders; hearing aids; health; education; research; 


\section{Type of organization \\ standards Designation \\ scope \\ standardization Activities}

Keywords

A. Elizabeth Erman, Executive Director

560 Sylvan Avenue

P.O. Box 1267

Englewood Cliffs, New Jersey 07632

(201) 568-2163

FAX: (201) 568-7318

Founded: 1907

Standards Staff: 1

Trade Association

Standards Developer

Official methods.

Importers, grinders, and distributors of spices, oleo resins, and dehydrated vegetable seasonings.

Maintains a Standards Committee whose function is to adopt standards of quality for whole spices, seeds, and herbs imported at American ports of entry. Also, through the ASTA's Research Committee, in cooperation with RESEARCH 900, developed the values of the base nutrient composition of spices including ash, fat, fiber, moisture, protein, calories, and vitamin content. Cooperated with the Wisconsin Alumni Research Foundation to develop the content of twenty-one mineral elements in spices.

Developed a publication, Official Analytical Methods, for Analyzing spices. Also developed a publication, Official Microbiological Methods, which aims to designate official methods for the detection and enumeration of microorganisms occurring on spices, seeds, and herbs and to provide helpful information and guidelines to those responsible for the assessment of microbiological quality of spices and seasonings.

spice; herb; food;

\section{AMERICAN SPORT FISHING ASSOCIATION}

Michael Hayden, President

1033 North Fairfax Street

Suite 200

Alexandria, Virginia 22314

(703) 519-9691

FAX : (703) 519-1872

Founded: 1933

Standards Staff: 1 
Type of

Organization

standards

Development

scope

Standardization

Activities

Availability

Reywords
Trade Association

standards Developer

Standards developer since 1933.

Draft standards available for review.

Manufacturers and importers of fishing tackle and allied products organized to educate, guide, and assist its members in matters of common interest so that they maintain a high standard of conduct, efficiency, and usefulness to industry, government, and the public.

Administers fly line standards which are universally accepted and were prepared in cooperation with the American Casting Association and the International Casting Federation. Supplies each manufacturer with these standards for packaging with their fly lines. Developed standards for rod seats and reel feet for the purpose of improving compatibility between rods and reels.

Distributed directly.

fishing tackle; fly line; fishing reels; fishing rods; recreation;

\section{AMERICAN STATISTICAL ASSOCIATION}

Daniel G. Horvitz, Executive Director

1429 Duke street

Alexandria, Virginia 22314-3402

(703) 684-1221 FAX: (703) 684-2037

e-mail: asainfo@asa.mhs.compuserve.com

Founded: 1839

Type of

Organization

Standards

Development

Standards

Designation
Scientific society

Works through other organizations to develop standards

The American statistical Association Committee on National and International statistical standards was formed in 1979. About 100 American statistical Association members are actively involved in standards activities which focus primarily on the standards being developed within Iso.

Examples of areas with committee involvement: Iso 3534-1, Statistics -- Vocabulary and Symbols; CD 11453 statistical Interpretation of Data; ISO 8422 Sequential Sampling Plans for Inspection by Attributes; W13-42, Uncertainty of Measurements; IsO 9000 series, Quality Management; etc. 
Standardization Activities

Keywords
None

The American Statistical Association has well over 10000 members. The Committee on National and International Statistical standards provides liaison with national and international standards writing Committees engaged in the codification of statistical methods; and provides for competent timely review and informed participation in the development of standards through delegates to such Committees, who are empowered to vote as delegates of the American Statistical Association.

The codification of statistical methods including testing and measurement.

statistics; design of experiments; sampling; accuracy; normality; uncertainty;

\section{AMERICAN TEXTILE MACHINERY ASSOCIATION}

Harry W. Buzzerd, Executive Vice President

11 Park Place

Falls Church, Virginia 22046

(703) 533-9251

FAX: (703) 241-5603

Founded: 1933 Standards Staff: 1

Type of

Organization

Scope

Standardization Activities

Availability

Keywords
Trade Association

Standards Developer

A nonprofit trade association devoted to the advancement of the United states based manufacturers of textile machinery, ancillary equipment and parts. Major activities include government affairs, market development, technical services, and educational programs.

Develops criteria to help overcome industry problems; issued criteria for dust and noise measurement. Provides guidelines for innovative machinery technology. Worked with ANSI to develop the Safety and Health standards for the Textile Industry.

Distributed directly.

textile machinery; safety; 
Type of

Organization

Standards

Development

Kay M. Villa, Assistant Director - Product

Services Division

$1801 \mathrm{~K}$ Street, NW

Suite 900

Washington, DC 20006-1301

(202) 862-0500

FAX: (202) 862-0570

e-mail: kvilla@atmi.org

Founded: 1949

Standards Staff: 5

Trade Association

Standards Developer

All participants in the voluntary standards development committees are volunteers and represent the breadth of industry sectors involved in the manufacturing and supply of textile/apparel commodities. These include textile manufacturers; notions suppliers; apparel manufacturers, retailers, academia; consultants; and consumers, numbering approximately forty. Only one standard has been published; however, other standards are being developed in the area of computer integrated manufacturing. ANSI approval is required for any standards developed under ATMI. Draft copies of standards are available for review from the organization.

ATMI and its members also work through other organizations including the American Association for Textile Chemists and Colorists, American Society for Testing and Materials, National Fire Protection Association, and the Joint Industry Fabrics standards Committee to develop voluntary test methods and voluntary product standards.

Fabric and Sundries Linkage Council (FASLINC). Manual - Industry specific electronic data interchange standard based on Version 3 Release 3 of ANSI ASC X-12. Future computer integrated manufacturing standards will have ANSI designation.

Certification

Secretariats

Scope
None.

Secretariat ISO TC $38 / \mathrm{SC} 19$ Textile Flammability. U.S. TAG Administrator ISO TC 72 .

ATMI is the national trade association of the textile manufacturing industry. Approximately 140 members operate in more than 30 states and account for 80 percent of all textile fibers consumed by mills in the United States. 
Standardization

Activities

Availability

Formerly

Keywords

AMERICAN THORACIC SOCIETY
Computer integrated manufacturing standards are used by all sectors of the industry to convey product information during manufacturing phases and consumer distribution.

Distributed directly.

Merger of American Cotton Manufacturers Association and the Cotton Textile Institute to form the American Cotton Manufacturers Institute in 1949. Absorbed the National Federation of Textiles in 1958. Current name adopted in 1962. Merged in 1964 with the Association of Textile Merchants of NY. Absorbed the National Association of Finishers of Textile Fabrics in 1965, the National Association of Wool Manufacturers in 1971, and the Thread Institute in 1989.

computer integrated manufacturing; electronic data interchange; environmental management; fabrics; flammability, textiles; safety; health;
Type of

Organization

Standards

Development

Government Adoption

Certification

Scope
Marilyn T. Hansen, Executive Director

1740 Broadway, 16th Floor

New York, New York 10019-4394

(212) 315-8778

FAX: (212) 315-6498

Founded: 1905

Standards Staff: 2

Professional Society

Standards Developer

Standards developed in areas of pulmonary medicine, environmental health, infectious disease control, respiratory therapy, and medical devices. Standards not processed through ANSI. Draft standards available for review to members.

Standards related to the treatment and control of tuberculosis are developed jointly with the Centers for Disease Control of the U.S. Public Health Service.

No certification or accreditation programs.

A professional society dedicated to the prevention and control of lung disease, works to provide optimal health care services for individuals with lung disease. Emphasizes research and professional education. Serves as the medical section of the American Lung Association. Provides a forum for review of issues related to all aspects of lung health and the development of programs for the control of lung disease. Functions on a national level 
Standardization

Activities

Availability

Formerly

Keywords through cooperation with federal agencies and national voluntary health organizations.

Develops standards and classifications for tuberculosis and other respiratory diseases. Provides standards for spirometers which are adhered to by all product manufacturers. Standards developed by the society are incorporated into accreditation programs for health care institutions. Maintains close liaison with various government agencies primarily the Department of Health and Human Services. Acts as an advisor to federal agencies in their development of regulations and standards.

Distributed directly and through state and local affiliates of the American Lung Association.

National Tuberculosis Association/American Trudeau Society (1960)

pulmonary; tuberculosis; medical devices; spirometry; lung disease; public health; health care;

AMERICAN VACUUM SOCIETY

Yvonne Towse, Office Manager

120 Wall street, 32nd Floor

New York, New York 10005

(212) 248-0200

FAX: (212) 983-6745

e-mail: avsnyc@vacuum.org

WWW: http://Www.vacuum.org

Founded: 1953

Standards staff: 1

Type of

Organization

Standards

Designation

scope

Standardization Activities

Availability
Scientific Society

Developer of Recommended Practices

AVS prefix, 5-2.

Scientists, engineers, and others interested in vacuum technology. Promotes education and research.

Establishes recommended practice for nomenclature, measuring techniques and such items as flanges and fittings on vacuum equipment. Standards drafted and reviewed under the auspices of the AVS Committee.

Distributed directly. 


\section{AMERICAN WALNUT MANUFACTURERS ASSOCIATION}

Larry R. Frye, Executive Director

260 South First Street

Suite 2

Zionsville, Indiana 46241

(317) $873-8780$

FAX: (873) 873-8788

Founded: 1912

Type of

organization

Standardization

Activities

Keywords
Trade Association

Works through other organizations to develop standards

Cooperates in the development of grade rules for walnut lumber which are published by the National Hardwood Lumber Association. These grade rules are in general use both in the United States and foreign countries.

wood; hardwood; timber;

\section{AMERICAN WATCHMAKERS-CLOCKMAKERS INSTITUTE}

Michael P. Danner, Administrative Director

P.O. Box 11011

Cincinnati, Ohio 45211

(513) $661-3838$

FAX: (513) 661-3131

Founded: 1960

Standards Staff: 1

Type of

Organization

Certification

scope
Technical Society

Standards Developer

Program includes examinations for certified watchmakers and master certified watchmakers. Also participates in state licensing.

A nonprofit corporation dedicated to the advancement of horology. Six thousand watchmakers and others who sell, service, or collect horological items. Activities include technical bulletins, a certification program, professional seminars, a monthly magazine, technical library, lending library and museum. 
standardization

Activities

Availability

Formerly

Keywords
Involved in standards of craftsmanship through the dissemination of technical bulletins, and certification examinations. Aims to standardize the technical teaching techniques in the United states through its Education committee, which operates through the schools.

Participated in the American National Standards Institute's program on the standardization of Corundum Bearings in Horology, reviewed standards on chronometers for the U.S. Army, and reviewed railroad time standards for the National Institute of standards and Technology. Worked with the British Horological society to determine the proper placement of jewels in a 17-jewel watch.

Distributed directly.

Merger of Horological Institute of America and the United Horological Association of America.

horology; watchmaking; instruments;

AMERICAN WATER WORKS ASSOCIATION

Type of

Organization

standards

Development

Standards

Designation

Government

Adoption

secretariats
Edward E. Baruth, Director, Standards and Materials Development

6666 West Quincy Avenue

Denver, Colorado 80235

(303) 794-7711 FAX: (303) 794-7310

WWW: http: //www.awwa.org

Founded: $1881 \quad$ Standards Staff: 14

Scientific society

Standards Developer

Standards developer since 1890 .

130 active voluntary consensus standards.

All processed through ANSI.

50 standards under development.

1300 members active in standards activities.

AWWA or ANSI prefixes.

The Department of Defense (DoD) has adopted numerous AWWA standards.

U.S. TAG for ISO/TC 5/SC 2, Cast Iron and Ductile Iron Pipe. 
Represents its 55000 members in all areas concerning water supply. 2000 volunteers participate in the development of technical documents. Holds three conferences, as well as other special conferences, each year. Publishes a monthly technical journal, news magazine, and publication for water system operating personnel; and an informational biweekly newsletter.

standardization Activities

Availability

Keywords
Develops standards for a variety of pipe, fittings, valves, wells, pumps, water treatment chemicals, water storage tanks, water meters, and procedures for installation and use of these products. Solicits both membership and public approval in formulating standards. Use of standards is voluntary.

Standard Methods for the Examination of Water and Wastewater, a compilation of 190 laboratory tests, is published jointly by AWWA, The American Public Health Association and the water Pollution Control Federation.

Participates in ISO/TC 5/SC 2, Castiron and Ductile Iron Pipe, and ISO/TC $30 / \mathrm{SC} 7$, water Meters.

Distributed directly and through IHS, and Global.

water; pipe; valves; fittings; wells; pumps; tanks; water treatment chemicals; sanitation; reservoirs; construction; public health; meters;

Dr. H. Glenn Ziegenfuss, Technical Director

550 N. W. LeJeune Road

Miami, Florida 33126

(305) 443-9353 × 312

FAX : (305) 443-5951

WWW: http://www.amweld.org

Founded: 1919 Standards Staff: 16

Type of

Organization

standards

Development

Standards Designation
Technical society

Standards Developer

Developing welding standards since 1922.

1300 members participating in standards activities, including representation on 37 standards committees of ANSI, NFPA, AWWA, API, ASME, ASTM, and others.

130 active standards.

AWS, ANSI/AWS, AWS/SAE, AWS/AWWA, Or AWS/AASHTO prefixes. 
Government

Adoption

secretariats

Scope

Standardization

Activities

Availability

Reywords
The Department of Defense has adopted 24 AWS filler metal specifications and four other standards.

American Council of the International Institute of Welding (IIW). ANSI Z49, safety in welding and Cutting.

US TAG for ISO/TC 44, Welding and Allied Processes and

ISO TC/ SC 44 and SC 5 .

ISO TC/107 SC 5 .

ISO $\mathrm{TC} / 146 \mathrm{SC} 2$.

ISO/TC 44 Subcommittees.

Founded to advance the science, technology, and application of welding. Prepares standards such as codes, specifications, recommended practices, methods, classifications, guides and technical reports. Holds symposiums and technical meetings. Cooperates with other organizations in the preparation and review of welding standards. Active in the International Institute of Welding and the Iso Committee on Welding. Participates through ANSI in establishing the U.S. position on draft international standards.

AWS technical committees prepare standards covering four broad categories:

Welding fundamentals, including metric practice, symbols, testing, definitions, filler metals, safety and health, and computerization.

welding processes, including resistance welding, thermal spraying, brazing, soldering, oxyfuel, ARC, friction, and high energy.

Inspection of welds, including methods, mechanical testing, and qualification of welders and procedures.

Industrial applications of welding, including structural, marine construction, water tanks, automotive, sheet metal, piping and tubing, iron castings, machinery and equipment, railroad, and robotics.

Sold directly and through ANSI, IHS, and Global domestically, and through several foreign agencies.

brazing; soldering; filler metals; welder qualification; welding; thermal cutting; safety; manufacturing; structural welding; thermal spraying; 
Kimberly A. Korbel, Executive Director

515 King Street

Alexandria, Virginia 22314-3103

(703) 549-6003

FAX: (703) 684-6048

Founded: 1981

Standards staff: 1

Type of

Organization

Standards

Development

Certification

Scope

Standardization

Activities

Availability

Formerly

Keywords
Trade Association

Standards Developer

Standards developer since 1944

No certification, qualification, or accreditation programs

A nonprofit trade association of companies which manufacture from wire rod, all forms of carbon alloy and stainless wire and wire products.

Maintains a Technical Committee which publishes Standards Manuals for round wire and flat and shaped wires. These contain recommended standards for wire and rod. Represents the wire and rod industries to ANSI and ASTM.

Distributed directly.

Independent Wire Producers

Specialty Wire Association

specialty wire; wire;

\section{AMERICAN WOOD-PRESERVERS ASSOCIATION}

John F. Hall, Executive Vice President

P.O. Box 286

Woodstock, Maryland 21163-0288

(410) 465-3169

FAX: (410) 465-3195

Founded: 1904

Standards staff: 2

Type of

Organization

Standards

Development
Technical society

Standards Developer

Standards developer since 1930.

250 members actively participating in standards development. 1800 members given opportunity to vote on standards approval. Several standards developed in cooperation with ANSI. 
standards

Designation

Govermment

Adoption

Scope

Standardization

Activities

Availability

Keywords

Type of

organization

Standards

Development

Standards

Designation

Government

Adoption
AWPA prefix.

AWPA standards are used in federal specifications.

Federal specification TT-W-571 on Wood Preservation parallels AWPA standards.

An international technical society devoted to research and development of wood preservation chemicals and treating practices for use in the United States and other countries.

Develops standards and specifications for wood preservatives and their introduction into the materials to be preserved. standards cover preservatives, treatment of commodities, analysis methods, and conversion tables.

Distributed directly.

wood; preservation; treated wood; construction; building;

AMERICAN WOOD PRESERVERS BUREAU

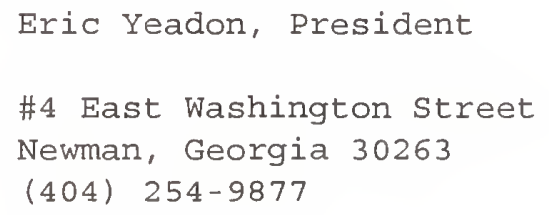

Eric Yeadon, President

\#4 East Washington street

Newman, Georgia 30263

(404) 254-9877

FAX: (404) 254-0084

Founded: 1971

Trade Association

Standards Developer

Standards developer since 1971.

Developed 23 standards.

None processed through ANSI.

LP, General Purpose.

MP, Marine Piling.

$C P$, Construction poles.

MLP, Marine structures.

The AWPB Quality Mark is accepted by the Federal Housing Administration, Farmer's Home Administration, Veteran's Administration, Navy, and DoD. It is recognized by the building codes, ICBO, BOCA, and SBCC, as well as local and other organizations. 
Scope

\section{Standardization Activities}

Availability

Reywords
Certifies treated wood inspection agencies to license pressure treating plants to apply the AWPB Quality Mark to properly treated wood.

A not-for-profit volunteer quality control and certifying organization with 300 members. Provides a nationally known Quality Mark certifying a definite preservative treatment. Operates a wood preservative laboratory to standardize methods and assure quality control. A three-man Board of Review of retired scholars handles disputes.

All AWPB pressure treated lumber and plywood procedures are based on the American Wood-Preservers' Association standards.

Sold directly.

wood; preservation; treated wood; marine; construction; building;

AMT - The Association for Manufacturing Technology

Anthony M. Bratkovich, Engineering Director

7901 Westpark Drive

McLean, Virginia 22102

(703) 893-2900

FAX : (703) 893-1151

Founded: $1902 \quad$ Standards Staff: 3

Type of

organization

Representation

Scope

Standardization Activities
Trade Association

Standards Developer

Working through member companies and staff representation on ASME, NFPA, IEEE, EIA, ASTM, AGMA, and others, most of which are ANSI accredited writing organizations.

Comprised of companies producing over 80 percent of United States total machine tool output. Objectives are to be the industry spokesman before the public and the Government; to provide technical, economic, educational, and informational service to its members; and to promote higher technical and safety standards in industry.

Promotes and supports industry representation in promulgating standards by sponsoring various machine tool oriented standard writing committees. Cooperates with standardization committees of other trade associations and supports industry representation on committees of the International Organization for Standardization and the International Electrotechnical Commission. Develops and maintains machine tool safety standards. 
Type of

Organization

Standards

Development

Government

Adoption

Certification

secretariats

scope
Ronald R. Christensen, Executive Director

481 N. Frederick Avenue

Suite 500

Gaithersburg, Maryland 20877-2504

(301) 924-7077 FAX: (301) 924-7089

e-mail: info@aoac.org

Founded: $1884 \quad$ Standards Staff: 3

Scientific Society

Standards Developer

More than 2100 validated analytical methods for food, feed, fertilizer, pesticides, pharmaceuticals, residues, microbiologicals, hazardous substances, water, and other commodities.

FDA, EPA, State Departments of Agriculture, Agriculture Department of Canada. Used in official regulatory laboratories in many countries.

Certifies analytical test kits through subsidiary, the AOAC Research Institute

Category "A" liaison to ISO/TC 34 Agricultural Food Products, ISO/TC 69 Applications of Statistical Methods, ISO/TC 93 Starch, ISO/TC 134 Fertilizer and Soil Conditions, and ISO/TC 190 Soil Quality. Secretariat to Inter-Agency Meeting (IAM), a subcommittee to the Codex Committee of Methods of Analysis and Sampling (CCMAS). Recognized international observer organization to Codex Alimentarius Commission.

Coordinates the work of some 800 volunteer scientists in government and private laboratories worldwide to develop, test, validate, approve and publish official methods of analysis for food, agricultural commodities, chemicals, and pharmaceuticals. Publishes Official Methods of Analysis, Journal of the AOAC, and collaborative study data. Conducts an Annual Meeting and regional meetings, internationally. 


\section{standardization} Activities

Availability

Formerly

Keywords
Validates analytic methods used by industry and government laboratories in some 70 countries for determining compliance with government regulations, research, and quality control. Scientists participate in the AOAC methods validation process to validate and approve official methods.

Distributed directly.

Association of official Agricultural Chemists (1965)

Association of official Analytical Chemists (1991)

laboratory analysis; quality control; food; methods; agriculture; pesticides; fertilizer; feed; pharmaceuticals; analytical chemistry; government officials; microbiologicals; residues; water;

\section{ARCHITECTURAL WOODWORK INSTITUTE}

Greg Heuer, Director, Members Service

13924 Braddock Road

suite 100

Centerville, Virginia 22020

(703) 222-1100

FAX: (703) 222-2399

Compuserve: 76665,737

e-mail: gheuer@capaccess.org

Founded: 1954

Standards staff: 2

Type of

Organization

standards

Development

Government

Adoption

Certification
Trade Association

Standards Developer

More than 90 experts participate in consensus development of Architectural Woodwork Quality Standards. None are processed through ANSI.

6th Edition Quality Standards adopted by American

Institute of Architects (AIA); Construction specifications Institute (CSI); Government Services Administration (GSA); Corps of Engineers (COE); Naval Facilities Engineering Command (NAVFEC); and numerous state and local facilities units.

The AWI National Quality Certification Program (QCP) licenses woodwork manufacturers to apply the QCP Label to items of woodwork which comply with the 6th Edition Quality standards as specified by the design professional. In addition, program representatives assist woodwork manufacturers in meeting the 6 th Edition Quality standards, and inspect fabrication, finishing, and installation of architectural woodwork for compliance. 

woodwork through education, standards, certification and marketing, while promoting integrity, quality and value among customers, design professionals, suppliers and all AWI members. Promotes the use of architectural woodwork by reaching and informing customers, design professionals and the woodworking community with programs of value. Establishes quality standards through research and testing and maintains a certification program as our commitment to quality.

Standardization

Activities
Carries on a sustained program of standardization in the fields of cost accounting, estimating, detailing and billing, and the fabrication of architectural woodwork, sometimes known as special millwork, detail millwork, or contract millwork. This is done through publications such as the AWI Cost Accounting Manual, Quality Standards for Architectural Woodwork and Guide specification for Architectural Woodwork.

sold directly.

Absorbed Millwork Cost Bureau and Southern Woodworkers Association at founding in 1954.

wood products; millwork; lumber; building;

Keywords

ART AND CREATIVE MATERIALS INSTITUTE

\author{
Deborah Fanning, Executive Vice President \\ 100 Boylston Street, Suite 1050 \\ Boston, Massachusetts 02116 \\ (617) $426-6400$ \\ FAX: (617) 426-6639 \\ Founded: 1936 \\ Standards staff: 2
}

Type of

Organization

standards

Development

Standards

Designation
Trade Association

Standards Developer

5 active standards.

Z356.1 through .5. 
ACMI sponsors a certification program to ensure that art and craft materials are evaluated by a qualified toxicologist and labeled, if necessary, for any acute or chronic potential health hazards. All ACMI-certified products conform to the chronic hazard labeling standard, ASTM D 4236. The Certified Products Bureau of the Institute, initiated in 1940, ensures the safety and quality of the products of subscribers to the bureau. Certified products are identified by a CP, AP, or HL Health Label Seal, all registered Trademarks. The CP Seal ensures both nontoxicity and specific quality requirements; the AP Seal ensures nontoxicity only; the HL Health Label ensures that the product is properly labeled. The products covered by the seals are crayons, chalk, finger paints, modeling clay, liquid and powdered tempera, semimoist water colors, block printing ink, school paste and related school art products, as well as ceramic products and numerous adult art materials.

Scope

\section{Standardization Activities}

Availability

Formerly

Keywords
An association of manufacturers of art, craft and other creative materials which conducts a wide range of activities.

Maintains a Certification Committee which is responsible

for the standardization activities.

Works with the American National Standards Institute to develop and update quality standards for products within the scope of the institute. Current standards are 2356.1 for Crayons; 2356.2 for Chalk; 2356.3 for Adhesives; 2356.4 for Modeling Materials; and Z356.5 for Paints and Inks.

Distributed directly.

Crayon, water Color and Craft Institute (1983)

Art \& Craft Materials Institute (1994)

crafts; art; safety; education; consumer products;

\section{ASBESTOS INFORMATION ASSOCIATION NORTH AMERICA}

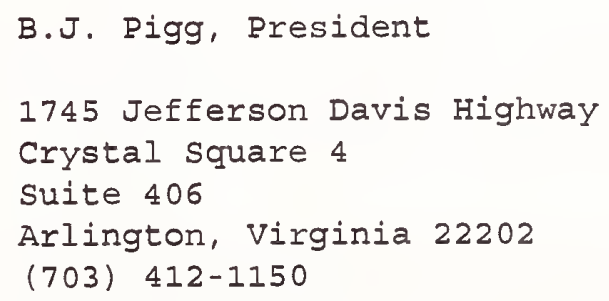

FAX: (703) 412-1152

Standards staff: 1 


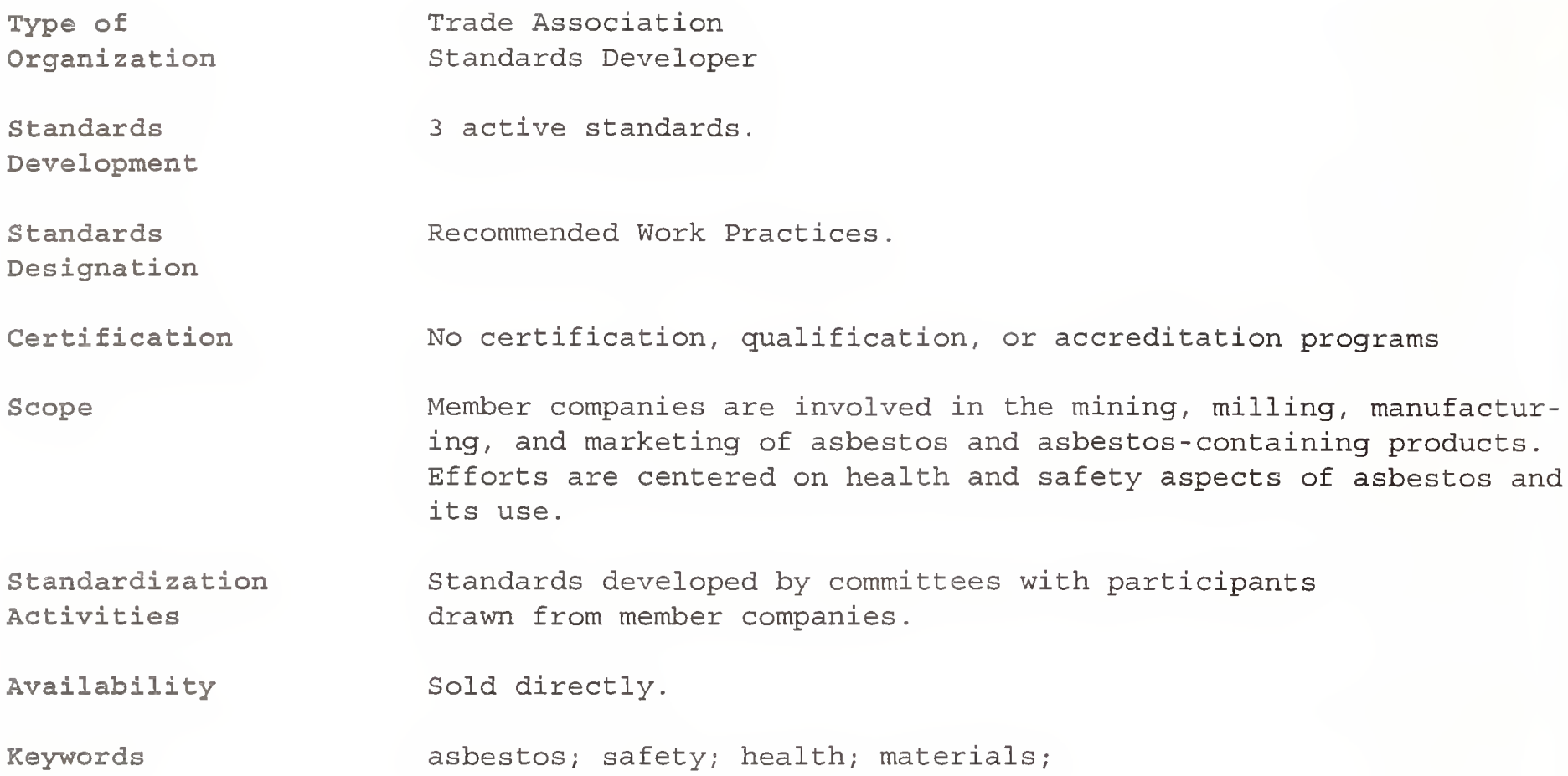

ASPHALT EMULSION MANUFACTURERS ASSOCIATION

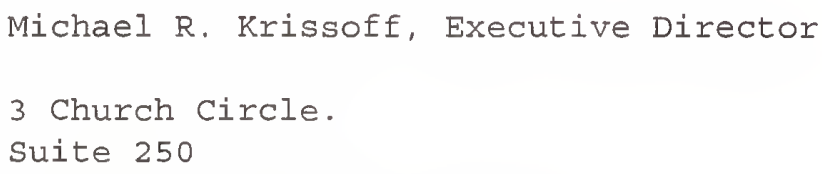
members in the United States, Canada, Mexico, and in many countries overseas. The technical work of the association is done in the committees and subcommittees of the association's international Technical Committee. 
Standardization

Activities

Availability

Keywords

ASPHALT INSTITUTE
The International Technical Committee prepares guide specifications for the proper use of emulsions AEMA is involved with the American Society for Testing and Materials. Individual AEMA members hold committee chairmanships and subcommittee chairmanships within the ASTM structure, and particularly in ASTM Committee D-4. AEMA is also active in the American Association of State Highway Transportation Officials and is involved with the Materials and Services Division of the American Road Builders Association, where it reviews state and road building specifications and participates in the stabilization Committee.

Distributed directly.

materials; asphalt; asphalt emulsion; slurry seal; seal coat; construction;

Edward L. Miller, President

Asphalt Institute Building

Research Park Drive

P.O. Box 14052

Lexington, Kentucky 40512-4052

(606) $288-4960$

Founded: 1919

FAX: (606) 288-4999

Standards Staff: 2

Trade Association

Standards Developer

25 active standards.

Works closely with other organizations in the development of standards including the American Society for Testing and Materials, the American Association of State Highway and Transportation Officials. Staff members serve on technical committees of standards making organizations. Promulgates standards of other organizations.

Works with other organizations in providing training for asphalt technician/inspector certification programs.

An international business league (trade association) representing the manufacturers of asphalt or processors of asphalt materials and affiliated businesses. Publishes informational and technical literature. Maintains field offices in the continental united states. Conducts extensive programs of education, research, and engineering service related to asphalt products. 
Standardization

Activities

Availability

Formerly

Keywords
Works closely with its member companies, and serves upon appropriate standards making committees of the American Society for Testing and Materials, the American Association of State Highway and Transportation Officials, and others. Works in collaboration with kindred organizations such as the National Asphalt Pavement Association, the Asphalt Emulsion Manufacturers Association, the Asphalt Roofing Manufacturers Association, the Highway Users Federation, the Transportation Research Board, and others. Prepares Asphalt Institute Guidelines many of which are subsequently processed as ASTM and AASHTO standards.

Distributed directly and through Global and IHS.

Asphalt Association (1929)

asphalt; highways; pavements; construction; materials;

ASPHALT ROOFING MANUFACTURERS ASSOCIATION

Type of

Organization

Representation

scope
Richard D. Snyder, Executive Vice President

6000 Executive Blvd.

Suite 201

Rockville, Maryland 20852

(301) $231-9050$

FAX: (301) 881-6572

Founded: 1919

Trade Association

Works through other organizations to develop standards

Technical Committees cooperate in the formulation and improvement of standards and specifications covering asphalt roofing products developed by the Federal Government, ASTM, Underwriters Labs, Factory Mutual, and others.

A national trade association representing North American companies that produce asphalt shingles, roll goods, built and modified bitumen roofing systems and allied roofing products. Provides basic membership services, including technical materials related to the performance of asphalt based roofing products and systems. 
Standardization

Activities

Formerly

Keywords
Works with standards producing organizations to coordinate industry standards activities and to provide expertise when requested. A Code Task Force works cooperatively with the association's Residential Roofing Committee and Modified Bitumen Roofing Built-Up Roofing Committee to assure recommended applica tion practices adhere to building code requirements.

Asphalt Roofing Industry Bureau (1970)

roofing; asphalt shingles; fiberglass shingles; construction; building; built-up roofing; modified bitumen roofing;

ASSOCIATED AIR BALANCE COUNCIL

Kenneth M. Sufka, Executive Director

$1518 \mathrm{~K}$ street, NW

Suite 503

Washington, DC 20005

(202) 737-0202 FAX: (202) 638-4833

Founded: $1965 \quad$ Standards Staff: 6

Type of

Organization

Standards

Development

Standards

Designation

Government

Adoption

Certification

scope

Standardization Activities
Trade Association

Standards Developer

Standards Developer since 1965.

All members participate in standards activities.

AABC National Standards.

Army Corps of Engineers

Test and Balance Certification for membership

A nonprofit organization of qualified independent test and balance agencies. Promotes professional standards for the industry and a scientific approach to testing and balancing air handling systems. Represents its membership at national and international levels.

Activities directed toward fulfilling the minimum requirements for total system balance. AABC National standards (a performance standard for the Total system Balancing industry), revises and replaces all National Standards previously published by the council. 
Availability

Keywords

ASSOCIATED GENERAL CONTRACTORS OF AMERICA

Type of

Organization

Representation

Scope

Standardization Activities

Keywords

ASSOCIATED

Type of

Organization
Hubert Beatty, Executive Vice President

1957 E Street, NW

Washington, DC 20006

(202) 393-2040

FAX: (202) 347-4004

Founded: 1918

Trade Association

Works through other organizations to develop standards

Represented on committees of National Institute of Building sciences and ANSI

A national trade association that represents general contractors and all related business interests engaged in commercial construction.

Engages in a wide variety of standards related activity covering fields such as training and competency of onsite construction workers and supervisors, contract documents for use by contractors and owners for a wide range of contractual variations, safety and health procedures for construction sites, federal procurement regulations, and teaching construction skills at the secondary school and college levels. Cooperates with other groups, including ANSI, building trade unions, architects/engineers, and various federal agencies.

construction; building;

Founded: 1955

Standards Staff: 1

Trade Association

Standards Developer 


\author{
Standards \\ Development \\ scope \\ Standardization \\ Activities
}

Availability

Keywords

\section{ASSOCIATION FOR COMPUTING MACHINERY}

Type of

Organization

\section{Standards \\ Designation}

Scope

1515 Broadway

Founded: 1947

ACM prefix.
3 active standards.

Encourages and promotes the voluntary exchange among locksmiths of technical service data on security products; evaluates the position of the locksmith in the security industry; establishes a uniform code of ethics and conducts trade promotion activities.

Maintains a security standards Committee which administers the standardization activity and is now working on standards for security devices in relation to locks. Works closely with the American Society for Testing and Materials' program for voluntary standards in locking devices, Committee T-12 on Security systems and Equipment. Was successful in getting industry rapport to standardize and improve the quality of packaging for key blanks. Recommended a Standard City Ordinance on Building Security. Currently is working on a recommended standard for state licensing or registration of locksmiths. The Key Blank Boxes, Building Security, and Locksmith License are the three current standards of ALA, all considered national in scope.

Distributed directly.

locksmithing; keys; locks; building; public safety;

Joseph DiBlasi, CEO

New York, New York 10036

(212) 869-7440

FAX: (212) 869-1228

Standards Staff: 2

Scientific Society

Standards Developer

An international educational and scientific society of 65000 computer professionals advances the science and art of information processing; promotes free interchange of information between computer scientists and the general public; develops and maintains the integrity and competence of individuals engaged in the information processing profession. 
Standardization

Activities

Availability

Keywords

ASSOCIATION FOR EDUCATION AND REHABILITATION OF THE BLIND AND VISUALLY IMPAIRED

Kathleen Megivern, Executive Director

$206 \mathrm{~N}$. Washington Street

Alexandria, Virginia 22314

(703) 836-6060 FAX: (703) 683-2926

e-mail: aernet@laser.net

Founded: $1853 \quad$ Standards Staff: 5

Type of

Organization

Certification

Scope

Standardization

Activities

Formerly

Keywords
The Association for Computing Machinery's (ACM)

Technical Standards Committee promotes the dissemination and understanding of standards related information in the ACM and to coordinate ACM participation in standards related activities. Much of the committee's work is accomplished by e-mail. Represented on several technical committees of X3-Information systems. Particularly active in the standardization of programming languages. Member of the ANSI Information Systems Standards Board. Developed SIGGRAPH CORE standard on 3-dimensional computer graphics. A program for processing standards through ANSI is under consideration.

Distributed through ACM Order Department, P.O. Box 64145, Baltimore, Maryland 21264 .

computers; programming languages; computer graphics; information;
Professional Society

standards Developer

Maintains a certification service for blindness professionals.

A professional organization of 5000 members which serves educators and rehabilitation specialists of the visually handicapped in the United States and Canada.

Participates in training institutes, the development of special standards. Cooperate with national and international agencies interested in the education and rehabilitation of visually handicapped children and youth.

Merger of American Association of Workers for the Blind and Association for Education of the Visually Handicapped (1984)

visually handicapped; blindness; education; rehabilitation; 
Marilyn Wright, Standards Manager, Standards and Technology

1100 Wayne Avenue, Suite 1100

Silver Spring, Maryland 20910

(301) 587-8202

FAX: (301) 587-2711

e-mail: mwright@aiim.mo.md.us

WWW: http://www.aiim.org

Founded: $1943 \quad$ Standards Staff: 6

Type of

Organization

Standards

Development

Standards

Designation

Government

Adoption

Certification

Secretariats

scope

Standardization

Activities
Professional and Trade Association

Standards Developer

Develops standards, recommended practices, and

technical reports.

200 individuals participating in standards activities.

35 active standards and recommended practices.

15 technical reports.

13 technical tools.

Published documents are designated ANSI/AIIM MS. Tech-

nical Reports are designated as ANSI/AIIM TR. (Prior to July 1, 1983, the Association was known as the National Micrographics Association and used the acronym NMA. Documents published and printed prior to then used the NMA acronym, whereas the AIIM acronym is now used.)

Documents are submitted for adoption to the Department of Defense (DOD) or as part of the Federal Information Processing Standards Series (FIPS).

No certification, qualification, or accreditation programs

U.S. TAG to ISO/TC 171, Document Imaging Applications. Secretariat to SC 2, Applications, of ISO/TC 171

Serves its professional and trade members in promoting solution development, education, and information exchange in the document management industry.

ANSI/AIIM Standards committees and ad hoc groups collect data, evaluate proposed procedures, tests, drafts, and publish documents to meet the technical needs of the document and image management industry. These documents are published as standards, recommended practices, and technical reports. Areas covered include the recording, storage, re trieval, and distribution of images, quality requirements; dimensions; product standardization; test methods; definitions for terms and phrases; and uniform product descriptions. 


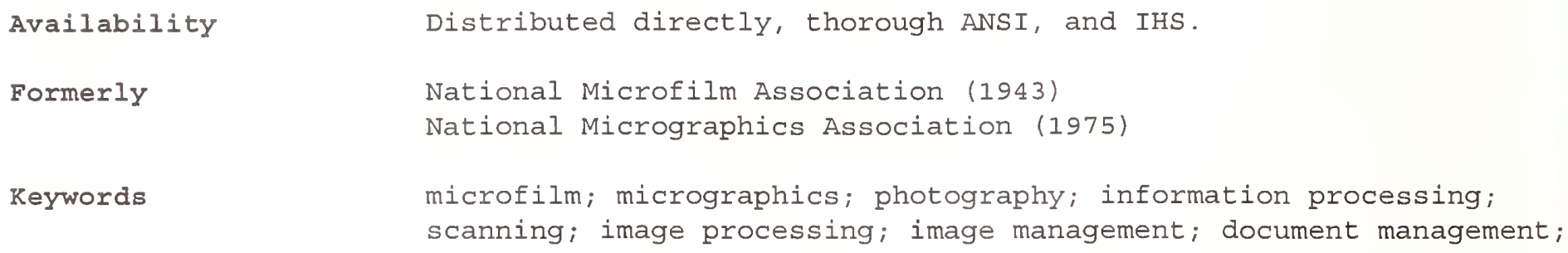

Keywords

Distributed directly, thorough ANSI, and IHS.

National Microfilm Association (1943)

National Micrographics Association (1975)

microfilm; micrographics; photography; information processing; scanning; image processing; image management; document management;

ASSOCIATION FOR SUPPLIERS OF PRINTING AND PUBLISHING TECHNOLOGIES

Mary M. Abbott, Director of Standards Programs

1899 Preston white Drive

Reston, Virginia 22091-4367

(703) $264-7200$

FAX: (703) 620-0994

e-mail: 70732,2023

Founded: 1933 Standards Staff: 5

Type of

Organization

Standards

Development

Standards

Designation

Certification
Trade Association

Standards Developer

17 American National standards.

1 Technical Report.

8 standards under development.

All standards are processed through ANSI for designation as American National Standards.

Draft standards available directly through NPES.

Published documents are designated as:

B65 Safety specifications for Printing Equipment.

CGATS Graphic technology.

IT8 Digital Data Exchange.

No certification, qualification or accreditation programs. 
scope

standardization Activities

Availability

Formerly

Keywords
CGATS - Committee for Graphic Arts Technologies standards. B65 - Safety Standards for Printing Equipment.

ISO/TC 130 WG 2 - Prepress Digital Data Exchange.

ISO/TC 130 WG 5 - Safety and Ergonomics.

U.S. TAG to ISO TC 130 - Graphic Technology.

NPES The Association for Suppliers of Printing and Publishing Technologies is a United states trade association serving over 300 members comprised of manufacturers of equipment, systems, software and supplies used in printing, publishing and graphic communications.

NPES administers 19 standards committees, including both ANSI and ISO committees, developing standards relating to printing and publishing. NPES publishes and sells the ANSI CGATS and ANSI B65 standards and technical reports, as well as ISO standards developed by ISO TC 130.

Standards are distributed directly through NPES and ANSI.

National Printing Equipment and Supply Association (1991) National Printing Equipment Association (1978)

DDAP; TIFF/IT; SWOP; densitomitry; colorimetry; digital data exchange; color data definition; safety; symbology; digital ads; printing inks; graphic technology;

ASSOCIATION FOR THE ADVANCEMENT OF MEDICAL INSTRUMENTATION

Theresa C. Zuraski, Vice President, Standards

3330 Washington Boulevard

Suite 400

Arlington, Virginia 22201

(703) 525-4890

FAX: (703) 276-0793

Founded : 1967

Standards Staff: 8

Type of

Organization

standards Development
Professional Association

Standards Developer

Standards Developer since 1967. 2000 members and nonmembers participating in standards activities. 55 American National standards, 1 AAMI standard, 1 AAMI recommended practice, and 10 AAMI technical information reports, 3 AAMI monographs.

Draft standards available for review. 
Standards

Designation

Government

Adoption

Certification

Secretariats

Scope
American National standards, AAMI Final standards, AAMI Recommended Practices, AAMI Technical Information Reports, AAMI monographs.

The Department of Defense has adopted 2 AAMI standards. The Food and Drug Administration utilizes AAMI standards for various regulatory purposes. HCFA has adopted one AAMI standard.

Certification program for experts in FDA Good Manufacturing Practices (GMPs) and related standards will be introduced in 1996.

IEC/SC 62D, Electromedical Equipment.

IEC/SC 62D/WG 6, Cardiac pacemakers.

ISO/TC $84 /$ WG 1 , Reusable syringes and needles.

ISO/TC $84 / \mathrm{SC} 1 /$ WG 1 , Sterile, single use, intravascular catheters.

ISO/TC 150/SC 2, Cardiovascular Implants.

ISO/TC 150/SC 2/WG 1, Cardiac Valves.

ISO/TC 150/SC 2/WG 2, CardiaC pacemakers.

ISO/TC $150 / \mathrm{SC} 2 / \mathrm{WG} 3$. Vascular prostheses.

ISO/TC 150/SC 2/WG 4, Blood/gas exchangers.

ISO/TC 150/SC 2/WG 5, Renal replacement, detoxification

and apheresis.

ISO/TC $173 / \mathrm{SC} 3 /$ WG 2 , Aids for Ostomy and

Incontinence/Urinary absorbing aids.

ISO/TC 194/WG 1, selection of tests.

ISO/TC 194/WG 9, Interactions with blood.

ISO/TC 194/WG 11, EO and other sterilization process residuals.

ISO/TC 194/WG 12, Sample preparation and reference materials.

ISO/TC 198, Sterilization of health care products.

ISO/TC 198/WG 2, Radiation Sterilization.

ISO/TC 198/WG 3, Moist Heat Sterilization.

ISO/TC 198/WG 4, Biological Indicators

ISO/TC 198/WG 8, Microbiological Methods

ISO/TC 198/WG 9, Aseptic processing

ISO/TC 210, Quality management and corresponding

aspects for medical devices.

ISO/TC 210/WG 1, Application of quality systems to

medical devices.

ISO/TC 210/WG 3, Symbols, definitions and nomenclature

for medical devices.

An international technical association whose members include over 5000 individual health care practitioners; nearly 200 hospitals, universities, government agencies, laboratories and medical societies; and nearly 180 medical device companies. Mission is to help developers and users with the development and utilization of medical technology. Accomplished through publications, standards, educational conferences, certification of health care professionals, and numerous technical communication programs. 
Standardization

Activities

Availability

Keywords

ASSOCIATION OF AMERICAN FEED CONTROL OFFICIALS

Type of

Organization

Standards

Development

Scope

Standardization

Activities
Barbara J. Sims, Secretary

Texas Feed and Fertilizer Control Service

P.O. Box 3160

College Station, Texas 77841

(409) 845-1121 FAX: (409) 845-1389

Founded: $1909 \quad$ Standards Staff: 4

Assists the manufacturers of medical devices and the users of medical technology by developing and approving device product standards and guidelines for the safe use and safe environment relative to medical technology. Participates with government, industry, consumers, and the professional community to develop standards. Accredited by the American National Standards Institute. Involved with international standards activities of

Develops standards (national and international) in the areas of electromedical equipment, cardiovascular implants, and artificial organs, biocompatibility testing,hospital and indus trial sterilization technology, quality management (of medical devices), medical devices for injection, aids for ostomy and incontinence, and devices for general hospital use.

Distributed directly and through ANSI.

medical devices; medical instrumentation; sterilization; safety; health care; dialysis; biological evaluation; quality assurance;

Professional Society

Standards Developer

14 committees and 35 product investigators active in standard development.

None processed through ANSI.

Draft standards and revisions available for review for nonmembers.

A nonprofit association of feed control officials whose membership includes persons charged by law with execution of state, provincial, dominion, and federal laws in North America, Hawaii, and Puerto Rico regulating the production, labeling, distribution, and sale of animal feeds and livestock remedies.

Directed toward development of uniform feed laws and regulation for implementation by various agencies and development of definitions for feed terms and feed ingredients for use by control officials and the feed industry. 
Availability

Keywords
Distributed through Charles P. Frank, Georgia Department of Agriculture, Plant Food, Feed \& Grain Division, Capitol Square, Atlanta, Georgia 30334 (404) 656-3637.

animal feed; livestock remedies; agriculture; government officials;

ASSOCIATION OF AMERICAN PLANT FOOD CONTROL OFFICIALS

Type of

Organization

standards

Development

Government Adoption

Scope

Standardization Activities
D. I. Terry, secretary

c/o University of Kentucky

Lexington, Kentucky 40546

(606) 257-2668 FAX: (606) 257-7351

e-mail: terrydav@uklans.uky.edu

Founded: 1946

Professional Society

Standards Developer

Active standards: 5; Standards developer since 1946, 100 volunteer members.

Model legislation and standards available for review.

None processed through ANSI.

Several states have adopted one or more of the

standards and most states accept the principles of uniformity promoted by AAPFCO.

Officials of agencies concerned with enforcement of laws relating to control of sale and distribution of mixed fertilizer and

fertilizer materials. Members in the United States, Canada, and Puerto Rico.

Develops model laws and standards for fertilizer labeling, terms and definitions, enforcement policies, and tonnage reporting. These are developed through various committees which solicit input from regulatory officials, professional agronomists, the fertilizer industry, and federal agencies. Model laws for fertilizer, liming, agricultural ammonia, chemigation, and soil amendments are the basis for legislation in a number of states. 
Distributed directly.

Association of American Fertilizer Control officials

fertilizers; limestone; agriculture; government officials;
Type of

organization

Scope

Standardization

Activities

Availability

Formerly

Keywords
AMERICAN PUBLISHERS

Nicholas A. Veliotes, President

71 Fifth Avenue

New York, New York 10003

(212) 255-0200

FAX: (212) 255-7007

Founded: 1970

Trade Association

Works through other organizations to develop standards

Its members are producers of hardbound and softbound general, educational, trade, reference, religious, scientific, technical, and medical books; instructional materials; periodicals and tests; audio and video tapes, computer software, looseleaf services, electronic products and services including online databases, CDROM and CD-I.

Works with the Book Manufacturers Institute (BMI) and the National Association of State Textbook Administrators (NASTA) to comprise a three-member Advisory Commission on Textbook Specifications (ACTS) which develops the Manufacturing standards and Specifications for Textbooks (elementary and high school).

Distributed through ACTS.

Merger of American Educational Publishers Institute and American Book Publishers Council

books; book publishing; publishing; communications; 


\begin{tabular}{|c|c|}
\hline & $\begin{array}{l}\text { Information and Public Affairs } \\
50 \text { F street, NW } \\
\text { Washington, DC } 20001 \\
\begin{array}{ll}\text { (202) } 639-2100 & \text { FAX: (202) } 639-2286\end{array}\end{array}$ \\
\hline & standards staff: \\
\hline $\begin{array}{l}\text { Type of } \\
\text { organization }\end{array}$ & $\begin{array}{l}\text { Trade Association } \\
\text { Standards Developer }\end{array}$ \\
\hline $\begin{array}{l}\text { Standards } \\
\text { Development }\end{array}$ & $\begin{array}{l}\text { The Manual of standards and Recommended Practices ( } 19 \\
\text { volumes) contains nearly } 1400 \text { documents. }\end{array}$ \\
\hline $\begin{array}{l}\text { Standards } \\
\text { Designation }\end{array}$ & $\begin{array}{l}\text { Specifications are designated with an "M" prefix, } \\
\text { Standards with an "S" prefix, Recommended Practices with an "RP" } \\
\text { prefix. }\end{array}$ \\
\hline Certification & $\begin{array}{l}\text { The Research and Test Department is responsible for conducting } \\
\text { certification testing of new designs of cars and components, } \\
\text { quality control checks on components and materials, lubricant } \\
\text { testing, and analysis of failed components. }\end{array}$ \\
\hline scope & $\begin{array}{l}\text { Membership consists of } 108 \text { railroads, including } 9 \text { Canadian, } 4 \\
\text { Mexican, and } 59 \text { associate members. Association members haul } \\
\text { approximately } 90 \text { percent of the nation's rail traffic and account } \\
\text { for } 82 \text { percent of the rail mileage. The association serves its } \\
\text { members in matters that require cooperative handling to better } \\
\text { enable the railroads to operate as a national system and to } \\
\text { contribute toward the purposes of the national transportation } \\
\text { policy set forth by congress. It is an umbrella organization } \\
\text { consolidating a number of smaller, more specialized groups and is } \\
\text { organized by departments which span the fields of law, operations } \\
\text { and maintenance, research and testing, railway economics and } \\
\text { statistics, finance and accounting, railway information and public } \\
\text { affairs, legislation, and data systems. }\end{array}$ \\
\hline $\begin{array}{l}\text { Standardization } \\
\text { Activities }\end{array}$ & $\begin{array}{l}\text { AAR specifications, standards and recommended practices } \\
\text { are issued by the Mechanical Division on authority of the Divi- } \\
\text { sion's General Committee. The Division and its standards deal } \\
\text { with the design, construction, performance, maintenance, repair, } \\
\text { and inspection of locomotives, freight cars, and other railroad } \\
\text { mechanical equipment that is interchanged among railroads. }\end{array}$ \\
\hline & $\begin{array}{l}\text { The Communications and Signal Division develops recommended } \\
\text { practices for engineering, design, construction, operation, and } \\
\text { maintenance of frail communication and signal systems. It main- } \\
\text { tains liaison with appropriate professional organizations such as } \\
\text { the American National standards Institute and the Institute of }\end{array}$ \\
\hline
\end{tabular}


Electrical and Electronics Engineers, and with government agencies. It is the national radio frequency coordinator to the Federal Communications Commission for assignment of radio frequencies for the railroads in the United States, and the United states/Canadian coordinator along the border.

The Data Systems Division, through RAILINC Corporation, a subsidiary of AAR, stimulates the development and application of data processing and information techniques and established procedures which promote their efficient and productive use and simplify the interchange of data. This division serves as the principal railroad representative to American National standards Committee $\mathrm{X} 3$ and the Transportation Data Coordinating Committee. Its committees are examining the industry's coding and standards needs in the area of data elements, teleprocessing protocols, etc.

Other AAR activities involved in standardization include the Safety Division's Hazardous Material systems Division, which tests and classifies, for transportation purposes, materials considered hazardous under government regulation and makes recommendations covering packaging, labeling, and handling en route. The Division maintains field inspector at key locations throughout the United States and Canada.

Standardization and simplification of railroad accounting and treasury practices and requirements is accomplished through the Economics and Finance Department. This department prepares various publications on rules, standard forms, procedures, and codes, as well as economic and statistical data covering railroad operations and their financing.

Availability

Keywords
The Manual of Standards and Recommended Practices is sold directly.

transportation; railroads; accounting; finance; explosives; safety; communications; data processing; 


\author{
Type of \\ Organization \\ Representation \\ Scope \\ Standardization \\ Activities
}

Keywords

\section{ASSOCIATION OF BEDDING AND FURNITURE LAW OFFICIALS}

Type of

Organization

scope

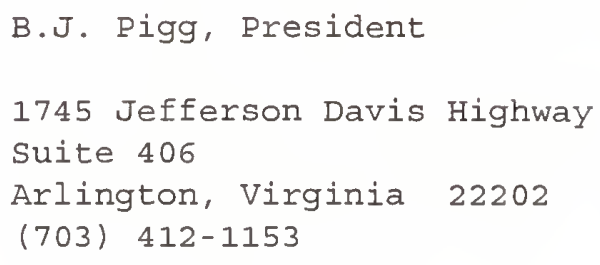

construction; asbestos cement; asbestos cement pipe; sewer pipe;

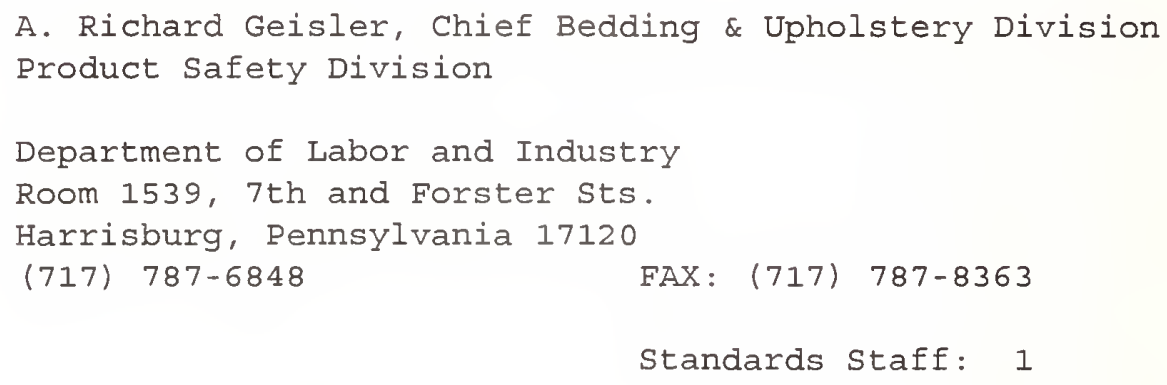




\section{Standardization Activities}

Availability

Keywords
Encourages and promotes the adoption of uniform bedding and upholstered furniture laws, rules, regulations, nomenclature, labeling requirements, and enforcement procedures. Develops tests and adopts standard methods of inspection and sampling of bedding and upholstered furniture and the analyses of filling materials. Develops standard methods of determining the efficiency of insecticides, fumigants, sterilizing and disinfecting processes and equipment as applied to bedding, upholstered furniture, and filling materials. Secures uniformity in the statement of analytical results; promotes, conducts, and encourages research in chemistry and allied fields as these relate to analyses of filling materials used in bedding and upholstered furniture.

sold directly.

bedding; upholstered furniture; insecticides; fumigants; sterilization; government officials; consumer products;

ASSOCIATION OF EDISON ILLUMINATING COMPANIES

W.O. Whitt, Executive Director

600 North 18th street

P.O. Box 2641

Birmingham, Alabama 35291-0992

(205) 250-2530

Founded: 1885

FAX: (205) 250-2540

standards staff: 1
Type of

organization

standards

Designation

Scope

Standardization Activities
Trade Association

Standards Developer

AEIC CS prefix.

A trade association of investor-owned electric utilities in the United states engaged in the distribution of electric service for sale to the general public. Its objective is the advancement of electric service to the public for light, heat, and power.

Maintains representation on several ANSI Committees and on other similar technical organizations involved in standardization relating to the electric utility industry. Prepares and publishes specifications for high voltage underground cable design used in the industry. 

Availability
sold directly.
Keywords
energy; electric power; electrical equipment;

ASSOCIATION OF ENGINEERING GEOLOGISTS

Edwin A. Blackey, Jr., Executive Director

323 Boston Post Road

Suite 3D

Sudbury, Massachusetts 01776

(508) 443-4639

FAX : (508) 443-2948

Founded: 1957 Standards Staff: 1

Type of

Organization

Scope

Standardization

Activities

Availability

Keywords
Professional Society

Standards Developer

Promotes high ethical and professional standards in the field of geology; members are graduate geologists and geological engineers.

Maintains two committees active in standards development. The Building Codes Committee is active on a local level as advisors to county and municipal governments considering code revisions, including code provisions for development of flood plains and tidal marshland. The Committee on Engineering Geology Mapping symbols develops standard map symbols for use by all states and counties.

Distributed directly.

geology; mapping; construction;

ASSOCIATION OF HIGHER EDUCATION FACILITIES OFFICERS

Wayne E. Leroy, CAE, Executive Director

1446 Duke street

Alexandria, Virginia 22314-3492

(703) 684-1446

FAX: (703) 684-2772

Founded: 1914

Standards staff: 1

Type of

Professional Society

Organization

Standards Developer 
Standardization

Activities

Keywords
Develops professional standards in the administration, care, operation, planning, and development of college and university physical plants.

Participates with other organizations in the standards development and review process.

physical plant; facilities management; construction; maintenance; education;

\section{ASSOCIATION OF HOME APPLIANCE MANUFACTURERS}

Jack Weizeorick, Vice President of Engineering Services

20 North Wacker Drive

Chicago, Illinois 60606

(312) $984-5800$

FAX: (312) 984-5823

Founded: 1967

Standards Staff: 4

Type of

Organization

Trade Association

Standards Developer

Standards

Development

Standards developer since 1967

73 members participate in standards activities.

26 active standards include metric equivalents.

20 standards AlNSI approved.

Standards

Designation

Government

Adoption

Certification

Secretariats

ANSI/AHAM and AHAM prefixes.

The General Services Administration has adopted several AHAM standards for procurement purposes.

Sponsors five certification programs for Room Air Conditioners, Refrigerator-Freezers, Humidifiers, Dehumidifiers, and Room Air Cleaners

IEC SC 59A, Electric Dishwashers

IEC SC 59H, Microwave Appliances

IEC SC 61B, Safety of Household Microwave Ovens

An international nonprofit association of companies manufacturing major and portable appliances. Functions in five major areas: product standards and certification, government relations, consumer affairs and communications, statistical reports, and international trade. Other functions included industrial relations and market research. 
Standardization Activities

Availability

Formerly

Keywords

\section{ASSOCIATION OF IRON AND STEEL ENGINEERS}

Type of

Organization

Standards

Development

Scope

Suite 2350

Technical Society

Standards Developer
Develops voluntary appliance performance standards and makes safety recommendations to Underwriters Laboratories and the American Gas Association. The Engineering Council determines policy and directs product engineering committees to determine contents of standards with special consideration on product safety. Develops international standards through representation on technical committees of the International Electrotechnical Commission.

Maintains liaison with the Federal Government's National Institute of standards and Technology, General Services Administration, Food, and Drug Administration, Federal Trade Commission, Consumer Product Safety Commission, and Department of Energy.

AHAM standards are national in scope. Their use is promoted through publications and press releases, through certification, and by the American National Standards Institute's recognition.

Sold directly and through ANSI.

American Home Laundry Manufacturer's Association (1916-1966)

home appliances; safety; consumer products;

Lawrence G. Maloney, Managing Director

Three Gateway Center

Pittsburgh, Pennsylvania 15222

(412) 281-6323 FAX: (412) 281-4657

Founded: $1907 \quad$ Standards Staff: I

11 standards and technical reports.

Fosters an exchange of ideas toward advancing the iron and steel producing industry in matters related to steel plant engineering, maintenance, and operations including electrical, mechanical, welding, combustion, lubrication, and rolling mills. Engages in standardization, engineering, and computer applications. 
Standardization Activities

Availability

Formerly

Keywords
Develops standards for the steel industry which include D-C Mill Motor Standards, Alloy steel Chain and Alloy steel Chain Slings for Overhead Lifting, Specification for Electric Overhead Traveling Cranes for Steel Mill Service, Specification for Design of Ladle Hooks, Insulated Conductors for Crane and Mill Auxiliary Motors, Specifications for Design of Hot Metal Ladles, Brake Standards for Mill Motors, Guide for Design and Construction of Mill buildings, New Steel Pressure-Containing Components for Blast Furnace Installations, Repair of Steel Pressure-Containing Components for Blast Furnace Installation.

Also sponsors engineering activities for the purpose of developing data for future standards and for the improvement of steel mill operating practice.

Distributed directly.

Association of Iron and Steel Electrical Engineers (1936)

electrical equipment; industrial equipment;

\section{ASSOCIATION OF OFFICIAL SEED ANALYSTS}

Jim Lair, Secretary-Treasurer

University of Nebraska

268 Plant Science

Lincoln, Nebraska 08583-0911

(402) $472-1444$

FAX: (402) $472-7904$

Founded: 1908

Standards Staff: 2

Type of

Organization

Scope

Standardization Activities
Scientific Society

Standards Developer

Officials of federal, state and provincial seed testing and research laboratories. Develops uniform rules fore testing field, vegetable flower and tree seeds, encourages the use of high quality seed, promotes research, and fosters the training of seed analysts.

Maintains committees in research, rules, referee, and public service areas to develop standardized methods of seed testing that will permit duplication of results when the same sample is tested by different stations. Quality factors for which tests are made include purity of sample, percentage germination, rate of occurrence of noxious weed seeds, varietal purity, and assaying for fungicidal seed treatment. The Research Committee makes technical information available to the Rules Committee which prepares a new draft revision of the rules every fifth year for approval. The Rules Committee also interprets questionable and 
Keywords

ASSOCIATION OF OFFICIAL SEED CERTIFYING AGENCIES

Type of

Organization

Certification

Scope

Standardization

Activities

Availability

Formerly

Keywords

Box 9812

Mississippi, MS 39762

(601) 325-4567

Trade Association

Standards Developer disputed points of the Rules for Testing Seeds. The Referee Committee circulates samples among the member stations to determine whether they are testing in accordance with the rule s and to identify any weaknesses in the rules. The public service committee encourages association member to publicize the benefits of the associations's work and stimulate interest in seed testing.

seed testing; government officials; agriculture;

Vance H. Watson, Executive Vice President

FAX: (601) 325-8118

Founded: 1919 Standards staff: 2

The adopted standards are used to establish seed certification regulations by the U.S. Department of Agriculture.

Establishes and maintains minimum standards and procedures for certifying seed. Membership consists of a representative from each state certifying seed.

The Association develops and maintains seed certification minimum standards for genetic purity and identity. These standards and procedures are used by individual state seed certifying agencies in supervising the production and marketing of certified seed and are reviewed annually. Individual state seed certifying agencies may not certify seed for interstate commerce unless the Association's (and USDA) minimum standards are used.

The Association standards are printed in a certification book and may be purchased directly.

International Crop Improvement Association (until 1968)

seeds; genetics; agriculture; 
James P. Souders, Executive Director

4200 Somerset Drive

Suite 215

Prairie Village, Kansas 66208

(913) 341-3808

(800) $422-2762$

FAX: (913) 341-3742

e-mail: 76015.3151@compuservecom

Founded: 1956

Standards staff: 3

Type of

Organization

\section{Standards}

Development

\section{standards}

Designation

Scope

\section{Standardization}

Activities

Availability

Formerly

Keywords
Professional Society

standards Developer

Guidelines and standards developer since 1981. More

than. 500 members participate in standards activities. 12 guidelines and 1 standard published.

ARMA prefix.

ANSI/ARMA prefix.

An international organization of professionals involved in records and information management. Represents interests in the management of documentation, preservation, disposal, and the efficient handling of recorded information including records management systems, records retention, vital records, records centers, computerized information, micrographics technology, word processing, and others.

Directs activities toward fulfilling user-defined requirements of the profession. A seven-person standards Committee represents government, manufacturers, and users, and is responsible for final approval of Guidelines and standards developed by working committees. These committees cover the following areas: filing Equipment and Supplies, Filing systems, GlossaryRecords management Terms, Job Descriptions, Records Center Operations, Records Retention, Technology Applications and Vital

Records.

ARMA Guidelines are published and made available to the membership and the general public.

Distributed directly.

American Records Management Association

records; files; information processing; office products; records management; 
John Mead, President

1001 Winstead Drive

Cary, North Carolina 27513

(919) 677-0060

FAX: (919) 677-0211

Founded: 1968

Standards Staff: 12

Type of

Trade Association

Organization

Standards Developer

Scope

Membership consists of manufacturers of nonwoven fabrics, raw material suppliers, and nonwoven fabric end users. INDA works on a national and international level to promote the nonwoven fabric industry. INDA publishes nonwoven publications, develops conferences, organizes committees to deal with industry issues.

Standardization

Activities

Availability

Keywords

ASSOCIATION

Type of

Organization

standards

Development

Certification

scope
Supports the INDA Standard Test Methods Committee, ASTM subcommittee D13.64 under committee D13 on Textiles and provides representative to ISO. Also works with AATCC, TAPPI, and other standards developing organizations.

Distributed directly.

nonwoven fabrics; nonwoven textiles;

CEILING INDUSTRIES - INTERNATIONAL

Michael A. Gardner, Technical Director

307 E. Annandale Road

Falls Church, Virginia 22042

(703) 684-8300

FAX: (703) 534-8307

Founded: 1918 Standards Staff: 1

Trade Association

Standards Developer - Proprietary and working through technical societies

Standards developer since 1918.

1400 plus members participate in standards activities.

none

1400 firms engaged in the application of acoustical tile, drywall, partitions lathing and plastering, fireproofing, and insulation. 
Standardization Activities

Availability

Formerly

Keywords

ATM FORUM

Type of

Organization

standards

Development

Standards

Designation

Certification
Concentrates on application/installation standards development development but also monitors and participates in materials and test methods specifications development.

Technical Subcommittees address standardization of materials, systems and application/installation procedures for acoustic systems, carpentry, coatings, demountable partitions, exterior insulation and finish systems (EIFS), fireproofing, flooring systems, lathing, furring, plastering, texturing, insulation, light gage steel framing systems (load and non-load bearing, integrated ceilings systems, open plan systems, door-frame-hardware, and allied fields. Final approval by the Association's Board of Directors when recommended by Technical Committee.

Through the Technical Department, AWCI participates in the activities of ASTM Committees C1I; E6; ACIS24.

Sold directly.

Contracting Plasters International Association (1956)

Contracting Plasterers and Lathers International Association

(1970)

International Association of Wall and Ceiling Contractors (1976) Merger of International Association of Wall and Ceiling Contractors (1976) and Gypsum Drywall Contractors International (1979)

walls; ceiling; drywall; plaster; acoustic; asbestos; building;

Anne M. Ferris, Executive Director

303 Vintage Park Drive

Foster City, California 94404-1138

(415) 578-6993 FAX: (415) 525-0182

e-mail: aferris@atmforum.com

Founded: $1991 \quad$ Standards staff: 5

Industry Consortium

Standards Developer

Eleven specifications have been published and a similar number are in various stages of development. None are processed through ANSI. Working documents are available to Forum members.

ATM $x \times x v 1.0$.

Example: ATM UNIV3.1, User-Network Interface.

None. 
Standardization

Activities

Availability

Keywords standards, and fostering industry cooperation and awareness

The ATM Forum Technical Committee works with other

standards bodies, such as ANSI and ITU-T (International Telecommunications Union) selecting appropriate standards, resolving differences among standards, and recommending new standards when existing ones are absent or inappropriate. New standards are developed by eleven working groups in such areas as network management, traffic management, signaling, and testing.

All ATM specifications except ATM UNIV3.0 and v3.1 are available directly from the ATM Forum. The ATM UNI specifications are available through Prentice Hall, 515-284-6751.

networking; interoperability; communications; voice; data; video; asynchronous transfer mode; ATM;

AUTOMATED IMAGING ASSOCIATION

Type of

Organization

Standards

Development
James A. Peyton, Manager of Standards Development

900 Victors Way

P.O. Box 3724

Ann Arbor, Michigan 48106

(313) 994-6088

FAX: (313) 994-3338

Founded: 1984

Standards Staff: 2

Trade Association

Standards Developer

Standards developer since 1986.

100 representatives participate in the five A15. Standards subcommittees. Most standards processed through ANSI. Draft standards available for review. 


\section{Standards}

Designation

Secretariats

scope

\section{Standardization}

Activities

Availability

Keywords
AIA/A15.0X.

A15.01, A15.05, A15.07, A15.08, A15.09

Dedicated to promoting the acceptance and productive use of image processing, image analysis and machine vision technologies. The use of these technologies will include both scientific and industrial applications from all aspects of product manufacturing, physical sciences, governmental and research communities. The association's membership includes manufacturers of both related and peripheral products, integrators, end users, consultants and research groups directly involved with these technologies.

Standardization in the area of image processing technology including System Communication (A15.01), Performance (A15.05), Terminology (A15.07), Sensor Interfaces (A15.08), Marking and Labeling (A15.09).

Draft standards available for review; ANSI-approved standards available from the association and ANSI.

image processing; machine vision; automatic inspection; automation;

\section{AUTOMATIC METER READING ASSOCIATION}

Joyce Paschall, Executive Director

60 Revere Drive, Suite 500

Northbrook, IL 60062
(847) $480-9628$
FAX: (847) $480-9282$

Founded : 1986

Trade Association

Standards Developer

Work with the Institute of Electrical and Electronics Engineers (IEEE)

A nonprofit nongovernmental educational association whose purpose is to advance the state of telemetry technology for meter reading, energy management, distribution and control. The AMRA exists to further the universal deployment of telemetry services and establish a forum for the research and development of standards, guidelines and practices. Functions in the areas of automatic meter reading and energy management through telemetry technologies (telephone, radio, power line carrier, cable, etc.) primarily for electric, gas and water utilities. 
Standardization Activities

Keywords

The AMRA Standards Committee works with the Institute of Electrical and Electronics Engineers (IEEE) to develop guide lines and voluntary standards designed to (1) foster the interchangeability of and encourage multiple sources for system components; (2) promote compatibility of existing and future products; (3) facilitate component and system enhancements, including new features, options and additional applications; (4) simplify and lower the cost of system implementations, including specification and selection process; and (5) minimize risk to manufacturers and users.

These guidelines and voluntary standards will cover system component inputs and outputs (including data protocols, hardware interfaces, power requirements, and component protection), environmental conditions, installations, and such other areas as the needs of the Association members may dictate.

The Standards Committee will work to (1) promote the continued development, testing, and integration of new automatic meter reading and telemetry services, equipment and procedures; (2) work with the relevant standards setting bodies of associated industries to promote the consistency of related standards and guidelines; and (3) provide a forum for Association members and other interested parties to develop solutions and approaches to standardization and compatibility issues.

telemetry; communications; data and information processing; distribution load control; utilities; electrical and electronic equipment; automation;

\section{AUTOMOTIVE INDUSTRY ACTION GROUP}

William Fleming, Managing Director

26200 Lahser Road

suite 200

Southfield, Michigan 48034

(801) 358-3570

FAX: (801) $358-3253$

WWW: http://www.aiag.org

Founded: 1982

Standards staff: 50

Type of

Organization
Trade Association

Standards Developer 
standards

Development

Certification

scope

standardization Activities

Availability

Keywords
Develops standards, standard business practices, and guidelines.

More than 1000 individuals participate in standards activities. 17 active standards and standard business practices

30 Implementation Guidelines for ASC X12 Standards

28 Guidelines.

9 white papers.

Distribute 6 Chrysler/Ford/General Motors-developed QS 9000 and related documents.

Administer the certification process associated with the Chrysler/Ford/General Motors Quality System Standards, QS 9000/QSA, Registrar Training

Seeks to improve the productivity of its members and the North American Automotive Industry by providing an Organization to:

- Foster cooperation and communication between customers and their suppliers to improve business processes and practices

- Address existing and emerging common issues and apply new and current technology to increase the efficiency of the industry

- Promote a sense of urgency in adopting developed standards and business practices

- Cooperate and communicate with other industry, governmental and technical organizations

AIAG Member Committees and Focus Groups (Truck Advisory Group and construction Industry Action Group) focus on business processes or supporting technologies and methodologies. They conduct research and pilot programs; develop, publish and provide training on standards, conventions, standard business practices, white papers and guidelines in the areas of automatic identification(bar coding), CAD/CAM (STEP), EDI/Electronic commerce, continuous quality improvement, finance and procurement, materials and project management, returnable containers and packaging systems, and North American Customs (NAFTA Content Reporting).

Distributed directly.

barcode; EDI; electronic commerce; STEP;

$\mathrm{CAD} / \mathrm{CAM}$; QS 9000; quality; returnable containers; 
E. K. Fox, President

P.O. Box 33116

Indialantic, Florida 32903

(407) 722-9993

FAX: (407) 722-9931

Founded : 1945

Standards Staff: 3
Type of

Organization

Standards

Development

Standards

Designation

Government

Adoption

\section{Certification}

Scope

Standardization Activities
Trade Association

Standards Developer

Develops Standards (since 1947).

25 individuals participating in standards activity.

2 active safety standards and 1 Procedural Guide.

Draft standards available thru ANSI's Public Review procedures.

Standards are prefixed with "ALI" or with "ANSI/ALI" if

they are so adopted, for example "ANSI/ALI B153.1-1990."

ANSI/ALI B153.1 has been furnished to Federal and state OSHA divisions and is frequently cited by state OSHA agencies. The "ALI Automotive Lift Certification Program," accepted by inspectors in many states, has not received mandated recognition by federal or state agencies.

ETL Testing Laboratories (Cortland, NY) currently is ALI's thirdparty provider and administrator for our "ALI Automotive Lift Certification Program" initiated in 1993 for the purpose of testing, listing and labeling automotive lifts that meet the criteria of the ALI "Procedural Guide." The Guide describes test requirements and requires: (1) conformance to ANSI/ALI B153.1 for performance; (2) listing to applicable electrical standards; (3) conformance to a documented quality control procedure; and (4) frequent factory surveillance and plant inspections by the administrator.

ALI is an association open to U.S. and Canadian manufacturers of automotive lifts and companies which are the sole domestic distributors of an automotive lift line that is manufactured elsewhere. ALI has 20 members which sell in excess of 85 percent of all units shipped annually in the United States and Canada. Most ALI activities, services and publications relate to automotive lift user safety.

ANSI/ALI B 153.1 (1990) has been sponsored by ALI since it was first adopted in 1947 as CS-142. It was then a Commercial (construction) Standard jointly developed with the DOC's Bureau of 
Standards. It first became an ANSI Safety (performance) Standard in 1974 (revised 1982 and 1990).

ALI ALOIM-94 is a new industry standard covering operation, inspection and maintenance of lifts. It was submitted in 1995 for adoption as an ANSI Standard (Canvass Method).

ALI's "Procedural Guide for the Automotive Lift Institute Certification Program" was first adopted in 1993 and is the cornerstone for a new industry standard that, when adopted, will specify third-party testing, listing and labeling of automotive lift industry products.

Availability

Keywords
Available from ALI; ANSI/ALI B153.1-1990 also through ANSI.

automotive lift; vehicle hoist; garage safety;

\section{AUTOMOTIVE REFRIGERATION PRODUCTS INSTITUTE}

Frank Allison, Executive Director

P. O. Box 470462

Fort Worth, Texas 76147-9462

(817) 338-1161

FAX: (817) 338-1451

Founded: 1983

Standards staff: 2

Type of

organization

\section{Standards}

Development

scope

Keywords
Trade Association

Standards Developer

Founded September, 1983 to develop Performance standards for the Automotive Refrigeration Industry.

Members are manufacturers and suppliers of automotive refrigerants, also container manufacturers, packagers and distributors, and those manufacturers of parts and tools necessary to assemble and test automotive refrigeration products.

automotive refrigeration; air-conditioning; 


\begin{tabular}{|c|c|}
\hline & $\begin{array}{l}401 \text { North Michigan Avenue } \\
\text { Chicago, Illinois } 60611 \\
\text { (312) } 644-6610\end{array}$ \\
\hline & Standards staff: 3 \\
\hline Type of & Technical society \\
\hline organization & Standards Developer \\
\hline $\begin{array}{l}\text { Standards } \\
\text { Development }\end{array}$ & 42 active standards. \\
\hline Certification & $\begin{array}{l}\text { Upon application, equipment is certified in accordance with the } \\
\text { procedure set forth by the certification Board. Standards are } \\
\text { used by manufacturers and enforcement agencies. }\end{array}$ \\
\hline scope & $\begin{array}{l}\text { A nonprofit organization dedicated to achieving sanitation in the } \\
\text { baking industry. It is supported by trade associations represent- } \\
\text { ing manufacturers of baking machinery for wholesale and retail } \\
\text { uses, and interested professional sanitarian and engineering } \\
\text { organizations. Writing and publication of standards and certi- } \\
\text { fication of equipment promoting the sanitary design, construction, } \\
\text { and installation of food-processing equipment are the only pur- } \\
\text { poses and functions of this committee. }\end{array}$ \\
\hline $\begin{array}{l}\text { Standardization } \\
\text { Activities }\end{array}$ & $\begin{array}{l}\text { Develops sanitation standards for baking equipment and } \\
\text { is the recognized sanitation standards organization for the baking } \\
\text { industry. Government and industry representatives work together } \\
\text { in preparing and editing these standards. Task committees are } \\
\text { appointed for each specific standard or revision. Final task } \\
\text { committee proposals are acted on by the general committee and the } \\
\text { BISSC Board of Directors. BISSC standards are published every } 4 \\
\text { years in book form. Latest edition: } 1994 \text {. }\end{array}$ \\
\hline Availability & Distributed directly. \\
\hline & baking equipment; machinery; sanitation; \\
\hline
\end{tabular}

\section{BATTERY COUNCIL INTERNATIONAL}

Edward M. Craft, Executive secretary

401 North Michigan Avenue

Chicago, Illinois 60611

(312) 644-6610

Founded: 1924
FAX: (312) 321-6869

standards staff: 1 
Type of

Organization

Representation

Scope

Standardization

Activities

Formerly

Keywords
Trade Association

Works through other organizations to develop standards

Works with SAE, and International Electrotechnical Commission.

Manufacturers, suppliers of materials, and national distributors of lead-acid storage batteries.

Through committees, battery standards and specifi-

cations are recommended for use by the industry. The Environmental, Industrial Health, and Technical Committees work with government organizations to help set standards and regulations. Publishes a Battery Replacement Data Book. Revised yearly, this book outlines the types of battery sizes and specifications used in automobiles, both foreign and domestic.

The National Battery Manufacturers Association (1940)

The Association of American Battery Manufacturers (1970)

lead-acid; battery; electrical equipment;

\section{BELICORE - BELI COMMUNICATIONS RESEARCH}

Type of

Organization

Standards

Development

Certification
Cliff Halevi, Project Director-Standards

Morris Corporate Center

455 South Street

Morristown, New Jersey 07960-6438

(908) 758-2000 FAX: (908) 758-4545

e-mail: akr@cc.bellcore.com

Research Institute

Standards Developer

Bellcore develops proposed Generic Requirements for

equipment or services. These requirements are utilized on a voluntary basis by members of industry. Bellcore has developed more than 1000 Generic Requirements.

Bellcore's Certification and Registration service provides a client with a mark recognizing that a product has capabilities that are 100 percent conformant with a specified set of criteria. The criteria are derived from widely recognized sources such as standards promulgated by recognized standards bodies or generic requirements proposed and published by Bellcore. Once certification is approved, the Bellcore mark can be displayed on a product subject to the terms of an agreement. A Bellcore directory lists 
standardization Activities

Availability

Keywords such products. Registration relates to quality processes used by a client at a specific site, and the 100 percent conformance of those processes to specified process criteria. If approved, the client may use the Bellcore Registration Mark on literature and in advertising under an appropriate agreement. The registration is also listed in an appropriate Bellcore directory. Periodic site visits, tests and inspections are performed to determine whether the product or process adheres to the specifications of the original test sample and the certification or registration remains valid.

Interoperability and network integrity are key elements of the information technology and telecommunications needs of Bellcore clients. In addressing client needs, Bellcore experts provide clients with solutions for new or emerging services, capabilities, and technologies. Bellcore participates in and provides leadership to a number of United States and international standards bodies. Clients for Bellcore's standards program receive timely reports on activities in such standards bodies as T1-Telecommunications, X3-Information Technology, Internet Engineering Task Force, Telecommunications Industry Association, Institute for Electrical and Electronics Engineers, and the International Telecommunications Union. These reports highlight and provide analysis of issues of particular interest to clients.

Publicly available Bellcore technical information can be ordered through:

Bellcore Customer Service

8 Corporate place

Piscataway, New Jersey 08854-4156

1-800-521-CORE (2673) (USA and Canada)

908-699-5800 (all Others)

WWW Site: http://Www.bellcore.com.

telecommunications; information technology; networking; certification; generic requirements; information infrastructure; internet; switching; signaling; digital services; fiber optics; synchronous optical network; network integrity; disaster management; security; asynchronous transfer mode; ISDN; ATM; SONET; 
Bruce D. Cottew, Executive Director

1700 South First Avenue

Suite $25 \mathrm{~A}$

Iowa City, Iowa 52240

(319) 351-2112 FAX: (319) 351-7767

e-mail: http://www. netins.net/showcase/bcahome/

Founded: 1948 Standards Staff: 3

Type of

Organization

scope

standardization

Activities

Availability

Formerly

Keywords
Standards Developer

Organization of players, retailers, proprietors, manufacturers, distributors, and importers of billiards. Serves as a national clearinghouse for billiard activities; makes rules and interpretations.

Prepares standards for equipment and rules for billiard

and pool games, as well as tournament play. Maintains a specifications Committee and Rules Committee to coordinate these activities. Publishes the Official Rule Book for all Pocket and Carom Billiard Games.

Distributed directly.

National Billiard Council (1963)

billiards; recreation;

\section{BINDING INDUSTRIES OF AMERICA}

70 East Lake Street

Chicago, Illinois 60657

(312) $372-7607$

Founded: 1960

Trade Association

Standards Developer

20 volunteer members participate in developing standards.

3 current, active standards; all processed through ANSI.

Draft standards are available for review.

$\mathrm{BIA} / \mathrm{ANSI} / \mathrm{V} 101$.
FAX: (312) 704-5025

Standards Staff: 1
Standards

Designation
Type of

Standards

Development 

training, networking, standards development and other information through newsletters and magazines to trade graphic finishers, loose-leaf manufacturers and suppliers to those industries.

Standardization

Activities

Availability

Keywords

BIOLOGICAL STAIN COMMISSION
Standards developed for vinyl, paper board and metals

for use in manufacturing of 3 -ring binders. Vinyl standards include testing for cold crack, conventional stability, gauge-taber stiffness, etc. Board and metals from standards.

Sold directly.

three-ring binders; office supplies;
Type of

Organization

Standards

Development

Certification

Scope
David P. Penney, Ph.D., Treasurer

Department of Pathology, Box 626

The University of Rochester Medical Center

Rochester, New York 14642

(716) 275-2751 FAX: (716) 273-1027

e-mail: dpenney@cc.urmc.rochester.edu

Founded: $1922 \quad$ Standards Staff: 1

Scientific Society

Standards Developer

70 standards.

The commission maintains a program of stain certification. Manufacturers and distributors voluntarily submit samples for examination. If the sample meets the commission's specifications, it is approved for marketing as a Certified Biological stain, and the commission issues certification labels to be affixed to bottles in which it is sold. Certification is on a batch basis, the labels issued by the commission bearing distinctive certification numbers identifying the specific batches with which they are to be used. A sample of each batch is kept on permanent file, and the commission investigates complaints of any unsatisfactory results obtained with a certified stain.

A nonprofit organization of professional scientists in biology, medicine, and related fields devoted to the establishment of standards for biological stains. 
Standardization Activities

Availability

Formerly

Keywords

BLUE ANCHOR

Type of

Organization

scope

Standardization Activities

Formerly

Keywords
Establishes standard specifications for the identification, purity, performance and labeling of the more important biological stains, in order that they may be relied upon as standard tools in biological and medical research. International in scope, the commission has the cooperation of scientific societies whose interests lie in this field, as well as the interest and cooperation of manufacturers and distributors of biological stains.

The Commission's standards are included in the appendix of Conn's Biological stains.

Commission on Standardization of Biological Stains (1944)

biological stains; testing; medical instruments;

Dennis N. Icardi, President

P.O. Box 15498

Sacramento, California 95851

(916) 929-3050 FAX: (916) $921-9362$

Founded: $1901 \quad$ Standards Staff: 3

Agricultural Cooperative

Standards Developer since 1930

A fresh fruit marketing cooperative handling the fruit of 1000 growers organized into local associations and contract shippers. All fruit is subject to the standardization program.

Issues standards on all deciduous tree fruit and table grape commodities. Updates the Rules and Regulations for each annual season. The standardization policy is set by a standardization Committee and enforced by authorized agents of the Field Department. Standards required for company members only. Works with various federal and state marketing orders covering pears, plums, peaches, nectarines, and grapes.

California Fruit Exchange

food; fruit marketing; agriculture; 
BOOK INDUSTRY STUDY GROUP

Type of

Organization

Scope

standardization

Activities

Keywords

BOOK MANUFACTURERS INSTITUTE
Stephen P. Snyder, Executive Vice President
45 william Street, Suite 245
Wellesley, MA 02181-4007
$\begin{array}{ll}\text { (617) 239-0103 } & \\ \end{array}$

Trade Association

standards Developer

A nonprofit organization whose members come from all areas of the publishing industry. Specializes in industry research.

Committees review existing standards and select those appropriate for the book industry. Endorsed Bookland EAN bar code for books, Code 128 Representation of the ANSI/NISO standard for serial identification, and the UCC/EAN shipping container standard for bar coding book cartons and shipping containers. The Book and serial Industry Systems Advisory Committees (BISAC and SISAC) develop standards, some of which are passed on to the National Information standards Organization (NISO) to become ANSI/NISO standards. BISAC and SISAC developed unique electronic data interchange formats and are now mapping data elements for AsC X12 conversion.

books; serials; publishing; communications; data and information processing;
Type of

Organization

Government

Adoption

Secretariats

Scope
Stephen P. Snyder, Executive Vice President

45 William street

suite 245

wellesley, MA 02181-4007

(617) 239-0103

FAX: (617) 239-0106

Founded: 1933

Standards staff: 2

Trade Association

Standards Developer

Quality standard adopted by most states

Advisory Commission on Textbook specifications (ACTS)

A trade association for book manufacturers and suppliers of book materials and book manufacturing equipment. 
Standardization Activities

Availability

Formerly

Keywords
Together with the Association of American Publishers and the National Association of state Textbook Administrators, provides delegates to the Advisory Commission on Textbook specification (ACTS) which meets twice each year. ACTS has developed a set of manufacturing standards and specifications which must be met before the purchase of a particular textbook will be considered by most state adoption agencies. This booklet, titled Manufacturing standards and specifications for Textbooks (MSST), contains quality standards and specifications for paper, printing, and binding, and provides sample forms which should be used by both the state agencies and the publishers of textbooks. The MSST covers only elementary and high school textbooks.

Distributed directly.

Employing Bookbinders of America (1933)

books; textbooks; education; communications;

BRASS AND BRONZE INGOT MANUFACTURERS

Celine A. Stachura, Administrative Assistant

200 S. Michigan Avenue

Room 1100

Chicago, Illinois 60604-2480

(312) 372-4000

FAX: (312) 939-5617

Founded: 1989

Type of

Organization

Representation

scope

Standardization

Activities
Trade Association

Works through other organizations to develop standards

ASTM, SAE, foundry societies, and others

Manufacturers of ingot brass and bronze for the foundry industry.

Cooperates with the American Foundrymen's Society, the Non-Ferrous Founders' Society, and affiliated and similar organizations in developing methodology and standards for the production of copper base alloy castings. Participates with ASTM, SAE, Copper Development Association, and military and federal specifications bodies and others in the development of standards and specifications covering ingot brass and bronze. Involved in development of standard reference materials for NIST and has sponsored and directed basic research relating to copper based alloys. Maintains a Technical Committee to consider related subject matter. 
Formerly

Keywords

Non-Ferrous Ingot Metals Institute; Brass and Bronze Ingot Institute (1928); Association of Brass and Bronze Ingot Manufacturers (1950).

brass; bronze; casting alloys; materials;

BRICK INSTITUTE OF AMERICA

Type of

Organization

scope

Standardization Activities
J. Gregg Borchelt, P.E., Vice President of Engineering and Research

11490 Commerce Park Drive

Suite 300

Reston, Virginia 22091

(703) 620-0010

Founded: 1934

FAX: (703) 620-3928

Standards staff: 4

Trade Association

Standards Developer

National association of brick manufacturers and the national authority on brick construction. Promotes the further and proper use of brick.

Standards development, review, writing, and promulgation are the responsibilities of the Engineering and Research Division. Maintains an exchange and liaison with similar organizations in other countries. Also maintains close liaison with government agencies writing standards in the construction industry field, National Institute of Standards and Technology, National Institute of Building Sciences, and the Departments of Housing and Urban Development, Defense, Energy, Labor, and Commerce. Works with other standards writing organizations in the development of standards involving or related to Brick Masonry as follows: American Concrete Institute, American Society of Civil Engineers, The Masonry Society - ACI 530, ASCE 5, Tms 402 Building Code Requirements for Masonry structures, ACI 530.1, ASCE 6, TMS 602. Specifications for Masonry Structures; American Society for Testing and Materials - Committees C-12 on Mortar for Unit Masonry, C-15 on Manufactured Masonry Units, D-1 on Paint and Related Coatings and Materials, E-5 on Fire Testing and E- 6 on Performance of Building Constructions; Building Seismic safety Council, National Fire Prevention Association

Engaged in research for the development of new standards dealing with masonry design and applications. Currently working on veneer and limit states design standard for masonry in conjunction with the Masonry Standards Joint Committee of the American Concrete Institute, the American society of Civil Engineers, and The Masonry Society. 
Availability

Formerly

Keywords
Distributed directly.

Structural clay Products Institute

masonry; brick; construction; building;

\section{BUILDERS HARDWARE MANUFACTURERS ASSOCIATION}

Peter Rush, Executive Director

c/o Association Management Group

355 Lexington Avenue

New York, New York 10017

(212) $661-4261$

FAX: (212) 370-9047

Founded: 1925

Standards staff: 4

Type of

Organization

standards

Development

Standards

Designation

Government

Adoption

Certification

scope

Standardization

Activities
Trade Association

Standards Developer

Standards developer since 1966.

70 members active in standards development.

23 active standards.

23 processed through ANSI.

4 standards in development.

ANSI/BHMA prefix.

The Department of Defense has adopted all BHMA sponsored ANSI standards.

Sponsors three certification programs; one for locks, one for door closers and one for exit devices. ETL Testing laboratories is administrator and testing agency for locks and closers. Underwriters Laboratories is the administrator and testing agency for exit devices.

A national trade association representing manufacturers of builders hardware. Provides programs for its members in the areas of industrial relations, management, and statistical programs.

Is accredited by ANSI to develop standards for builders hardware using the canvass method. Participates on NFPA and ASTM Committees. 
Availability

Formerly

Keywords

BUILDING OFFICIALS AND COI
Distributed directly, through ANSI, Door and Hardware Institute, and IHS.

Hardware Manufacturers Statistical Association (1925-1961)

hardware; buildings;
Type of

Organization

Standards

Development

standards

Designation

Government

Adoption

Certification

Secretariats

scope
CODE ADMINISTRATORS INTERNATIONAL

Paul K. Heilstedt, PE, Chief Executive Officer

4051 West Flossmoor Road

Country Club Hills, Illinois 60478-5795

(708) 799-2300

FAX: (708) 799-4981

Founded: 1915

Standards staff: 80

Professional Society

Standards Developer

Promulgates the BOCA National Code Series of model

codes for reference adoption by municipal and state governments.

BOCA National Building Code; BOCA National Mechanical

Code; BOCA National Plumbing Code; BOCA National Fire Prevention Code; BOCA National Property Maintenance Code; BOCA National Energy Conservation Code.

Codes are adopted by 18 states and 5000 local governments, predominantly in East and Midwest portions of the United states

Maintains a voluntary education and certification program for construction code officials and other members.

Council of American Building Officials (CABO) One and Two Family Dwelling Code.

International Code Council (ICC)

A nonprofit municipal service membership organization involved in the field of code administration and enforcement, and community development. Goals are to serve the public by advocating the use of safe, suitable, modern construction techniques and materials, through its model codes program; and to serve jurisdictions and their code administrators by providing technological know-how and services related to all specialty areas of code administration and enforcement, in addition to a complete model codes maintenance program. 
standardization Activities

Availability

Formerly

Keywords
Membership services include code interpretations, materials and product evaluation reports, plan review, education programs and documents, and administrative reviews. The BOCA National Codes reference and adopt hundreds of consensus standards produced by standards writing organizations.

An annual code development process for each of the BOCA Codes permits anyone to propose a change and participate in the deliberations. All activities are in support of the use of the codes. All activities carried on by the technical and professional staff under the direction of its Chief Executive Officer, appointed by the Board of Directors. BOCA codes state performance requirements for materials under given conditions, and establish evaluation criteria, resulting in reduced construction costs and allowing ingenuity on the part of the designer.

Distributed directly. All codes produced every three years in new editions (current 1995).

Building Officials Conference of America (1970)

safety; building; codes; plumbing code; mechanical code; fire code; maintenance code; energy conservation; construction; government officials; health;

BUILDING OWNERS AND MANAGERS ASSOCIATION INTERNATIONAL

Michael Jawer, Assistant Vice President, Government and Industry Affairs

1201 New York Avenue NW.

Suite 300

Washington, DC 20005

(202) 408-2684

FAX: (202) 371-0181

Founded : 1908

Standards staff: 1

Type of

Organization

Standards

Development

Secretariats
Trade Association

Standards Developer

Standards developer since 1915.

ANSI Z65.1 Method for Measuring Floor Area in Office Buildings 
Scope

Standardization

Activities

Availability

Formerly

Keywords
A trade association serving owners and managers of commercial real estate, primarily office buildings. Studies operating costs, rental conditions, occupancy, fire and safety, and other conditions affecting the office building industry.

Publishes the ADA Compliance Guidebook; ADA Answer Book; Refrigerant Manual; Emergency Planning Guidebook. Active as a member of three model code organizations (BOCA, ICBO, SBCCI) and the National Fire Protection Association. Also concerned with ASHRAE Standards 15 (Mechanical Refrigeration) and 62 (Indoor Air Quality). Member of the National Institute of Building sciences (NIBS).

Distributed directly and through ANSI.

National Association of Building Owners and Managers (1908) Building Owners and Manager Association International (1968)

rentable space; usable space; floor measurement; high-rise office buildings; energy efficiency; building or facilities management; accessibility; indoor air quality; asbestos; refrigerant management;

\section{BUSINESS AND INSTITUTIONAL FURNITURE MANUFACTURERS ASSOCIATION}

Type of

Organization

standards

Development

secretariat

Standards

Designation
Russell R. Coyner, Executive Director

2680 Horizon Drive, SE

Suite A1

Grand Rapids, Michigan 49546

(616) 285-3963

Founded: 1973

FAX: (616) 285-3765

Standards staff: 6

Trade Association

Standards Developer

Standards developer since 1973.

240 member company representatives participating in standards development and maintenance activities.

7 active standards.

6 ANSI/BIFMA Safety and Performance standards.

1 BIFMA upholstered Furniture Flammability standard.

US TAG ISO/TC 136

ANSI/BIFMA prefix or BIFMA. 
Government

Adoption

Certification

scope

standardization

Activities

Availability

Keywords
The General Services Administration has adopted

ANSI/BIFMA standards for use in Commercial Item Descriptions. Memo of Standards Harmonization with Canadian General standards Board.

Voluntary certification

A national trade association that represents the United States companies and companies in other nations engaged in the manufacture of office and institutional furniture. Functions on a national and international level, representing its membership in a wide range of engineering, statistical, and other relationships with public and government agencies.

Develops standards for the performance and testing of office and institutional furniture including tests for:

1. office chairs, 2. lateral files, 3. vertical files, 4. desks, 5. lounge furniture, and 6. panel systems furniture, and uphol stered furniture flammability for non live-in occupancies. Maintains an Engineering standards Committee with many subcommit tees. Works through other organizations to develop standards specifically, Human Factors and Ergonomics Society. Active in Ergonomics, Environmental regulations and Product Liability areas as well.

Distributed directly and through ANSI.

furniture; office furniture; institutional furniture; office products; environments; desks; chairs; files; panel systems; ergonomics;

CAN MANUFACTURERS INSTITUTE

Robert R. Budway, President

1625 Massachusetts Avenue NW.

Washington, DC 20036

(202) $232-4677$

FAX: (202) 232-5756

Founded: 1939

Standards Staff: 2

Type of

Organization

scope
Technical Society

Standards Developer

A nonprofit membership corporation representing United states manufacturers of all metal cans. The membership is concerned with government specifications for cans and legislation affecting cans and can standards. 
Standardization

Activities

Availability

Keywords

CARPET AND RUG INSTITUTE

Type of

Organization

Representation

scope

Standardization Activities

Formerly

Keywords
Maintains Can Standards Committee, which develops standards on sanitary cans for sizes in general demand. Creates ad hoc subcommittees as necessary to study and/or recommend specific standards for full committee action. Publishes Recommended CMI Voluntary Industry Can Standards. Recommended standards are strictly voluntary, but conforming is encouraged as being beneficial to can manufacturers and can users.

Distributed directly.

can manufacture; packaging;

E. Ken McIntosh, Director of Technical Services

Box 2048

Dalton, Georgia 30722

(706) $226-3877$

FAX: (706) 278-8835

Founded: 1963 Standards Staff: 4

Trade Association

Works with other organizations to develop standards

AATCC, ASTM, NFPA and other standard development organizations

Membership consists of manufacturers representing 95 percent of all carpet produced in the United States, and suppliers of raw materials and services. Works on a national and international level to promote carpet and rugs, to develop standards to be used by the industry, installers, and end users, and to provide satisfaction with carpet and rugs.

Participate in development of standard tests used by industry and interested parties to test various components or characteristics of carpets and rugs.

American Carpet Institute and the Tufted Textile Manufacturers Association

carpet; rugs; consumer products; 
William H. LeVan, Executive Vice President

5959 Shallow Ford Road

Suite 419

Chattanooga, Tennessee 37421

(615) 892-0137

FAX: (615) 892-0817

Founded: 1949

Standards Staff: 2

Type of

Organization

Standards

Development

Standards

Designation

Government

Adoption

Certification

Scope

Standardization

Activities

Availability

Reywords
Trade Association

Standards Developer

Standards developer since 1949.

Technical Committee develops Standards pending approval of the Institute's Board of Directors; ASTM A74-94, ASTM A888-94, CISPI 301-90, CISPI 301-95, endorsed by CISPI.

CISPI prefix.

HUD, WW-P-401E; PBS (PCD) 15410; DOD 4270.21; CEGS

$15400 ; \mathrm{CE} 300.01 ; \mathrm{CE} 300.02 ; \mathrm{CE} 600.01 ; \mathrm{NAVFAC}$ TS-15301; and NAVFAC TS-15401

No certification, qualification, or accreditation programs

Aids the United States plumbing industry in cooperation with the soil pipe manufacturers. Efforts include product improvement, standardization of soil pipe and fittings, and testing, evaluation, and development in the interest of public health and safety.

Develops standards for cast iron soil pipe and fittings which are accepted throughout the United States. These standards set dimensions and specifications which provide interchangeability between all manufacturer's pipes and fittings. The CISPI Standards are national in scope. The Technical Committee administers CISPI's Standardization Activities.

The Institute's Technical Committee meets two times a year to review standards, engage in research and development activities, and update CISPI publications.

Through ASTM and plumbing wholesalers and distributors.

cast iron; plumbing; sanitation; construction; building; 
Type of

Organization

standards

Designation

Government

Adoption

Certification

scope

\section{Standardization}

Activities

Formerly

Keywords
Jack W. Davidson, President

515 116th Avenue, NE, Suite 275

Bellevue, washington 98004

(206) 453-1323

FAX: (206) 455-1314

Founded: 1915 Standards Staff: 3

Trade Association

Standards Developer

Grading Rules for Certi-Split Red Cedar Shakes - 1985.

Grading Rules for Certigrade Red Cedar Shingles - 1984.

Grading Rules for Cert-Sawn Red Cedar Shakes - 1981.

Adopted by all national model building codes which are now recognized by the U.S. Department of Housing and Urban Development (HUD)

Contracts for unannounced third-party inspections of over 300 shake and shingle mills in the northwest United states and Canada. Prints and issues labels for product identification for use by complying mills.

Membership includes manufacturers, distributors and users of red cedar shakes and shingles. In addition, inspects and labels shakes and shingles manufactured from species other than red cedar under the auspices of the wood Shake and Shingle Association, an in-house subsidiary. Promotes the acceptance and use of shake and shingle roofing and siding materials through advertising and trade promotion.

Develops and revises standards relating to the quality, packaging and application of shakes and shingles.

Red Cedar Shingle and Handsplit Shake Bureau - 1988 RCSHSB formed from merger of Red Cedar shingle Bureau and $\mathrm{H}-$ andsplit Cedar Shake Association - 1963

Red Cedar Shingle Bureau formed in 1915

wood products; roofing; side wall; grading rules; inspection; lumber; building; 
Jan Foxen, Executive Vice President

579 West North Avenue

suite 301

Elmhurst, Illinois 60126

(708) 833-1919

FAX: (708) 833-1940

Compuserve 75031,2577

Founded: 1949

Standards staff: 1

Type of

organization

Representation

Scope

Standardization Activities

Formerly

Keywords
Trade Association

Works through other organizations to develop standards

ASTM

An international organization serving the needs of specialty subcontractors who sell and install ceiling systems, as well as other related products and systems.

Provides programs for exchanging information about the industry and its trends, and develops working alliances with other organizations within the construction contracting industry to deal with common problems.

Participated in the development of the American Society for Testing and Materials (ASTM) standard specification for Metal Suspension Systems for Acoustical Tile and Lay-in Panel Ceilings (ASTM C635-69), and standard Recommended Practice for Installation of Metal Ceiling suspension systems for Acoustical Tile and Lay-in Panels (ASTM C636-69). Also active in the development of Recommended Standards for Seismic Restraint of Direct-Hung Suspended Ceiling Assemblies.

National Acoustical Contractors Association (1969)

Ceilings and Interior systems Contractors Association (1949)

acoustical tile; ceilings; buildings; contractor; 
Type of

organization

Standards

Development

Standards

Designation

Secretariats

Scope

Standardization

Activities

Availability

Keywords

CERTIFIED AUTOMOTIVE PARTS ASSOCIATION

Type of

Organization

Certification

Scope

1518 K Street, NW.

Suite 306

(202) 737-2212

Founded: 1987
Trade Association

Standards Developer

30 active standards.

ANSI B212. $\mathrm{x}$.

Promulgates its documents through ANSI/ASC B212. Accredited Standards Committee for cemented carbide.

Manufacturers of cemented tungsten carbide cutting tools, dies, and wear parts.

Actively engaged in standardization activities through ANSI/ASC Committee B212, TC-1; develops standards dealing with the dimensional, physical, metallurgical, and chemical aspects of cenented carbide products; cooperates with ISO, ASTM, NIST, and others in standards development; standards include turning tools, wire, bar and tube drawing dies; and sampling and testing methods for hard metals.

Distributed directly.

carbide; materials, manufacturing;

Jack Gillis, Executive Director

Washington, DC 20005

FAX: (202) 737-2214

Standards staff: 2

Certification Organization

Standards Developer

Included in certification is inspection of the factory, evaluation of quality control manuals used in the manufacture of the parts, inspection and review of the manufacturing process, materials testing, corrosion testing of metal parts and the evaluation of the fit and finish of the final product.

The CAPA program certifies sheet metal and plastic auto body parts. The program is open to all manufacturers of such parts. There are currently over 1100 competitive aftermarket auto body 


\section{standardization Activities}

Keywords parts which have been certified as meeting CAPA's standards for quality, fit and finish.

Standards are developed under the auspices of CARA's Technical Committee which is made up of representatives from the insurance, auto body parts manufacturers, and parts distribution industries. These standards are developed with the assistance of independent technical testing laboratories.

aftermarket auto body parts; transportation; automobile; manufacturing;

\section{CERTIFIED BALLAST MANUFACTURERS}

M. C. Davies, Secretary

1422 Euclid Avenue

Suite 772

Cleveland, Ohio 44115

(216) 241-0711

FAX: (216) 241-0713

Founded: 1939

Type of

Organization

Representation

Certification

Scope

standardization Activities
Trade Association

Works through other organizations to develop standards

ANSI, UL.

Certification program for ballasts operating standard fluorescent lamps. Open to any manufacturer who wishes to qualify. To be certified CBM, ballasts must meet performance requirements of ANSI specifications C82.1, including the electrical requirements specified in the C78 standard for the lamp type to be operated. Ballasts must also be UL listed and High Power Factor. Compliance is repeatedly verified by ETL Testing Laboratories, an independent testing organization, which periodically selects samples at random from manufacturers' current CBM production and tests them, as prescribed in ANSI C82.2 and C82.3.

Major producers of ballasts for fluorescent lamps. Promotes fluorescent lighting by encouraging the manufacture of ballasts which provide quality performance.

Works through ANSI to develop standards for fluorescent ballasts. 
CHAIN LINR FENCE MANUEACTURERS INSTITUTE

\author{
Type of \\ Organization \\ scope \\ Standardization \\ Activities
}

Availability

Keywords
Mark Levin, CAE, Executive Vice President

1776 Massachusetts Avenue NW.

suite 500

Washington, DC 20036

(202) 659-3537 FAX: (202) 857-1220

Founded: 1960

Standards staff: 1

Trade Association

Standards Developer

Provides a forum to exchange ideas; promotes the use of chain link fence; collects statistics and works with consumers to develop guidelines for fence products.

Coordinates the entire fence specification field with the American Society for Testing and Materials. Works toward setting universal standards for fence specification. Develops voluntary consensus standards. Promotes the usage of ASTM standards throughout the industry. Publishes a Product Manual which includes ASTM standards.

Distributed directly.

fence; construction;

CHEMICAL FABRICS AND FILM ASSOCIATION

Charles M. stockinger, Executive secretary

1300 Sumner Avenue

Cleveland, Ohio 44115-2851

(216) 241-7333

FAX: (216) 241-0105

Founded : 1927

Standards staff: 2

Type of

Organization

standards

Development
Trade Association

Standards Developer

12 member companies participating in standards activities.

Draft standards available for review by nonmembers. None processed through ANSI. 
A voluntary, nonprofit trade association which includes among its members 12 North American manufacturers of chemically coated fabrics and PVC sheet and film. Represents its membership in technical, environmental, and governmental affairs of interest to the industry. One of its objectives is to inform and educate the consuming public regarding the uses and merits of chemical fabrics and film; interested in encouraging high standards of quality and service throughout the industry.

Standardization Activities

Availability

Formerly

Reywords
Directed toward the setting of voluntary performance and quality standards for various product lines. Solicits input from all interested parties. Works closely with the American Society for Testing and Materials. Committees review and make recommendations on government standards, specifications, and documents; and participate in standards programs with the National Institute of Standards and Technology, Underwriters Laboratories, and other standard setting organizations related to the industry.

Standards are voluntarily adopted by manufacturers and users and applied to various product lines when performance, reliability, and safety are essential.

Distributed directly.

Institute of Leather Cloth and Lacquered Fabric Manufacturers (1932)

Pyroxylin and Resin Coaters Institute (1943)

Plastic Coatings and Film Association (1948)

Vinyl Fabrics Institute (1955)

coated fabrics; sheet and film; upholstery; vinyl; wall covering; materials;

\section{CHEMICAL MANUFACTURERS ASSOCIATION}

Diana Artemis, Associate Director

2501 M Street NW.

Washington, DC 20037

(202) 887-1386

FAX: (202) 463-1593

e-mail: uscmadta@ibmmail.com

Founded: $\quad 1872$

Standards Staff: 2

Type of

Organization
Trade Association

Standards Developer 
Standards

Development

Standards

Designation

Scope

Standardization

Activities

Availability

Formerly

Keywords
Processed through ANSI.

ANSI .

A nonprofit trade association whose company members represent more than 90 percent of the productive capacity of basic industrial chemicals within this country.

As a standards developer using the canvass method, sponsors American National Standard Z129.1, Precautionary Labeling of Hazardous Chemicals. As a standards developer using the committee method, sponsors American National standards Committee B96, Welded Aluminum-Alloy Storage Tanks.

Provides over 50 members to serve as its representatives on national standards committees, boards, and councils dealing with standards for plant equipment, packaging equipment, transportation equipment, and occupational safety and health. Standards organizations include ANSI, AAR, ASME, NFPA, and SSCI.

Participates heavily in standards development proposed by other organizations for adoption as American National Standards by the canvass route. Standards organizations include API, CEMA, IEEE, ISA, MSSVFI, NEMA, SPI, and UL. Also participates in ASTM committees dealing with occupational health and safety, waste disposal, spills, and analysis of industrial chemicals.

Distributed through ANSI.

Manufacturing Chemists Association (1979)

labeling; hazardous chemicals; materials; processes;

CHEMICAL SPECIALTIES MANUFACTURERS ASSOCIATION

D. Douglas Fratz, Director, Scientific Affairs

1913 Eye Street NW. Washington, DC 20006

(202) $872-8110$

FAX: (202) 872-8114

Founded: 1914

Standards Staff: 3

Type of

Organization

Trade Association

Standards Developer 
standards

Designation

Government

Adoption

scope

Standardization

Activities

Availability

Formerly

Keywords
CSMA prefix or CSMA Bulletin No.

CSMA product performance evaluation methods have been used for government procurement purposes by GSA. Many have been adopted by ASTM.

Four hundred companies involved in manufacturing, formulating, packaging, and marketing chemical specialties products, including home, lawn, garden, transportation, institutional, and industrial products. Works in various areas, including federal and state governmental affairs (both legislative and regulatory), communications, public relations, marketing, legal affairs, and scientific and technical affairs.

Develops standard product characterization methods, product performance evaluation test methods, and recommended practices for manufacturers and formulators of chemical specialties products through numerous scientific and technical committees in CSMA's six divisions: (1) Aerosol; (2) Industrial and Automotive Specialties; (3) Detergents; (4) Antimicrobial Products; (5) Pesticides; and (6) Polishes and Floor Finishes.

Has numerous representatives on committees of voluntary consensus organizations such as ANSI, ASTM, NFPA, ANMC, and AOAC. Standards originated and promoted by CSMA are now ASTM, AOAC, SAE, or other standards as well.

Published manuals and compendiums including: Aerosol Guide; Detergents Division Test Methods Compendium; Microbiological Test Methods Compendium; Waxes, and Polishes and Floor Finishes Test Methods and General Information.

Distributed directly.

National Association of Insecticide and Disinfectant Manufacturers (NAIDM)

chemical specialties; household chemicals; aerosols; automotive chemicals; disinfectants; sanitizers; detergents; cleaners; pesticides; insecticides; waxes; polishes; floor finishes; materials; consumer products;

Robert G. Smerko, President

2001 L street, NW.

Suite 506

washington, DC 20036

(202) 775-2790

FAX: (202) 223-7225

Founded: 1924
Standards staff: 1 
Type of

organization

Representation

Scope

Standardization

Activities

Keywords

CLEANING EQUIPMENT TRADE ASSOCIATION

Type of

Organization

Standards

Development

Standards

Designation

Scope chloride.

Suite 105
Trade Association

Works through other organizations to develop standards

Standards committees of ANSI, ASTM, AWWA, NFPA, and committees of the Association of American Railroads

Concerned with the safe production, distribution, and use of chlorine, sodium and potassium hydroxides, and sodium hypochlorite; and the distribution and use of hydrogen chloride. Committees provide comments on draft standards pertinent to the chloralkali industry.

Publishes literature and drawings of equipment as guidelines and recommended safety practices for handling chlorine, sodium and Potassium hydroxides, sodium hypochlorite and hydrogen

chlorine; sodium hydroxide; caustic soda; potassium hydroxide; caustic potash; sodium hypochlorite; bleach; hydrogen chloride; hydrochloric acid; anhydrous hydrogen chloride; chemicals; safety;

John Hoppenstedt, Executive Director

2535 Pilot knob Road

St. Paul, Minnesota 55120

(612) 686-7086

FAX: (612) $686-7088$

Founded: 1980

Trade Association

Standards Developer

Standards developer since 1981.

50 members participate in standards activities.

12 members are represented on the standards committee

for UP Standard 1776.

Safety Standards for Cleaning Machines.

An international trade association of manufacturers and distributors which sell commercial-industrial cleaning machines, including cold water high pressure cleaners and blasters, hot water high pressure cleaners, steam cleaners, and water jetting equipment. 
Activities directed toward the development of nation-

ally recognized Equipment safety standards intended to provide a basis for common understanding and reference within the cleaning equipment industry among suppliers, manufacturers, distributors, dealers, resellers or installers, and owner-users. These also serve as reference guides for government agencies and industry when making purchasing decisions. Anticipates standards adoption as national consensus standards through ANSI.

Distributed directly.

Cleaning Equipment Manufacturers Association (CEMA)

cleaning machines; water blasters; industrial equipment; steam cleaners;

\section{COATED ABRASIVES MANUFACTURERS INSTITUTE}

Charles M. Stockinger, Managing Director

1300 Sumner Avenue

Cleveland, Ohio 44115

(216) 241-7333 FAX: (216) 241-0105

Founded: 1933 Standards Staff: 2

Type of

organization

\section{standards}

Development

Secretariats

scope

Standardization

Activities
Trade Association

Standards Developer

5 member companies participate in standards activities.

Standards processed through ANSI.

Draft standards available for review.

CAMI Technical Committee serves as Technical Committee on Coated Abrasives of the B74 Committee. CAMI Safety and Industrial Health Committee serves as the Technical Committee B7 of the B74 Committee.

A voluntary, nonprofit association of manufacturing companies which coat and manufacture various types and forms of coated abrasive products in the United states.

Develops standards for grading of certain abrasive grains on coated abrasive products. These specifications include grading requirements for screen grit size and sedimentation grit sizes of aluminum oxide, silicon carbide, garnet, emery, and flint abrasive grains for use on coated abrasive products; procedures for recovery of abrasive grains from products to be tested; and procedures for testing recovered abrasive grains to determine if they conform to grading requirements. 
Availability

Keywords
Definitions of the trade terms used and methods for identifying products which conform to this standard are included.

Also develops standards which establish the minimum safety requirements related to the usage of coated abrasive forms. Requirements apply to hand-held and fixed-mounted machine operations that use some form of coated abrasive product, and to $\mathrm{s}$ afety-related maintenance precautions for machines and machine parts. Also contain safety requirements pertinent to operator and bystander protection, dust collection, and potentially hazardous environmental conditions.

Distributed directly and through ANSI.

abrasives; manufacturing; safety; industrial equipment;

\section{COLLEGE OF AMERICAN PATHOLOGISTS}

Type of

Organization

Representation

standards

Development

Certification
Lee VanBremen, Executive Vice President

325 Waukegan Road

Northfield, Illinois 60093-2750

(847) 446-8800

FAX: (847) 446-8807

Founded: 1947

Standards Staff: 1

Professional Society

Standards Developer and works through other organizations to develop standards

American National Standards Institute Association for Advancement of Medical Instrumentation Commission on World Standards

National Committee for Clinical Laboratory standards World Association of Societies of Pathology World Health Organization

A Standards Coinmittee of seven members and four nonmembers coordinate liaisons with national and international standards setting organizations. The committee identifies problems in standards development and coordinates their solution.

The Standards and Reference Materials Program develops and certifies bottled standards and reference materials for standardization of medical laboratory tests, and supervises a cyanmethemoglobin certification program. The bottled materials offered through this program allows external verification of accuracy in test reagents and assay systems. The surveys Program provides external quality assessment in the form of proficiency testing services. This program assists participating laboratories in meeting federal and state regulations. CAP also sponsors voluntary accreditation 


\section{secretariats}

Scope

Standardization Activities

Availability

Keywords programs for laboratories, forensic urine drug testing, athletic drug testing, and reproductive laboratories. These programs coordinate on-site inspections for a "macro" evaluation of laboratories. The CAP has deeming authority to accredit laboratories per the Health Care Financing Administration CLIA ' 88 regulations.

Commission on World Standards of the World Association of Societies of Pathology (WASP), the WASP Secretariat on Forensic Pathology and the WASP Secretariat on Informatics.

The College of American Pathologists is a not-for-profit professional society of more than 13600 physicians specializing in the practice of pathology. The college is dedicated to leadership, quality, service and advocacy in laboratory medicine. The CAP pursuit of excellence is made possible by member participation in the development of various laboratory improvement programs offered by the college.

The CAP laboratory improvement programs provide a continuum for medical laboratories and industry to move toward more standardized testing and practices. The external quality assessment schemes of proficiency testing and accreditation allow for identification of areas which are in need of standardization. Once a need for standardization is identified, a solution, either in the form of bottled standard or paper standard, is coordinated.

Participation in the Laboratory Improvement Programs can be requested directly from the CAP. Standards are available directly.

pathology; medicine; medical; laboratory; proficiency; accreditation; standards; reference materials; health care; 
Type of

Organization

Government

Adoption

Certification

Scope

Standardization

Activities

Availability

Keywords
Margaret Walch, Associate Director

409 West 44 th street

New York, New York 10036

(212) 582-6884

FAX: (212) 757-4557

Founded: 1915

Standards Staff: 3

Trade Association

Standards Developer

DoD Color Card

No certification, qualification, or accreditation programs

Membership comes from the textile and fashion industries, and the interior design and environmental fields. Issues seasonal color forecasts of dyed fabrics for women's and men's apparel twice a year. Issues a yearly forecast of interior colors for the interior and environmental fields; these forecasts are applicable to companies producing dyestuffs, paints, automobiles, airplanes, home furnishings, textiles, plastics, cosmetics, and other products. Standardizes government and industry colors; offers consultations; maintains archives and fabric swatch library.

Produces a Standard Color card of America for the purpose of simplifying color work by establishing color standards favored for use in the United states. The card presents a comprehensive palette of preferred American colors and is primarily directed to the textile, fashion, and environmental industries.

Distributed directly.

textile; fashion; interior design; color; sports; consumer products; general;

COMMERCIAL REFRIGERATOR MANUFACTURERS ASSOCIATION

Robert T. Chancler, Executive Director

1101 Connecticut Avenue NW.

suite 700

Washington, DC 20036

(202) 857-1145

FAX: (202) 223-4579

Founded: 1933

Standards Staff: 1 
Type of

Organization

standards

Development

standards

Designation

Certification

Scope

Standardization

Activities

Availability

Keywords
Trade Association

Standards Developer

one active standard.

CRS prefix.

No certification, qualification, or accreditation programs.

Manufacturers of refrigerated display cases and cabinets, food service refrigerators, and sectional cooling rooms.

Develops and revises Voluntary Minimum Standard for

Retail Food Store Refrigerators - Health and Sanitation, CRS-S178

- as required.

Sold directly.

refrigerators; refrigeration;

\section{COMPOSITE CAN AND TUBE INSTITUTE}

Kristine Garland, Executive Vice President

1630 Duke Street

Alexandria, Virginia 22314

(703) 549-2233

FAX: (703) 549-4912

Founded: 1933

Standards Staff: 1

Type of

Organization

Scope

Standardization

Activities
Trade Association

Standards Developer

A nonprofit international organization which fosters the collective interests of the composite can, tube, core, and fiber drums industry and their suppliers.

Administers a Technical Committee active in standards development.

Does not participate in international programs or federal government standardization activities, except when requests are received for specific information.

Publishes standard testing procedures to provide uniform methods for both manufacturers and users to measure and test the physical characteristics of composite cans, tubes, and cores. Develops and publishes recommended industry standards covering dimensions for certain high volume types of composite cans to accommodate custom- 
Availability

Formerly

Keywords ers' closing and handling equipment. Publishes guidelines as sources of information for manufacturers and users of industry products. Publishes and revises testing procedures.

Distributed directly.

National Fibre Can and Tube Association (1970)

composite cans; composite tubes; packaging; cores; fiber drums;

COMPRESSED AIR AND GAS INSTITUTE

Type of

Organization

Standards

Scope

Standardization Activities

Availability

Keywords
John H. Addington, Secretary-Treasurer

1300 Sumner Avenue

Cleveland, Ohio 44115

(216) 241-7333

FAX: (216) 241-0105

Founded: 1915

Standards Staff: 2

Trade Association

Standards Developer

35 member companies participate in the standards Development development for industry products used in manufacturing, construction, mining, and other industries.

A national trade association of companies which manufacture air and gas compressors, pneumatic machinery and compressed air and gas drying equipment.

Representative standards that the institute has developed include performance statements which identify parameters for performance evaluation of centrifugal compressors; a test standard for rating compressed air dryers; and the test code for sound measurement of pneumatic equipment, ANSI S5.1. The latter standard was developed jointly with the European Committee of Manufacturers of Compressed Air Equipment.

Sold directly.

noise control; construction; manufacturing; industrial equipment; safety; machinery; 
Carl T. Johnson, President

1725 Jefferson Davis Highway

Suite 1004

Arlington, Virginia 22202

(703) 412-0900

FAX : (703) 412-0128

Founded: 1913

Standards Staff: 15

Type of

Organization

Standards

Development

Standards

Designation

Government

Adoption

Certification

Scope

Standardization

Activities
Trade Association

Standards Developer

Standards developer since 1913.

250 member companies participating in standards

activities.

90 active standards, including metric.

CGA prefix; in some instances, standards also bear ANSI

and Canadian Standards Association (CSA) designations.

Standards comply with Department of Transportation and

other government agencies where applicable (federal, state, and local regulations).

No certification, qualification, or accreditation programs

Provides, develops, and coordinates technical activities in the compressed gas industries, including end-uses of products, so that they may serve the best interest of the public and industry. Active primarily in the fields of safety and technical specifications pertaining to the compressed gas and related product and service industries, including the medical fields of anesthesia and respiration.

Collaborates with national organizations such as the NFPA, the National LP-Gas Association, ASTM, ANSI, AAR, and the American Society of Anesthesiologists, to develop far-reaching specifications and standards of safety to benefit industry and the public.

Compiles information and publishes material, such as the Handbook of Compressed Gases, and pamphlets which contain a description of the used gases and give in detail the safest methods for handling and storing gases. Provides audiovisual presentations.

Conducts national and regional technical meetings and seminars to discuss practices, standards, and problems related to the broad spectrum of the compressed gas industries. 


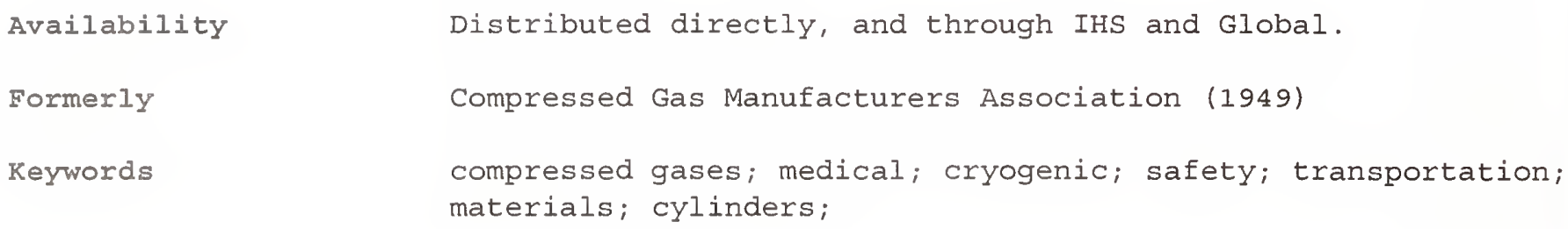

CONCRETE PLANT MANUFACTURERS BUREAU

Type of

organization

Standards

Designation

Government

Adoption

Certification

Scope

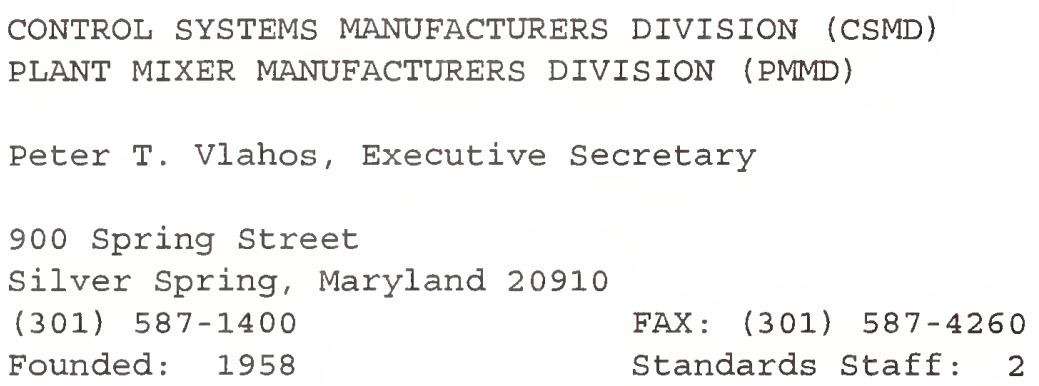

CPMB, CSMD and PMMD ratings plates are affixed to concrete plants, control systems and plant mixers meeting Bureau standards.

Develops engineering standards with a view toward simplification and standardization of sizes, capacities, and other criteria associated with the manufacture of concrete plants. 


\section{Standardization Activities}

Availability

Keywords
Develops standards for concrete plants and concrete mixers. Bureau standards subject to approval by the National Ready Mixed Concrete Association. Represented on committees of the National Ready Mixed Concrete Association. Participates in the development of governmental specifications or their interpretation.

Distributed directly.

concrete; concrete plants; materials; construction;

CONCRETE REINFORCING STEEL INSTITUTE

Victor A. Walther, Jr., President, CAE

933 North Plum Grove Road

Schaumburg, Illinois 60173

(847) $517-1200$

FAX: (847) 517-1206

Founded : 1924

Standards Staff: 1

Type of

Organization

Scope

\section{Standardization} Activities

Availability

Keywords
Trade Association

Represents mill producers, fabricators, and suppliers of reinforcing bars. Associated members include producers and suppliers of other products used in concrete construction and fabricating equipment manufacturing. Increases the use of reinforcing bars through research, education, promotion, improved efficiency for lower final costs through better design, improved materials, and construction techniques.

Technical activities are conducted by the CRSI

Engineering Practice Committee and subcommittees on bar supports, placing reinforcing bars, concrete joist construction, detailing reinforced concrete, and splicing reinforcing steel.

Sold directly.

reinforcing steel; concrete; joists; construction; building; 
Type of

Organization

Standards

Designation

Standards

Development

Government

Adoption

Certification

Secretariats

scope

Standardization

Activities

Availability

Keywords
Patrick O'Brien, Executive Director

6089 Frantz Road

Suite 101

Dublin, Ohio 43017

(614) 798-2252

FAX: (614) $798-2255$

Founded: 1972 Standards Staff: 1

Professional and Trade Association

Standards Developer

Standards published in accordance with Construction specifications Institute (CSI) format.

Develop standards in concrete cutting industry.

None.

Certification program being developed for operators of concrete cutting equipment. Certification will begin in April 1996.

None

Association of contractors, manufacturers and affiliated members from the concrete construction and renovation industry. The CSDA mission is to promote the selection of professional sawing and drilling contractors and their methods.

Initial standard defines diamond cutting techniques. Additional standards will be added in the future.

Distributed directly.

concrete cutting; diamond cutting; concrete removal; core drilling; wire sawing;

Bailey H. Squier, Director CIM Standards and Technology

1250 E. Copeland Road

Suite 500

Arlington, Texas 76011

(817) 860-1654

FAX: (817) $275-6450$

Founded: 1972

Standards Staff: 2 
Type of

Organization

standards

Designation

standardization

Activities

scope

Formerly

Reywords
$R \& D$ Consortium

Standards Developer

ANSI / CAM-I .

The scope of CAM-I standards development is focused on

information preparation for computer aided/integrated manufactur-

ing systems and methods related to standard software input/output, interfaces, and language specifications. In general, CAM-I does not operate in the field of hardware standards. CAM-I is an accredited standards developer under the ANSI canvass and organization methods. CAM-I develops proposed standards, and encourages development of needed standards by other organizations. It also proposes and fosters national and international standards in association with ANSI, ISO, and other standards groups. CAM-I Research Programs identify needed standards, evaluate benefit to member companies and industry in general, and fund their development.

A not-for-profit research and development membership consortium of industrial manufacturers advancing the state of the art in manufacturing technology, management, and education. An accredited standards Developer, which processes member-defined and funded industry standards.

Computer Aided Manufacturing, International

advanced manufacturing; enterprise integration; cost management systems; quality assurance; DMIS; SOI; strategic supply chain management; advanced management systems;

\section{CONSTRUCTION INDUSTRY MANUFACTURERS ASSOCIATION}

James H. Stollenwerk, President and Secretary

111 East Wisconsin Avenue

Bank One Plaza 940

Milwaukee, Wisconsin 53202

(414) 272-0943

FAX: (414)272-1170

Founded: 1911

Standards Staff: 2

Type of Organization
Trade Association

Standards Developing Organization 
Standards

Development

Standards

Designation

Government

Adoption

Certification

Scope

Standardization

Activities
Power Crane and Shovel Association (PCSA) develops

standards for cranes and excavators. The (LEMB)

develops standards for vibratory rammers and plates

PCSA Standard; LEMB prefix.

PCSA Standards \#4 and \#5 are referenced by

incorporation into ASME/ANSI B30.5 (Mobile and Locomotive Cranes) are requirements within 29 CFR Part 1926 subpart N.

PCSA Standards and published reference material qualify cranes and equipment to meet specific requirements for manufacturing and operation.

LEMB Standards provide for the uniform method of rating the equipment.

CIMA is a nonprofit United States based international trade organization which represents 500 companies manufacturing and marketing construction related machinery and equipment used around the world in the road building, general construction, housing, material-handling, mining, energy management environmental waste management and forestry fields. Also included in the CIMA membership are the support teams of publishers, financial institutions and construction services providers. CIMA activities serve the technical, safety, statistical, public relations and government affairs interest of its member companies, to benefit them and the entire construction industry.

The Association represents the construction equipment manufacturing industry at state and federal levels and it also offers opinions and recommendations for international agreements between the United States government and its trading partners.

CIMA disseminates to the construction equipment manufacturing industry the relative "Performance standards" in the areas of international, federal and state regulations as they pertain to product compliance, product safety, health and the environment. The term "Performance standard" relates to equipment nomenclature performance criteria for machine safety, protective devices, operational procedures, machine capability limitations, noise characteristics, etc., as opposed to engineering standards which dictate theory and design.

Industry representatives within CIMA Bureaus act on technical issues, including machine nomenclature, classification, specifications, special applications, voluntary consensus standards, regulations, research and equipment procedures (on testing and documentation) and safety oriented issues for machines such as: cranes, roller compactors, soil stabilizers, milling machines, asphalt pavers, rock drills, etc. 
Availability

Keywords
CIMA is active in commercial standards that relate to member industries, i.e., product safety, product maintenance, machine operations, certification, testing, inspection, etc. CIA member Bureaus write and publish commercial standards which often become the bases for consensus standards.

CIMA Publications are sold directly.

construction; road building; mining;

CONSTRUCTION SPECIFICATIONS INSTITUTE

Type of

Organization

Standards

Development

Standards

Designation

Government

Adoption

Scope
Gregory Balestrero, Executive Director

601 Madison Street

Alexandria, Virginia 22314

(703) 684-0300

FAX: (703) 684-0465

Compuserve: 72113,1665

Founded: $1948 \quad$ Standards Staff: 18

Technical Society

Standards Developer

Standards developer since 1964.

350 guide specifications.

SPECTEXT - 440 sections.

SPECTEXT II - 100 sections.

None processed through ANSI.

Drafts not available for review.

MASTERFORMAT; SPECTEXT; SPECTEXT II; Manual of PraC-

tice.

The Department of Defense has adopted CSI MP-2-1

MASTERFORMAT, Master List of Titles and Numbers for the construc-

tion industry; Section Format and Page Format.

A national technical society dedicated to the advancement of construction technology through communication, education, research, and service. CSI serves the interests of more than 19000 architects, engineers, specifiers, contractors, product manufacturers, and others in the construction industry. 
Standardization

Activities

Availability

Keywords

CONSUMER FEDERATION OF AMERICA

Type of

Organization

Representation
Stephen Brobeck, Executive Director

1424 16th street NW.

Washington, DC 20036

(202) 387-6121

FAX: (202) 265-7989

Founded: 1968

Activities are directed toward standardization of the

language and format of construction specifications, as well as format, organization, and coordination of the contents of the

Publishes a Manual of Practice which provides techniques, procedures, and formats for the preparation and organization of construction documents. Included is MASTERFORMAT which was jointly issued with CSI's Canadian counterpart, Construction Specifications Canada. MASTERFORMAT provides a uniform system for organizing project cost data, and for filing product information and other technical data. The 16-Division concept presented in MASTERFORMAT has been adopted by government and private practices as a uniform approach for the organization of information conProduces SPECTEXT and SPECTEXT II through its research affiliate, The Construction Sciences Research Foundation (CSRF). SPECTEXT is a 440 section library of master guide specifications for construction projects prepared in accordance with CSI recommended practices. SPECTEXT II is for smaller, less complex projects. CSI has also developed a product information retrieval system (SPEC-DATA II) and an automated computerized system for specification text manipulation adaptable to all types of master specification programs.

sold directly.

specifications; formats; construction documentation; construction; information processing;

Consumer Advocacy Organization

Works through other organizations to develop standards

ASTM Committee F-15.

Consumer Products FDA.

Cosmetic Ingredient Review. 
Scope

Standardization

Activities

Keywords
Consumer membership organization composed of more than $200 \mathrm{na}-$ tional, state, and local groups committed to the goals of consumer advocacy and education. Advances pro-consumer policy before Congress, the Administration, regulatory agencies, and the courts; assists state and local consumer groups; and increases public and media awareness of consumer needs.

Provides the consumer perspective for organizations which develop standards.

consumer advocacy; consumer products;

\section{CONTAINERIZATION AND INTERMODAL INSTITUTE}

Barbara Spector Yeninas, Executive Director

185 Fairfield Avenue

Suite 2-D

West Caldwell, New Jersey 07007

(201) 226-0160

FAX: (201) 226-4274

Founded: 1960

Type of

Organization

Scope

Standardization

Activities

Formerly

Keywords
Trade Association

Works through other organizations to develop standards

A membership trade association of shippers, carriage operators, terminal and port managers, and equipment manufacturers engaged in serving the containerization industry.

Works through ISO and ANSI to develop standards. Works closely with the Transportation Association of America, Society of Packaging and Handling Engineers, Packaging Institute, society of Automotive Engineers, and the National Defense Transportation Association.

Containerization Institute

containerization; intermodal transportation; cargo handling; transportation; packaging;

Sandi Savaglia, Member Services Administrator

111 East Wisconsin Avenue

Milwaukee, Wisconsin 53202

(414) 272-0943

FAX : (414) $272-1170$ 
Type of

Organization

Standards

Development

Standards

Designation

Government

Adoption

Certification

scope

Standardization Activities

Availability

Keywords
Trade Association

Standards Developer

Standards developer since 1937.

12 members participating in standards activities.

Standards not processed through ANSI.

Contractors Pump Bureau standards.

Standards have been adopted by many state and local governmental agencies and by the U.S. Navy.

Certification is by the individual manufacturer who states that his products are manufactured in accordance with the standards of the Contractors Pump Bureau.

A national organization of manufacturers of pumps for use in the construction industry. Standards currently in use are the 15th revision adopted by the Bureau in July 1976.

Aimed toward the proper understanding and utilization and the various types of pumps used for construction. Assists users to determine the type and size of pump best suited for a specific job. Developed the Certified Performance seal used by manufacturers. Does not test, inspect or certify pumps. Active standards self-priming centrifugal pumps, trash pumps, diaphragm pumps, and electrically driven submersible pumps.

Distributed directly.

pump; construction; industrial equipment;

CONVEYOR EQUIPMENT MANUFACTURERS ASSOCIATION

Robert A. Reinfried, Executive Vice Dresident

9384-D Forestwood Lane

Manassas, VA 22110

(703) 330-7079

FAX: (703) 330-7984

Founded: 1933

Standards Staff: 2

Type of

Trade Association

Organization

Standards Developer

Standards

20 active standards; works through ANSI.

Development 


\section{Standards \\ Designation}

Scope

\section{Standardization}

Activities

\begin{abstract}
Availability
\end{abstract}
Formerly

Keywords
CEMA and ANSI/CEMA prefixes.

A trade association of 90 Manufacturers and engineers of conveyors and conveying systems, portable and stationary machinery used in transport of raw materials and finished products in warehouses and on assembly line operations.

Develops standards for design, manufacture, and application of conveying machinery and component parts. Activities administered by CEMA Product sections and CEMA Engineering Conference. Member of the American National Standards Institute. Also works with other organizations, such as the American Society of Mechanical Engineers, and with Federal Government organizations including the Occupational Safety and Health Administration, Office of Standards and the Bureau of Mines.

sold directly and through ANSI.

Association of Conveyor and Material Preparation Equipment Manufacturers (1935)

Conveyor Association (1945)

conveyors; machinery; industrial equipment;

\section{COOKWARE MANUFACTURERS ASSOCIATION}

Hugh Rushing, Executive Vice President

P.O. Box 531335

Mountain Brook, Alabama 35253-1335

(205) $802-7600$

FAX: (205) 802-7610

Founded: 1922 Standards Staff: 1

Type of

Organization

Standards

Development

Standards

Designation

Certification
Trade Association

Standards Developer

Standards developer since 1963.

23 members participating in standards activities.

16 active standards.

All processed through ANSI.

Draft standards available for review.

CMA prefix.

No certification, qualification, or accreditation programs. 
Scope

standardization

Activities

Availability

Former $1 y$

Keywords

COOLING TOWER INSTITUTE

Type of

Organization

Standards

Development

Standards

Designation
A national trade association that represents United States companies engaged in the manufacture of cookware, bakeware, and miscellaneous cooking accessories. Promotes the welfare of the cookware industry, improves services to the public, and carries out activities in furtherance of the industry consistent with the public interest.

Establishes voluntary standards for products manufactured within the industry. Standards are intended as guides to aid the manufacturer, user, and general public. Standards cover procedures for determining sizes and capacities, uniform terminology for finishes and decorations, specifications for plastic handles and knobs, safety and health guidelines, metal specifications, and metric guidelines. Standards activity is the responsibility of a Standards Engineering Committee of domestic cookware/bakeware manufacturers. ANSI Z61.1-1979 has adopted all CMA standards for metal cookware and bakeware.

Sold directly and through ANSI.

Aluminum Ware Association (1963)

Metal Cookware Manufacturers Association (1981)

cookware; bakeware; microwave; food; consumer products;
Virginia A. Manser, Administrative Manager

P.O. Box 73383

Houston, Texas 77090

(713) 583-4087 FAX: (713) 537-1721

Founded: 1950 Standards Staff: 8

Technical society

standards Developer

Standards developer since 1950.

425 members participate in standards activities. 40 active standards.

None processed through ANSI.

STD - Standard.

ATC - Acceptance Test code.

WMS - Wood Maintenance standard.

NCL - Nomenclature. 
Government

Adoption

Certification

scope

standardization

Activities

\section{Availability}

Keywords
Many government bids include CTI standards as part of the specifications.

The Cooling Tower Institute may certify that a line of towers will perform in accordance with the manufacturers' published ratings. Under STD-201.

A nonprofit, technical association dedicated to the improvement of technology, design, performance, and maintenance of cooling towers and cooling tower systems. Consists of manufacturers, users, and suppliers of equipment and chemicals, as well as engineering firms having an interest in problems related to cooling water including water and air pollution. International membership.

The standards activities of the Cooling Tower Institute are accredited by ANSI and center on fulfilling user-defined requirements of the industry and its customers. There are 10 published standards, including recommended grades, grading rules, and allowable design stresses for redwood lumber; methods and instrumentation for determining water cooling capability of mechanical draft towers; and recommended material, manufacturing limitations, design requirements and allowable loads for timber fasteners. The Institute is also active on standards committees of NACE, ASME, and others.

sold directly and through IHS.

cooling; industrial equipment; water;

\section{COPPER DEVELOPMENT ASSOCIATION}

Arthur Cohen, Manager standards and Safety Engineering

260 Madison Avenue

New York, New York 10016

(212) $251-7200$

Founded: 1963

FAX: (212) 251-7234

Standards staff: 2

Type of

Organization

Representation

Trade Association

Works through other organizations to develop standards

ASTM, ASME, AWWA, SAE, NACE

Standards

Standards Handbook.

Designation

secretariats

U.S. TAG for ISO/TC 26, Copper and Copper Alloys. 
scope

Standardization

Activities

Availability

Formerly

Keywords

CORDAGE INSTITUTE

Type of

organization

standards

Development

scope

Standardization

Activities
An engineering development and market research organization for the copper and brass industry; develops new markets for copper and copper alloys; creates new concepts; builds prototypes and proves commercial feasibility for new applications of copper, brass, and bronze. Provides technical support to users of copper and copper alloys.

Carries out standardization activities for brass mill and foundry products. Publishes the Standards Handbook which covers tolerances; alloy data, both wrought and cast; terminology; engineering data; sources; and a specifications cross index. Cooperates with ISO and Pan American Standards Commission (COPANT). Reviews federal and military standards. A Technical Service and Standards Advisory Committee coordinates publication activities and participation in voluntary standard organizations.

Distributed directly.

Copper and Brass Research Association

copper; brass; bronze; materials;

G.P. Foster, Executive Director

350 Lincoln street

Hingham, Massachusetts 02043

(617) 749-1016

FAX: (617) 749-9783

Founded: 1920

Standards Staff: 2

Trade Association

Standards Developer

Standards developer since 1924.

Composed of rope and twine manufacturers in the United states, with some Canadian manufacturers and Cordemex of Mexico as special members. Promotes interests of the industry and improves its services to the public; compiles and distributes information; cooperates in handling problems common to the industry.

Maintains a Technical Committee which develops or participates in developing voluntary, consensus specifications for hard fiber and synthetic rope and twines. Works closely with the U.S. Army, U.S. Navy, the Maritime Administration, the Coast Guard, the General Services Administration, and others. Works with the Defense Supply Agency (Defense Industrial Supply Center) in regard to military requirements. Cooperates with private organizations including American Merchant Marine Association 
(towing hawsers on ocean going vessels); American Society of Mechanical Engineers (sling specifications); National Ski Area Association (rope tow and rescue rope specifications); New York City Fire Department (rescue ropes); public utility companies (specifications and test methods); National Fire protection Association; and Oil Companies International Marine Forum.

Advises users, consumers and engineers on technical aspects of cordage, twines and ropes.

Ongoing projects include review of testing procedures for breaking strength standards, safety factors, updating of current DI specifications for ropes, chemical and temperature resistance of cordage fibers, resource or expert witness and testing laboratories, and development of standards for abrasion and wet tensile strength.

Participates in the activities of Technical Committee 38 - Textiles of the International Organization for Standardization (ISO), American Society for Testing and Materials (ASTM), Oil Companies International Marine Forum (OCIMF), National Fire Protection Association (NFPA) .

Publishes technical data, including Quality Control-Minimum Standards; Specifications for Natural and Man-made Fiber Ropes; Standard Test Methods for Synthetic Fiber Ropes; Bend Tests Made on Natural and Synthetic Fiber Ropes; The Cordage Industry Directory; the Safe Use of Rope; Agricultural Twine Standards; Tying Twine standard; Cordate and Rope Definitions; standard Terminations for Testing; and General Rope Usage.

Availability

Keywords
Distributed directly.

rope; cordage; industrial equipment; twine; netting;

Kyd D. Brenner, Vice President

1701 Pennsylvania Avenue, NW. Washington, DC 20006

(202) 331-1634

Founded: 1913
FAX: (202) 331-2054

Standards staff: 1 


\begin{tabular}{|c|c|}
\hline Type of & Trade Association \\
\hline Organization & Works through other organizations to develop standards \\
\hline Representation & $\begin{array}{l}\text { Nine member companies active in a variety of standards organiza- } \\
\text { tions }\end{array}$ \\
\hline Scope & $\begin{array}{l}\text { Association for the United states corn wet milling industry. } \\
\text { Provides services in the areas of research, public information, } \\
\text { and government relations. }\end{array}$ \\
\hline $\begin{array}{l}\text { standardization } \\
\text { Activities }\end{array}$ & $\begin{array}{l}\text { Cooperates with United states and international } \\
\text { standards developing organizations. Maintains an Analytical } \\
\text { Quality Systems Committee which develops and publishes Standard } \\
\text { Analytical Methods of the Member Companies for use in analyzing } \\
\text { industry products. Cooperates with analytical groups such as AOAC } \\
\text { in this endeavor. Does not issue product standards or specifica- } \\
\text { tions, but cooperates with governmental bodies such as FDA, FCC, } \\
\text { USDA, USP, and Food and Agriculture Organization/World Health } \\
\text { Organization (FAO/ WHO). This activity is coordinated by the } \\
\text { Scientific and Applied Development Committee. }\end{array}$ \\
\hline Formerly & $\begin{array}{l}\text { Corn Industries Research Foundation (1966) } \\
\text { Associated Corn Products Manufacturers (1932) } \\
\text { American Manufacturer's Association of Products from Corn (1923) }\end{array}$ \\
\hline keywords & corn; corn products; corn starch; agriculture; food; \\
\hline
\end{tabular}

CORPORATION FOR OPEN SYSTEMS INTERNATIONAL

Ed Albrigo, President

8260 Willows Oaks Corporate Drive

Fairfax, Virginia 22130

(703) 205-2700 FAX: (703) 846-8590

Founded: 1986 Standards Staff: 5

Type of

Organization

Representation
$\mathrm{R} \& \mathrm{D}$ Consortium

Works through other organizations to develop standards

Cos contributes to, observes, or interacts with all the Information Technology related standards bodies and all those organizations that relate to the IT standards bodies including ISO, CCITT, IEEE, ANSI, NIST, SPAG, POSI, OSI/NMF, X-OPEN, OSF and others. 
scope

Standardization

Activities

Keywords
COS is a research and development consortium funded by a coalition of computer and communications manufacturers, major commercial and industrial users of networked systems, elements of the civilian and defense arms of the United States government and foreign government and commercial organizations. It includes the North American MAP/TOP Users Group and has numerous university, trade and user group association affiliates.

COS selects and implements test suite specifications and profiles based on international OSI/ISDN and related standards, contributes to the setting of conformance testing standards, and administers a product certification program - the cos MARK - which serves as a means of promoting high quality conformance and interoperability testing for OSI/ISDN products and services and is an indicator to prospective product purchasers of product interoperability. COS also works with users of open systems to promote the necessary requirements for enterprise, multi-vendor interoperability.

OSI; open systems interconnection; ISDN; integrated services digital network; MAP; manufacturing automation protocol; TOP; technical and office protocol; interoperability; data communications; networking;

COSMETIC, TOILETRY AND FRAGRANCE ASSOCIATION

E. Edward Kavanaugh, President

110117 th Street, NW.

Suite 300

Washington, DC 20036

(202) 331-1770

FAX: (202) 331-1969

Founded: 1894

Standards Staff: 8

Type of

Organization

standards Development
Trade Association

Standards Developer

Developer of more than 300 specifications (voluntary standards) and 500 chemical descriptions since 1942. Development of standard nomenclature for raw materials since 1972. Development of Technical Guidelines (voluntary standards) series that began with microbiology guidelines (1969), and expanded into quality assurance (1972), safety substantiation (1975), and finally Occupational and Environmental Safety and Health (1984). None of these publications are processed through ANSI. 
A national trade association representing the cosmetic and personal care products industry. Active membership includes 250 companies that manufacture or distribute 80 percent of the finished cosmetic products marketed in the US. Also includes 265 associate member companies from related industries which provide services to the cosmetic industry. These include manufacturers of raw materials and packaging testing facilities. CTFA represents its membership internationally in a range of scientific and regulatory areas.

Standardization Activities
Availability

Formerly
Specifications developed by a 20-member committee of analytical chemists representing both cosmetic product manufacturers and suppliers. Has responsibility for the publication of the CTFA Compendium of Cosmetic Ingredient Composition, which includes specifications that chemically characterize and describe cosmetic ingredients, and test methods and spectra that correspond to these specifications; descriptions of raw materials are provided where specifications have not been developed. Specifications are strictly voluntary and designed to represent the type of ingredients used by the industry. The CTFA Compendium represents the largest collection of authentic specifications on cosmetic ingredients.

In compliance with Food and Drug Administration's regulations, the Association provides standard nomenclature for cosmetic raw materials. A twelve member committee develops this nomenclature. CTFA Technical Guidelines are developed by committees from member companies (15-35). The specific areas addressed by industry expertise are: quality assurance; microbiology; safety testing; and occupational and environmental safety and health (OESH). Guidelines are reviewed by the Scientific Advisory Committee that comprises representatives from all member companies. A public review, announced by a press release, precedes publication. Updates are developed as needed. The current series contains 23 guidelines in the area of quality assurance; 10 guidelines addressing safety substantiation and safety testing; 16 microbiological quality guidelines plus 4 specific methods for preservation testing/validation; 11 OESH guidelines.

Sold directly.

Toilet Goods Association (1935-1971) 
cosmetic ingredients; cosmetics; toiletry; fragrance; laboratory testing; materials; consumer products; personal care products;

COTTON WAREHOUSE ASSOCIATION OF AMERICA

Donald L. Wallace, Executive Vice President

1150 Connecticut Avenue, NW.

Suite 507

Washington, DC 20036

(202) 331-4337 FAX: (202) 331-4330

Founded: 1969

Standards staff: 1

Type of

Organization

scope

Standardization

Activities

Availability

Formerly

Keywords
Trade Association

Standards Developer

Consists of cotton compress and cotton warehouse owners and operators in the cotton belt states from the Carolinas to California. Associate membership is available to industry-related businesses, such as insurance companies, banks, equipment dealers, manufacturers, steamship and truck lines.

Maintains special Committees on Bale Preparation, Insurance and Standards, and Research and Engineering, which work closely with United States manufacturers of cotton bale ties and buckles, with a view to improving their quality, strength, and reliability. Resulting standards, widely used since 1956, cover width of ties, thickness of ties, minimum elongation of ties under stress, flatness of ties, weight and minimum tensile breaking strength of both ties and buckles.

Distributed directly.

Merger of the American and the National Cotton Compress and Cotton Warehouse Associations (1969)

cotton; materials;

\title{
COUNCIL OF AMERICAN BUILDING OFFICIALS
}

\author{
Richard P. Kuchnicki, Chief Executive Officer \\ 5203 Leesburg Pike, Suite 708 \\ Falls Church, Virginia 22041 \\ (703) $931-4533$ \\ FAX: (703) $379-1546$ \\ Founded: 1972 \\ Standards Staff: 20
}




Type of
Organization
secretariat
scope
Standardization
Activities

Keywords
Model Code Organization

Standards Developer

ANSI/CABO A117.1, American National standard for Building and Facilities--Providing Accessibility and Usability for Physically Handicapped People

CABO is a consortium of the following model building code organizations :

Building officials \& Code Administration International, International Conference of Building officials, and the southern Building Code Congress International

The members of CABO are the three model building code organizations. Through CABO they coordinate development of their respective codes and cooperate with other organizations and the federal government. CABO itself has been used as a vehicle for the development of the one and Two Family Dwelling Code and the Model Energy Code which in turn is based on the ASHRAE standard for energy conservation in new building design. It has also developed the CABO Manufactured Home Construction and Safety Standards.

safety; building; codes; energy conservation; construction; accessibility; government officials;

\section{DAIRY AND FOOD INDUSTRIES SUPPLY ASSOCIATION}

Type of

Organization

Standards

Development
Thomas M. Gilmore, Ph.D., Technical Director

1451 Dolley Madison Blvd.

McLean, Virginia 22101-3850

(703) 761-2600

FAX: (703) 761-4334

Founded: 1912

Standards staff: 2

Trade Association

Standards Developer

Standards developed since 1944.

1000 Members and non-members of DFISA cooperate in standards development. Draft standards available to 3-A Committee members through DFISA.

69 3-A Sanitary Standards; and 10 3-A Accepted Practices. None processed through ANSI. 


\section{standards \\ Designation}

Government

Adoption

Certification

scope

\section{Standardization}

Activities

Availability

Keywords
3-A Sanitary Standards; 3-A Accepted Practices

Cited in recommended Grade "A" Pasteurized Milk

Ordinance of U.S. Public Health Service.

Cited in U.S. Department of Agriculture plant regulations.

Accepted by state and local public health and agriculture agencies throughout United States and Canada by Department of Defense.

Equipment complying with the standards may carry 3-A symbol, contingent upon authorization from the 3-A Symbol Council. Selfcertification process.

DFISA represents the manufacturers of supplies and equipment for the dairy industry. The 3-A mission is to provide sanitary criteria for food and dairy equipment.

DFISA cosponsors the 3-A Sanitary Standards program with other dairy and egg processor trade associations; houses the secretary of the program and coordinates the work of 50 specific task committees which develop the standards. Implements standards activity through the DFISA Technical Committee and 50 working task committees, comprise of DFISA members and nonmembers DFISA sponsors the 3-A Sanitary standards program for dairy equipment and the E-3-A Sanitary Standards for specialized egg processing equipment. Cooperates with local, state and federal agencies, equipment manufacturers and processors, distributors, and public health officials in developing 3-A Sanitary Standards.

Published in Diary of Food and Environmental Sanitation Distributed by International Association of Milk, Food, and Environmental Sanitarians (IAMFES), 6200 Aurora Avenue, Des Moines, Iowa, 50322-2838 (515) 276-3344 or (800) 369-6337.

dairy; food; equipment; egg; cleanability;

\section{DATA INTERCHANGE STANDARDS ASSOCIATION}

Regina Girouard, Manager, Secretariat Services

1800 Diagonal Road

Suite 200

Alexandria, Virginia 22314

(703) 548-7005

FAX: (703) $548-5738$

e-mail: rgirouar@disa.org

WWW: http://www.disa.org 
Type of

organization

Standards

Development

Standards

Designation

Government

Adoption

Certification

Secretariats

Scope
Professional Association

Standards Developer

In 1987, DISA became the secretariat to ANSI's Accredited Standards Committee (ASC) X12, which develops standards for electronic data interchange (EDI). In 1990, DISA became the secretariat for the Pan American EDIFACT Board (PAEB), which develops the Pan American poition on the international, EDIFACT standards for EDI. ASC X12 membership is approximately 875. Membership in the PAEB is by country; full member countries are the United States, Brazil and Chile; associate members are Argenina, Colombia, and Venezuela. X12 standards for EDI are initially published as Draft standards for Trial Use (DSTUs, fully implementable). ASC X12 had published 260 DSTUs as of December 1995. ASC X12 has had 20 standards designated American National Standards by ANSI; in 1997, ASC X12 will forward approximately 300 DSTUs for consideration as American National Standards. The PAEB participates in developing EDIFACT standards that are published with two designations: Status 1 Draft Messages (fully implementable) and Status 2 United Nations Standard Messages (UNSMs, also fully implementable).

DISA publishes both the $\mathrm{X} 12$ and EDIFACT Standards as works in progress and as approved for implementation. Contact DISA's Technical Department for more information.

X12 standards for EDI are most commonly referred to as "transaction sets" and carry a three-digit identifier along with a title descriptive of their function, for example, Transaction Set 820, Purchase Order. EDIFACT standards are most commonly referred to as "messages" and carry a six-letter acronym, for example, INVOIC.

The U.S. Government has adopted both the ASC X12 and UN/EDIFACT standards as Federal Information Processing standards (FIPS).

None.

ASC X12 Pan American EDIFACT Board, U.S. TAG for ISO TC 154 U.S. TAG for JTC 1 SC 30, Open-edi.

DISA provides EDI standards groups with comprehensive support in development, balloting, and publication /distribution of their work products. It also acts as the national leader in providing education about EDI standards and their implementation. 
Standardization

Activities

Availability

Formerly

Keywords
Members in ASC X12 and the PAEB comprise DISA's core customers; PAEB participants are individuals who are Members of national organizations chosen to represent a particular country's interest in international EDI standards development. ASC X12 members range from individuals interested in the progress of EDI to United States national and multinational corporations that recognize the competitive advantage they can gain by participating in standards development. In addition, many software companies and companies that run communications networks participate in ASC X12 and PAEB.

ASC X12 operates by a consensus-driven process. The committee is organized into subcommittees that represent functional areas of industry and commerce--for example, X12N Insurance Subcommittee develops standards for use in property and casualty as well as health care insurance. Other ASC X12 subcommittees develop standards for common transactions in areas such as finance, education administration, materials management, government, and transportation. These subcommittees forward their work to a Technical Assessment Subcommittee; when work is deemed technically accurate, it is forwarded to the entire ASC X12 membership for ballot. Approved work is published as Draft standards for Trial Use and two types of Technical Reports--Reference Models and Tutorials.

Participants in the PAEB develop the Pan American position on international EDI standards being considered worldwide for publication by the United Nations. The PAEB position is forwarded twice each year to the bi-annual meetings of all regional EDIFACT Boards and results in approved draft massages and U. N. Standard Messages.

X12 and EDIFACT Standards for EDI are available directly. X12 American National Standards are available from ANSI as Version 3, X12 Standards for EDI.

Although DISA has never gone by any other name, the former secretariat to ASC X12 was the Transportation Data Coordinating Committee or TDCC. Previous to 1992, the Pan American EDIFACT Board was known as the North American EDIFACT Board.

electronic data interchange; EDI; transaction sets; X12; EDIFACT; TDCC; electronic commerce; 


\author{
Type of \\ Organization \\ Representation \\ Scope \\ Standardization \\ Activities
}

Formerly

Keywords

DFA OF CALIFORNIA

Type of

organization

Standards

Development
Michael R. Wokitsch, Executive Director

505 Busse Highway

Park Ridge, Illinois 60068

(708) 825-8124

FAX: (708) 825-1693

Compuserve: 70430,35

Founded: 1951

Professional Society

Works through other organizations to develop standards

ANSI X3

National and international organization of 33000 members engaged in data processing, systems development, and use and management of computers and related equipment.

Participates in standards development in the data standardization field through its membership and active representation on the American National standards Committee X3 on Computers and Information Processing. Encourages and publicizes efforts toward the development of standards in data processing equipment, terminology, data codes, analysis, documentation, and computer programming languages through its quarterly publication Information Executive. Solicits review and comment by its members on proposed standards.

National Machine Accountants Association (1951-1962)

data processing; information systems management; computers;

Frank A. Mosebar, President

P.O. Box $270-$ A

303 Brokaw

Santa Clara, California 95052

Founded: 1908 Standards Staff: 3

Trade Association

Standards Developer

Standards developer since 1909. 


\section{Standards}

Designation

\section{Certification}

\section{Secretariats}

\section{Scope}

Standardization

Activities

\section{Availability}

Formerly

Keywords
DFA Dried Fruit and Tree Nut Grades and Specifications.

DFA of California Certificate of Quality is issued for shipments meeting industry requirements and grades for superior quality. Certificates issued as a result of this type of inspection have achieved worldwide acceptance and establish a prime focal evidence of a "delivery" by the shipper. Services also include prune, walnut, and fig inspections as required by federal or state marketing orders governing these products, and inspections of the majority of dried apples, cut fruits, and pistachio nuts produced in California under private contract.

U.S. Technical Advisory Group for Iso/TC 34 - Subcommittee 13, Dried Fruit.

ECE, Group of Experts on dry and dried fruit.

An association of California's dried fruit and tree nut processors handling 95 percent of California's annual one billion dollar dried fruit and tree nut production.

Establishes grade standards, considered national in scope, for dried fruits and tree nuts. These define defects and certain quality standards as set forth in USDA grades and industry specifications. Standards comply with both the domestic and foreign requirements. Buyers need to know that goods shipped comply with contract descriptions. Standards developed encompass industry specifications for dried fruit and tree nuts produced in California. Also acts as the research agency in developing such standards as may be required for new products developed in the dried fruit industry. Cooperates with foreign governments and submits food additives petitions used in the dried fruit and tree nut industries.

Distributed directly.

Dried Fruit Association of California

dried fruit; tree nuts; agriculture; food; inspection;

William Cuff, President

1050 South Diamond Street

P.O. Box 1727

Stockton, California 95201

(209) 467-6000 FAX: (209) 467-6250

Founded: 1912 
Type of

Organization

Standards

Development

Certification

scope

Standardization

Activities
Availability

Formerly

Keywords
Trade Association.

Standards Developer.

80 domestic, 6 Canadian, 44 foreign, 129 special

customer standards.

DWGI employs a Quality Control Department and the services of DFA of California to certify products during processing and at time of shipment.

A nonprofit cooperative association owned by 2200 walnut growers who produce 48 percent of the walnuts grown in the state of California.

Develops standards for shelled walnuts with all statements of tolerances restraints and definitions concerning size, color, and defective kernels from United states standards for shelled Walnuts (Juglans regia), 23 F.R. 10354, January 25, 1959, and Department of Agriculture, Consumer and Marketing

Service Walnut Color Chart of 1967, except where superseded by the Code of Federal Regulations, Title 21, Section 128.10, March 30, 1972, or other applicable sections. Established four color and five size standards for inshell walnuts with tolerances and definitions concerning size, color, and grade defects from United States Standards for Grades of Walnuts (Juglans regia) in the Shell, 29 F.R. 12865, September 12, 1964, as amended september 1, 1968,33 F.R. 10840 .

Standards are national in scope and DWGI markets walnuts under the Agricultural Marketing Agreement Act of 1937, as amended, with administration by the walnut Marketing Board in Sacramento. DWGI's involvement with other governmental agencies includes the Department of Agriculture, Fruit and Vegetable Division, Food and Drug Administration, state Food and Drug Administration, Economic Research Service, Foreign Agricultural Service, and the Department of Commerce.

Standards promoted through 88 domestic and 33 foreign brokers.

Distributed directly.

California Walnut Growers' Association (1956)

walnuts; edible nuts; agriculture; food; 
J. J. Wherry, Manager

30200 Detroit Road

Cleveland, Ohio 44145

(216) 899-0010

Founded: 1963

Trade Association.

Standards Developer.

4 active standards.

ANSI approved.

ANSI B74.x.

Manufacturers of grinding wheels and blades in which diamonds are used as the abrasive.

The Standards and Safety Committee has developed

standards for shapes and sizes of diamond grinding wheels and hand hones, size and density of diamond abrasive grain, and an identification code for diamond wheel shapes. These have been processed through ANSI. Also cooperates with ISO/TC 29/WG 5 on international standards.

Directly and through ANSI.

grinding wheels; diamond abrasives; manufacturing;

\section{DISTILLED SPIRITS COUNCIL OF THE UNITED STATES}

F. A. Meister, President/CEO

1250 Eye street, NW

Washington, DC 20005

(202) $628-3544$

Works through other organizations to develop standards.

The Distilled Spirits Council of the United States represents producers and marketers of distilled spirits in the United states. Its primary mission is to advance the interests of the industry, while educating
Founded: 1973

Trade Association.

FAX: (202) 682-8888

Type of

Organization

Scope 
standardization

Activities

Formerly

Keywords the general public about the distilled spirits industry's economic, public policy and cultural contributions.

Through its standing committees of technical experts from member companies, develops recommended guidelines pertinent to the industry. Initiates studies, as needs are foreseen or dictated by developments in the regulatory and/or private sectors. Cooperates with federal agencies and other groups. Projects include plant fire protection recommendations and metric size standards, both domestic and international.

Distilled Spirits Institute

The Bourbon Institute

Licensed Beverage Industries

alcoholic beverages; distilled spirits; metric; fire protection;

DOOR AND HARDWARE INSTITUTE

Type of

Organization

Standards

Development

Government

Adoption

Scope

Standardization

Activities
Gerald S. Heppes, CAE, Executive Director

14170 Newbrook Drive

Suite 200

Chantilly, Virginia 22021-2223

(703) 222-2010

FAX: (703) 222-2410

Founded: 1934

standards staff: 2

Trade Association.

standards Developer.

22 active standards.

Standards processed through ANSI.

Draft standards available for review.

Invitation to review announced through ANSI.

"A115" Series for steel and wood doors has been adopted

by the Department of Veterans Affairs, GSA, and DoD.

Wholesalers and specifiers distributing doors and builders' hardware to architects, contractors, and builders. Conducts management and technical courses and statistical surveys. Sponsors technical research and establishes standards.

Formulates standard specifications for preparation of standard steel doors and frames for builders' hardware. Works closely with BHMA, NAAMM, ISDSI, NWWDA and SDI in developing standards. Solicits technical input from all affected interests, including government and industry organizations. 


\section{DOOR OPERATOR AND REMOTE CONTROLS MANUFACTURERS ASSOCIATION}

John H. Addington, Executive Director

1300 Sumner Avenue

Cleveland, Ohio 44115-2851

(216) $241-7333$

FAX: (216) 241-0105

Founded: 1959

Standards Staff: 3

Type of

Organization

scope

standardization Activities

Reywords
Trade Association.

Works through other organizations to develop standards.

A national trade association comprised of manufacturers of vehicular door operators -- residential, commercial, or industrial -and/or remote controls for the operation.

Maintains a technical committee which developed a Minimum Standard for Heavy Duty Industrial and Commercial Draw Bar Type Electrically Powered Door Operators. It no longer develops standards but cooperates with Underwriters Laboratories in its development of UL 325, Standard for Safety for Door, Drapery, Gate, and Window Operators and Systems. Also cooperates with the Federal Communications Commission regarding the rules and equipment authorization procedures for radio frequency devices. Cooperates with the Consumer Products Safety Commission and the National Safety Council on the safe use of the equipment.

doors; remote control; hardware; buildings;

DUCTILE IRON PIPE RESEARCH ASSOCIATION

Troy F. Stroud, P.E., President

245 Riverchase Parkway East

Suite 0

Birmingham, Alabama 35244

(205) $988-9870$

FAX: (205) $988-9822$ 
Founded : 1915

Type of

Organization

Representation

Scope

Standardization

Activities

Formerly

Keywords

EDISON ELECTRIC INSTITUTE
Trade Association.

Works through other organizations to develop standards.

Four members active in voluntary standards including representatives on standards committees of ANSI, ASTM, AWWA, ASME, NFPA, and others.

American manufacturers of ductile iron pipe, dedicated to maintaining the highest piping standards through a program of continuing research. Ductile iron pipe is used extensively for water and wastewater applications.

Participates in national committees that develop prod-

uct standards pertaining to ductile iron pipe, including standards for manufacture, design, installation, joints, coatings, linings, fittings, and other appurtenances. Utilities and consulting engineers frequently incorporate these standards in purchase orders and contract specifications. Members also provide standards committees with research and test data concerning their products.

Cast Iron Pipe Publicity Bureau (late-1920's)

Cast Iron Pipe Research Association (1979)

pipe; fittings; water; wastewater; plumbing; sanitation; industrial equipment;

Garry N. Miller, Manager, Standards and Technical Support

701 Pennsylvania Avenue NW.

Washington, DC 20004-2608

(202) 508-5173 FAX: (202) 508-5225

e-mail: garrymee@eei.com

Founded: 1933

Standards staff: 2

Trade Association.

Work through other organizations.

EEI member companies participate in standards development through more than 300 representatives serving on more than 100 standards committees of ANSI, IEEE, ASME, NIST, NEMA, NFPA, ASTM, and others. These standards committees develop over 500 standards of interest to electric utilities. 
Edison Electric Institute is the association of the United states investor-owned electric utilities and industry affiliates worldwide. Its U.S. members generate approximately 79 percent of all the electricity in the country and service 76 percent of all ultimate customers in the nation. EEI provides the principal forum where electric utility people exchange information on developments in their business and maintain liaison between the industry and the federal government. Its officers speak on issues of national interest on behalf of the electric utility industry.

Standardization Activities
Standards participation activities are directed towards increasing use of cost-effective programs and innovative tech niques in standards to maximize the effectiveness of its represen tatives serving on national and international standards commit tees.

Electric utility companies make extensive use of standards and actively participate in committees developing applicable standards. These include standards for electric power generation, transmission and distri-bution equipment, such as boilers, all types of turbines, transformers, circuit breakers, and valves; all aspects of radiation measurement and protection; standards for safety and health, air and water quality, computers; fire protection; and many others.

Although the Institute is not a standards developing organization, it works within the voluntary standards system to coordinate electric utility industry standards activities and act as the industry voice. The EEI Policy Committee on Energy Resources has overall responsibility for directing all EEI activities relating to codes and standards. It recommends policy to the EEI Board in regard to participation in standards development work within the voluntary consensus organizations and coordination with government agencies which develop or reference standards in the regulatory process.

The Standards Coordinating Task Force coordinates high priority standards activities of interest to the industry and provides relevant information to member companies through a formal program which interfaces directly with standards developing organizations. It also monitors and coordinates participation in the development of metrication programs within the electric utility industry.

In addition, each EEI Technical Committee, Generation, Transmission and Distribution, is responsible for monitoring the work of standards developing committees in their subject area. The EEI Technical Committees accomplish this through their codes and Standards subcommittees which, in cooperation with the Association of Edison Illuminating Companies, advise the Electric Light and Power representatives on standards committees of the industry's position on proposed new or revised standards. 
ELASTIC FABRIC MANUFACTURERS COUNCIL OF NORTHERN TEXTILE ASSOCIATION

Karl Spilhaus, President

230 Congress Street

Boston, Massachusetts 02110

(617) $542-8220$

FAX: (617) 542-2199

Founded: 1953

Standards staff: 1

Type of

Organization

Trade Association.

Standards

standards Developer.

Designation

NTA-EC prefix.

Scope

Standardization

Activities
Availability

Formerly

Keywords
Represents the elastic fabrics industry of the United states. Became part of Northern Textile Association in 1970.

Actively engaged in the establishment, review, revision, and promulgation of standard test methods, performance standards, and specifications for standard types of knitted, woven and braided elastic fabrics and non-elastic braided trimmings. Current standards in-clude: Woven Waistband Elastic Minimum Performance standard/A Performance standard for Webbing Used in Men's and Boys' Underwear and Pajamas; Methods of Testing Wide Elastic Fabrics-Tension and Stretch, NTA-EC-1-71.

In addition to counseling engineering societies, such as the American Society for Testing and Materials and federal agencies, the EFMC's Technical committee is a source for interlaboratory testing and test methods, review of product characteristics, and the development of suggested tolerances and specifications.

Distributed directly.

Elastic Fabric Manufacturers Institute (1970)

textiles; fabrics; braids; trim; webbing; elastic; 
Bruce J. Benes, Executive Vice President

1331 Baur Boulevard

St. Louis, Missouri 63132

(314) 993-2220

FAX: (314) 993-1269

Founded: 1933

Standards Staff: 2

Type of

Organization

scope

Standardization

Activities

Availability

Formerly

Keywords
Trade Association.

Standards Developer.

An international trade association of companies that sell, service, and repair industrial electric motors, generators, transformers, controls, and similar electro-mechanical equipment. Over 2700 members worldwide.

Develops standards and limited warranties for the electrical apparatus sales and service industry that cover the mechanical and electrical aspects of repair, rebuilding, and testing electro-mechanical equipment. This includes single and polyphase AC induction motors, DC motors and generators, transformers (liquid and dry types), hermetic motors, and hand power tools. Also defines the condition of electrical equipment for sale, and has written standard warranties for each condition specified. Developed set of electrical safety standards.

Distributed directly.

National Industrial Service Association (1960)

electrical equipment; electric motors; generators; machinery;

ELECTRICAL GENERATING SYSTEMS ASSOCIATION

David L. Kellough, Executive Director

10251 West Sample Road

Suite $B$

Coral Springs, Florida 33065

(305) 755-2677

FAX: (305) 755-2679

Founded: 1965

Standards staff: 1

Type of

Organization
Trade Association. Standards Developer. 
scope

Standardization

Activities

Availability

Formerly

Keywords
An international industry organization representing manufacturers and distributors involved with the generation, transmission, storage, and control of electrical energy not directly supplied by the public utility companies.

Maintains a cooperative standards program for developing and promulgating standards and specifications to serve the industry and its customers; provides an effective liaison between the industry and its customers, both civilian and military, for the interchange of information and ideas; and assists its customers in obtaining the most advanced and reliable products from the industry.

Distributed directly.

Engine Generator set Manufacturers Association (1971)

Electrical Generating systems Marketing Association

electrical generators; electrical power; energy; electrical equipment;

ELECTRONIC INDUSTRIES ASSOCIATION

Dan Bart, Vice President, Standards and Technology

2500 Wilson Boulevard

Suite 400

Arlington, Virginia 22201

(703) 907-7703

FAX: (703) 907-7501

e-mail: dbart@tia.eia.org

WWW: http://www.eia.org

Founded: $1924 \quad$ Standards Staff: 14

Type of

Organization

standards

Development

standards

Designation
Trade Association.

Standards Developer.

Has developed standards since 1926, and became ANSI accredited in 1988. The Engineering Department provides the home for over 200 EIA Engineering Committees and Subcommittees that develop EIA and JEDEC standards and other technical publications. Over 5000 technical personnel from member companies participate in standards activities through committees, subcommittees and task groups.

EIA prefixes such as ANSI/EIA, EIA, EIA/IS, QC, PQC, or JEDEC prefixes such as JESD, and JEP. 
Government Adoption

Certification

secretariats

scope

Standardization Activities

Availability

Formerly

Keywords
The Department of Defense adopts EIA Standards applicable to their needs.

EIA is the National Standards Organization which is responsible for the International Electrotechnical Commissions's IECQ certification system within the United states.

IEC TC 46 (Cables, Wires, Waveguides, R.F. Connectors, and Accessories for Communication and signaling).

IEC SC 46B (Waveguides and Accessories).

IEC SC 46D (Connectors for R.F. Cables).

IEC TC 47 (Semiconductor Devices).

IEC SC 47D (Mechanical Standardization of Semiconductor

Devices).

IEC TC 48 (Electromechanical Components and Mechanical structures

for Electric Equipment).

IEC SC 48B (Connectors, L.F.).

IEC TC 76 (Laser Equipment).

IEC TC 86 (Fibre Optics).

IEC SC 86C (Fibre Optic systems specifications).

A national trade association of companies involved in the manufacture of electronic components, equipment, and systems for consumer, industrial, and government applications. They represent their members in national and international standards arena.

Involved in standardizing components, such as resistors, capacitors, switches, transformers, inductors, transistors, integrated circuits, television tubes, broadcast equipment, data transmission, numerical control, printed circuits, radios, phonographs, satellite communications, and tape systems. Processes standards through ANSI and the IEC. Standards are in use throughout the world either by direct application or by adoption as an international standard. Engineering standards are designed to eliminate misunderstanding between manufacturers and purchasers, facilitate interchangeability and improvement of products, and assist the purchaser in selecting and obtaining with minimum delay the proper product for his particular need.

Distributed through IHS, Global Engineering Documents and ANSI.

Radio Manufacturers Association (1958)

Radio-Electronics-Television Manufacturers Association (1957)

Absorbed: Magnetic Recording Industry Association

electronics; industrial equipment; electrical equipment; defense; consumer products; data processing; 
Melvin A. Goldberg, Executive Director

509 Madison Avenue

New York, New York 10022

(212) 754-3343

Founded: 1963

Standards Staff: 1

Type of

Organization

Scope

Standardization

Activities

Formerly

Keywords
Trade Association.

Standards Developer.

The Electronic Media Rating Council is responsible for determining criteria and standards for audience measurement services; establishing and administering a system of accreditation for audience measurement services; providing and administering an audit system designed to insure users that audience measurements are conducted in conformance with the criteria, standards and procedures developed.

The Rating Council is composed of representatives from TV and radio networks, broadcast groups and industry associations representing cable, radio, television, advertising agencies and advertisers. The council sets the minimum standards which rating services are expected to meet to merit accreditation. The standards involve such items as ethical and operational standards (governing the quality and integrity of the entire activity) and disclosure standards (specifying the detailed information about a rating service which must be made available to users, as well as the form in which the information should be made available).

Broadcast Rating Council (1982)

audience measurement; ratings; radio; television; cable; audit; accreditation; communications;

\section{ELECTROSTATIC DISCHARGE ASSOCIATION}

Ann Razzano-Stedman, Office Manager

7902 Turin Road

Suite 4

Rome, New York 13440-2069

(315) 339-6937

FAX: (315) 339-6793

Founded: 1982

Standards Staff: 1 
Type of

Organization

\section{standards}

Designation

Government

Adoption

Certification

Secretariats

scope

Standardization

Activities

Availability

Formerly

Keywords
Professional Society.

Standards Developer.

Published documents are designated ANSI/ESD or ESD. (Prior to January 1, 1993, the Association was known as the Electrical Overstress/Electrostatic Discharge Association and used the acronym EOS/ESD. Documents published and printed prior to that used the EOS/ESD acronym where the ESD acronym is now used.)

Documents are submitted for adoption to the Department of Defense (DoD).

Certification of ESD technicians and ESD professionals is done using qualifications standards designated by the ESD Association. Program is administered through NARTE.

U.S. TAG to IEC 15D, Electrostatics.

The design, hardening and prevention aspects of electrical overstress. This especially includes the phenomena of electrostatic discharge and its control as applicable in design, manufacturing and end use. Emphasis shall be placed upon design requirements, evaluation and test procedures and standardization of these practices.

ESD Association standards committee collects data, evaluates proposed test methods, drafts and publishes documents to meet the technical needs of the electronic industry. These documents are published as draft standards, standards and advisories.

Areas covered include FAB manufacturing, chip design, PCB manufacturing, handling of sensitive devices, measurement of static control devices, packaging of devices and definitions for terms and phrases.

Distributed directly and through ANSI.

Electrical Overstress/Electrostatic Discharge Association (1993)

electrical overstress; electrostatic discharge; ESD; EOS; static; 
Type of

organization

\section{Standards}

Development

Government Adoption

Secretariats

Scope

Standardization Activities
William A. Baker, Manager, Market support Services

P.O. Box 11700

Tacoma, Washington, 98411

(206) 565-6600

FAX: (206) 565-7265

Founded: 1933

Standards Staff: 5

Trade Association.

Standards Developer.

Eleven active standards.

None processed through ANSI.

Draft standards available for review by members and others at discretion of EWA.

PS 1 and PS 2 adopted by all government agencies.

other EWA standards recognized by most federal, state and local jurisdictions.

Secretariat for NIST Industry Standards Committee which was organized to review and keep current Voluntary Product standards PS 1 and PS 2 .

A nonprofit industry trade association engaged in ad-vertising, promotion, quality testing and inspection, product and applied research, and codes and standards activities. Membership consists of mills involved in the manufacture of plywood and other structural-use panels, glued-laminated timber, I-joists, and of structural composite lumber.

EWA standardization activities are administered by the Technical Services Division and encompass engineering design, manufacture, and application of engineered wood products produced by its members. Standards are submitted for reference and adoption in building codes and other construction standards. Leader in the development of performance criteria for qualification of structural panels in accordance with their end use, which are incorporated into performance standards and policies.

Cooperates with the Department of Commerce, National Institute of Standards and Technology; the Department of Housing and Urban Development, Federal Housing Administration; Department of Transportation; Department of Defense; National Institute of Building Sciences; and the General Services Administration. Also participates on committees of the American Society for Testing and Materials. 


\section{Availability}

Formerly

Keywords

\section{ENTOMOLOGICAL SOCIETY OF AMERICA}

Raymond L. Everngam, Jr., Managing Editor

9301 Annapolis Road

Lanham, Maryland 20706-3115

(301) 731-4535

FAX: (301) 731-4538

e-mail: info@entsoc.org

Founded: 1889

Standards Staff: 1
Type of

Organization

Standards

Designation

Scope

Standardization Activities

Availability

Keywords
Scientific Society.

Standards Developer.

Approved Common Names of Insects.

Professional society of entomologists and others interested in the study and control of insects. Maintains specialized education, placement service, and research programs. Compiles statistics.

Committees work to standardize and define common and scientific names of insects and related arthropods, as well as insecticide names.

Distributed directly.

insects; entomology; insecticides; pesticides; public health; materials; 
John A. Legler, Executive Vice President

4301 Connecticut Avenue, NW

Suite 300

Washington, DC 20008

(202) 244-4700

FAX:(202) $966-4824$

Standards staff: 3

Type of

organization

standards

Designation

secretariats

scope

standardization

Activities

Availability

Formerly

Keywords
Trade Association.

Standards Developer.

ANSI Z245.x.

ANSI Accredited standards Committee 2245 on Refuse Processing, Collection and Disposal.

2000 companies involved in solid and hazardous waste management and suppliers of waste equipment.

Develops safety standards primarily associated with the solid waste management industry. Includes procedures for the manufacturing, installation, and operation of equipment and facilities. Standards Committee includes manufacturers, distributors, end-users or operators, government regulation and/or enforcement agencies, and special purpose or trade associations.

Distributed through ANSI, and WASTEC.

Corporate reorganization in 1993

National Solid Wastes Management Association and Waste Equipment Manufacturers Institute

solid waste; refuse; public health; sanitation;

industrial equipment; recycling; resource recovery;

EQUIPMENT AND TOOL INSTITUTE

Donn R. Proven, Executive Manager

1806 Johns Drive

Glenview, Illinois 60025

(708) 729-8550

FAX: (708) 729-3670

Founded: 1947

Standards staff: 2 
Type of

organization

scope

Standardization

Activities

Availability

Keywords
Trade Association.

Standards Developer.

Manufacturers of automotive service equipment and tools.

Prepares test equipment performance guidelines. Main-

tains the Performance Test Group which communicates with vehicle manufacturers to insure equipment compatibility and with federal and state agencies to insure equipment complies with performance regulations. Pub-lishes guidelines which provide performance criteria that can be used to characterize service equipment as being of a professional grade for the automotive technician. Equipment includes voltmeters, ohmmeters, brake testing equipment, wheel alignment, headlamp testers, timing devices, gauges, exhaust emission analyzers, and others.

Distributed directly.

automotive equipment; instruments;

\section{EQUIPMENT MANUFACTURERS INSTITUTE}

John Crowley, Director of Engineering Programs

10 Riverside Plaza

Suite 1220

Chicago, Illinois 60606-3710

(312) 321-1470

FAX: (312) 321-1480

e-mail: AEA-EMI@ix.netcom.com

Founded: 1893

Type of

Organization

Representation

scope

Standardization

Activities
Trade Association.

Works through other organizations to develop standards.

ASAE, SAE, ANSI.

Provides an ongoing forum for manufacturers of farm construction and industrial equipment to work together in order to have an effective voice in decisions affecting their products, their companies, their industries, and the economic well-being of their customers.

EMI is not a standards development organization.

Committees of the Institute utilize industry expertise to develop proposals which are submitted to engineering standards organizations for consideration as possible voluntary standards. Almost all EMI standards proposals are submitted to the American Society of Agricultural Engineers, the Society of Automotive Engineers, 
Formerly

Keywords and (indirectly) to the American National standards Institute and the International Organization for standardization.

National Association of Agricultural Implement and Vehicle Manufacturers

National Association of Farm Equipment Manufacturers (1933)

Farm Equipment Institute (1965)

Farm and Industrial Equipment Institute (1990)

farm equipment; agricultural equipment; industrial equipment; construction equipment; agriculture; construction;

\section{EXPANDED SHALE, CLAY AND SLATE INSTITUTE}

Type of

Organization

scope
Standardization Activities
John P. Ries, Managing Director

Post Office Box 21526

Salt Lake City, Utah 84121

(801) $272-7070$

FAX: (801) $272-3377$

Founded: 1952 Standards Staff: 2

Trade Association.

Standards Developer.

The Expanded Shale, Clay and slate Institute (ESCSI) is the international trade association for manufacturers of rotary kiln produced expanded shale, clay, and slate lightweight aggregate.

ESCSI promotes the extensive use of rotary kiln produced lightweight aggregate in the concrete masonry, ready-mix and precast markets. Based on research and development, educational material is disseminated to all phases of the building industry. The association works closely with other technical organizations to maintain product quality, life-safety, and professional integrity throughout the construction industry and related building code bodies.

Active in ASTM, ACI, CSI, and ASCE in promulgating building codes, test methods, recommended practices, specifications, and standards for structural lightweight concrete, lightweight concrete masonry, and/or lightweight aggregates.

Publishes Guide Specifications for Structural Lightweight concrete. Members' products meet requirements of standard Specification for Lightweight Aggregates for structural Concrete, ASTM C330. 
Availability

Formerly

Reywords
Distributed directly or through members.

Expanded Shale Institute (1952)

concrete; masonry; aggregates; construction; materials;

EXPANSION JOINT MANUFACTURERS ASSOCIATION

Richard C. Byrne, Secretary

25 North Broadway

Tarrytown, New York 10591

(914) 332-0040 FAX: (914) 332-1541

Founded: 1955

Standards Staff: 1

Type of

Organization

Scope

standardization

Activities

Keywords
Trade Association.

Standards Developer.

Manufacturers of joints for piping systems. Fosters and studies the problems peculiar to expansion joints.

Through its Technical Committee, engages in the improvement of standards which were developed in the interest of public safety and for guidance in design and determination of service capacities and quality of bellows expansion joints.

expansion joints; industrial equipment;

FACTORY MUTUAL RESEARCH CORPORATION

Carl E. Miller, Senior Vice President and

Chief Operating officer

1151 Boston-Providence Turnpike

Post Office Box 9102

Norwood, Massachusetts 02062

(617) $762-4300$

FAX: (617) $762-9375$

Founded: 1835

Standards Staff: 190

Type of

Organization

Product Test and Certification Laboratory.

Standards Developer. 
FMRC engineers participate in standards committees of the NFPA, ASME, ASTM, AWWA, IEEE, ISA, ANSI, ISO, and IEC.

Standards

Designation

Government

Adoption

Certification

scope

Standardization

Activities
Data Sheets, Loss Prevention Data, D.S. prefix Approval standards.

Certain FMRC standards are referenced in codes and regulations of various local, state, and federal agencies. OSHA has designated FMRC as a test agency for certain types of equipment requiring approval.

Operates an approval service for a wide range of fire protection and property loss control products; registers quality systems for compliance with the ISO 9000 series of quality standards. In addition, the approvals staff evaluates products to certify that they meet certain standards of other organizations (e.g., ASTM).

A nonprofit corporation, providing loss control standards development, basic research, applied research, and full-scale testing primarily for industrial, commercial, and institutional policyholders insured by Allendale Mutual, Arkwright, and Protection Mutual. Maintains full-scale testing laboratories and modeling techniques.

Prepares loss prevention data sheets based on staff studies of industrial processes and hazards, loss experience, test work, and research by FMRC scientists and engineers, property inspections by field engineers and input from industry, professional and trade associations, and other sources. Subject matter includes building design and materials, fire protection equipment and systems, heating and electrical equipment, pressure vessels and boilers, hazardous materials and processes, and mechanical equipment. These sheets provide recommended guidelines for the protection of industrial, commercial, and institutional properties against fire, explosions, wind, boiler and machinery accidents, and other insured perils.

Provides Approval standards covering various types of fire protection equipment, flammable liquid equipment, fuel and combustion controls, boiler combustion safeguards, industrial trucks, electrical equipment, fire and burglar alarm systems and services, building material assemblies, and products. These specify requirements for approval and listing of equipment, materials, and services intended for loss control purposes and for potential hazards. An approval process includes inspection and audit of the product manufacturer's production and quality control facilities, with periodic follow-up. Approved products are typically labeled as "Factory Mutual Approved" or "FM Approved." 


\section{FACTS INSTITUTE FOR RESEARCH, STANDARDS AND TERMINOLOGY}

Donald C. Pierce, Director

95 Mitchell Blvd.

San Rafael, California 94903

(415) 472-0800 FAX: (415) 472-2841

Founded: $1995 \quad$ Standards Staff: 1

Type of

Organization

\section{standards}

Development

Scope

Standardization

Activities

Availability

Keywords
Standards Developing Organization.

First standard developed in 1995; approximately 40 volunteer committee members; 1 active standard document.

A not-for-profit organization dedicated to the professional and scientific advancement of the arts. Committees develop, fund and manage projects which advance the general knowledge and further application of the sciences in art. The purpose of research, consensus standards, and terminology is to further industry education and to better serve the public in all areas of the arts.

The picture framing committee, established in 1995, is comprised of 40 members representing both manufacturing and retail interests. Its initial standard defines matboard and glazing terminology used in the picture framing industry. Additional standards are under development.

Decor Magazine, $330 \mathrm{~N}$. Fourth St., St. Louis, MO 63102; LarsonJuhl, 3900 Steve Reynolds Blvd., Norcross, GA 30093; PFM PubCo., 225 Gordon's Corner Plaza, Manalapan, NJ 07726.

picture framing; matboard; glazing; glass; acrylic sheet; 


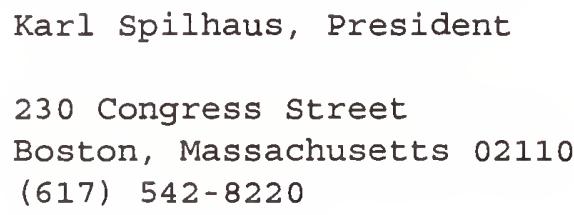 \\ Type of
Organization
}

Keywords

Keywords
FIBRE BOX ASSOCIATION \\ Availability}

FAX: (617) 542-2199

Standards staff: 1 
Type of

organization

scope

standardization

Activities

Availability

Keywords
Trade Association.

Standards Developer.

A nonprofit trade association representing manufacturers of corrugated and solid fibreboard. Aims to promote the industry's general welfare; to represent members before appropriate government, transportation, industrial, or other agencies; to compile and disseminate statistical information; and to develop data useful to its members in marketing their products.

Holds membership in the International Corrugated Case Association and participates in pertinent activities of the American National standards Institute and the International Organization for standardization. Advises federal government bodies preparing standards and specifications involving corrugated and solid fibreboard, particularly the General Services Administration.

In conjunction with the Packaging Machinery Manufacturers' Institute, it has issued five joint voluntary standards and one recommended practices bulletin, referenced in the FBA Handbook.

Distributed directly.

cardboard; box; corrugated board; fiberboard; packaging;

\section{FINANCIAL ACCOUNTING FOUNDATION}

Joseph S. LaGambina, Executive Vice President

401 Merrit

Post Office Box 5116

Norwalk, Connecticut 06856-5116

(203) 847-0700 FAX: (203) 849-9714

Founded: 1973

Standards Developer.

Type of

Organization

standards

Designation

Government

Adoption

FASB Statement.

GASB statement.

Securities and Exchange Commission (for the FASB). Rules of Conduct of American Institute of CPAs. Various state laws (for the GASB). 
Independent, nonprofit organization. Sponsored jointly by American Institute of CPAs, Financial Executives Institute, Association of Investment Management and Research, Institute of Management

Accountants, American Accounting Association, Securities Industry Association, Government Finance Officers Association, National Association of state Auditors, Comptrollers and Treasurers. Issues statements, interpretations, technical bulletins, concepts statements; follows "due process" procedures that include use of task forces of experts, issuance of papers, public hearings, release of exposure drafts.

Standardization Activities

Availability

Formerly

Keywords
Develops standards for accounting and financial reporting that govern the general purpose financial reports published by business corporations, state and local government entities, and other organizations. These standards form the base of "generally accepted accounting principles."

Follows due process procedures designed to ensure broad public participation at each stage in the standard setting process. Board meetings and deliberations are open for public observation.

Has Advisory Councils to advise on agenda projects, priorities, and technical solutions to accounting issues.

Distributed by the Financial Accounting Foundation.

Financial Accounting Standards Board

accounting; financial reporting;

\section{FLEXIBLE PACKAGING ASSOCIATION}

Type of

Organization

Standards

Development
Mark G. Wygonik, Director of Technology and Regulatory Affairs

1090 Vermont Avenue, NW.

Suite 500

Washington, DC 20005

(202) 842-3880 FAX: (202) 842-3841

Founded: 1950

Standards staff: 3

Trade Association.

Standards Developer.

Developer of voluntary guidelines for flexible packaging materials. 32 active standards for cellophane, polyethylene, polyester, and laminated and coated products, sterile medical packaging, and test methods. 
Represents converters of packaging materials and suppliers of film, adhesives, printing inks, and converting machinery. Services include government relations, technical information, statistical information, educational and public relations, and membership.

Standardization Activities

Availability

Formerly

Keywords
Continuous review of industry's need for voluntary regulations. Specifications often serve as the basis for agreement between a converter or supplier and their customers (end-users). Specifications recognized as equal to those of ASTM (American Society for Testing and Materials) and TAPPI (Technical Association of the Pulp and Paper Industry). Works toward eliminating duplication of effort by other standards organizations, although some overlap is required.

Sold directly.

National Flexible Packaging Association

packaging; plastic film; cellophane; polyethylene; printing; polyester; laminating; bags; aseptic packaging; medical packaging;

Stuart Matthews, President and CEO

601 Madison street

Suite 300

Alexandria, Virginia 22314

(703) 522-8300 FAX: (703) 525-6047

Founded: 1945

Type of

Organization

Scope

Standardization Activities

Keywords
Nonprofit Foundation for safety information exchange. Works with other organizations to develop standards.

Fosters the exchange of safety ideas and information to enable government and industry worldwide to continually upgrade safety standards and practices.

Acts through consultation, committee participation, publications, workshops, and regional and international seminars.

flight safety; safety; aviation; transportation; 


\author{
Type of \\ Organization \\ Standards \\ Development \\ Standards \\ Designation \\ Certification \\ Scope \\ Standardization \\ Activities
}

Availability

Formerly

Keywords
Chris Johnson, Executive Secretary

1300 Sumner Avenue

Cleveland, Ohio 44115

(216) 241-7333

FAX: (216) 241-0105

Founded: 1921

Standards Staff: 3

Trade Association.

Standards Developer.

Standards developer since 1955.

100 member companies participate in standards

development through product sections.

18 published standards.

4 processed through ANSI.

FCI or ANSI/FCI prefixes.

No certification, qualification, or accreditation programs.

A nonprofit association of manufacturers of devices for fluid control and fluid conditioning. Includes pressure, temperature, and volumetric regulators; modulating service control valves; solenoid valves; steam traps; fluid clarification equipment such as strainers, separators and filters; silent check valves; pressure and temperature gauges; process control switches and related equipment.

Develops, promotes, and adopts standards. Holds membership in the American National standards Institute; maintains liaison with International organization for standardization and the International Electro-technical Commission. Works with Instrument Society of America, National Fluid Power Association, and Scientific Apparatus Manufacturers Association on domestic standards.

Distributed directly and through ANSI.

National Association of Steam and Fluid Specialty Manufacturers (1941)

National steam Specialty Club (1956)

gauges; regulators; valves; fluid controls; instruments; industrial equipment; 
Robert H. Ecker, Executive Director

2017 Walnut Street

Philadelphia, Pennsylvania 19103

(215) $569-3650$

FAX: (215) 569-1410

Founded: 1933

Standards Staff: 3

Trade Association

Standards Developer

Works through ASTM, NAVSEA and U.S. Coast Guard to develop standards.

FSA has been developing handbooks for at least 20

years, but has only (in the past 10 years) developed its own standards. None have been submitted to ANSI. Currently has 5 active standards defining test methods for sealant materials, measurement, and gasket performance.

Government

Adoption

Certification

scope

Formerly

Reywords
Currently 4 standards are referenced by federal agencies.

FSA does not certify or accredit.

FSA is an international trade association. Members are involved in the production and marketing of virtually every kind of fluid sealing device in the world. Pub-lishes handbooks and technical data on many aspects of fluid sealing and collect; analyzes and disseminates information about trends in business, markets, materials, technology, government regulations and trade which may affect our membership. Current membership is 82 companies.

Changed name from Mechanical Packing Association (1970)

gaskets; packing; expansion joints; mechanical seals; molded packing ;

George Melnykovich, Ph.D., President

200 Daingerfield Road

Alexandria, Virginia 22314

(703) 684-1080

FAX: (703) 548-6563

Founded: 1885 
Type of

Organization

Scope

Standardization

Activities

Formerly

Keywords
Trade Association.

Works through other organizations to develop standards.

Firms manufacturing machinery and providing services and supplies for the canning, freezing, and food processing industry.

A Technical and Sanitation Committee is responsible for the administration of standards related activities (in cooperation with associations dealing with the establishment of standards) for materials used in the production, preparation, processing, and packaging of foods and other products which are packaged in glass, metal, fibre, and/or plastic. Cooperates with the National Food Processors Association and the Can Manufacturers' Institute in the standardization of sizes of tin cans and with the Glass Container Association of America in developing standard sizes of glass containers.

Canning Machinery and Supplies Association

canning; food processing; packaging;

\section{FORGING INDUSTRY ASSOCIATION}

Type of

organization

Standards

Development

Representation

Scope

Standardization Activities
Karen Lewis Taylor, Director of Membership Development

25 Prospect Avenue West

suite 300

Cleveland, Ohio 44115

(216) $781-6260$

FAX: (216) 781-0102

Founded: 1913

Standards staff: 2

Trade Association.

Works with others to develop standards.

Four guidelines on allowances and tolerances for

forgings and rolled rings.

Members represent FIA on standards committees of ANSI, ASME, NFPA, and others.

A nonprofit corporation composed of North American producers of forgings and producers of raw materials, equipment, or services commonly used in the forging industry.

Works within the voluntary standards system to coordinate forging industry safety and product standards and acts as the industry voice. Represents the industry to standards developing organizations such as ANSI, ASME, and NFPA. FIA is also represented by members on American National standards Committees. 
Publishes Guidelines for Tolerances for Hot Forged Impression Die Forgings; Hammer, Press and Upsetter; Tolerances for Precision Aluminum Forgings; and Allowances and Tolerances for Seamless Rolled Rings.

Formerly

Keywords
American Drop Forging Association (1935)

Drop Forging Association (1965)

Open Die Forging Institute Absorbed (1982)

Canadian Forging Association Absorbed (1983)

forging; rolled rings; machinery; materials;

\section{FRICTION MATERIALS STANDARDS INSTITUTE}

Type of

organization

scope

\section{Standardization}

Activities

Formerly

Keywords
Gilbert N. Laycock, Executive Director

588 Monroe Turnpike

Monroe, Connecticut 06468-2363

(203) 452-1877 FAX: (203) 452-7951

Founded: $1948 \quad$ Standards Staff: 2

Trade Association.

Works through other organizations to develop standards.

An association of worldwide manufacturers of friction materials (brake linings, brake blocks, and clutch facings). Members represent over 80 percent of United States and Canadian manufacturers of friction materials.

Standardization activities, administered by the Data Book and Technical Committee, comprise 25 percent of the total program. Issues catalogs using a standard numbering system for all current automotive brake linings, brake shoes, and clutch facings. A copyrighted numbering system is authorized for use by the Institute, its members and their customers. FMSI's standard numbering system is worldwide in scope. Publishes the Automotive Data Book.

Brake Lining Manufacturers Association (BLMA)

materials; brake linings; automotive; machinery; clutch facings; 
Type of

Organization

Representation

Certification

Secretariats

Scope

Standardization

Activities

Keywords
C. Reuben Autery, President

1901 North Moore Street

Arlington, Virginia 22209

(703) 525-9565

FAX: (703) 525-0718

Founded: 1936

Standards Staff: 10

Trade Association.

Works through other organizations to develop standards.

Over two hundred representatives of member firms active in 50 standards committees of ANSI, ASTM, ASHRAE, ASME, NFPA, and others.

GAMA operates programs which randomly select gas and oil furnaces and boilers, and gas, oil, electric, and heat pump water heaters from participating members and tests them in accordance with DOE efficiency test pro-cedures at ETL Testing Laboratories, Inc., to verify the manufacturers' established efficiency ratings which are published semi-annually.

Secretariat to ISO/TC 161. Convenor of Working Group 2 of ISO/TC 161. Administrator of U.S. Technical Advisory Group for ISO/TC 161 on gas controls.

A trade association for more than 250 manufacturers of residential, commercial, and industrial gas and oil fired appliances and equipment; gas, electric, heat pump, and oil water heaters; gasand oil-fired central furnaces; and equipment used in the production, transmission, and distribution of natural gas.

Works through the national standards promulgation procedures of other groups and organizations, which develop and maintain 80 standards. In this manner, a high quality manufacturers' input is provided in the development and constant maintenance of standards for gas and oil appliances and equipment, recognized as American National Standards by the American National Standards Institute.

Cooperates with government agencies, such as the Department of Commerce, Department of Energy, Consumer Product Safety Commission, Federal Housing Administration, Federal Trade Commission and General Services Administration.

gas appliance; oil fired appliances; furnaces; water heaters; gas transmission equipment; energy; building; consumer products; industrial equipment; 
Mark Sutton, Executive Director

6526 East 60 th street

Tulsa, Oklahoma 74145

(918) 493-3872

FAX: (918) 493-3875

Founded: 1921

Standards Staff: 8

Type of

organization

\section{standards}

Designation

Secretariats

Scope

\section{Standardization}

Activities

\section{Availability}

Formerly

Keywords
Trade Association.

Standards Developer.

Standards; Technical Publication TP; Research Report RR.

ASTM Technical Division $\mathrm{H}$ of Committee D-2 on Petroleum Products and Lubricants.

An international trade association of 150 member companies that produce and process natural gas, or engage in processing, transport, storage, or marketing of natural gas liquids. Six technical subcommittees prepare and maintain industry standards applicable to the gas processing industry. Standards include plant design and analytical procedures for natural gas and gas liquids.

Develops and maintains product specifications for natural gas liquids (propane, butane, natural gasoline), principally for large inter-company industrial custody transfer. Specifications require and include industry standards for gas and liquid measurement, gas and liquid analysis, storage facilities, and physical property data. Also maintains specifications for LP-Gas consumer products (commercial propane and commercial butane). A continuing research program is directed toward development of measurement data and thermodynamic properties of natural gas and gas liquid mixtures.

Sold directly and through IHS.

Natural Gas Processors Association (1964)

liquefied gas; natural gas; energy; consumer products; 


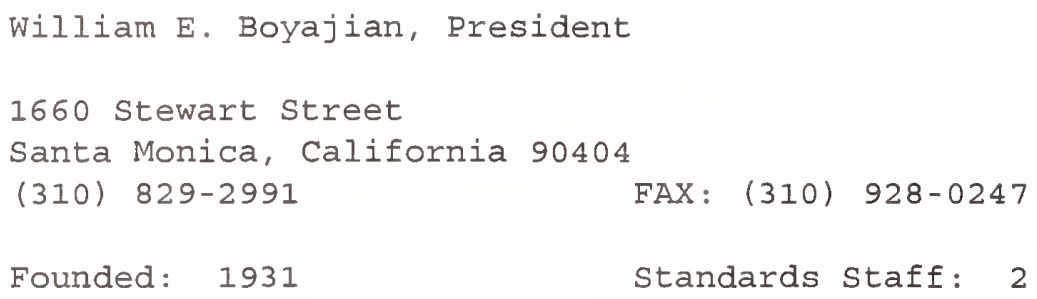

Type of

Organization

standards

Designation

Certification

scope

Standardization Activities

Keywords
Nonprofit Educational and Research Institution. Standards Developer.

Diamond and Gemstone Quality standards.

Grading reports issued by GIA's Gem Trade Laboratories are referred to as Diamond Quality Reports, although in the jewelry industry they are most often called certificates.

Promotes the jewelry trade, serves the needs and professional interests of members, and upgrades profes-sional skills through educational programs in the identification and quality analysis of gemstones and pearls, jewelry making and repair, retailing and store management. Maintains gem testing and research laboratories and develops testing and grading equipment.

Key elements of the Institute's education program are standard grading systems developed by the Institute to evaluate and appraise diamonds and colored stones. Standards for quality analysis and grading were first established for polished diamonds in 1953 .

diamonds; gemstones; jewelry; quality; grading; testing; consumer products;

GENERAL AVIATION MANUFACTURERS ASSOCIATION

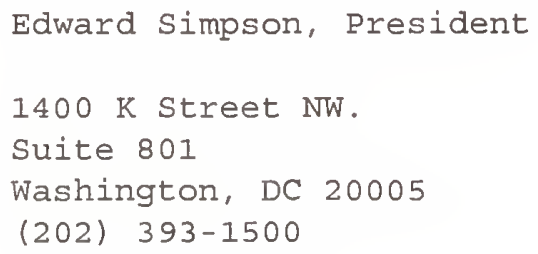

FAX: (202) 842-4063

Standards staff: 1
Type of

Organization 
standards

Designation

Government

Adoption

scope

standardization

Activities

Availability

Keywords
Standards developer since 1974.

Eight active standards.

None processed through ANSI.

Draft standards not available for review.

GAMA Specifications .

The FAA accepts compliance with GAMA specifications in lieu of its own standards or regulations or as an acceptable means of meeting FAA regulations.

A national trade association representing United states manufacturers engaged in the research, development, and manufacture of general aviation aircraft, aircraft engines, avionics, and component parts of general aviation aircraft.

Directed toward meeting industry needs with respect to dissemination of operating, maintenance and safety information, or toward meeting government certification requirements. GAMA standards include specifications for pilot's operating handbook, manufacturers' maintenance data, decals to ininimize the misfueling of general aviation aircraft, electronic publications, and specifications for tape to mark fueling nozzles. In the case of standards developed to fulfill government requirements, FAA participates in the development and approval of the standards. Standards have been used worldwide by aircraft manufacturers in order to meet FAA's requirements. Monitors the activities of other standards developing organizations, including RTCA, SAE, ASTM, and ISO.

Distributed directly.

aviation; avionics; transportation; maintenance; pilot training;

\section{GLASS ASSOCIATION OF NORTH AMERICA}

William J. Birch, Executive Vice President

White Lakes Professional Building

3310 Harrison Street

Topeka, Kansas 66611

(913) 266-7013

Founded: 1994

FAX: (913) 266-0272

Business Association.

Type of

Standards Developer. 
scope

Standardization

Activities

Availability

Formerly

Keywords

GLASS PACKAGING INSTITUTE

Type of

organization

scope

Standardization

Activities

Keywords
A nonprofit organization of firms engaged in glass distribution, installation and fabrication.

Develops specifications, standards, and testing procedures for a variety of glass products. Technical committees are involved in Standards and Engineering, Appliance Specifications, Construction specifications, spandrel specifications and Consumer Safety Glazing Legislation. Publishes the tempered Glass Engineering and Standards Manual, the Laminated Glass Design Guide, the Glazing Manual and the Sealant Manual.

Distributed directly.

Glass Tempering Association

glass tempering; laminated glass; materials; building; glazing; distribution; installation;

Lewis D. Andrews, Jr., President

$1627 \mathrm{~K}$ Street, NW

Suite 800

Washington, DC 20006

(202) 887-4850

Founded: 1945

FAX: (202) 785-5377

Standards Staff: 2

Trade Association.

Standards Developer.

Represents the manufacturers of glass containers and closures producing 90 percent of the United States' output. Promotes the continued growth and acceptance of glass containers as desirable, competitive packages of beverages, foods, and other commodities.

Maintains a Technical Committee augmented by specific subcommittees and task groups. This committee meets regularly with qualified specialists from participating firms to review and investigate unique technical problems developing in the industry. Participated in the development of the Department of Commerce Voluntary Product standard for Carbonated Soft Drink Bottles (PS 73-89), which covers major considerations in the manufacture and control of containers for carbonated soft drinks.

packaging; glass containers; 
John H. Lutley, President

111216 th Street NW.

Suite 240

Washington, DC 20036

(202) 835-0185

FAX: (202) 835-0155

Founded: 1976

Standards Staff: 1

Type of

Organization

Standards

Designation

Certification

Secretariats

Scope

Standardization Activities

Availability

Keywords
Trade Association.

Standards Developer.

Unified Number Designations.

No certification programs; supplier self-certification.

ASTM Committee B-2, Section on Unified Numbering System Designations for Precious Metals.

An international trade association of miners, refiners, fabricators, and bullion dealers. Extends the market for the use of gold through publications, seminars, joint symposiums with technical organizations, and trade shows.

Develops standard alloy designations for gold alloys for the Unified Numbering System for Metals and Alloys issued by the Society of Automotive Engineers (SAE) and the American Society for Testing and Materials (ASTM).

Distributed directly and through ASTM and SAE.

gold; precious metals; bullion; alloys; materials;

\section{GRAPHIC COMMUNICATIONS ASSOCIATION}

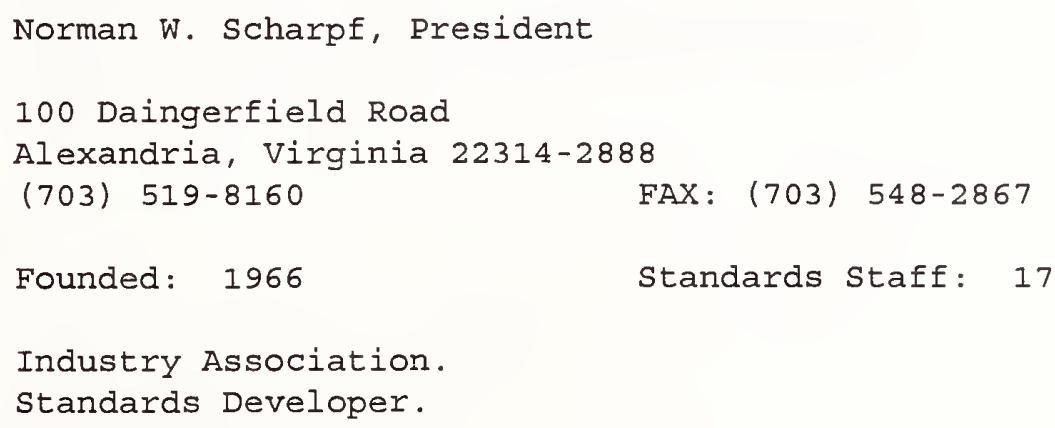


Standards

Development

Standards

Designation

Government

Adoption

Certification

scope

Standardization

Activities

Availability

Formerly

Keywords
Standards developer since 1976.

300 members plus staff participate in standards activities. 30 active standards or recommended specifications.

5 processed through ISO.

Draft standards available for review.

GCA Standard; recommended specifications.

Department of Defense, Internal Revenue Service, and others have adopted GCA standards.

Produces Standard Reference Materials for testing conformance to IT2 standards; developed conformance test suite for X3V1-related sections of ISO 8879; developing public identifier registration for ISO 8879 .

An international membership association of printers, publishers, suppliers, and related industry firms dedicated to advancing the application of electronic technologies and modern management techniques in the graphic communications industry.

Develops standards and specifications for text processing and textual database identification; specifications for computer preparation of publications mailing labels; structures for magnetic tape transmittal of name and address information for printing and publishing applications; production specifications for web offset publications; operation codes for the pressroom; computer protocols for various functional areas; printing and publishing industry standards for electronic data interchange (ANSI X12) and bar codes (ANSI X3.182\& MH10.8M). Leads various industry specification committees, and takes a membership role in ANSI IT2, X3V1, ITI and related task groups.

Distributed directly and through Printing Industries of America, Inc.

Graphic Communications Computer Association; PIA Computer section printing; computers; text; mailing; information processing; communications; graphics; 
Cheryl L. Kasunich, Executive Vice President

1200 A Scottsville Road

Rochester, New York 14624

(716) 436-2150

FAX: (716) 436-7689

Founded: 1947

Standards Staff: 1

Type of

Organization

Representation

standards

Development

Standards

Designation

Scope

Standardization Activities

Formerly

Availability

Keywords
Trade Association.

Standards Developer.

CGATS .

More than 50 volunteers participate in developing your standards.

Two active standards.

None processed through ANSI.

Draft standards are available for review.

GAA .

Association of printing firms using the gravure printing process. Promotes quality printed products through the cooperation of publisher, printer, engraver, supplier, and advertising agency.

Provide guidelines for halftone input film and digital files for gravure publication proofing and printing and colormetric specifications of gravure publication proofing and printing. Standards are produced through a network of councils and subcommittees on a voluntary basis. Two hundred and seventy member firms observe GAA standards in publication, packaging and specialty gravure.

Merger of Gravure Technical Association and Gravure Research Institute (1988)

Distributed directly.

printing; ink; paper; photomechanical printing; communications; packaging;

J. Jeffrey Wherry, Manager

30200 Detroit Road

Cleveland, Ohio 44107

(216) 899-0010

FAX: (216) $892-1404$ 
Type of

Organization

Standards

Development

Standards

Designation

Secretariats

Scope

Standardization

Activities

Availability

Formerly

Keywords
Trade Association.

Standards Developer.

Standards developer since 1914; four processed through ANSI.

B74.X.

Accredited Standards Committee B7 on Use, Care, and Protection of Abrasive Wheels.

Accredited Standards Committee B74 on Abrasives.

Manufacturers of wheels, stones, and other bonded abrasive products for grinding, sharpening, and polishing.

Carried on by the Standards and the Safety Committees. Work of the Standards Committee deals with simplification matters. Initiated program for simplification of sizes of grinding wheels. Assists in the development of American National standards covering the products of the industry. These include:

B74 - The development of identification and dimensional standards and standard test methods for bonded, coated, and loose abrasives in the natural and manufactured categories.

B7 - Specifications for safety in the use of bonded, coated, and loose abrasives, excluding natural sandstones; including safety requirements for abrasive products, abrasive machines and accessories, and requirements for the proper storage, handling, and mounting of abrasive products.

Also participates in international standardization work with the International Organization for Standardization (ISO) and the Federation of European producers of Abrasives (FEPA).

Distributed directly and through ANSI.

Grinding Wheel Manufacturers Association (1948)

abrasive wheels; grinding wheels; abrasives; abrasive grain; diamond abrasives; machinery; 
Jerry A. Walker, Executive Director

810 First street, NE.

Suite 510

Washington, DC 20002

(202) 289-5440

FAX: (202) 289-3707

Founded: 1930

Standards Staff: 3

Trade Association.

Standards Developer.

GA prefix.

Standards

Designation

scope

Standardization

Activities

Availability

Keywords
Promotes the use of gypsum and gypsum products. Conducts technical research programs in fire, sound, and structural testing of gypsum products and related accessories. Contributes to building codes through education in the application and uses of gypsum products, and to the life-safety aspects of fire protection by providing advisory services in the interests of the industry and users of its products. Serves as the gypsum information center for all federal, state and local jurisdictions, as well as architects, specification writers and contractors.

Maintains committees in the areas of Building Codes, Operations and Regulatory Affairs, Promotion, Safety, and Technical. Prepares and publishes GA-216, Recommended Specifications for the Application and Finishing of Gypsum Board and GA-600, Fire Resistance and Sound Control Design Manual, as referenced by the Commentary to the BOCA National Building Code, SBCCI Standard Building Code and the ICBO Uniform Building Code. Has over 65 years of leadership in the ASTM C-11 Standards Committee on Gypsum and Related Building Materials and systems.

Distributed directly.

gypsum; construction; materials; drywall; wallboard;

\section{HACK AND BAND SAW MANUFACTURERS ASSOCIATION OF AMERICA}

Charles M. Stockinger, Secretary/Treasurer

1300 Sumner Avenue

Cleveland, Ohio 44115

(216) 241-7333

FAX: (216) 241-0105 


\author{
Type of \\ Organization \\ Standards \\ Development \\ Standards \\ Designation \\ Scope \\ Standardization \\ Activities
}

Availability

Formerly

Keywords

HAIR INTERNATIONAL

Type of

Organization

Certification

scope
Trade Association.

Standards Developer.

Standards developer since 1920.

Two active standards.

ANSI prefix.

A trade association consisting of 8 United states manufacturers of hack and band saw blades. Promotes common business interests of the industry.

Has been active in the standardization of hack saw blade sizes and band saws. Currently active on ASME B94 TC 19 standardization Committee for Hack, Band, and Hole Saws, and on ISO/TC 29 WG 15, Band Saws. Continuously reviews and recommends changes in standards due to rapid addition of new blades and applications in the marketplace. Currently working with machine manufacturers for band saw length standardization.

Distributed directly and through ANSI.

Merged Hack Saw Association and Metal Cutting Band Saw Association (1959)

cutting; saws; manufacturing;

Don Nye, Executive Director

124-B East Main street

Palmyra, Pennsylvania 17078

(717) 838-0795

FAX: (717) 838-0796

Founded: 1924

Standards staff: 1

Professional society.

Standards Developer.

Examinations to certify ability to do hairpiece work, styling, coloring, relaxing, and merchandising are required for the professional certification of barbers.

Aims to professionalize the industry through education and standardization. 


\section{Standardization} Activities

Formerly

Availability

Keywords

HAND TOOLS INSTITUTE
Administers a National Education Council and Executive Committee which are active in standards activities. Standard rules and regulations are written for and apply to barber colleges, individual students and barbers, hairstylists, textbooks, and for judging contestants in contests. State regulations, however, supersede Hair International rules and regulations. Advocates use of a barber stylist standardized examination and educational program for the profession. Current projects include standardization of advanced educational methods in barber schools, as well as for shows and educational seminars.

Promotes its standards through mailings, personal contact, a monthly magazine, and barber shows.

Associated Master Barbers and Beauticians of America

Distributed directly.

barbers; hair; beauticians; education;

Richard C. Byrne, Executive Director

25 North Broadway

Tarrytown, New York 10591

(914) 332-0040

FAX : (914) 332-1541

Founded: 1935 Standards staff: 1

Trade Association.

Standards Developer.

65 members participate in standards development.

25 active standards.

Processed through ANSI.

ANSI B107. $\mathrm{x}$

Promotes and furthers the interests of its members relative to manufacturing, safety, standardization, international trade, and government relations. Provides a broad spectrum of educational data of industry interest, such as statistical and marketing surveys. Educates the hand tool user on the safe and proper use of hand tools. 
Standardization

Activities

Availability

Formerly

Keywords

HARDWOOD PLYWOOD AND VENEER MANUFACTURERS ASSOCIATION

E.T. Bill Altman, President

1825 Michael Faraday Drive, Box 2789

Reston, Virginia 22090

(703) 435-2900 FAX: (703) 435-2537

Founded: 1921

Trade Association.

Type of

organization

Certification

Scope

Standardization

Activities

Availability

Standards Developer. bond, structural, flamespread, and formaldehyde emissions. products. Promotes the sale and use of hardwood plywood.

Publishes the American National Standard for Laminated for Hardwood and Decorative Plywood, ANSI/HPMA HP-1-1994, HP-SG-86, Structural Design Guide for Hardwood Plywood; and a plywood, veneer, and flooring. Participates on various ASTM committees.

Monitors U.S. model building codes with reference to hardwood plywood products.

Distributed directly.
Develops and advances standards dealing with performance, design and safety. Representatives serve on U.S. TAGs to Iso standards committee.

Distributed directly and through ANSI.

Service Tools Institute

tools; industrial equipment; consumer products;

HPVA has inspection, testing, and certifying programs for glue

A North American trade association for hardwood plywood and veneer manufacturers and prefinishers of hardwood plywood. Functions on a national and international level. Publishes newsletters and educational material, holds conferences; conducts surveys; and develops statistical reports on shipments of plywood and industry Hardwood Flooring, ANSI/HPMA LHF 1987; American National Standards voluntary standard for sliced decorative wood face veneer, industry standard DFV-1 1988. Cooperates with all government agencies to write federal and military specifications which affect hardwood 
Robert Hankin, PhD, President

5110 N. 40 th Street

Suite 250

Phoenix, Arizona 85018

(602) 381-1091

FAX: (602) 381-1093

e-mail: info@hibcc.org

WW: http://www.hibcc.org/

Founded: 1983

Standards Staff: 20

Type of

Organization

Standards

Development

Trade Association.

Standards Developer.

The Health Industry Business Communications Council

(HIBCC) is an industry-sponsored nonprofit council, which was organized by major health care associations in 1983. The HIBCC Board of Directors, which oversees HIBCC operations and sets policy, is composed of individuals appointed from the ranks of Member Organizations. These now include: The American Hospital Association, American Medical Association, American Society for Automation in Pharmacy, Department of Defense, Health Industry Distributors Association, Health Industry Group Purchasing Association, Health Industry Manufacturers Association, Health Information and Management Systems Society, National Wholesale Druggists Association and Pharmaceutical Manufacturers Association.

HIBCC supports numerous technical committees composed of individuals representing all segments of the industry who meet regularly to develop and maintain the various HIBCC standards. It is through this continuous review and broad industry participation that HIBCC standards meet the industry's needs by taking advantage of the latest communications technologies.

HIBCC produces two bar code standards:

HIBC Supplier Labeling Standard, and

HIBC Provider Applications Standard.

Four EDI Manuals cover specific business functions:

Insurance,

Finance,

Contract Administration, and

Materials Management. 
Draft standards are available from HIBCC.

Standards

Designation

Scope

Standardization

Activities

Availability

Keywords
Published documents are designated with HIBCC acronym.

Facilitator of electronic communications through development of appropriate standards for information exchange among all health care trading partners.

Standardized manufacturer, customer, and product identification codes, including the Labeler Identification Code (LIC), Health Industry Number (HIN), and Universal Product Number (UPN); computerized EDI protocols in ANSI X12 approved message formats; and participation in national and international standards organizations working to further enhance electronic communications standards.

HIBCC received ANSI Accreditation, Organizational Method in July, 1995.

Bar codes; Standards, Universal Product Number (UPN), Labeler Identification Code (LIC), Database and Health Industry Number (HIN) Systems obtained through HIBCC; HIBCC EDI Usage Convention Manuals obtained through washington Publishing, c/o EDI Support Services Inc., PO Box 203, Chardon OH 44024.

EDI; electronic commerce; bar coding; Labeler Identification Code (LIC); Health Industry Number (HIN); universal identification number; Universal Product Number (UPN) ;

HEALTH INDUSTRY MANUFACTURERS ASSOCIATION

James Benson, Vice President, Science and Technology

1200 G street NW

Suite 400

Washington, DC 20005

(202) 783-8700

FAX: (202) 783-8750

Founded: 1975

Type of

Organization

Secretariats
Trade Association.

Works through other organizations to develop standards.

U.S. Technical Advisory Groups for IEC/TC 62 and TC 62A. 
scope

\section{Standardization Activities}

Keywords

HEALTH LEVEL SEVEN
330 manufacturers of medical devices and in vitro diagnostics. Focuses on legislative and regulatory international and health policy issues affecting the industry.

Works through other organizations to ensure that member views are represented on policy issues related to voluntary and regulatory standards. Cooperates with AAMI, ASTM, NCCLS, ANSI, and other organizations.

health; medical equipment; diagnostic products;

Mark McDougall, Executive Director

3300 Washtenaw Avenue

Suite 227

Ann Arbor, Michigan 48104-4250

(313) 677-7777

FAX: 313) 677-6622

e-mail: hq@h17.win.net

Founded: 1987 Standards Staff: 4

Professional and Trade Association.

Standards Developer.

ANSI Accredited Standards Developing Organization First standard (Version 1.0) published October 1987. Version 2.2, published in 1994 has been submitted to ANSI for designation as an American National Standard. HL7 has 1,570 members involved in the standards development process.

HL7 Standard, Version 2.2.

HL7 standards are being used by the Department of Veterans Affairs, Health Care Financing Administration, and the Center for Disease Control.

No certification, qualification or accreditation programs.

Health Level Seven (HL7) develops standards for the electronic exchange of clinical, financial and administrative information among independent health care oriented computer systems; e.g., hospital information systems, clinical laboratory systems, enterprise systems and pharmacy systems. HL7's 1500 members represent hospitals, computer vendors and consultants. The HL7 standard is supported by most information system vendors and used in the majority of large U.S. hospitals today. It is also used internationally in such countries as Australia, Austria, Belgium, Canada, 
standardization

Activities

Availability

Keywords

HEALTH PHYSICS SOCIETY

Type of

Organization

Standards

Development
Germany, Holland, Israel, Japan, New Zealand and the United Kingdom

Each year HL7 convenes three Working Group meetings

that usually draw between 250-300 people per meeting. HL7 has seven Technical Committees and five special Interest Groups that are responsible for defining the HL7 standards. The current HL7 standard defines transactions for transmitting data about patient registration, admission, discharge and transfers, insurance, charges and payors, orders and results for laboratory tests, image studies, nursing and physician observations, diet orders, pharmacy orders, supply orders, and master files. HL7 is currently developing transactions for exchanging information about appointment scheduling, problem lists, clinical trial enrollments, patient permissions, voice dictations, advanced directives, and physiologic signals. Task forces in HL7 are also busy developing prototypes transactions with new state-of-the-art technologies.

Distributed directly. Also, HL7 has pioneered distribution of its minutes and standard drafts at no cost through Internet FTP servers at dumccss.mc.duke.edu and supports a discussion group on the HL7@Virginia.edu list server.

EDI; healthcare standards; informatics; interface; connectivity;

Richard J. Burk, Executive Secretary

1313 Dolley Madison Blvd.

Suite 402

McLean, Virginia 22101

(703) 790-1745 FAX: (703) 790-2672

e-mail: hpsburkmgt@aol.com

Founded: $1956 \quad$ Standards Staff: 3

Professional society.

standards Developer.

Standards developer since 1956.

100 members participate in standards activities.

17 active standards.

10 in development stage.

All processed through ANSI. 


\section{Government}

Adoption

\section{Secretariats}

Scope

standardization

Activities

Availability

Keywords

HEAT EXCHANGE INSTITUTE
Several HPS/N13 standards have been adopted by government agencies, such as the NRC.

ANSI N13 Committee on Radiation Protection.

ANSI N43 Committee.

Encourages the development of scientific knowledge and practical means for the protection of man and his environment from the harmful effects of radiation, while encouraging its optimum utilization for the benefit of mankind.

Standards development directed toward the area of radiation protection including radiation monitoring, air sampling, personnel dosimetry, bioassay, environmental surveillance, and radiation emergency response. Standards are widely used by nuclear facilities, regulatory agencies, research and academic institutions, and medical facilities, which participate in their development.

Draft standards distributed directly. Published standards distributed through ANSI.

dosimetry; radiation; nuclear energy; public health;
John H. Addington, Secretary/Treasurer

1300 Sumner

Cleveland, Ohio 44115

(216) $241-7333$

FAX: (216) 241-0105

Founded: 1933

Standards Staff: 3

\section{Type of}

Organization

Trade Association.

Standards Developer.

The HEI is a nonprofit trade association committed to the technical advancement, promotion, and understanding of a broad range of utility and industrial-scale heat exchanger and vacuum apparatus. The Institute concentrates its efforts on the manufacturing and engineering aspects of steam surface condensers, closed feedwater heaters, power plant heat exchangers, liquid ring vacuum pumps, and steam jet ejectors, and deaerators. 
Standardization

Activities

Keywords

HELICOPTER ASSOCIATION INTERNATIONAL

Type of

Organization

Representation

Certification

Scope

Standardization

Activities operation.
Develops standards concerning steam surface condensers, closed feedwater heaters, power plant heat exchangers, liquid ring vacuum pumps, and steam jet ejectors, and deaerators.

condensers; feedwater heaters; heat exchangers; vacuum pumps; steam jet ejectors; energy; industrial equipment; deaerators;

Trade Association.

Works through other organizations to develop standards.

Federal Aviation Administration, National Transportation Safety Board, National Fire Protection Association, and other national and international organizations developing standards for safety, test, performance, and environment affecting helicopter design or

Participates in development and coordination of certifications promulgated by federal, state, and international authorities.

Nearly 1300 member companies, including 591 civil helicopter operators in 64 countries. Its 19 committees represent the helicopter industry in federal and state regulatory matters; and provide civil helicopter operator user input in the areas of federal aviation regulation, heliport development, environmental, and related subjects. Develops, promotes, and conducts helicopter safety and management education programs worldwide. Works with the National Transportation Safety Board and the Federal Aviation Administration to identify accident cause factors and trends relating to accident prevention.

Develops, coordinates, and reviews recommended federal, state, and local standards and criteria for heliport and helicopter operations; assists community planners and heliport developers in environmental assessment and analysis of proposed heliports in communities and city business districts; participates in the de 
Formerly

Keywords velopment of National Fire protection Association codes involving vertiports/heliport/helicopter fire protection and crash/rescue services. Develops, coordinates, and recommends to federal, state, and local authorities standards and criteria for the establishment of civil public-use heliports, hospital heliports, off-shore helidecks, private and personal use heliports.

Helicopter Association of American (HAA) 1981

helicopter; heliport; aviation; safety; transportation; emergency medical service;

HOME AUTOMATION ASSOCIATION

Charles McGrath, Executive Director

808 17th street, NW, Suite 200

Washington, DC 20006-3910

(202) 223-9669 FAX: (202) 223-9569

e-mail: 75250.1274@compuserve.com

Founded: $1988 \quad$ Standards Staff: 1

Type of

Organization

Representation

Scope

Standardization

Activities

Keywords
Trade Association.

Works through other organizations to develop standards.

Represents manufacturers, utilities, dealers, installers, engineers, home builders, distributors, consultants.

Members meet to discuss issues that effect the compatibility of several industries (HVAC, security, lighting, audio video, appliances, etc., ) and to develop interoperable products and integrated systems.

HAA's Standards and Codes Compatibility Task Force is addressing the need for standards for power line media, packet format, languages and other system elements, as well as features which assure compliance with the National Electrical Code and related government requirements.

communications; consumer products; information processing; computers; electrical; electronic; energy; HVAC; security; environment; heating; 
Division of Air Movement and Control Association

D.O. Rammien, Executive Director

30 West University Drive

Arlington Heights, Illinois 60004

(708) 394-0150 FAX: (708) 253-0088

e-mail: AMCA@delphi.com

Founded: 1955 Standards Staff: 2

Type of

Organization

Representation

Standards

Development

Standards

Designation

Government

Adoption

Certification

Scope

standardization

Activities
Trade Association.

Standards Developer: Primarily works through other organizations to develop standards.

AMCA, ASHRAE, NFPA, and UL.

At any one time, HVI may have up to thirty

representatives participating in standards development.

HVI started developing standards in 1959. Today it maintains one independent standard and promotes usage of recognized consensus standards.

HVI (HVI 916, Rev. 4/95).

Standards and procedures are referenced by the Department of Housing and Urban Development and the Department of Energy. The state of Washington cites the HVI Label as proof of acceptability.

Conducts a program for certifying air flow performance and sound emission for residential air exhaust or inlet devices, and for certifying air flow and energy efficiency performance for residential heat recovery ventilators. All ratings are based on independent testing at Texas A \& M University, ORTECH International, or another approved independent testing laboratory. Also conducts a program for certifying net free area of static ventilating devices.

A voluntary organization for manufacturer self-regula-tion of residential exhaust, inlet, heat recovery, and static/passive ventilating devices. The organization is made up of manufacturers located in the United states and Canada. Participants in the organization produce a major portion of industry products marketed in North America.

Writes recommended practices for manufacturers.

Develops certified ratings for air flow, sound emission, and energy efficiency that are used to satisfy requirements set for 
kitchens, bathrooms, bedrooms, and other rooms in houses. HVI is recognized as a quality control or testing agency by the model code organizations. The purpose of the activities is to promote the well-being of the industry while protecting the consumer from exaggerated performance claims.

Availability

Formerly

Keywords

HUMAN FACTORS SOCIETY
Distributed directly.

Home Ventilating Institute

ventilating; acoustics; sound; heat recovery, energy recovery;

Lynn strother, Executive Director

P.O. Box 1369

Santa Monica, California 90406

(310) $394-1811$

FAX: (310) 394-2410

Founded: 1957

Standards Staff: 1

Type of

Organization

Professional Society.

standards Developer.

standards

Development

100 members active in standards activities. One

standard published, ANSI/HFS 100, Human Factors.

Engineering of Visual Display Terminal Workstations.

Secretariats U.S. TAG to ISO 159.

Scope

An interdisciplinary organization of professional people involved in the human factors field. Promotes the discovery, exchange, and application of knowledge concerning the relationship of people to their machines and their environment. Advocates the consideration of operators, maintainers, and users in the design of equipment and facilities. Supports the development of working and living environments that are comfortable and safe.

Standardization Activities

Availability

Keywords
Has developed a standard on visual display terminal (VDT) workplace design through ANSI Safety and Health Management Board.

Sold directly and through ANSI.

human factors; ergonomics; safety; workplace design; office products; public health; 
Type of

Organization

Standards

Development

Certification

Secretariats

Scope

Standardization

Activities

Availability
Allen P. Wherry, Secretary Treasurer

9 Sylvan Way

Parsypany, New Jersey 07054

(201) 267-9700

FAX: (201) 267-9055

Founded: 1917

Standards staff: 3

Trade Association.

Standards Developer.

Standards developer since 1917.

70 member companies participating in standards activities.

No certification, qualification, or accreditation programs.

American National standards Committee B215, Pumps; U.S. TAG for ISO/TC 115 .

A nonprofit, national trade association that represents U.S. companies engaged in the manufacture of pumps; and is dedicated to excellence in engineering, manufacturing, and application of pumping equipment.

Publishes standards in the public interest, designed to enhance understanding between the manufacturer and the purchaser, and to assist the purchaser in selecting and obtaining the proper product for his particular need. Cooperates with other organizations, including the American National standards Institute, the American Society of Mechanical Engineers, the National Electrical Manufacturers Association, and the National Fire Protection Association, in writing standards subject to constant review and revision when necessary. The standards program is based on work performed by Technical Committees specializing in particular types of pumps. The present standards edition is an extensive rework of previous editions with four principal sections: centrifugal, vertical, reciprocating, and rotary pumps. Provides information on: classes, types, and nomenclature; ratings; test codes; applications; and installation, operation, and maintenance; and measurement of airborne sound from pumping equipment and construction materials. Also publishes the Engineering Data Book.

sold directly. 
Formerly

Keywords

HYDRONICS INSTITUTE

Type of

Organization

Standards

Development

Government

Adoption

Certification

Scope

Standardization Activities
Hydraulic Society

pumps; fluids; industrial equipment;

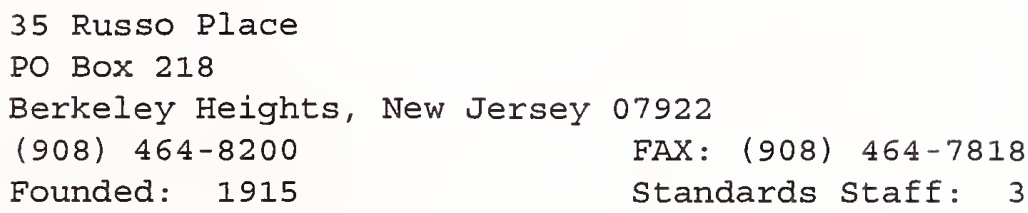

Trade Association.

Standards Developer.

Standards developer since 1940 .

Equipment performance ratings are specified in standard specifications of several federal and state agencies.

Equipment rating resulting from tests are certified by the Ratings Committee, and are published in books for

general distribution to specifiers. Under new procedures established by DOE and FTC, the Institute tests and certifies the performance of residential boilers as meeting the standards of the regulations. Such certification is provided to municipalities and to users.

Manufacturers of hydronic (hot water and steam) heating and cooling equipment. Compiles statistics; sponsors educational programs. Assists government agencies, professional societies, and other trade associations in developing standards for residential and commercial buildings, hot water heating, steam, piping and system design criteria, residential cooling, panel heating, snow melting.

Sponsors and funds research programs, the results of which form the basis for developing standards for testing heating boilers, comfort radiation equipment, immersion water heaters, and for establishing their ratings and installation criteria. Performs certification tests as requested for both members and nonmembers. Performs re-tests on products from manufacturers' stock, which are chosen at random. 
Provides guidance to government agencies at no cost in developing mechanical specifications, energy conservation standards, performance standards.

Formerly

Institute of Boiler \& Radiator Manufacturers (1970)

Steel Boiler Institute (1963)

Better Heating-Cooling Council (1970)

Keywords

heating; cooling; boilers; hot water; snow melting; panel heating; building; industrial equipment;

ILLUMINATING ENGINEERING SOCIETY OF NORTH AMERICA

Rita M. Harrold, Director, Education and Technical Development

120 Wall Street, Floor 17

New York, New York 10004-5001

(212) 248-5000 FAX: (212) 248-5017

Founded: $1906 \quad$ Standards Staff: 2

Type of

Organization

Standards

Development

Government

Adoption

Scope

Standardization

Activities
Technical society.

Standards Developer.

Standards developer since 1907.

350 members participating in standards activities. 8 active standards.

All processed through ANSI.

Portions of several standards have been adopted by OSHA and by the states through EPACT.

A technical society devoted to advancing the art, science, and practice of illumination by investigation, evaluation, and dissemination of knowledge to consumers, producers, and general interest groups through educational, literary, and scientific means.

Maintains 106 technical committees and subcommittees

that study and report to its Board of Directors on lighting of all areas, such as airports and aircraft, industrial facilities, institutions, offices, public conveyances, residences, schools, service stations, parking areas, sports and recreational areas, stores, streets and highways, theaters and television studios. Other subjects include light sources, maintenance, light control and luminaire design, nomenclature, quality and quantity of light, testing procedures for illumination characteristics, photobiology and light power limits for energy conservation. Standards define nomenclature and lighting criteria for offices, schools, industry, roadways, tunnels, interior living spaces, and casinos. Two joint standards are being written with ASHRAE on energy conservation to be submitted for ANSI public review. 


\section{INCHCAPE TESTING SERVICES/ETL TESTING LABORATORIES}

Eric Birch, President

3933 US Route 11

Cortland, New York 13045

(607) 753-6711

FAX: (607) 756-9891

Founded: 1896

Type of

Organization

Certification
Product Test and Certification Laboratory.

Standards Developer.

ETL's primary activity is product certification. It conducts safety and performance testing on a wide range of consumer products. These tests are conducted according to industry standards which are national and international in scope. Directories are published periodically showing products such as HVAC equipment, gas appliances, building materials, fluorescent ballasts, refrigerator/freezers and carpeting.

ETL's certification programs are nationally recognized and used by agencies, such as General Services Administration (GSA), and trade associations, such as GAMA, ARI, SEI, AHAM and BHMA. ETL is also an independent third party testing laboratory providing safety listing and labeling services, by testing to nationally recognized standards such as UL, ANSI, ASTM and IEC. ETL's listing, labeling and follow up program is accepted in the United States, Canada, military branches, and the building code agencies such as SBCCI, ICBO and BOCA. ETL has also been designated as a Nationally Recognized Testing Laboratory (NRTL) by the occupational Safety and Health Administration (OSHA).

An independent third party testing, inspection, certi-fication and safety labeling agency. ETL presently operates within the following disciplines: HVAC, Fire and Flammability, Refrigeration, Design Services, Electrical Performance, Electrical Safety, Acoustical, Mechanical and Photometric. 
Standardization

Activities

Formerly

Keywords
Develop standards for testing and certification

procedures through experimental testing to determine appropriate test methods. Members of ETL's professional staff are active participants in standards committees sponsored by ANSI, ASHRAE, IEC, NEMA, NFPA, SAE, IEEE, and IES.

Electrical Testing Laboratories, Inc.

testing; electrical equipment; fire and flammability; acoustics; HVAC; safety listing and labeling; photometrics; mechanical;

INDIANA LIMESTONE INSTITUTE OF AMERICA

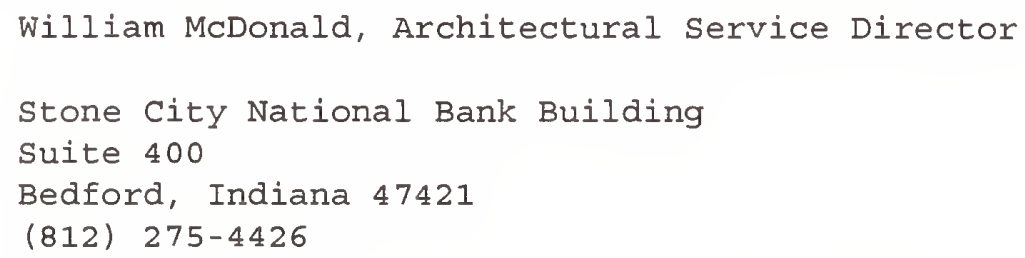

Type of

Organization

Standards

Development

Scope

Standardization

Activities

Availability
Trade Association.

Standards Developer.

$I$ active standard.

Serves the construction industry, the architectural profession, and the limestone industry as a coordinating agency for the dissemination of accurate, unbiased information on limestone standards, recommended practices, grades, colors, finishes, and all technical data required for specifying, detailing, fabricating, and erecting Indiana limestone. The Institute is supported by quarriers, fabricators and associates of Indiana limestone building stone.

Maintains a Technical Committee responsible for standardization activities. The Indiana Limestone Handbook, the only ILIA standard, is the national standard for the industry. In addition, government agencies include references to ILIA as the standard source for information on Indiana limestone in their standards and specifications.

Distributed directly. 


\section{INDUSTRIAI DIAMOND ASSOCIATION OF AMERICA}

\begin{tabular}{|c|c|}
\hline & $\begin{array}{l}\text { Fred A. Gray, Executive Director } \\
\text { P O Box } 1070 \\
\text { Skyland, North Carolina } 28776 \\
\begin{array}{ll}\text { (704) 684-1986 } & \\
\text { e-mail: } 76113.1364 @ \text { CompuServe.Com } & (704) 684-7372\end{array}\end{array}$ \\
\hline & Standards Staff: 2 \\
\hline $\begin{array}{l}\text { Type of } \\
\text { Organization }\end{array}$ & $\begin{array}{l}\text { Trade Association. } \\
\text { Standards Developer. }\end{array}$ \\
\hline Scope & $\begin{array}{l}\text { The Industrial Diamond Association of America's activity has } \\
\text { evolved from the natural diamond areas to superabrasives and, most } \\
\text { recently, to ultrahard materials. Members include materials } \\
\text { suppliers, tool manufacturers, component producers and } \\
\text { educational/research affiliates. Geographical concentration in } \\
\text { the United States, Canada and Mexico. }\end{array}$ \\
\hline $\begin{array}{l}\text { Standardization } \\
\text { Activities }\end{array}$ & $\begin{array}{l}\text { Develops standards for industrial diamonds. With the } \\
\text { American Society of Manufacturing Engineers, it cosponsors Ameri- } \\
\text { can National Standards Institute (ANSI) Project B-67, Industrial } \\
\text { Diamonds and Accessories for Their Use. Through this project, an } \\
\text { American National Standard for Diamond Dressing Tools has been } \\
\text { developed and approved. With the Grinding Wheel Institute, the } \\
\text { association also cosponsored ANSI Project B-74.1, Identification } \\
\text { Code for Diamond wheel Shapes. Other American National Standards } \\
\text { activities in which the association has participated include: } \\
\text { B-74.16, Checking the Size of Diamond Abrasive Grain, and B-74.17, } \\
\text { Test for Bulk Density of Diamond Abrasive Grain. } \\
\text { In cooperation with the National Institute of Standards and } \\
\text { Technology, the association developed a separate Cornmercial } \\
\text { Standard for grading of diamond powder, known as CS261-63, Grading } \\
\text { of Diamond Powder in Sub-Sieve Sizes. }\end{array}$ \\
\hline Availability & Distributed directly. \\
\hline Reywords & $\begin{array}{l}\text { diamonds; manufacturing; materials; ultrahard materials; s- } \\
\text { uperabrasives; }\end{array}$ \\
\hline
\end{tabular}


Type of

Organization

Standards

Development

Scope

Standardization

Activities
Steve Warner, Operations Director

345 Cedar Building

Suite 800

St. Paul, Minnesota 55101-1088

(612) 222-2508

Founded: 1912

FAX: (612) 222-8215

Standards staff: 3

Trade Association.

Standards Developer.

IFAI members actively participate on committees of

ASTM, AATCC, BOCA, EPA, FHWA, GRI, ISO, ICBO, NFPA, SAE and USCG.

A trade association with 11 product-related divisions, ranging from the Safety \& Protective Products Division to the Truck Cover \& Tarp Division. IFAI also has two country sectors: IFAI-Canada and IFAI-Japan. Over 2100 member firms represent all levels of the industrial fabrics industry including fiber producers, weavers, coaters, finishers and laminators.

IFAI promulgates a voluntary industry standard (and model flammability code) for materials used in camping tentage, designated as CPAI-84. CPAI-84, which has been adopted by several states, is being revised and updated. Another voluntary industry standard that has been adopted by several states is CPAI-75, a rate-of-burn standard for sleeping bags, to be updated in 1996. IFAI has also developed CPAI-63, a quality assurance standard for cotton tarpaulins; and CPAI-CLI, standard test methods for woven coated and/or laminated polyolefins.

The IFAI Transportation Division, acting as the SAE Committee on Textiles and Flexible Plastics, establishes standard test methods for automotive interior trim and textiles for North American automotive manufacturers.

The IFAI Awning Division is establishing a set of standard test methods for assessing the comparative performance of awning and canopy fabrics.

IFAI's American Casual Fabric Furniture Association has established a set of standard test methods for assessing the comparative performance of casual (outdoor) furniture fabrics. 
The United States Industrial Fabrics Institute (USIFI)

is assisting the Department of Defense's Defense Personnel Support Center in their standards modernization effort.

The IFAI Geomembrane Division is working with EPA to develop voluntary guidelines and standards associated with nonhazardous industrial waste disposal.

Availability

Formerly

Keywords sold directly.

Canvas Products Association International (CPAI)

textiles; fabrics; tents; tarpaulins; fabric

structures; flammability; synthetic lining/cover containment;

INDUSTRIAL FASTENERS INSTITUTE

C.J. Wison, Director of Engineering

1105 East Ohio Building

Cleveland, Ohio 44114

(216) 241-1482

FAX: (216) 241-5901

Founded: 1931

Standards Staff: 6

Trade Association.

Standards Developer.

An association of North American manufacturers of bolts, nuts, screws, rivets, and all types of special industrial fasteners. Advances fastener technology and application engineering.

Standardization Activities
Works cooperatively with national and international technical organizations, developing fastener standards and technical practices assuring users of maximum engineering efficiency and reliability, at minimum cost of assembly. There are more than 500000 standard and 3000000 special sizes, kinds, and shapes of fasteners and engineering components.

Publishes the Fastener Standards Book, a major reference book for users of mechanical fasteners. This is a collection of pertinent standards, which documents all types of general purpose commercial industrial fasteners. The standards book is used by design engineers and production managers in all industries. The Sixth Edition was published in June of 1988. 
In 1996, IFI will publish the third edition of Metric Fastener Standards which presents the internationally agreed upon system of engineering standards for commercial and industrial metric fasteners.

Availability

Formerly

Keywords

INDUSTRIAL PERFORATORS

Type of

Organization

Representation

Scope

Standardization

Activities
Distributed directly and through IHS.

American Institute of Bolt, Nut, and Rivet Manufacturers

fasteners; metric; manufacturing;

\section{ASSOCIATION}

Dolores Morris, Secretary-Treasurer

710 North Plankinton

suite 622

Milwaukee, Wisconsin 53203

(414) 271-2263

FAX: (4I4) 27I-5154

Founded: 1961

Trade Association.

Works through other organizations to develop standards.

Active in standardization of perforated materials through pertinent ASTM and ISO Committees.

A national trade association of manufacturers engaged in the production of perforated materials. Develops programs and activities to assist members achieve managerial expertise in marketing, manufacturing and other areas of company operations.

Originally developed standards for products used in the mining and aggregate industries. This led to the publication of a series of standards widely used in these industries.

Finalized a series of standards for Industrial Perforated Metal, which has been adopted and published by ASTM Committee E 29.

Active in ISO/TC 24 which is involved with setting metric standards for perforated materials on a world wide basis. Also works closely with EUROPERF, which is the Trade Association of European Perforators.

perforators; screen; punched-plate; industrial equipment; 
John A. Davenport, AVP and Director-Research

85 Woodland Street

$P \circ$ BOX 5010

Hartford, Connecticut 06102-5010

(860) 520-7362 FAX: (860) 549-5780

Founded: $1890 \quad$ Standards Staff: 9

Type of

Organization

\section{Standards}

Development

Certification

scope

Availability

Formerly

Keywords
Industrial property insurance.

Develops loss prevention guidelines and recommended practices for use by those insured and loss prevention staff. These are published as the IRInformation series; approximately 275 guideline documents in three volumes.

No certification, qualification or accreditation programs.

These documents serve as the basis for Industrial Risk Insurers' loss prevention and control recommendations.

Available on a subscription basis through the Librarian-Industrial Risk Insurers.

Factory Insurance Association (1975)

Oil Insurance Association (1975)

loss prevention; loss control; fire protection; boilers; machinery; highly protected risks;

\section{INDUSTRIAL SAFETY EQUIPMENT ASSOCIATION}

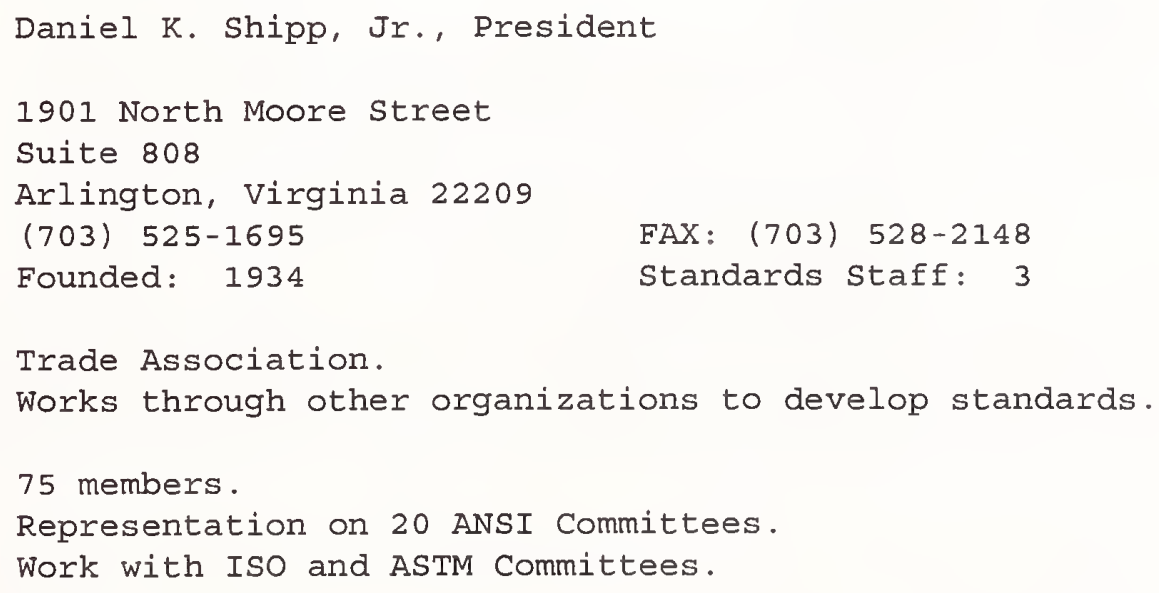


The membership of ISEA established an independent organization, the Safety Equipment Institute (SEI), in 1981. SEI administers a nongovernmental program to test and certify industrial safety products. SEI certification is voluntary, requiring annual product testing and quality assurance audits at manufacturing sites. Current programs include industrial helmets, eye and face protective products and emergency eyewash and shower equipment. Certification of respirators is performed by NIOSH and MSHA.

Secretariats

Standards

Designation

Scope

Standardization Activities

Formerly

Keywords
ANSI $\mathrm{Z} 308.1$ and $\mathrm{Z358.1}$.

ANSI/ISEA 101.

ANSI/ISEA 102.

A nonprofit organization of manufacturers of personal protective products for industrial environments. Dedicated to the safety of workers who rely on protective equipment and to the welfare of the safety equipment industry. Membership is international.

Works for the development of standards which assure the high performance of safety products. Provides manufacturers' input to standards development through official representation to such organizations as the American National Standards Institute, National Fire Protection Association, National society for the Prevention of Blindness, and the American Society for Testing and Materials. Product categories involved in standard activities include: emergency eyewash and safety shower, eye and face protection, fall protection, head protection, hearing protection, industrial first aid, industrial safety and health instruments, industrial warning devices, machinery guards, respiratory protection, safety cans, and safety wearing apparel.

Industrial Safety Equipment Manufacturers Association of the United States of America (1936)

safety; personal protection; industrial equipment;

INDUSTRIAL TRUCK ASSOCIATION

William J. Montwieler, Executive Director

$1750 \mathrm{~K}$ Street, NW.

Suite 210

Washington, DC 20006

(202) 296-9880

FAX: (202) 296-9884

Founded: 1952

Standards staff: 2 
Type of

Organization

Scope

Standardization

Activities

Availability

Formerly

Keywords
Trade Association.

Standards Developer.

Manufacturers of powered industrial trucks, tractors, and their major components.

Through its General Engineering Committee, develops a Manual of Recommended Practices, which is used as source material to advance safety and efficiency in the design, manufacturing, and use of industrial trucks. Cooperates with the American National Standards Institute, ASME Standards Committees, and ISO, as well as with the National Fire protection Association in matters affecting powered industrial trucks.

sold directly.

Electric Industrial Truck Association (1951)

industrial trucks; industrial equipment; tractors; fork lift;

INFORMATION TECHNOLOGY INDUSTRY COUNCIL

Rhett Dawson, President

1250 Eye Street, NW

Suite 200

Washington, DC 20005

(202) 737-8888

FAX: (202) 638-4922

WWW: http://www.x3.org

http://www.itic.org

http://jtcltag.org

Founded: 1916

Standards Staff: 10

Type of

Organization

Standards

Development

Secretariat
Trade Association.

Standards Developer.

Over 1200 organizations participate in the development

of ASC X3 domestic standards and JTC 1 international standards.

220 ANSI X3 standards.

76 ANSI/ISO standards.

More than 1200 ongoing projects.

Accredited Standards Committee X3, Information Processing Systems. Administrator for U.S. TAG for ISO/JTC I, Information Technology, and ISO TC 211 on Geomatics and Geographical. 
Scope

Standardization

Activities

As a not-for-profit organization, ITI provides its association members a forum for industry consultation and united action; a means for communicating facts and views of the industry to the government, other industries, and the general public. The standards development portion of the organization is open to all materially and directly affected organizations.

The staff assigned to the Trade, Technology and Standards policy area cover policy issues affecting the information technology industry's products in the areas of standards, testing, certification, quality assurance, and related legislation and regulations in all countries where such goods and services are produced and/or sold. Through predominately ITI member committees, issues in such areas as the environment, ergonomics, health and safety, hardware, software, and systems functionality and performance characteristics are identified and analyzed with subsequent ITI positions developed. Currently active committees include:

The Ergonomics Committee which deals with issues such as existing and proposed national and international standards and regulatory activities covering ergonomics/human factors related to the IT products.

Environment and Safety Management Committee (ESMC) and its subgroups which are concerned themselves with environment and safety standards, testing, certification, materials, life cycle management and quality assurance regulations - both domestically and internationally.

ESC-1, Product Life Cycle Environmental Management, which addresses standards, regulatory activities and other proposals related to the technical aspects of product life cycle management as they pertain to the IT industry.

ESC-2, Product safety, which addresses electrical safety standards, testing and certification issues through Underwriters Laboratories in the United states, Canadian Standards Association in Canada, comparable national organizations in other countries of the world, and the International Electrotechnical Commission (IEC).

ESC-3, Power Interface, which addresses issues related to power supplied by the electric utilities and power supplies used in IT products.

ESC-5, Electromagnetic Interference, which deals with standards and regulations on the limits of electromagnetic emissions from industry products through the Federal Communications Commission and comparable agencies in the other countries where ITI members do business, as well as the International special committee on Radio Interference (CISPR). 
Availability

Formerly

Keywords
ESC-6, Product Acoustics, which works on standards and regulations worldwide covering acoustic noise emitted from IT products.

ESC-9, Installation Codes and Requirements, which is concerned with requirements of the National Electrical Code in the United States, the Canadian Electrical Code in Canada, and comparable codes in other countries that apply to IT products.

Plastics Task Group which works with flammability and impact resistance requirements for plastics, as well as plastics recycling requirements, as they apply to IT products.

Information Technology and Telecommunications Equipment Task Group (ITTE TG) which focuses on the worldwide certification requirements for telecommunications and information processing equipment.

ITI/ITAC Joint standards Committee (composed of ITI and its Canadian counterpart, the Information Technology Association of Canada), which works to harmonize standards and regulations of the United states and Canada that apply to IT products.

ITI/UL Policy Committee (comprised of UL top executives, ITI management and relevant committee officers) which meets annually to discuss electrical safety policy matters of importance to the IT industry.

ITI/CSA/ITAC Policy Committee (composed of executives from ITI, ITAC and the Canadian Standards Association) which meets annually to discuss electrical safety policy matters and to work on harmonization of North American safety standards related to the IT industry.

Distributed through ANSI and ISO.

Computer and Business Equipment Manufacturers Association (1995)

automation; computers; data processing; information processing; information systems; office machines; data communications; information technology; programming languages; storage media; vocabularies; 
Thomas J. Dammrich, President

2215 Sanders Road

Suite 250

Northbrook, Illinois 60062

(708) 677-2850 FAX: (708) 677-9570

e-mail: thomasdammrich@ipc.org

WWW: http://WwW.ipc.org/

Founded: 1957 Standards Staff: 7

Type of

Organization

Standards

Development

Standards

Designation

Government

Adoption

Certification

scope

Standardization Activities
Trade Association.

Standards Developer.

Standards developer since 1957.

2000 member companies participating in standards

activities.

75 active standards.

Standards and specifications processed through ANSI.

Draft standards available to IPC representatives and applicable organizations.

IPC.

The Department of Defense has adopted 17 standards, with others pending.

Qualification programs being developed.

An international trade association of 1800 member companies representing manufacturers and users of electronic interconnection devices. Also includes key suppliers to the industry and representatives from over 60 government agencies.

Develops standards which are used worldwide by produc ers and users of rigid and flexible printed boards, flat cable, hybrid circuits, and various discrete wiring techniques.

Works closely with many organizations including UL, DOD, ANSI, EIA, and JEDEC. Members actively serve on a wide range of military and industry standards committees including the IEC, ANSI, EIA, ISHM, IEEE, and UL. Technical input solicited from and supplied by the 1800 member companies of the IPC, and key government agencies and industry organizations.

IPC standards are used throughout the electronics industry in the interconnecting and packaging of electronic circuits. They cover dimensions and tolerances, acceptability levels and definitions and terms. Widely used IPC standards include a compilation of 
Availability

Formerly

Keywords

visual quality standards; design and performance documents for soldering single, two sided and multi-layered printed wiring boards; solderability standards and surface mount documents. In addition, conducts round robin testing programs for state-ofthe-art product performance, including testing of multilayer boards, evaluation of plated through-holes, fine lines, and laminates and alternatives to CFCs.

Distributed directly and through ANSI, Global, and IHS.

Institute of Printed Circuits (1977)

printed circuits; printed boards; printed wiring boards; printed circuit boards; flat cable; electronics; electrical equipment; hybrids ;

\section{INSTITUTE OF CASTER MANUFACTURERS}

Jack L. Lagershausen, Executive Secretary

115 South Lasalle street \#1400 Chicago, Illinois 60603

(312) 201-0101

FAX: (312) 201-0214

Founded: 1933 Standards staff: 1

Type of

organization

Standards

Development

standards

Designation

Scope

standardization Activities

Availability
Trade Association.

Standards Developer.

Standards developer since 1950.

Forty members participate in standards activities. Industrial Caster standard MH11.1 processed through ANSI.

ICM Guides.

A national trade association representing manufacturers of industrial casters and wheels. Maintains liaison with the Defense Supply Agency, DISC, Department of the Army, and GSA.

Publishes "Guide to Understanding and Specifying

Industrial Casters and wheels," which includes standard information on casters and wheels (1995 edition).

sold directly. 
INSTITUTE OF CLEAN AIR COMPANIES

Jeffrey C. Smith, Executive Director

1707 L Street, NW.

suite 570

Washington, DC 20036

(202) 457-0911

FAX: (202) 331-1388

e-mail: icac@tmn.com

Founded: 1960

Standards staff: 2

Type of

organization

Scope

standards

Development

Formerly

Keywords

INSTITUTE OF ELECTRICAL AND ELECTRONICS ENGINEERS

Type of

Organization

445 Hoes Lane

Post Office Box 1331

e-mail: stds.info@ieee.org

WW: http://Www.ieee.org/

Founded: 1884

Professional Society.

Standards Developer.
Trade Association.

Standards Developer.

Members are suppliers of stationary source air pollution control and monitoring systems, equipment, and services in North America. Works to promote the industry and to encourage improvement of technical and engineering standards.

Develops technical standards, guidelines, and other publications which educate or otherwise help purchasers and users of air pollution control equipment, regulators, and the public.

Industrial Gas cleaning Institute

air pollution control; emission monitoring;

Andrew G. Salem, Managing Director of Standards

Piscataway, New Jersey 08855-1331

(908) 562-3800 FAX: (908) 562-1571

Standards staff: 42 


\section{standards}

Development

\section{standards \\ Designation}

Government

Adoption

Secretariats

scope

\section{Standardization}

Activities

Availability

Formerly

Keywords
30000 members active in standards development. 680 standards; 530 standards projects underway. Many processed through ANSI.

An ANSI accredited organization.

IEEE std $x x$-year.

30 IEEE standards have been adopted by the federal government.

16 American National Standards Committees (some as co-secretariat)

A transnational professional society of 315000 engineers and scientists in electrical engineering, electronics, and allied fields.

The Standards Board has overall responsibility for standards development and approval, and the responsibility for participation in and cooperation with other organizations on standards issues. The Board currently has nine standing committees that provide assistance and make recommendations, offering expert advice concerning procedural and developmental matters, new opportunities, and future avenues to be explored.

IEEE develops and publishes standards on a variety of topics, including bio-medical engineering communications, computer and software engineering, electrical safety, and commercial and industrial power systems. All IEEE standards are prepared by dedicated expert volunteers acting in their own fields of interest; yet are approved by a widespread, strict consensus process. Proposed standards are examined by the review committee to ensure that a proper balance of interested parties exists, and that coordination and balloting procedures have been maintained.

Distributed directly and through commercial distributors. Japanese standard Association (JSA), Book Supplies Bureau, British standards Institute (BSI), Korean Standard Association (KSA).

Formed by a merger in 1963 of the American Institute of Electrical Engineers and the Institute of Radio Engineers.

bio-medical engineering; communications; computers; electric power; local area networks (LANs); electrical safety; software quality assurance; software engineering; 
Janet A. Ehmann, Executive Director

940 East Northwest Highway

Mount Prospect, Illinois 60056

(708) 255-1561

FAX: (708) 255-1699

Type of

Organization

scope

Secretariats

standardization

Activities

Formerly

Keywords
Founded: 1954

Professional Society.

Works through other organizations to develop standards.

Devoted to the development and promotion of recommended practices standards, specifications, research, simulation techniques, testing techniques, contamination control techniques, and the development of design criteria for equipment operation. The Institute is a member of the International Committee of Contamination Control societies (ICCCS). Recommended practices have been developed by its Contamination Control Division in several areas.

Iso Technical Committee 209, "Cleanrooms and Associated Controlled Environments."

Considers and investigates matters related to contamination units and standards, as well as recommended practices, pertaining to, or applicable in, environmental engineering. Cooperates with other national technical organizations in matters regarding environmental standards, testing and engineering. Cosponsors meetings or group efforts with such organizations as American Society for Testing and Materials, American Institute of Aeronautics and Astronautics, Parenteral Drug Association, and the Department of Defense. Sponsors a representative to the International Electrotechnical Commission concerned with international standardization of environmental test methods.

American Association for Contamination Control (1973)

testing; contamination control; environment; quality assurance; clean rooms; minienvironments;

\section{INSTITUTE OF INDUSTRIAL ENGINEERS}

Woodrow Leak, Executive Director

25 Technology Park

Norcross, Georgia 30092

(404) 449-0460

FAX: (404) 263-8532

Founded: 1948

Standards Staff: 1 
Type of

Organization

\section{standards}

Development

\section{Standards}

Designation

Secretariats

Scope

Standardization

Activities

Availability

Formerly

Reywords
Professional Society.

Standards Developer.

50 volunteer members active in standards development.

Standards processed through ANSI; All are designated American

National standards.

Draft standards and revisions available for review by non-members.

ANSI 294.

American National Standards Committee Z94, Industrial Engineering Terminology.

An international society devoted to productivity improvement through the application of industrial engineering techniques. Serves more than 40000 members in 87 countries. Provides a unique cross-section of products and services including books, journals, magazines, films, seminars, conferences, and certification.

Focuses on the terms and phrases used in the practice of industrial engineering. These terms and phrases are developed through 17 subcommittees that represent the various disciplines of industrial engineering.

Distributed directly and through ANSI.

American Institute of Industrial Engineers

industrial engineering; productivity; manufacturing;

\section{INSTITUTE OF INTERNAL AUDITORS}

Type of

Organization
Susan B. Lione, Manager of Standards

249 Maitland Avenue

Altamonte Springs, Florida 32701-4201

(407) $830-7600$

FAX: (407) 831-5171

Founded: 1941

Standards Staff: 2

Standards Developer. 
standards

Development

Government

Adoption

Scope

Certification

Availability

Keywords
Standards for the Professional Practice of Internal

Auditing were developed in 1978. The standards are monitored, updated, and adapted by the IIA's Internal Auditing Standards Board, an international volunteer committee consisting of 12-18 members. All substantial changes to the standards and their related guidelines are made through statements of Internal Auditing Standards (SIASs), which are then codified into the appropriate sections of the standards. All sIASs are sub-mitted to the membership for comment before approval.

Adopted by 12 United States states and 13 other government bodies and translated into 20 languages.

The IIA is an international association dedicated to the continuing professional development of the individual internal auditor and the internal auditing profession. The IIA offers various programs and products to enhance the practice of internal auditing, including standards, certification, seminars, conferences, educational products, a bimonthly magazine, and research publications.

The IIA's certification program, established in 1973, provides the only internationally recognized certification for internal auditors - the Certified Internal Auditor designation.

Distributed directly.

internal auditing; internal auditors; auditing; accounting;

INSTITUTE OF MAKERS OF EXPLOSIVES

J. Christopher Ronay, President

112019 th street NW.

Suite 310

Washington, DC 20036

(202) 429-9280

FAX: (202) 293-2420

Founded: $1913 \quad$ Standards Staff: 1

Type of

Organization

Standards

Development

Standards

Designation
Safety Association.

Standards Developer.

Standards developer since 1913.

IME prefix. 
Government Adoption

scope

Standardization Activities

Availability

Keywords
IME recommendations are contained in federal and state regulations.

The safety association of the commercial explosives industry in the United States and Canada. Member companies include manufacturers of commercial explosives, fuses, and blasting detonators.

Develops standards related to safety in the transportation, storage, handling and use of commercial explosive materials. Works closely with regulatory agencies at the international, federal, state and local levels.

Sold directly.

explosives; safety materials; blasting;

INSTITUTE OF NUCLEAR MATERIALS MANAGEMENT

Barbara A. Scott, Executive Director

60 Revere Dr. \#500

Northbrook, Illinois 60062

(708) $480-9573$

FAX: (708) $480-9282$

Founded: 1958

Professional Society.

Works through other organizations to develop standards.

Approximately 125 INMM members active in standardization as representatives on the standards committees of ANSI, ASTM and others.

Nuclear materials specialists and nuclear materials interns are certified by examination and the results reviewed by a certification committee.

ANSI N14, Transportation of Fissile and Radioactive Materials. ANSI N15, Methods of Nuclear Material Control.

A nonprofit organization of individuals working in governmental, industrial and academic institutions where nuclear materials are utilized. The Institute advances the application of principles of accounting, auditing, engineering, mathematics, physics, statistics, and physical security for the safeguarding of nuclear fuel facilities. INMM also promotes research in the fields of nuclear safeguards, materials accounting, materials control, physical protection, waste management, and transportation. 
Standardization

Activities

Keywords

INSTITUTE OF TRANSPORTATION ENGINEERS ment ;
Directed toward meeting requirements of industry

related to safeguarding nuclear materials. Principal activities include serving as ANSI secretariat for N14 and N15. INMM standards are used extensively in Department of Energy and Department of Defense facilities, as well as by government contractors and NRC licensees. In addition, INMM standards are used world-wide by related organizations and commercial enterprises.

nuclear materials safeguards; nuclear materials waste management; nuclear material transportation; defense; energy; safety; environ-

\begin{tabular}{|c|c|}
\hline & Thomas W. Brahms, Executive Director \\
\hline & $\begin{array}{l}525 \text { School street SW } \\
\text { Suite } 410 \\
\text { Washington, DC } 20024-2729 \\
(202) 554-8050\end{array}$ \\
\hline & standards staff: 2 \\
\hline $\begin{array}{l}\text { Type of } \\
\text { Organization }\end{array}$ & $\begin{array}{l}\text { Scientific Society. } \\
\text { Standards Developer. }\end{array}$ \\
\hline $\begin{array}{l}\text { Standards } \\
\text { Development }\end{array}$ & $\begin{array}{l}300 \text { members participate in standards development. } \\
27 \text { active equipment standards and recommended practices. } \\
\text { None processed through ANSI. } \\
\text { Draft standards available for review. }\end{array}$ \\
\hline $\begin{array}{l}\text { Standards } \\
\text { Designation }\end{array}$ & $\begin{array}{l}\text { ST - equipment standards. } \\
\text { RP - recommended practices. }\end{array}$ \\
\hline $\begin{array}{l}\text { Government } \\
\text { Adoption }\end{array}$ & $\begin{array}{l}\text { The Federal Highway Administration of Department of } \\
\text { Transportation has adopted a number of ITE equipment standards as } \\
\text { part of the U.S. Manual on Uniform Control Devices. Many state } \\
\text { and local agencies have also adopted these standards. }\end{array}$ \\
\hline Certification & No certification, qualification, or accreditation programs. \\
\hline Secretariats & $\begin{array}{l}\text { A major sponsor of National Committee on Uniform Traffic Control } \\
\text { Devices. }\end{array}$ \\
\hline Scope & $\begin{array}{l}\text { A professional society of those responsible for planning, design- } \\
\text { ing, implementing, operating, and maintaining surface transporta- } \\
\text { tion systems of the world. Seven thousand members in } 73 \text { coun- }\end{array}$ \\
\hline
\end{tabular}


Standardization

Activities

Availability

Formerly

Keywords

tries. Provides publications, educational programs, testimony, and other services to benefit the transportation profession and the general public.

Develops equipment standards and recommended practices. Equipment standards for traffic control devices include signs, signals, and markings. Cooperates with all interested parties in developing standards.

Distributed directly.

Institute of Traffic Engineers (1976)

safety; transportation; traffic control devices; traffic signals; pavement markings; roadway design;

INSULATED CABLE ENGINEERS ASSOCIATION

E. E. MCIlveen, secretary-Treasurer

P.O. Box 440

South Yarmouth, Massachusetts 02664

(508) 394-4424 FAX: (508) 394-1194

Founded: 1925

Type of

Organization

Technical Society.

Standards Developer.

Standards

Standards developer since 1925.

Development

100 members participating.

50 active standards.

Many standards processed through ANSI.

Standards

Designation

ICEA, ICEA/NEMA, or ANSI/ICEA prefix.

Government

Adoption

Certification

Scope 
Standardization

Activities

Availability

Formerly

Keywords

INSULATED STEEI DOOR SYSTEMS INSTITUTE

Type of

Organization

Standards

Development

Government

Adoption

Certification

scope

Standardization

Activities development.
Publishes recommended practices and treatises resulting

from engineering research conducted by the Association. Publications on cable standards recognized by the National Electrical Manufacturers Association (NEMA), Institute of Electrical and Electronics Engineers (IEEE) and the American National Standards Institute (ANSI).

Distributed through designated Secretariats. Listings available from Headquarters.

Insulated Power Cable Engineers Association

electrical cable; insulated cable; electrical equipment, communications; cable;

Steven C. Wherry, Managing Director

30200 Detroit Road

Cleveland, Ohio 44145

(216) 899-0010 FAX: (216) 892-1404

Founded: $1975 \quad$ Standards Staff: 3

Trade Association.

Standards Developer.

Eight member companies participate in standards

Ten active standards including seven ANSI Standards.

The ISDSI standards have been adopted by numerous government agencies.

No certification, qualification, or accreditation programs.

A national trade association representing United States companies engaged in the manufacture of insulated steel door systems (consisting of door, frame, and total perimeter seal), which are specially designed and marketed for the residential market and tested to the Institute standards.

Promulgates minimum standard specifications for the manufacture of insulated steel door systems to assure quality products for the residential market. Works closely with numerous government agencies, including Department of Housing and Urban Development, Department of Navy, Corps of Engineers, and the Farmers Home Administration. Also cooperates with various code 
organizations and with the National Association of Home Builders, the Door \& Hardware Institute, and Builders Hardware Manufacturers Association.

Availability

Keywords
Distributed directly.

doors; buildings;

INTER-SOCIETY COLOR COUNCIL

Dr. Danny C. Rich, Secretary

Datacolor International

5 Princess Road

Lawrenceville, New Jersey 08648

(609) 895-7427 FAX: (609) 895-7461

e-mail:73700.3514@compuserve.com

Founded: 1933

Technical Society.

Works through other organizations to develop standards.

Coordinates work leading to the description and specification of color, and promotes the practical application of such work to color problems arising in science, art, and industry. Membership consists of 24 delegates from national societies and individual members, all with a common interest in color.

Standardization Activities
Not a standardizing body, but many of the results of its work are incorporated by its member bodies into standards which they issue or sponsor. This work is carried out by subcommittees of the ISCC Problems Committee.

Examples of preliminary work done within the ISCC include the ISCC-NIST Method of Designating Colors and a Dictionary of Color Names (NIST Circular 553); designations of filters for theatrical lighting; definitions of color terms; recommendations for illuminating and viewing conditions in the colorimetry of reflecting materials; standard methods for mounting textile samples for colorimetric measurement; standard practice for the visual examination of small color differences; the determination of sets of maximally different nonfluorescent colors; and identification of pigments in use in artists paint leading to a method for lightfastness determination and an artists' paint specification. 
INTERNATIONAL ASSOCIATION OF ELECTRICAL INSPECTORS

Type of

Organization

Representation

Certification

scope

Standardization Activities
D. H. Cox, Executive Director

901 Waterfall Way \#602

Richardson, Texas 75080

(214) 235-1455

FAX: (214) 235-3855

Founded : 1928

Standards staff: 2

Trade Association.

Works through other organizations to develop standards.

20 members and 20 alternates on the National Electrical Code promulgated by the National Fire Protection Association. Also participates on the ANSI C80, C73 and ANSI C2 committees; the UL Standards Review Council; and NFPA committees 70A, 70B, 70E, and 79.

Member of the National Board of Governors for the certification of electrical inspectors, administered by the Educational Testing Service, Princeton, New Jersey.

Promotes cooperation between inspectors, the electrical industry, and the public. Collects and disseminates information relative to the safe use of electricity. Over 20000 members including inspectors, contractors, electricians, consulting engineers, utilities, and testing labs. Seventy-five percent of its meetings and publication programs are devoted to standardization activities. Maintains liaison in its code activities with its members in Canada and Japan.

Cooperates in the formulation of standards for the safe use of electrical materials, devices, and appliances. Also promotes the uniform understanding and application of the National Electrical Code, as well as other electrical codes and standards. Maintains liaison with the federal government in many standardization activities, particularly for the use and application of the National Electrical Code. Cooperates with the Department of Housing and Urban Development, the Consumer Product Safety Commission, as well as with the occupational safety and Health Administration (OSHA) of the Department of Labor. Also serves on various NFPA, ANSI, and UL standards writing committees. 
Dick Woods, Executive Director

20001 Walnut Drive South

Walnut, California 91789

(909) 595-8449

FAX: (909) 594-1537

Founded: 1926

Standards Staff: 1

Type of

Organization

Standards

Development

Standards

Designation

Government

Adoption

Certification

Secretariats

scope

Standardization

Activities
Trade Association.

Standards Developer and works through other

organizations to develop standards.

Product and Installation standards are processed

through IAPMO's Annual Conference.

Eight standards are processed through ANSI.

Draft standards are available for review.

57 standards are currently published.

PS, IAPMO Product Standards.

IS, IAPMO Installation Standards.

The Uniform Plumbing Code is used in over 2500

jurisdictions in the United States and is the mandatory code for 13 states.

Develops monthly listing of 10000 products that have been tested and meet the requirements of applicable standards and the Unified plumbing Code. Certification must be updated and renewed annually and manufacturers are subject to reinspection during the year of listing.

Accredited Standards Committees $\mathrm{Z124}$, and A40

Established by and for inspection officials of cities, counties, and states with the goal of bringing about uniformity in plumbing codes and their interpretation. Sponsors the Uniform Mechanical Code.

Presently writes installation and product standards for conventional plumbing products. Promulgates both installation and material standards for plumbing in the mobile home and recreational vehicle industry. Standardization activities are administered by the IAPMO Standards Committee and IAPMO Mobile Home standards Committee. Works with the Department of Housing and Urban Development, the Department of Labor, and the National Institute of Standards and Technology. 
Availability

Formerly

Keywords
Los Angeles Area Plumbing Inspector Association (1926)

Plumbing Inspectors Association of Southern California (1929)

Plumbing Inspectors Association of California (1930)

Pacific Coast Plumbing Inspectors Association (1934)

Western Plumbing Officials Association (1945)

building code; plumbing code; mobile home; recreational vehicle; safety building; government officials;

INTERNATIONAL BRIDGE, TUNNEL AND TURNPIKE ASSOCIATION

Neil D. Schuster, Executive Director

2120 L street NW.

Washington, DC 20037

(202) 659-4620 FAX: (202) 659-0500

Founded: 1932

Type of

Trade Association.

Organization

Works through other organizations to develop standards.

Representation

National Committee on Uniform Traffic Control Devices

National Fire Protection Association.

Scope

A nonprofit association serving the needs of toll and tax supported bridges, tunnels, and highways. Concerned with the improvement of highway transportation in general. Members operate over 340 toll facilities with a combined value of approximately $\$ 50$ billion.

Standardization

Activities

Keywords
Works closely with the government and allied agencies and associations, such as the National Committee on Uniform Traffic Control Devices and the National Fire Protection Agency, to promote safety and improvement in highway transportation.

construction; transportation; tunnels; bridges; highways; finance; electronic toll collection;

INTERNATIONAL BROTHERHOOD OF ELECTRICAL WORKERS

J.J. Barry, International President

1125 15th street NW. Washington, DC 20005

(202) 733-7000

FAX: (202) 467-6316

Founded: 1891

Standards staff: 7 
Type of

organization

Representation

Scope

Standardization Activities

Keywords
International Labor Union (Canada and United States). Works through other organizations to develop and revise standards.

Sixty members and staff active in activities including NFPA, ANSI, IEEE, ASTM, CSA (Canada) and other organizations.

850000 members employed in electrical industries, including electrical construction and maintenance, power generation, transmission and distribution, telecommunications, radio, TV broadcasting, electrical product manufacturing.

IBEW staff and selected IBEW members are active on all code panels of NFPA 70, The National Electrical Code. IBEW staff are members of ANSI C-2 National Electric Safety Code Technical subcommittees and administrative groups. The IBEW participates in other standards relative to electrical work and equipment used in the performance of work.

Although not a standards body, the IBEW cooperates and participates in the work of standards bodies which affect electrical workers and public safety considerations for electric supply and utilization.

labor; union; electrical equipment; electric power; workers;

INTERNATIONAL CADMIUM ASSOCIATION

Hugh Morrow, President, North America

12110 Sunset Hills Road

Suite 110

Reston, Va 22090

(703) $709-1400$

FAX: (703) 709-1402

Founded: 1980

Standards Staff: 4

Type of

Organization

Representation
Trade Association.

Works through other organizations to develop standards.

26 member companies.

40 members on standards committees of ASTM, ANSI, NACE, SSPC, NEMA, NAMF, DCMA, AWS, ISO, AESF, MFSA, and a number of others. 
Scope

Standardization

Activities

Formerly

Keywords

INTERNATIONAL CAST POLYMER ASSOCIATION

Type of

Organization

Standards

Designation
Ms.Bari Moorefield, Executive Vice President

1735 N. Lynn street

Suite 950

Arlington, Virginia 22209

(703) 276-2644

FAX: (703) 524-2303

Founded: 1974

The cadmium industry's market development and informational organization in North America. Promotes increased usage of cadmium metal and chemicals through technology transfer, technical services, regulatory activities, and publicity programs. Maintains an awareness of studies on the environmental effects of cadmium and of the regulations affecting the manufacture, use, and disposal of cadmium-containing products. A nonprofit trade association supported by producers and consumers of cadmium both in North America and throughout the world. International Cadmium Association was formed by merger of the Cadmium Council in North America and the Cadmium Association in Europe.

Promotes the increased use of cadmium metal and developing bodies within its area of interest by designating Council members to coordinate with the appropriate code bodies.

Participates in developing standards including specifications for cadmium electroplating for corrosion and wear properties, color -cadmium, and other cadmium-containing batteries, cadmium chemical stabilizers in plastics, and for a wide variety of soldering and brazing alloys.

Cadmium Council (1995)

electroplating; corrosion protection; pigments; batteries; chemicals; materials; recycling; human health; environmental effects;

Trade Association.

Standards Developer.

ANSI $\mathrm{Z} 124 . \mathrm{x}$. 


\section{Government}

\section{Adoption}

Certification

\section{scope}

Standardization

Activities

\section{Availability}

Reywords
All major code bodies and most state codes reference the 2124 Standards.

CMI administers a certification program for cultured marble lavatories, shower receptors and bathtubs utilizing third party independent testing laboratories.

Represents manufacturers of cultured marble products, such as lavatories, bathtubs, shower receptors, water closets and flat stocks. Focuses on improving the quality of cultured marble in the marketplace and increasing market penetration of members' products.

Represented on ANSI 2124 Committee that is responsible for standards covering bath tubs (Z124.1), shower pans (Z124.2), lavatories (Z124.3), water closets (Z124.4), and kitchen and bar sinks $(2124.6)$.

Distributed through ANSI.

cultured marble; plumbing fixtures; building; materials;

\section{INTERNATIONAL CENTRE FOR DIFFRACTION DATA}

Daniel C. Richardson, General Manager

12 Campus Boulevard

Newtown Square, Pennsylvania 19073

(610) $325-2750 \quad$ FAX: (610) $325-9823$

Founded: 1941 Standards Staff: 28

Type of

Organization

Scope

Formerly

Availability

Reywords
Scientific Society.

Developer of Standard Reference Database.

Membership consists of scientists from academic, government, and industrial institutions who are actively engaged in developments in the field of x-ray powder diffraction and related disciplines. A paid professional staff edits, maintains, and distributes the Powder Diffraction File, a database for identification of materials by using $x$-ray powder diffraction techniques.

Joint Committee on Powder Diffraction Standards

The Powder Diffraction File (PDF) is distributed directly.

chemical analysis; $\mathrm{x}$-ray diffraction; crystallography; databases; 


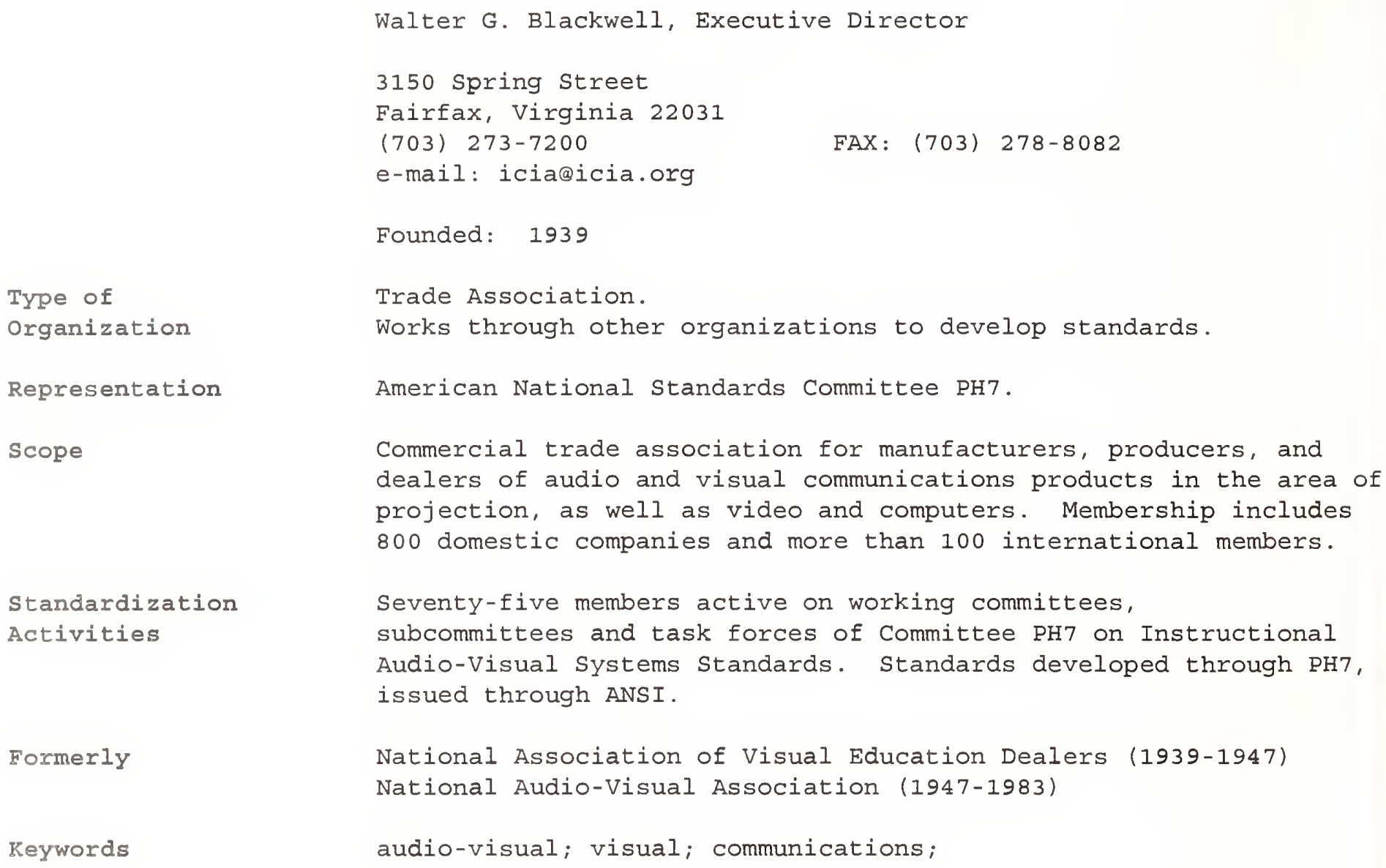

INTERNATIONAL CONFERENCE OF BUILDING OFFICIALS

Jon S. Traw, President

5360 Workman Mill Road

Whittier, California 90601

(310) 699-0541

Founded: 1922

FAX: (310) 699-8031

Standards staff: 110

Type of

Organization

Professional Association.

Standards Developer.

Standards

Development

Developer and co-developer of 14 codes for all aspects of building construction. Invokes nearly 1000 standards of ASTM, UL, NFPA, ANSI and others. 
Certification

scope

Standardization

Activities

Availability

Formerly

Keywords
Uniform Building Codes.

Jurisdictions which enforce the Uniform Building Code and its related documents are spread throughout the United sates as well as territories of many of the Pacific and Caribbean Islands. The uniform codes have also served as the basis for the Tri-Services Manual for the Army, Navy and Air Force.

Provides a voluntary certification program. Code enforcement categories of certification include, but are not limited to, building inspector, electrical inspector, plumbing inspector, mechanical inspector, combination inspector, rehabilitation/conservation inspector, fire inspector, and plans examiner. Special certification includes reinforced concrete inspection, prestressed concrete inspection, structural masonry inspection, and structural steel/welding inspection.

Objective is to furnish a complete set of Uniform Codes for state, county, and city administrative authorities responsible for enforcement of building laws to ensure a high level of safety to life from fire, structural, and exit hazards. Maintains and improves the codes on a continuous basis.

Publishes the Uniform Building Code, Uniform Mechanical Code, Uniform Fire Code, and other related documents setting forth minimum standards for safe construction in buildings and structures. Also develops criteria for acceptance of new products through its subsidiary corporation. Issues recommendations to the member jurisdictions in order that manufacturers may obtain uniform recognition of their new products.

sold directly.

Pacific Coast Building Officials Conference (1922)

International Conference of Building Officials (1958)

building code; mechanical code; fire code; solar; solid fuel; safety; construction; building; government officials; energy conservation; building conservation; certification; 
John L. Fiegel, Executive Director

120019 th street, NW

suite 300

Washington, DC 20036

(202) 429-5111

FAX : (202) 429-5113

Founded: 1909

Standards Staff: 1

Type of

organization

standards

Development

Scope

Standardization

Activities

Formerly

Keywords
Trade Association.

Works through others.

Several members serve on standards committees of ASTM, ASHRAE, ANSI, AGA, and others.

750 members, utilities, municipalities, universities, institutions, manufacturers, consultants, engineers, government officials, and others working in the district heating and cooling/cogenerated heat and power (DHC/CHP) industry. Serves worldwide interests in DHC/CHP, particularly in the United states and Canada. Most commercial DHC/CHP systems, operated by investor owned utilities, are members of IDEA. Provides a principal forum to exchange information and maintains a liaison with federal agencies and related professional organizations.

None.

International District Heating \& Cooling Association

heating; cooling; district heating and cooling; cogenerated heat and power; energy; energy recovery; utilities;

INTERNATIONAL ELECTRICAL TESTING ASSOCIATION

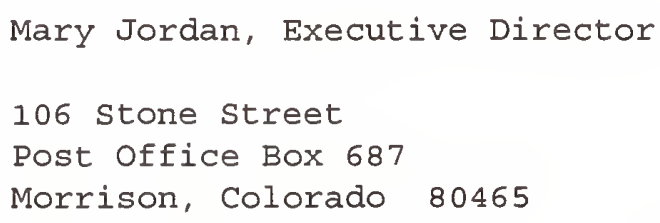

Mary Jordan, Executive Director

106 stone street Post Office Box 687 Morrison, Colorado 80465 (303) 697-8441

Founded: 1972

Trade Association. Standards Developer.
FAX: (303) 697-8431

Standards staff: 2
Type of

Organization 


\section{Standards}

Development

\section{Standards}

Designation

Government

Adoption

Certification

Scope

Standardization

Activities

Availability

Formerly

Keywords
Acceptance and Maintenance Testing Specifications for

electrical power distribution and utilization equipment.

NETA ATS-1995 Acceptance Testing Specification.

NETA MTS-1993 Maintenance Testing Specification.

Specifications adopted by GSA, the Postal Service, and military departments.

The International Electrical Testing Association is responsible for the certification of independent testing organizations and their technical personnel.

An international organization representing independent electrical power system testing and maintenance companies in areas of common interest, such as specifications for acceptance and maintenance testing, qualifying of technical personnel, qualifying of companies, NFPA and governmental committees, representation, etc.

Develops testing guidelines for electrical power transmission and utilization equipment, including: Automatic Reclosures and Sectionalizers, Capacitors, Circuit Breakers, Direct Current systems, Disconnects, Emergency Systems, Fiber-Optic Cables, Ground Fault Systems, Instrument Transformers, Instrumentation, Metal Motor Control, Network Protectors, Outdoor Bus Structures, Power Cables, Power Transformers, Protective Relays, Rotating Machinery, Safety Equipment, Thermographic Testing, Short Circuit studies and Overcurrent Coordination Studies, Surge Arrestors, Switchboard Assemblies, Switches, Systems. The specifications are based on ANSI, NEMA, and other industry consensus standards.

Distributed directly.

National Electrical Testing Association

electricity; certification; safety;

\section{INTERNATIONAL FABRICARE INSTITUTE}

Terry Burns, Executive Vice President

12251 Tech Road

Silver Spring, Maryland 20904

(301) 622-1900

Founded: 1972

FAX: (301) 236-9320

Standards Staff: 3 


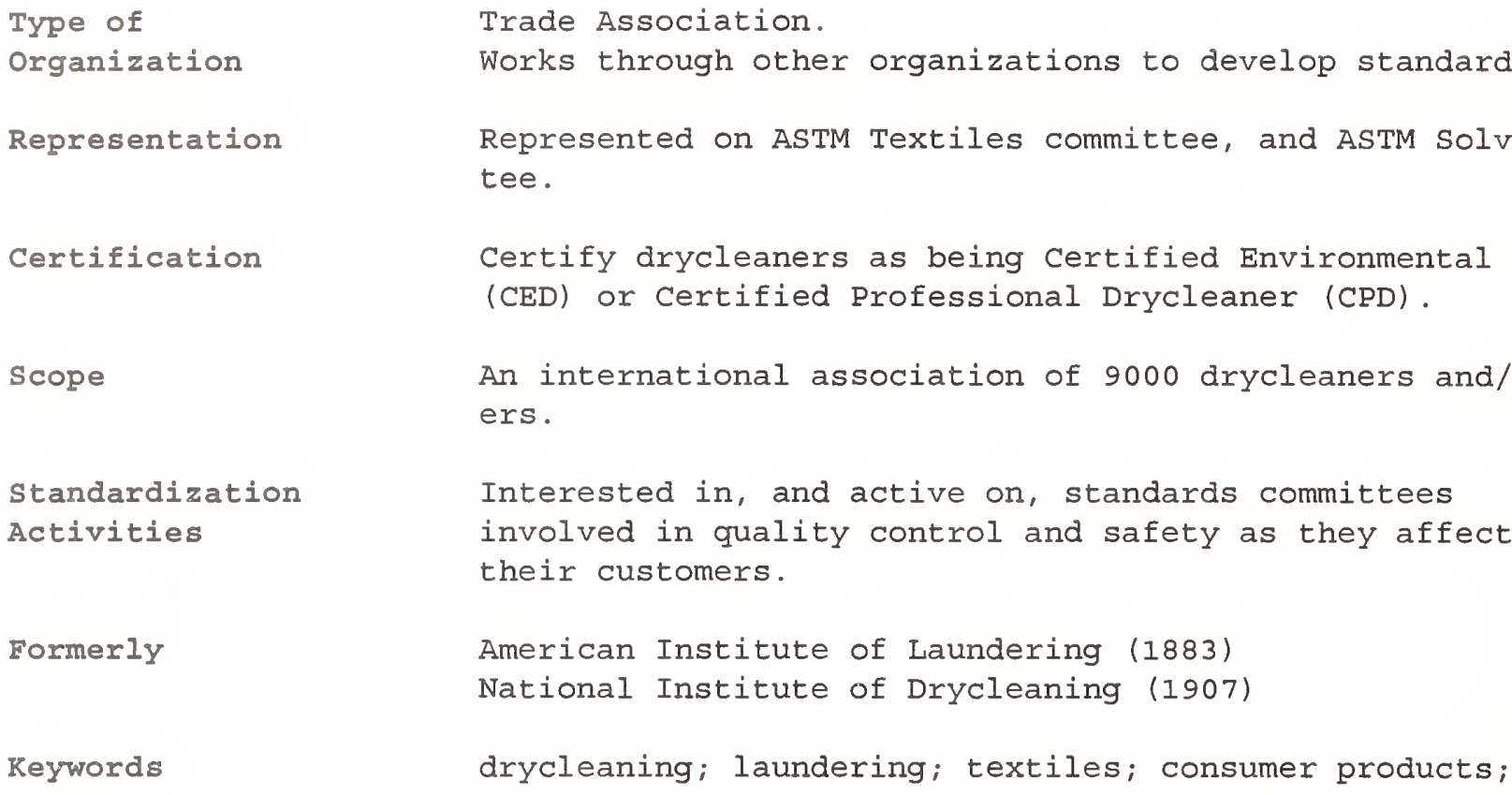

INTERNATIONAI INSTITUTE OF AMMONIA REFRIGERATION

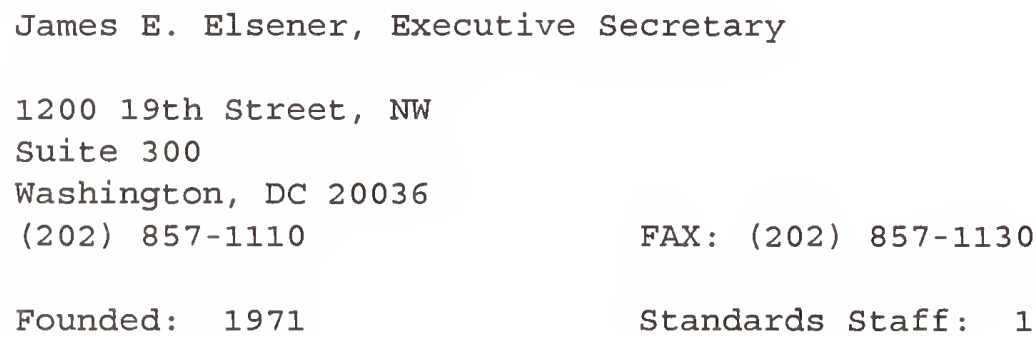


A not-for-profit organization formed to promote education, information and standards for proper and safe use of ammonia as a refrigerant. Introduces and encourages constructive educational efforts in the fields of design, safety, installation, operation, maintenance, application, and other subjects to furnish a better understanding of the use of ammonia as a refrigerant.

\section{Standardization \\ Activities}

Availability

Reywords

Developed and maintains ANSI/IIAR 74-2-1984, American

National Standard for Equipment Design and Installation of Ammonia Mechanical Refrigeration systems.

Distributed directly or through ANSI.

ammonia; refrigeration; CFC alternative; cooling;

\section{INTERNATIONAL MASONRY INSTITUTE}

Joan Baggett Calambokidis, President

82315 th street NW.

Suite 1001

Washington, DC 20005

(202) 383-3903 FAX: (202)783-0433

Founded: 1970

Type of

Organization

Representation

scope

Standardization

Activities

Reywords
Trade Association.

Works through other organizations to develop standards.

Participates in the standards activities of ASTM, ACI, ASCE, NFPA, and others.

Formed through a joint trust agreement between the Mason Contractors Association of America and the International Union of Bricklayers and Allied Craftsmen. Activities include promotion and national advertising for masonry construction, training of craftsmen, and development of areas related to masonry materials, design and construction.

Participates on committees involved in the development of standards associated with masonry and masonry construction including ASTM, ACI, ASCE, NFPA, and ANSI. Monitors and recommends changes to the national model co.des: BOCA, ICBO, and SSBC.

masonry; construction; 


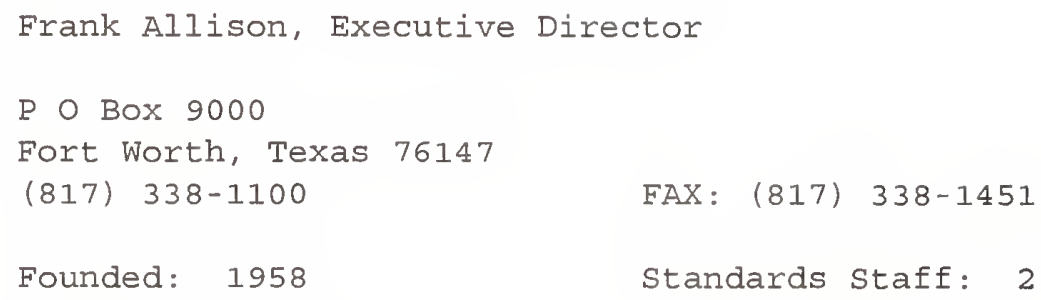

Keywords

air-conditioning; mobile air-conditioning; transportation; automotive;

\section{INTERNATIONAL MUNICIPAL SIGNAL ASSOCIATION}

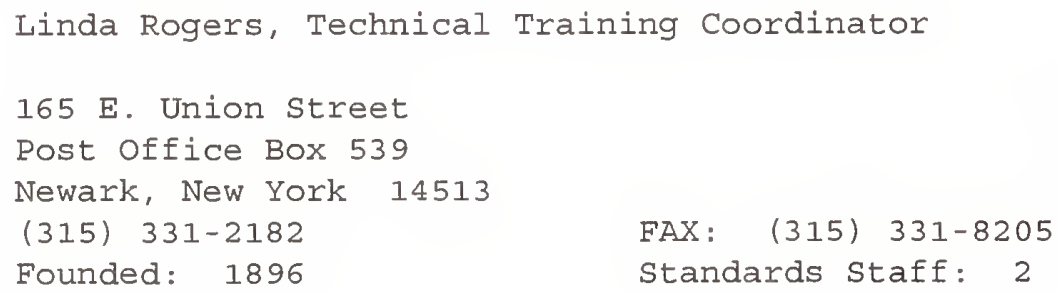


Type of

Organization

\section{Standards}

Development

\section{standards}

Designation

Government

Adoption

Certification

scope
Standardization Activities

Availability

Keywords
Technical society.

Standards Developer.

50 active standards.

None processed through ANSI.

IMSA prefix.

IMSA Wire and Cable Specifications have been recognized by the Department of Transportation and the Bureau of Public Roads.

Offers certification in the public safety fields of Traffic Signal Technician, Fire Alarm Technician, Signs and Markings Specialists, and Radio Dispatcher. Also offers certification for Work Zone Traffic Control and Roadway Lighting

A nonprofit, technical and educational association. Membership consists of 5500 members in the United States, Canada, Mexico, and the free countries of the world actively engaged in the engineering, construction, maintenance and operation of electrical, electronic and graphic communication systems used in public safety services, such as fire and police alarms, traffic control, radio communications, street lighting, signs and markings and related systems. Develops standards and manuals for use by the members and industry. Collects and disseminates educational material. Encourages unification in public safety fields for the purpose of improving the efficiency of public safety services.

Develops standards for various types of signal and communications wire and cable which must meet the requirements of ASTM and Underwriters Laboratories. Maintains a Cable Committee which updates and revises standards. Participates on Technical Committees of the National Committee on Uniform Traffic Control Devices, the Institute of Transportation Engineers Technical Council Committee, and the National Fire Protection Association. The Federal Communications Commission for Fire and EMS Radio Service recognizes IMSA as the Fire Frequency Coordination Body.

Distributed directly.

electrical equipment; wire; cable; safety; communications; 
1400 Abbott Road

Suite 310

East Lansing, Michigan 48823-1900

(517) 333-3437 FAX: (517) 333-3813

e-mail: ista@pobox.com

Founded: $1948 \quad$ Standards Staff: 2

Type of

Organization

standards

Development

Certification

Scope

standardization

Activities

Availability

Formerly

Reywords
Trade Association.

Standards Developer.

3 Preshipment Test Procedures.

Accredits laboratories to perform testing services in accordance with ISTA procedures so that they, in turn, can certify that packages tested meet approved criteria and be designated "ISTA Safe Transit Tested."

A voluntary, cooperative program which aims to reduce in-transit damage through a standardized program of preshipment testing, certification, and identification.

Committee research and discussion leading to the standards for the preshipment testing of packaged products. Activity covers both testing procedures and performance levels.

Sold directly.

National Safe Transit Association (1992)

packaging; containerization; transportation; testing;

INTERNATIONAI SLEEP PRODUCTS ASSOCIATION

Russell L. Abolt, Executive Vice President

333 Commerce street

Alexandria, Virginia 22314

(703) 683-8371

FAX: (703) 683-4503

Founded: 1915

Type of

Organization
Trade Association.

Works through other organizations to develop standards. 
Represents manufacturers of mattresses and bedsprings, as well as suppliers of machinery, raw and finished materials, components and other supplies, and services necessary to the manufacture of sleep products.

standardization Activities

Formerly

Keywords
Since 1922, instrumental in the development of voluntary "size standards" for bedding products and components. These have included the NIST Simplified Practice Recommendation, R-2 series, issued as ANSI Standards, 2357.1-1981, superseded in 1989 by ISPA voluntary product dimensional guideline. Also cosponsored Bar Code Marking standard for the Furnishings Industry.

National Association of Bedding Manufacturers

bedding; mattresses; consumer products;

\section{INTERNATIONAL SOCIETY OF ARBORICULTURE}

Chris Coleman, Executive Director

6 Dunlap Court

P.O. BOX GG

Savoy, Illinois 61801

(217) 335-9411 FAX: (217) 355-9516

Founded: 1924 Standards Staff: 1

Type of

Organization

Standards

Development

Secretariats

Scope

standardization

Activities

Availability

Formerly

Keywords
Professional Society. Standards Developer.

1 active standard.

Processed through ANSI.

ANSI Committee 2133.1 , Safety in Tree Care Operations.

Individuals engaged in commercial arboriculture; city, state, national government employees, and others interested in shade tree welfare. Conducts research programs.

Fosters the use of a standard which provides safety criteria for workers and the public. This standard presents safety requirements for pruning, trimming, repairing, maintaining, and removing trees; for cutting brush; and for the equipment used in such operations.

Distributed through ANSI.

International Shade Tree Conference

arboriculture; horticulture; tree care; safety; 
Type of

Organization

Standards

Development

Standards

Designation

Scope

Standardization

Activities

Availability

Formerly

Keywords
John Kurtz, Executive Vice President

435 North Michigan Avenue

Suite 1717

Chicago, Illinois 60611

(312) $644-0828$

FAX: (312) 644-8557

Founded: 1966

Standards staff: 1

Trade Association.

Standards Developer.

1 active standard.

ANSI approved.

SNT prefix.

An organization financed and directed by manufacturers of collated fasteners and power tools for driving them. Membership represents eighty percent of the pneumatic power tools and related fasteners produced in the world. Promotes and furthers the utilization of machine-applied staples, nails and similar fasteners and their power tools.

Maintains a Technology Committee which is responsible for the development of standards in performance, safety, code approvals, and technical coordination with government agencies, code bodies, volunteer standards organizations, and other related associations .

Develops standards on tool design and operation and guidelines on performance testing of fastened connections. Representatives participate in standards development of other organizations involving driven fasteners.

Cooperates with federal, state, and local governments in the application of standards and with voluntary public organizations and code bodies in establishing acceptable fastening criteria and product applications.

sold directly.

Industrial Stapling and Nailing Technical Association (1975) Industrial Stapling Manufacturers Institute (1972)

fasteners; nails; staples; tools; power fastening; pneumatic fastening; industrial equipment; manufacturing; 
Scott Bradner, Vice President for Standards

12020 Sunrise Valley Drive

Suite 210

Reston, Virginia 22091-3429

(703) 648-9888 FAX: (703) 648-9887

e-mail: ietf-web@cnri.reston.va.us

WWW: http://info.isoc.org

Founded: 1992

Standards Staff: 6

Type of

Organization

Standards

Development

Standards

Designation

Government

Adoption

Certification

Scope

Standardization Activities
Technical Society.

Standards Developer.

Develops Internet-Drafts and Request for Comments

(RFCs). Internet Drafts have no formal status and can be changed or deleted at any time. RFCs are the official Internet document series; however, not all RFCs are standards. More than 3000 individuals participate in standards activities. A typical draft represents the efforts of more than 1000 participants.

51 Internet-Drafts.

8 Draft Internet Standards.

52 Proposed Internet Standards in process.

$\operatorname{RFCxxxx}$.

The Internet Society's Internet Assigned Number

Authority is chartered by the Federal Network Council to act as the clearinghouse to coordinate the assignment and use of numerous unique parameter values for Internet protocols.

At this time there are no certification, qualification, or accreditation programs.

One of the principal rationales for the Internet Society is to provide an institutional home and financial support for the Internet standards process. The society does this on an international basis, and acts as a neutral, internationally recognized body, devoted to the support of Internet administrative infrastructure. The Internet society currently consists of more than 5000 individual members and 100 network, product, information and systems management providers, and research and educational institutions.

The working principles for Internet Standards development are codified in RFC 1602 (or the current version of the document). At the technical and developmental level, the Internet is made possible through creation, testing and implementation of Internet standards. These standards are developed by the Internet Engineering Task Force. The standards are then considered by the Internet Engineering Steering Group, with appeal to the Internet 
Architecture Board, and promulgation by the Internet society as international standards. The RFC Editor is responsible for preparing and organizing the standards in their final form. The standards may be found at numerous sites distributed throughout the world. (see, for example, the ds.internic.) At the applications level, the MIT World Wide Web Consortium plays the leading role in developing and promulgating wWW standards.

The Internet Engineering Task Force (IETF) is the protocol engineering and development arm of the Internet. The IETF is a large open international community of network designers, operators, vendors, and researchers concerned with the evolution of the Internet architecture and the smooth operation of the Internet. It is open to any interested individual.

The actual technical work of the IETF is done in its working groups, which are organized by topic (e.g., routing, network management, security, etc.). Much of the work is handled via mailing lists; however, the IETF also holds meetings three times per year. Proceedings of the IETF meetings are made available in the following forms:

- Hypertext proceedings

- Gopher proceedings

- FTP from ftp.ietf.cnri.reston.va.us in/ietf-onlineproceedings, and

- Hard copy proceedings.

The internal management of the IETF is handled by the area directors. Together with the Chair of the IETF, they form the Internet Engineering Steering Group (IESG). The operational management of the Internet standards process is handled by the IESG under the auspices of the Internet society. The Internet Architecture Board (IAB) is a body of the Internet Society responsible for overall architectural considerations in the Internet. It also serves to adjudicate disputes in the standards process.

The Internet Society maintains a membership relationship with the International Telecommunications Union (ITU), which facilitates standards coordination between Internet Society and ITU activities, particularly in the Telecommunications sector (ITU-T). This coordination includes the exchange of information, and joint meetings, exhibits, and workshops. 
Keywords

\section{IRRIGATION ASSOCIATION}

Type of

Organization

Standards

Development

Certification

Scope

Standardization

Activities

Availability

Keywords global network; World Wide Web; telecommunications; protocols; intellectual property;

All Internet standards are available at no cost on the

Internet. An RFC Index is available in the Database and Directory Services part of the InterNIC.

RFCs may be obtained via e-mail or FTP from many RFC

Repositories throughout the world. Details on obtaining standards via FTP or e-mail may be obtained by sending an message to: rfc-info@ISI.EDU with the message body help: ways_to_get_stds. For Example:

To: rfc-info@ISI.EDU.

Subject: getting std's.

help: ways_to_get_stds.

protocolsi intellectual propertyi 
Type of

organization

Standards

Development

Standards

Designation

Government

Adoption

Certification

Secretariats

scope

Standardization

Activities
Glenn F. Harvey, Executive Director

67 Alexander Drive

P.O. Box 12277

Research Triangle Park, North Carolina 27709

(919) 549-8411

FAX: (919) 549-8288

WWW: http://Www.isa.org/

Founded: 1945

Standards Staff: 7

Technical Society.

Standards Developer.

Standards developer since 1945.

4000 members participating in standards activities. 101 active standards; 150 active committees.

Standards are processed through ANSI.

Draft standards available for review.

ISA-S, ISA Standard.

ISA-RP, ISA Recommended Practice.

ISA-TR, ISA Technical Report.

NRC, DOD, USCG and others.

No certification, qualification, or accreditation programs.

Secretariat of IEC SC 31C Increased Safety Apparatus, IEC SC 31L Combustible Gas Detectors and IEC SC 65B Devices. ISA also serves as the administrative secretariat for U.S. TAG for IEC/TC 65, Industrial Process Measurement and Control; IEC/TC 66 on Electronic Measuring Equipment; IEC/TC 31, SC/31G on electrical apparatus for explosive atmospheres; and TC 85 measuring equipment for electromagnetic quantities.

Chartered as a nonprofit educational organization, its membership comprises more than 49000 practitioners, scientists, educators, and students worldwide involved in industrial instrumentation and control technology.

Advocates the advancement of the technology of process measurement and control instrumentation through education. Augments the exchange of knowledge and information through a wide variety of publications and by developing consensus industry standards.

Prepares and promotes national and international

standards which are competent, unbiased, widely applicable, and authoritative. Standards and practices committees span a wide 
spectrum of industries and technical interests dealing with measurement and control instrumentation. Topics include symbol ogy, computer hardware and software, intrinsic safety, thermocouples, flowmeters, transducers, rotameters, face-to-face dimensions of control valves, control valve sizing, control valve capacity test procedures, manifold designs, pneumatic circuits, annunciators, dynamic response testing, specification forms, piping and instrument drawings, instrumentation for nuclear and fossil fuel power plants, installation practices, terminology, composition analyzers, environmental conditions for digital systems, strain gages, liquid level gages, batch control, combustible and toxic gas detectors, programmable electronic systems, fire detection instruments, and continuous weighing instrumentation.

Availability

Keywords
Distributed directly and through ANSI, IHS, and Global.

instrument; measurement; process measurement; control telemetry; metrology; analysis; automatic controls; scientific instrumentation; valves; industrial equipment;

ITA, THE INTERNATIONAI RECORDING MEDIA ASSOCIATION

Charles Van Horn, Executive Vice President

505 Eighth Avenue

Floor 12A

New York, New York 10018

(212) $643-0620$

FAX: (212) 643-0624

Founded: $\quad 1970$

Standards Staff: 2

Type of

Organization

standards

Development

standards

Designation

Scope
Trade Association.

Standards Developer.

Standards developer since 1978.

Five current standards.

None processed through ANSI.

ITA, The International Recording Media Association.

An international trade association that represents companies of many nations in the consumer and industrial electronics sector, specifically tape and disc, both audio and video, as well as home entertainment firms related to tape/disc/audio/video. 
Standardization Activities

Availability

Formerly

Keywords

JEWELERS VIGILANCE COMMITTEE
The Audio Technical Committee is responsible for an ongoing standardization program in all aspects of audio and video tapes and discs. Five standards are currently active. These include standards for audio cassettes, 8 track cartridges, splicing tape and duplication guidelines for 8 track and 4 track cartridges, and Minimum Standards of Audio Tape Products. Committee members also participate on IEC, ISO, EIA, AES, SMPTE, and ANSI Committees.

By written request to the address above.

International Tape/Disc Association

tape; cassette; audio; video; disc; communications; acoustics;
Type of

Organization

Standards

Development

Government

Adoption

Scope

Standardization

Activities

Availability
Joel A. Windman

Executive Vice President and General Counsel

401 East 34 th Street, N13A

New York, New York 10016

(212) 869-9505

Founded: 1912

Standards Staff: 1

Trade Association.

Standards Developer.

Standards developer since 1913.

Adopted by the Department of Commerce and the Federal Trade Commission.

National organization supported by the jewelry industry, specializes in marking, labeling, terminology, and trade problems.

Works with government to assist industry and consumers. Develops voluntary product standards in the areas of precious metals, precious stones, and watches. Standardization work contributed to Federal Trade Commission's development of Guides for the Jewelry Industry. Conducted and revised a standardization study on the National Gold and Silver stamping Act.

Distributed directly and through the Federal Trade Commission. 
jewelry; precious metals; precious stones; materials; consumer products;

JOINT NEUROSURGICAL COMMITTEE ON DEVICES/DRUGS

Dr. Allan Friedman, Dr. Francis Gamache, Cochairmen

c/o American Association of Neurological Surgeons

22 South Washington street

Park Ridge, Illinois 60068

(312) 692-9500

Founded: 1974

Type of

Organization

Representation

Scope

Standardization

Activities

Formerly

Reywords
Professional society.

Works through other organizations to develop standards.

ASTM, AAMI, ANSI, FDA Advisory Panel, World Federation of Neurosurgical Societies.

An educational and advisory group sponsored by the American Association of Neurological Surgeons and the Congress of Neurological Surgeons to assist in the writing of neurological standards by participating in the activities of standards developing organizations. Also active as an advisory group for such organizations as the American Medical Association, the American College of Surgeons, the FDA, and the U.S. Congress.

Coordinates participation in committees developing standards for materials, devices, and practices used by neurosurgeons. Current activities center on ASTM F4.05, Subcommittee on Neurosurgery, and Committees of the Association for the Advancement of Medical Instrumentation (AAMI). Standards of interest include: tissue adhesives, aneurysm clips, carotid clamps, cranial tongs, stereotactic devices, surgical microscopes, RF generators, transcutaneous electrical nerve stimulators, intracranial pressure-monitoring devices, and computed tomography practices. Monitors activities of ISO/TC 150/SC 3 and IEC/TC 62 through ASTM and AAMI.

Merger of committees on Materials and Devices of the American Association of Neurological Surgeons and the Congress of Neurological Surgeons (1974)

medical devices; neurosurgery; materials; instrumentation; medical care; 


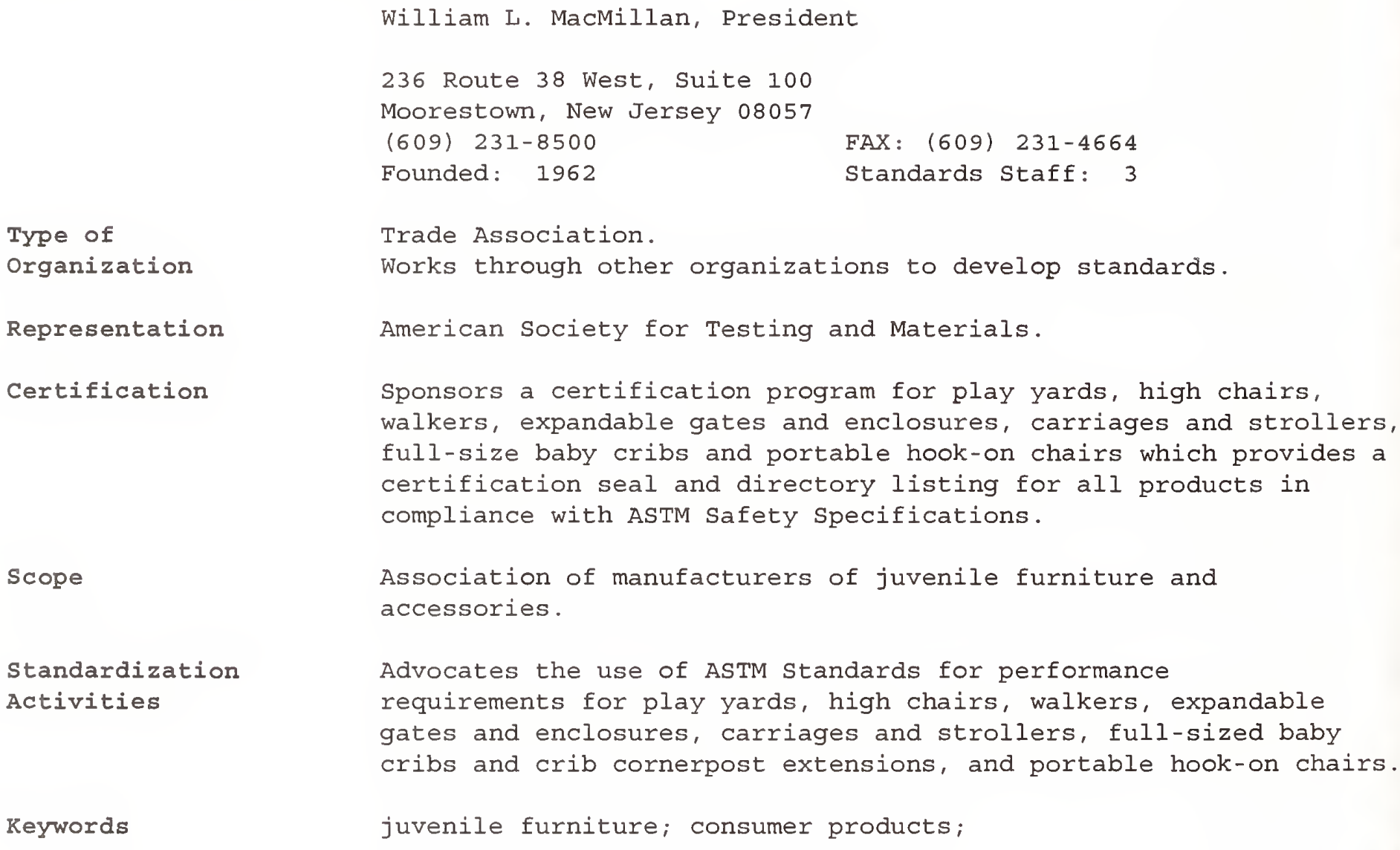

LABORERS INTERNATIONAL UNION OF NORTH AMERICA

Arthur A. Coia, General President

905 16th street NW.

Washington, DC 20006

(202) 737-8320 FAX: (202) 737-2754

Founded: 1903

Type of

Organization

Certification
Labor Union.

Works through other organizations to develop standards.

Training facilities are set up throughout North America to gain a high competency level and certification of skills for members who are in the construction and environmental remediation industries. 
standardization

Activities

Formerly

Keywords
Active in all model codes with continuous voting representation on the ASME A.40 Committee. Has a specific interest in standards development because of the health and safety of labor workers, as well as the public.

Prior to 1965, International Hod Carriers, Building and Common Laborers' Union of America

union; utilities; pipe installation; construction; safety; environmental remediation;

\section{LASER INSTITUTE OF AMERICA}

\author{
Peter Baker, Executive Director \\ 12424 Research Parkway \\ Suite 130 \\ Orlando, Florida 32826 \\ (407) 380-1553 FAX: (407) 380-5588 \\ e-mail: lia@mail.creol.ucf.edu \\ www. creol.ucf.edu $\backslash$ lia
}

Founded: 1968

Standards Staff: 1

Professional Society.

Standards Developer.

ANSI.

ANSI Z136 Committee on Laser Safety.

A nonprofit membership organization devoted entirely to the educational advancement and promotion of the technology and applications of lasers. Conducts continuing education courses, seminars and technical symposia nationwide, and offers a variety of educational materials and publications.

Develops standards on the Safe Use of Lasers. Provides guidance in hazard education and control measures to industry and health care facilities, and all personnel involved with lasers in manufacturing, communication, and medical applications. Details laser safety and training programs, as well as medical surveillance. Provides protocols for the various conditions of eye and skin exposure and methods for determining the information required for hazard evaluation and control. These consensus standards have been adopted by the national and international federal and state regulatory bodies, including the military, as basic documents or inputs to IEC and WHO standards dealing with laser safety. 
LEAD INDUSTRIES ASSOCIATION

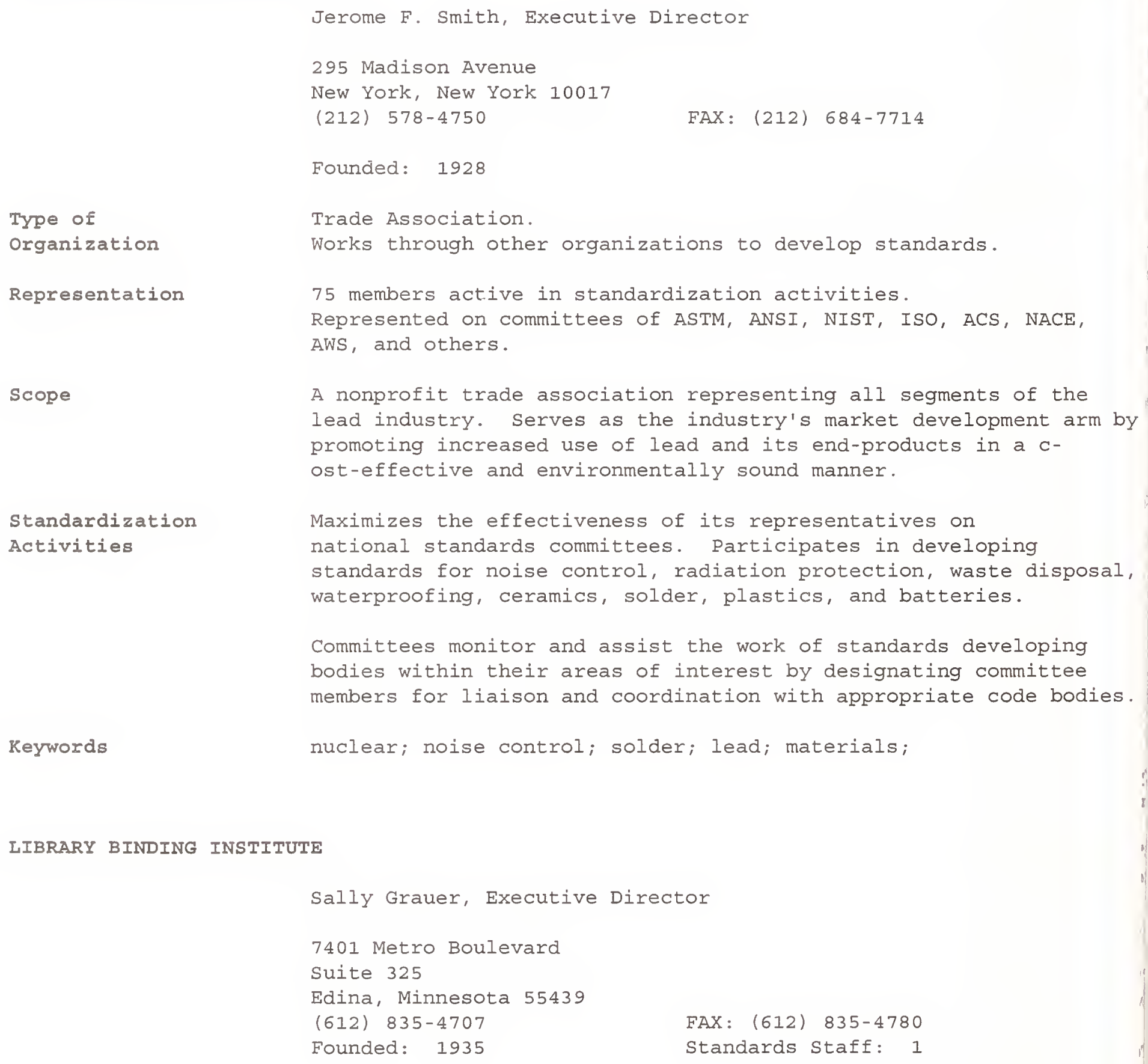

LIBRARY BINDING INSTITUTE 


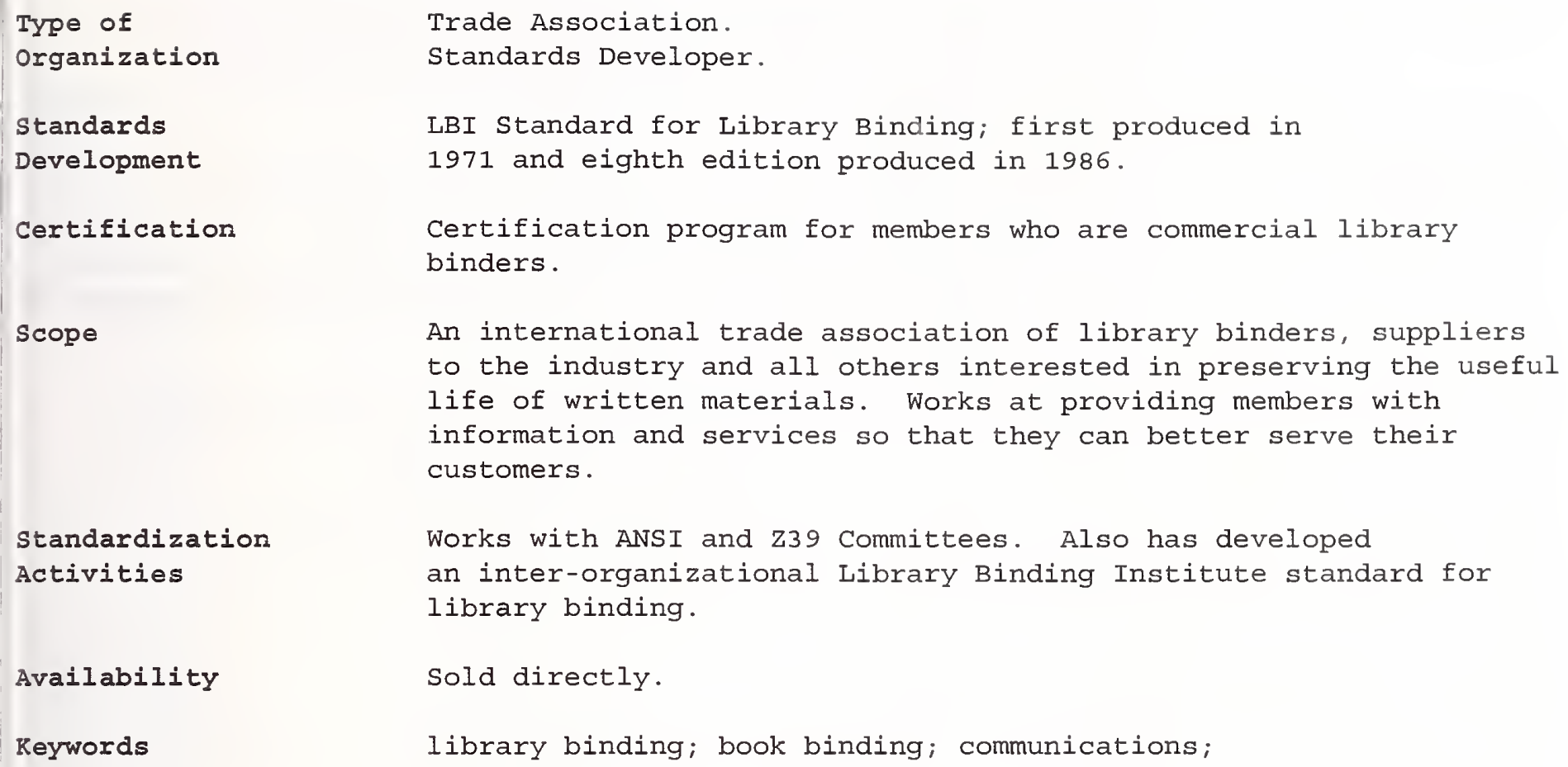

library binding; book binding; communications;

Standardization Activities

Availability

Keywords

\section{LIGHTNING PROTECTION INSTITUTE}

C. Andrew Larsen, Executive Director

3335 N. Arlington Hts. Road

Suite $\mathrm{E}$

Arlington Hts., Illinois 60004

(708) 255-8008 FAX: (708) 577-7276

Founded: 1955 Standards Staff: 1

Type of

Organization

\section{Standards}

Development

\section{Standards}

Designation

Certification
Trade Association.

Standards Developer.

Standards developer since 1982 .

12 members participating in LPI standards development.

4 members participating in NFPA standards development.

None processed through ANSI.

LPI prefix.

Offers product certification for lightning protection systems, as well as certification in 5 skill areas including, Master

Installer, Journeyman Installer, Systems Designer, Systems Inspector, and Systems Designer/Inspector. 
An association comprised of both manufacturers and dealers who supply and install components used in lightning protection systems for buildings and other structures and related industry professionals i.e., architects, engineers and consultants.

Standardization Activities

Availability

Formerly

Keywords
Develops standards designed to cover all materials and components which might be under stress while a lightning protection system is conducting lightning current. Also covers metals from the standpoint of durability as they are subjected to weathering and possible damage from corrosion, physical impact, or reaction with dissimilar metals.

Distributed directly and through LPI manufacturer. members.

Lightning Rod Manufacturers Association (1955)

lightning rods; lightning protection; building safety;

MAGNETIC MATERIALS PRODUCERS ASSOCIATION

Type of

Organization

standards

Development

Government

Adoption

Scope

Standardization

Activities
August L. Sisco, Executive Secretary

11 S. Lasalle Street

Suite 1400

Chicago, Illinois 60203

(312) 201-0101 FAX: (312) 201-0214

Founded: 1959

Standards Staff: 1

Trade Association.

Standards Developer.

28 members participate in standards development.

Department of Defense has adopted 0100.

Primary objective is to promote the progress and development of the magnetic materials industry through standardization programs and other activities as necessary.

MMPA publishes 0100-90, standard Specifications for Permanent Magnet Materials; PC 110, Standard Specifications for Ferrite Pot Cores; FTC 410, Standard Specifications for Ferrite Toroid Cores; UEI 310, Standard Specifications for Ferrite U, E \& I Cores; PMG-88, Permanent Magnet Guidelines; and SFG-92, soft Ferrites, A Users's Guide. 
Availability

Formerly

Keywords sold directly.

Permanent Magnet Producers Association

magnetic materials; cores; electronic; materials;

MANUFACTURED HOUSING INSTITUTE

Jerry C. Connors, President

2101 Wilson Boulevard

Suite 610

Arlington, Virginia 22201

(703) 558-0400

Founded: 1936

FAX: (703) 558-0401

Standards staff: 3

Type of

Organization

Representation

Secretariats

scope

Standardization Activities
Trade Association.

Works through other organizations to develop standards.

The technical staff and membership participate in development of national standards by a consensus committee for manufactured housing and in cooperation with ASHRAE, NFPA, ASTM, NCSBCS, UL, and others endorsed by ANSI.

Secretariat for a consensus committee which makes annual recommendations to the U.S. Department of Housing and Urban Development (HUD) to update the Federal Manufactured Home Construction and Safety standards.

A nonprofit trade association comprised of manufacturers, suppliers, insurers, financiers, retailers, community developers and community owners engaged in producing and servicing manufactured homes. Serves as a liaison to congress and federal agencies in order to promote and protect the interest of the manufactured housing industry and its consumers. Provides monthly statistical reports on the industry and marketing strategies. Maintains finance, site development, government relations and public relations program and sponsors annual expositions and forums.

The standards program is designed to assist members in making the manufactured home a safe, comfortable residence for the owner to live amid attractive surroundings. Advises the U.S. Department of Housing and Urban Development on the Federal Manufactured Home Construction and Safety Standards and Procedural and Enforcement Regulations (24 CFR 3280, 3282, 3283). These federal standards regulate the design and construction of the homes that are constructed by MHI members. 
MANUFACTURERS STANDARDIZATION SOCIETY OF THE VALVE AND FITTINGS INDUSTRY

Olen Thornton, Executive Director

127 Park Street, NE

Vienna, Virginia 22180-4602

(703) 281-6613

FAX: (703) 281-6671

Founded: 1924

Standards Staff: 4

Type of

organization

standards

Development

standards

Designation

Govermment

Adoption

Secretariats

scope

Standardization

Activitie日

Availability

Keywords
Trade Association.

Standards Developer.

Standards developer since 1924.

95 members.

61 current standards or guidelines documents, all data presented bi-dimensionally.

MSS SP prefix.

One third of standards have been adopted for government agency use, more expected.

U.S. TAG's for ISO/TC 153 and SC 5, 10, and Working Group 14 of SC 1 , in ISO/TC 5 .

Addresses the needs for standardization, specification, and documentation related to industrial valves, fittings, flanges, pipe hangers, valve actuators and associated seals.

Develops and reviews standards. Publishes documents available. Maintains informal liaisons with ASME, API, AWWA, ASTM, UL and other committees/organizations.

Hard copy sold directly; microform and electronic format available through IHS.

valves; fluid controls; industrial equipment; fittings; flanges; pipe hangers; actuators; packings; gaskets; 
David L. Rocha, Acting President

One state street

Providence, Rhode Island 02908

(40I) 274-3840

FAX: (40I) 274-0265

Founded: $1903 \quad$ Standards Staff: 1

Type of

Organization

Standards

Development

Standards

Designation

Government

Adoption

Secretariats

scope

standardization Activities

Availability

Keywords
Trade Association.

Standards Developer.

Standards developer since 1933.

FTC rules for the jewelry industry.

Current rules adopted 1957, amended 1959.

Jewelers Vigilance Committee.

A national education and information organization for jewelry and silver product manufacturers.

Engaged in marking, stamping, nomenclature, precious

metals, semiprecious metals, stones, pearls, country origin marks, and related practices. Industry committees agree on proper standards in keeping with the U.S. National Stamping Act. These proposals are submitted to FTC for inclusion into "rules for the jewelry industry." Rules are generally enforced by FTC, periodic checks of merchandise are made by MJSA and JVC to assure that the standards are being properly followed.

Distributed through the Federal Trade Commission.

jewelry; precious metals; precious stones; gold; silver;

materials; consumer products; 
Type of

organization

Representation

Scope

Standardization

Activities

Formerly

Keywords
Pennie Sabel, Managing Director

30 Eden Alley

Suite 201

Columbus, Ohio 43215

(614) 228-6194

Founded: 1907

Trade Association.

Works through other organizations to develop standards.

ASTM C18 Dimension Stone Committee.

ANSI Al08.1 Installation of Ceramic and Marble Tile;

Installation Materials.

ASTM E06 Performance of Building Construction.

Objective is to encourage increased usage of dimension stone in North America. Membership composed of producers, fabricators, importers, exporters, sales agents, distributors, finishers, installing contractors, and those who sell products and services to the industry.

Helps establish standards for dimension stone through ANSI and ASTM committees. Promotes quality of workmanship; publishes design manual and color reference volumes.

Merger of National Association of Marble Dealers and National Association of Marble Producers (1944)

marble; granite; limestone; sandstone; slate; bluestone; quartzite; dimension stone; building; furniture; materials;

MARKING DEVICE ASSOCIATION

David G. Lister, Managing Executive

435 North Michigan Avenue

Suite 1717

Chicago, Illinois 60611

(312) 644-0828

FAX: (312) 644-8557

Founded: 1910

Standards Staff: 1

Type of

Organization
Trade Association.

Standaras Developer. 
Manufacturers of marking devices including rubber and metal stamps, name plates, and seals.

standardization Activities

Availability

Keywords
Prepares standards for various kinds of metal marking tools and dies. Included are standards for size and depth of marking characters, styles of symbol stamps, stock sizes for various stamp blanks. Other standards in use include those for bores and keyway sizes for roll dies, roller die blanks, and type and type holders for interchangeable steel type.

Develops standard terminology for all kinds of marking devices, including metal marking tools and dies, rubber stamps, seals, stencils, and marking inks.

Distributed directly.

marking devices; stamps; stencils; seals; inks; office products; manufacturing ;

\section{MASONRY AND CONCRETE SAW MANUFACTURERS INSTITUTE}

J. Jeffrey Wherry, Executive Director

30200 Detroit Road

Cleveland, Ohio 44145

(216) 899-0010

FAX: (216) $892-1404$

Founded: 1981

Standards Staff: 3

Trade Association.

Standards Developer.

ANSI B7.5.

Membership consists of manufacturers of conventional abrasive blades, masonry saws, concrete saws, diamond wheels, and others.

Develops safety standards for the use of masonry and concrete saws. Works with ANSI and promulgates its documents through the Grinding Wheel Institute's Accredited Standards Committee B7.

Developed the ANSI Safety Code for The Construction Use and Care of Gasoline Powered, Hand Held, Portable, Abrasive, Cutting Off Machines. 
Availability

Keywords
Distributed directly and through ANSI.

abrasive blades; diamond wheels; masonry saws; concrete; industrial equipment;

MATERIAL HANDLING INDUSTRY

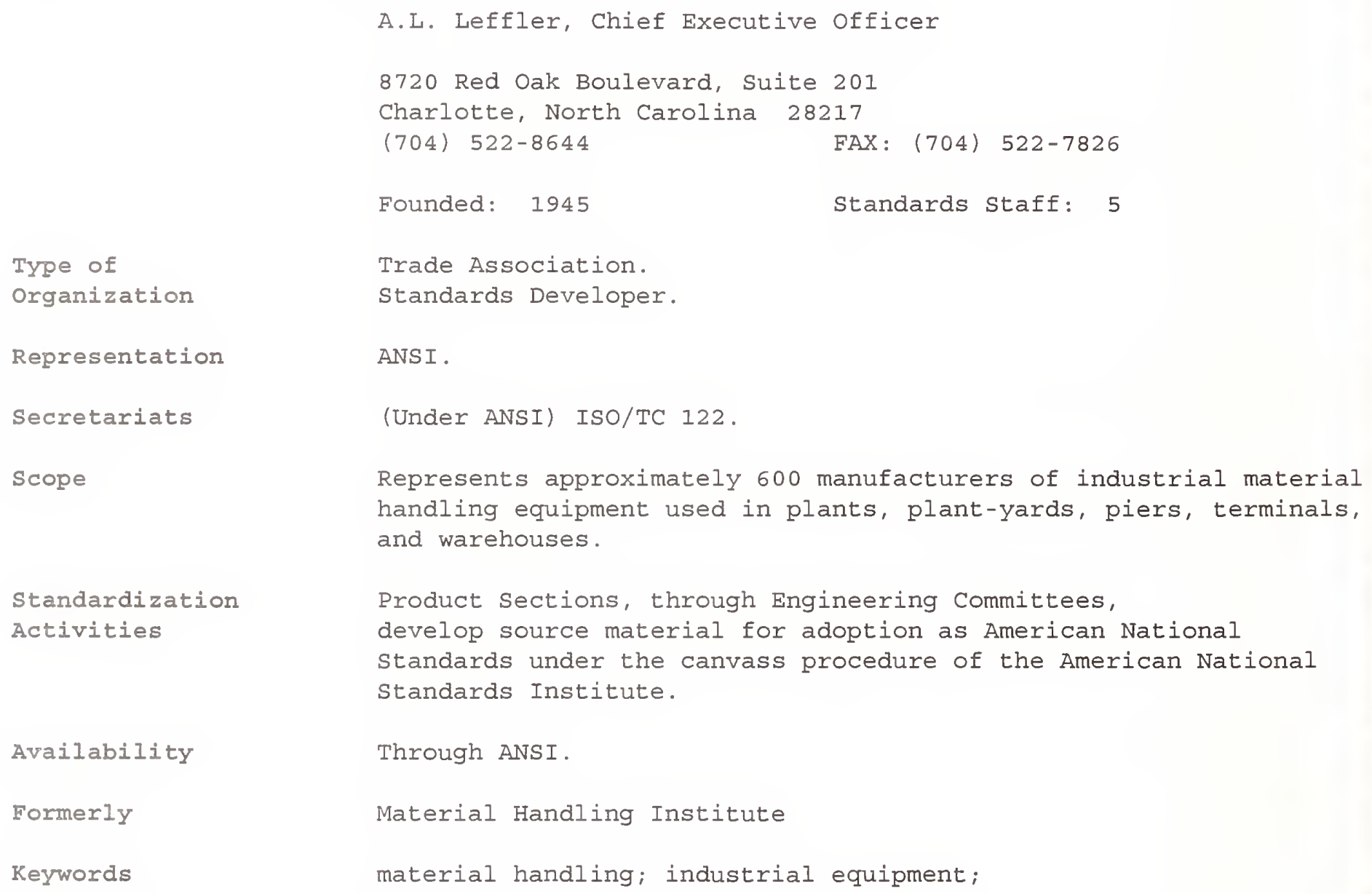


Standards

Development

scope

Standardization

Activities

Availability

Formerly

Keywords
45 members active in standards development.

Establishes standards of quality and performance of materials and methods for installation and use of ceramic tiles.

Member of ANSI AI08 and ANSI A137-I Committees; member of Tile Council of America Handbook for Ceramic Tile Installation Committee; issues bulletins on the installation of ceramic tiles.

Distributed directly.

Methods and Materials Standards Association

tile; mortar; building; materials; ceramic products;

MECHANICAL CONTRACTORS ASSOCIATION OF AMERICA

James R. Noble, Executive Vice President

1385 Piccard Drive

Rockville, Maryland 20850

(301) $774-1878$

FAX: (301) 990-9690

Founded: 1889

Trade Association.

Works through other organizations to develop standards.

A construction trade association of 1400 firms employing approximately 150000 persons. Members build and service systems that move both liquid and gas fluids. These mechanical contractors fabricate and install heating, ventilating, air conditioning, plumbing, and process piping systems in multi-residential, commercial, public industrial, and institutional facilities.

Standardization

Activities

Participates in national standards development with

American National Standards Institute (ANSI); American Society of Mechanical Engineers (ASME); National Safety Council (NSC); American Society of Heating, Refrigerating and Air-Conditioning Engineers (ASHRAE); American Welding Society (AWS); for development of consensus standards related to heating, ventilating, air conditioning (HVAC), plumbing, piping, welding, safety, and other construction-related topics. MCAA is a cosponsor of ANSI A40, Safety Requirements for Plumbing.

heating; piping; ventilating; air-conditioning; plumbing; welding; safety; construction; building; 


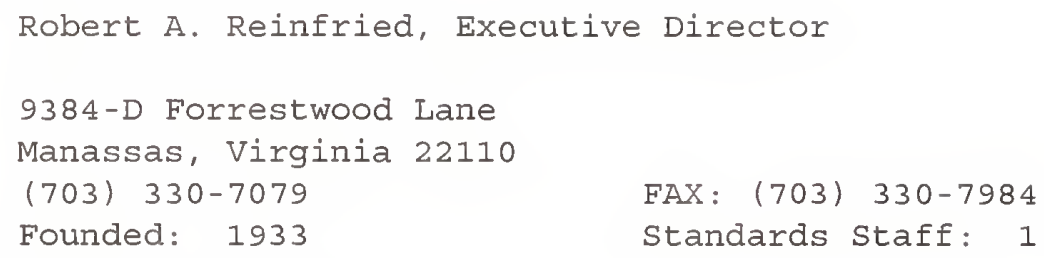

Type of

Organization

standards

Development

standards

Designation

Scope

Standardization

Activities

Availability

Formerly

Keywords
Trade Association.

Standards Developer.

Standards developer since 1936.

Thirteen member companies participate in standards activities. Standards processed through ANSI.

MPTA and RMA/MPTA prefixes.

Manufacturers of multiple $\mathrm{V}$-belt drive sheaves for mechanical power transmission machinery.

Concerned with the development of standards and other programs concerning $V$-belt drive systems and devices, variable speed drives, synchronous drives, and other belt drives. Maintains liaison with the Rubber Manufacturers Association. $\mathrm{V}$-belt and synchronous drive standards are developed in liaison with RMA.

V-belt drive standards are available through RMA.

Multiple V-Belt Drive and Mechanical Power Transmission Association

belt drives; machinery; industrial equipment;

METAL BUILDING MANUFACTURERS ASSOCIATION

Charles M. Stockinger, General Manager

1300 Sumner Avenue

Cleveland, Ohio 44115-2851

(216) 241-7333

FAX: (216) 241-0105

Founded: 1956

Standards Staff: 3

Type of

Organization

Trade Association.

Standards Developer. 
Promotes the uses of metal buildings; deals with technical and trade promotional problems pertinent to the industry; compiles and publishes information of benefit to the industry and others interested in metal buildings; cooperates in the adoption and maintenance of standards for metal buildings.

Standardization

Activities

Availability

Reywords
A Technical Committee prepares recommendations concern-

ing such projects as methods used in application of design loads, recommended minimum thicknesses of steel used in manufacturing metal buildings in order to assure proper service, and other general recommendations for use by model code bodies in preparing or revising these codes to have properly constructed metal buildings. Works in conjunction with the American Iron and steel Institute, model code bodies, the American Institute of steel Construction, and other code committees to assure users that proper installations are made.

Distributed directly.

metal buildings; building; structures;

\section{METAL LADDER MANUFACTURERS ASSOCIATION}

R. L. Werner, Secretary
P.O. Box 580 , Osgood Road
Greenville, Pennsylvania 16125
$(412) 588-8600$
Founded: 1949
Trade Association.
Type of


Availability

Keywords

METAL POWDER INDUSTRIES FEDERATION

Type of

organization

Standards

Development

Scope

Standardization

Activities

Availability

Formerly

Keywords sold directly and through ANSI.

metal ladders; ladders; planks; scaffolds; industrial equipment; consumer products;

Donald G. White, Executive Director

105 College Road East

Princeton, New Jersey 08540-6692

(609) 452-7700

FAX : (609) 987-8523

Founded: 1945

Standards Staff: 3

Trade Association.

Standards Developer.

More than 100 active standards.

One processed through ANSI.

Serves technical and trade interests of metal powder producing and consuming industries. Composed of the Metal Powder Producers Association, Powder Metallurgy Parts Association, Powder Metallurgy Equipment Association, Refractory Metals Association, Metal Powder Technology Association and Metal Injection Molding Association.

Issues materials and test standards in the field of power metallurgy dealing with ferrous and nonferrous materials, including self-lubricating bearings metal injection mold products and industry practices. Jointly issues safety standard for metal powder compacting presses with ANSI. Maintains a standards Board and four standards committees to coordinate its activities.

Reviews federal specifications issued by the General Services Administration. Participates on ISO Committee TC 119; ASTM; and $\mathrm{SAE} ;$ and AGMA powder metal committee 4f; Metal Powder, and Metal Powder Products.

Distributed directly.

Metal Powder Association (1957)

metal powder; powder metallurgy; metallurgy; materials; bearings; compacting presses; metal injection molding; 
M. Lance Miller, Executive Director

302 Third street

Suite one

Neptune Beach, Florida 32233

(904) 249-0448

FAX: (904) 249-0459

e-mail: metaltreat@aol.com

Founded: 1933

Standards Staff: 2

Type of

Organization

Standards

Development

Standards

Designation

scope

Standardization

Activities

Availability

Reywords
Trade Association.

Standards Developer.

Standards developer since 1975.

None processed through ANSI.

MTI-2000, Quality Assurance Specification for

Performance of Heat Treating Processes.

Firms engaged in commercial heating of metals, tools, and other metal products. Conducts regional and national meetings for exchange of information; acts for its members in national affairs affecting the industry.

Prepared a set of quality assurance standards which outlines a standard of good process and equipment control and provides customers with specific and meaningful criteria for comparing or evaluating equipment, processes, process controls, and record keeping systems in the heat treating facility where this standard is employed. Also provides procedures which establish a measure of uniformity among its users so that customer surveys may be made more quickly with better comparability and consistency.

sold directly.

metal treating; heat treating; manufacturing; materials;

\section{MONORAIL MANUFACTURERS ASSOCIATION}

Claude G. Carraux, Managing Director

8720 Red Oak Boulevard

Suite 201

Charlotte, North Carolina 28217

(704) $522-8644$

FAX: (704) $522-7826$

Founded: 1933

Standards staff: 2 
Type of

Organization

Standards

Development

Standards

Designation

scope

standardization

Activities

Availability

Keywords

MULTI-HOUSING LAUNDRY ASSOCIATION

David L. Goldenberg

4101 Lake Boone Trail

Suite 201

Raleigh, North Carolina 27607

(919) 787-5181

FAX: (919) 787-4916

Founded: 1959

Type of

Organization

Representation

Standards

Development

Trade Association.

Works through other organizations to develop standards. the Building Officials Code Administrator (BOCA), the Southern of Housing and Urban Development.

MLA first began working on the development of standards in 1968 when, in conjunction with the U.S. Federal Housing
Trade Association.

Standards Developer since 1933.

Ten member companies participate in standards activities.

Two active standards; both processed through ANSI.

including monorails, stacker cranes, and underhung traveling

Works with ASME, ANSI, American Welding society, ican Foundrymen's Society, and others to develop design and tandards and specifications for underhung cranes and

Sold directly and through ANSI.

monorail; underhung crane; industrial equipment;

ANSI, the International Conference of Building officials (ICBO), Building Code Congress (SBCCI), the International Association of Plumbing and Mechanical Officials (IAPMO), and the U.S. Department Administration's office of Technical standards, Department of Housing and Urban Development, they developed and published a Laundry Guide, that set out technical standards and recommendations for location, design and layout of common area 


\section{Government}

Adoption

\section{Certification}

Scope

\section{Standardization}

Activities

Availability

Formerly

Keywords laundry rooms in multi-family housing. MLA members are involved in four active standard: American National Standard on Accessible and Useable Buildings and Facilities, CABO/ANSI Al17.1; Fair Housing Accessibility Guidelines issued by the Department of Housing and Urban Development; MLA Laundry Guide; and Plumbing Codes developed by IAPMO, ICBO, BOCA and SBCCI.

Standards and recommendations on standards are submitted to federal agencies with regulatory authority over housing, including the Department of Housing and Urban Development and the Architectural and Transportation Barriers Compliance Board.

No certification, qualification or accreditation programs

MLA is an association of approximately 100 companies that purchase, install and service laundry room equipment in a variety of multi-family dwellings, including apartment buildings, military bases and college dormitories. MLA serves its members by collecting and disseminating information about significant developments in products, equipment, laundry room design, legal and management issues relevant to improving the quality of the services provided by association members. This work has included participation in the development of guidelines and standards that pertain to laundry room design and management.

MLA works with other standards setting organizations, including ANSI, and federal and state government agencies, to evaluate, provide technical advice and recommendations on standards for design, layout and management of common area laundry rooms in multi-family housing facilities.

Distributed directly.

National Association of Coin Laundry Equipment Operators, Inc. laundry; clothes; washer; washing machine; dryer; 
Type of

organization

standards

Development

Standards

Designation

Government

Adoption

Certification

Secretariats

scope
Helena Buist, Director, Technical Activities Division

P.O. Box 218340

Houston, Texas 77218

(713) 492-0535 FAX: (713) 492-8254

e-mail: 75357,243@compuserve.com

Founded: $1943 \quad$ Standards Staff: 5

Technical society

Standards Developer

Standards developer since 1969.

3300 members participating in standards activities.

100 active standards, conversion to metric ongoing.

3 processed through ANSI.

Draft standards available for review to members.

NACE MR, Material Requirement (such as MRO175).

NACE TM, Test Methods (such as TMO284).

NACE RP, Recommended Practice (such as RPO285).

NACE EG, Emergency Guideline (such as EG-1).

Several standards are referenced in state and federal regulations.

Professional recognition program with five categories, each of which is designed to recognize levels in corrosion work; one category is for coating inspectors (certification program is not directly tied to standards program).

U.S. Technical Advisory Group, ISO/TC 35/SC 12, Preparation of Steel Surfaces before Application of Paint and Related Products, and ISO/TC 35/SC 14 on Anti-Corrosive Paint Systems for steel structures.

Assists the public and industrial communities to conserve energy and materials through corrosion control and materials selection. Provides a forum for the presentation of new technology and evaluation of existing technology; publishes literature and software concerned with the science and engineering of corrosion; supports the needs of other learned societies by supplying information regarding the science and engineering of corrosion control and materials selection; establishes and publishes technical standards and practices to guide producer and user industries; promotes the recognition of corrosion engineering as a profession by means of education, accreditation, and certification programs. 
Availability

Formerly

Keywords
Standardization activities accomplished through approximately 350 technical committees which are composed of representatives from industries in which corrosion is a problem. Identifies corrosion problems and solutions and assembles information to define the problems. Develops standards which are reviewed by interested industry parties. Standards represent a consensus of persons substantially concerned with their subjects.

Makes concerted efforts to involve other technical societies in relevant standardization activities through formal liaison.

Primary focus on standardization has been related to development of performance standards. Standards have been proposed regarding performance (resistance to corrosion) of offshore steel platforms, performance of cathodic protection systems, and performance of materials in corrosive environments.

Distributed directly, and through IHS, CSS, and American Technical Publishers.

National Association of Corrosion Engineers (1994)

corrosion; materials; coatings; pipeline;

\section{NATIONAL AIR DUCT CLEANERS ASSOCIATION}

Kenneth M. Sufka, Executive Director

$1518 \mathrm{~K}$ Street, NW

Suite 503

Washington, DC 20005

(202) 737-2926

FAX: (202) 347-8847

Founded: 1989

Standards Staff: 4

Type of

Organization

\section{Standards}

Development

\section{Standards}

Designation

Government

Adoption
Trade Association

Standards Developer

Standards Developer since 1989.

Association Standards Council consists of five Project Committees.

NADCA Standard 1992--1, Mechanical Cleaning of NonPorous Air Conveyance System Components.

Widely specified in Army, Navy and other government agency project specifications 
scope

Standardization

Activities

Availability

Keywords

NATIONAI ARBORIST ASSOCIATION

Type of

organization

Secretariat

Scope

Standardization

Activities

Keywords
A nonprofit organization of qualified HVAC system cleaning companies. Promotes professional standards for the industry and public education of the dangers of poor indoor air quality. Represents its membership at national and international levels.

Activities directed toward fulfilling the minimum requirements for total HVAC system cleaning. NADCA standard 199201 (performance standard for the HVAC system cleaning industry) is currently the only standard addressing HVAC system hygiene.

Sold directly.

HVAC systems; air handling; mechanical hygiene; air duct cleaning;

Robert Felix, Executive Vice President

Route 101, Box 1094

Amherst, New Hampshire 03031-1094

(603) 673-3311 FAX: (603) 672-2613

e-mail: 76142.463@COMPUSERVE.COM

Founded: $1938 \quad$ Standards Staff: 2

Trade Association

Standards Developer

ANSI A300, American National Standard for Tree Care Operations - Tree, Shrub and other woody Plant Maintenance - Standard Practices.

A trade association of more than 1000 commercial tree service firms. A strong supporter of the voluntary standards system.

Instrumental in the development of ANSI Z133.1, American National standard for Tree Care operations - Pruning, Trimming, Repairing, Maintaining, and Removing Trees, and Cutting Brush - safety Requirements, and all five of its revisions.

trees; safety; 
A. L. Sisco, Executive Vice President

11 South Lasalle street

Suite 1400

Chicago, Illinois 60603

(312) 201-0101

FAX: (312) 201-0214

Founded: 1937

Standards Staff: 2

Type of

Organization

Standards

Development

Standards

Designation

Scope
Standardization Activities
Trade Association

Standards Developer

Eleven standards

Two processed through ANSI.

NAAMM Standard, NAAMM Recommended Voluntary Standard, ANSI/NAAMM prefix.

A nationwide association of fabricators of architectural, commercial, residential, ornamental, miscellaneous, and hollow metal products. Promotes mutual interests and cooperation among members of industry; promotes educational and informational activities; compiles and disseminates statistics; furnishes technical information to architects and engineers; maintains and improves technical standards of the industry; conducts studies and surveys to increase the use of the markets for industry products; promotes and assists in the development of new products.

Five divisions active in standards activities including Architectural Metal Products Division, Flagpole Division, Hollow Metal Manufacturers Association Division, Metal Bar Grating Division, and Metal Lath/steel Framing Association Division. Voluntary standards and specifications developed for metal stairs, metal stair railings, pipe railings, flagpoles, hollow metal doors and frames, metal bar grating, metal lath and plaster assemblies and lightgage steel framing which are widely accepted by architects, engineers, specification writers, code groups, and government agencies.

Publishes the Metal Stair Manual, Metal Finishes Manual, Pipe Railing Manual, Metal Flagpole Manual, Guide Specification for Design Loads of Metal Flagpoles, Hollow Metal Manual, Metal Bar Grating Manual, Heavy Duty Metal Bar Grating Manual, Welding Standard for Fabrication of Metal Bar Grating, Specifications for Metal Lathing \& Furring and Lightweight Steel Framing Systems Manual. Also revises and updates standards on a regular basis. Also provides representation to ASTM committees where appropriate to the development of performance and testing standards. 


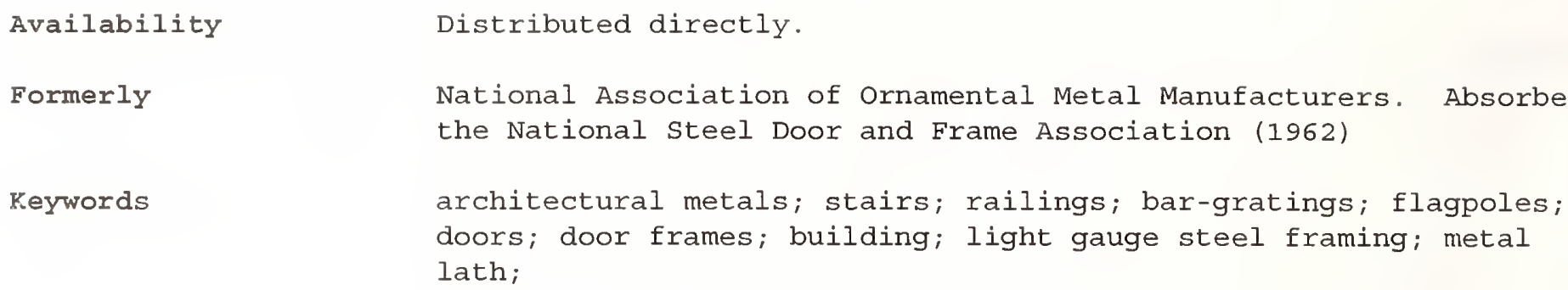

NATIONAI ASSOCIATION OF BROADCASTERS

Type of

Organization

standards

Development

standards

Designation

Certification

secretariats

scope

Standardization Activities
Lynn Claudy, Vice President - Science \& Technology

$1771 \mathrm{~N}$ street NW.

Washington, DC 20036

(202) 429-5346

FAX: (202) 775-4981

Founded: 1922

Standards staff: 2

Trade Association

Standards Developer

Standards developer since 1941.

NAB and NARTB prefixes.

No certification, qualification, or accreditation programs

NAB is the secretariat of the Advanced Television Systems Committee whose purpose is to coordinate the development of voluntary national standards for Advanced Television systems in the United stattes. NAB is also secretariat of the National Radio systems Committee (NRSC) whose purpose is to better the relationship between broadcasters and radio receiver manufacturers through technical improvements.

Represents membership of 5000 radio and over 900 television stations, including the major networks. Represents the industry before Congress, the white House, and federal regulatory agencies.

Maintains standards committees regarding the retention and review of existing $\mathrm{NAB}$ standards and practices. As a member of the Joint Committee on Inter-society Coordination composed of the NAB, EIA, IEEE, NCTA, and SMPTE, the NAB participates in many 


\section{Availability}

Formerly

Keywords standards setting committees representing broadcasters and broadcasting interests. Standards pertain to radio and television technical improvements, and producing test records and CDS.

Distributed directly.

National Association of Radio and Television Broadcasters (NARTB) (1951-1957)

disc recording; tape recording; cartridge tape; cassette tape; broadcast; advanced television systems; NRSC; AM engineering; FM engineering; technical improvement; communications;

\section{NATIONAL ASSOCIATION OF CHAIN MANUFACTURERS}

William F. Westerhold, Director

P O BOX 3143

York, Pennsylvania 17402

(717) 840-1304

Founded: 1932

Standards Staff: 1

Type of

Organization

Scope

Standardization Activities

Formerly

Keywords
Trade Association

Standards Developer

Eight manufacturers of welded chain, weldless chain, and tire chains. In addition to standardization, the Association promotes the use of chain and serves as a liaison in contacts with technical and professional groups and federal governmental agencies.

The Association has two committees involved in various aspects of standards development and coordination.

Along with development of industry standards, members of these groups serve on various standards setting bodies including ASTM, ASME, and others.

The Chain Institute

chain; tire chains; industrial equipment; transportation; 
Type of

Organization

Scope

Standardization Activities

Availability

Keywords
Anthony R. Giancola, Executive Director

440 First street, NW

Washington, DC 20001

(202) 393-5041 FAX: (202) 393-2630

e-mail: tonyg@spaceworks.com

Founded: 1956 Standards Staff: 2

Professional society

Standards Developer

Identifies various technical and management problems common to most counties and documents their solutions. Conducts workshops and holds a Management Research Conference annually. Affiliated with the National Association of Counties.

Publishes Action Guide Manuals which emphasize guide-

lines for county engineering management and procedures for simplified engineering and technical analysis. Subjects include: organization-personnel purchasing; cost records; advanced road programs; county planning; planning county road systems; solid waste management; traffic operations; maintenance management; public support; safety improvements; soils and sub soil conditions, pavement; and bridge management; maintenance; rehabilitation; purchasing; bridge inspection; soil erosion and water pollution prevention; aerial photography; drainage; travel generation; and subsurface soils exploration. Works closely with federal departments, the Transportation Research Board, and state agencies.

Distributed directly.

county; government officials; construction; transportation; management;

NATIONAL ASSOCIATION OF GARAGE DOOR MANUFACTURERS

John H. Addinton, Executive Director

1300 Sumner Avenue

Cleveland, Ohio 44115-2851

(216) 241-7333

FAX: (216) 241-0105

Founded: 1968

Standards staff: 3 
Type of

organization

\section{standards}

Development

Scope

\section{standardization}

Activities

\section{Availability}

Formerly

Reywords
Trade Association

Standards Developer

Six active standards.

Two processed through ANSI.

Promotes the quality and safety of sectional overhead type doors.

Developed American National standard, A216.1-1977

(NAGDM 102-1976), Specifications for Sectional Overhead Type Doors. Standard includes performance criteria and test methods for acceptable safety, quality, and durability of sectional

overhead type doors intended for residential use and commercial or industrial use on garages, warehouses, service stations, and other places requiring doors generally used for vehicular traffic.

Distributed directly and through ANSI.

Midwest Garage Door Manufacturers Association (1972)

doors; overhead doors; buildings;

\section{NATIONAL ASSOCIATION OF GRAPHIC AND PRODUCT IDENTIFICATION MANUFACTURERS}

James A. Kinder, Executive Vice President

17300 Redhill Avenue

Suite 100

Irvine, California 92714

(714) 261-9588

FAX: (714) 261-2594

Founded: 1951 Standards Staff: 2

Trade Association

Standards Developer

Standards developer since 1969.

Nameplate Industry Standards and Practices.

Military Specifications for nameplates

Membership accounts for approximately two-thirds of the total business volume of the name plate manufacturing industry in the United states. The term "name plate" refers to any metal or plastic plate that has been etched, embossed, stamped, engraved, 
Standardization

Activities

Availability

Formerly

Keywords or imprinted and which is fastened to another object for purposes of identification, instruction, or decoration.

Standards represent a relatively small but highly significant portion of the association's activities. In 1969 published Metal Name Plate Industry Standards and Practices, which was updated in 1987 under the name of Name Plate Industry standards and practices. This book is the only set of standards in existence for the industry in the United states Among the subject areas covered are: nomenclature, finishes, fabrication tolerances, materials, fastening methods, inspection, reject procedure, delivery, and equipment preparation. Copies have been distributed throughout the industry and to customers of the industry in both private and public sectors for their information and use in writing specifications. The Book of standards Committee is responsible for compiling and coordinating changes.

Available to GPI members only.

National Association of Name Plate Manufacturers National Association of Metal Nameplate Manufactures (1968)

nameplates; industrial equipment; office products; household appliances ;

\section{NATIONAL ASSOCIATION OF HOSIERY MANUFACTURERS}

Type of

Organization

Standards

Designation

Scope

Standardization

Activities
Sid Smith, President and CEO

200 North Sharon Amity Road

Charlotte, North Carolina 28211

(704) 365-0913

FAX : (704) 362-2056

Founded: 1905

Standards Staff: 1

Trade Association

Standards Developer

Commercial Standards, CS prefix.

Composed of manufacturers who knit or otherwise process hosiery of any type. Develops standards for hosiery sizing, measurement, performance, and quality.

Active in technical research leading to standards concerning size systems and terminology for various types of hosiery. NAHM sizing standard is an industry standard using body measurements for the sizing of men's, women's, and children's knee-high and shorter hosiery. Developed a simple method for use 
in describing women's pantyhose in order to provide wearers with proper fitting garments. Instrumental in developing measurement standards.

Availability

Keywords
Distributed directly.

sizes; hosiery; clothing; consumer products;

\section{NATIONAL ASSOCIATION OF INDUSTRIAL AND OFFICE PROPERTIES}

Thomas J. Bisacquino, Executive Vice President

2201 Cooperative Way

3rd Floor

Herndon, Virginia 22071-3034

(703) $904-7100$

FAX : (703) 904-7942

Founded : 1967

Standards Staff: 1

Type of

Organization

Scope

Standardization

Activities

Formerly

Keywords
Trade Association

Works through other organizations to develop standards

The National Association of Industrial and Office Properties (NAIOP) is the trade association for developers, owners, and investors in industrial, office and related commercial real estate. Founded in 1967, NAIOP is comprised of 5000 members in 51 North American chapters and offers its members business and networking opportunities, education programs, research on trends and innovations and strong legislative representation.

Cooperates to develop and utilize standards in the areas of paved streets, utility systems for multiple users, setback or percentage coverage requirements, landscaping, offstreet parking, and architectural control.

National Association of Industrial and Office Parks

industrial parks; office parks; building; construction; facilities management;

\section{NATIONAL ASSOCIATION OF JEWELRY APPRAISERS}

James V. Jolliff, Executive Director

Post Office Box 6558

Annapolis, Maryland 21401

(301) 261-8270

Founded: 1981

Standards staff: 3 
Type of

organization

standards

Development

Certification

scope

standardization

Activities

Availability

Keywords
Professional Association

Standards Developer

Developer of Jewelry Appraisal Standards since 1981

600 members participating in standards activities

related to minimum criteria in writing narrative appraisal reports.

Certification of qualified and accredited member appraisers. Correspondence course and testing of Certified Master Appraisal credential.

A professional association exclusively devoted to the jewelry appraisal profession. The association functions on a national and international basis. Works to disseminate information through educational programs, improve methods of appraisal valuation, and share opinions on areas of common interest.

The standardization activities of the association are directed toward user-defined requirements for the industry and those who require a professional opinion as to value. They are provided to members only.

Major activities include educational programs, Appraisal Forms, Related Work Sheets, and Terminology. New areas of standards which are applicable to the industry are being developed and reviewed.

Distributed directly to members only.

jewelry appraisers; gems; diamonds; gemology; consumer products; gemological instruments and equipment;

NATIONAL ASSOCIATION OF MANUFACTURING OPTICIANS

Type of

organization

scope

\author{
William J. Flannery III, President \\ R. R. 2, Box 35 Q \\ Rockwall, Texas 75087 \\ (214) 771-8848 \\ FAX : (214) 722-8484 \\ Founded: 1975 \\ Standards staff: 1 \\ Trade Association \\ Standards Developer \\ A nonprofit trade association of individuals and businesses en- \\ gaged in the manufacture and production of prescription eyewear or \\ related ophthalmic goods and services.
}


standardization Activities

Availability

Reywords
Dedicated to standards development through regulation, legislation, and education of the public. Cooperates with ANSI, the Total Ophthalmic Community Conference, ISO. Developed a bar code for optical products.

Distributed directly.

ophthalmology; optician; optics; ophthalmic products;

\section{NATIONAL ASSOCIATION OF PHOTOGRAPHIC MANUFACTURERS}

John Gignac, Director - National Standards

Eduard R. Scherrer, Director - International Standards

550 Mamaroneck Avenue

Suite 307

Harrison, New York 10528-1612

(914) 698-7603 FAX: (914) 698-7609

e-mail: natlstds@aol.com

Founded: 1946 Standards Staff: 1 full-time

3 part-time

Type of

Organization

\section{Standards}

Development

\section{Standards}

Designation

Secretariats
Trade Association

ANSI accredited Standards Developer

526 members active in standards development.

189 active international standards.

285 ANSI approved standards.

ANSI accredited organization.

ASC/PH prefix.

ASC/IT prefix.

ANSI/NAPM IT.

NAPM/IT 1, Photographic Films, Plates, and Papers

NAPM/IT 2, Image Evaluation

NAPM/IT 3, Photographic Equipment

NAPM/IT 4, Photographic Processing

NAPM/IT 7, Instructional Audiovisual systems standards

NAPM/IT 9, Physical Properties and Permanence of Imaging

Materials

NAPM/IT 10, Electronic Still Picture Imaging

NAPM/TC 11, Optics and Optical Instruments

NAPM/TC 12, Imaging Materials Recyclability

ISO/TC 42, Photography

U.S. Technical Advisory Group ISO/TC 42

U.S. Technical Advisory Group ISO/TC 172 
An association for manufacturers of image technology products. Promotes and encourages a wider understanding and appreciation of image technology, and a greater use of image technology products worldwide.

Standardization

Activities
Availability

Keywords
Promotes standardization of all photographic products, and methods of testing product performance. Ensures interchangeability and compatibility of photographic components and materials.

NAPM is an ANSI Accredited Standards Development organization under the ANSI Organization Method. It provides the secretariat support for nine Technical Committees involved in the development of National standards primarily in the field of imaging through photo-chemical, electronic and hybrid technologies. This includes all related system aspects of imaging and media and includes interfacing, transcoding and accompanying signals.

NAPM also acts as the secretariat for the International Organization for standardization (ISO) Technical Committee 42 on Photography. In addition, NAPM sponsors the United states Technical Advisory Groups (TAGs) responsible for developing the United states national body positions for input to ISO/TC 42 and ISO/TC 172 on optics and optical Instruments.

The overall standards program is managed by the NAPM standards Advisory Committee (SAC) which reports directly to the NAPM Board of Directors.

International activities include developing international photographic standards under Iso procedures, and maintaining close liaison with other international standards developing organizations in allied fields. Promotes participation in the activities of the International Electrotechnical Commission (IEC) through NAPM's domestic and international standards committee secretariats.

Draft standards distributed directly. Published standards distributed through ANSI.

image technology; photography; photographic products; photographic optics; $x$-ray; film; photographic accessories; electronic imaging; 


\section{Type of}

organization

Standards

Development

Standards

Designation

scope

Standardization

Activities

Availability

Keywords
Merritt B. Chastain, Jr., Managing Director

Commercial National Bank Building

333 Texas street

Suite 717

Shreveport, Louisiana 71101-3666

(318) 227-2769

FAX: (318) 222-0482

Founded: 1965

Standards staff: 8

Trade Association

Standards Developer

Standards developer since 1965

One hundred twenty companies participate in standards

activities; continuously reviewed and revised.

None processed through ANSI.

Draft standards available for review by members.

NAPCA Bulletin.

The trade association for the plant pipe coating application industry. Comprised of companies engaged in application of protective coatings to steel pipe in permanent plants and those engaged in the manufacture or sale of materials, supplies, equipment, or services, and those utilizing coating products. Promotes the general welfare of the industry, stimulates the use of coating and related materials, standardizes and improves specifications and materials, aids consumers and manufacturers in their coating material research, cooperates with other industries and organizations, and disseminates information to its members, its customers and the public.

Develops and revises pipe coating application specifications, standards, and suggested procedures. Publishes Pocket Edition of National Association of Pipe Coating Applicators Specifications and Plant Coating Guide which contains all current and revised specifications. Most recent revisions completed in 1994 .

Distributed directly.

pipe coating; corrosion protection; insulation; coating; construction; 


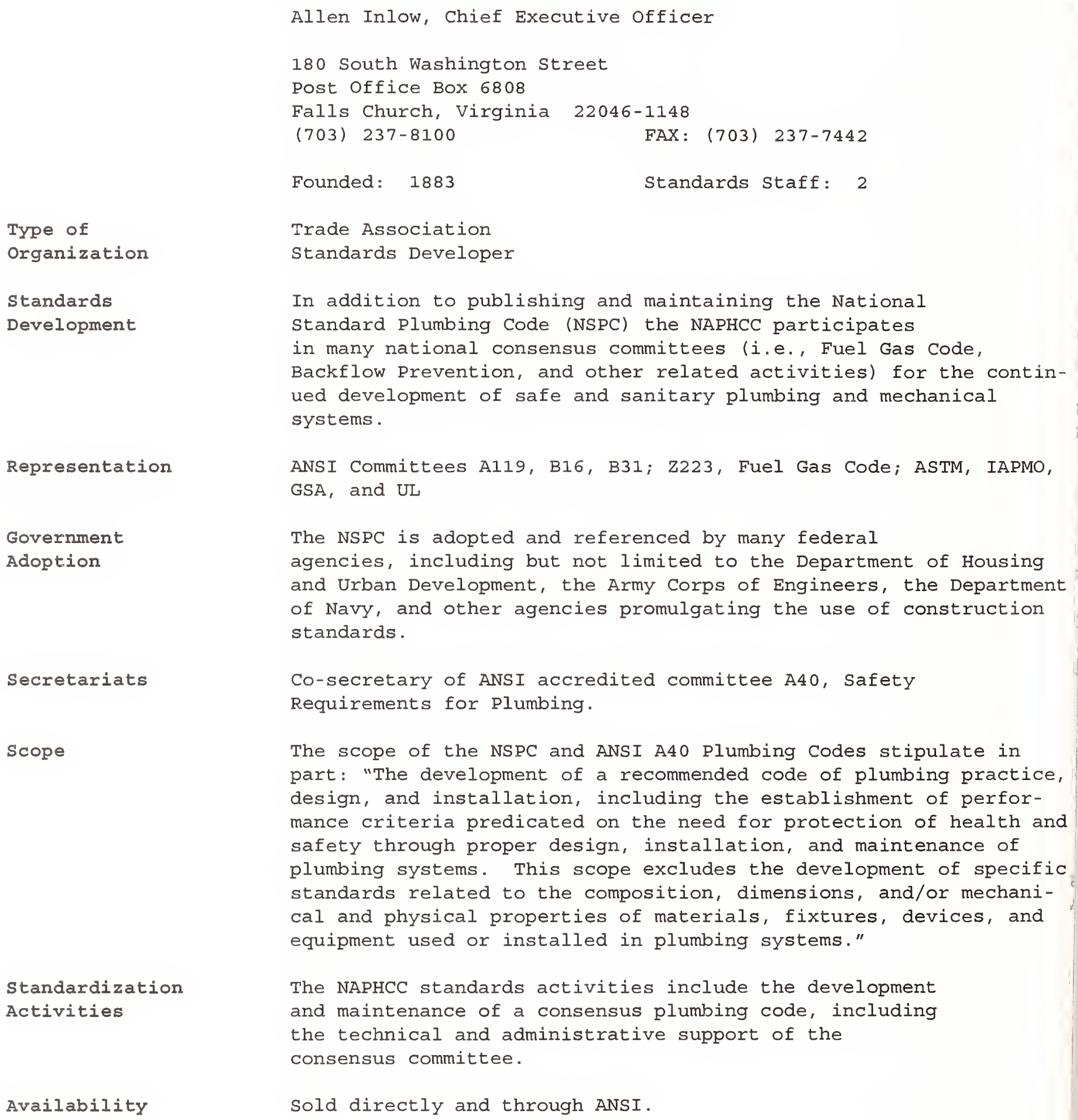

The scope of the NSPC and ANSI A40 Plumbing Codes stipulate in part: "The development of a recommended code of plumbing practice, design, and installation, including the establishment of performance criteria predicated on the need for protection of health and safety through proper design, installation, and maintenance of plumbing systems. This scope excludes the development of specific standards related to the composition, dimensions, and/or mechanical and physical properties of materials, fixtures, devices, and equipment used or installed in plumbing systems."

The NAPHCC standards activities include the development and maintenance of a consensus plumbing code, including the technical and administrative support of the consensus committee.

sold directly and through ANSI. 
NATIONAL ASSOCIATION OF PUNCH MANUFACTURERS

Alan M. Hamilton, Executive Secretary

7402 Chestnut Ridge Road

Lockport, New York 14094

(716) 433-2917

FAX: (716) 433-2917

Founded: 1963

Standards staff: 1

Type of

Organization

standards

Development

\section{Standards}

Designation

Certification

Scope

standardization Activities
Trade Association

Standards Developer

Started to develop standards in 1963.

22 participating members.

31 standards, 18 inch-based and 13 metric.

Al1 are processed through ANSI.

Draft standards are available through ASME and ANSI.

ANSI B94.X.

None.

Devoted to standardization of all punches, dies, and retainers used in custom made dies by various companies for the stamping industry. Piercing components are chosen for standardization and standards developed, then are recommended to American society of Mechanical Engineers International for review, approval and recommendation to American National standards Institute. ANSI piercing components standards are used by North American die building and stamping industries.

Piercing components for custom made stamping dies are chosen for standardization. The NAPM standards Committee then researches common usage and determines the best range of sizes and tolerances to fit the users' requirements. These standard recommendations are presented to B-94 of ASME International for circulation to a wide range of makers and users. There are 31 standards in the inch and metric systems in use for present day usage. These standards are available to Iso for international usage. 
Availability

Keywords

NATIONAL ASSOCIATION OF PURCHASING MANAGEMENT

Available through ANSI.

punches; tools; die components;

\author{
Type of \\ Organization \\ scope \\ Standardization \\ Activities
}

Formerly

Reywords

NATIONAL ASSOCIATION OF RELAY MANUFACTURERS

Type of

Organization ment concepts.

(414) $351-4548$

Founded: 1947

Trade Association

Standards Developer

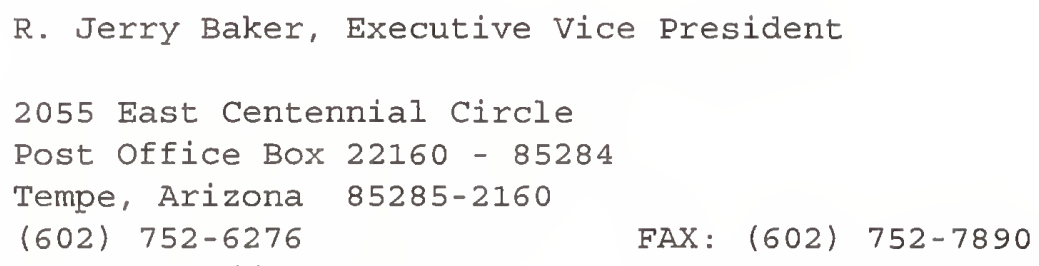

WWW : http://WwW. NAPM.org

Founded: 1915

Educational and Research Association

works through other organizations to develop standards

Provides national and international leadership in purchasing and materials management research and education. Provides opportunities for expansion of professional skill and knowledge. Encourages public understanding of the purchasing and materials manage-

Promulgates standards through company standardization programs. Sponsors educational programs which are related to the broad field of standardization and simplification. In an effort to further advance sound principles of purchasing and to elevate the purchasing profession.

National Association of Purchasing Agents (1968)

purchasing; materials management; business;

D.E. Dangott, Executive Director

9459 N. Broadmoor Road Milwaukee, Wisconsin 53217

FAX: (414) 351-4548

Standards Staff: 2 
Promotes the standardization of terminology and test procedures in the manufacture and uses of relays. Annually sponsors a National Relay Conference to provide engineers and specialists concerned with relays the opportunity to present results of their technical investigations to representatives of prominent relay manufacturers, users, and academicians.

Standardization Activities

Availability

Keywords
Maintains standards committees which coordinate member activities with relay users and Government agencies in establishing specifications for relays. Cooperates with Electronic Industries Association and others to write standards for reed switches, solid state relays, and all types of electromechanical and hybrid relays. Develops other specifications for low carbon and silicon steels, and EMI iron for use in magnetic circuits for relays. Publishes Engineers Relay Handbook which contains specifications relating to terminology and test procedures 5th edition 1996. It is an all-encompassing engineering reference source, covering all relays from electromechanical to hybrid and solid state. Also publishes a booklet, Definitions of Relay Terms. Annually publishes technical proceedings.

Distributed directly.

relays; electrical equipment;

\section{NATIONAL ASSOCIATION OF ROCKETRY}

James P. Miller, President

1311 Edgewood Drive

Altoona, Wisconsin 54720

(715) 834-8074

Founded: $1958 \quad$ Standards Staff: 4

Type of

Organization

Standards

Development

Government

Adoption

Certification
Scientific society

Standards Developer

Standards developer since 1958.

10 manufacturers participate in standards activities.

2 active standards.

48 state governments use NAR Safety Certification as a prerequisite for sale.

Certifies model rocket motors for safety prior to their sale in 48 states. Certification is based upon the reliability of the motors, casing temperatures, and the total impulse. Contest certifies model rocket motors prior to their use in Association sanctioned contests. 
Scope

Standardization

Activities

Availability

Formerly

Keywords
Recertifies model rocket motors every third year. Established a random sampling program to spot check motors for sale to consumers on hobby shop shelves. Maintains records of motor failures filed by its members, these records are provided to the manufacturers as input for product correction and development.

A national hobby service organization for model rocketeers. Provides a monthly magazine, technical materials, liability insurance, and education programs for its members. Sanctions local clubs and local contests. Homologates national model rocket flight records. Serves as the U.S. Representative to the FAI CIAM, Subcommittee on space Models where it interacts internationally with other hobby organizations. Chairs the NFPA Committee on Pyrotechnics and works closely with the HIA to monitor state and national hobby legislation.

Establishes standards of performance, reliability, and safety which are the basis for the NAR certification program.

Distributed directly.

Model Missiles, Inc. (1958)

pyrotechnics; model rockets; aeromodeling; recreation; space models;

\section{STATE TEXTBOOK ADMINISTRATORS}

Linda Dierstein, President

Indiana Department of Education

Textbook Adoptions

State House, Room 229

Indianapolis, Indiana 46204
(317) 232-9127
FAX: (317) 232-9121

Professional society

Standards Developer

NASTA prefix.

Standards

Designation

Scope
Textbook/instructional materials directors of state education agencies responsible for the purchase and distribution of textbooks for schools. 
Standardization Activities

Availability

Formerly

Keywords
Works with an Advisory Committee which develops specifications for hard cover textbooks and non-print materials. specifications cover margins, uniform labeling, paper, binding, and stitching. Cooperates with BMI (Book Manufacturer's Institute) and AAP (Association of American Publishers) to develop specifications. Publishes Manufacturing standards and Specifications for Textbooks developed by a commission comprised of NASTA, BMI, and AAP.

Distributed directly.

National Association of State Text Book Directors (25 years ago) textbooks; book publishing; education;

\section{NATIONAL ASSOCIATION OF STORE FIXTURE MANUFACTURERS}

Klein Merriman, Executive Director

1776 N. Pine Island Road

Suite 102

Plantation, Florida 33322

(954) 424-1443

FAX: (954) 473-8268

Founded: 1956

Standards Staff: 3

Type of

Organization

standards

Development

scope

Standardization

Activities

Availability

Keywords
Trade Association

Standards Developer

Develops specifications for the manufacture of store fixtures.

Represents over 500 fixture manufacturers in the United States, Canada and Mexico. The mission of NASFM is to raise the professional, educational and ethical standards of the store fixture manufacturing industry and to promote the value of members' products and services to their customers.

The association publication "Specifications for the Manufacture of Store Fixtures" is periodically reviewed, updated and republished by the association.

Distributed directly.

store fixtures; fixtures; retail; displays; merchandising; 
Elliott McEntee, President and CEO

607 Herndon Parkway

Suite 200

Herndon, Virginia 22070

(703) 742-9190

FAX: (703) 787-0996

Founded: $1974 \quad$ Standards Staff: 3

Trade Association

Standards Developer

Standards developer since 1974

A national trade association involved in developing payments standards for automated clearing house ( $\mathrm{ACH}$ ) transactions. In 1994, the ACH Network processed more than 3 billion transactions for applications such as direct deposit, direct payment preauthorized debits), corporate cash concentration, corporate trade payments, and financial electronic data interchange (EDI), thirty-eight member $\mathrm{ACH}$ Associations representing over 14000 financial institutions. NACHA sponsors the Bankers EDI Council, Bill Payment Council, Cross-Border Council, Electronic Check Council, and the Electronic Benefits Transfer Council.

Involved in developing standards for electronic

transfers of funds and information. Develops and maintains rules governing the exchange of ACH transactions. Also, Councils develop issue specific rules, guidelines, and standards for financial EDI, electronic bill payment applications, cross-border ACH payments, electronic check truncation and clearing, and electronic benefits transfers.

Distributed directly.

financial; direct deposit; direct payment; preauthorized debits; EDI; electronic bill payment; electronic checks; cross-border payments;

Larry M. Eils, Director, Public Health and Safety

20 North Wacker Drive

suite 3500

Chicago, Illinois 60606

(312) $346-0370$

FAX: (312) 704-4140 
Type of

Organization

standards

Development

standards

Designation

Government

Adoption

Certification

scope

Standardization

Activities

Availability
Trade Association

Standards Developer

Standards developer since 1959.

Three standards.

NAMA Standard for the Sanitary Design and Construction

of Food and Beverage Vending Machines (as amended, April, 1990).

NAMA Vending Industry Data Transfer standard (as

amended, April, 1994).

NAMA International Multi-Drop Bus Interface Standard

(as amended August, 1994).

Adopted by many states, counties and municipalities

and, by reference, the Army, Air Force, and Navy. Results of evaluation activity are recognized nationwide.

Evaluation and testing are conducted by retained consultants. Reevaluation is conducted annually.

The national association of the vending and contract food service industry. Membership includes national/regional/local operating companies, machine manufacturers, distributors, and product suppliers. Services include legislation, government relations, education, conventions, state affiliate organizations, public relations, publications, and public safety.

Maintains a 24-member Automatic Merchandising Health

Industry Council comprised of representatives from national public health associations, state and local regulatory officials, federal regulatory and military agencies, vending operators, machine manufacturers and suppliers. Recommends to NAMA all administrative policies and procedures and maintains the Construction standard used in the machine evaluation program. Works with Underwriters Laboratories on UL standards 541 and 751.

Maintains a Vending Technology Standards Committee comprised of software developers for vending, manufacturers of control boards, coin mechanisms, bill validators, card readers and vending machines and other suppliers of electronic components to the industry. Recommends to NAMA what changes need to be made to keep the two electronic standards current.

Distributed directly. 
NATIONAL BARK AND SOIL PRODUCERS ASSOCIATION

Type of

Organization

standards

Development

Scope

standardization

Activities

Availability

Formerly

Keywords
Robert C. LaGasse, Executive Director

10210 Leatherleaf Ct.

Manassas, Virginia 22111-4245

(703) 257-0111

FAX: (703) 257-0213

Founded: 1971

Standards Staff: 1

Trade Association

Standards Developer

Standards developer since $1972^{\circ}$.

Represents producers of bark and soil products in the United States and Canada. Disseminates information about the use of products to horticulture firms, garden shops, and the public.

The industry forum for development of bark and soil

product standards; works with other organizations, such as the National Conference on Weights and Measures to develop standards. Has defined ten product categories. Grade standards serve as guidelines for producers and are used on product bags as an indication of quality.

Distributed directly.

National Bark Producers Association

bark; mulch; soil; agriculture; compost;

NATIONAI BOARD OF BOILER AND PRESSURE VESSEL INSPECTORS

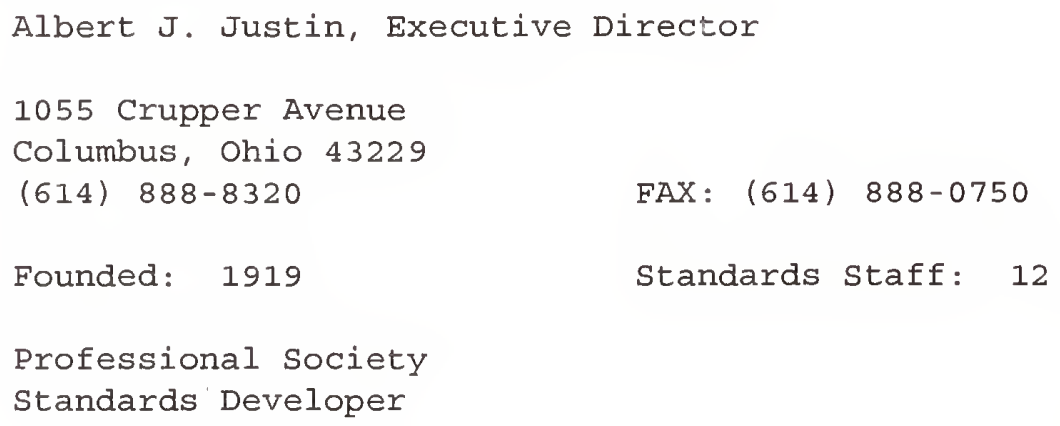




\section{standards \\ Designation}

\section{Certification}

secretariat

standardization Activities

Availability

Keywords
National Board Inspection Code, (an ANSI Standard); National Board Boiler Blowoff Equipment; Relieving Capacities of Safety Valves and Relief Valves; Model

Boiler and Pressure Vessel Laws.

States, municipalities, and Canadian provinces that have boiler and pressure vessel laws recognize the National Board inspector's commission and National Board stamping of boilers and pressure vessels as meeting their safety law requirements for new construction. Transfer of such objects between states is facilitated by National Board stamping. Relieving capacities of safety valves and pressure relief valves as certified by the National Board is used by various state, municipal, and provincial jurisdictions to insure adequate volumetric relief of the pressurized medium in event of runaway conditions.

The following Iso Committees: TC 185 Safety Devices for Protection Against Excessive Pressure, TC 11 Boilers and Pressure Vessels, and the National Board Inspection Code (NBIC)

The National Board of Boiler and Pressure Vessel Inspectors represents the agencies empowered to assure adherence to the ASME Boiler and Pressure Vessel Construction Code and the NBIC. The National Board of Boiler and Pressure Vessel Inspectors' purpose is to promote safety through uniformity in the construction, installation, repair, maintenance, and inspection of boilers and pressure vessels.

Promotes in the following areas of standardization: (1) boiler and pressure vessel law enforcement; (2) uniform boiler laws and rules throughout the jurisdiction of its members; (3) uniform qualifications for boiler and pressure vessel inspectors; (4) uniform stamping of boilers and pressure vessels that are inspected during construction by such boiler and pressure inspectors who hold valid National Board Commissions; and (5) uniform relieving capacity ratings of safety valves and pressure relief valves for boiler and unfired pressure vessel service.

Distributed directly.

boilers; pressure vessels; safety valves; 


\author{
Type of \\ Organization \\ standards \\ Development \\ scope \\ Standardization \\ Activities
}

Availability

Keywords

NATIONAL CARGO BUREAU

Type of

Organization

Certification
Kurt M. Swenson, Secretary

c/o Rock of Ages Corporation

369 North state street

Concord, $\mathrm{NH} 03301$

(603) 225-8397

FAX: (603) 225-4801

Founded: 1916

Standards Staff: 1

Trade Association

Standards Developer

Standards developer since 1916.

A national trade association of companies involved in the quarrying and manufacture of granite for architectural applications. They represent their members in national and international areas of interest.

Publishes Specifications for Architectural Granite annually. Specifications are reviewed and updated annually. Also provides listing of available types of granite from members classified by color, name, quarry location and quarrier. Also provides other assistance on architectural granite upon request.

Distributed directly.

granite; building materials; architecture; architectural granite; building granite;

Capt. James J. McNamara, President

30 Vesey Street

New York, New York 10007

(212) 571-5000

FAX: (212) 571-5005

Founded : 1952

Standards Staff: 8

Trade Association

Standards Developer

The bureau is authorized by the U.S. Coast Guard to certify the loading of bulk grain cargoes and to approve grain loading plans in accordance with current regulations. The Bureau is officially 
recognized by the Coast Guard and the Department of Labor as a cargo gear certification agency.

A nonprofit organization whose membership is comprised of persons prominently identified with steamship management or marine insurance underwriting organizations.

Dedicated to the safe loading, stowing, securing, and unloading of cargo and cargo containers on all vessels, and for the design, strength, safety, and suitability of cargo handling gear and cargo containers, including the security and integrity of containers.

Standardization Activities

Formerly

Keywords
Assists the U.S. Coast Guard in administering the provisions of the Dangerous Cargo Act and the applicable regulations in Title 46, of the Code of Federal Regulations, Shipping, with respect to inspection of vessels for suitability for loading dangerous cargo; examination of stowage of dangerous cargo; making recommendations as to towage requirements of dangerous cargo; and issuance of certificate of loading setting forth that the stowage of dangerous cargo is in accordance with the regulations.

Participates in activities of the International Maritime Organization (IMO) by being active on the IMO Maritime Safety Committee, the subcommittee on Containers and Cargos, and the Subcommittee on the Carriage of Dangerous Goods. This subcommittee revised the international regulations for the carriage of bulk grain.

Absorbed Bureau of Inspection of Board of Underwriters of New York; Board of Marine Underwriters of San Francisco (1952)

cargo handling; containerization; shipping; insurance; transportation;

\section{NATIONAL CERTIFIED PIPE WELDING BUREAU}

Jack Hansmann, Executive Secretary

1385 Piccard Drive

Rockville, Maryland 20850-4329

(301) 869-5800

FAX: (301) 990-9690

Founded: 1944

Standards Staff: 2

Type of

Organization
Trade Association

Works through other organizations to develop standards 
Representation

scope

Standardization

Activities

Keywords

NATIONAI CIVIC IEAGUE

Type of

Organization

scope

Standardization Activities
20 members represented on standards committees of organizations such as ASME, ANSI, and AWS.

A department of the Mechanical Contractors Association of America, Inc. Engages in research and educational work; supplies information and data on welding; creates a force of welders uniformly trained and qualified; and promotes, develops, and maintains the quality of welding in the piping industry.

Cooperates with other organizations to provide guidance and input for the standards development process. Works toward development of uniform procedure specifications for welding methods.

pipe; welding; manufacturing;

Christopher Gates, President

1445 Market street

Suite 300

Denver, Colorado 80202

(303) 571-4343

FAX: (303) 571-4404

Founded: 1894

Standards staff: 1

Research and Advocacy

Civic leaders, educators, public officials, civic organizations, libraries, and businesses interested in improving state and local government and techniques of citizen action. Serves as a clearinghouse for information on state constitution, city and county charters, legislative apportionment, fiscal procedures, among others.

Model laws devised, published, and distributed by this organization are intended to serve as standards and to stimulate uniformity in state, county, and city legislation. These include a model bond law, budget law, city charter (which provides the council-manager form of government), model county charter, election administration system, model real property tax collection law, registration system, model state constitution, and others. 
Formerly

Keywords
National Municipal League/Citizens Forum on Self-Government

model laws; government; officials;

NATIONAL CLAY PIPE INSTITUTE

Type of

Organization

Government Adoption

secretariats

scope
E. J. Sikora, Vice President

Post Office Box 759

253-80 Center street

Lake Geneva, Wisconsin 53147

(414) 248-9094

Founded: 1944

Standards Staff: 2

Trade Association

Standards developer by working through ASTM

Federal agencies involved directly and indirectly in construction activities have adopted ASTM standards for Vitrified clay Pipe and its installation.

ASTM Committee C-4.

An international trade association, representing the major U.S. manufacturers of Vitrified Clay Pipe, with Associate Members in several foreign countries. Renders engineering advisory services to design engineers, Government officials, and others. Conducts scientific research, national advertising, and public relations programs on behalf of the industry at various independent research laboratories and universities.

Publishes the Clay Pipe Engineering Manual for engineers, city and state officials, and architects. Also technical brochures of an educational nature relating to the use of Vitrified Clay Pipe in sanitary sewer systems.

Active in the American Society for Testing and

Materials. Assists in the development of federal specifications.

Sold directly.

National Clay Pipe Manufacturers (1961)

vitrified clay pipe; sewers; sanitation; construction; 


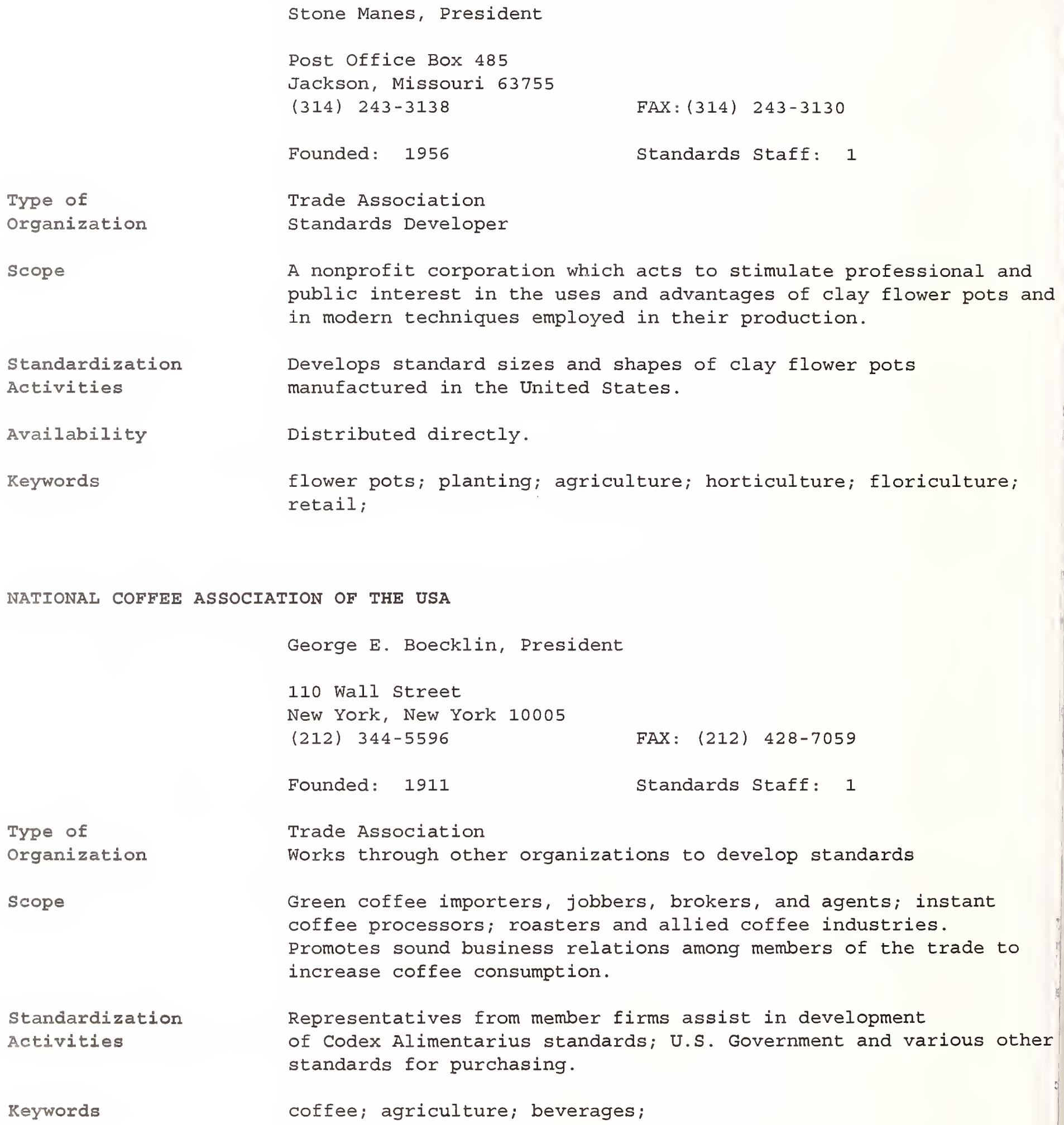


Glen R. Anderson, Executive Director

401 N. Michigan Avenue, 22nd Floor Chicago, Illinois 60611

(312) 321-6894

FAX: (312) 321-6869

Founded: 1962

Standards staff: 1

Type of

organization

Scope

Standardization

Activities

Availability

Keywords
Trade Association

Standards Developer

Manufacturers of continuously coated metal coil, other than metal plated coil. Fosters development of standard test methods, exchanges technical information, collects statistics, and promotes coated coil.

Maintains a Technical section which works to develop test methods and evaluate new processes. Activities include accelerated testing, physical testing, and standards development in the areas of color, laminate, aluminum, and steel. Supports ASTM, ANSI, and AISI in this work. Publishes a Technical Manual and Bulletins.

Distributed directly.

coil coating; metal coating; materials;

NATIONAL CONCRETE MASONRY ASSOCIATION

Mark B. Hogan, Vice President of Engineering

2302 Horse Pen Road

Herndon, Virginia 22071-3499

(703) 713-1900

FAX: (703) 713-1910

Founded: 1920

Standards Staff: 5

Type of

Organization

Representation
Trade Association

Works through other organizations to develop standards

All national model code organizations; ASTM committees and the standards committees of the Masonry Society, the American Concrete Institute and the American Society of Civil Engineers.

A nonprofit trade association representing concrete masonry manufacturers throughout the United States, Canada, and 21 other countries. Encourages development of the state-of-the-art and science of manufacturing concrete masonry; creates a standard of excellence in manufacturing; develops criteria for the proper use 
Standardization

Activities

Keywords

NATIONAL CONFERENCE OF STATES ON BUILDING CODES AND STANDARDS

Type of

Organization

Representation

Secretariat

Scope of concrete masonry products and concrete pavers and encourages such use; and facilitates the interchange of practical knowledge among its members and related industries and organizations.

Activities of the association are developed by the Technical Committees and are subject to approval by the Board of Directors. Maintains continuing liaison and participation in the standardization and specification activities of the major national code bodies in the United States, the American Society for Testing and Materials, the American Concrete Institute, American society of Civil Engineers, Building Seismic Safety Council, American Institute of Architects and the Construction Specifications Institute. Liaison and product specification assistance conducted on a regular basis with agencies of the federal government and design firms.

concrete masonry; building; construction;
505 Huntmar Park Drive

Suite 210

Herndon, Virginia 22070

(703) 437-0100

Founded: 1967

Professional society

Works through other organizations to develop standards

Delegates are governor-appointed representatives of the 50 states, the District of Columbia, and several territories. Members include state and local building officials, architects, engineers, developers, building contractors, manufacturers of industrialized/modular buildings and manufactured homes; and product manufacturers and suppliers.

Serves as the secretariat of the Industrialized Buildings Commission, the administrative arm of the Interstate Compact on Industrialized/Modular Buildings.

Promotes intergovernmental reform in the field of building codes and standards and development, acceptance, and use of innovative building materials and technology. Founded by a number of state governors interested in better coordination of state building code 


\section{Standardization} Activities

Reywords and public safety activities. Party to an Executive Branch Agreement with the National Governors' Association and a Memorandum of Understanding with the National Institute of Standards and Technology.

Responsible for the NCSBCS/ANSI A225.1-1994 standard on Manufactured Home Installation, which may be obtained directly from the association. Through its delegates, participates in the development and maintenance of building codes and standards at the state level. Monitors the design and construction of manufactured housing nationwide under a contract with the U.S. Department of Housing and Urban Development. Works under a grant from the U.S. Department of Justice on accessibility issues. Provides state government with a voice in other standards writing organizations. Publishes the two-volume (state and city) Directory of Building Codes and Standards, the Introduction to Building Codes, and other reference works, all of which are available directly from the association.

government; buildings; construction; manufactured homes; energy; safety; indoor air quality; accessibility;

\section{NATIONAL COORDINATING COUNCIL ON EMERGENCY MANAGEMENT}

Elizabeth B. Armstrong, CAE, Executive Director

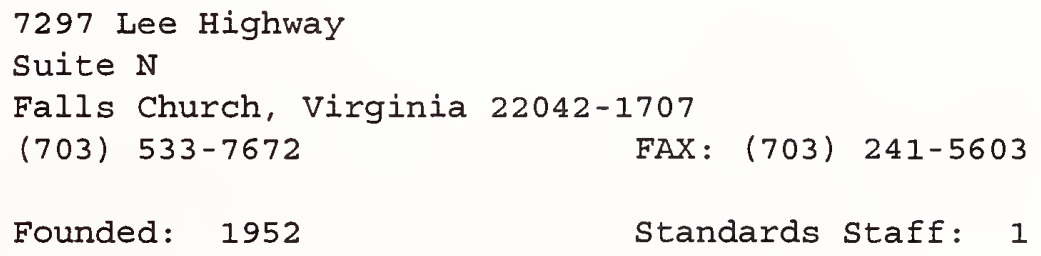

Type of

Organization

Scope

Standardization

Activities
Professional Society

Standards Developer

Membership consists of 1700 emergency management professionals from local, state and federal government; private industry; and the military.

Established a voluntary certification program in 1993; development of the professional standards upon which the certification requirements are based was funded by the Federal Emergency Management Agency. The Certified Emergency Manager (CEM) designation is awarded to candidates who satisfy requirements in the areas of experience, references, education, training, professional contributions, and scenario essay response. 

Availability
Directly.
Formerly
United States Civil Defense Council
Keywords
emergency; disaster; preparedness; public safety;

NATIONAL CORRUGATED STEEL PIPE ASSOCIATION

Joseph B. Morris, Executive Vice President

1255 Twenty-third street, NW

Suite 850

Washington, DC 20037

(202) 452-1700

FAX: (202) 833-3636

Founded: 1955 Standards Staff: 1

Type of

Organization

standards

Development

Standards

Designation

Scope

Standardization

Activities

Availability
Trade Association

Standards Developer

Standards developer since 1956.

74 member companies participating in standards activities. 5 active standards. None processed through ANSI.

CSP prefix.

A national trade association that represents corrugated steel pipe fabricators, steel suppliers, and manufacturers of related products. Improves and expands the use of corrugated steel pipe and plate for culverts, sewers, bridges, subdrains, and other drainage facilities.

Maintains an active Technical Advisory Committee which develops CSP standards along with participating in and monitoring the work of other technical bodies such as ASTM, AASHTO, and AISI. Engineering organizations, specifying agencies, and users of corrugated steel pipe use standards. Widespread activities of the association make it possible for county, state, federal, city, consulting and other engineers, as well as construction personnel, to become thoroughly acquainted with design, use, installation, and acceptance of corrugated steel pipe throughout the United states.

Distributed directly. 


\section{NATIONAL COTTON COUNCIL OF AMERICA}

\section{Type of \\ Organization \\ Representation}

Secretariats

Scope

\section{Standardization Activities}

Phillip C. Burnett, Executive Vice President

P.O. Box 12285

Memphis, Tennessee 38182

(901) $274-9030$

FAX: (901) 725-0510

Founded: 1938

Standards Staff: 4

Trade Association

Works through other organizations to develop standards

Members provide input or serve on various committees of standards developers, such as ASTM, ISO, AATCC, ACGIH, OSHA, CAL/OSHA, CPSC, EPA, and ANSI.

Joint Cotton Industry Bale Packaging Committee (JCIBPC). NCCA is one sponsor of the International cotton Calibrations standards Committee.

The National cotton Council is the central organization of the United states cotton industry representing growers, ginners, warehousemen, merchants, cooperatives, manufacturers, and cottonseed crushers. It serves its members through programs of technical services, foreign operations, communications services, economic services, and legislation.

Works with industry and government agencies in developing needed fiber/textile test methods, product standards, and safety/health environmental standards affecting the cotton industry. Develops specifications to improve the quality and protection of the American cotton bale and to improve its appearance and saleability in domestic and foreign markets. Sets cotton bale standards to guide handlers and processors in evaluating and communicating bale conditions. Through the JCIBPC, develops specifications for acceptable cotton bale packaging materials. These are adopted by reference by the commodity Credit Corporation as a requirement for CCC loan eligibility.

cotton; bale packaging; fiber testing; cottonseed; textiles; safety environment; agriculture; 
Lynn A. Jones, Executive Vice President

P.O. Box 172267

Memphis, Tennessee 38187-2267

(901) 682-0800 FAX: (901) 682-2856

Founded: 1897 Standards staff: 2

Type of

Organization

Standards

Development

Scope

Standardization

Activities

Availability

Keywords
Trade Association

Standards Developer
232 members actively participate in the use of NCPA

Trading Rules.

Virtually all contracts between members and between members and non-members are subject to the provisions of the Trading Rules of the National Cottonseed Products Association.

Trading Rules provide for handling, sampling, and analysis of cottonseed and cottonseed products and for handling normal variation in quality and in actual delivery weights. Trading rules, such as those for cottonseed oil trading rules, relate final compensation to the yield or out-turn of refined oil from the crude oil.

Distributed directly.

cottonseed; edible oil; food; agriculture; vegetable oil;

NATIONAL COUNCIL FOR PRESCRIPTION DRUG PROGRAMS

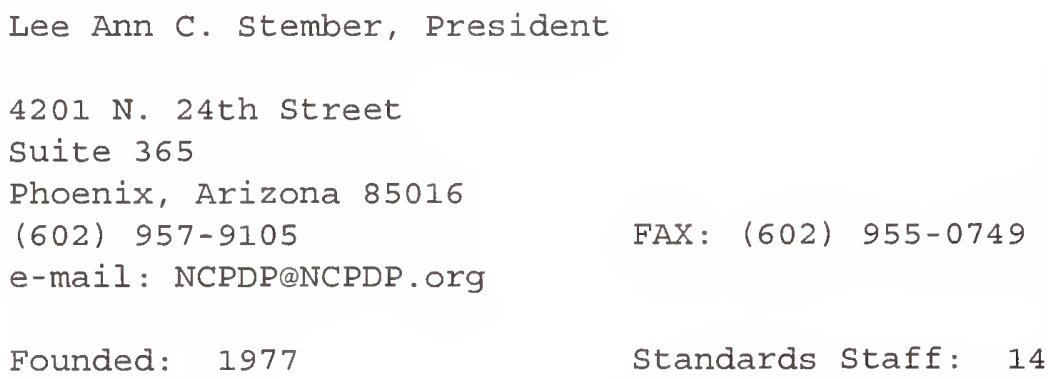

Type of

Organization

Standards

Development
Professional and Trade Association

standards Developer

NCPDP first started developing standards in 1977 with the development of the Universal Claim Form. NCPDP has approximately 1100 members of which approximately 250 actively participate in the 11 work groups that establish the standards. 
standards

Designation

Government

Adoption

Certification

scope

Standardization

Activities

Availability

Keywords
NCPDP has seven active standards and all draft standards are available for review by contacting NCPDP. NCPDP is in the process of applying for ANSI accreditation.

By name and version/release of the standard.

NCPDP standards have successfully been adopted through 37 state Medicaid agencies and continues to work with others in their implementation.

None

NCPDP creates and promotes prescription data interchange and processing standards to the pharmacy services sector of the health care industry, and provides a continuing source of accurate and reliable information that supports the diverse needs of its 1100 members.

NCPDP's Telecommunication standard, Version 3.2 is widely used in the industry and is expected to process over 1 billion claims in 1995. Other standards cover billing format, drug utilization review, magnetic stripe format, x12 implementation, and related topics.

Distributed directly.

pharmaceutical claims processing; EDI; member enrollment; product identification; standard billing;

\section{NATIONAI COUNCII ON RADIATION PROTECTION AND MEASUREMENTS}

W. Roger Ney, Executive Director

7910 Woodmont Avenue

Suite 800

Bethesda, Maryland 20814

(301) 657-2652

FAX: (301) 907-8768

Founded: 1964

Standards staff: 3

Type of

Organization

standards

Development

scope
Scientific society

Standards Developer

Recommendations developed since 1928.

75 published reports which contain recommendations.

A nonprofit corporation which seeks to promulgate information and recommendations based on leading scientific judgment on matters of radiation protection and measurement and to foster cooperation among organizations concerned with these matters. 
Standardization

Activities

Availability

Formerly

Keywords
Collects, analyzes, develops, and disseminates in the public interest information and recommendations about protection against radiation and radiation measurements, quantities, and units, particularly those concerned with radiation protection. Provides a means by which organizations concerned with scientific and related aspects of radiation protection and of radiation quantities, units, and measurements may cooperate for effective utilization of their combined resources. Develops basic concepts about radiation quantities, units, and measurements about the application of these concepts and about radiation protection. Cooperates with the International Commission on Radiological Protection, the International Commission on Radiation Units and Measurements, and other national and international organizations, governmental and private.

Maintains about 50 scientific Committees to draft proposed recommendations.

Distributed directly.

National Committee on Radiation Protection and Measurement Advisory Committee on $\mathrm{X}$-Ray and Radium Protection

radiation protection; radiation measurement; environmental; safety;

NATIONAL DIMENSION MANUFACTURERS ASSOCIATION

Steven V. Lawser, Executive Director

1000 Johnson Ferry Road

Suite A-130

Marietta, Georgia 30068

(770) $565-6660$

Founded: 1929

Standards staff: 1

Type of

Organization

standards

Development

Standards

Designation
Trade Association

standards Developer

Standards Developer since 1929.

All members participate in standards development.

NDMA . 
Objectives are to establish and maintain the rules and standards

for the industry; conduct and stimulate trade promotion activities for the industry; and to hold educational plant tours and meetings that promote exchange of manufacturing techniques and ideas in the industry among its members.

\section{standardization} Activities

Formerly

Availability

Keywords
Cooperates with all lumber, furniture, cabinet and related wood using manufacturers/associations in bringing about standardization programs on grading rules for wood component products. Publishes the "NDMA Rules and Specifications for Dimension and Woodwork." These Rules are recognized by the National Hardwood Lumber Association, and are considered international in scope.

Hardwood Dimension Manufacturers Association

Sold directly.

wood components; trim; stairs; furniture; cabinetry; woodwork; moulding ;

\section{NATIONAL ELECTRICAL CONTRACTORS ASSOCIATION}

H. Brooke Stauffer, Director, Codes and Standards

3 Bethesda Metro Center

Suite 110

Bethesda, Maryland 20814

(301) 657-3110

FAX: (301) 215-4500

Founded: 1901

Trade Association

Standards developer and works through other

organizations to develop standards

NECA participates in ANSI, NFPA and ASTM standards activities.

NECA published its original standard of Installation in 1962. NECA is currently applying for ANSI accreditation to develop a series of recommended installation practices for electrical products and systems.

NECA 1.

\section{Standards}

Designation

Government Adoption
NECA's Standard of Installation is not adopted for regulatory use by federal agencies, or state and local governments. 
Certification

Scope

Standardization

Activities

Availability

Keywords

NATIONAL ELECTRICAL MANUFACTURERS ASSOCIATION
NECA does not sponsor certification or accreditation programs.

A nationwide trade association representing the electrical contracting industry. Provides management services and labor relations programs. Sponsors research and educational programs; compiles statistics; conducts seminars.

Sets basic standards for electrical equipment and materials and methods of their installation. The NECA Technical Service maintains competent representation on interindustry and other standards agencies. NECA's standard of Installation defines good workmanship and has been an authoritative guide to determine the "neat and workmanlike manner" requirements of the National Electrical Code.

Prevents and reduces accidents by providing continuing information to its members on OSHA requirements.

Sold directly.

electrical products; safety; installation;

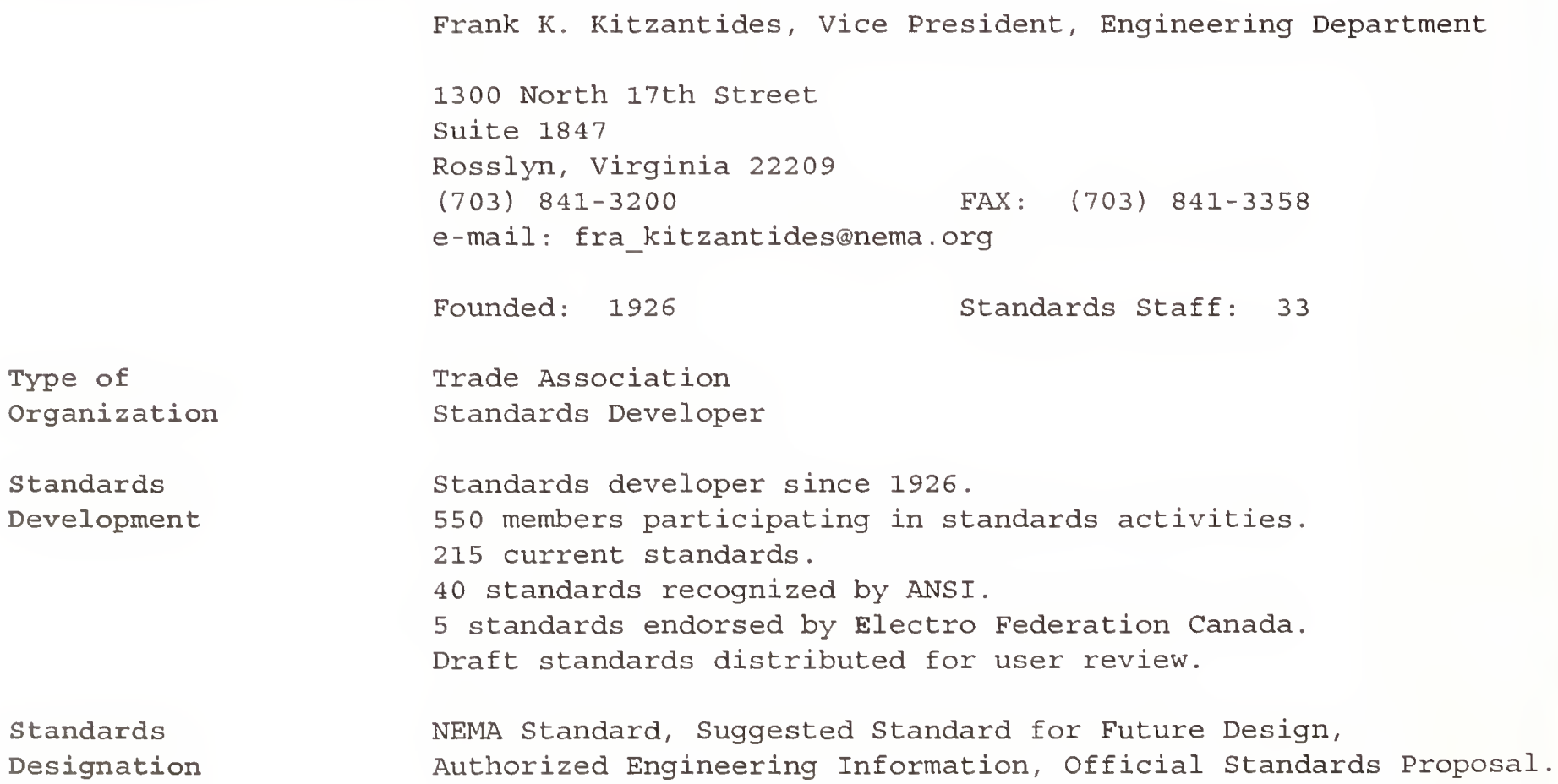

Type of

Organization

Standards

Development

Standards

Designation 
41 standards have been adopted by DoD.

24 ANSI committees dealing with electrical equipment ISO/TC $184 / \mathrm{SC} 5 ; \mathrm{SC} 2 \mathrm{~J} ; \mathrm{SC} / 15 \mathrm{C} ; \mathrm{SC} 22 \mathrm{G} ; \mathrm{TC} 37 ; \mathrm{SC} 37 \mathrm{~B} ; \mathrm{TC} 72$.

A trade association of manufacturers of equipment and apparatus used for the generation, transmission, distribution, and utilization of electric power. Membership comprises 630 electrical manufacturing companies in the United states. Membership is limited to corporations, firms, and individuals in the united States, Canada, and Mexico engaged in the manufacture or promotion of products included within 70 NEMA product subdivisions. Products include transformers, wire and cable, switchgear, industrial control and systems, lighting, building equipment, diagnostic imaging and therapy systems products and industrial automation equipment.

Standards are designed and written to eliminate misunderstandings between manufacturers and users of electrical products and to provide for safety in the application of these products. Involves all interested parties in standards development and review. Cooperates with organizations such as the American Society for Testing and Materials, National Fire Protection Association, Underwriters Laboratories, the Institute of Electrical and Electronics Engineers, and others. Also cooperates with federal agencies.

Supports ANSI and has representation on standards committees and sponsors several of them. Also represented on ANSI standards Boards and the Organizational Member Council. Participates in the International Electrotechnical Commission (IEC), the IEC system for Conformity Testing to standards for safety of Electrical Equipment (IECEE), and in the International Organization for standardization (ISO).

NEMA also participates in the development of safety standards affecting electrical equipment. Cooperates with other branches of the industry in an effort to secure acceptance throughout the country of the National Electrical Code and the National Electrical Safety Code. Members also cooperate in an independent advisory capacity with the Underwriters Laboratories in the development of electrical safety standards.

Sold directly by NEMA and through IHS, American Technical Publishers Ltd., and Global. 
Type of

Organization

standards

Development

standards

Designation

Secretariats

scope

Standardization

Activities
Edward A. Donoghue, Consultant-Codes and Safety

185 Bridge Plaza

No. Rm 310

Fort Lee, New Jersey 07024

(201) 944-3211

FAX: (201) 944-5483

Founded: $1934 \quad$ Standards Staff: 1

Trade Association

Standards Developer

Standards developer since late 1950's. 100 members

participating in code and standards activities

pertaining to elevators, escalators, dumbwaiters, and moving

walks.

Two active standards.

None processed through ANSI.

Vertical Transportation standard.

U.S. TAG for ISO/TC 178, Lifts and Escalators

Promotes the interests of its members by acting as representative in collective bargaining with the International Union of Elevator Constructors advancing sound engineering practices within the industry in cooperation with government agencies in activities related to elevator codes and the installation, service, and maintenance of elevators and related products; compiling and furnishing statistical information.

Actively participates with code and standards organi-

zations and enforcing authorities in developing, maintaining, and applying safety codes and standards that pertain to elevators, dumbwaiters, escalators, and moving walks. Develops requirements for the handicapped using vertical transportation, codes for personnel elevators, personnel and material hoists, model building codes, electrical codes, requirements for elevator fire doors, and metric codes. 
Promotes the adoption of new state and local elevator codes, revises existing elevator safety codes and secures uniform interpretation of the Safety Code for Elevators and Escalators ANSI/ASME A17.1. Representatives of the NEII Central Code Committee are members of ASME A17, NFPA 70, 80 and 101, BOCA, SBCC, ICBO, and ASTM.

The standards Committee is responsible for the development of industry standards for elevators, dumbwaiters, and escalators. The Vertical Transportation standard gives architects and building owners standard dimensions from which they can produce building layouts.

The International standards Committee coordinates the Activities of the United States Technical Advisory Group for ISO/TC 178 Lifts and Escalators.

Availability

Formerly

Reywords
Distributed directly.

National Elevator Manufacturers Industry (1969)

elevators; escalators; dumbwaiters; moving walks; lifts; building; safety; physically handicapped;

\section{NATIONAL ENVIRONMENTAL BALANCING BUREAU}

Michael P. Dolim, Executive Vice President

8575 Grovemont Circle

Gaithersburg, Maryland 20877-4121

(301) 977-3690

FAX: (301) 977-9589

Founded: 1971

Standards Staff: 2

Type of

Organization

Standards

Development

Government

Adoption

Certification
Trade Association

Standards Developer

Four (4) procedural standards publications.

Procedural standards for Testing, Adjusting, and Balancing of Environmental systems is referenced in Federal Guide Specifications.

NEBB offers certification for firms that meet all requirements established for Performance of Air systems, Performance of Hydronic systems, and sound and Vibration Measurement, Cleanroom Performance Testing and Building systems Commissioning. 
A nonprofit organization sponsored by the Mechanical Contractors Association of America (MCAA) and Sheet

Metal and Air Conditioning Contractors National Association (SMACNA).

Standardization

Activities

Availability

Keywords
Works in conjunction with other organizations to develop industry procedural standards for testing, adjusting, and balancing (TAB) of environmental systems in buildings. Represented on the American Society for Heating, Refrigerating and Air conditioning Engineers (ASHRAE) 111 Committee, Testing, Adjusting, Balancing. Develops manuals that provide a comprehensive set of systematic procedures representing the state-of-the-art of TAB work. Manuals cover air/Hydronic TAB, sound and vibration measurement procedures for environmental systems in buildings, cleanroom performance testing, and building systems commissioning.

Distributed directly.

balancing; sound; vibration; air handling; Hydronic systems; HVAC Systems; environmental systems; acoustics; building; cleanrooms; certification; commissioning;

NATIONAL FASTENER DISTRIBUTORS ASSOCIATION

Kenneth R. Dickson, Executive Director

725 Southwick Circle

Somerdale, New Jersey 08083-2311

(609) 627-4333 FAX: (609) 627-7531

Founded: 1968

Type of

Organization

Representation

Scope

Standardization

Activities
Trade Association

Works through other organizations to develop standards

The Association is a member of ANSI, ASME, ASTM, the American National Metric Council, and the Industry Bar Code Alliance.

209 manufacturers and distributors in the fastener industry with members located in 41 states employing 18,000 people.

An information gathering group that disseminates data to the proper standards committees. Writes specifications only if the situation cannot be handled by an 
existing standards developing organization. Currently developing a bar code standard.

fasteners; manufacturing;

\section{NATIONAI FEDERATION OF ABSTRACTING AND INFORMATION SERVICES}

\section{John Schnepp}

Common Practices and Standards Committee

1518 Walnut Street

Suite 307

Philadelphia, Pennsylvania 19102

(215) 893-1561

FAX: (215) $893-1564$

Founded: 1958

Technical Society

Works through other organizations to develop standards

65 members active in standardization activities including involvement in ANSC-Z39, ANSC-X3, ISO/TC 46, UNESCO's UNISIST Project, Federal Information Processing standards (FIPS), AAP's Electronic Publishing subcommittee, and others.

A nonprofit federation of organizations involved in abstracting and indexing services, operating information centers, or conducting research in information science. Improves the extent and quality of the documentation and use of the world's literature through research programs, publications, and seminars. Concerned with developing communications, cooperation, and coordination among all segments of the information processing and dissemination community including primary publishers, libraries, commercial and industrial abstracting and indexing services, data analysis centers, information dissemination centers, and teachers and researchers in the field. Also serves as a communication forum for its members through meetings, workshops, committee activities, and publications.

Standardization Activities
Although NFAIS is not a standards setting body, it works within the voluntary standards community to foster the development and use of standards relevant to its membership. Because NFAIS members are involved in various aspects of the processing and disseminating of information, their interest in standards ranges widely. Relevant standards may pertain directly to abstracting and indexing practices. Also of interest are standards dealing with information science, primary publishing, library work, data processing, and computer readable information 
transfer. Relevant standards may also arise from individual subject areas or disciplines with which the information deals, such as engineering, biology, philosophy, or art.

NFAIS, through its Common Practices and standards Committee (CP\&S), serves as a communications link between the voluntary standards setting community and the information publishing and distribution community. The CP\&S Committee coordinates the NFAIS response to ballots or requests for comments pertaining to draft standards. This is accomplished by polling the NFAIS membership and, in some cases, by resolving minority votes on specific standards. By the same mechanism, NFAIS recommends and votes on qualified individuals to run for office or to serve on committees in standards setting bodies.

Further, NFAIS encourages the active participation of its members on standards setting bodies. Through its members and officers, NFAIS plays a role in the work of such standards setting bodies as: ANSI Committees X3-Information Processing and Z39-Library and Information Sciences and Related Publishing Practices; Iso Committees TC 46-Documentation and TC97-Computers and Information Processing; UNESCO through its UNISIST and ISDS (International Serials Data System) agencies; IFLA (International Federation of Library Associations); ICSU-AB (International Council of Scientific Unions - Abstracting Board); FIPS; and the AAP Electronic Publishing Subcommittee.

In addition to its support for the development of voluntary standards, NFAIS also encourages the general adoption of those standards considered most applicable and useful to the information processing and distribution community. Periodically, NFAIS surveys the implementation of standards by its members in order to determine which standards are being used and the ways in which they are used. Such surveys also provide information on the common practices and the de facto standards of members which may be candidates for formal standardization.

Formerly

Keywords
National Federation of Science Abstracting and Indexing Service (NFSAIS), 1972 .

abstracting; indexing; information services; online searching; bibliographic data bases; information processing; communications; 


\section{NATIONAL FEDERATION OF STATE HIGH SCHOOL ASSOCIATIONS}

Robert F. Kanaby, Executive Director

11724 Plaza Circle

Kansas City, Missouri 64153

(816) $464-5400$

FAX: (816) 464-5571

Founded: 1920

Standards Staff: 8

Type of

Organization

standards

Development

Scope

Standardization Activities

Availability

Formerly

Keywords
Academic Federation

Standards Developer

Prepares rules and standards for 13 interscholastic sports.

Represents 20000 high schools and 10 million secondary school students, primarily to secure proper adherence to the rules of various state high school associations during interstate competition. Establishes standards for sanctioning domestic athletic events.

Publishes and distributes playing rules for domestic competition in interscholastic sports: baseball, basketball, football, gymnastics, soccer, swimming and diving, track and field, volleyball, ice hockey, wrestling, field hockey. Sixty-six rules related publications are published including 28 rule books and 13 rule examinations. Provides national interpretation of the rules and advocates safety standards which are incorporated in the rule publications.

Distributed directly.

National Federation of State High School Athletic Associations (1970)

athletic competition; sports; safety; recreation;

\section{NATIONAL FENESTRATION RATING COUNCIL}

John D. Rivers, Administrator

1300 spring street

Suite 120

Silver Spring, Maryland 20910

(301) $589-6372$

FAX: (301) 588-0854

e-mail: NFRCUSA@aol.com

Founded: 1989

Standards Staff: 4 


\author{
Type of \\ Organization \\ Standards \\ Development \\ Standards \\ Designation \\ Government \\ Adoption \\ Certification
}

Scope

Standardization

Activities

Availability

Keywords
Educational and Scientific

Ratings Developer

Develops rating procedures for fenestration products. 6 rating procedures.

Ratings procedures are designated NFRC 100-91, NFRC 200, etc.

Federal Regulations and those of six states and the CABO Model Energy code

Three programs: one to accredit laboratories; one to license independent certification agencies; and one to certify fenestration products in accordance with rating procedures.

NFRC is a coalition of the fenestration and building industries, government, utilities, code officials and consumer groups working to develop a voluntary, national energy rating system for windows, doors, skylights and other fenestration products. A uniform national energy performance rating and labeling system will enable builders and consumers to directly compare fenestration products.

NFRC is working to combine U-factor, solar heat gain factors, optical properties, air infiltration condensation resistance, annual and long term energy performance and other characteristics into a uniform rating system that reflects energy performance. This effort is supported by a rigorous system of laboratory accreditation to ensure competence and accuracy in the implementation of the various rating techniques employed. Product certification and labeling processes have also been standardized to ensure consistency in product labeling and consumer information.

Distributed directly.

windows; doors; skylights; fenestration; energy performance;

NATIONAL FIRE PROTECTION ASSOCIATION

Arthur E. Cote, Vice President and Chief Engineer

Batterymarch Park

Quincy, Massachusetts 02269

(617) 770-3000 FAX: (617) 770-0700

e-mail: library@nfpa.org

WWW: http://www.wpi.edu/ fpe/nfpa.html 
Type of Organization

Standards Development

standards

Designation

Government Adoption

Certification

Secretariats

Standardization Activities
Technical and Educational Organization Standards Developer

Standards developer since 1896.

Approximately 5200 individuals serve on more than 200 NFPA Technical Committees which develop new codes and standards and continually monitor existing documents.

National Fire Codes, 1989 Edition, includes approximately 300 fire protection, prevention and suppression codes, standards, recommended practices, guides, and manuals, all of which are ANSI approved standards. Draft documents and revisions are published for public review and comment.

NFPA prefix.

In the United States, NFPA documents are referenced by the Occupational Safety and Health Act (OSHA); adopted by Congress for recipients of Medicare and Medicaid; adopted by Coast Guard, Departments of Veterans Affairs, Health and Human Services, Housing and Urban Development; adopted by numerous state and local governments. In addition, various governments around the world adopt NFPA documents at both the national and local levels.

Administers Certificated Marine Chemist program.

International: Conference of Fire Protection Associations United States: Joint Council of National Fire Service Organizations

An independent, nonprofit organization with approximately 65000 individual members and 100 national trade and professional association members worldwide. Activities are technical and educational in nature. Gathers and analyzes fire statistics; performs on-site investigation of significant fires; and works on anti-arson projects. National sponsor of Fire Prevention Week.

Active Standards Council which administers standardization activities of more than 200 technical committees. Standards widely used as the basis of legislation and regulation at all levels of government; many referenced by the federal government and used by insurance authorities for risk evaluation and premium rating. Many documents are used outside North America. 
Availability

Keywords

NATIONAL FIRE SPRINKLER ASSOCIATION
FAX: (914) 878-4215

Standards Staff: 5
Type of

Organization

standards

Development

scope

standardization Activities
Distributed directly and through IHS, and Global.

fire prevention; fire protection; fire code; safety;
Trade Association

Standards Developer

106 representatives and 65 committees active in standards development.

A national trade association of fire sprinkler manufacturers and installers. Advances the art of automatic control of fire through automatic sprinklers, and the conservation of life and property from fire.

Cooperates with national technical bodies in the preparation of standards and fire protection sections of building codes and ordinances. Sets standards for design, installation, inspection, and maintenance of automatic sprinklers.

Cooperates with the American Insurance Association, Insurance Services Office, Underwriters Laboratories (UL), and Factory Mutual Engineering and Research in the formulation of standards, specifications, and regulations for fire apparatus and their use.

Officially represented on sectional committees functioning under the procedure of the American National standards Institute (ANSI) engaged in the development and revision of code for pressure piping, pipe threads, and pipe flanges and fittings.

The NFSA is a member of the Southern Building Code Congress, the International Conference of Building officials, and code Administrators International. Maintains consistency between codes and standards and coordinates the industry's activities in the model code field with those in the standard making bodies, including National Fire Protection Association, American Society for Testing and Materials, American National standards Institute, Underwriters Laboratories, Factory Mutual system, and others. 


\section{NATIONAI FISHERIES INSTITUTE}

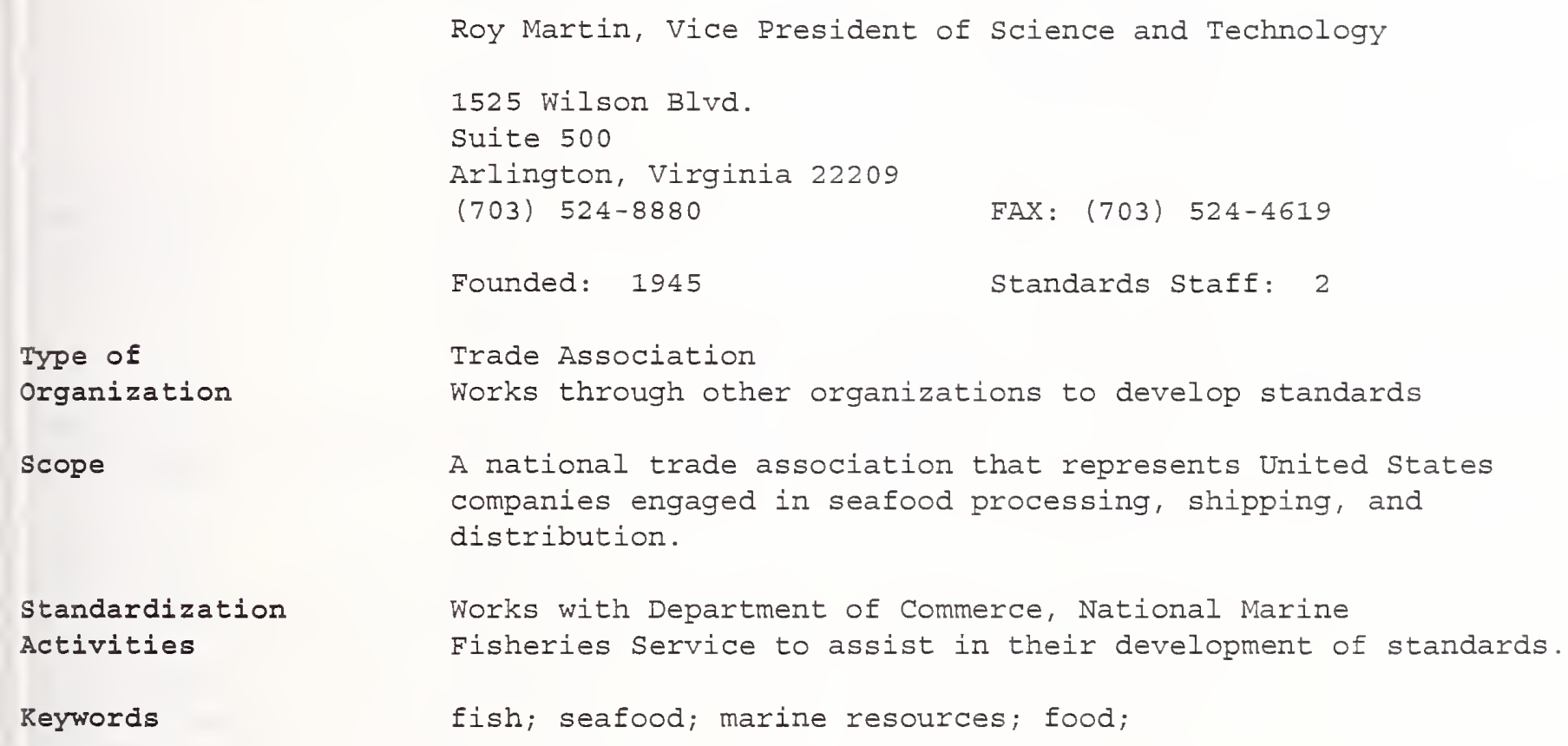

fish; seafood; marine resources; food;

Standardization

Activities

Reywords

\section{NATIONAL FLUID POWER ASSOCIATION}

Shirley C. Seal, Manager of Standards Development Industry/National

3333 North Mayfair Road

Suite 311

Milwaukee, Wisconsin 53222-3219

(414) $778-3344$ FAX: (414) $778-3361$

e-mail: nfpa@execpc.com

WWW: http://Www.nfpa.com

Founded: 1953

Standards Staff: 3

Type of

Organization
Trade Association

Standards Developer 
Standards

Development

Standards

Designation

Certification

Secretariats

Government

Adoption

Secretariats

scope

Standardization

Activities

Availability

Keywords
Standards developer since 1953.

380 members participating in standards activities.

55 active NFPA standards.

117 promulgated through ANSI.

NFPA Recommended Standards, and ANSI/B93.x and

ANSI/NFPA T-.....

No certification, qualification, or accreditation programs.

ASC $B 93$

ISO/TC 131

ISO/TC $131 / \mathrm{SC} 4$

ISO/TC $131 / \mathrm{SC} 7$

4 adopted by DoD.

ANSI/B93, Fluid Power Systems and Products. ISO/TC 131, Fluid Power systems.

A nonprofit trade association serving manufacturers of fluid power (hydraulic and pneumatic) products with 182 corporate members nationwide.

Standards activities account for half of the total association programs. Administered through a technical board, under which are organized 16 committees and 150 project groups. standards cover dimensions, specifications, methods of testing or rating, terminology, symbols, and procedures for systems, as well as individual components, including fluid power cylinders, valves, pumps, motors, sealing devices, conductors, fittings, filters, fluids, servovalves, accumulators, and pneumatic logic devices. solicits technical input from all affected interests.

Committees and staff participate in standards programs of ANSI, SAE, ASME, ASTM, ISA, and ASLE.

Sold directly and through ANSI, Global, and IHS.

fluid power; hyoraulic; pneumatic;

NATIONAL FOOD PROCESSORS ASSOCIATION

John R. Cady, President

1401 New York Avenue NW. Suite 400 Washington, DC 20005

(202) 639-5900

FAX: (202)639-5932 
Type of

Organization

scope standardization

Activities

Formerly

Keywords
Trade Association.

Works through other organizations to develop standards.

A national trade association established to help members maintain and improve product quality. Operates research laboratories in Washington, DC; Berkeley, CA; and Seattle, WA. Represents 600 member companies which pack processed-prepared fruits, vegetables, meats, fish and specialty products, including canned, frozen, dehydrated, and other processed food products. Also includes companies that provide equipment, supplies, and services to food processors.

Maintains liaison with the National Conference on Weights and Measures for the purpose of developing constructive and uniform laws and regulations on the state level. Also maintains liaison with the U.S. Technical Advisory Group and delegates to meetings of ISO/TC 52 and its subcommittees on international standards for metal cans for food.

National Canners Association

food processing; food; packaging; food safety; food labeling; pesticide use;

\section{NATIONAL FOREST PRODUCTS ASSOCIATION}

Barry Cullen, President

1250 Connecticut Avenue NW.

Washington, DC 20036

(202) 463-2765

FAX: (202) 463-2791

Founded: 1902

Standards staff: 5

Type of

Organization

\section{standards}

Development

Government Adoption
Trade Association

Standards Developer

Active in 27 committees.

22 active standards and guides.

Specifications adopted by the Department of Housing and Urban Development, Veterans Administration, Farmers Home Administration, Department of Defense, General Services Administration, Health and Human Services Administration, and the Council of American Building Officials. 
Standardization Activities

Availability

Formerly

Reywords

NATIONAL GOLF CAR MANUFACTURERS ASSOCIATION

Type of

Organization

Standards

Development

Standards

Designation

Certification

scope

Counsel

Two Ravinia Drive

Suite 310

Atlanta, Georgia 30346

(770) $394-7200$

Founded : 1984

Trade Association

Standards Developer through ANSI.

None
Develops and distributes 6 recommended specifications and standards for the use of lumber and wood products and 16 general construction data guides. Serves on standards committees of ANSI, ASTM, and the National Fire Protection Association.

Standards activity includes development of wood structural design data, design values for wood construction, span tables for joists and rafters, the design of wood frame structures, and permanent wood foundations.

Sold or distributed directly.

National Lumber Manufacturers Association (1965)

wood; lumber; construction; building;

Fred L. Somers, Jr., Secretary-Treasurer/General

FAX: (770) $395-7698$

Standards staff: 1

Develop and maintain safety and performance standards for golf cars. These are published in accordance with American National standards Institute (ANSI) criteria and distributed

ANSI/NGCMA Z-130.1 Golf Car standard.

Membership consists of OEM manufacturers representing approximately 95 percent of all golf cars produced in 
the United States. NGCMA develops and maintains performance and safety standards for use by the golf industry.

golf cars;

\section{NATIONAL GROUND WATER ASSOCIATION}

Kevin B. McCray, CAE, Executive Director

One Ground Way at 2600 Airport Drive

Columbus, Ohio 43219

(614) 761-1711 FAX: (614) 761-3446

Founded: $1948 \quad$ Standards Staff: 11

Type of

Organization

Representation

Certification

scope

Standardization

Activities

Reywords
Technical Society

Works through other organizations to develop standards

American Water Works Association; American Society for Testing and Materials.

Offers a voluntary Certification Program for both ground water contractors and ground water scientists and engineers. Contractor certification includes one general and 12 specific examinations.

An organization of water well drilling contractors, manufacturers, wholesale suppliers and professional geologists, hydrologists, and engineers interested in the problems of locating, developing, and utilizing underground water supplies. Objectives of the

association include the promotion of scientific development and the advancement of the science of ground water hydrology.

Business Information Committee cooperates with various organizations in developing standards for well construction and the sampling and monitoring of ground water resources. The National Ground water Information Center, a service of the Association, maintains an online data base of standards applied throughout the ground water industry.

wells; water wells; hydrology; public health; 
Ernest J. Stebbins, Executive Manager

Box 34518

Memphis, Tennessee 38134-0518

(901) 377-1818

FAX: (901) 382-6419

Founded: 1898

Standards staff: 9
Type of

Organization

Standards

Designation

Certification

Scope

Standardization Activities

Availability

Reywords
Trade Association

Standards Developer

NHLA prefix.

The association maintains qualified inspectors in the principal hardwood markets and producing districts of the United states and Canada who are authorized to issue certificates of inspection of hardwood lumber and cypress, the correctness of the grades and measurements shown on the certificate being guaranteed by the financial resources of the association. This official inspection service is available to the members and nonmembers on federal, state or local government contracts. Extensive use of this service has been made by the U.S. Defense Supply Agency.

United states and Canadian hardwood lumber and veneer manufacturers, distributors, and consumers. Inspects measures, and certifies hardwood lumber.

One of the principal functions is the maintenance of standards for the grading of hardwood lumber, and an inspection staff for the official application of the standards.

Issues biennially a new edition of the Rules for the Measurement and Inspection of Hardwood Lumber, Cypress, and Thin Lumber. NHLA's grade rules are recognized as standard throughout the world.

Maintains a school in Memphis, Tennessee for training hardwood inspectors.

Distributed directly.

wood products; lumber; inspection; grading rules; building; 
Patricia Harris, Executive Director

4733 Bethesda Avenue

Suite 300

Bethesda, Maryland 20814

(301) 654-2512

FAX: (301) 975-1721

WWW: http://www.niso.org

Founded: 1939 Standards Staff: 3

Type of

Organization

standards

Development

Standards

Designation

Government

Adoption

Secretariats

scope

Standardization

Activities

Availability

Keywords
Professional Association

Standards Developer

500 members serve on NISO standards committees. More than 50 published standards.

239.

Some NISO-developed standards have been adopted by DoD or as FIPS standards.

ISO/TC $46 / \mathrm{SC} 4$ Automation in Documentation and Information

A professional association which develops technical standards used in libraries, information services and systems, and publishing.

NISO standards address the communication needs of information services, libraries, publishing, and the book trade in such areas as: communication formats and information transfer, transliteration, preservation of materials, forms and records, identification systems, publication formats, and library equipment and supplies. NISO is designated by ANSI as the U.S. TAG to ISO/TC 46 Computer Applications in Information and Documentation.

Distributed by Transaction Publishers; draft standards available directly from NISO.

library; publishing; information services; books; communications; 
David A. Harris, President

1201 L street NW.

Washington, DC 20005

(202) 289-7800 FAX: (202) 289-1092

Founded: 1978 Standards Staff: 25

Type of

Organization

Secretariats

scope

Standardization Activities
Scientific society

Standards Developer

Building seismic Safety Council

Building Thermal Envelope Coordinating Council

wood Protection Council

Congressionaliy authorized, nonprofit, nongovernmental scientific/technical institution. Functions and responsibilities relate to building regulations in the following four areas: development, promulgation, and maintenance of nationally recognized performance criteria, standards, and other technical provisions for maintenance of life, safety, health, and public welfare suitable for adoption by building regulating jurisdictions and agencies, including test methods and other evaluative techniques relating to building systems, subsystems, components, products, and materials with due regard for consumer problems; (2) evaluation and prequalification of existing and new building technology; (3) conduct investigations in direct support of building regulations and evaluation of new technology; and (4) assembly, storage, and dissemination of technical data and other information directly related to the preceding areas.

Improves the regulatory environment and facilitates

the introduction of new and existing products and technology into the building process. Advises both the public and private sectors of the economy with respect to the use of building science and technology in achieving nationally acceptable standards and other technical provisions for use in federal, state, and local housing and building regulations. Publications and services are available to all those who procure, design, construct, use, operate, maintain, and retire physical facilities. Services of the Institute are also useful to other public and private organizations which perform related research and other tasks on which building standards and regulations are based.

The members of the Institute elect a 36-member Consultative Council which provides a direct line of communications with all appropriate trade, professional and labor organizations, private and public standards, code and testing bodies, public regulatory agencies and consumer groups. The council is responsible for 
Availability

Reywords

overseeing the consensus procedures and conduct of consensus activities of the Institute.

Using Compact Disc-Read Only Memory (CD-ROM) technology, the Institute publishes the Construction Criteria Base (CCB). The CCB contains guide specifications, design and construction criteria and standards developed and used by various federal construction agencies. Many of the public and private standards referenced in the guide specifications, including model codes, are contained in the $\mathrm{CCB}$ which is available on a subscription basis.

Distributed directly.

housing; building; performance criteria; technology; regulations; guide specifications;

\section{NATIONAL INSTITUTE OF INFANT SERVICES}

John A. Shiffert, Executive Director

Diaper Service Accreditation Council

2017 Walnut street

Philadelphia, Pennsylvania 19103

(215) $569-3650$

Founded: $1938 \quad$ Standards Staff: 1

\section{Type of}

Organization

Certification

Scope

Standardization Activities
Scientific Society

Standards Developer

Sponsors an autonomous professional Diaper Service Accreditation Council which has promulgated standards for plant sanitation, customer service, and marketing practice. The council accredits diaper service applicants who go through self-evaluation and inspection by an independent site committee for evaluation against the standards. Accredited members must maintain all standards as they may be changed in annual review by the council.

Conducts research into the requirements of diaper processing to meet the sensitivity of infant skin.

Standards are established through a process by which an independent accredited medical laboratory under the supervision of a clinical pathologist conducts microbiological and patch test studies on infants to establish standards. The laboratory then devises testing procedures by which random sample diapers can be tested routinely against the prescribed standards. 
Availability

Formerly

Keywords

NATIONAL INSTITUTE OF OILSEED PRODUCTS

Type of

Organization

Certification

Scope

Suite 202

(202) $785-8450$

Founded: 1934 Series.
Standards are raised from time to time as new knowledge is revealed by the continuing research program. The diaper test now include five major areas: (1) a sanitary score, awarded on the basis of microorganisms found on the sample; (2) a pH test by the calorimetric procedure, to show that the sample meets the acceptable range of 4.5 to $6.5 ;$ (3) evidence of impregnation of the sample with an EPA-approved bacteriostat; (4) a softness test with freedom from stiffness or spilling; and (5) an absorbency test so that water added drop by drop enters the fabric immediately. A diaper service must meet these standards in order to establish qualification and maintain membership.

Distributed directly.

Merger of the Diaper Service Industry Association and the National Institute of Diaper Services (1971)

infant service; public health; diapers; consumer products;
1101 Fifteenth street, NW

Washington, DC 20005

Trade Association

Standards Developer

Chemists Certification Program requires annual successful completion of the American Oil Chemists' Society Smalley Check Sample

An international trade organization with the principal objective of promoting the general business welfare of persons, firms and corporations engaged in the buying, selling, shipping, storage and use of vegetable oils and raw materials. Includes over 300 member firms in 26 countries. 
standardization Activities

Availability

Keywords
Maintains and publishes annually, uniform trading rules to promote effective and efficient trading within the oilseeds industry. The publication includes not only the uniform trading rules, but also a list of certified chemists, samplers, and weighers; Tank Truck Guidelines; the FOSFA International and NIOP joint list of acceptable previous cargoes; and a complete membership roster.

Cooperates with the International Association of Seed Crushers (Europe), Philippine Coconut Oil Producers Association, Philippine Copra Exporters Association, and the U.S. Department of Agriculture in efforts to improve product quality and establish higher standards of trade practices, which are then incorporated in the rules.

Distributed directly.

oil seed; vegetable oil; food; agriculture;

\section{NATIONAL INSURANCE CRIME BUREAU}

John G. Di Liberto, President and CEO

10330 South Roberts Road

Palos Hill, Illinois 60465

(708) $430-2430$

FAX: (708) 430-2446

Founded: 1992

Standards Staff: 15

Type of

Organization

Standards

Development
Service Organization

Works through other organizations to develop standards

Since 1975 the NICB through US DOT has assisted the US vehicle manufacturing industry in developing vehicle identification number standards and marking locations. Vehicle identification numbers and locations of specific markings are mandated by U.S. Department of Transportation (US DOT), and National Highway Traffic Safety Administration (NHTSA).

The NICB formulates and implements policies for the prevention of vehicle theft, vehicle arson, and vehicle fraud as well as all types of insurance fraud. NICB cooperates with duly constituted public authorities in the prosecution of individuals engaged in vehicle and insurance related crimes.

The NICB is an agency for the location and identification of stolen vehicles and for the promotion of anti-vehicle theft and fraud activities. NICB is a crime prevention organization supported by more than 1000 property-casualty insurance companies, 
Standardization

Activities

Availability

Former ly

Keywords providing assistance to law enforcement, insurance companies and the public.

Cooperates with vehicle manufacturers in the adoption of a standard vehicle identification number, as well as in a standard method of stamping and affixing such numbers.

NICB Prints and distributes to law enforcement agencies a Passenger Vehicle Identification Manual, a Commercial Vehicle Identification Manual, and a Manual for the Investigation of Vehicle fires. NICB also prints and distributes to insurance companies, lists of potential fraud indicators for use in recognizing patterns which could indicate fraudulent activity. Services of the NICB are for the benefit of, not only the insurance industry and law enforcement, but the public as well.

NICB publications are available to government agencies, law enforcement agencies and the insurance industry by telephoning or faxing the National Insurance Crime Bureau.

National Automobile Theft Bureau (1992)

automobile theft; vehicle theft; law enforcement;

NATIONAL KITCHEN AND BATH ASSOCIATION

Paul A. Kohmescher, Executive Director

687 Willow Grove street

Hackettstown, New Jersey 07840

(908) 852-0033

FAX : (908) 852-1695

Founded: 1963

Standards Staff: 5

Type of

Organization

standards

Development

Certification

scope
Trade and Professional Association

Standards Developer

Develops standards which set guidelines for good kitchen and bathroom design.

Certified Kitchen Designers (CKD) and Certified Bathroom Designers (CBD).

More than 6000 members consisting of manufacturers, distributors, manufacturers' representatives, retailers and independent designers. Serves its members in setting design standards, promoting consumer awareness and providing educational opportunities. 


\section{Standardization}

Development

Availability

Formerly

Keywords
Develops and promulgates 31 guidelines on good kitchen design and 27 guidelines on good bathroom design.

Distributed directly to members and available to others upon request.

American Institute of Kitchen Dealers (1983)

kitchen; bathroom;

\section{NATIONAL LIME ASSOCIATION}

Harry L. Francis, Technical Manager

200 N. Glebe Road

Suite 800

Arlington, Virginia 22203

(703) $243-5463$

FAX: (703) 243-5489

Founded: 1902

Standards Staff: 1

Type of

Organization

Representation

Secretariats

scope

Standardization

Activities
Trade Association

Works through other organizations to develop standards

Active in ASTM, AWWA, and other organizations in developing standards.

ASTM C7 on Lime; ASTM C12 on mortar; AWWA lime specification committee.

An association of commercial producers of quicklime and hydrated lime. Members provide about 85 percent of the commercial lime used in the United States - for steelmaking; water, sewage and waste treatment; sulfur dioxide removal from flue gasses; industrial chemicals; stabilization for road and airfield construction; mortar and plaster, etc.

Engages in committee work with American Society for Testing and Materials, American National Standards Institute, American Road and Transportation Builders Association, American Water Works Association, Air Pollution Control Association, Construction Specifications Institute, etc., in standards related to lime. Instrumental in working to develop specifications which will be reasonable and helpful to the hundreds of users of lime and lime products. 
Keywords

NATIONAL LUBRICATING GREASE INSTITUTE

Type of

Organization

standards

Development

Standards

Designation

Certification

Scope

Standardization

Activities

NLGI.
Publications include guidelines for using lime for water supply and Treatment; Lime Handling, Application \& Storage in Treatment Processes; Lime Stabilization Construction Manual; Flexible Pavement Design Guide; Effective Use of Lime in Asphalt; Specifications for Lime and Its Uses in Plastering stucco, Unit Masonry, and Concrete; Map of Commercial Lime Producers.

lime; calcium oxide; calcium hydroxide; magnesium oxide; magnesium hydroxide; burnt lime; quick lime; hydrated lime; high calcium lime; dolomitic lime; mortar; soil stabilization; flue gas desulfurization; neutralization;

Duane J. Fike, General Manager

4635 Wyandotte street

Kansas City, Missouri 63112

(816) $931-9480$

FAX: (816) 753-5026

Founded: 1933

Standards staff: 1

Trade Association/Technical society

Standards Developer

200 members active in standards development.

NLGI Reference systems available for use as research tools in the development and evaluation of lubricating grease formulations.

A technical society whose objectives are the development of better lubricating greases for the consumer and better grease lubricating engineering service to the industry. Collects and disseminates technical data.

Develops standards within ASTM and Recommended Practices with SAE. Also maintains liaison with other groups including API, STLG, Independent Lubricant Manufacturers Association (ILMA), National Petroleum Refiners Association (NPRA), and Petroleum Packaging Committee (PPC). Maintains Technical Committee charged with developing data pertinent to the manufacture, standardization, and application of industry products. Works with ISO to develop standardized definitions. Developed NLGI Chassis and Wheel Bearing service Classification 
Availability

Formerly

Reywords

System. NLGI consistency numbers recognized worldwide as the measure of one important grease characteristic. Cooperates with various Government agencies including DoD, NIST, FTC, and ICC.

Distributed directly.

National Association of Lubricating Grease Manufacturers, Inc. (1936)

greases; lubricants; petroleum products; consistency number; materials;

\section{NATIONAL MARINE ELECTRONICS ASSOCIATION}

Type of

Organization

standards

Development

\section{standards}

Designation

Representation

Scope

Standardization

Activities
Cathryn Moyer, Executive Director

7074 Bembe Beach Road

Suite 203

Annapolis, Maryland 21403

(410) 263-1742

FAX: (4105) 263-1743

Founded: 1957

Standards Staff: 2

Trade Association

Standards Developer

Standards Committee composed of design engineers, representing manufacturers and service dealers of marine electronic communication and navigation equipment. Committee membership is on a voluntary basis and functions under a chairman at the direction of the association Board of Directors.

NMEA 0180, NMEA 0182, NMEA 0183.

IEC/TC 80/WG 6, Digital Interfaces

A nonprofit trade association of companies involved in the manufacture, distribution, sales and service of ship-board marine electronic devices for communications, navigation, automation and acoustics. Aims to distribute industry information, contribute to United states and international rules and regulations and provide leadership to improve quality of industry.

Beginning in 1980, established standard interface formats for transmission of data communications between marine electronic equipments to eliminate incompatibility among manufacturers and facilitate the ability of sellers and purchasers to interchange devices regardless of brands. Standards in use 
Availability

Keywords throughout the worlds by voluntary application. In 1988, a working group (WG 6) was established by TC 80 of the IEC to produce a draft standard for digital interface for navigation equipment within a ship. NMEA, working through ANSI, is the technical committee representing the United states, IEC TC 80. The NMEA 0183 standard will be adopted as official international standard, IEC 1162-1 (single talker/multi-listener). Work is underway by the NMEA to develop a low cost instrument network standard (multi-talker/multi-listener), future IEC 1162-3.

Distributed directly.

marine electronics; navigation; data transmission; telecommunications;

\section{NATIONAI MODEL RAILROAD ASSOCIATION}

Deborah Z. Millard, Office Manager

4121 Cromwell Road

Chattanooga, Tennessee 37421

(615) 892-2846 FAX: (615) 899-4869

Founded: 1935 Standards Staff: 1

Type of

Organization

standards

Development

standards

Service Organization

Standards Developer

Has developed standards since 1936.

Designation

Certification

scope
NMRA standards.

NMRA Recommended Practices.

Grants an NMRA Conformance Warrant to products conforming to NMRA standards after the Conformance-Inspection Committee checks manufactured products for compliance. Items meeting the standards and specifications are granted an NMRA Conformance Warrant which may be used in advertising as long as continued compliance is indicated by repeat inspections.

Advances the hobby of scale model railroading through the development, adoption, and regulation of standards; promotes cooperation and understanding between producers and users of hobby materials; and increases opportunities for fellowship among model railroaders. Membership comprises about 27000 persons active in the field in the United states and throughout the world. 
standardization

\section{Activities}

Availability

Reywords
Establishes and maintains design standards for the manufacture of components for use in the hobby. These are intended to insure interchange between items produced by various sources and to improve performance. Adopted in 1936, specifications have been followed continuously by producers of scale railroad models and parts since that time, including refinements as the state of the art progressed.

Standards define track and wheel relationships, electrical power specifications, and clearance dimensions between rolling stock and trackside structures. NMRA recommended practices cover desirable characteristics other than those necessary for physical

interchange and are intended to enable manufacturers to improve their product in a manner most suited to the user's needs. A General Engineering Committee is charged with responsibility for development of standards and recommended practices.

Distributed directly.

scale models; railroads; hobby; recreation;

\section{NATIONAL OAK FLOORING MANUFACTURERS ASSOCIATION}

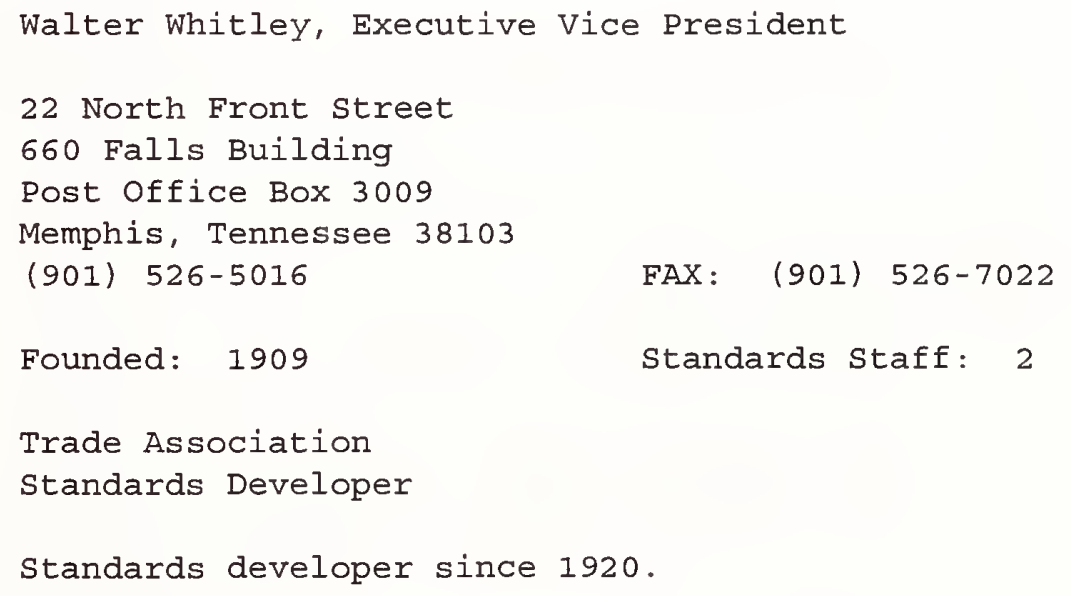

Use of the association's registered trademark "NOFMA" is granted to members whose stock of oak flooring has been found to comply with the association's official grading rules. Maintains a reinspection service available to retail dealers who purchase products of member companies in the event there is doubt concerning the quality of stock purchased. 

conducts grade labeling and inspection services; maintains research program in grading, handling, packaging, and installation. Compiles statistics and sponsors installation school. An affiliate of the National Forest Products Association. Works with the VA, FHA, and other Government agencies dealing with housing, also the National Association of Home Builders, and the National Lumber and Building Material Dealers Association.

Standardization Activities

Availability

Formerly

Keywords
Standardization and simplification activities carried on by its Grading, Milling, and Inspection Committee. Adopted official rules on oak, birch, beech, hard maple, and pecan flooring which cover in detail the grades and sizes of quartered and plain sawn stock. Cooperates with the federal government in the formulation of the federal specification for hardwood flooring (Lumber and Timber: Hardwood, MM-I-736C), which includes references to the grading rules of the association. Maintains rigid supervision of species, manufacturing, kilndrying, bundling, and other features pertaining to oak, birch, beech, and hard maple so that sizes and grades will be maintained.

sold directly.

Oak Flooring Manufacturers of United States (1930)

Southern Oak Flooring Industries (1933)

oak; grading rules; inspection; flooring; wood floors; lumber; building; wood products;

NATIONAL OILSEED PROCESSORS ASSOCIATION

Sheldon J. Hauck, President

1255 23rd Street, NW

Washington, DC 20037

(202) $452-8040$

FAX: (202) 833-3636

Founded: 1930

Standards Staff: 2

Type of

Organization

Certification
Trade Association

Standards Developer

Provides certification for official Weighmasters; Automatic Sampler Installation at Vessel Loading Facilities; and Automatic Sampler Installation at Barge Loading Transfer Facilities. 
Thirteen regular member firms engaged in the actual processing of oilseeds; 25 associate member firms who are consumers of vegetable oil or oilseed meal, including some refiners and mixed feed manufacturers. Promote the domestic and international marketing of all types of oilseed products through development of equitable trading rules for buyers and sellers of such products; foster intense research activity aimed at improving and increasing yields and productivity of oilseed crops; promote the sale of oilseed products internationally; and educate domestic and international consumers to the benefits of utilizing oilseed products.

\section{Standardization Activities}

\section{Availability}

Formerly

Keywords
Adopts standard specifications for crude, domestic soybean oil covering quality, grade, and methods of analysis. Establishes recommended soybean oil and meal trading rules. Helps establish product definitions for the formula feed industry.

Sold directly.

National Soybean Processors Association (1929-1989)

soybean meal; soybean oil; agriculture;

\section{NATIONAL PARTICLEBOARD ASSOCIATION}

Rich Margosian, Executive Vice President

18928 Premiere Court

Gaithersburg, Maryland 20879

(301) 670-0604

FAX: (301) $840-1252$

Founded: 1960

Standards Staff: 3

Type of

Organization

Standards

Development

Standards

Designation

Government

Adoption

Certification
Trade Association

Standards Developer

Active Standards:

4 active standards.

2 ANSI standards.

NPA or ANSI prefixes.

The U.S. Department of Housing and Urban Development references 2 standards.

Certification of products for particleboard and medium density fiberboard producers. 
Secretariats

Scope

Standardization

Activities

Availability

Reywords

NATIONAL PEST CONTROL ASSOCIATION

Type of

Organization

Representation

Scope

Standardization

Activities panels; Resources
ANSI A 208, standards developed by the canvass method.

Represents manufacturers of particleboard and medium density fiberboard to governmental agencies, sponsors voluntary standards development activities, compiles industry statistics, coordinates product and application research, and publishes technical and promotional literature.

Eighteen member companies and 40 non-NPA companies, agencies, and interested parties participate in standards activities. NPA currently sponsors four industry standards: ANSI A208.1-1989 Wood Particleboard; ANSI A208.2-1986 Medium Density Fiberboard For Interior Use; NPA 9-87 Voluntary Standard for Formaldehyde Emission From Medium Density Fiberboard (MDF); NPA 182 standard for particleboard Mobile Home Decking.

Sold directly and through ANSI.

particleboard; fiberboard; formaldehyde; wood products; wood

Richard D. Kramer, Director of Research, Education \& Technical

8100 Oak street

Dunn Loring, Virginia 22027

(703) $573-8330$

FAX : (703) 573-4116

Founded: 1933

Standards staff: 3

Trade Association

Works through other organizations to develop standards

ASTM, NIBS, DOD, HUD, USDA

Represents the urban pest control industry in the United States. Member firms engage in control of insect, and certain vertebrate pests. These pests left to multiply in urban or suburban centers would damage stored food, wood based dwellings, or actively transmit organisms that result in fatal or debilitating human disease. Although NPCA has many international members its major function is to represent domestic urban pest control interests.

Publishes specific guidelines such as Good Practice

Statements and various reference procedures that are developed by technical and/or management committees and formally approved in some cases by vote of the entire membership or by vote of its board of directors. NPCA works actively on ASTM committee E-35 and D225 and committees of the National Institute of Building 
Sciences, particularly Indoor Air Quality. Both organizations promulgate standards that involve aspects of urban pest management. structural protection; subterranean termite control; indoor air quality; public health; sanitation;

\section{NATIONAL PRINTING INK RESEARCH INSTITUTE}

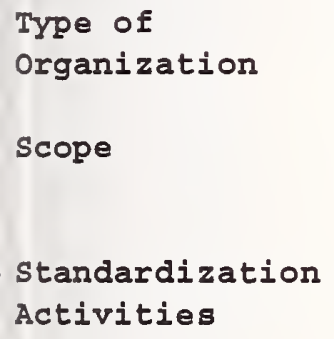

J. M. Fetsco, Technical Administrator

Sinclair Lab Building \#7

Lehigh University

7 Asa Drive

Bethlehem, Pennsylvania 18015

(610) $758-3588$

Founded: 1946 Standards Staff: 2

Scientific Society

Engages in projects to investigate problems of mutual interest to the printing ink and printing industries.

Publishes raw material data handbooks on materials used in manufacturing printing ink. Coordinates with ASTM on developing test methods used within the printing ink industry. Develops monographs on subjects of interest to the printing ink industry.

Distributed directly.

ink; printing ink; communications;

Bruce J. Swiecicki, Vice President, Technical Services

1600 Eisenhower Lane

Lisle, IL 60532

(708) 515-0600

FAX : (708) 515-8774

Founded: 1931

Standards Staff: 3 
Type of

Organization

Representation

Scope

Standardization

Activities

Keywords
Trade Association

Works through other organizations to develop standards.

Representatives on standards Committees of ANSI, ASTM, NFPA, ASME and API.

A vertically structured national trade association of companies and individuals involved in the production, transportation, distribution, and marketing of liquefied petroleum gas.

Provide input to and representation on various standards making organizations. Focus is on standards associated with the safe handling and use of LP-Gas and the associated equipment and material.

energy; safety; liquified petroleum gas; LP-Gas;

NATIONAL RETAIL FEDERATION

Type of

Organization

Standards

Development

Scope

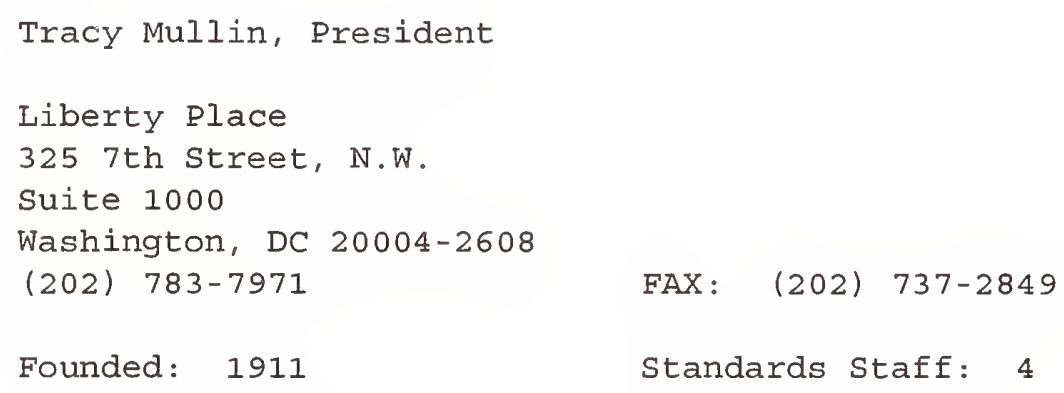

The nations largest trade association representing the general merchandise retail industry with 4500 individual corporate members operating approximately 45000 department, chain, specialty and independent stores in the United States and an additional 1000 stores in 50 nations abroad. NRF's members' aggregate domestic sales are in excess of $\$ 150$ billion annually and they employ more then three million workers. Devoted to the exchange of information among retailers and to research and education. Takes an active part in the formulation of standards and specifications relative to retail store organization, retail trade terminology, business practices, and specifications for commodities used in the trade. Cooperates actively with ANSI and other technical and trade organizations and the government. 


\section{Standardization Activities}

Formerly

Reywords
Endorsed the Universal Product Code (UPC) for uniform merchandise identification acceptable to both general merchandise retailers and vendors. Develops and maintains standard color and size codes for common usage between retailers and manufacturers. Participates in the General Merchandise and Apparel Implementation Committee of the Uniform Code Council (secretariat for the UPC) in standards definition and approval for merchandise marking, shipping, container labeling and identification and definition of standards for ANSI X.12 Electronic Data Interchange (EDI) fields, usage and transaction sets. Is active on the EDI Advisory Committee of the Uniform Code Council and in the Federation of Automated Coding Technologies (FACT). Offers the standard Color and Size Code Handbook.

National Retail Merchants Association (1990)

merchandise; retailing; merchandise identification; sizes; business; consumer goods;

\section{NATIONAL RIFLE ASSOCIATION OF AMERICA}

Wayne R. Lapierre, Jr., Executive Vice President

11250 Waples Mill Road

Fairfax, Virginia 22030-7400

(703) 267-1000 FAX: (703) 267-3989

e-mail: nra-contact@nra.org

Founded: $1871 \quad$ Standards Staff: 2

Type of

Organization

Certification
Educational and Sports Association

standards Developer

Standards for paper targets are enforced through a licensee process. When the specified standards are met, an "Official NRA Target" designation is given to the manufacturer for printing on the target. The NRA certifies marksmanship and firearm safety instructors, referees, and coaches; and approves, when certain standards have been met, training and qualification courses for police departments, shooting range safety officers, and military and civilian rifle and pistol clubs. The NRA sets safety standards for firearms instruction courses and ranges, and is recognized as the leader of firearm safety education in the United States.

Nonprofit membership organization with more than 3.3 million members and 12000 affiliated local clubs and state organizations all interested in firearms or the shooting sports. 
Standardization

Activities

Availability

Keywords
Prepares and provides standard construction plans for a large variety of shooting ranges for different guns and events. Also standardized are paper and metal targets used in training and competition. These standards are researched and established by various specialized program committees and channeled through NRA's Competition Rules and Programs Committee and Board of Directors. Standards are included in annually revised competitive rule books, in annual meeting reports, and special shooting range literature and program outlines and manuals.

Distributed directly.

shooting ranges; targets; safety; recreation; sports; firearms training;

NATIONAL ROOF DECK CONTRACTORS ASSOCIATION

Tom Barnkemp, President

11 South Lasalle street

Suite 1400

Chicago, IL. 60603

(312) 201-0101

FAX: (312) 201-0214

Founded: 1959

Standards Staff: 1

Type of

Organization

Trade Association

scope

Works through other organizations to develop standards

Promotes the welfare of the structural roof deck systems industry by analyzing and informing the membership of conditions affecting the industry, informing the membership of improved operating methods and procedures, and conducting education and research activities.

standardization Activities

Formerly

Keywords
Develops or assists in the development of standard tests and test methods for industry products. Participate in model code development and with other government and public bodies involved with building, construction, and the installation of structural roof deck systems.

Gypsum Roof Deck Foundation Association (1980)

built-up roofing; building; 
William A. Good, Executive Vice President

10255 W. Higgins Road

Suite 600

Rosemont, IL. 60018

(708) 299-9070

FAX: (708) 299-1183

Founded: 1886

Standards Staff: 1

Type of

Organization

Scope

Standardization

Activities

Availability

Reywords
Trade Association

Standards Developer

Works with other organizations to develop standards

Contractors applying membrane, metal, sprayed foam, slate, tile, and wood roofs. Sponsors instruction for roofing superintendents and holds management institutes.

Dedicated to the improvement of systems standards for all roofing systems. Studies materials and application procedures and standards through various technical committees. Has joint liaison groups with various materials manufacturer organizations and government bodies. Conducts test programs with other industry organizations on a joint basis. Aims to enhance the development of improved material and application standards for the roofing industry.

Produced a Roofing and Waterproofing Manual that provides recommended procedures, practices and evaluative comments on roofing specifications, construction details, and roofing materials. Cooperates with the National Institute of Standards and Technology to conduct technical conferences. Also conducts an international symposium on roofing technology every five years.

Distributed directly.

roofing; building;

Ronald J. Koziol, Standards Administration

1121 Spring Lake Drive

Itasea, Illinois 60143-3201

(708) 285-1121

WWW: http://www.nsc.org/nsc

Founded: 1913
FAX: (708) 285-1315

Standards Staff: 6 
Type of

Organization

Representation

Secretariats

Scope

Standardization

Activities

Keywords

NATIONAL SASH AND DOOR JOBBERS ASSOCIATION
Type of

Organization

Scope

Standardization

Activities

Type of
Organization
Scope
Standardization
Activities

Technical Society

Works through other organizations to develop standards

ANSI, UL

ANSI A10, D16, Z16, Z41, Z244, Z365

A nonprofit, nongovernmental public service organization. Aims to determine and evaluate methods and procedures that prevent accidents and mitigate injury and economic loss resulting from accidents, and to provide leadership to expedite the adoption and use of those methods and procedures that best serve the public interest. Functions in the areas of occupational safety and health, traffic safety, motor transportation safety, product safety, and consumer safety.

Focuses on standards concerned with safety of products or systems and with accident/injury record systems. In its materials and publications, references all of the appropriate codes and standards adopted by nationally recognized consensus standard producing organizations. Represented on ANSI's Organizational Member Council, the Safety and Health standards Board, and the ANSI/OSHA Coordinating Committee.

safety; accident prevention; occupational health; traffic safety; consumer products; social welfare;

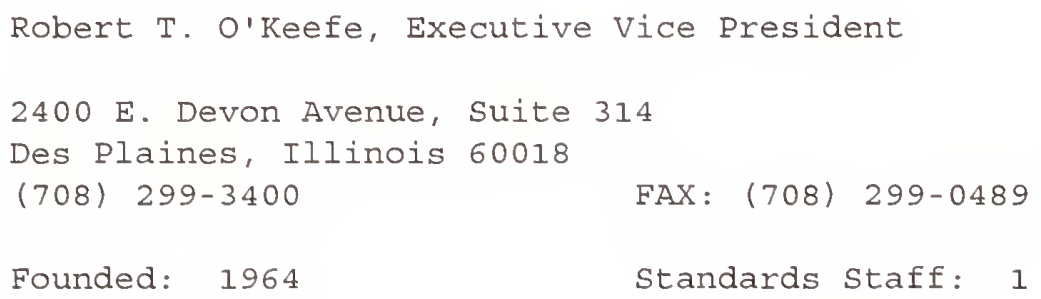
related building products, including new products; advocates and promotes the sale of such products through sash and door jobbers; promotes the growth of the industry.

The association supports the development of standards related to window and door products. In cooperation with the National Wood, Window and Door Association (NWWDA), helped prepare and further commercial standards relating to double hung casement, awning, and single hung wood window units which have been incorporated into NWWDA's Industry standard 2. 
Formed by the merger of the Northern Sash and Door Jobbers Association (1935) and the Southern Sash and Door Jobbers Association (1935)

windows; doors; sash; millwork; building; wood products;

NATIONAL SCHOOL SUPPLY AND EQUIPMENT ASSOCIATION

Tim Holt, Executive Vice President

8300 Colesville Road

Suite 250

Silver Spring, Maryland 20910

(301) 495-0240 FAX: (301) 495-3330

Founded: $1916 \quad$ Standards Staff: 1

Type of

organization

Certification

scope

Standardization

Activities

Availability

Formerly

Keywords
Trade Association

Works through other organizations to develop standards

Issues certification when operable and folding walls are tested for sound transmission loss in accordance with ASTM E90.

Manufacturers and distributors of school supplies, equipment, and instructional materials. Operating Divisions address the needs of manufacturers and users of auditorium, theater, bleacher, and classroom seating, as well as play ground equipment, and operable partitions.

Operable Partition section of NSSEA has endorsed ASTM E557-77 which provides a standard for the application and installation of operable partitions. Also issues testing procedures for measuring sound transmission loss.

Distributed Directly.

National School Service Institute (1958)

partitions; school equipment; noise control; education; buildings; 
Sid Roslund, Director of Technical Services

133 S. Van Gordon

Suite 300

Lakewood, Colorado 80228

(303) 987-1111

FAX: (303) 986-2345

Founded: 1962

standards staff: 1

Type of

organization

Standards

Development

Government

Adoption

Secretariat

Scope

Standardization Activities

Availability

Keywords
Trade Association

Standards developer

Standards Developer since 1963.

U.S. Department of Agriculture Forest Service, and states where skiing exists.

National Ski Areas Association

A trade association of ski area operators and suppliers of ski equipment. Twelve hundred members located in all states and several foreign countries. Aims are to promote skiing and safety in skiing, to protect natural resources in meeting the needs of the skiing public and ski area operators, and to ensure legitimate interests of ski area operators.

Maintains committee composed of operators, users, authorities having jurisdiction, manufacturers and independent specialists of aerial ropeways. Developed the American National Standard B77.1 for Passenger Tramways and Lifts, Surface Lifts, and Tows. Promotes this standard for the ropeway industry, used by ski lift manufacturers, ski area personnel, ski area insurance programs, and state and federal authorities having jurisdiction.

Distributed through ANSI.

aerial tramways; cable cars; cableways; ski lifts; sports; skiing; recreation; ropeways;

NATIONAL SOFT DRINK ASSOCIATION

William L. Ball, III., President

1101 16th street NW.

Washington, DC 20036

(202) 463-6732

FAX: (202) 463-8178

Founded: 1919

Standards staff: 2 
Type of

organization

\section{Standards}

Development

\section{standards}

Designation

Government

Adoption

Scope

Standardization

Activities

Availability

Formerly

Reywords
Trade Association

Standards Developer

Three active standards.

VPS, ANSI/VPS, and VS prefixes.

PS 73-89 Carbonated Soft Drink Bottles (1989)

Provides manufacturers of soft drinks throughout the United states and others interested in the welfare of the industry a forum to discuss matters of common interest, provides a medium for improving soft drink plant operating procedures, conducts research on problems relating to the industry, and provides informational and educational services in the interest of the consumer.

Instrumental in the development of voluntary standards or guide lines, designed for the betterment of the consumer and the bottling and packaging activities of the industry.

Sold directly, through Government Printing Office, and ANSI.

American Bottlers of Carbonated Beverages (1967)

soft drinks; beverages; packaging;

NATIONAL SPA AND POOL INSTITUTE

Carvin Di Giovanni, Technical Director

2111 Eisenhower Avenue

Alexandria, Virginia 22314

(703) 838-0083 FAX: (703) 549-0493

e-mail: R.Galvin.NSPI@MCIMAILCOM

Founded: 1956 Standards Staff: 2

Type of Trade Association

organization Standards Developer 
A national trade association comprised of approximately 4800 swimming pool builders, manufacturers, pool equipment manufacturers and suppliers, architects, engineers, public officials, and others allied with the pool industry. Sets guidelines and ethical standards for pool builders and service technicians by certification and education programs and adherence to ANSI standards.

Standardization

Activities

Availability

Keywords
Accredited by the American National standards Institute (ANSI) as the United States standards developer for voluntary standards for residential in ground, residential aboveground (on ground) and public swimming pools; residential (portable and in ground) and public spas/hot tubs. Cooperates with the American Public Health Association, National Institutes of Health Center For Disease Control and Prevention, U.S. Consumer Product Safety Commission, National safety Council, Underwriters Laboratories, National Sanitation Foundation, National Electrical Code, National Building Code Groups (BOCA, SBCCI, ICBO, CABO), National Recreation and Park Association and the Young Men's Christian Association (YMCA). Provides information and assistance to a number of government agencies and maintains liaison to a number of international swimming pool and spa organizations such as Aqua Europa, Administers technical committees in the areas of dimensional design, chemical treatment, circulation systems, accessory equipment and publications.

Distributed directly.

swimming pools; spas; hot tubs; consumer products; safety; sanitation;

NATIONAL STANDARDS EDUCATORS ASSOCIATION

Type of

Organization

Representation
Walter J. McGee, Executive Director

Post Office Box 773

Placentia, California 92670

(714) $996-3682$

Founded: 1987 Standards Staff: 3

Industrial education association

Works through other organizations to develop standards.

Many members represented on standards committees of organizations such as ASME, ANSI, and ISO. 
Certification

Scope

Standardization Activities

Keywords
The association has initiated its campaign for proficiency testing of the American work force in the field of dimensional metrology. In conjunction with the American Society of Mechanical Engineers, they have focused on the Y14 and B89 standards for its first personnel certification programs.

A nonprofit organization of 100 industrial executives, managers, engineers, technicians, educators, and students that promotes, within United States industrial and educational societies, the significance and expert knowledge of those standards in common use within American industry.

The association promotes the concept of "management by accountability." This concept fosters the use of certifications, accreditations, registrations, and licensures to combat the plague of standards illiteracy in America. It has warned industry that a nation that cannot relate to its own standards will not long be competitive in a global market requiring compliance to foreign and international standards. The association promotes testing of our industrial work force on proficiency in those standards and specifications common to their line of work.

education; quality assurance; management; general;

\section{NATIONAL STONE ASSOCIATION - Pulverized Limestone Division}

Larry Quinlivan, Vice-President, Marketing

1415 Elliot Place, NW

Washington, DC 20007-2599

(202) 342-1100

FAX: (202) 342-0702

Founded: $1990 \quad$ Standards Staff: 2

Professional and Trade Association Standards Developer

The Technical Committee of the PLD is made up of representatives from member companies. The committee reviews standards and test procedures for application to the pulverized limestone industry. Recommendations for adoption are made by the committee to member companies based on their findings.

The PLD makes standards limestone materials available to its members, these standards are designated "PLD Standard $\mathrm{XX}-\mathrm{Y}$ " (where $\mathrm{XX}$ is the last two digits of the year, $\mathrm{Y}$ is a sequential designation). 


\begin{tabular}{|c|c|}
\hline Certification & $\begin{array}{l}\text { No certification, qualification or accreditation } \\
\text { program. }\end{array}$ \\
\hline Scope & $\begin{array}{l}\text { The Pulverized Limestone Division promotes the general improvemen } \\
\text { of the manufacture and sales of finely ground limestone products } \\
\text { so that consumers and the general public will be better served by } \\
\text { the industry. }\end{array}$ \\
\hline $\begin{array}{l}\text { Standardization } \\
\text { Activities }\end{array}$ & $\begin{array}{l}\text { The PLD standards and test procedures are made } \\
\text { available to member companies to help assure consistent quality } \\
\text { standards throughout the industry for the benefit of members and } \\
\text { customers alike. }\end{array}$ \\
\hline Availability & Distributed directly. \\
\hline Keywords & minerals; agriculture; \\
\hline
\end{tabular}

NATIONAL TERRAZZO AND MOSAIC ASSOCIATION

Edward A. Grazzini, Executive Director

3166 Des Plaines Avenue

Suite 132

Des Plaines, Illinois 60018

(708) 635-7744 FAX: (708) 635-9127

Founded: 1923 Standards Staff: 5

Type of

Organization

Trade Association

standards

Standards Developer

Development

25 active standards.

Government

Adoption

All technical manuals and design catalogs are accepted by Government agencies.

scope

Contractors who install terrazzo and mosaic work and firms which produce or manufacture materials. Provides information to building owners, architects, builders, and terrazzo contractors. conducts research on installation methods.

standardization

Activities
Maintains a Technical Committee and Quality Control

Committee active in standards development. Publishes Technical Data Book which contains 25 standard national specifications for the installation of both cementitious and resinous terrazzo. Also develops standards on various application and grinding techniques. 


\section{NATIONAL TIRE DEALERS AND RETREADERS ASSOCIATION}

Gurnie Hobbs, Director

Membership Services Division

1250 I Street, NW

Suite 400

Washington, DC 20005

(202) 789-2300

FAX : (202)682-3999

Founded: 1921

Standards Staff: 4

Type of

organization

Scope

Standardization

Activities

Availability

Formerly

Keywords
Trade Association

Standards Developer

An organization of 5000 independent tire dealers and retreaders in the United States, Canada, and abroad. Concerned with matters which affect the tire dealer and his ability to do business including product development, marketing, legislation, new tires, retread, service, and after market areas. Heavily committed to retreading, NTDRA maintains a field force of six highly qualified plant inspectors, inspecting 800 retread plants annually.

Develops recommended industry standards to keep the science of retreading at a high level.

Distributed directly.

National Association of Independent Tire Dealers Absorbed the Tire Retreading Institute (1978)

tire; automotive service; automobile parts; retread; transportation;

NATIONAL WOOD WINDOW AND DOOR ASSOCIATION

Ric Markway, Vice President Technical Services

1400 E. Touhy Avenue

Des Plaines, Illinois 60018

(312) 299-5200

FAX: (312) 299-1286

Founded: 1926

Standards staff: 3 


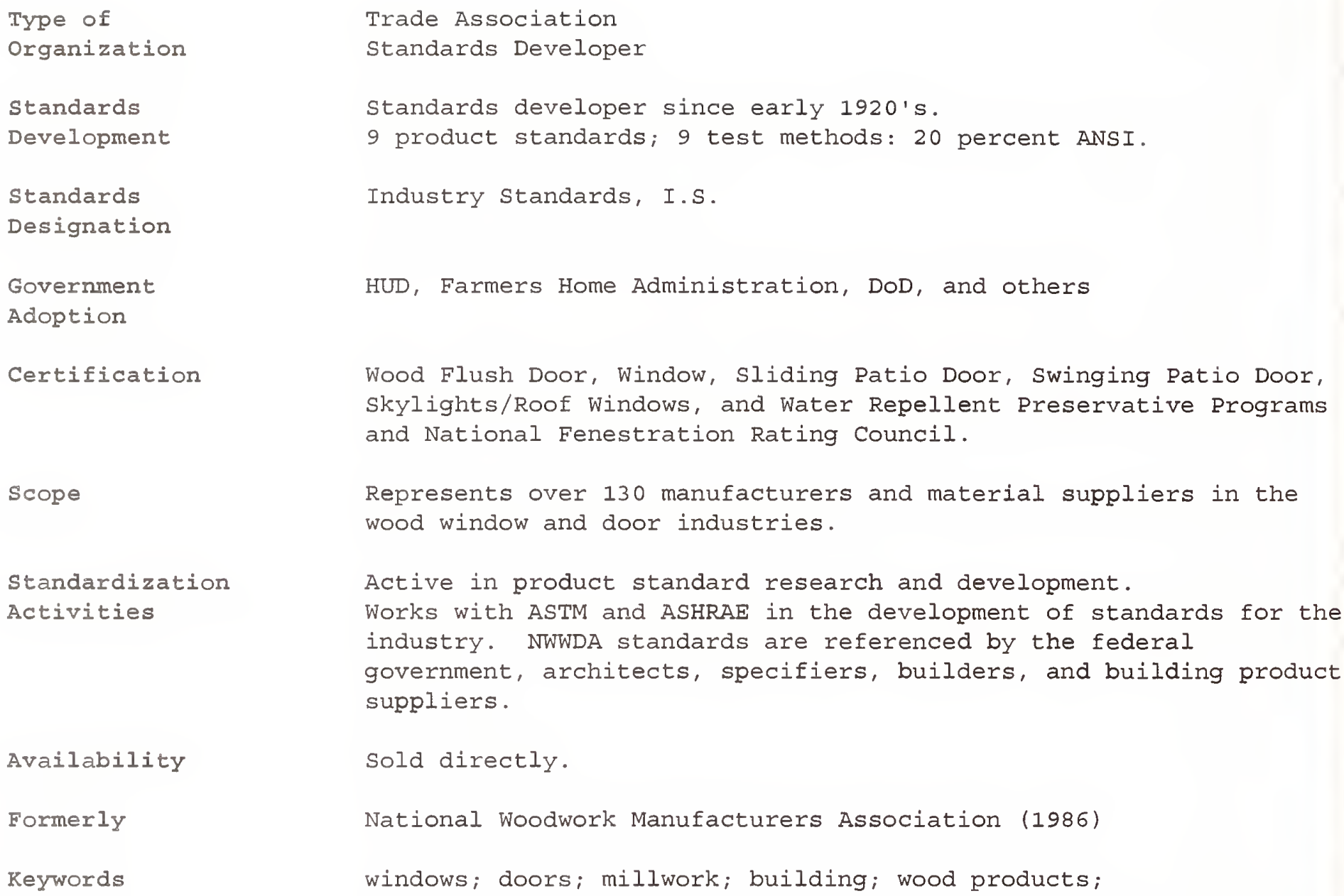

Wood Flush Door, Window, Sliding Patio Door, Swinging Patio Door, skylights/Roof Windows, and water Repellent Preservative Programs and National Fenestration Rating Council.

Represents over 130 manufacturers and material suppliers in the wood window and door industries.

Active in product standard research and development. Works with ASTM and ASHRAE in the development of standards for the industry. NWWDA standards are referenced by the federal government, architects, specifiers, builders, and building product suppliers.

Sold directly.

National Woodwork Manufacturers Association (1986)

windows; doors; millwork; building; wood products;

\section{NATIONAL WOODEN PALLET AND CONTAINER ASSOCIATION}

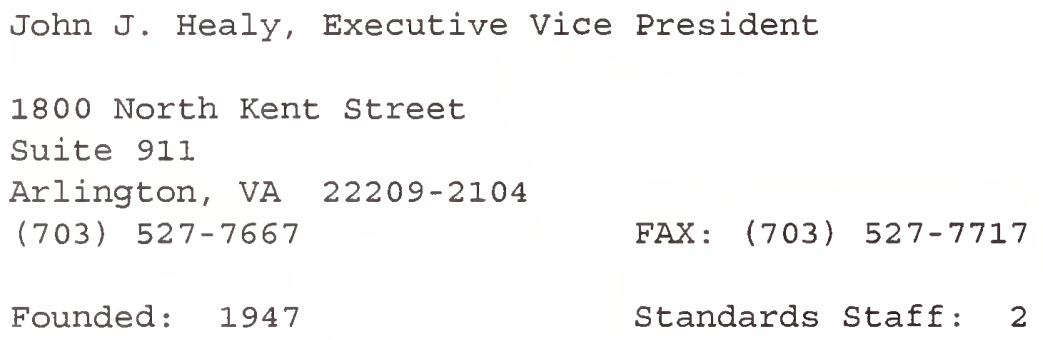

Type of

Organization

Standards

Development
Trade Association

Standards Developer

Standards development was initiated in 1990 and 150 members and nonmembers participate. Developer of The Uniform Standard for wooden Pallets which has been processed through ANSI. 
SPEQ is a certification program affording pallet customers the opportunity to design a pallet specifically engineered to their performance needs. Once armed with a PDS design, adherence to the quality provisions of the standard is checked by an independent third party inspection service. Upon successfully passing periodic random audits, SPEQ suppliers/recyclers are recertified and permitted to mark their product to indicate compliance.

Trade association consisting of pallet and container manufacturers, recyclers, brokers, and associated industries. International membership exceeding 550 companies. NWPCA mission is to assist members to create cost-effective, environmentally responsible solutions to meet their customers changing unit load material handling needs. Primary activities include sponsoring industrial research and development, standards development, trade promotion, education, and legislative/regulatory monitoring.

Developed the first U.S. Industrial standard for the manufacture and repair of wood pallets. Introduced in 1994, and processed for adoption as an ANSI standard. Uniform standard for wood pallets is a quality assurance standard designed to complement customer's pallet performance requirements and standards. Also complements the Pallet Design System (PDS), the first computer-aided design (CAD) system for wood pallets. PDS and the standard serve as the base programs for the specified Pallets, Engineered for Quality (SPEQ) Program.

Copies of the standard are available directly from NWPCA.

Merger of National Wooden Box Association and National Wood Pallet Manufacturers Association (1947)

pallets; paletization, unit load management; packaging; containers;

John V. Bergen, Ph.D., Executive Director

940 West Valley Road

Suite 1400

Wayne, Pennsylvania 19087

(610) 688-0100

FAX: (610) 688-0700

Founded: 1968

Standards Staff: 23

Type of

Organization

Voluntary Consensus Standards Developer 
standards

Development

Standards

Designation

Secretariats

Certification

Scope

Standardization

Activities
Accredited by ANSI.

Over 1800 scientists participate in 155 projects

128 standards and guidelines available; 54 at approved level, 25

at tentative level, and 49 at proposed level

Approximately 20 percent of NCCLS standards are

processed through ANSI for designation as American National

Standards 179 active members (professional organizations,

governmental agencies, industrial organizations) 1600

corresponding members (hospitals, state agencies, universities,

clinical laboratories, international organizations).

NCCLS standards are designated by a code indicating the discipline, the project number, the publication level and, if applicable, the edition; e.g., GP18-P (General Laboratory Practices/Proposed), M2-A5 (Microbiology/Approved/5th Edition).

Administrator of ISO/TC 212, Clinical Laboratory Testing and In Vitro Diagnostic Test Systems; Technical Advisory Group ISO/TC 212; Technical Advisory Group ISO/TC 76, Transfusion, Infusion, and Injection Equipment for Medical Use.

Administers the National Reference System for the Clinical Laboratory (NRSCL) which provides the scientific basis to ensure that clinical laboratory tests results can be interchanged within defined limits of accuracy and precision.

An international, interdisciplinary, nonprofit organization that serves the world's medical science community by improving the quality of laboratory practices and medical testing through voluntary consensus processes. In addition to developing voluntary consensus standards and guidelines, NCCLS maintains a communication forum for its laboratory constituencies to address and resolve issues that are critical to laboratory quality. NCCLS's membership is made up of medical laboratory professional associations, agencies of the federal, state, and provincial governments, manufacturers of laboratory equipment and reagent products, trade associations, and individual health care provider institutions and clinical laboratories. Members participate in the development of proposed, tentative, and approved NCCLS standards and guidelines.

Develops standards in eight areas: clinical chemistry, evaluation protocols, general laboratory practices, immunology and ligand assay, hematology, microbiology, molecular methods, and alternate site testing. 
Publications focus on laboratory procedures, bench and reference methodologies, and scientific evaluation protocols, providing realistic standards and guidelines for clinical laboratory testing. Standards publications include those relating to antimicrobial susceptibility testing, blood collection, and clinical laboratory instrumentation.

Availability

Formerly

Keywords
Distributed directly. Interested parties may obtain a complimentary subscription to "Standards status" providing announcements related to the status of NCCLS standards development including information on availability of proposed and tentative standards for review and comment, and announcements of publication of approved standards.

National Committee for Clinical Laboratory Standards

clinical chemistry; medical instruments; laboratory; testing; immunology; hematology; microbiology; ligand assay; molecular methods; public health; reference technology; physician's office laboratory; alternative site testing;

NEBRASKA POWER LABORATORY

\author{
Dr. Louis I. Leviticus \\ BSEL Building - East Campus \\ University of Nebraska \\ Lincoln, Nebraska 68583-0832 \\ (402) 472-2442 FAX: (402) 472-8367 \\ e-mail: BSEN011@UNLVM.UNL.EDU \\ Founded: 1926 \\ Testing, research and development organization \\ Standards Developer \\ Represented on relevant SAE, ASAE and OECD committees \\ as well as active in ISO Technical Advisory groups \\ Witness certification tests at manufacturer's facilities. \\ cooperates in performing laboratory services for other \\ organizations and is active in international standards \\ development. Chief activity is testing and research for \\ performance, protective structure and noise testing of tractors \\ according to SAE and OECD standards.
}


Standardization

Activities

Keywords
Develop new standards to meet new technology requirements such as test methods for new biofuels, including exhaust emissions testing.

NETWORK MANAGEMENT FORUM

agricultural equipment; tractors; acoustics; emissions;

Type of

Organization

standards

Development

Standards

Designation

Government

Adoption

Certification

scope

Standardization

Activities
Elizabeth Adams, Managing Director

$1201 \mathrm{Mt}$. Kemble Avenue

Morristown, New Jersey 07960

(201) 425-1900

FAX: (201) 425-1515

e-mail: eadams@nmf.org

Founded: $1988 \quad$ Standards Staff: 9

Nonprofit Industry Consortium

Create procurement and development specifications based on international standards in the telecommunications industry which serve as implementation agreements for automating and integrating management systems.

Business level agreements designated as "SMART"

Management systems interface specifications designated as OMNIPoint.

Computing platform specifications designated as SPIRIT.

Documents are used by DISA and are part of the GNMP

document.

Also adopted by Canadian, British and Australian governments.

No certification programs.

The NMF has more than 160 members in 30 countries. It is an international forum of telecom service providers, computer and communications system suppliers and enterprise network operators focused on the problems of managing complex service networks. It serves as a place where cross-industry, worldwide agreement can be reached on the key issues that enable timely deployment of high quality, cost effective telecommunications services.

NMF establishes working teams to investigate and determine business requirements, information exchange agreements and technical specifications. Work is done in conjunction with other standards bodies and organizations such as ITUT, ANSI T1, IETF, OIW, AOW, ETSI, X/Open, OSF, OMG, ATMF and ATIS. 
Availability

Keywords

The NMF does not create standards. Rather, it takes base standards, matches them to a specific business problem then refines them to a specific enough level of detail through the consensus of its membership so that interoperability between systems is assured.

Results are published in a series of guidebooks, papers, solution Sets (specifications) and electronically.

Distributed directly, through Phillips Publishing and electronically at http://www.nmf.org.

network management; service management; OsS; process reengineering; telecommunications management;

NORTH AMERICAN DIE CASTING ASSOCIATION

Type of

Organization

scope

Standardization Activities
Derek L. Cooks, Technical Director

2000 North Fifth Avenue

River Grove, Illinois 60171-1992

(312) 452-0700

FAX: (312) 452-0147

Founded: $1954 \quad$ Standards Staff: 2

Trade Association

Works through other organizations to develop standards

A not-for-profit organization which serves the interests of its members with the overall objectives of improving industry technology productivity and profitability. Member services include providing information and statistics for managers, administrators and engineers. The association has active research and educational programs and produces a considerable number of publications of both technical and managerial nature.

The association maintains close links with organizations which set (or are involved with) standards pertaining to the die casting industry. These include the American National Standards Institute, the American Society for Testing Materials, Occupational Safety \& Health Administration and the Environmental Protection Agency. 
die casting; cast metals; net shape; metals;

\section{NORTH AMERICAN INSULATION MANUFACTURERS ASSOCIATION}

\section{Type of \\ Organization \\ Representation}

Certification

scope

Standardization Activities

Formerly

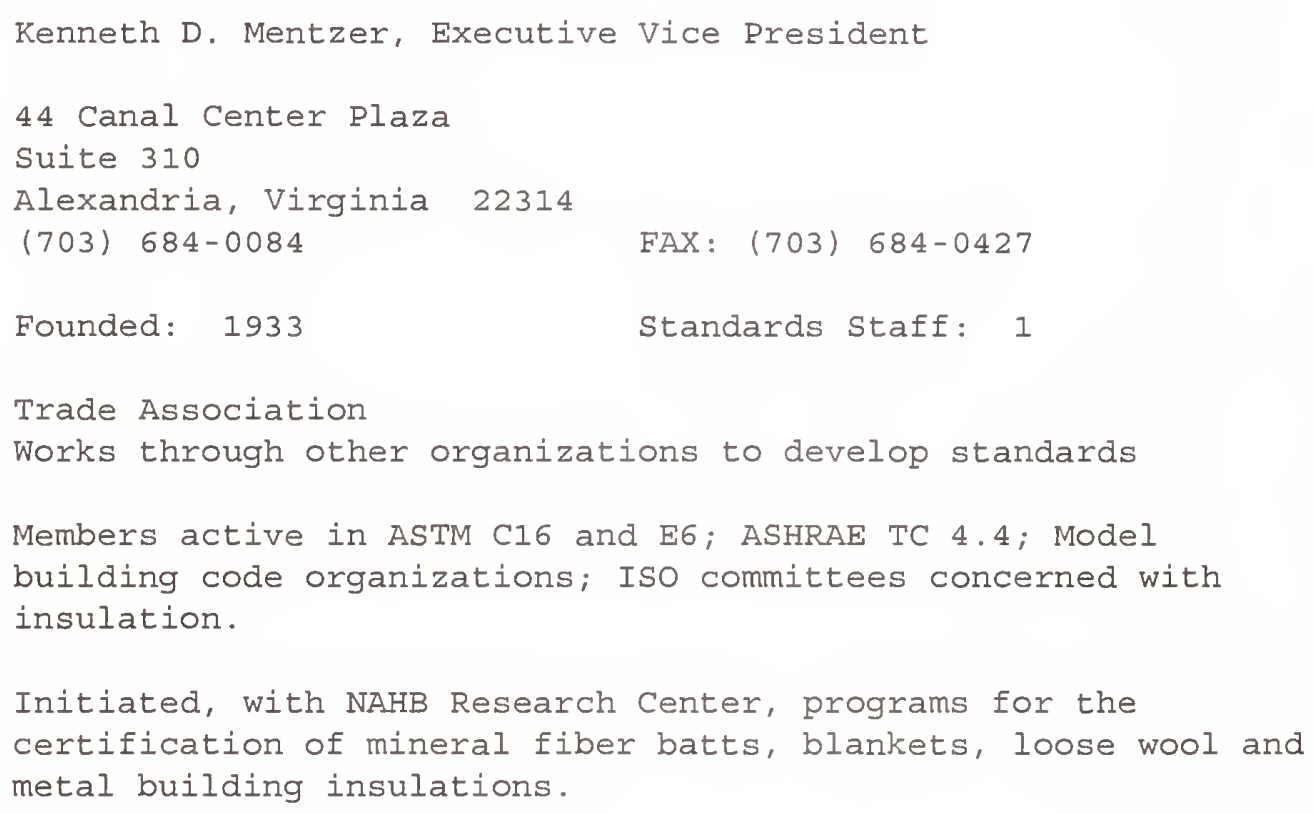

A nonprofit organization rendering services to promote energyefficiency and environmental preservation through the safe manufacture and use of fiber glass, rock wool and slag wool insulation products.

Develops standards and specifications, national in scope, referring to fiber glass, rock wool and slag wool insulation products. Cooperates with and advises government agencies at all levels on thermal performance standards that will contribute to the conservation of energy. Also advises and consults with other energy suppliers and professional organizations regarding standards, research, applications, and other related matters.

National Association of Rock and Slag wool Industries (1933) National Rock and Slag Wool Association (1936) National Mineral Wool Association (1938) National Mineral Wool Insulation Association (1960) Mineral Insulation Manufacturers Association, Inc. (1978) Mineral Insulation Manufacturers Association 


\section{NORTHEASTERN LUMBER MANUFACTURERS ASSOCIATION}

Stephen S. Clark, Executive Vice President

272 Tuttle Road

Post Office Box 87A

Cumberland Center, Maine 04021

(207) 829-6901 FAX: (207) 829-4293

Founded: $1933 \quad$ Standards Staff: 2

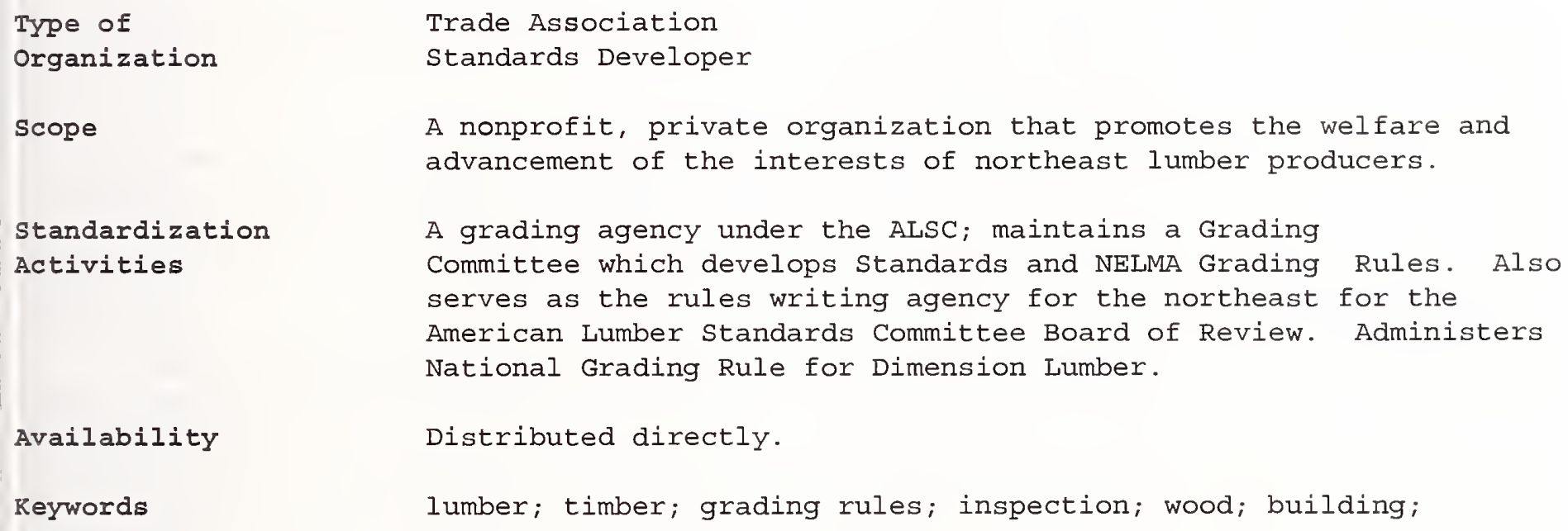

lumber; timber; grading rules; inspection; wood; building;

Availability

Keywords

\section{NORTHERN TEXTILE ASSOCIATION}

see ELASTIC FABRIC COUNCIL

and FELT MANUFACTURERS COUNCIL

Diana Knoll, Publications Supervisor

3475 Plymouth Road

Ann Arbor, Michigan 48105

(313) $769-8010$

FAX: (313) 769-0109

WWW: http://WwW.nsf.com 
Founded: 1944 Standards Staff: 11

Type of

Organization

Standards

Development

Government

Adoption

Certification

scope

Standardization

Activities

Availability

Formerly

Keywords
Standards Developer and Testing Organization

Standards developer since 1944.

43 active standards and criteria.

Voluntary program involving the active cooperation and

participation of the manufacturer, the user, and the regulatory officials.

Accredited by ANSI.

33 standards processed through ANSI.

Many United states regulatory jurisdictions require by

law, regulations, or department policy, products which comply with NSF standards or criteria.

Products determined in compliance with NSF standards or criteria by NSF Certification Services are authorized for listing and display the NSF Mark.

A noncommercial and not-for-profit standards writing, research, testing, and educational organization. Seeks answers in environmental health and establish public and environmental health standards with the cooperation of all concerned.

Involves approximately 2300 domestic and foreign manufacturers who use the NSF Mark on products meeting the applicable standard or criteria. Publishes and distributes a list of available standards as well as annual listings covering food service equipment, plastic piping system components and materials, swimming pool equipment, drinking water direct and indirect additives, and special categories, including plumbing components for mobile homes and recreational vehicles, water and wastewater treatment devices, bio-hazard cabinetry, and flexible membrane liners and environmental management systems.

Distributed directly and through IHS and Global.

National Sanitation Foundation

food equipment; plastic pipe; swimming pool; mobile homes; recreational vehicles; water; waste; environment; public health; sanitation; building; environmental management; drinking water additives; 
Robert L Dziuban, Executive Director

P.O. Box 2000

Merrifield, Virginia 22116-2000

(703) $359-2830$

FAX: (703) 359-2834

Founded: 1894

Standards Staff: 1

Type of

organization

Representation

secretariats

scope

Standardization

Activities

Availability

Formerly

Reywords
Trade Association

Standards developer

Represents its American members to both ASTM and ANSI by providing relevant data and input to the creation of consensus standards which affect the manufacturer, laboratory, professional, and consumer.

ANSI Committee 280 , Ophthalmic Standards

An association for independent ophthalmic prescription eyeglass and contact lens fabricators located in the United States, Canada, and other foreign countries.

Its primary objective is the creation and maintenance of voluntary standards which meet the safety and effectiveness needs of the consumer by providing products which perform within the current state of the manufacturing art.

Participates with industry and professionals in the maintenance of existing standards to eliminate design in favor of performance requirements wherever possible, and to keep industry standards in line with advances in technology. As new technologies develop, the Association assumes an active role in the assessment of proper performance standards and testing techniques.

Distributed directly.

American Association of Optical wholesalers (1894)

Central States Wholesalers Association (1939)

Association of Independent Optical Wholesalers (1942)

Optical Wholesalers Association (1962)

Optical Laboratories Association (1977)

ophthalmic products; eyeglass; spectacle; contact lens; optical laboratory; low vision aids; intraocular lenses; ophthalmic instruments; frames; sunglasses; 


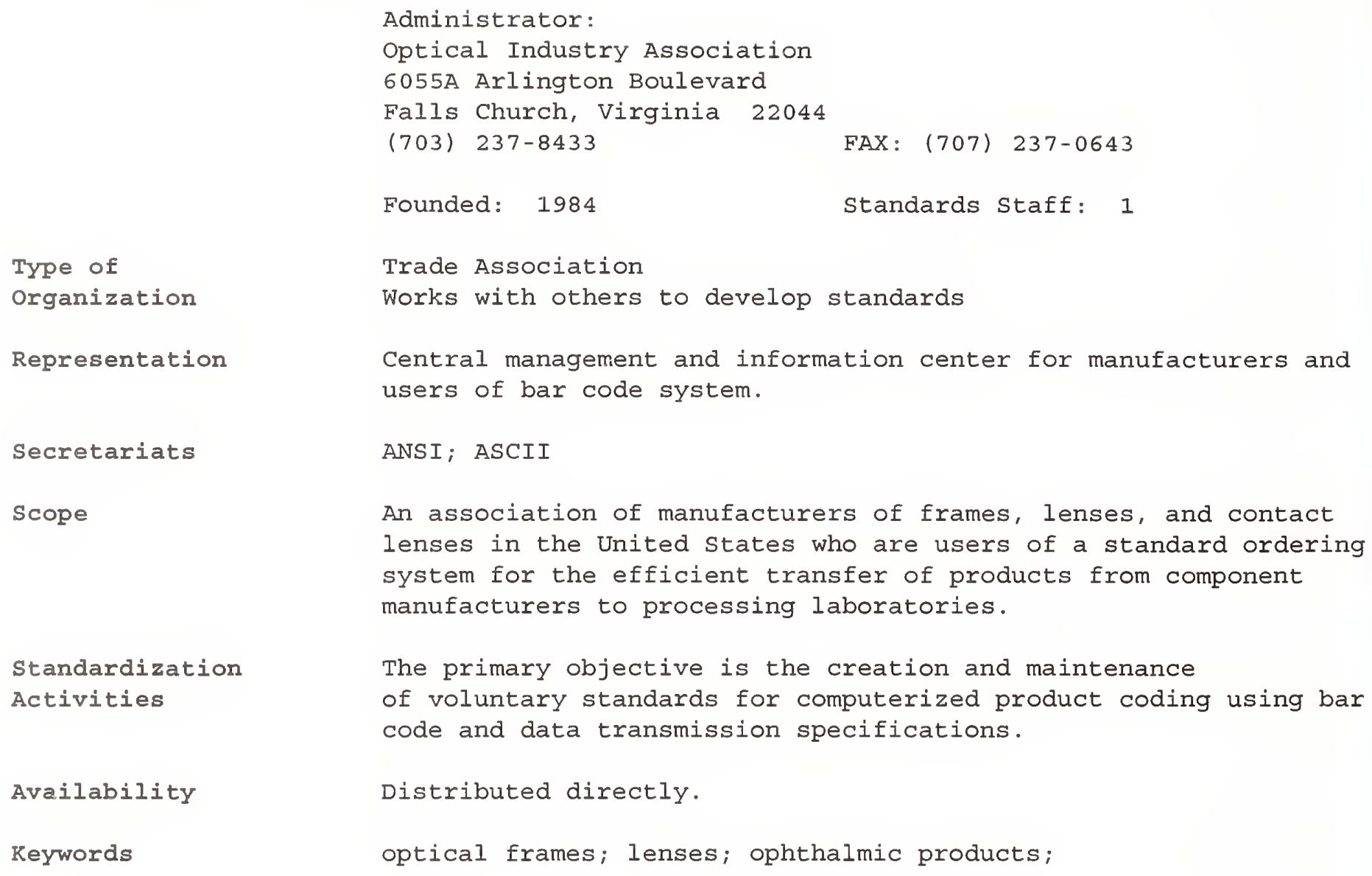

standardization Activities

Availability

Distributed directly.

Keywords

optical frames; lenses; ophthalmic products;

The primary objective is the creation and maintenance of voluntary standards for computerized product coding using bar code and data transmission specifications.

OPTICAL SOCIETY OF AMERICA

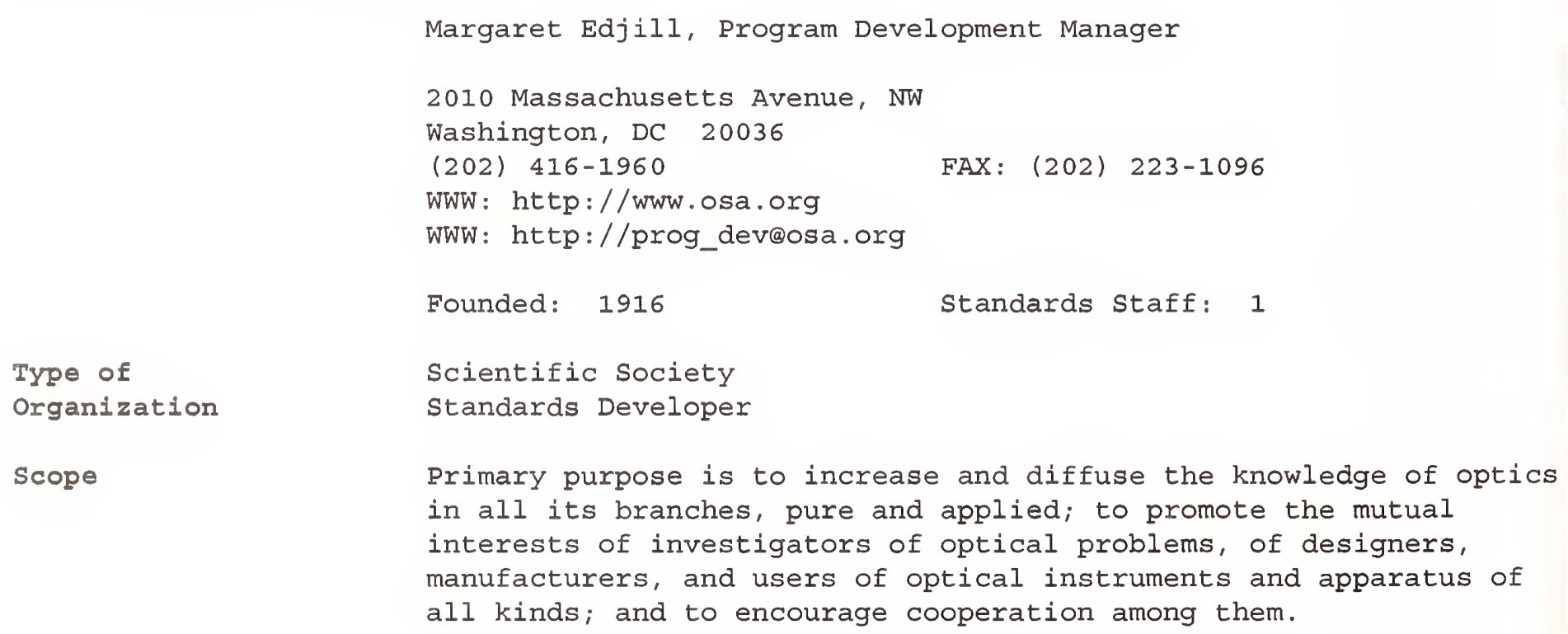

Type of

Organization

scope 
Standardization Activities

Availability

Keywords
Standardization and specification work is handled by a joint society committee which publishes reports in the society's journal on visual sensitometry; colorimetry; photometry; standard wavelengths; nomenclature and standards; photography; radiometry; and spectrophotometry. The most elaborate of these technical reports appeared as a book, The science of Color, and as a set of uniformly spaced color samples. Cooperates with other technical organizations in standardization within the various branches of optics. Has a standing committee for review of Iso standards. Cooperates actively with the International Commission for Optics, the International Commission on Illumination and the American National Standards Institute. Maintains representation on boards or committees of the American Institute of Physics, the National Research Council, the American Association for the Advancement of Science, and the Inter-Society Color Council.

Sold directly.

optics; optic instrumentation; colorimetry; photography;

\section{ORTHOPEDIC SURGICAL MANUFACTURERS ASSOCIATION}

Max Sherman, Executive Secretary

Post Office Box 1846

Warsaw, Indiana 46581-1846

(219) 269-1928

FAX: (219) 267-3845

Founded: 1955

Type of

Organization

Representation

Scope
Trade Association

Works through other organizations to develop standards

ASTM, ISO, and ANSI

Manufacturers and distributors of orthopedic devices and instrumentation used in reconstructive surgery done by orthopedic surgeons. Established to promote the patient's best interest by standardization of materials and sizing. Develops guidelines, fosters research, disseminates knowledge and information relating to scientific and practical problems, cooperates with professional health associations, interfaces with governmental agencies, and promotes high ethics in all phases of the surgical supply industry. 
Standardization

Activities

Keywords

OUTDOOR POWER EQUIPMENT INSTITUTE

Type of

Organization

Standards

Development

Certification

Secretariats

Scope

Standardization

Activities

Availability

Formerly Tillers.
24 member firms have employees active in development of medical device standards. Representatives serve as officers and members of various standards development organizations including ASTM, ISO, and ANSI. They participate in policy making decisions and in the content of test methods and standards pertaining to medical devices.

orthopedic surgery; medical devices;

Dennis C. Dix, President and CEO

341 South Patrick street

Alexandria, Virginia 22314

(703) $549-7600$

FAX: (703) 549-7604

Founded: 1952

Standards staff: 2

Trade Association

Standards Developer

Standards developer since 1956.

78 members participate in standards activities.

AlI OPEI sponsored standard are developed under ANSI's

Canvass Procedures. All draft standards are available for review.

Through the services of an independent testing

laboratory, OPEI conducts a 3rd party voluntary certification

program for each of the OPEI sponsored voluntary standards

approved and published by ANSI.

For each of the standards listed above and U.S.

Technical Advisory Group to Iso/TC 23/SC 13, Powered Lawn and Garden Equipment.

A national trade association representing manufacturers of power lawn mowers, snow throwers, roto tillers, commercial turf care equipment, garden tractors and related equipment and attachments.

Developed ANSI B71.1 Power Lawn Mowers; B71.3, Snow

Throwers; B71.4, Commercial Turf Care Equipment; B71.5, Sound Test Method; B71.6, Shredder/Grinders; B71.7, Logsplitters; and B71.8,

Published standards may be obtained through ANSI.

Draft proposed standards may be obtained directly.

Lawn Mower Institute, Inc. 
lawn equipment; lawn mowers; snow throwers; shredders;

logsplitters; roto tillers; garden tractors; agriculture;

acoustics; consumer products;

\section{PACKAGING MACHINERY MANUFACTURERS INSTITUTE}

Type of
Organiza

organization

Scope

\section{Standardization}

Activities

Keywords
Charles D. Yuska, President

4350 North Fairfax Drive

Suite 600

Arlington, Virginia 22203

(703) 243-8555

FAX: (703) 243-8556

Trade Association

Works through other organizations to develop standards

A voluntary nonprofit association of United States companies manufacturing packaging machinery and packaging-related converting machinery. Seeks to solve problems of the packaging machinery industry and provides information and services to member companies, users of packaging and converting machinery, the Government, and the general public.

Maintains Product Safety and Technical Information Committees. A member of the American National Standards Institute and supports its work with the International Organization for Standardization. Works with the Occupational Safety and Health Administration to publish a safety standard for the Care, Use, and Construction of Packaging Machinery.

Cooperates with associations such as the Fibre Box Association and the Adhesives Manufacturers Association of America in promoting recommended practices on the storage, maintenance, and application of adhesives used in conjunction with automatic packaging machinery.

packaging; machinery;

\section{PAINTING AND DECORATING CONTRACTORS OF AMERICA}

Paula D. Clements, Executive Director

3913 Old Lee Highway, Suite 33B

Fairfax, Virginia 22030

(703) 359-0826 FAX: (703) 359-2576

Founded: 1884 
Type of

Organization

Scope

Standardization

Activities

Keywords
Trade Association

Works through other organizations to develop standards

Represents painting and decorating contractors

throughout the United States. Endeavors to maintain high standards of workmanship and safety in the painting, decorating, drywall, wallcovering, and coating industries. Committee activities involve labor, public, and government relations.

Works with the National Safety Council, OSHA, ANSI, and other organizations such as Associate specialty Contractors, American Subcontractors Association to develop standards for wall covering, scaffolding and ladders, and general safety in the industry.

painting; wallcovering; safety;

PAPERBOARD PACKAGING COUNCIL

John A. McIntyre, President

888 17th Street, NW

Suite 900

Washington, DC 20006

(202) 289-4100 FAX: (202) 289-4243

Founded: 1967 Standards Staff: 2

Type of

Organization

scope

standardization

Activities
Trade Association

Develops recommended practices

A nonprofit national trade association representing companies in the production and conversion of paper-board into folding cartons and packages. Functions include marketing information and statistics, industrial relations, safety, technical and production, and government affairs.

Maintains a Technical and Production Committee, and special ad hoc groups established for the administration of standards activities.

Issues guidelines and standards for the paperboard packaging industry, as a set of voluntary industry standards and specifications recommended for users and suppliers of folding paper cartons. Cooperated with the federal government in the development of simplified practice recommendations for margarine cartons, rectangular ice cream cartons, and bacon carton. Involved in standards for printing nutritional labeling and Universal Product Code symbols on fluid milk cartons. Also cooperates with the Government in reviewing and commenting on federal specifications. 
Keywords

PERLITE INSTITUTE
Distributed directly.

Merger of several groups including the Folding Paper Box Association and The Institute for Better Packaging.

packaging; containers; cardboard;

Paul J. Julius, Managing Director

88 New Dorp Plaza

Staten Island, New York 10306

(718) $351-5723$

FAX: (718) 351-5725

Founded: 1949

Standards Staff: 2

Type of

Organization

Trade Association

Standards Developer

Standards

Development

Standards developer since 1949.

65 members participating in standards activities.

20 active standards.

None processed through ANSI.

Draft standards not available for review.

Standards

Designation

Government

Adoption

Scope
Standardization Activities
PI prefix.

Various government agencies have adopted ASTM standards on perlite including GSA, FHA, and VA.

A national and international nonprofit trade association which sponsors research leading to standardization of specifications and methods of testing perlite and perlite products. Collects data, initiates and correlates research, and develops specifications and test methods. Cooperation with technical and engineering societies, other trade associations, and government agencies interested in standards.

Activities are directed toward fulfilling producer, and customer requirements. Works closely with Underwriters Laboratories (UL), International Conference of Building officials (ICBO), Southern Building Code Conference International (SBCCI), National Institute of standards and Technology (NIST), Building officials and Code Administrators (BOCA), and other agencies and industry organizations. 
Publishes test methods and related standards containing test methods for evaluating quality of expanded perlite, and American Society for Testing and Materials specifications applicable to perlite. Publishes standards for perlite products used in building, industrial, and horticultural industries.

Availability

Keywords

PERSONAL COMPUTER MEMORY CARD INTERNATIONAL ASSOCIATION
Distributed directly.

perlite; insulation; aggregate; abrasives; materials;

Bill Lempesis, Executive Director and COO

2635 N. First street

Suite 209

San Jose, California 95134

(408) 433-2273

FAX: (408) 433-9558

e-mail: blempesis@pcmcia.org

WWW: http://www.pc-card.com

Founded: 1989

Standards staff: 9

Type of

Organization

Trade Association

Standards

Standards Developer

Development

Develop standards for PC cards.

Scope

Association of over 500 companies representing computer manufacturers.

Standardization

Activities

Promote the worldwide adoption of PC Card technology by defining technical specifications and proactively marketing the technology.

Availability

Distributed directly.

Keywords

PC Card; PCMCIA; mobile computing; computers; computer peripherals; security cards;

PHARMACEUTICAL RESEARCH AND MANUFACTURERS OF AMERICA

Thomas $\mathrm{X}$. White, Associate Vice President,

110015 th street, NW

Washington, DC 20005

(202) 835-3546

FAX: (202) 835-3797

Founded: 1958 


\section{Type of}

Organization

Representation

Scope

\section{Standardization}

Activities

Formerly

Keywords
Trade Association

Works through other organizations to develop standards

Participates in standards developing activities of the Food and Drug Administration, the U.S. Pharmacopoeia, the National Formulary, AAMI, ANSI, ASTM, and other public and private standards setting organizations.

A nonprofit trade organization representing firms that discover, develop, and produce prescription drugs and biological products. The Association's members produce most of the prescription drugs marketed in the United States, and a large part of the world's supply. The Association's principal objectives are: (1) to encourage high standards in the research, development, production and marketing of drug products; (2) to develop and disseminate information about the pharmaceutical industry to the public, all levels of government, the media, international organizations, and other groups; (3) to help keep industry abreast of government actions and public concerns; and (4) to work with member companies, other health related organizations, government and consumer entities, and the public to advance medical science and improve health-care services.

Participates in developing methods of analysis and standards for drugs and biologicals. Participation is either by staff (approximately one to two person years per year) or representatives of member companies drawn from PhRMA's Science and Regulatory Sections.

Pharmaceutical Manufacturers Association (name change May 1994)

drugs; pharmaceuticals; biologicals; health care;

\section{PHOTOGRAPHIC SOCIETY OF AMERICA}

Terry S. Stull, Operations Manager

3000 United Founders Boulevard

Suite 103

Oklahoma City, Oklahoma 73112

(405) 843-1437

Founded: 1933

Standards staff: 10

Type of

Organization

User Association

Standards Developer 
Standards

Development

Standards

Designation

Scope

Standardization

Activities

Availability

Formerly

Keywords
3 active technical standards.

8 active uniform practices.

PSA Technical Standards.

PSA Uniform Practices.

A nonprofit organization, international in scope.

Promotes the arts and sciences of photography and furthers public education in the field. Interests of members include the uses of all types of photographic materials, their applications, and characteristics of their manufacturer.

Through its Technical standards Committee, formulates technical standards. Affiliated with ANSI and has representatives on $\mathrm{PH}$ sectional committees on photography, as well as membership on the Photographic Technical Advisory Board. Representatives selected to represent its interests are chosen on the basis of their competence as users and their technical knowledge in the field. Establishes practices and requirements for judging and exhibition, safe handling, and other rules which contribute to the success of international photographic and camera events on a worldwide basis.

Distributed directly.

Associated Camera Clubs of America

photography; camera; film;

PIPE FABRICATION INSTITUTE

Lois A. Moore, Executive Director

Post Office Box 173

612 Lenore Avenue

Springdale, Pennsylvania 15144

(412) 274-4722 FAX: (412) 274-4722

Founded: 1913 Standards Staff: 1

Type of

Organization

Scope
Technical Society

Standards Developer

Producers and designers of high pressure/high temperature piping systems for chemical plants, refineries, central power stations, and ships; concerned with technical and economic problems of the piping industry. 
standardization

Activities

Availability

Keywords

PIPE LINE

CONTRACTORS
The standards and technical bulletins developed by the Engineering Committee cover the design, fabrication and erection of industrial and high pressure/high temperature piping to meet the requirements of power plants including nuclear, fossil, chemical, petroleum, and process piping. Through its members, the institute is officially represented on various code bodies and national engineering societies.

Distributed directly and through IHS.

pipe; pipe fabrication; industrial equipment;
Type of

Organization

Representatives

Scope

standardization

Activities

Keywords
J. Patrick Tielborg, Managing Director and General Counsel

1700 Pacific Avenue, Suite 4100

Dallas, Texas 75201-4675

(214) 969-2700 FAX: (214) 969-2705

Founded: 1947

Trade Association

Works through other organizations to develop standards

Four contractor members serve on the API-AGA 1104 Joint Welding Committee composed of industry representatives and sponsored by the American Petroleum Institute and the American Gas Association.

Association of contractors, equipment manufacturers, suppliers, and dealers of main-line pipe line. Represents the industry in labor negotiations. Promotes cooperation, efficiency, and safety in the main-line pipe line construction industry.

Reviews and revises API Standard 1104, Standard for Welding Pipe Lines and Related Facilities.

petroleum pipe lines; construction; 
Thomas S. Walsh, PhD, Executive Director

1275 K Street, NW

suite 400

Washington, DC 20005

(202) 371-5306

FAX: (202) 371-1022

Founded: 1949

Standards Staff: 4

Type of

Organization

Scope

Standardization

Activities
Trade Association

Standards Developer

Dedicated to creating broader markets and market opportunities for plastics pipe and related products.

Maintains a Technical Committee which represents its members in standards Writing and Code Writing organizations, including: ASTM F-17, Thermoplastic Piping systems; ANSI B31.3, Chemical and Petroleum Piping Code; American Petroleum Institute, (oil and gas production piping); American Water Works Association, (water distribution piping); the National Sanitation Foundation (potable water quality); North American society For Trenchless Technology; National Association of sewer service Co.

Maintains a Hydrostatic Stress Board which writes standard policies and procedures for the forecasting of the long-term strength of plastic piping products and plastics piping thermoplastic materials. The Board also issues listings of Hydrostatic Design Stress recommendations for thermoplastics materials. These recommendations are referenced by many ASTM and other standards.

The Fuel Gas Division develops educational material used by gas companies and federal and state agencies for the training of operators and inspectors in proper and safe use of plastics gas piping; maintains close liaison with Department of Transportation and other government agencies which regulate the use of plastics piping for fuel gas; maintains close liaison with user group technical committees such as those of the American Gas Association and the American Petroleum Institute.

The Municipal and Industrial Division develops technical information, guides and manuals related to the use of plastics piping for municipal and industrial applications; it represents members before appropriate associations and organizations.

The Municipal and Industrial Division assists AWWA in development of appropriate standards and maintains liaison with key government agencies including EPA, HUD, etc. 


\section{PLUMBING AND DRAINAGE INSTITUTE}

Sol Baker, Executive Director

1106 W 77th street, South Drive Indianapolis, Indiana 46260-3318

(317) 251-6970 FAX: (317) 253-8295

Standards Staff: 1
Organization

\section{Standards}

Development

standards

Designation

Government

Adoption

Certification

Scope
Type of plastic pipe; pipe; building; construction; gas distribution; water distribution; sewer and waste; industrial; trenchless technology;
Trade Association

Standards Developer

9 active standards.

7 processed through ANSI.

PDI-G, PDI-WH, and ANSI prefixes.

Used extensively by General Services Administration, Department of the Army, Coast Guard, and Department of Veterans Affairs.

Provides certified testing, rating, and installation procedures for grease interceptors and water hammer arresters. Testing equipment is maintained by independent laboratories. Furnishes certification seals which provide evidence that a product has met PDI performance standards.

An association of manufacturers of plumbing and drainage products. Promotes the advancement of plumbing engineering and the plumbing industry through public relations, research, and product standardization.

Maintains an Engineering Committee which engages in product certification and standards development in the areas of backwater valves, hydrants, floor and roof drains, grease interceptors, water-hammer arrestors, plumbing fixture supports, and cleanouts. Cooperates with the American Society of Mechanical Engineers in the development of ANSI standards. 
Availability

Formerly

Keywords
Distributed dixectly and through ASNE.

Plumbing and Drainage Manufacturers Association (1954)

Plumbing Manufacturexs Association (1949)

plumbing; dxainage pxoducts; building; sanitation;

\section{POLYURETHANE MANUFACTURERS ASSOCIATION}

\author{
Type of \\ Organization \\ Scope \\ Standardization \\ Activities
}

Arailability

Keywords

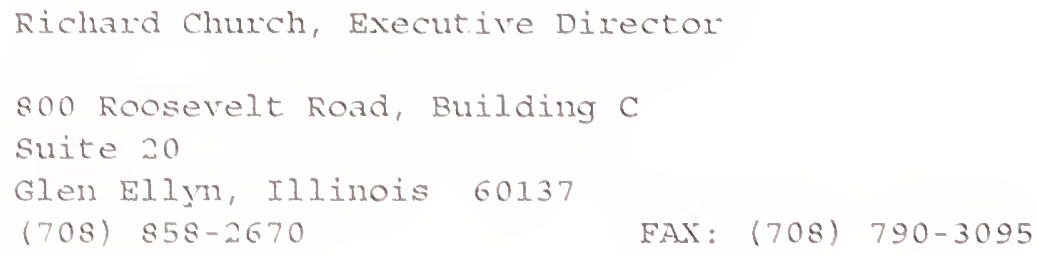

A pxivate, nonprofit trade association of companies involved in the manufacture of solid polyurethane thexmosetting elastomers and their related chemical and equipment suppliexs. Promotes and maintains an oxganization fox the mutual adrancement and welfaxe of its members and the polruxethane industry.

Maintains a standaxds Committee whose puxpose is to select and standardize physical test procedures suitable for use with solid polyurethane elastomers, and to promote and disseminate these recommended practices throughout the industry. The two phase program consists of evaluation and selection of existing specifications suitable for use with solid polyuethane; and modification of new test pxoceduxes suitable fox use as an educational tool. specifications booklet being revised to include new standaxds for cast uxethanes and specifications fox RIM processing of urethumes.

Distributed directly.

polyuethane; materials; 
Donald R. Sauder, Executive Vice President

102 Woodmont Boulevard

Suite 360

Nashville, Tennessee 37205

(615) $298-1250$

FAX: (615) 298-9858

Founded: 1930

Standards Staff: 2

Type of

Organization

Standards

Designation

Scope

\section{Standardization}

Activities

Trade Association

Standards Developer

PEI, ASTM, and ANSI prefixes.

Manufacturers of major appliances and sanitaryware with porcelain enameling facilities contract porcelain enamel companies and suppliers to the industry. Conducts market development programs, develops test methods for evaluation of porcelain enamel properties.

Works primarily through the voluntary standards development system utilizing the committee system of ASTM and ANSI. Also develops and maintains standards and specifications for specialized sectors of the porcelain enameling industry. In addition, serves as conduit of industry input into governmentinitiated standards.

Distributed directly.

porcelain enamel; appliances; plumbing fixtures; cookware; materials;

\section{PORTABLE POWER EQUIPMENT MANUFACTURERS ASSOCIATION}

Donald E. Purcell, President

4720 Montgomery Lane

Suite 812

Bethesda, Maryland 20814

(301) 652-0774

FAX: (301) 654-6138

Founded: 1977

Standards Staff: 2

Type of

Organization

Trade Association

Works through other organizations to develop standards

No certification, qualification, or accreditation programs. 


\begin{tabular}{|c|c|}
\hline Secretariats & ANSI B175 Committee. \\
\hline Scope & $\begin{array}{l}\text { A nonprofit industry organization representing manufacturers of } \\
\text { gasoline and electrically powered chain saws and their component } \\
\text { parts. }\end{array}$ \\
\hline $\begin{array}{l}\text { Standardization } \\
\text { Activities }\end{array}$ & $\begin{array}{l}\text { PPEMA standardization programs are confined to partici- } \\
\text { pation in the development of standards under the auspices of } \\
\text { national and international voluntary standards setting } \\
\text { organizations, and in cooperation with federal and state } \\
\text { government agencies. These programs include not only those } \\
\text { sponsored or initiated by PPEMA and its members but also those } \\
\text { recommended by government agencies. Participated in the } \\
\text { development of ANSI B175.1 Safety Requirements for Gasoline } \\
\text { Powered Chain Saws, 1979; and Bl75.la, Supplement to Safety } \\
\text { Requirements for Gasoline Powered Chain Saws, 1983. }\end{array}$ \\
\hline Formerly & Chain Saw Manufacturers Association \\
\hline eywords & chain saws; saws; industrial equipment; \\
\hline
\end{tabular}

PORTABLE SANITATION ASSOCIATION

Type of

Organization

standards

Developer

Certification

Secretariats

Scope
William F. Carroll, Executive Director

7800 Metro Parkway, Suite 104

Bloomington, Minnesota 55425

(612) 854-8300 FAX: (612) $854-7560$

Founded: 1971 Standards Staff: 3

Trade Association

Standards Developer

Standards developer since 1976

3 active standards

35 members participating in standaras activities

Processed through ANSI

Draft standards available for review

Portable Sanitation Health and Safety Worker Certification.

ANSI Z4.1, Z4.3, Z4.4.

An international trade association that represents U.S. and foreign firms engaged in the leasing, renting, selling, and manufacturing of portable sanitation equipment, services and supplies for construction, recreation, emergency, and other uses. Devoted to the proper handling of human waste by the most modern, 
Standardization Activities

Availability

Keywords sanitary means, giving the greatest concern to the preservation of an unspoiled environment.

Develops standards directed toward providing clean, sanitary restroom facilities for any gathering of people that do not have adequate permanent facilities close at hand. Assists manufacturers supplying the industry in market research and types and kinds of equipment which will fill these needs.

Recommends standards to BOCA, SBCCI, OSHA, Council of American Building officials (CABO), IAPMO, and various other state, county, and local health departments.

Standards include minimum sanitation requirements for temporary labor camps to protect the health and safety of persons residing in the camps or in the vicinity of the camps. Also provides standards for adequate toilet facilities in places of employment.

Distributed through ANSI.

sanitation; toilets; public health;

\section{PORTLAND CEMENT ASSOCIATION}

John P. Gleason, Jr., President

5420 Old Orchard Road

Skokie, Illinois 60077

(708) $966-6200$

Founded: 1916

Trade Association

Works through other organizations to develop consensus standards

Staff members are active in three model codes organizations and eight standards organizations, serving on seventy committees of ASTM, ANSI, ACI, ASCE, AASHTO, AREA, NFPA, ASHRAE, and others.

Construction Technology Laboratories (CTL), a contract research facility wholly owned by PCA, provides compliance certifications to clients in the form of test and/or investigative reports on a project-by-project basis. CTL does not have a product labeling program, nor associated product qualification programs. 
Standardization

Activities

Keywords

Represents the cement manufacturing industry. Serves the industry by extending and improving the uses of cement and concrete through research and development, market promotion, educational programs, and public affairs activities including representation with government. Cooperates with other concrete industry associations and national organizations representing business and industry. Provides a range of services to its members as well as to those private and public segments of the economy that serve the needs of the construction community in the United States and Canada.

Develops new standards and updates existing standards to reflect the latest findings in scientific research and test programs in the fields of cement and concrete technology, advanced engineering developments in all areas of concrete design and construction, and results of structural investigations and field experiences in the uses of concrete.

Does not write proprietary standards, but works with national standards writing organizations to develop building codes, design standards, and material and test standards. The Research and Technical Services group and the Market Development group of PCA participate in this activity. CTL staff also participate in such activities.

cement; concrete; test laboratories; fire protection; environment; energy;

POST-TENSIONING INSTITUTE

Gerard J. McGuire, Executive Director/RETD

1717 West Northern Avenue

Suite 114

Phoenix, Arizona 85021

(602) $870-7540$

FAX: (602) 870-7541

Founded: $1976 \quad$ Standards Staff: 1

Type of

Organization

Representation
Trade Association

Works through other organizations to develop standards.

ACI, AASHTO, AWWA, ASCE 
Membership consists of post-tensioning material fabricators, manufacturers of prestressed steel, concrete construction organizations, professional engineers, and architects. Promotes the use of post-tensioning materials through research; development of recommendations, specifications and publications.

Standardization Activities

Availability

Formerly

Keywords
Publishes "Guide Specifications for Post-Tensioning Materials" and "Recommendations for Grouping of Post-Tensioned Prestressed Concrete Members." Generally works through committees of the American Concrete Institute and American Association of State Highway officials for standards development, American water Works Association and American Society of Civil Engineers.

Through PTI.

Post-Tensioning Division of the Prestressed Concrete Institute, 1975

construction; concrete; post-tensioning; prestressed concrete; unbonded post-tensioning; certification and training cable stayed bridges;

\section{POWDER ACTUATED TOOL MANUFACTURERS' INSTITUTE}

James A. Borchers, Executive Director

1000 Fairgrounds Road, suite 200

st. Charles, Missouri 63301

(314) 947-6610 FAX: (314) 946-2157

Founded: 1952 Standards staff: 1

Type of

Organization

Representation

Certification

Scope

Standardization Activities
Trade Association

Works through other organizations to develop standards

ANSI, ISO.

Certification is through each individual manufacturer on their particular tool.

Furthers the development of a powder actuated systems industry; encourages the safe use and effective application of powder actuated fastening systems; encourages research; cooperates with organizations engaged in similar work.

Participates on ANSI A10.3 Committee for Safety Requirements for Powder Actuated Fastening systems. Serves on the ISO/TC 29 Subcommittee for standard power loads used in powder actuated fastening systems. 
PRECAST/PRESTRESSED CONCRETE INSTITUTE

Type of

Organization

Certification

scope

standardization

Activities

Availability

Formerly

Keywords
Thomas B. Battles, President

175 West Jackson Boulevard

Chicago, Illinois 60604

(312) 786-0300

FAX: (312) 786-0353

Founded: 1954

Standards staff: 4

Trade Association

Standards Developer

The Plant Certification Program certifies a plant's capability to produce architectural and structural precast and prestressed concrete of the highest quality. Recognized as a Quality Assurance Inspection Agency by the Council of American Building Officials (CABO).

A trade association representing the manufacturers of precast, prestressed concrete products used as structural and architectural elements in building, bridges, and other structures. The professional membership helps develop working documents, such as, handbooks, design guides and manuals, guide specifications, and state-of-the-art reports to assist other professionals to use the product in a correct and economical manner.

Develops guide specifications, design guides, and other documents in which standards of the ASTM, ACI, ANSI, AASHTO, AREA, etc., are cited to aid the engineer or architect in designing and specifying industry products.

Distributed directly.

Prestressed Concrete Institute

concrete; prestressed concrete; construction; architectural precast concrete; glass fiber reinforced concrete; erection; buildings; bridges; 
Glen R. Anderson, Executive Vice President

Type of

Organization

scope

Standardization

Activities

Availability

Keywords
401 North Michigan Avenue

Suite 2200

Chicago, Illinois 60611

(312) 644-6610

Founded: 1953

FAX: (312) 527-6640

Standards Staff: 2

Trade Association

Standards Developer

An organization of North American manufacturers of pressure sensitive tape (excluding surgical tape and label stock). Works with code and specification writing agencies.

Maintains research on test methods and standards of nomenclature, and on characteristics of products under all conditions of temperature and humidity. Publishes Test Methods booklet consisting of twenty-eight testing procedures for pressure sensitive tapes. Each test has been developed, revised, and edited by the Technical Committee of the Council in cooperation with interested government agencies over an extended period of time.

Also publishes an annual tape products directory designed to inform industrial, commercial and retail consumers of the variety of pressure sensitive tapes and the applications in which they have been successfully used. The tapes are listed by company, giving the tape identification number, description, principle uses, and manufacturer's values. The values given are in accordance with the PSTC Test Methods for tensile strength, adhesion, thickness and elongation.

Distributed directly.

tape; packaging;

PREVENT BLINDNESS AMERICA

Richard T. Hellner, President

500 E. Remington Road

Schaumburg, Illinois 60173

(708) $843-2020$

FAX: (708) 843-8458

Founded: 1908

Standards staff: 2 


\author{
Type of \\ Organization \\ Representation \\ scope

\section{Standardization} \\ Activities
}

Availability

Formerly

Keywords
Scientific society

Standards Developer

ANSI K61, Z80, Z87

ASTM F8.57

The oldest voluntary health agency nationally engaged in the prevention of blindness through a comprehensive program of community service, public and professional education, and research.

With advice and guidance of professional scientific advisory committees, develops standards for vision screening of preschool and school age children, for eye safety programs in schools and industry, for glaucoma screening, and for services providing low vision aids to the partially sighted.

Sold directly and through ANSI.

Formed by Merger of New York state Committee for the Prevention of Blindness and the American Association for the Conservation of Vision (1918), National Committee for the Prevention of Blindness (1927), National Society to Prevent Blindness (1995)

blindness prevention; eye protection; public health; social welfare; vision screening;

PRIMARY GLASS MANUFACTURERS COUNCII

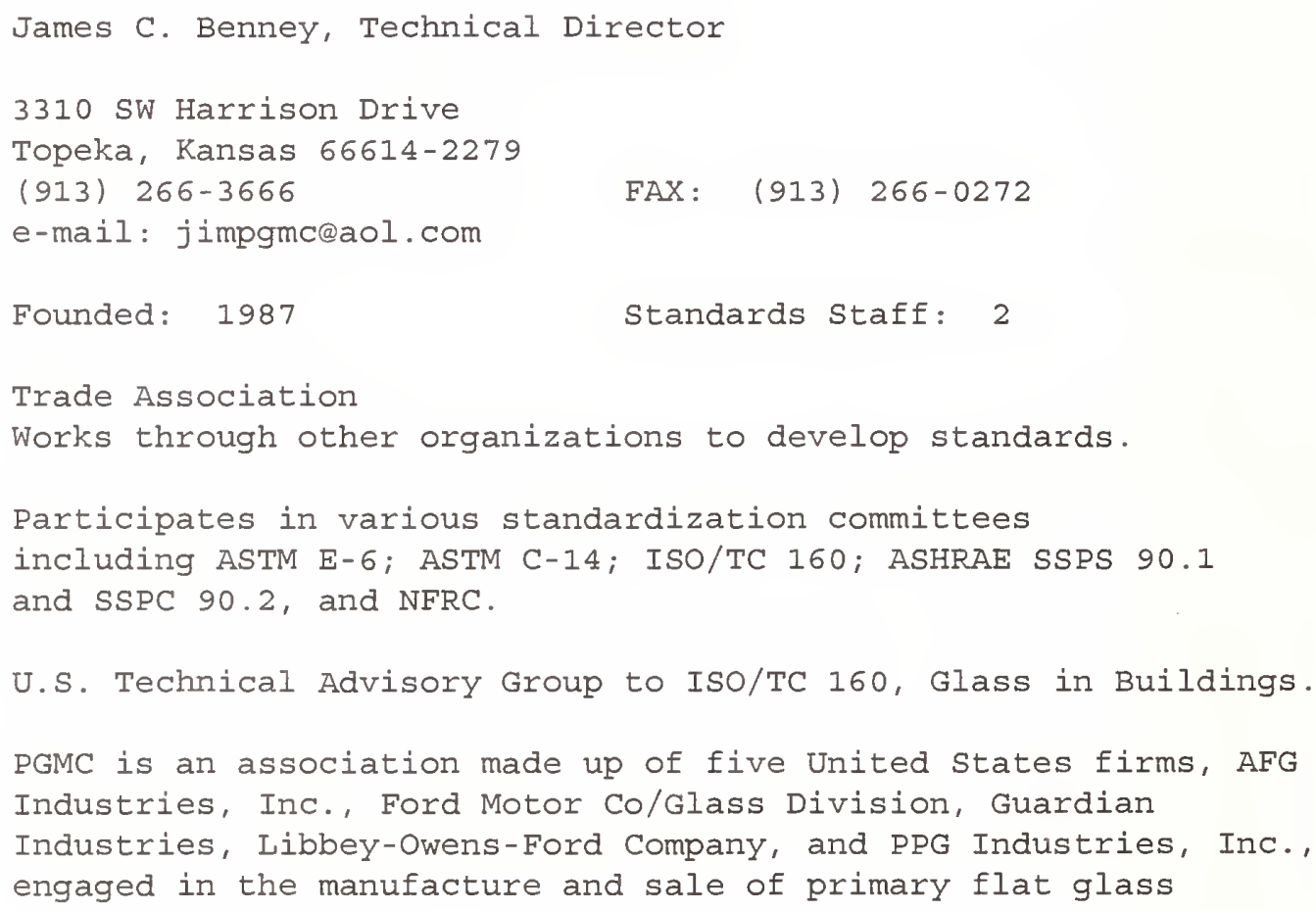



influential role in the development of glass-related specifications and performance standards and in advancing the appropriate use of glass and glass products in the construction industry.

PRINTING INDUSTRIES OF AMERICA

Ray Roper, CAE; President and CEO

100 Daingerfield Road

Alexandria, Virginia 22314

(703) $519-8100$

FAX: (703) 548-3227

Standards Staff: 3

Type of

Organization

Scope

Standardization

Activities

Availability
Trade Association

Standards Developer

PIA is the umbrella organization of the graphic arts industry. It is a federation of national, regional, state, and city associations. Sections include Binding Industries of America, Graphic Arts Marketing Information Service, Graphic Communications Association, International Thermographers Association, Label Printing Industries of America, Magazine Printers Section, NonHeatset Web Section, and Web Offset Association.

Maintains a continuing interest in the development of standards for promoting technical progress and production efficiencies. Activities include: development of industry specifications for production and inventory control applications; computer specifications for inter-industry communication and electronic data interchange; publication of Virgin Vinyl and Related Standards for Loose Leaf Binders through its affiliate, Binding Industries of America; preparation of standards for printing plate sizes through its National Association of Lithographic Platemakers Section; participation with Magazine Publishers Association and others in the development of standard specifications for advertising reproduction material for magazine web offset printing through its Graphic Communications Association and International Business Forms Industries affiliates.

Distributed directly. 
Formerly

United Typothetae of America (1945)

Printing Industry of America, Inc. (1965)

Absorbed: Lithographers and Printers National Association (1964)

Keywords

printing; lithography; communications; paper; information; processing;

PROCESS INDUSTRY PRACTICES INITIATIVE

Type of

Organization

Standards

Development

Certification

Scope

Standardization

Activities
Construction Industry Institute

John T. Lowe, Director

3208 Red River

Suite 300

Austin, Texas 78705-2650

(512) $471-3437$

FAX: (512) 473-2968

e-mail: jtlowe@attmail,com

Founded: $1993 \quad$ Standards Staff: 4

Coalition of Process Industry owners and contractors

Developer of Recommended Practices

More than 250 individuals from 27 member companies are participating in the development of recommended practices in the following areas:

Civil/structural/Architectural, Electrical, Environmental, Insulation, Machinery, Process and Instrument Diagrams, Piping, Pressure Equipment, and Process Control. Specific practices include design, selection and specification, and installation. information.

None.

PIP is a member funded sub-unit of the construction Industry Institute. Its mission is to increase the value of the engineering-procurement-construction process for the United States process industry in the global marketplace, and enhance Responsible Care ${ }^{\circledR}$ compliance and safety. This is done by developing recommended practices for the detailed design, procurement, and construction of process facilities, including their maintenance and operation. Participation is voluntary and open to all companies qualified for Chemical Manufacturers Association membership and the contractor companies serving them.

Develop voluntary "Recommended Practices" for the detailed design, procurement, and construction of process manufacturing facilities, primarily through harmonization of internal member standards. These "Practices" are generally "how to's" and are not focused on product specifications. Versions of 
Availability

Keywords the U.S. voluntary recommended practices can be used as the basis for meeting international requirements. Currently there are 50 practices issued and another 100 in various stages of development

Directly from Construction Industry Institute, 3208 Red River, Austin, Texas 78705-2650, (512) 471-8155.

process industry; construction industry; environment; machinery; piping; pressure equipment; process control;

\section{PROJECT MANAGEMENT INSTITUTE}

Deborah Bigelow, Executive Director

130 South State Road

Upper Darby, Pennsylvania 19082

(610) $734-3330$

WWW : http: //Www.pmi.org

Founded: 1969

Type of

Organization

Representation

Scope

Standardization

Activities

Professional Society

ANSI management.
Works through other organizations to develop standards

A nonprofit organization devoted exclusively to the field of project management. Foster recognition of the need for professionalism in project management; provides a forum for free exchange for project management problems, solutions, and applications; coordinates industrial and academic research efforts; develops common terminology and techniques to improve communications; provides interface between users and suppliers of hardware and software systems; and provides guidelines for instruction and career development in the field of project

Functions are performed through the Professional Liaison Committee which coordinates with the Technology, Research Policy and Education Committees. Participates in national activities through the American National Standards Committee XK36.3 and internationally, through liaison with an appointed observer to Internet. Does not deal with the federal government directly. Several members are federal employees in agencies involved with project management. 
RACK MANUFACTURERS INSTITUTE

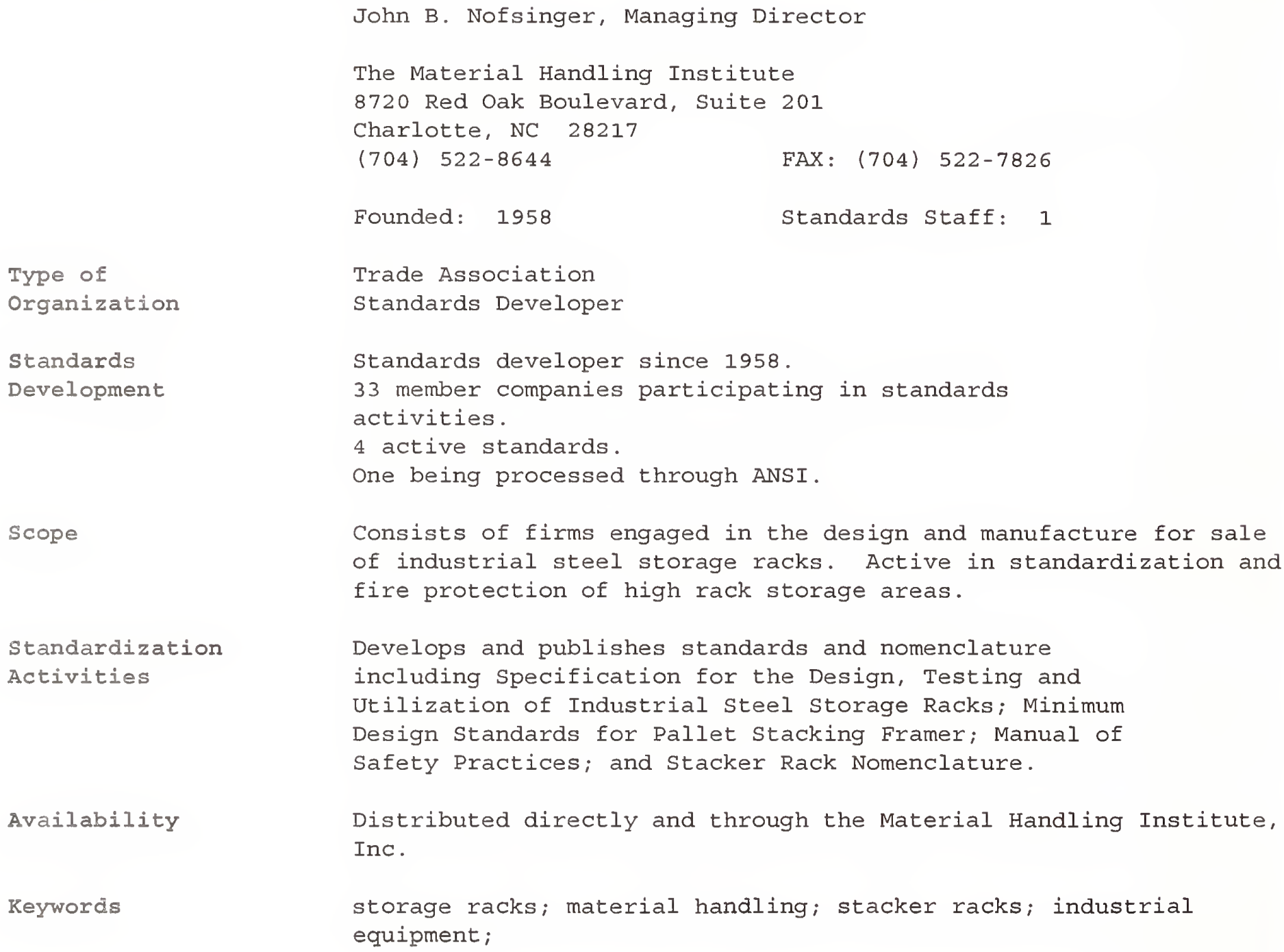

RADIO TECHNICAL COMMISSION FOR AERONAUTICS

David S. Watrous, President

1140 Connecticut Avenue, NW

Suite 1020

Washington, DC 20036

(202) 833-3993

FAX: (202) 833-9434 
Type of

Organization

standards

Development

Standards

Designation

Government

Adoption

Certification

Scope

Standardization

Activities

Availability

Keywords
Standards Developer

Over 185 member organizations; simultaneously operate 15-20 separate committees each working on one or more standards; a committee includes 20 to 250 volunteers.

83 active standards, three special Task Force Reports, two documents accepted as international standards (ISO/XXXX); airborne equipment environmental testing and aviation software certification.

Minimum Aviation System Performance Standards, Minimum Operational Performance standards, and Guidance Documents (RTCA/DO-XXX) .

RTCA is utilized as a Federal Advisory Committee. Recommendations provide the foundation for decisions regarding aviation policy, procedures and equipment. The Federal Aviation Administration uses RTCA recommended standards as the basis for Technical standard orders. RTCA products are also used by ICAO panels and industry.

None.

RTCA takes a "systems" approach in addressing air transportation issues. Focus is on Communications, Navigation, Surveillance/Air Traffic Management concepts, requirements, procedures and equipment(hardware and software). RTCA deliberations are open to anyone with an interest/input regarding the subject under discussion. These deliberations typically result in consensusbased, performance standards. RTCA members include both domestic and international government and private sector organizations, e.g., users (airlines, general aviation, Department of Defense), aviation associations, air traffic entities, airports, equipment suppliers and service suppliers.

Seeks solutions to problems involving the application of electronics and telecommunications to aeronautical operations. These solutions are frequently in the nature of recommended technical standards and common operational requirements which are acceptable to government, industry, and users. Cooperates with European Organizations for Civil Aviation Equipment (EUROCAE).

Sold directly, and distributed through document marketing organizations.

aeronautical; avionics; communications; electronics; navigation; surveillance; MASPS, MOPS; CNS/ATM; GNSS; data link; ADS-B; 
Type of

Organization

standards

Development

Standards

Designation

Government

Adoption

Certification

scope

Standardization

Activities

Availability

Formerly

Keywords

\author{
W.T. Adams, President \\ Post Office Box 19087 \\ Washington, DC 20036 \\ (202) 639-4006
}

Founded: 1947

Standards staff: 6

Technical society

Standards Developer

Standards cover all aspects of maritime telecommunications. None processed through ANSI. Draft standards not available for review by non-RCTM members.

RTCM Recommendations, usually with designator special Committee (SC) Report Number.

RTCM Recommendations, where appropriate, are adopted by cognizant government agencies such as FCC and U.S. Coast Guard.

No certification, qualification, or accreditation programs

180 member organizations active in all aspects of maritime telecommunications including any transmission, emission, or reception of signs, signals, writing, images, and sounds; or intelligence of any nature by wire, radio, optical, and other electromagnetic and visual systems.

Standardization activities are primarily focused on user-defined requirements for maritime telecommunications. special Committees formed to address standards areas are open to participation by all RTCM member organizations. Liaison is maintained with appropriate national and international organizations working in similar areas.

Distributed directly.

Radio Technical Commission for Marine Services

maritime; shipping; boating; radio; electronics; telecommunications; radiodetermination; radionavigation; radiolocation; radar; transportation; communications; electronics; 
Delmar J. Stauffer, Executive Director

2021 Spring Road

Suite 600

Oak Brook, Illinois 60521

(708) $571-2670$

FAX: (708) 571-7837

Founded: 1915

Type of

Organization

Representation

scope

Standardization

Activities

Keywords

RAILWAY TIE ASSOCIATION

Raymond R. Wingard, Executive Director

Post Office Box Drawer 1039

Gulf Shores, Alabama 36547

(334) 968-5928

Founded: 1919

Trade Association

Standards Developer

3 standards.

Standards

Development

Standards

Designation

scope

Professional society

Specifications for Cross Ties and Switch Ties. Wood Tie Fastener Performance Specification.
A member of the Medical Devices Standards Board, ANSI, and the National Council of Radiation Protection and Measurements.

A professional society which promotes the study and practical application of radiology, radium, electricity, and other branches of physics related to medical science.

Supports activities of the organizations listed above and reports to its members annually on standards activities.

radiology; radiation; medical devices;

Standards Staff: 1

Selectie economic analysis model for alternative ties in track.

Membership consists of those interested in the manufacture, procurement and chemical preservation of wood railroad cross ties. Cooperates with government agencies in conservation of forest products. Collects statistics, promotes standardization of cross ties, and provides models for economic analysis. 
Standardization

Activities

Availability

Formerly

Keywords

RECORDING INDUSTRY ASSOCIATION OF AMERICA

Hilary B. Rogen, President

102019 th street, NW, suite 200

washington, DC 20036

(202) 775-0101

Founded: 1952

Trade Association

Type of

Organization

Standards

Development

Certification

scope

Standardization

Activities

4 active standards. of the recording industry.
Administered by an Executive Committee, a Committee on

Research and Development, and other active committees. Active in international activities through its Canadian membership.

Cooperates with Government agencies on cross tie specifications. works with the Association of American Railroads Research Center and several railroads in Research and Development and in-track testing of ties, including tests at Pueblo, Colorado Test Track Center.

Distributed directly.

National Association of Railroad Tie Producers

railway ties; cross ties; transportation;

No certification, qualification, or accreditation programs

A nonprofit trade association for the United states sound recording industry. Promotes mutual interests of recording companies and the betterment of the industry. Initiates and sponsors programs and activities geared to the needs and problems

The Engineering Committee provides an ongoing review to maintain high technical standards for phonograph records, prerecorded sound recording media to insure uniformity and compatibility. Cooperates with ANSI, IEC, and EIA, and has drafted its own dimensional standards to facilitate equipment design and assure interchangeability. 
Availability

Formerly

Reywords
Distributed directly.

Record Industry Association of America (1952)

phonograph records; cassettes; videodiscs; videocassettes; recording; communications;

\section{RECREATION VEHICLE INDUSTRY ASSOCIATION}

Bruce A. Hopkins, Vice President, Standards

1896 Preston White Drive

Reston, Virginia 22090

(703) 620-6003

Founded: 1963

Trade Association

Standards Developer

4 active standards.
Standards

Development

Secretariats

scope

Standardization

Activities

Availability
FAX: (703) 620-5071

Standards staff: 13

ANSI Committee A119, Recreation Vehicles and Recreation Vehicle Parks; ANSI EGS-1, Standard for Engine Generator sets for Recreation Vehicles; standard for Park Trailers; ANSI 12V Low voltage systems in Conversion Vehicles.

Manufacturers and suppliers of recreational vehicles. Provides the industry a base from which to communicate with legislators, government agencies, automotive manufacturers, the media, and the general public.

Coordinates the activities of committees that establish minimum requirements for installation of plumbing, electrical, heating, and other safety related systems in recreation vehicles, park trailers, and for design and construction features for recreation vehicle parks and campgrounds. Monitors state RV agencies; does compliance inspections on member manufacturers; provides educational programs on compliance standards. Monitors proposed standards and keeps industry informed of changes. Requires that manufacturers comply with existing standards as a condition for membership. Representation on standards committees of ANSI and NFPA.

Distributed directly. 
Formerly

Keywords
American Institute of Travel Trailer and Camper Manufacturers (1968)

Recreation Vehicle Institute (1974)

recreation; transportation; recreational vehicles; conversion vehicles; RV parks;

REDWOOD INSPECTION SERVICE

A division of California Redwood Association

Christopher Grover, General Manager

405 Enfrente Drive

Suite 200

Novato, California 94949

(415) 382-0662

FAX: (415) 382-8531

Founded: 1961

Standards Staff: 4

Type of

Organization

standards

Development

Standards

Designation

Certification

Scope

Standardization

Activities
Trade Association

Standards Developer

Developed standard for California Redwood Lumber through authorization of the American Lumber Standard Committee and PS-20.

Standard Specifications for Grades of California

Redwood Lumber.

Adopts official grademarks signifying that products so marked have been graded in accordance with standard specifications of the Redwood Inspection Service. Grademarks are applied by qualified graders of member companies or by cooperating grading agencies operating within requirements established by the American Lumber standards Committee.

A nonprofit organization for the primary purpose of establishing uniform grades of redwood lumber, consultation with government agencies concerning grades and grading of redwood and other species of lumber. Promulgates rules for the redwood lumber industry. Membership includes 85 percent of the redwood producers. Rules are developed by a Quality standards Committee and approved by Board of Directors.

Adopts standard specifications for grades, sizes, patterns, and grademarks for redwood lumber; planning mill products; special purpose uses for redwood lumber including tank stock, stadium seat stock, foundation sills, structural grades, structural glue laminating grades, and miscellaneous products including railroad ties and cooling tower material. Cooperates with other lumber organizations and with the American Lumber 
Availability

Keywords

REFRACTORIES INSTITUTE

Type of

Organization

Representation

Scope

Standardization

Activities

Keywords standard Committee in keeping current the American Lumber standard set forth in the U.S. Department of Commerce Product standard 20. Grading rules for redwood lumber are in accordance with these standards and approved by ALSC.

sold directly.

wood products; grading rules; inspection; lumber; building;

Robert W. Crolius, President

500 Wood street, Suite 326

Pittsburgh, Pennsylvania 15222

(412) 281-6787

FAX: (412) 281-6881

Founded: 1951

Standards staff: 2

Trade Association

Works through other organizations to develop standards.

Active in ASTM Committee C-8 on Refractories and Iso Committee TC-33 on Refractories.

A national trade association representing a large segment of the refractories industry which is comprised of over 130 companies, operating more than 250 establishments and employing more than 15000 hourly workers throughout 37 states. Primary purposes are to promote demand for the industry's products, to conduct and stimulate research aimed at improving products and processes, to aid in the development of new product applications, to keep its members abreast of new developments and to work cooperatively with government agencies involved with the industry.

Cooperates with national technical associations test methods for refractories. Informs member companies of United States and international standardization activities regarding refractories.

refractories; fireclay; firebrick; insulating refractories; dolomite; materials; 
RESILIEITT ELOOR COVERING INSTITUTE

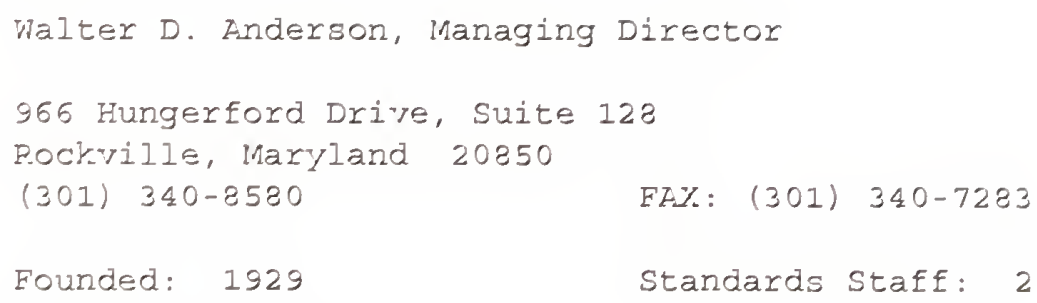

Standardization A.ctivities

Developed standards for tile and sheet vinyl products, including adhesives and installation and maintenance instructions. Works with the federal government in developing standards for resilient tile and sheet rinyl for use by the government.

Availability Distributed directly.

Reywords

floor corering; vinyl tile; sheet vinyl; building;

RESISTAHCE WELDER MANUFACTURERS ASSOCIATION

Shannon K. Coghlan, Executive Director

1900 Frch street

Philadelphia, Pennsylvania 19103

(215) $564-3484$

FZI: (215) $564-2175$

Founded: 1931

Type of

organization

Scope
Trade zssociation

Standards Developer

7. trade association representing North American companies engaged in manufacturing resistance welding machines, electrodes and components (controls, transformers, etc.) Engages in a raried program of activities embracing the development of standard specifications for numerous types of resistance welding equipment, research and development work and cooperation with other 
Standardization

Activities

Availability

Keywords associations and industries with mutual or parallel interests and problems.

Developed specifications for resistance welding machines: spot, press, portable, seam, upset butt, flashbutt, etc.; electrode alloy materials; nomenclature, definitions, etc. Developed standard classification for resistance welding electrode alloys, stating minimum permissible physical and electrical qualities. Identified and classified trade names and numbers. Also developed standards for spot welding electrode holders welding electrodes (spot and seam), together with recommended electrode alloys for spot welding of similar and dissimilar metal combinations. Developed standard nomenclature and definitions on resistance welding equipment and techniques. Cooperates with the National Electric Manufacturers' Association and the American Welding Society to develop standards.

Distributed directly.

resistance welding; manufacturing; spot welding; welding electrodes;

\section{ROBOTIC INDUSTRIES ASSOCIATION}

James A. Peyton, Manager of Standards Development

900 Victors Way

Post Office Box 3724

Ann Arbor, Michigan 48106

(313) 994-6088

FAX: (313) 994-3338

Founded: 1974

Type of

Organization

standards

Development

Standards

Designation

Government Adoption

secretariats
Trade Association

Standards Developer

Standards developer since 1982.

Over 250 representatives participate in the seven R15 standards Subcomittees. Most of RIA standards are processed through ANSI Subcomittees. Draft standards available for review.

RIA/R15.x.

The Occupational Safety and Health Administration references ANSI/RIA R15.06-1986 in its Guidelines for Robotic Safety. OSHA Training Manual, Chapter 18 - Robotic Safety, 1994.

Domestic: R15.01, R15.02, R15.03, R15.04, R15.05, R15.05WG1, R15.06, and R15.07.

International: U.S. TAG/ISO/TC $184 / \mathrm{SC} 2$. 
The Robotic Industries Association provides leadership for the responsible advancement of the entire robotics industry in North America. Some of the Association's objectives include providing mutual communications and organization of groups within the robotic industry to initiate and pursue programs of common technical, marketing, or management interest; and developing robotic industry and robotic system standards which will enhance the use and application of automation equipment.

Standardization Activities

Availability

Keywords
Standardization in the field of robotics, including activities within the following technical committees: Electrical Interface (R15.01), Human Interface (R15.02), Mechanical Interface (R15.03), Communication/Information (R15.04), Performance (R15.05), Reliability (R15.05-WG1), Safety (RI5.06), and Simulation/Offline Programming (R15.07).

Draft standards available from RIA. ANSI-approved standards available from RIA and ANSI.

robotics; robot systems; flexible manufacturing system; automation;

RUBBER MANUFACTURERS ASSOCIATION

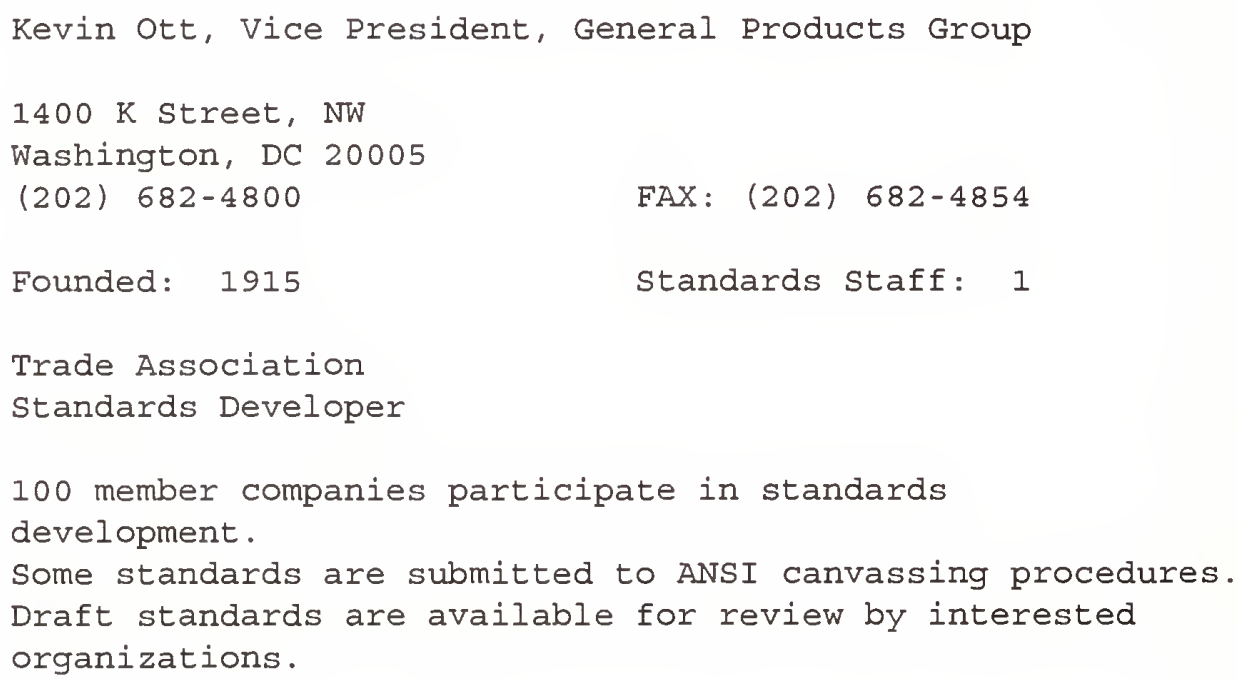

Trade Association

Standards Developer

100 member companies participate in standards development.

Some standards are submitted to ANSI canvassing procedures. Draft standards are available for review by interested organizations.

Type of

Organization

Standards

Development

Standards

Designation

Government

Adoption

Certification
RMA; Joint RMA/MPTA/RAC (Mechanical Power Transmission Association/Rubber Association of Canada); Joint RMA/TFI (The Fertilizer Institute); Joint RMA/CGA (Compressed Gas Association).

Some RMA documents are cited by some federal regulatory agencies, e.g., OSHA.

No certification, qualification or accreditation programs. 
Standardization Activities

\section{Availability}

Formerly

Reywords

SALT INSTITUTE

ISO/TC 41/SC 4 - Synchronous Belt Drives.

A national trade association of the rubber industry, representing over 100 member companies which manufacture finished rubber products. Operates on state, national and international levels and represents its members before legislative and regulatory bodies, as well as in other standards writing forums.

Committees review and make recommendations on governmental standardization proposals and participate in the standards programs of ANSI, SAE, ASTM, DOT, OSHA, DOD, DOC and others. Develops standards and specifications for hose, conveyor belting, power transmission belting, sealing products, molded and extruded products, protective linings, roll coverings, and coated materials.

Distributed directly, through member companies, and through ANSI.

New England Rubber Club (1909)

Rubber Club of America (1917)

Rubber Association of America (1929)

rubber; elastomeric; hose; conveyors; transmission belts; industrial equipment; seals; coated materials; materials;

Bruce M. Bertram, Technical Director

700 North Fairfax Street, Suite 600

Alexandria, Virginia 22314

(703) 549-4648

FAX : (703) 548-2194

Founded: 1914

Standards Staff: 1

Type of

Organization

scope

Standardization Activities
Trade Association

Works through other organizations to develop standards

A nonprofit association supported by the world's major salt producers. Its $8 \mathrm{U} . \mathrm{S}$. members produce 95 percent of the dry salt produced in the United States. Activities include information services, government relations, member services, and field services.

Serves as the national and the international standards representative for the salt industry. Cooperates with the National Academy of Sciences and the Department of Labor, General Services Administration, and the U.S. Army Natick Laboratories. Also works with the American National Standards Institute, the American Society for Testing and Materials, the American Water Works Association, the U.S. Pharmacopeia, the American Association 
of State Highway and Transportation Officials, and the American Feed Manufacturers Association.

Formerly

Keywords

SCAFFOLDING, SHORING AND FORMING INSTITUTE

Type of

Organization

Standards

Development

Scope

Standardization Activities

Availability

Formerly

Keywords

1300 Sumner

Cleveland, Ohio 44115

13 standards prepared.

Sold directly.
The Salt Producers Association (1963)

salt; sodium chloride; materials;

John $\mathrm{H}$. Addington, Managing Director

(216) 241-7333 FAX: (216) 241-0105

Founded: $1960 \quad$ Standards staff: 1

Manufacturing Trade Association

Professional Society Standards Developer

None processed through ANSI.

14 manufacturers of scaffolding, suspended powered scaffolding, shoring and forming. Establishes recommended criteria and inspection procedures for the proper and safe use of scaffolding to support formwork in concrete construction.

Provides recommended safety requirements for shoring concrete formwork and scaffolding including flying deck forms, rolling shore brackets, horizontal shoring beams, single post shores, steel frame shoring. Also provides recommended scaffolding erection procedure.

Steel scaffolding and shoring Institute

scaffolding; shoring; suspended powered scaffolding; forming; construction; safety;

SCALE MANUFACTURERS ASSOCIATION

\author{
Robert A. Renfried, Executive Director \\ 9384-D Forestwood Lane \\ Manassas, Virginia 22110 \\ (703) 330-7079 \\ FAX: (703) $330-7984$ \\ Founded: 1945 \\ Standards staff: 2
}


Type of

Organization

Standards

Development

standards

Designation

Certification

Scope

Standardization

Activities

Availability

Keywords
Trade Association

Standards Developer

Standards developer since 1945.

34 members in association.

3 active standards.

SM prefix.

No certification, qualification or accreditation programs.

A national trade association that represents United states manufacturers of scales, balances and major weighing elements.

Directed toward fulfilling user-defined requirements of the industry and its customers through participation in both national and international standardization efforts.

Distributed directly.

scale; weighing machines; instruments;

\section{SCREEN MANUFACTURERS ASSOCIATION}

Frank S. Fitzgerald, CAE, Executive Vice President

2545 South Ocean Boulevard

Suite 410

Palm Beach, Florida 33480-5453

(407) 533-0991

FAX: (407) 533-7466 
Type of

Organization

Standards

Development

Standards

Designation

Scope

Standardization

Activities

Availability

Keywords

SEALED INSULATING

Type of

Organization

Representation

scope

Keywords
Trade Association

Standards Developer

Nine active standards.

SMT, SMA, and ANSI prefixes.

Manufacturers of metal window, patio, door, and porch insect screens; sponsors research programs; compiles statistics. sponsors certification programs.

Develops and maintains testing procedures and specifications for metal and solar screens.

Sold directly.

screens; building; insect; solar;

\section{GLASS MANUFACTURERS ASSOCIATION}

J. Dollard Carey, Executive Vice President

401 N. Michigan Avenue

Suite 2400

Chicago, Illinois 60611

(312) 644-6610

FAX: (312) 321-6869

Founded: 1963

Trade Association

Works through other organizations to develop standards

Works with ASTM

Manufacturers of insulating glass and suppliers to the industry. Provides government liaison, publishes information on test methods.

insulating; glass; building; 
Bernard Brill, Executive Vice President

7910 Woodmont Avenue

Suite 1212

Bethesda, Maryland 20814

(301) 656-1077

FAX: (301) 656-1079

Founded: 1932

Standards staff: 1

Type of

Organization

\section{standards}

Development

Government

Adoption

scope

standardization

Activities

Availability

Formerly

Reywords
Trade Association

Standards Developer

Two active standards.

General Services Administration has adopted Wiping, Cotton, and Cotton-Synthetic dated October, 1981.

Smart (Secondary Materials and Recycled Textiles) is an international association which seeks to strengthen the economic opportunities of its members. It promotes the interdependence of all its industry segments by providing a common forum for networking, education, and trade. Smart focuses on common problems and opportunities in the management, promotion, research and development of the wiping materials, used clothing, and textile recycle industry.

Publishes descriptions of wiping cloths for use by all phases of industry. Descriptions cover material, content, and grade of wiping cloths.

Distributed directly.

International Association of Wiping Cloth Manufacturers Sanitary Institute of America

rags; textiles; used clothing; wipes;

\section{SECURITY INDUSTRY ASSOCIATION}

Virginia Williams, Director of Technical and Education Services

635 Slaters Lane

Suite 110

Alexandria, Virginia 22314

(703) 683-2075

FAX: (703) 683-2469

Founded: 1969

Standards Staff: 2 
Type of

Organization

Standards

Development

Standards

Designation

Certification

Scope

Standardization

Activities
Trade Association

Standards Developer

Develop Standards and Technical Reports, host standards development activities for other related organizations, provide technical input to other standards writing bodies as required.

Standards development began approximately 1987; ANSI accreditation under the Canvass method obtained in 1991.

Approximately 1000 participants or interested parties

10 active standards

13 standards subcommittees

All subcommittee activities, information distribution, and draft standards for review are open to all interested parties on request and at no charge.

Equivalent metric units are included in all standards where applicable.

SIA $\mathrm{XX}-\mathrm{XXX}-\mathrm{YR}$ or

ANSI/SIA $\mathrm{xX}-\mathrm{XxX}-\mathrm{YR}$

released as an SIA document: SIA ss-\#\#-Yy

where:

ss is the subcommittee.

\#\# is the sequential number of standards from that subcommittee.

$\mathrm{X}$ is the type of standard (design, application, vocabulary, etc.). yy is the year the standard was last updated.

No certification, qualification, or accreditation programs. Validation checklists are provided to assist implementors in self-certification.

SIA works to increase the growth and professionalism of the security industry. Membership is of suppliers of security products and services; currently 60 percent

manufacturers, 35 percent service providers, and 5 percent distributors. Activities include standards, education, government affairs, public relations, commissioned research, trade shows, and information recourses.

SIA standards and technical reports apply to products and systems in the electronic security industry, i.e., where the purpose is to prevent or deter loss of property or life through electronic means. Standards are primarily for product design and performance, through some cover application of products.

Technical Reports are advisory documents regarding technical limitations, common practices, or overviews of security technology. 
Availability

Formerly

Keywords

Subcommittees are formed around product types. Draft standards are circulated for comment and revised through group discussion of the comments received. Final document approval is obtained by subcommittee vote, then ratification by the SIA standards Committee (review of due process). SIA standards are then canvassed in accordance with procedures registered with ANSI. Eligibility to vote on a subcommittee is based on active participation. Participation in subcommittee activity is open to the public at no charge and without restriction.

Distributed directly.

Security Equipment Industry Association (SEIA)

security; safety; protection; alarms; communicators; detectors; monitoring; false alarms; low voltage;

\section{SEMICONDUCTOR EQUIPMENT AND MATERIALS INTERNATIONAL}

William A. Brown, Manager, International standards

805 East Middlefield Road

Mountain View, California 94043-2295

(415) 964-5111 FAX: (415) 967-5375

e-mail: semihg@semi.org

Founded: $1970 \quad$ Standards Staff: 13

Type of

Organization

standards

Development

\section{Standards}

Designation
Trade Association

Standards Developer

Standards developer since 1974.

450 active standards.

Draft standards available for review.

None processed through ANSI.

Programs supported in North America, Europe and Japan;

under development in P.R. China, Korea and Russia.

C Chemicals and Gases.

E Equipment Automation/Hardware, Equipment Automation/Software.

G Packaging.

M Materials.

P Micropatterning.

$S$ Safety Guidelines.

T Traceability.

D Flat Panel Display. 
With 1450 corporate members, SEMI serves the international semiconductor community by fostering the advancement of knowledge about equipment, materials, and services distinct to the production and use of semiconductor devices. Founded in 1970 to develop the SEMICON trade shows, SEMI activities have expanded to include technical symposiums, market research seminars, trade issues, and standards development.

Standardization Activities

Availability

Keywords
The SEMI Standards Program encompasses virtually every facet of semiconductor manufacturing and has established specifications and test methods in ten critical areas: chemicals, equipment (including automation and communications), materials, packaging, micropatterning facilities, safety, traceability and flat panel displays. Emphasis in standards development is placed upon: communication between suppliers and customers; interchangeability of products and components; technology transfer; safety; and efficiencies in design, production, and inventory.

Nearly 3000 engineers, scientists, and technicians volunteer to serve on standards setting technical committees in Japan, Europe, and the United States Many committees have established a liaison with one or more of the following standards organizations: ASTM, ANSI, CGA, JEIDA, SEAJ, DIN, JEDEC, IEEE, and NIST. Membership in the SEMI international standards programs is open to all interested individuals.

A balloting procedure designed to allow maximum fair participation precedes the approval of any specification. Procedural reviews of all standards ensure that the formal balloting process has been properly performed.

The SEMI Standards, an 11-volume publication, is revised annually for publication in April.

Distributed directIy and through IHS and on the WWW at http://www. semi.org.

semiconductors; high technology; manufacturing; chemicals; equipment; materials; packages; photomasks; automation; communications; integrated circuits; gases; micropatterning; flat panel displays; safety; 
Type of Organization

Certification

Scope

standardization

Activities

Formerly

Reywords
Arnold S. Kuhns, President

15708 Pomerado Road

Suite N208

Poway, California 92064

(619) 451-8868

FAX: (619) 451-9268

Founded: 1978

Standards Staff: 7

Standards Developer

Manufacturer self-certification program for various products used in automotive aftermarket.

An international standards setting organization involved with companies worldwide in the areas of motorsports, road wheels and consumer products.

Activities are directed towards fulfilling user defined requirements of the motorsports, road wheels and consumer products industries. Standards are minimum performance in nature and compliance with the specifications enables the user to selfcertify product.

SEMA Foundation, Inc.

motorsports; road wheels; consumer products;

\section{SGS UNITED STATES TESTING COMPANY}

Richard Franconeri, Quality Assurance Director

291 Fairfield Avenue

Fairfield, New Jersey 07004

(201) 575-5252

FAX: (201) 575-8271

Founded: 1880

Type of

Organization

Certification

Scope
Independent Test Laboratory

Standards Developer

Conducts testing for certification and labeling to assure products meet specified standards.

An independent commercial laboratory engaged in product testing for quality assurance. 
Standardization

Activities

Formerly

Reywords

SHEET METAL, AND AIR CONDITIONING CONTRACTORS NATIONAI ASSOCIATION

John H. Stratton, Director of Technical Services

4201 Lafayette Center Drive

Chantilly, Virginia 22021-1209

(703) $803-2980$

FAX: (703) 803-3732

Founded: 1944

Standards staff: 3

Trade Association

Standards Developer

16 active standards.

None processed through ANSI.

NFPA standard $x \mathrm{x}$.

Eight standards are referenced by federal agencies:

DOD; GSA; NAVFAC; Army Corps of Engineers; state Department; U.S. Air Force. State and local government use is indirect through adoption of ICBO, BOCA and SBCCI Model Codes which predominantly adopt and use the HVAC Duct Construction standards and Fibrous Glass Duct Construction standards. Any authority adopting NFPA standard 90A will incorporate these two standards. Any authority adopting NFPA standard 91, the ACGIH Industrial Ventilation Manual (OSHA invokes the Industrial Ventilation Manual) picks up the Round and Rectangular Industrial DCS of SMACNA.

Scope
A nonprofit trade association dedicated to the advancement of the sheet metal, heating, ventilating, air-conditioning, industrial sheet metal, and roofing industries. Activities and services are carried out in four departments: technical, labor relation, legislative affairs, and business management. 
Standardization Activities

Availability

Formerly

Keywords

SILVER INSTITUTE
The Technical Services Department administers standards activities. Although some standards are developed for labor relations and safety practices, the majority fall into two categories: duct construction and architectural sheet metal.

Publishes Accepted Industry Practice for Industrial Duct Construction, Architectural sheet Metal Manual, Building systems Analysis and Retrofit Manual, Ducted Electric Heat Guide for Air Handling Systems, Energy Conservation Guidelines, Energy Recovery Equipment and Systems Air-to-Air, Fibrous Glass Duct Construction Standards, Fire, Smoke and Radiation Damper Guide for HVAC Systems, Guide for steel stack Design and Construction, HVAC Air Duct Leakage Test Manual, HVAC Duct Construction Standards-Metal and Flexible, HVAC Systems-Duct Design, HVAC Systems-Applications, HVAC Systems Commissioning Manual, HVAC systems-Testing, Adjusting and Balancing, Indoor Air Quality Manual, IAQ Guidelines for occupied Buildings under construction. Installation Standards for Residential Heating and Air Conditioning Systems, Labor Units Manual, Management Change Order Manual, Managers Guide for Welding, Rectangular Industrial Duct Construction Standards, Retrofit of Building Energy Systems and Processes, Round Industrial Duct Construction Standards, Seismic Restraint Guidelines for Mechanical systems Manual, Thermoplastic Duct (PVC) Construction Manual, Welding Guidelines/Troubleshooting Chart, Standards Practice in sheet Metal Work.

Distributed directly.

Sheet Metal Contractors National Association (1956)

air-conditioning; air handling; indoor air quality;

John H. Lutley, Executive Director

111216 th street, NW

Suite 240

Washington, DC 20036

(202) 835-0185 FAX: (202) 835-0155

Founded: $1971 \quad$ Standards Staff: 1 
Type of

organization

standards

Designation

Government

Adoption

Certification

scope

Standardization

Activities

Availability

Keywords
Trade Association

Standards Developer

Unified Number Designations.

Government use, not adoption.

No certification programs, supplier self certification.

An international trade association of miners, refiners, fabricators, and bullion dealers. Extends the market for the use of silver through publications, seminars, joint symposiums with technical organizations, and trade shows.

Develops standard alloy designations for silver alloys for Unified Numbering System for Metals and Alloys issued by the Society of Automotive Engineers (SAE) and the American Society for Testing and Materials.

Distributed directly and through ASTM and SAE.

silver; precious metals; bullion; alloys; materials;

SINGLE PLY ROOFING INSTITUTE

Type of

Organization

Standards

Development

standards

Designation

Scope
Dave Roodvoets, Technical Director

175 Highland Avenue

Needham, Massachusetts 02194

(617) 444-0242

FAX: (617) 444-6111

Founded: 1982

Standards Staff: 2

Trade Association

Standards Developer

SPRI began independent standards development in 1995. In 1988 developed a standard in conjunction with the Rubber Manufacturers Association. 100 individuals participate in developing standards. 1 active standard processed through ANSI. Draft standards are available from the organization. ANSI/SPRI.

SPRI is a nonprofit trade association representing sheet membrane and component suppliers to the commercial roofing industry. Its function is to develop methods for improving the conditions and 
advancing the bests interests of the flexible sheet membrane manufacturing industry. There are 50 member companies.

\section{Standardization Activities}

Availability

SKI INDUSTRIES AMERICA
SPRI committees collect data, evaluate proposed procedures and publish documents to meet the technical needs of the commercial roofing industry.

Directly from SPRI.

Chris Stoddard, Committee Administrator

20 Maple Street

Post Office Box 2883

Springfield, Massachusetts 01101

(413) 781-4732

FAX: (413) 781-6105

Founded: 1989

Standards Staff: 2

Type of

Organization

Standards

Development

Government

Adoption

Secretariat

scope

\section{Standardization} Activities

Availability
Trade Association

Standards Developer

Standards developer since 1963.

U.S. Department of Agriculture Forest Service, and states where skiing exists.

ANSI B77.1

A trade association of ski area operators, manufacturers, and suppliers of ski equipment. Twelve hundred members located in all states and several foreign countries. Aims are: to promote skiing and safety in skiing, to protect natural resources in meeting the needs of the skiing public and ski area operators, and to ensure legitimate interests of ski area operators.

Maintains committee composed of operators, users, authorities having jurisdiction, designers, and manufacturers of aerial tramways. Developed American National Standard B77.1, Safety Requirements for Passenger Tramways and Lifts, Surface Lifts, and Tows. Promotes this safety standard for the ski lift industry, used by ski lift manufacturers, ski area personnel, ski area insurance programs, and state and federal authorities having jurisdiction.

Distributed directly and through ANSI. 
Type of

Organization

Representation

Standards

Development

Government

Adoption

Keywords

SMALL MOTOR MANUFACTURERS ASSOCIATION

Elizabeth Bevington-Chambers, Executive Director

Post office Box 378

Sherborn, Massachusetts 01770

(508) 655-4409

FAX: (508) 651-3920

Founded: 1975

Standards Staff: 4

Type of

Organization

Standards

Development
Trade Association

Standards Developer

Standards developer since 1975.

185 member companies participate in standards activities.

12 active standards plus 2 under development. 
Standardization Activities

Availability

Reywords
No certification, qualification, or accreditation programs.

An international industry organization representing original equipment manufacturers, users, suppliers, and other interested parties involved in the manufacture of fractional and subfractional horsepower electric motors and their controls.

The Technical Committee works with Underwriters Laboratories, Canadian Standards Association, government agencies and other associations in developing standards. Topical areas include: tachometers; general motor terminology; permanent magnet motors; permanent split capacitor motors; universal motors; shaded pole motors; and technical reference information for brushes, contacts, magnets, and other materials of motor construction. Promotes manufacturer/user interface.

Distributed directly.

electrical equipment; tachometers; industrial equipment; motors; magnets;

SNELL MEMORIAL FOUNDATION

Hal A. Fenner, Jr., M.D., President

Post Office Box 493

St. James, New York 11780

(516) 862-6440 FAX: (516) 862-6545

Founded: 1957 Standards Staff: 7

Type of

Organization

Certification

Secretariats
Nonprofit research corporation

Standards developer

Approves manufacturers products meeting its standards and other criteria for certification under contractual agreements, providing, among other matter, ongoing random sample testing of helmets taken from dealer shelves. Through its certification program, the Foundation is able to keep in the forefront of improvements in the state of the manufacturing art, both as to methodology and materials, and to obtain data useful in its research program and its development of more sophisticated test procedures.

ANSI Z90, Vehicular Head Protection 
A nonprofit corporation whose primary purpose is to conduct research in brain trauma and head protective devices and to develop and utilize advanced techniques for related critical measurements. Establishes upper level standards for protective devices, maintains an ongoing research program in head injury and a program in education related to vehicular safety. Linked with European counterpart, snell Memorial Foundation (UK).

Standardization Activities

Availability

Keywords

SNOWMOBILE SAFETY AND CERTIFICATION COMMITTEE

Type of

organization

Standards

Development

Standards

Designation

Edward J. Klim, Chairman

271 Woodland Pass

Suite 220

(517) 332-0886

Trade Association

Standards Developer

29 active standards. certification.
Promulgated in 1959 the first standard for road user crash helmets in the United states. Its helmet standards are generally recognized as carrying the most stringent safety performance requirements for road user protective headgear in the world today. Has also established standards of safety performance criteria for skiers, bicyclists, and equestrian protective helmets. Standards are not minimum standards; but, rather, represent the upper levels of protective criteria which manufacturing is capable of meeting, and as that capability increases, the level of the standard is raised.

Distributed directly.

helmets; head protection; vehicular safety; brain trauma; bicyclists; motorcyclists; equestrians; safety; social welfare; sports;

East Lansing, Michigan 48823

FAX: (517) $332-1760$

Founded: 1974 Standards Staff: 1

Standards developer since 1974.

4 manufacturers participate in standards activities.

standards processed by SAE.

Draft standards available for review.

SSCC/10, safety standards for snowmobile Product 
Government

Adoption

Certification

scope

\section{Standardization \\ Activities}

Availability

Keywords
All or portions of the standard accepted by

Connecticut, Maine, Maryland, Massachusetts, Michigan, Minnesota, Montana, New Hampshire, Oregon, Pennsylvania, Rhode Island, Vermont, Wisconsin and Canada.

Certification program administered since 1975. Each conforming machine bears a Certification Label which signifies that the United states Testing Company, has independently confirmed that the vehicle has been manufactured in compliance with SSCC safety standards. In the area of operator education, provincial and state safety training programs are certified by the SSCC as being in compliance with uniform standards. To date, the instructional programs of 16 states and provinces have been certified.

A nonprofit membership association organized to promote, foster, and encourage by any and all lawful means, safe, enjoyable opportunities for snowmobiling through operator safety training and education programs; safe trail, use area and facility development; development of voluntary snowmobile machine safety standards and the independent certification thereof.

Has established a comprehensive machine standards program for snowmobile manufacture. Since February 1, 1975, all snowmobiles produced by participating manufacturers conform to the minimum safety standards for snowmobile product manufacture in effect on the date of their manufacture. Incorporated in the standards are requirements for seats, controls, brake and fuel systems, shields and guards, electrical and lighting systems, reflectors, hand grips, general hazard requirements and emergency starting.

Sold directly.

snowmobile; safety; acoustics; recreation;

\section{SOCIETY FOR EXPERIMENTAL MECHANICS}

Kenneth A. Galione, Managing Director

7 School Street

Bethel, Connecticut 06801

(203) 790-6373 FAX: (203) 750-6373

e-mail: sem@transit.nyser.net

Founded: $1943 \quad$ Standards Staff: 1

Type of

Organization
Scientific Society

Standards Developer 
Standards

Development

standards

Designation

Certification

scope

Standardization

Activities

Availability

Formerly

Keywords

SOCIETY FOR INFORMATION DISPLAY

Dr. Andras I. Lakatos, President

1526 Brookhollow Drive

Suite 82

Santa Ana, California 92705-5421

(714) 545-1526

FAX: (714) 545-1547

e-mail: socforinfodisplay@mcimail.com

WW: http://Www.display.org/sid

Founded: 1962

Standards Staff:

Type of

Organization
Professional society

Standards Developer 
Standards

Development

\author{
Standards \\ Designation \\ Scope \\ Standardization \\ Activities
}

Availability

Keywords

SOCIETY FOR TECHNICAL COMMUNICATION

William C. Stolgitis, Executive Director

901 N. Stuart Street

Suite 904

Arlington, Virginia 22203-1854

(703) 522-4114

FAX: (703) 522-2075

e-mail: stc@tmn.com

Founded: $1957 \quad$ Standards Staff: 1

Type of

Organization

scope
Joint standards with Electronic Industries Associations Standards Committee maintains liaison with other standards formulating groups within the industry.

SID is international in scope with membership in academic, commercial and government organizations. Display theory, display effects of displays are all within the area of activities

Flat panel, cathode-ray and other display devices and systems definitions, test methods and tutorial documents. Two standards. These are JT20 for Cathode-Ray Display Devices and JT33 for Flat Panel Displays.

Directly through EIA or SID.

displays; definitions; characterization; viewability; data processing; electronics; television; communications;

A nonprofit, educational membership organization whose purpose is to advance the theory and practice of technical communication in all media. It has chapters in the United States, Canada, and other countries.

Activities include chapter programs, an annual international technical communication conference, publication of a journal, and standards and reference material used in technical documentation, manuals, reports, and writings. 
Standardization

Activities

Formerly

Keywords
Maintains a standards Council which is interested primarily in guidelines which bear directly upon the profession of technical communications, and data and procedural standards for science, engineering, and the arts that must be applied, interpreted, or referenced in technical communication. Cooperates with the American National standards Institute, the Metric Association, and others concerned with publication of technical information.

Merger of Association of Technical Writers and Editors, and Society of Technical Writers (1957)

technical writing; technical information; communications; metric;

SOCIETY OF ALLIED WEIGHT ENGINEERS

Type of

Organization

Standards

Development

Standards

Designation
Robert E. Johnston, Executive Secretary

5530 Aztec Drive

La Mesa, California 91942-2110

(619) 465-1367 FAX: (619) 465-2561

Founded: 1939 Standards Staff: 1

Professional Society

Developer of recommended practices

Develop Society of Allied Weight Engineers, Inc. (SAWE)

Recommended Practices. Currently, ten (10) SAWE Recommended

Practices are active. They were developed through

government/industry volunteer member working committees.

Typically, several dozen members are involved with the several

committees. Once approved by a working committee, formal Board of Directors approval is required before Recommended Practices are adopted. First Recommended Practice was approved in 1981. None are processed through ANSI. None are distinctly metric.

Approved Recommended Practices are designated Society

of Allied Weight Engineers, Inc., Recommended Practice Number -... Example: "Society of Allied Weight Engineers, Inc., Recommended Practice Number 5, Mass Properties Control System For wheeled and Tracked Vehicles, Issue No. 1, Issued 13 May 1986." 
Standardization Activities

Availability

Formerly

Reywords
No certification, qualification, or accreditation programs.

The Society of Allied Weight Engineers was organized to promote recognition of mass properties as a specialized discipline within the entire spectrum of professional engineering. The principal means of accomplishing this objective is an annual international conference for the presentation and discussion of engineering papers, including engineering standards and recommended practices, and to publish and distribute the papers, reports and recommended practices. There are approximately 1000 individual and/or company members worldwide.

Government/industry working committees collect data, evaluate proposed procedures, determine nomenclature, etc., while developing and/or revising Recommended Practices through year-long reviews (sometimes several years) culminated by formal approval at the cognizant Government/Industry Workshop at the annual international conference. Formal approval by SAWE Board of Directors is also required before a Recommended Practice can be made available for use.

Distributed directly.

Society of Aeronautical Weight Engineers, Inc. (1973)

balance; center of gravity; mass properties; moment of inertia; weight control;

SOCIETY OF AUTOMOTIVE ENGINEERS

Herb Kaufman, Manager, Technical Division

400 Commonwealth Drive

Warrendale, Pennsylvania 15096

(412) 776-4841 FAX: (412) 776-0243

WWW: http://www.sae.org/

Founded: $1905 \quad$ Standards Staff: 125

Type of

Organization

standards

Development
Professional Society

Standards Developer

Standards developer since 1905.

14000 members participating in standards activities.

1400 ground vehicle standards documents published in the SAE

Handbook.

2250 Aerospace Standards.

2300 Aerospace Material Specifications.

Over 1500 documents annually are processed through ANSI. 
Standards

Designation

Government

Adoption

Accreditation

Secretariats

Scope
J-Reports, Ground Vehicle Industry standard, Recommended Practice and Information Report. AMS, Aerospace Material Specification.

MAM, Metric Aerospace Material Specification.

AS, Aerospace standard.

MA, Metric Aerospace standard.

ARP, Aerospace Recommended Practice.

MAP, Metric Aerospace Recommended Practice.

AIR, Aerospace Information Report.

The Department of Defense has adopted over $1300 \mathrm{SAE}$

documents. SAE standards are recognized in government publications as methods for measuring or testing for minimum technical

requirements in areas where government regulatory control has been established.

SAE operates several accreditation programs under the sponsorship of industry and government. The Lubricants Review Program and Oil Labeling Assessment Programs are operated for the U.S. Army. The JGES Verification Program is operated under a contract for NIST. A new Defense Contractor Accreditation (NADCAP) program will audit and approve suppliers to the aerospace industry.

Sponsors several secretariats and/or Technical Advisory Groups for ISO Technical Committees and subcommittees including ISO/TC 20, TC 22, TC 70, TC 96, TC 127, TC 188, and TC 204.

A not-for-profit educational, scientific, and engineering society dedicated to advancing the arts, sciences, standards, and engineering practices connected with the design, construction, and utilization of self-propelled mechanisms, prime movers, components thereof, and related equipment to preserve and improve the quality of life.

Prime objectives are to provide educational opportunities for engineers and to provide a medium through which they can advance the arts and science of engineering and promote public welfare. There are only individual memberships in SAE. Therefore, members perform their SAE functions as individuals, not as representatives of their employers. SAE interfaces with every agency of the government concerned with the design, manufacture, or regulation of vehicles. Because of the government's interest in regulatory activities relating to transportation equipment, and as a large volume purchaser of vehicles of all types, government agencies have historically drawn upon SAE and its Cooperative Engineering Program for information and assistance. 


\section{Standardization Activities}

Availability

Formerly
Develops and publishes technical literature and formulates engineering standards, specifications, and test procedures that are used in the design and manufacture of ground and aerospace vehicles.

Engages in technical standardization work for the motor vehicles, aircraft, airline, space vehicles, farm tractor, earthmoving, roadbuilding machinery, and other manufacturing industries using internal combustion engines. Standards are the product of 600 Technical Committees. Standards are revised as needed to keep them up-to-date with new engineering developments. obsolete standards are discontinued. Standards in the SAE Handbook include: safety performance test codes; material specifications; and dimensional requirements on such subjects as vehicle lighting, tires, brakes, ride and vibration, steels, nonmetallic materials, screw threads, and involute splines. Although voluntary, SAE standards are widely used throughout industry and many federal and state regulations reference them for minimum performance on safety items.

SAE Aerospace Standards, Recommended Practices, and Information Reports are design and/or parts standards applicable to missile, airframe, ground-support equipment, propulsion, propeller, accessory equipment, and airline industries. Aerospace Recommended Practices give dimensional, design and/or performance recommendations intended as guides for standard engineering practice. The Aerospace Information Reports contain useful engineering data and information.

SAE Aerospace Material Specifications cover materials, material tolerances, quality control procedures and processes. They list chemical composition, detailed technical requirements, and crossreference similar specifications and materials for corrosion and heat resistant steels; wrought low-alloy steels; cast iron and low-alloy steels; aluminum, magnesium, copper, titanium and miscellaneous nonferrous alloys; nonmetallics; special property materials; and refractory and reactive materials.

Distributed through ANSI, IHS, Global, American Technical Publishers, and the Defense Printing Service, CD-ROM.

Society of Automobile Engineers (1917) 
vehicles; automobiles; trucks; buses; aircraft; aerospace;

engines; tractors; farm equipment; construction equipment; ground support equipment; fuels; lubricants; material; metals; alloys; refractories; defense; materials; transportation;

SOCIETY OF CABLE TELECOMMUNICATIONS ENGINEERS

Type of

Organization

Certification

scope

Standardization

Activities

Formerly

Keywords
William Riker, President

140 Philips Road

Exton, Pennsylvania 19341-1318

(610) $363-6888$

FAX: (610) $363-5898$

Founded: 1969

Standards staff: 3

Professional Society

Standards Developer

Technical certification programs available at three levels: Installer, Broadband Communications Technician and Broadband Communications Engineer.

Membership is primarily comprised of engineers, technicians and installers working in the cable telecommunications industry. The Society provides numerous training programs on broadband technology.

ANSI approved standards developer. Five engineering subcommittees working on broadband industry hardware and interfaces.

Society of Cable Television Engineers, Inc.

broadband; telecommunications; cable television;

SOCIETY OF FIRE PROTECTION ENGINEERS

Brian Meacham, P.E., Technical Director

One Liberty Square

Boston, Massachusetts 02109-4825

(617) 482-0686 FAX: (617) 482-8184

e-mail: sfpehqtrs@delphi.com

Founded: 1950

Type of

Organization
Professional society

Works through other organizations to develop standards 
Representation

scope

Keywords
603 representatives serve on technical committees of the National Fire Protection Association

Multinational professional society of fire protection engineers with more than 4150 members.

fire safety;

\section{SOCIETY OF MOTION PICTURE AND TELEVISION ENGINEERS}

Carlos V. Gilrod, Jr., P.E., Director of Engineering

595 W. Harsdale Avenue

White Plains, New York 10607

(914) 761-1100

FAX: (914) 761-3115

e-mail: eng@smpte.org

WWW: http://www.smpte.org/

Founded: 1916

Standards staff: 5

Type of

Organization

Standards

Development

Standards

Designation

Government

Adoption

Certification

Secretariats

Scope

Standardization

Activities
Professional Society

Standards Developer

Standards developer since 1916.

250 members participating in standards activities.

160 active standards processed through ANSI.

Draft standards available for review.

SMPTE prefix.

Example: ANSI/SMPTE 273M-1995, SMPTE Standards for

Television-status Monitoring and Diagnostics Protocol.

DoD adopts these standards regularly.

No certification, qualification, or accreditation programs.

ISO/TC 36, Cinematography

A nonprofit organization concerned with the engineering aspects of motion pictures, television, instrumentation, high-speed photography, and the allied arts and sciences. Develops technical standards for motion picture engineering and television.

Activities divided among eight parent technology committees. Cooperates with national and international organizations such as AES, EIA, IEEE, major foreign national standards bodies. International Telecommunication Union (ITU), ISU, and IEC. 
Availability

Formerly

Keywords
Distributed directly or through ANSI.

Society of Motion-Picture Engineers

motion pictures; television; video recording; photography; communications ;

SOCIETY OF NAVAI ARCHITECTS AND MARINE ENGINEERS

Type of

Organization

Representation

Scope

Standardization

Activities
Francis M. Cagliari, Executive Director

601 Pavonia Avenue, Suite 400

Jersey City, New Jersey 077306

(201) 798-4800 FAX: (201) 798-4985

Founded: $1893 \quad$ Standards Staff: 3

Professional Society

Works through other organizations to develop standards

ASTM F-25

A technical, professional society of individual members serving the maritime and offshore industry and its suppliers. Activities include all aspects of research, design, production, maintenance and operation of ships, submersibles, yachts, boats, offshore and ocean bottom structures, and other advanced marine vehicles. Provides a forum for exchange of technical information. Administers a research program involving 100 individuals as voluntary members and permanent staff in cooperation with government and regulatory agencies, scientific and research laboratories, academic institutions, and the marine industry.

Although not a standards developing organization, one of its technical panels has the responsibility of initiating standards and specifications for the shipbuilding standards Committee F-25 of the American Society for Testing and Materials (ASTM). This is Panel SP-6 (Standards and Specifications) of the Ship Production Committee. In this way, SNAME interfaces directly with the F-25 standards development activity. F-25 draws upon the expertise of the SNAME Technical and Research Program by soliciting comments on the need for certain shipbuilding standards and by using these same panels when conducting the necessary consensus review under the ASTM process. These standards are published periodically by ASTM.

Standards developed to date include various shipbuilding parts, such as cable brackets, hangars, pipe fittings and flanking, certain containers, angle irons, etc. Panel SP- 6 is also involved in a program for the redrawing of selected naval military specifications into commercial ASTM standards. SNAME members are 
Certain panels of the Society are also called upon to comment on the standards for small boats undertaken by Underwriters Laboratories (UL).

marine; shipbuilding; boats; transportation;

SOCIETY OF SANITARY ENGINEERING

Type of

Organization

Standards

Development

Standards

Designation

Certification

scope

Standardization Activities

Availability

Formerly
Diana Corcoran, Executive Secretary

28901 Clemens Road

Westlake, Ohio 44145

(216) 835-3040 FAX: (216) 835-3488

Founded: $1906 \quad$ Standards Staff: 3

Technical Society

Standards Developer

38 active standards.

Standards submitted for ANSI approval.

SSE or ASSE prefix.

SSE Seal Program.

Plumbers, contractors, apprentices, journeymen, inspectors, engineers, health officials, and manufacturers interested in promoting public health and sanitation. Conducts research on plumbing and sanitation.

Develops performance standards for plumbing system components. Standards provide a tool for measuring quality and effectiveness of a product. Products meeting these standards are identified by the ASSE Seal. Components of plumbing systems include backflow prevention devices, pressure regulators, water hammer arresters, water mixing and shower control valves, antisiphon hydrants, and other devices which directly affect public health and safety.

Distributed directly and through IHS.

American Society of Sanitary Engineering 
Larry L. Thomas, President

1275 K street NW, suite 400

Washington, DC 20005

(202) $371-5200$

Founded: 1937

Trade Association

Standards Developer

Sponsors a certification program for molded expanded polystyrene block insulation based on ASTM C578. Sponsors jointly with AAMA a certification program for vinyl window lineals based on ASTM D4727 and AAMA 303 .

scope

Standardization Activities
A trade and technical society of 2000 companies in the plastics industry interested in quality standards, research, uniform accounting, traffic rates, wage rate survey, tariffs, codes, public relations, informative labeling, safety, fire prevention, and food packaging. Membership consists of: injection, compression, and transfer molders; laminators; extruders; fabricators; calenders; printers; embossers; reinforced plastics processors; raw material suppliers; machinery and equipment manufacturers; tool, die and mold makers; research and development; and testing laboratories.

Cooperates and supports the preparation of standards for plastics products through organizations such as the American Society for Testing and Materials, the American National standards Institute, and the National sanitation Foundation. Financially supports the U.S. secretariat to the International Organization for standardization, ISO/TC 61, Plastics, and participates in its activities. Also participates in ISO/TC 138, Plastic Pipe, Fittings and Valves for the Transport of Fluids.

Two divisions of the society develop product performance standards and test methods, which are processed through the American society for Testing and Materials. These activities maintain liaison with code and regulatory agencies and work to have vinyl building components accepted as generic products in code standards. 
Linda Ladas, Administrative Manager

122 C street, NW

Washington, DC 20001

(202) 383-2650

FAX: (202) 383-2670

Founded: 1974

Standards Staff: 4

Type of

Organization

standards

Designation

Certification

scope

standardization

Activities

Availability

Keywords
Rating and Certifying Body

SRCC prefix.

The Solar Rating and Certification Corporation (SRCC) certifies several independent testing laboratories for solar collector and solar domestic hot water systems tests. SRCC randomly selects equipment for testing, interprets test data, and publishes a certified product rating directory.

Manufacturers and installers of solar energy systems and components, and distributors, contractors, and engineers whose purpose is to accelerate and foster commercialization of solar energy conversion for economic purposes. Compiles statistics and offers computerized services.

The Solar Rating and Certification Corporation develops solar industry certification for heating equipment. Members are also involved in international standards development activities.

Approximately 25-50 member companies are involved at different times in several certification organizations.

Distributed directly.

solar collectors; water heating; testing; energy; 
Type of

Organization

Standards

Development

Standards

Designation

Government

Adoption

Certification

scope

Standardization

Activities

Availability

gormeriy

Keyrords
W. J. Tangye, P. E., Chief Executive officer

900 Montclair Road

Birmingham, Alabama 35213

(205) 591-1853

FAX: (205) 592-7001

Founded: 1940 Standards staff: 10

Professional society

Standards Developer

Standards developer since 1945 .

5500 members active in standards activities.

The standard Building, Plumbing, Mechanical, Gas, Fire

Prevention and Housing codes.

These codes have been adopted by reference by some

2200 commuities primarily in the Southwest, South, and southeast.

Provides educational and certification programs for persons

involved in the administration and enforcement of building codes.

Promulgates codes that will assure the minimum acceptable level of life safety in the building environment. These cover the entire scope of the construction industry as related to buildings and structural occupied by the public. Also provides technical, educational and computer support to users of the codes.

Holds public hearings to update codes. Any interested party may submit proposed changes and participate in the public hearings, two of which are held each year.

Distributed directly.

southern standard codes

building code; mechanical code; gas code; fire code; safety; housing code; safety; construction; building;

\title{
SOUTHERN CYRRESS MANURACTURERS ASSOCIATION
}

\author{
Susan M Regan, Executive Vice President \\ 400 Penn Center Blvd. $\# 530$ \\ Pittsburgh, Pennsylvania 15235 \\ (412) 829-0770 FEX: (412) 829-0844 \\ Founded: 1917 Standards Staff: 2
}


Type of

organization

Scope

Standardization

Activities

Availability

Keywords
Trade Association

Standards Developer

Producers, wholesalers and distributors of cypress lumber and manufacturers of other cypress products.

Publishes grading rules for cypress lumber.

Distributed directly.

wood products; grading rules; lumber; cypress;

SOUTHERN FOREST PRODUCTS ASSOCIATION

Karl W. Lindberg, President

P.O. Box 641700

Kenner, Louisiana 70064-1700

(504) 443-4464 FAX: (504) 443-6612

Founded: $1915 \quad$ Standards Staff: 1

Type of

Organization

Scope

Standardization

Activities

Formerly

Keywords
Trade Association

Works through other organizations to develop standards

An association of 38 southern pine companies with 142 mills

(located from Texas to Virginia). Conducts marketing research and public affairs programs and a biennial machinery exposition.

Standards developed through organizations like the

Southern Pine Inspection Bureau, American Forest \& Paper

Association, American Wood Preservers Association, and the

American Society for Testing and Materials are used extensively in SFPA marketing efforts. These include span tables,

recommendations for end use applications, treating specifications, metric conversions, model building codes, and other similar activities dealing with lumber applications.

Southern Pine Association

lumber; wood products; 
Tom S. Jones, President

4709 Scenic Highway

Pensacola, Florida 32504-9094

(904) 434-2611

FAX: (904) 433-5594

Founded: 1940

Standards Staff: 8

Type of

Organization

Standards

Development

Standards

Designation

Government

Adoption

Certification

Scope
Service Bureau

Standards Developer

Standards developer since 1940.

374 subscribers representing 70 percent of Southern Pine production.

Five active standards.

SPIB prefix.

The Departments of Defense and Veterans Affairs, Federal Housing Administration, and various state and local regulatory agencies have adopted and recognized the southern Pine Inspection Bureau Grading Rules.

Maintains a certification program in which it licenses subscribers to use its registered grade-mark when subscribers meet the necessary qualifications. The Bureau maintains a similar program for companies that treat lumber by a pressure process for protection against insect and decay attack with approved chemicals in accordance with the standards of the American Wood Preservers Association. The quality of lumber treated by the pressure process is under the supervision of Bureau Quality Supervisors. Those treating plants which prove their proficiency and capability of maintaining the required level of treatment are licensed to apply the Bureau quality mark to their lumber.

An autonomous nonprofit agency and the recognized organization in the southern Pine industry for the formulation and maintenance of grading standards. Has carried on a standardization program since 1940 developing grading rules for Southern Pine lumber in conformance with the Board of Review of the American Lumber Standards Voluntary Products standard PS 20-94, published by the National Institute of Standards and Technology, National Evaluation Service of CABO, and ANSI.

Certified as a supervisory grading agency by the Board of Review of the American Lumber standards Committee. 
standardization Activities

Availability

Reywords
Actively participates in the formulation and maintenance of the American Lumber Standards for Softwood Lumber. Maintains representation on the Committee on wood of the American Society for Testing and Materials and American Wood Preservers Association. Member of ANSI.

Maintains standards of size and grade classifications for the benefit of the lumber using public and the lumber manufacturing industry. These include domestic and export grade rules and standards for glued lumber and mechanically graded lumber. Provides inspection facilities. These inspection facilities are used not only as a means of adjudicating disputes between buyers and sellers, but also for the certification of Southern Pine lumber before shipment from the mill. Grading and manufacture are under the supervision of Bureau Quality Supervisors. Those mills which prove their proficiency in grading and agree to maintain the established standards of size and grade moisture content are licensed to grade-mark their lumber with a Bureau mark.

Sold directly.

wood products; grading rules; lumber; wood preservation; inspection;

\section{SOUTHWEST RESEARCH INSTITUTE}

Joseph S. Kittle, Director

Program Development Office

Post Office Drawer 28510

San Antonio, Texas 78228-0510

(210) 522-5498 FAX: (210) 522-3496

Type of

Organization

Representation

standardization Activities
Nonprofit Research Institute

Works through other organizations to develop standards

ANSI, ASME, API, ASTM, IEEE, NFPA, SAE, National Marine Manufacturers Association, BOAC, SSBCI, USL, UL, ISO, IMO

Works with SAE and API under sponsorship of the Coordinating Research Council, Inc., in the development of rating standards used to subjectively rank the results of an engine oil test. These rating standards evaluate sludge, varnish, rust, and other visible phenomenon, such as ring sticking, scuffing, and wear. These standards are the only recognized subjective rating techniques used by industry in the evaluation of engine lubricants. In a similar capacity, develops standardized test procedures and performs certification testing to evaluate twocycle engine lubricants for the National Marine Manufacturers Association. Worked with ASTM and automobile manufacturers in the development of the industry-recognized sequence Tests for diesel 
Keywords

and gasoline engine lubricants. Participated in development of standards for electromagnetic compatibility which resulted in SAE J1338 and J1113. Evaluates the fire performance of a variety of materials, products, and construction elements. Performs a wide array of environmental testing up to and including seismic.

certification; lubrication; engines; testing; EMC; electrical equipment; materials; fire performance; fire testing; flame spread; environmental testing; seismic testing;

SPECIAI IIBRARIES ASSOCIATION

Type of

Organization

Representation

Scope

standardization

Activities
David Bender, Executive Director

170018 th street, NW

Washington, DC 20009-2508

(202) 234-4700 FAX: (202) 265-9317

e-mail: slal@capcon.net

Founded: 1909 Standards staff: 1

Professional society

Works through other organizations to develop standards

Represented on ANSI committees concerned with development of standards in the following areas: library/information science and publishing practices, photographic reproduction, and library equipment.

An international organization of more than 15000 librarians and information managers. Serves industry, business, government agencies, research, educational, and technical institutions requiring or providing specialized information.

Participates in the work of ANSI accredited organizations including PH5, Photographic Reproduction of Documents; Z39, Library/Information Science and Related Publishing Practices; 285, Library Equipment and Supplies. Works with maintenance organizations, especially the National Information Standards Organization (NISO) and ISO Technical Advisory Group 46. The SLA Standards Committee provides guidance in these areas. 
Robert T. Delfay, Executive Director

Flintlock Ridge office Center

11 Mile Hill Road

Newtown, Connecticut 06470-2359

(203) 426-1320

FAX: (203) 426-1087

Founded: 1926

Standards Staff: 1

Type of

Organization

Standards

Development

Standards

Designation

Government

Adoption

Scope

Standardization

Activities

Availability

Formerly

Keywords
Trade Association

Standards Developer

Standards developer since 1926.

41 representatives active in standards activity.

Draft standards available for review.

ANSI/SAAMI and SAAMI prefixes.

Used by Department of Defense in relation to manufacturing, testing, and performance specifications of commercial ammunition purchased by the United states government.

Serves the mutual interests of the United States sporting firearms and ammunition industry with emphasis on activities to assure safe use of these products by sportsmen and others having a lawful need for them.

Maintains a Technical Committee which reviews industry test methods, procedures, and recommended manufacturing safety practices; two subcommittees work in the areas of ammunition and firearms. Establishes definitive proof loads recommended for factory tasting of United states made sporting firearms, thus assuring greater safety to the user of such arms. Maintains liaison with the Department of Defense in relation to manufacturing, testing, and performance specifications of commercial ammunition purchased by the government

Sold directly and through ANSI.

The Society of American Manufacturers of Small Arms and Ammunition (1918-1926)

ammunition; firearms; defense; safety; sports; 
Nicholas Craw, President

9033 E. Easter Place

Englewood, Colorado 80112

(303) 694-7222

Founded: 1944

Standards Staff: 2
Type of

Organization

Scope

Standardization Activities

Availability

Keywords
Recreational/Technical society

Standards Developer

A nonprofit organization with 52000 members. Sanctions national and regional races and ten major professional racing series listed on the International Calendar. Sanctions rallies (precision driving tests over a given route at an exact speed), solo events (intricate driving maneuvers in a cleared area), concours d'elegance (rating cars by a correlation of age, condition, and equipment of the vehicle), and numerous international events and world championship races.

Develops safety standards for competitions, and standards and procedures for speed events for automobiles taking part in such events, for issuance of competition licenses, and for the organization and conduct of its events. These standards and procedures are published in General Competition Rules; Rally and Solo Rules; and Professional Racing Regulations.

Participates in American National Standards Committee Z90, Vehicular Head Protection, concerned with safety requirements for head protection for automobile drivers engaged in high hazard activities or occupations, as well as crash helmets for motorcyclists, designated as American National Standard z90.1.

Distributed directly.

sports; automobile racing;

STANDARDS COMMITTEE FOR HI-LOK, HI-TIGUE, AND HI-LITE PRODUCTS

Frank L. Gill, Chairman

2600 skypark Drive

Torrance, California 90509-2975

(310) 326-8110

FAX: (310) 784-4096

Standards Staff: 1 
Type of

organization

Certification

scope

Standardization

Activities

Availability

Keywords
Trade Association

Standards Developer

Licensees are under surveillance and approval by the Committee.

Actively engages in standardization activities for fasteners. Membership includes and is open to licensees of Hi-shear Corporation, users of products, and government standardization representatives.

Develops, publishes, and maintains hundreds of proprietary product standards, specifications, and process procedures for the proprietary Hi-Lok, Hi-Tigue, and Hi-Lite fasteners. Holds two official meetings each year, one of which is an international meeting held in Europe. Solicits input from all members.

Distributed directly.

fasteners; manufacturing;

STANDARDS ENGINEERING SOCIETY

Donald L. Kear, P.E, Cstd, Executive Director

1706 Darst Avenue

Dayton, Ohio 45403-3104

(513) 258-1955

FAX: (513) 256-9919

Founded: 1947

standards staff: 1

Type of

organization

Representation

Certification

Scope
Professional society

Standards Developer

Approximately 50 percent of the members participate in standardization activities of standards developers ranging from international organizations to trade associations. Membership is open nationally and internationally.

Certification program exists in Standards Application, Standards Management, Standards Information, and standards Development. certification is open to members and nonmembers.

A professional technical society of 450 standards practitioners for companies and government agencies. objectives include providing a forum for the exchange of information in the standardization discipline and promoting the knowledge and use of national and international standards. 
Standardization

Activities

Formerly

Keywords

STEEL DECK INSTITUTE

Type of

Organization

Standards

Development

Representation

Certification

Scope
SES does not generally develop standards as a society, but members represent their organizations on numerous national and international standards making committees. The Society, however, has approved an American National standard, "Recommended Practice for Standards Designation and Organization," that covers designations, titles, keywords, abstracts, and formats for standards.

Standards Engineers Society (1980)

standards profession; general; social welfare; standards users;
P.O. Box 9506

Canton, Ohio 44711

(216) 493-7886

Founded: 1936

Trade Association

Standards Developer

Standards developer since 1939.

Active in AISI, AISC and ASCE.

None processed through ANSI.

Technical personnel of member firms serve on standards committees and subcommittees of organizations such as AISI, AISC and ASCE.

Provides its members, as well as non-members, a product certification service conducted by independent engineers at appropriate charges.

Manufacturers of steel roofs and steel floor decks. Formulates technical recommendations for improvement of metal deck construction and develops standard design practices. Promotes proper building regulations. Conducts research on earthquake construction and fire and wind resistance. Compiles statistics. 
Standardization

Activities

Formerly

Reywords

STEEL DOOR INSTITUTE
Periodically publishes the Steel Deck Institute Design Manual for Composite Decks, Form Decks, and Roof Decks. It contains: Specifications and Commentaries, the Code of Recommended Standard Practice, Roof Deck Construction, Suggested Architect's Specifications, SDI Standard Load Tables, Roof Deck Fire Resistance Ratings, and Cantilever Criteria. Also publishes the Steel Deck Institute Diaphragm Design Manual.

Metal Roof Deck Technical Institute

steel decks; roofs; building;
J. Jeffery Wherry, Managing Director

30200 Detroit Road

Cleveland, Ohio 44145

(216) 899-0010 FAX: (216) 892-1404

Founded: $1954 \quad$ Standards Staff: 5

Trade Association

Standards Developer

Standards developer since 1954.

12 member companies participating in standards activities.

seventeen active standards including three ANIS standards.

SDI standards have been adopted by numerous government agencies.

No certification, qualification, or accreditation programs.

A nonprofit trade association of United States companies engaged in the production for sale of swing type steel doors and frames in the construction industry.

Administered by its Technical Committee, standardization activities represent a large percentage of the Institute's total program. Maintains liaison with numerous federal agencies including General Services Administration, Army Corps of Engineers, Department of Defense, Department of Housing and Urban Development, Federal Housing Administration and the Department of Veterans Affairs. Works closely with various code groups and has been instrumental in establishing and promulgating a great number of standards helpful to the construction industry, including: standardized specifications for steel doors and frames; standardized hardware locations and hardware preparation; building code improvements; and performance specifications. 
Availability

Keywords

STEEL FOUNDERS SOCIETY OF AMERICA

\author{
Type of \\ Organization \\ Standards \\ Development \\ Standards \\ Designation \\ Certification \\ Secretariats \\ scope \\ Standardization \\ Activities
}

Availability

Formerly

Keywords
Distributed directly.

steel doors; frames; building;

Malcolm Blair, Technical and Research Director

Cast Metals Federation Building

455 state street

Des Plaines, Illinois 60016

(708) 299-9160 FAX: (708) 299-3105

Founded: $1902 \quad$ Standards Staff: 2

Trade Association

Standards Developer

Standards developer since 1964.

80 members participating in standards activities.

14 specifications on foundry raw materials.

SFSA prefix.

No certification, qualification, or accreditation programs.

U.S. Subcommittee Advisory Group to IsO/TC, 17/SC 11, steel Castings

Manufacturers of steel castings. Compiles statistics and conducts research programs.

Develops own standards for foundry raw materials and works through other organizations to develop standards for the manufacture and use of carbon, low alloy and high alloy steel castings. Also participates in ASTM, ISO, ANSI, NACE, API, MSSVFI, ASME standards activities.

Distributed directly.

Alloy Casting Institute (1970)

steel; castings; high alloy; foundry; materials; 
Type of

Organization

Standards

Development

Certification

scope

Standardization

Activities

Availability

Keywords
R. Donald Murphy, Managing Director

1205 48th Avenue North, Suite A

Myrtle Beach, South Carolina 29577

(803) 449-0487 FAX: (803) 449-1343

Founded: 1928

Trade Association

Standards Developer

Standards developer since 1928.

Established certification procedures are required for member companies.

A nonprofit organization of manufacturers engaged in the manufacture and distribution of steel joists. Objectives are: to establish and standardize methods of design and construction for steel joists; to provide test and research data for public dissemination; to assist in the development of appropriate building code regulations; and to publish information relative to the proper use of steel joists in the interest of safety and public welfare.

Current standard specifications are recognized throughout the industry and include Load Tables for Open Web, Longspan, and Deep Longspan Steel Joists comprising K-Series, LH-Series and DLH-Series. In addition, the Institute has developed standard specification and weight tables for Joist Girders, which are primary structural members.

Sold directly.

joist; steel joists; building;

James F. Collins, President

1730 Rhode Island Avenue, NW

Suite 907

Washington, DC 20036-3101

(202) 296-1515 FAX: (202) 296-2506

e-mail: steelnet@aol.com

WWW: http://www.steelnet.org

Founded: 1988 Standards Staff: 2 
Type of

Organization

Scope

Standardization
Activities

Formerly

Reywords

STEEL PLATE FABRICATORS ASSOCIATION

Type of

Organization

Representation

Scope entities. others.
Trade Association

Works through other organizations to develop standards

A North American trade association with 59 members producing steel mill products, accounting for 40 percent of United States steel production. Most of the membership are electric furnace steel producers. The SMA provides a forum for the exchange of information on technical matters and operations; develops and supports public policy positions consistent with the interests of its members; and serves as a source of information on the steel industry to suppliers, customers, and various governmental

Does not issue standards but sponsors American Society for Testing and Materials Standards A615, A616, A617 (Rail and Axle Steel, Concrete Reinforcing Bars, and a Standards Specification for Hot Rolled Steel Fence Posts). Additional counsel and committee activity with ASTM are also undertaken by the association.

Organization resulted from the merger in 1988 of the steel Bar Mills Association and the National Steel Producers Association

steel; steel bars; materials;

Wade Newman, Executive Director

3158 Des Plaines Avenue

Des Plaines, Illinois 60018

(708) 298-0880 FAX: (708) 298-2015

Founded: 1933 Standards Staff: 2

Trade Association

Works through other organizations to develop standards

Representatives of member companies are appointed to serve on standards committees of AWWA, ASME, ANSI, API, AWS, NFPA and

A national trade association representing companies engaged in the fabrication and erection of all types of weldable metal plate into pressure and nonpressure tanks, processing and storage vessels, heat exchangers, penstocks, weldments, and other products for industries worldwide. 
Standardization Activities

Reywords
Works with standards developing organizations to update accepted standards in order to keep current with continuing improvement in materials and techniques.

steel fabrication; steel plate; manufacturing; industrial equipment ;

STEEL SERVICE CENTER INSTITUTE

David R. Roland, President

127 Public Square

Suite 2400

Cleveland, Ohio 44114-1216

(216) 694-3940

FAX : (216) 694-3940

Founded: 1909

Standards Staff: 1

Type of

organization

Representation

Scope

Standardization Activities

Formerly

Reywords
Trade Association

Works through other organizations to develop standards

Two safety specialists from member companies serve as voting delegates on ANSI B11 Committee.

A voluntary trade association representing the interests of some 80 percent of the metal service center industry which serves the metal supply needs of some 300000 manufacturers and fabricators through 1000 outlets.

Participates in the development of safety standards for powerdriven machines used by the industry as developed through Committee B11.

American Iron, Steel, and Heavy Hardware Association (1909)

American Steel Warehouse Association (1934)

Steel Service Center Institute (1959)

metal; steel; distribution; materials;

STEEL SHIPPING CONTAINER INSTITUTE

Richard B. Norment, Executive Director

1101 14th street, NW

Suite 1020

Washington, DC 20005-5601

(202) 408-1900

FAX: (202) 408-1972

Founded: 1944

Standards Staff: 2 
Type of

Organization

standards

Development

Standards

Designation

Government

Adoption

secretariat

Scope

Availability

Keywords

STEEL STRUCTURES PAINTING COUNCIL

Type of

organization

Standards

Development Pails
Trade Association

Standards Developer

SSCI serves as the Secretariat for the American

National standards Institute's ANSI MH2 Committee on new steel drums and pails. The current standards are issued in ANSI MH21996, which contains 24 separate standards for steel containers in common use.

ANSI MH2-1996.

By reference in military and federal specifications.

Accredited standards Committee $\mathrm{MH} 2$, steel Drums and

The steel Shipping Container Institute is the secretariat for this committee which is comprised of representatives of groups directly affected by the consensus standards for steel drums and pails. These groups include carriers, manufacturers, user groups and regulators who agree on the rules and regulations which are covered by these standards. Public canvass is conducted by ANSI after the committee agrees to content. Once any comments resulting from the canvass are resolved, the edited standards are published by ANSI and list the members of the committee including the SSCI secretariat.

Distributed through ANSI.

packaging; pails; drums;

Dr. Bernard R. Applemer, Executive Director

4024 th street

Pittsburgh, Pennsylvania 15213

(412) 281-2331

FAX: (412) 281-9992

Founded: 1950

Standards staff: 4

Technical society

standards Developer

Standards developer since 1950.

85 active standards.

No current standards processed through ANSI.

Draft standards available for review. 


\section{standards}

Designation

Government

Adoption

Certification

scope

\section{Standardization}

Activities

\section{Availability}

Reywords
SSPC prefix.

27 standards adopted by DoD.

Painting Contractor Certification Program.

Determines and outlines the best methods developed for cleaning and painting steel; issues specifications covering practical and economical methods of surface preparation and painting of steel structures; and evaluates through long-range research programs (involving field and laboratory work) the various methods, coatings, and costs necessary to prevent or reduce corrosion on steel structures.

35 committees with 1000 members participating in standards activities. Assimilates the newest technology into usable and effective specifications for the coatings industry. Develops standards through a comprehensive voluntary consensus process. Issues standards for surface preparation, paint application, painting systems, and paints. Surface preparation specifications describe hand and power tool cleaning, chemical cleaning, and all levels of blast cleaning. Develops visual standards for surface appearance after cleaning as an optional supplement to the surface preparation specifications. Paint application standards for: shop, field, and maintenance painting; measurement of paint film thickness; guides for safety in paint application; and a guide for maintenance repainting. Also has visual standards for evaluating the degree of rusting on painted steel surface.

Distributed directly and through IHS and Global.

protective coatings; anti-corrosion; painting; paint; steel; materials;

Wayne B. Geyer, Executive Vice President

570 Oakwood Road

Lake Zurich, Illinois 60047

(708) $438-8265$

FAX: (708) $438-8766$

Founded: 1916

Standards Staff: 3 
Type of

Organization

Standards

Development

Standards

Designation

Government

Adoption

Certification

scope

Standardization

Activities
Trade Association

Standards Developer

Began developing standards in 1952.

30-40 volunteer members typically participate in the

development of standards.

7 active standards.

ANSI accreditation first obtained in 1995.

Draft standards available for review only on case-by- case basis.

STI prefix.

The STI-P3 specification is referenced in

U.S. Environmental Protection Agency $40 \mathrm{CFR}$

280, technical requirements for underground storage tanks.

Manufacturers become qualified to fabricate in accordance with STI-P3, ACT-100, Permatank, F921 and Fireguard specifications. Through a licensing process, STI administers a strict quality technical assurance program, utilizing independent quality assurance inspectors who routinely visit fabrication shops.

A trade association representing steel tank manufacturers and suppliers throughout the world on a wide range of technical, code, and related areas. Current membership consists of approximately 72 fabricator shops, 18 affiliate members who provide tank-related products and services, and 10 associate and international members. Develops and issues specifications covering fabrication methods for steel underground and aboveground storage tank technologies. Researches and develops recommended engineering, testing and installation practices for storage tanks and applicable issues such as corrosion control and secondary containment.

Seven committees with 40 members participating in standards activities. Through research and development, steel storage tank technologies and fabrication standards are developed and licensed to manufacturers. Developed underground storage tank (UST) standards for: exterior corrosion protection of steel; external corrosion protection of FRP composite steel; fiberglass-jacketed steel USTs; and dual-wall steel USTs. Developed aboveground storage tank (AST) standards for: steel ASTs with integral secondary containment; diked ASTs; and thermally insulated steel ASTs. Various recommended installation practices on both underground and aboveground storage tanks are developed and made available to contractors and other interested parties within the industry. 
Type of

Organization

standards

Designation scope
Standardization Activities

Availability

Formerly

Keywords
Distributed directly.

steel tanks; underground storage; aboveground storage; corrosion protection; secondary containment; industrial equipment; construction; fuel storage; petroleum storage;
John H. Addington, Executive Secretary

1300 Sumner Avenue

Cleveland, Ohio 44115

(216) $241-7333$

FAX: (216) 241-0105

Founded: 1920

Standards staff: 2

Trade Association

Standards Developer

"A Specifiers Guide to Steel Windows."

A trade association composed of American steel window manufacturers. Through research and interchange of ideas among its members, develops and makes available to the building trade better products and services. Conducts surveys to determine usage data.

Issues Recommended Specifications for steel Windows

after performing simplification studies to identify preferred types and sizes. Circulates recommendations to members and interested parties.

Distributed directly.

Metal Window Institute

windows; steel windows; building;

STUCCO MANUFACTURERS ASSOCIATION

Robert F. Welch, Executive Secretary

507 Evergreen Road

Pacific Grove, California 93950

(408) 649-3466

FAX : (408) 647-1552

e-mail: rweclh@redsift.com

Founded: 1957

Standards staff: 1 
Type of

organization

Scope

Standardization

Activities

Availability

Keywords

SUMP AND SEWAGE PUMP MANUFACTURERS ASSOCIATION

Type of

organization

Certification

Scope

Standardization

Activities
Trade Association

Standards Developer

Promotes the use of colored stucco finish coats in building construction. Increases industry's service to contractors, architects, and the public.

Develops standards as needed. Although national in scope, standard variations are recognized because of geographic differences in climate, skilled manpower, and material availability.

Distributed directly.

stucco; masonry;

\author{
Pamela W. Franzen, Managing Director \\ P.O. Box 647 \\ Northbrook, Illinois 60065-0647 \\ (708) 559-9233 \\ FAX: (708) 559-9235
}

Founded : 1956

Trade Association

Standards Developer

Provides a certification and labeling program for all products which conform to specified standards.

A national trade organization representing the manufacturers of domestic sump sewage and effluent pumps, together with component and accessory suppliers. Activities include: development and promulgation of quality standards; spelling out design and performance criteria for sump sewage and effluent pumps used in homes; development and dissemination of statistical information designed to describe market size and activity; promotion of improved provisions in building codes on the use of such pumps; and education efforts designed to encourage proper and safe installation, maintenance, and use of domestic sump sewage and effluent pumps.

Developed the Domestic Sump Effluent and Sewage Pump Standards which are national in scope and designed to supply the purchaser and user with accurate performance data and to assist in the determination of proper application and selection of this equipment. They provide a uniform method of testing and rating, and include a specification system covering basic materials of construction for all major components. They also detail minimum 
specifications for motors, nameplate data, service cords, and control switches.

Availability

Formerly

Keywords
Distributed directly.

Sump Pump Manufacturers Association (1981)

pumps; buildings; industrial equipment;

TECHNICAL AND OFFICE PROTOCOL (TOP)

SEe CORPORATION FOR OPEN SYSTEMS INTERNATIONAL

TECENICAL ASSOCIATION OF THE PULP AND PAPER INDUSTRY

William L. Cullison, Executive Director

Technology Park/Atlanta

P.O. Box 105113

Atlanta, Georgia 30348

FAXO) $(44 \theta+140 \theta-6947$

e-mail: cbohanan@tappi.org

Founded: 1915 Standards Staff: 2

Type of

Organization

Standards

Development

Standards

Designation
Technical Society

Test Method Developer

Test methods developer since 1915.

276 Official, Provisional, and Classical Test Methods.

T -- Official, Provisional, and Classical Test Methods.

UM -- Useful Test Methods, which are published by TAPPI but have not been through the regulated review process; no new UMs have been published after 1989 .

Purposes are: to further the application of the sciences in the pulp and paper industry; to promote investigation, research, and interchange of ideas among its members in the field of pulp and paper manufacture and use; to promote education in the science and practice of pulp and paper manufacture; to arrange for the collection and dissemination of information; to provide technical facts, data, and testing procedures fundamental to pulp and paper manufacture and use; and to promote the professional, social, and economic welfare of its members. 
standardization

Activities

Availability

Reywords

TECHNICAL CERAMICS MANUFACTURERS ASSOCIATION

Type of

Organization

Scope

standardization

Activities

Availability

Formerly

Keywords packaging ;

25 North Broadway

(914) 332-0040

Trade Association

Standards Developer

Ceramic and steatite
Publishes testing procedures which include official, Provisional, Classical, and Useful Methods prepared by technical committees and approved by the various divisions of TAPPI in accordance with rules and regulations prescribed by the Test Methods Subcommittee of the Quality and standards Management Committee. Classical Methods are former Official or Provisional Methods which have been superseded by advanced technology. Useful Methods are those found useful in the industry but not worthy of consideration as Official or Provisional Methods.

Cooperates with the American Society for Testing and Materials anc the Intersociety Color Council in developing color standards, and the American National standards Institute in promoting American and International standards.

Distributed directly and through IHS and Global.

pulp; paper; forest products; wood products; corrugated container;

Richard C. Byrne, Secretary

Tarrytown, New York 10591

FAX: (914) 332-1541

Founded: 1978 Standards Staff: 2

Manufacturers of kiln fired ceramic compositions which result in ceramic products of many uses that withstand high temperature, long use, great mechanical, electrical and chemical stresses.

Develops standards for general test methods, inspection sampling, loss factor tests, resistance to thermal extremes, and other technical characteristics.

Distributed directly.

Dry Process Manufacturers Association

ceramic products; materials; 


\section{TELECOMMUNICATIONS INDUSTRY ASSOCIATION}

Dan Bart, Vice President, Standards and Technology

2500 Wilson Boulevard

Suite 300

Arlington, Virginia 22201

(703) 907-7703

FAX: (703) $907-7727$

e-mail: dbart@tia.eia.org

WWW: http://www.industry.net/tia

Founded: 1988 Standards Staff: 12

Type of

Organization

Standards

Development

Standards

Designation

Government

Adoption

Certification

secretariats

scope

Standardization Activities
Trade Association

Standards Developer

Developed standards under the auspices of EIA's ANSI

accreditation from 1988 and then became independently ANSI

accredited in 1991. The Engineering Department provides the home

for over 70 TIA Engineering Committees and subcommittees that

develop TIA standards and other technical publications. Over 1200 technical personnel from member companies participate in standards activities through committees, subcommittees and task groups.

TIA/EIA or EIA/TIA for American National Standards.

Also develops Interim Standards(IS) and Telecommunications Systems Bulletins (TSB) .

The Department of Defense adopts TIA Standards applicable to their needs.

None.

Administered through the Electronic Industries Association.

A national trade association of companies providing communications materials, products, systems, distribution services and professional services to the United States and countries around the world. TIA's member companies manufacture virtually all of the products used in the modern communications network. TIA is a full-service organization which provides numerous services including: government relations market support activities, such as trade shows and trade missions; standards setting activities; and educational programs. TIA represents the telecommunications industry in association with the Electronic Industries Association.

Accredited by the American National standards Institute in 1991, TIA is a major contributor of voluntary standards that promote trade and commerce in telecommunications products. Areas of expertise include: Antennas for Microwave Towers, Cellular Equipment for Analog, CDMA, TDMA, Cellular Intersystem standards, 
Citizen's Band ( $C B$ ) Radio, Data Interchange and Transmission Equipment including modems, Facsimile Equipment, Fiber Optics Cable Specifications, Cleaving specifications, Closures Specifications, Connectors, Specifications, Optical Fiber system Designs, Optical Fiber system Testing, Symbols, Terminology, Fiber Optic Test Procedures, Tools, Waveguide Specifications, Land Mobile Communications Equipment, Point-to-Point Microwave Towers, Personal Communications Services (PCS), Telephones/Terminal Equipment, Key Systems, Network Channel Terminal Equipment, Private Branch Exchange (PBX) and Telecommunications Wiring/Cabling.

Availability

Formerly

Reywords
Distributed through IHS, Global Engineering Documents and ANSI.

TIA was formed in April 1988 after a merger of the U.S. Telecommunications Suppliers Association (USTSA) and the Information and Telecommunications Technologies Group of the Electronic Industries Association (EIA/ITG).

cellular; citizen's band radio; data interchange; digital interfaces; facsimile; modems; land mobile communications; microwave; personal communications systems (PCS); network; telephones;

\section{TEXTILE RENTAL SERVICES ASSOCIATION OF AMERICA}

John J. Contney, Executive Director

1130 East Hallandale Beach Boulevard

Suite B

Post Office Box 1283

Hallandale, Florida 33008

(305) 457-7555

FAX: (305) 457-3890

Founded: 1913 Standards Staff: 3

Type of

Organization

Standards

Development
Trade Association

Standards Developer

Standards developer since 1978 in health care linen service and for linen, towels, and garments. 2200 members participating in standards activities. 28 active standards. None processed through ANSI. Draft standards available for review. 


\author{
standards \\ Designation \\ Certification \\ scope \\ Standardization \\ Activities
}

\section{Availability}

Formerly

Keywords
TRSA Guidelines For Healthcare Linen Service. TRSA Voluntary Purchasing standards.

No certification, qualification, or accreditation programs.

A national trade association representing companies world-wide engaged in the rental and commercial laundering/linen field. TRSA member companies provide laundry and linen service to all areas of United states hospitals and all types of commercial establishments.

Directed toward fulfilling user defined requirements of the industry and its health care customers. Works closely with the American Hospital Association and the Joint Commission on Accreditation of Hospitals. TRSA standards relate to processing, delivery, cleanliness, sanitation, and management standards of textile rental service. Technical input is solicited throughout the hospital industry and its related trade associations and accrediting agencies.

Distributed through TRSA member companies worldwide and directly.

Linen Supply Association of America (1978)

laundry; linen service; hospital; textiles; sanitation; public health;

TILE COUNCII OF AMERICA

Robert E. Daniels, Executive Director

Post Office Box 1787

Clemson, South Carolina 29633

(609) 921-7050 FAX: (609) 452-7255

Founded: $1946 \quad$ Standards Staff: 3

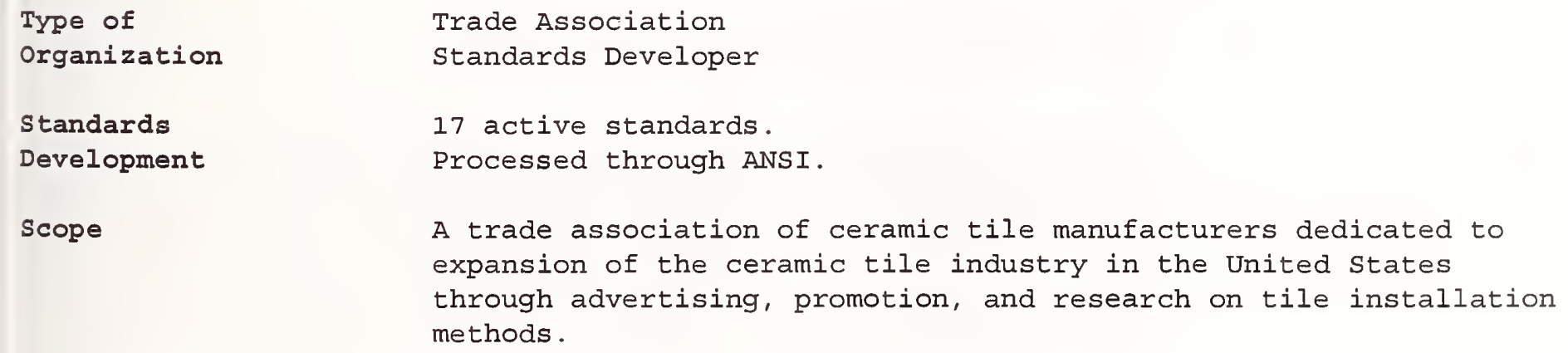


Standardization

Activities

Availability

Keywords

TIRE AND RIM ASSOCIATION

Type of

Organization

standards

Development

standards

Designation

secretariats

scope

standardization

Activities

Availability
Maintains contact with government agencies and other national organizations to assist with development and interpretation of standards and specifications for installation of ceramic tile.

Annually publishes the guide specification Handbook for Ceramic Tile Installation. This covers all accepted ceramic tile installation methods and references installation and material standards applicable to the methods.

Distributed directly and through ANSI.

tile; ceramic products; building;

J. F. Pacuit, Executive Vice President and Secretary

175 Montrose West Avenue

Copley, Ohio 44321

(216) 666-8121 FAX: (216) 666-8121

Founded: 1903 Standards Staff: 3

Technical standardizing Organization

Standards Developer

Standards developer since 1917.

None processed through ANSI.

Draft standards not available for review.

Tire and Rim standard.

U.S. Technical Advisory Group for ISO/TC 31, Tires, Rims, and Valves.

The technical standardizing body of the tire, rim, and related parts manufacturers for the United states

Serves as the primary standards developing organization in areas such as tire loads, tire inflations, tire dimensions, recommended rims, dual spacings, rim dimensions, valve and valve hole dimensions for tire and rim equipment used on passenger cars, bicycles, motorcycles, motor scooters, trucks, buses, recreational vehicles, trailers, earthmovers, road graders, agricultural tractors and implements, industrial vehicles, mobile homes, and aircraft.

Distributed directly. 


\section{TOY MANUFACTURERS OF AMERICA}

David A. Miller, President

200 Fifth Avenue

New York, New York 10010

(212) 675-1141

FAX: (212) 633-1429

Founded: 1916

Standards Staff: 4

Type of

Organization

standards

Designation

Secretariats

Scope

Standardization

Activities
Trade Association

Standards Developer

ANSI Z315.1, Safety Requirements for Tricycles; ASTM-

F963-86, Voluntary Product Safety Standard for Toys; ASTM F834-95, Standard Consumer Safety Specification for Toy Chests.

U.S. Technical Advisory Group for ISO/TC 181, Toy Safety

(participating member); ASTM. F15.22 subcommittee on Toy Safety.

The trade association for domestic producers and importers of toys, games, and holiday decorations with 250 members which together account for about 90 percent of the toy industry's total sales. The Association is recognized by government, the trade, the media, and consumers alike as the authoritative voice of the United states toy industry.

Helps toy makers meet the many challenges of the toy manufacturing marketplace. Its programs assist member companies in safety and quality control, credit and collection, distribution management, import/export trade, legal advice, public relations, statistics, consumer information, media relations, and advertising guidelines.

The Association actively participates, on both domestic and international levels, in the drafting of safety standards; and cooperates closely with governmental, safety, health, and consumer organizations in the development and application of standards for the safe use of playthings.

The industry's Voluntary Safety Standard ASTM F963-95 includes more than 100 separate testing and design specifications to assure that normal use and abuse of toys will not result in a hazard that could cause an injury. 
Availability

Keywords

TRAFFIC AUDIT BUREAU
Distributed directly and through ANSI and ASTM.

toys; consumer products; safety;
Anna Fountas, President

420 Lexington Avenue

Suite 2520

New York, New York 10170

(212) 972-8075

FAX: (212) 972-8928

Founded: 1933

Standards staff: 1
Type of

Organization

scope

Standardization

Activities

Availability

Keywords
Professional society

Standards Developer

Consists of advertisers, advertising agencies, and operators of outdoor advertising plants. Furthers the joint interests of its membership and the general public.

Establishes standard practices with respect to the circulation, evaluation, and visibility of outdoor advertising; supervises and directs practices in connection with the collection, recording, and authentication of traffic and other data related to outdoor advertising; and prepares and issues standardized factual statements of the circulation values of outdoor advertising plants.

Distributed directly.

advertising; communications;

TRUCK MIXER MANUFACTURERS BUREAU

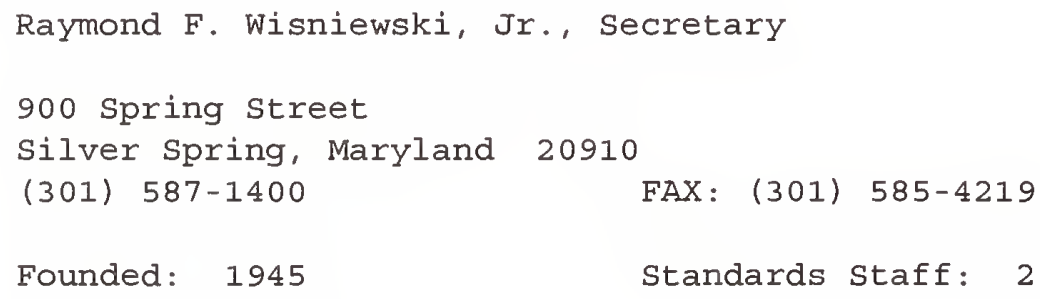


standardization Activities

Availability

Keywords
Represents manufacturers of concrete truck mixers.

Participates with government in the development and interpretation of specifications. Cooperates with the National Ready Mixed Concrete Association to develop standards. Standards cover truck mixers and agitators, whether truck or trailer mounted. Publishes Truck Mixer and Agitator Standards.

Distributed directly.

concrete; concrete mixers;

TRUCK TRAILER MANUFACTURERS ASSOCIATION

Donald W. Viermiaa, Vice President Engineering

1020 Princess Street

Alexandria, Virginia 22314

(703) $549-3010$

FAX: (703) 549-3014

Founded: 1941

Standards staff: 4
Type of

Organization

Standards

Development

Standards

Designation

Certification

scope

Standardization Activities
Trade Association

Standards Developer

Presently offers 70 Recommended Practices and 48 Technical Bulletins.

83 Trailer manufacturing companies participate in development.

None processed through ANSI.

Recommended Practices and Technical Bulletins are by Number.

No certification, qualification, or accreditation programs.

An international trade association that represents the manufacturers of truck pulled trailers, cargo tanks, and intermodal containers, and manufacturers supplying components and parts to the trailer, tank, and container manufacturing industry.

Recommended practices are issued as suggested solutions to design, specification, and manufacture or tests of truck trailers and their components. Examples include: trailer hitches and connections, air brake system tests, lighting devices, and tank construction.

Technical bulletins are issued to aid carriers or shippers in the operation of truck trailers or to improve their serviceability or use. Examples include: brake performance test methods, tank venting, corrosion prevention, and electrical wiring. 
Availability

Keywords

TRUSS PLATE INSTITUTE

Type of

Organization

standards

Development

Standards

Designation

Certification

scope
Works with organizations such as ANSI, ISO, the American Trucking Association, the Association of American Railroads, the Society of Automotive Engineers, American Petroleum Institute, U.S. Department of Transportation, U.S. Environmental Protection Agency, National Fire Protection Association, and others.

Distributed directly.

trailers; containers; tractor-trailers; transportation; cargo tanks;

Charles B. Goehring, Managing Director

583 D'Onofrio Drive, suite 200

Madison, Wisconsin 53719

(608) 833-5900 FAX: (608) 833-4360

Founded: $1961 \quad$ Standards Staff: 1

Trade Association

Standards Developer

15 members active in standards development.

TPI, PCT, DSB, and QST prefixes.

Provides an in-plant inspection service for manufacturers of metal plate connected wood trusses in accordance with Uniform Building Code (UBC) Standards under its Quality Control Inspection Program. TPI is recognized as an approved quality control agency for the inspection of metal plate connected wood trusses.

A nonprofit organization of manufacturers engaged in the production and distribution of metal connector plates for the trussed rafter industry; maintains the industry on a sound engineering basis by establishing methods of design and construction for wood trussed rafters using metal connector plates; provides test and research data for public dissemination; assists in the development of proper building code regulations; and disseminates information relative to the proper use of wood trussed rafters in the interest of safety and public welfare. 


\section{standardization Activities}

Availability

Reywords
Develops design standards for metal plate connected wood trusses, metal plate connected parallel chord wood trusses, and temporary bracing of metal plate connected wood trusses. publishes a quality control standard, and a commentary on handling, installation and bracing of wood trusses. Promotes product acceptance with code authorities. Also publishes design criteria.

Distributed directly.

wood trusses; wood rafters; wood products; building; metal connector plates; truss plates;

TUBE AND PIPE ASSOCIATION, INTERNATIONAL

Nancy Olson, Director of Membership

833 Featherstone Road

Rockford, Illinois 61107-6302

(815) 399-8700

FAX: (815) 399-7279

Founded: 1983

Standards Staff: 1

Type of

Organization

Standards

Development

Scope

Standardization

Activities

Availability

Formerly

Reywords
Educational Association

Standards Developer

TPA has 2 active voluntary tube and pipe bending

standards -- one for cold bending and one for induction bending.

An international educational association established to disseminate current and evolving technical and business information to producers and fabricators of tube and pipe.

Voluntary standards on tube and pipe bending are developed by Association Committees.

Directly from the association.

International Pipe Association, 1990

Tube and Pipe Fabicators Association, 1995

tube; pipe bending; pipe fabrication; pipe joining methods; 


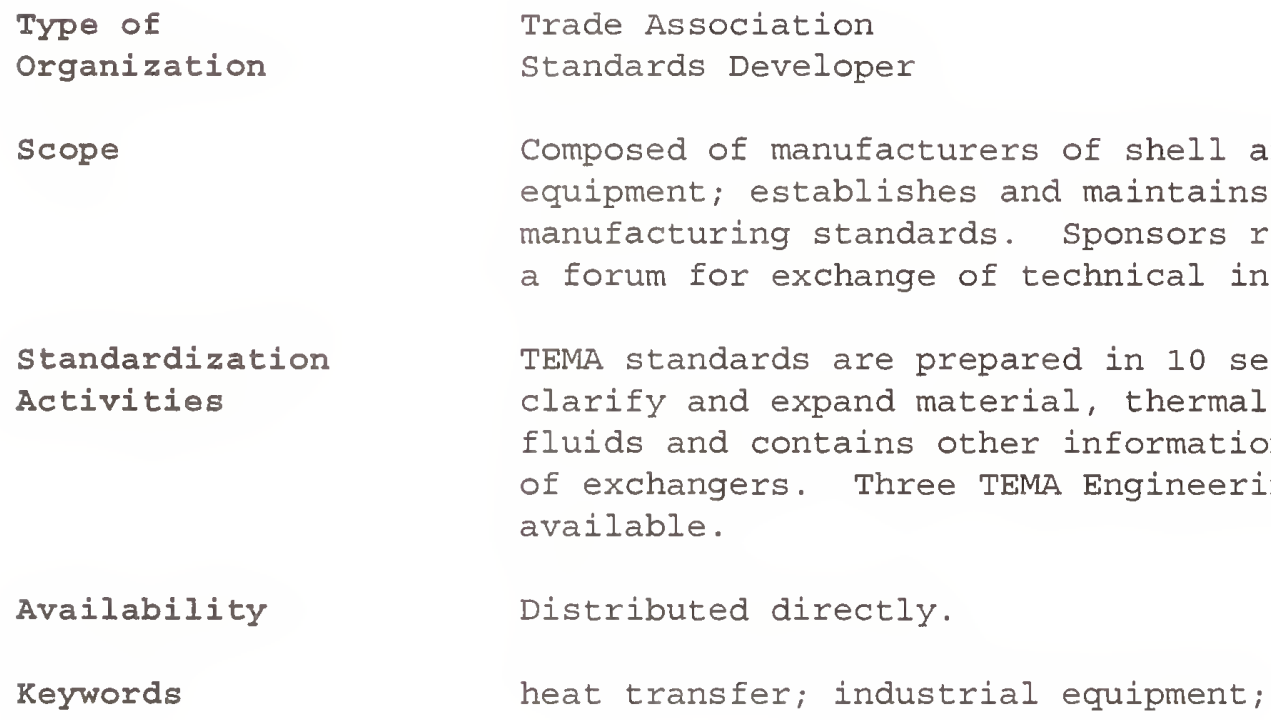

TUBULAR RIVET AND MACHINE INSTITUTE

Richard C. Byrne, Administrator

25 N. Broadway

Tarrytown, New York 10591

(914) 332-0040

FAX: (914) 332-1541

Type of

Trade Association

Standards Staff: 1

Organization

Standards Developer

Scope

Represents United States companies engaged in the manufacture of

Standardization rivets and rivet setting machines in technological areas.

Activities

Works within the voluntary standards system to coordinate industry standards activities and acts as an industry voice. Ten members active in standards development. Distributes Metric Dimensional Standards for General Semi-Tubular Rivets. Is represented on industry standards and ANSI committees. 

Availability
Distributed directly.
Formerly
Tubular and split Rivet Council
Keywords
rivets; fasteners; manufacturing;

TURFGRASS PRODUCERS INTERNATIONAL

Douglas H. Fender, CAE, Executive Director

1855-A Hicks Road

Rolling Meadows, Illinois 60008

(708) 705-9898

FAX: (708) 705-8347

Founded: 1967

Type of

organization

Scope

Standardization

Activities

Availability

Keywords
Trade Association

Standards Developer

Objectives are: to promote efficient and economical production of sod; to develop standards in the industry; to promote the production of better quality sod and its proper use; and to increase public awareness of the industry.

Developed national guideline specifications for sodding. Through use of sod specifications, assistance has been provided to various state and federal agencies, architects, landscape architects, contractors, and a wide variety of professional turfgrass managers.

Distributed directly.

sod; seed; turf; grass; agriculture;

\section{ULTRASONIC INDUSTRY ASSOCIATION}

Martha Graff, Coordinator

P.O. Box 628

Hilliard, Ohio 43206-8353

(614) $771-1972$

FAX: (614) 771-1984

Founded: 1956

Standards staff: 3

Type of

Organization
Trade Association

Standards Developer 
scope

Standardization

Activities

Availability

Formerly

Reywords

UNDERWRITERS LABORATORIES
Comprised of manufacturers of ultrasonic equipment and component parts. Promotes the industry; cooperates with government on legislation; and researches the use and safety of products.

Developed definitions covering basic industry terminology designed to promote a common language and facilitate understanding between manufacturers and users. Developed a standard rating covering ultrasonic generators.

Cooperates with the American National standards Institute, the Institute of Electrical and Electronics Engineers, National Safety Foundation, Acoustical Society of America, National Electrical Manufacturers Association, and American Society for Testing and Materials. Provides assistance to various government agencies such as the Departments of the Navy and Air Force, and maintains standardizing liaison with other government agencies, such as the Federal Communications Commission.

Distributed directly.

Ultrasonic Manufacturers Association (1973)

ultrasonic equipment; industrial equipment;
Type of

Organization

Standards

Development

Standards

Designation
Robert A. Williams, Corp. Manager, Standards and Research

333 Pfingsten Road

Northbrook, Illinois 60062

(708) 272-8800 ext. 42570

FAX: (708) 509-6257

WWW: http://WwW.ul.com

Washington, DC

(202) 638-2323

FAX: (708) 272-8129

Founded: 1894

Standards Staff: 80

Independent, Not-for-Profit Corporation Testing for

Public safety

Developer of Standards for Safety

Standards developer since 1903.

686 published and 70 proposed Standards for safety. 452 ANSI approved, 291 being processed through ANSI procedures.

Activities open to participation by interested parties.

UL Standards for Safety. 
Government

Adoption

Representation

Certification
The Department of Defense has adopted more than 150 Underwriters Laboratories Inc. (UL) Standards for Safety. In addition, other government agencies, including the General Services Administration and the United States Coast Guard, either require compliance with UL Standards for safety or accept UL certification as constituting compliance with applicable regulations.

UL personnel contribute to standards and code-making activities by serving as members of over 500 committees of national and international organizations including ANSI, NFPA, ASTM, IEC, ISO, and others.

UL offers five services by which products or systems may be identified as complying with the requirements of UL or other organizations or regulating agencies, or as otherwise having been investigated by UL in accordance with specified methods or procedures. These services, their applicability, and the method of identification are:

1. Listing -- Products that have been investigated with respect to reasonable foreseeable risks to life and property and for which the risks have been reduced to an acceptable degree. Products are identified by the UL Listing Mark.

2. Classifications -- Products that have been investigated with respect to one or more of the following: (a) specific risks only, (b) performance under specified conditions, ( ${ }^{\circ}$ ) regulatory codes, or (d) standards of organizations other than UL, including international standards. This service is generally applicable to industrial and commercial products. Products are identified by the UL Classification Marking.

3. Recognition -- Products that have only been investigated for use as components of equipment Listed or Classified by UL. Products are identified by the manufacturer's identification and a model number or the equivalent. Products may also be identified by the UL Recognized Component Mark.

4. Certificate -- Products that comprise a field installed system investigated at a specific location, or specific quantities of certain products, under such conditions that it is impractical to apply the Listing Mark or Classification Mark to each product. Products or systems are identified by a Certificate issued by the manufacturer or installer under UL's authorization. 
Secretariats

Scope
5. Registered Firm -- Facility Quality Assurance Systems, by means of assessment and subsequent surveillance, providing assurance of a firm's capability of working to their specifications. Facilities so registered are permitted to use the Registered Firm Mark in advertising, but not in connection with any product.

As an integral part of each of these five services, UL maintains a Follow-Up service under which UL conducts factory inspections and counterchecks of manufacturers' inspection and test procedures for determining continued compliance with the requirements under which the product or system was initially investigated.

In cooperation with EIA, UL serves as the National supervising Inspectorate (NSI) of the IEC Quality Assessment system for Electronics Components (IECQ-System) for the United States. The IECQ-System is designed to encourage international trade in electronic components. It is intended that components certified by an approved manufacturer in one participating country be acceptable to users in other participating countries without further testing. The NSI is the national organization responsible for the surveillance of all quality assessment necessary for the system, including these responsibilities: approval of manufacturers, independent distributors, and independent laboratories; supervision of the Certificate of Conformity; and audit testing of approves components.

ANSI C101.1, Leakage Current for Electrical Appliances IEC/SC 31A, Flameproof Enclosures

IEC/SC 31H, Apparatus for Use in the Presence of Ignitable Dust IEC/TC 61, Safety of Household and Similar Electrical Appliances IEC/TC 61D, Appliances for Air Conditioning for Household and Similar Purposes

IEC/TC 61/WG9, Temperature Limits for supplementary and Reinforced Insulation Under Abnormal Operation Conditions

IEC/TC 74, Safety of Data Processing Equipment and office Machines

objectives are: to evaluate products and systems or to conduct scientific investigations, studies, experiments, and tests to determine the relation of various materials, devices, construction, and methods to life, fire, and casualty hazards; to ascertain, define, and publish standards, classifications, and specifications for materials, devices, constructions, and methods affecting such hazards; and to provide other information tending to reduce or prevent damage from fire, crime, and casualty. 
standardization Activities
Availability

The primary business of UL is product safety through Facility Registration Product Certification, and UL's Standards for safety play an important part of this process of investigation, identification, and audit. Each of UL's engineering departments has prepared standards for use in this work. A catalog listing all available UL standards for safety is published twice yearly. Members of UL's five Engineering Councils assist and advise UL engineers in an effort to provide safety requirements that reflect realistic considerations of field experience and practical judgements, as well as sound engineering technology. UL Engineering Councils currently serve in the areas of Burglary Protection, Casualty, Electrical, Fire, and Marine.

The Consumer Advisory Council members advise UL in establishing levels of safety for consumer products. They also provide additional user field experience and information in the area of product safety and assist in educating the general public in the limitations and safer use of specific consumer products.

UL Standards for safety are developed under procedures that provide for participation, review, and comment from industry, government, insurance groups, consumers, other interested parties, and the general public. These procedures take into consideration the needs and opinions of a wide variety of interests concerned with the subject of the standard and afford due process to all those who will be affected by the standard.

UL's Technical Assistance to Exporters (TATE) program offers help to exporters in getting information about international and foreign national standards and information about foreign laboratories and certification programs. UL will investigate a product in accordance with a published foreign national standard or an international standard. UL-generated data may then be submitted to a foreign test station for considerations as a part of their investigation. UL also maintains a Technical Information Center (TIC) for providing access to information about standards, regulations, and submission procedures of foreign countries. The Technical Information Center also includes selected translations of foreign specifications.

Distributed directly and through ANSI, IHS, Global Engineering Documents, the British Standards Institution, and the Standards Association of Australia. Translations of some UL Standards for Safety into languages other than English are available from the following organizations: French -- AFNOR; Japanese -- JMI Institute and the Japan Standards Association; and Korean -- Korea Institute of Machinery and Metals. UL Standards for safety are available in microform and CD-ROM from IHS. 
Formerly

Keywords

UNIFORM CODE COUNCII

Type of

Organization

Standards

Development

standards

Designation

Government Adoption

Certification

Scope
Underwriters Electrical Bureau (1901)

safety; certification; testing; burglary; casualty; marine; electrical equipment; fire protection; recreation; general; industrial equipment; consumer products; air handling; plastics; commercial equipment; building material;

Stephen A. Brown, Vice President, Secretary and Counsel

424 South Washington street

Alexandria, Virginia 22314

(703) 684-1424

FAX: (703) 684-1426

e-mail: thvr78a@prodigy.com

Founded: $1971 \quad$ Standards staff: 25

Standards development organization

The UCC was created to administer the Universal Product Code (U.P.C.). Today, the UCC administers a variety of product identification standards and guidelines, and a variety of electronic data interchange standards. Typically, over 250 individuals participate in the development of standards.

Product identification standards are designated

ANSI/UCCX-YYYY, with $X=$ number of the standard and YYYY = year it became an American National Standard. Electronic Data interchange standards are designated by version and date, for example, Version 3050, 1995 is version 3, release 5 of 1995.

Two standards are currently referenced by the federal government.

No certification, qualification, or accreditation programs.

The UCC takes a global leadership role in establishing and promoting multi-industry standards supporting product

identification and electronic data interchange. With over 165000 members, the UCC's goal is to enhance the transaction and business processes that enable distribution channels to operate more efficiently and effectively while contributing added value to customers. 
Standardization Activities

Availability

Formerly

Keywords
UCC staff, committees, and ad hoc groups, working with relevant industry organizations and groups, determine the needs of users. Once user needs are determined, we interface with technology suppliers to see if standards solutions can be proposed.

Standards and guidelines are available through the UCC office: 8163 Old Yankee Road, Suite J, Dayton, Ohio 45458.

Uniform Grocery Product Code Council (1971) Uniform Product Code Council (1975)

product identification; EDI; electronic data interchange; $A D C$; automatic data capture; container marking; U.P.C.; Universal Product Code; AI; Application Identifiers; bar codes; UCC/EAN-128; SSCC-18; SCC-14; WINS; Warehouse Information Network standard; VICS EDI; Voluntary Interindustry Communication standard; UCS; Uniform Communication Standard; SIL; Standard Interchange Language ;

\section{UNITED LIGHTNING PROTECTION ASSOCIATION}

Elizabeth Cooper Wendover, President

Cooper Road, Box 329A

Millerton, New York 12546

(800) 668-ULPA

FAX: (518) 789-4902

Founded: 1935

Type of

Organization

Representation

Scope

standardization Activities
Trade Association

Works through other organizations to develop standards

100 members active in lightning protection activities of standards developers such as UL and NFPA.

Provides reliable educational materials on the hazards of lightning and what constitutes proper lightning protection. Members must conform to the highest standards of lightning protection systems, engineering, installation, and service to maintain membership.

Members serve on numerous committees and in other key roles in helping to establish various standards and codes, such as the Lightning Protection Code of the National Fire Protection Association and the Lightning Protection Installation Requirements Code of Underwriters Laboratories. Consulted frequently by building supply manufacturers, insurance firms, safety groups, and power companies to advise on potential hazards and proper lightning protection. 
UNITED STATES COUNCIL FOR AUTOMOTIVE RESEARCH

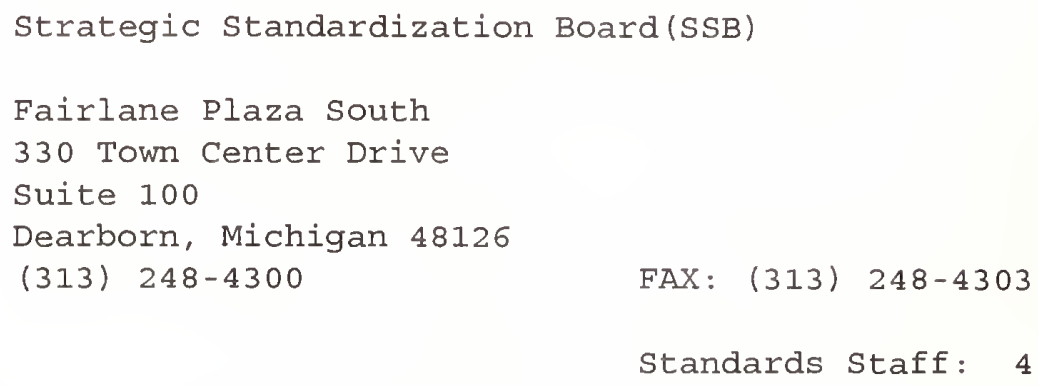

Type of

Organization

standards

Development

\section{Certification}

Scope
USCAR-Research Consortium

USCAR SSB-Standard Developer

Develops standards, recommended practices, and technical reports.

- Created first standard in 1994.

- Approximately 30 individuals participate in the standards development process.

- 5 active standards and recommended practices.

- The USCAR Strategic Standardization Board has a contractual relationship with SAE International for document maintenance, publishing, and distribution services. Draft standards are available for review from SAE.

The USCAR Strategic Standardization Board has no certification, qualification, or accreditation programs and has no intent to conduct such programs in the future.

USCAR Strategic Standardization Board represents the technical standardization interests of Chrysler, Ford, and General Motors to identify and act on important opportunities for voluntary standardization. Specific goals are reduction in complexity, costs, timing, and improvement in quality. Major thrusts include anticipating the international spread of standards, influencing the development of new worldwide standards to assure compatibility of existing and emerging technologies and, with the support of their suppliers, proposing parts for joint engineering standardization and variety reduction. 
Standardization

Activities

Availability

Keywords
The USCAR Strategic Standardization Board has developed standards related to engineering processes and commodity specifications. These processes and specifications are implemented through Chrysler, Ford, General Motors, and their suppliers via SAE industry documents and procedures.

Standards are distributed through SAE International.

automotive; polymers; engineering processes; fasteners;

UNITED STATES COUNCIL FOR INTERNATIONAL BUSINESS

Abraham Katz, President

1212 Avenue of the Americas

New York, New York 10036

(212) $354-4480$

FAX: (212) 575-0327

Founded: 1945

Trade Association

Works through global business organizations to develop

international standards

U.S. National Committee of the International Chamber of Commerce (ICC).

U.S. Committee of the International Organization of Employers (IOE).

U.S. Affiliate of the Business and Industry Advisory Committee (USA-BIAC) to the Organization for Economic Cooperation and Development (OECD).

Secretariats

U.S. Secretariat for the U.S. Coordinating Group on European Union Affairs (USICG)

A trade association of 300 United States based multinational corporations, law firms, and industry associations. Represents its members by keeping them informed of international business development having a major impact on their operations.

Works with ICC to harmonize trade practices and terminology resulting in Universal Standards and the Uniform Customs and Practice for Documentary Credits. Serves as the business voice in the International Labor Organization which is active in establishing international labor standards in the form of conventions, which are binding on states which ratify them, and nonbinding recommendations. Works with OECD to provide models for national legislation, such as tax provisions, and voluntary standards of behavior for multinationals. 
UNITED STATES CUTTING TOOL INSTITUTE

Type of

Organization

Representation

scope

Standardization

Activities

Formerly

Keywords
Charles M. Stockinger, Secretary/Treasurer

1300 Sumner Avenue

Cleveland, Ohio 44115-2851

(216) 241-7333 FAX: (216) 241-0105

Founded: $1988 \quad$ Standards Staff: 1

Trade Association

Works through other organizations to develop standards

ASME TC 6/Milling Cutter Bodies

A trade association of companies which produce cutting tools. Aims to reduce manufacturing costs through standardization and eliminate waste, while encouraging competition. Encourages advances in engineering and manufacturing techniques, research and safety in the industry. Functions as an industry voice in matters of business and national concern.

Promotes the standardization of sizes, dimensions and tolerances in cooperation with ANSI, ASME and other national and international engineering organizations. Actively participates in technical and advisory committees of major national standardizing bodies. Promulgates American National Standards on twist drills, reamers, taps and milling cutters which form the basis of federal specifications and individual company standards, as well as reflecting current United states industry practice in the formulation of Iso standards. Publishes the Metal Cutting Tool Handbook and pamphlets such as Drilled Holes for Tapping, Tolerances for Twist Drills and Reamers, and Standards and Dimensions for Taps and Dies.

Cutting Tool Manufacturers of America; Metal Cutting Tool Institute.

cutting tools; metal; manufacturing; 
David B. Fay, Executive Director

Golf House

P.O. Box 708

Far Hills, New Jersey 07931-0708

(908) 234-2300

FAX: (908) 234-9687

Founded: 1894

Standards Staff: 2

Type of

Organization

Scope

Standardization

Activities

Availability

Keywords
Trade Association

Standards Developer

National Club Membership consists of more than 9000 golf courses and clubs. Also more than 630000 individual Members. Serves as a governing body for golf in the United states promotes scientific work in green keeping, environmental research, and turf management. Provides data on various topics, including handicapping and tournament procedures.

Developed standards for golf balls and golf clubs. Maintains Rules of Golf used in the United States, with specifications concerning style and make of clubs, and size, weight, and velocity of golf balls included. These specifications are applicable to equipment and balls used in connection with tournaments.

Distributed directly.

golf; golf equipment; sports; national championships, rules;

UNITED STATES HIDE, SKIN AND LEATHER ASSOCIATION

A division of the American Meat Institute

Jerome J. Breiter, President

$1700 \mathrm{~N}$ Moore Street, Suite 1600

Arlington, Virginia 22209

(703) $841-5485$

FAX: (703) 841-9656

Founded: 1980

Standards Staff: 2

Type of

Organization

Scope
Trade Association

Standards Developer

A national trade association representing the hide and skin trade. Members include meat packers, hide processors, brokers and dealers, and exporters. Organized to promote and improve relations and conditions in the hide industry. Maintains liaison with allied trades, as well as the government. 
Standardization

Activities

Availability

Formerly

Keywords

U.S. METRIC ASSOCIATION

Type of

Organization

Representation

Certification

Scope

Standardization

Activities

Keywords
Primarily concerned with developing a descriptive package to protect buyers and sellers of hides and skins. Standards describe the product and deal with delivery, trim, grading, weight loss in shipment, and tolerances with an emphasis on exporting.

Distributed directly.

National Hide Association

American Association of Hides, Skins and Leather Traders

animal hide; leather; materials;

Valerie Antoine, Executive Director

10245 Andasol Avenue

Northridge, California 91325

(818) $368-7443$

FAX: (818) $368-7443$

Founded: 1916

Standards Staff: 1

Professional Society

Works through other organizations to develop standards

1000 members participate in standards activities of the major standards developers. Some members are on metric committees of various standards writing groups

USMA has a Certified Metrication Specialist (CMS) program that is administered by the USMA CMS Board. The CMS award is made after an applicant passes a stringent examination.

A nonprofit organization representing 2000 members from many industries. Provides metrication information to companies; provides consumer and educational services. Also publishes a newsletter, Metric Today.

Involved primarily in promulgating correct SI metric usage in cooperation with ANSI, ASME, ANMC, NAS, and other societies in order to draft metric standards and help determine correct usage of metric units.

metric; metric conversion; education; general; SI metric system; 
Type of

organization

standards

Development

standards

Designation

Government

Adoptions

Certification

Scope

Standardization Activities
Jerome A. Halperin, Executive Vice President

12601 Twinbrook Parkway

Rockville, Maryland 20852

(301) 881-0666

FAX: (301) 816-8299

WWW: http://www.usp.org

Founded: 1820

Standards Staff: 36

Nonprofit Scientific Society

Standards Developer

Standards developer since 1820.

138 members of the General Committee of Revision plus

about 500 persons in Expert Advisory Panels.

1450 USP Reference standards.

3550 Official Monographs.

1000 under development.

None processed through ANSI.

Draft standards available for review.

USP, United States Pharmacopeia.

NF, National Formulary.

The Food, Drug and Cosmetic Act makes USP and NF

standards enforceable by the Food and Drug Administration.

Comparable acts exist in most states. Canada and other countries recognize USP-NF in their laws and/or regulations. USP Dispensing Information is recognized as the authoritative compendia for medically accepted indications for drugs.

USP is not a certifying agency. FDA is required by law to certify each batch of insulin against USP standards before manufacturers release it.

Recognized authorities in medicine, pharmacy, and allied sciences. Revises and publishes the U.S. Pharmacopeia (USP) and the National Formulary (NF), the legal compendia of drug standards. Maintains a continuous current consensus of appropriate drug use information for health professionals and patients, published as USP Dispensing Information (DI).

Defines articles (i.e., drug substances, drug dosage forms, inactive ingredients, medical devices, and diagnostic agents); states standards for dietary supplements, strength, quality and purity; provides test methods to determine if articles meet standards; and establishes packaging and labeling requirements. Establishes authoritative therapeutic information for health professionals and patients. The elected volunteers of the Committee of Revision with the aid of Advisory Panels make the decisions. The employed staff coordinates these activities. 
Availability

Keywords
Cooperates with the World Health Organization, the Japanese Pharmacopoeia, the British Pharmacopoeia, and the European Pharmacopoeia. Also cooperates with the Foods Chemicals Codex, National Committee on Clinical Laboratory Standards, American Chemical Society, and ASTM. Publishes, bimonthly, the Pharmacopeial Forum, which is the drug standards development journal.

Subscriptions to USP 23 - NF 18 and to Pharmacopeial Forum are available directly, as are USP Reference standards and USP Dispensing Information in paper, diskettes, and CD-ROMs.

drugs; medical devices; diagnostic agents; nutrition; pharmaceuticals; pharmacopeias; chemicals; medicines; medical; drug information; patient drug use information; reference standards;

\section{U.S. PRODUCT DATA ASSOCIATION}

Type of

Organization

standards

Development

\section{Standards \\ Designation}

Certification

secretariats

Scope
Bob Willis, President

P O Box 3310

Gaithersburg, Maryland 20885-3310

(301) 975-4658

FAX: (301) $926-8730$

e-mail: uspro@scra.org

Founded: 1992

Standard Staff: 4
The IGES/PDES Organization (IPO) is currently developing two standards: Initial Graphics Exchange Specification (IGES), and Product Data Exchange using STEP, the adoption of the International standard for the Exchange of Product Model Data (STEP).

Both the IGES and PDES standards are designated ANSI/US $\mathrm{PRO} / \mathrm{IPO}-\mathrm{XXX}$.

No certification, qualification, or accreditation programs.

U.S. Tag to ISO TC 184/SC 4; ISO 13584, Parts Library; Manufacturing Management Data (MANDATE) standards.

US PRO is the standards development organization for product data exchange technology in the United States, working on behalf of industry. As a nonprofit organization, it provides management and strategic direction for vendor and user organizations engaged in research, development, implementation, and testing of standards and specifications for the exchange and sharing of product information. 
Standardization

Activities

Availability

Keywords
US PRO'S ANSI-accredited organization which develop standards is the IGES/PDES Organization. The standards activities are managed through separate but coordinated projects: Initial Graphics Exchange Specification (IGES); Product Data Exchange using STEP (PDES); and the Testing projects.

Sold directly and through ANSI.

IGES; PDES; STEP; MANDATE; CAD/CAM data; digital product data; drawings; geometric models; computer graphics;

U.S. TENNIS COURT AND TRACK BUILDERS ASSOCIATION

Carol T. Shaner, CAE, Executive Vice President

720 Light Street

Baltimore, Maryland 21230

(410) 752-3500

FAX: (410) 752-8295

Founded: 1965

Standards Staff: 2

Type of

Organization

Certification

Scope

Standardization

Activities
Trade Association

Standards Developer

The association has developed a voluntary Builder Certification program. To become a certified builder, a member must pass a written examination that demonstrates a high level of knowledge of tennis court construction.

Represents tennis court and track builders in the United States and internationally. Members include builders of tennis courts, game courts, and running tracks; manufacturers of court and track surface materials, fencing, lighting systems, and court

accessories; and professionals involved in the tennis and track industries.

Developed Tennis Court and Running Track Guide speci-

fications. Maintains technical committees to draft and update specifications. Also publishes a Maintenance and Repair

Specification Guide for tennis courts and Lighting and Fencing Specifications.

The latest publications program includes a series of technical data bulletins on tennis court dimensions (with metric equivalents), windscreens, and site investigation for tennis courts and tracks. The series also includes site preparation, earthwork drainage, base/court construction, guidelines for reconditioning fast-dry tennis courts, tennis court orientation, 
Keywords

USA RICE FEDERATION

Type of

Organization

scope

Standardization Activities and soil sterilization. It also covers color finish systems for tennis courts and resurfacing of asphalt courts. A track data series has also been initiated. The first bulletin covers the conversion of 440 yard tracks to 400 meters. Publishes a 400 meter even track markings layout in cooperation with the National Federation of state High Schools Association.

Participates in liaison committees with the U.S. Tennis Association, National Tennis Association, National sporting Goods Association, Illuminating Engineers Society, National Federation of State High Schools Association, and the U.S. Track \& Field Federation.

tennis courts; game courts; running tracks; sports;

David Graves, President

4301 N. Fairfax Drive

Suite 305

Arlington, Virginia 22203

(703) 351-8161

FAX: (703) 351-8162

Founded: 1994

Standards staff: 3

Trade Association

standards Developer

A national, nonprofit association. Charter members: Rice Millers' Association, USA Rice Council, U.S. Rice Producers' Group. Collects and compiles statistics; acts as a liaison between industry and government; arbitrates disputes; and assists in establishment of standards. Generally promotes rice research, production, milling and marketing.

Establishes standard contract terms and conditions for trade in rice and rice products. Adapts and uses grade and quality standards of the U.S. Department of Agriculture. 
VACUUM CLEANER MANUFACTURERS ASSOCIATION

Clifford J. Wood, Executive Vice President

P.O. Box 2642

North Canton, Ohio 44720

(216) 499-5998

FAX : (216) 499-5292

Founded: 1913

Type of

Organization

Scope

Standardization

Activities

Keywords

Trade Association

Works through other organizations to develop standards

Formed to promote the common business interests of vacuum cleaner manufacturers. Services include government affairs, industry statistics, engineering/technical and long range planning.

Individual member companies of the association, along with general interest representatives, develop United states vacuum cleaner standards through the ASTM F-11 Vacuum Cleaner Committee. Individual member companies also work with the Canadian Standards Association. Maintains a representative on the vacuum cleaner technical committee of the International Electrotechnical Committee involved in the development of international standards.

vacuum cleaners; floor care; appliances; consumer products;

VALVE MANUFACTURERS ASSOCIATION OF AMERICA

J. Stephen Larkin, President

1050 17th Street, NW, Suite 701

Washington, DC 20036

(202) 331-8105 FAX: (202)296-0378

Founded: 1938

Type of

Organization

Trade Association

Works through other organizations to develop standards

Representation

Members active in MSSVFI, API, AWWA, SME, ISA, NACE, ANSI, and ISO 
Standardization

Activities

Keywords

VARIABLE RESISTIVE COMPONENTS INSTITUTE

Type of

Organization

Standards

Development

Standards

Designation

Certification

Scope

Standardization

Activities
Although not a standards making body, VMA is a strong advocate of United States and international standards. Members of the industry are active in a variety of standards activities. VMA is represented on ASME B-16, ISO/TC 153, AWWA C504, and develops standards policy through its Technical Committee and Product Committees.

valves; actuators; flow control; industrial equipment;

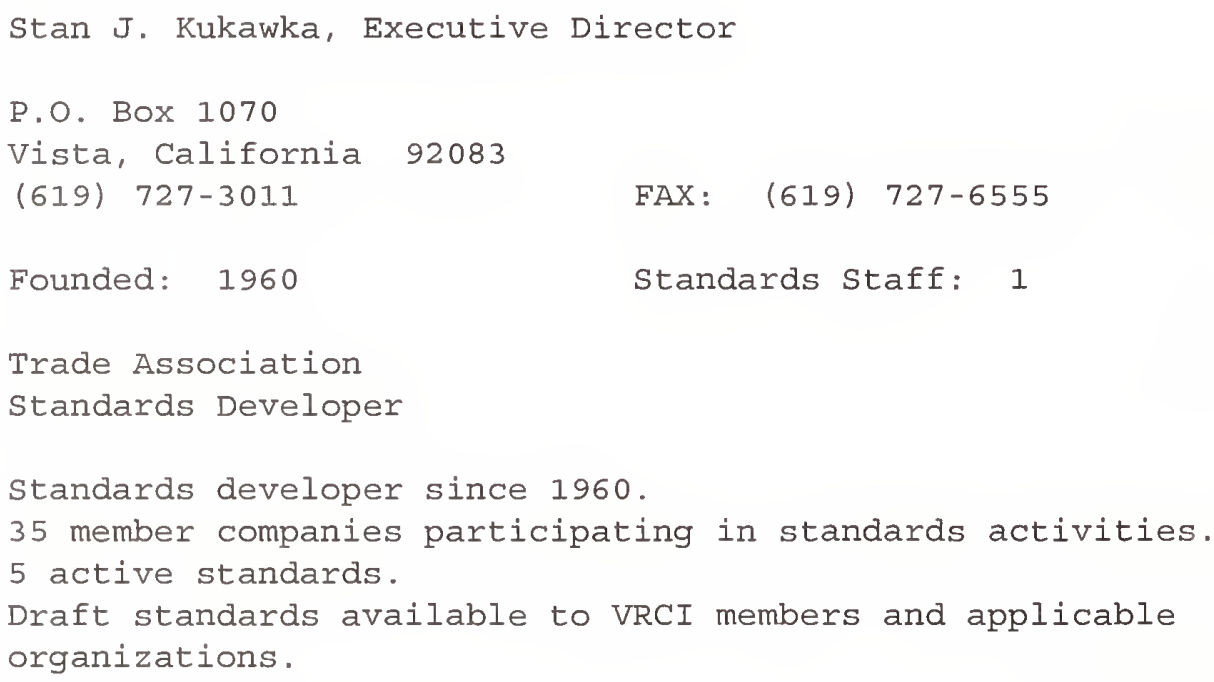

VRCI and ANSI prefixes.

No certification, qualification, or accreditation programs.

An international trade association representing manufacturers and users of variable resistive devices such as precision potentiometers, trimmers, and panel potentiometers.

Has made significant contributions to the field of standardization and the improvement of quality of variable voltage or resistive devices used in consumer, industrial, and military type applications. Standards cover wirewound and non-wirewound precision, trimming, and industrial potentiometers, potentiometer mounted switches, and surface mount trimming potentiometers. 
VINYL SIDING INSTITUTE

and

VINYL WINDOW AND DOOR INSTITUTE

SEe SOCIETY OF THE PLASTICS INDUSTRY potentiometers; resistive devices; electronic components; trimmers;

\section{VMEBUS INTERNATIONAL TRADE ASSOCIATION}

Ray Alderman, Executive Director

7825 E. Gelding Drive

Suite 104

Scottsdale, Arizona 85260-3415

(602) 951-8866

FAX: (602) 951-0720

Founded: 1984

Standards staff: 6

Type of

organization

Scope

Standards

Activities

Availability

Keywords
Trade Association

Standards Developer

Represents users and producers of Versatile Model

Europe bus (VMEbus) computer systems.

Develops standards in VMEbus and other related open bus technologies through the VITA Standards Organization (VSO). Accredited by ANSI as a Canvass Ballot Sponsor since June 1993.

Distributed directly.

VME; VME64; VMEbus; backplane; bus; microprocessor;

\section{WATER POLLUTION CONTROL FEDERATION}

Quincalee Brown, Ph.D., CAE, Director

601 Wythe street

Alexandria, Virginia 22314-1994

(703) 684-2400

FAX: (703) 684-2492

Founded: $1928 \quad$ Standards Staff: 2

Technical Professional society

Works through other organizations to develop standards 
Federation of 74 state, regional, and foreign associations and technical societies. Advances fundamental and practical knowledge of the water environment with emphasis on the technology, design, construction, operation, and management of water quality control systems and facilities. Seeks to disseminate technical knowledge and information through publications and conferences; promote good public information and sound regulations aimed toward proper water quality improvements; and improve the status of those working in this field.

Standardization

Activities

Keywords
In cooperation with the American Public Health Association and the American Water Works Association, produces Standard Methods for the Examination of Water and Wastewater. Develops and publishes education, training, design and operation and maintenance materials on: wastewater collection; wastewater treatment; sampling and testing; safety; hazardous waste; microbiology; disinfection; wetlands; air pollution; industrial wastes; financing; solids processing and handling regulations.

environment; wastewater; pollution; water pollution; industrial wastes; hazardous wastes; air pollution; bisolid; safety;

WATER QUALITY ASSOCIATION

Joseph F. Harrison, P.E., Technical Director

4151 Naperville Road

Lisle, Illinois 60532

(708) 505-0160

FAX: (708) 505-9637

Founded: 1948

Trade Association

Standards Developer

$S-100 \quad S-300$.

$S-200$ S-400.

Certifies water softeners, filters, reverse osmosis systems, and water distillers complying with Association standards. Sponsors voluntary certification programs for water treatment specialists and water treatment equipment installers.

Scope
A trade association of water conditioning equipment manufacturers and suppliers to the water conditioning industry. Conducts a national public relations program, and serves as the industry's liaison with the public, private, and government sectors. Fosters the further development of equipment, products, and services in the industry. 
Standardization Activities

Availability

Formerly

Reywords

WATER SYSTEMS COUNCIL
Developed two equipment standards, S-100 for

Household, Commercial and Portable Exchange Water Softeners, S-200

for Household and Commercial Water Filters, S-300 for Reverse

Osmosis Drinking Water Systems and S-400 for Distillation Drinking

Water systems. A testing program for all standards is conducted

by an independent testing laboratory, and certification is made

through the association following laboratory validation. These

standards have national application; and the voluntary testing

program is open to manufacturers of water softeners water filters, reverse osmosis systems and distillation systems. In addition to intra-industry promotion of the use of the equipment validation program, the association uses its public relations channels to inform consumers of the integrity of certified equipment. S-100, S-200, S-300 and S-400 have been developed through consultation with the National Institute of Standards and Technology, U.S. Department of Commerce; Federal Housing Administration; and other government agencies, as well as quasi-public and private organizations concerned with equipment standards. The association is currently harmonizing the standards for drinking water treatment units with the NSF international.

Distributed directly.

Water Conditioning Foundation (1974)

consumer products; drinking water; industrial equipment; water quality; water treatment; environment; plumbing; public health; sanitation;

Charles G. Stolberg, Executive Director

800 Roosevelt Road

Building $C$, suite 20

Glen Ellyn, Illinois 60137

(708) 545-9415

FAX: (708) 790-3095

Founded: 1932

Standards Staff: 1
Type of

Organization
Technical Society

Standards Developer 


\author{
Standards \\ Development \\ scope \\ Standardization \\ Activities
}

Availability

Formexly

Keywords
6 active standards.

Represents and serves leading manufacturers of domestic and farm water systems equipment.

Develops Testing and Rating standards, which are established in the public interest and are designed to supply the purchaser and user of automatic, electric water systems with accurate performance data and to assist in the determination of proper application and selection of this equipment. The standards cover shallow well water system pumps, deep well water system pumps, deep well submersible pump motor standards, and hydropneumatic tank volume standards.

Distributed directly.

National Association of Domestic and Farm Pump Manufacturers pumps; motors; water systems; wells; building;

WEST COAST LUMBER INSPECTION BUREAU

\author{
Bradley E. Shelley, Executive Vice President \\ P.O. Box 23145 \\ Portland, Oregon 97281 \\ (503) 639-0651 \\ FAX: (503) 684-8928 \\ Founded: 1911 Standards staff: 2 \\ Trade Association \\ Standards Developer \\ Develops lumber grading rules. \\ Drafts not available for review. \\ West Coast Lumber - Standard Grading Rules, No. 17.
}

\author{
Type of \\ Organization \\ Standards \\ Development \\ Standards \\ Designation \\ Certification
}

scope
Provides official grade stamps to mark lumber conforming to West Coast Grading Rules.

An industry owned, nonprofit corporation that provides lumber quality control services at its approximate cost. Serves members throughout western United states, with additional membership in several other states. Services available to any producer, user, distributor, or dealer handling west coast lumber products. Maintains uniform standards of lumber grading and manufacture, promotes the use of grade stamped lumber as an assurance to the 


\section{Standardization Activities}

Availability

Formerly

Keywords buyer, seller, and consumer that the interests of each are fully protected, and assists in the efficient use of West Coast lumber products.

One of the three major lumber grading rules writing agencies in the United states, in addition to the Western wood Products Association and Southern Pine Inspection Bureau. Responsible for the principal part of all the quality control programs for softwood lumber production in the United States. Supervises or grades three and one-half to five billion feet of lumber per year.

Bureau activities include the publication, and distribution of West Coast Grading Rules, supervision of the grading manufacturing practices of subscriber plants; grade stamping of west Coast lumber with official Bureau stamps; certificate inspection of lumber shipments; reinspection of lumber in dispute at destination; and assistance to specification agencies, buyers and consumers of West Coast products. Participates in ASTM, ASCE, and Department of Commerce Voluntary Product standard Programs.

Distributed directly.

West Coast Lumbermen's Association

wood products; grading rules; inspection; lumber; building;

\section{WESTERN WOOD PRODUCTS ASSOCIATION}

Robert H. Hunt, President

Yeon Building

522 SW Fifth Avenue

Portland, Oregon 97204-2122

(503) 224-3930

FAX: (503) 224-3934

Founded: 1964

(predecessors early 1900)

Standards Staff: 3

Type of

Organization

Standards

Development
Trade Association

Standards Developer

Standards developer since early 1900 's.

Prepared under the umbrella of the National Institute of Standards and Technology Voluntary Product Standard PS 20-94 and the American Lumber standards Committee. 
Standards
Designation

Government Adoption

Certification

scope

standardization Activities

Availability

Keywords
Western Lumber Grading Rules.

Machine Stress-Rated Western Lumber C/QC Procedures 102.86. Glued Products C/QC Procedures 101.86.

North American Export Standard for MSR Lumber.

All building code writing and purchasing agencies (federal and state and local) accept lumber graded pursuant to WWPA grading rules. Additionally, WWPA rules are accepted world wide.

WWPA and its Western Lumber Grading Rules are approved by the Board of Review of the American Lumber standard Committee. WWPA provides member companies with grade stamps to mark lumber graded under Association rules and supervision. A symbol indicates that the piece is graded under WWPA rules and the provisions of NIST Voluntary Products Standard PS 20-94.

WWPA consists of member companies throughout the 12 contiguous western states. WWPA maintains a lumber grade inspection bureau to assure grading standards on a uniform basis. WWPA provides promotion, advertising, technical, export and statistical services; and promotes forest conservation.

Writes rules for western lumber that conform to the National Institute of Standards and Technology Voluntary Product Standard PS 20-94, American Softwood Lumber Standard. Also writes rules for machine stress-rated lumber and glued lumber products in accordance with PS 20-94. Supervises member company grading procedures and practices through periodic sampling inspections of company graded lumber. Actively involved in writing and reviewing standards approved by the American Society for Testing and Materials (ASTM) and CEN Standards (European Community for Standardization).

sold directly.

wood products; lumber; grading rules; inspection; building; machine stress-rated; finger joint;

WIRE REINFORCEMENT INSTITUTE

Roy H. Reiterman, P.E., Technical Director

203 Loudoun street, SW

Leesburg, Virginia 22075-2718

(703) 779-2339 FAX: (703) $779-2340$

Founded: 1930 
Type of

Organization

Representation

scope

Standardization

Activities

Keywords

WOOD MACHINERY MANUEACTURERS OF AMERICA

Kenneth R. Hutton, Executive Vice President

1900 Arch Street

Philadelphia, Pennsylvania 19103-1498

(215) 564-3484

FAX: (215) 963-9785

e-mail: assnhqt@netaxs.comm (type WMMA)

Founded: 1899

Standards Staff: 1
Type of

Organization

Secretariats

Scope

Standardization Activities
Trade Association

Standards Developer

American National Standards Committee 01

Composed of over 140 manufacturers of machinery and equipment used in the production of lumber, veneer, millwork, and other wood products, but not including hand portable tools and equipment. Serves the industry by providing a forum to address technical and business issues and improve markets for United States made machinery.

Develops standards that enhance the safety and operability of woodworking machinery. Current publications include the widely recognized Noise Test Code and the Cutting Tool Safety Guidelines. Resources have been applied through ANSI to develop and maintain the voluntary consensus standard safety Requirements for Woodworking Machinery, ANSI 01.1, which defines standards for safe installation, operation, and maintenance of woodworking machinery and accessory equipment. Member of Capital Goods Standards Coalition involving U.S. companies in development of international safety standards for machinery. 
WOOD MOULDING AND MILLWORK PRODUCERS ASSOCIATION

Bob Weiglein, Executive Vice President

P.O. Box 25278

1730 Southwest Skyline

Portland, Oregon 97225

(503) 292-9288

FAX: (503) 292-3490

Founded: 1963

Standards staff: 2
Type of

Organization

standards

Development

standards

Designation

Scope

standardization Activities
Trade Association

Standards Developer

7 active standards.

None processed through ANSI.

WM prefix.

Composed of manufacturers of wood moulding and millwork. Provides promotion, standardization, and marketing information services.

Standards are initiated through a standing committee administered by the association staff. Available standards include the WM/Series Moulding Patterns and catalog of accurate, full scale renderings of the most popular wood moulding profiles used nationwide. This may be used as a standard basis for all United states moulding producers. Included in the current catalog are grading rules for standard mouldings and finger joint and priming standards.

Other available standards include: Industry standard WM 1-79, Wood Interior Door Jambs and Frames; WM 2-82, Vinyl Wrapped Interior Moulding and Millwork Products standard; WM 3-79, Exterior Wood Door Frames; WM 4-85, Wood Moulding Requirements; WM 5-81, Standard Certified Non-Structural Laminated or Finger Jointed Wood; and WM 8-89, Industry standard 20-Minute Fire-Rated Wood Door Frames. 
Availability

Keywords
Distributed directly and through members.

wood products; moulding; millwork; grading rules; lumber; building ;

WOODWORK INSTITUTE OF CALIFORNIA

Stanley R. Gustafson, C.E.O., Secretary

P.O. Box 980247

3164 Industrial Blvd.

West Sacrmento, California 95798-0247

(916) 372-9943 FAX: (916) $372-9950$

Founded: $1951 \quad$ Standards Staff: 6

Type of

Organization

Certification

scope

Standardization

Activities

Availability

Keywords
Trade Association

Standards Developer

The W.I.C. has established a Certification Licensing Procedure available to firms in California, Nevada and Oregon.

A regional trade association in California, Nevada and Oregon of independent and competing producers of millwork and allied products, whose purpose is the development and dissemination of information relative to uses, advantages, and utility of wood products.

Standards have been developed for materials and methods of fabrication for all types of architectural woodwork in California by the Woodwork Institute since 1951. The standards are developed by a Technical Committee and approved by the Board of Directors. Standards designation is the Manual of Millwork, M/M. Several governmental agencies have adopted the Woodwork Institute's standards.

Distributed directly.

wood products; millwork; building; architectural; certified compliance; 

Until recently it was fairly easy to identify private-sector standards developers. Their formal, de jure standards are developed using processes which are open, and which apply the principles of due process to achieve decisions through consensus. Procedures for assuring openness enable various interests to not only identify organizations which might be developing standards that could affect them, but to communicate with the standards developers and to receive notices of meetings, agendas, and draft standards. In recent years, however, many new nongovernment standards developers have emerged which do not follow traditional standards developing procedures. For whatever reasons, often expediency, these standards developers ignore or short cut the traditional procedures. The lack of openness makes it very difficult to identify the organizations which are developing standards in this manner, and, even when an ad hoc group or consortium is identified, it is difficult to communicate with an organization that has no formal structure or fixed secretariat.

A standard is not an end in itself -- it is an intermediary and a medium for communications. Organizations want to buy products and services, not standards. User demands drive markets and the markets should drive the standards, but standards have not kept pace with the markets in telecommunications, information technology, and other rapidly developing fields. Technologies with market lives measured in months cannot wait years for formal standards to emerge from traditional processes. The traditional developers recognize the need to provide more timely standards, but must balance that need with their obligation to maintain the right to due process by all materially affected interests. Consortia and ad hoc groups are more focused on achieving near-term results, and their standards are developed without heavy emphasis on formal due process procedures. In addition, the members of consortia and ad hoc groups are relatively homogeneous and single-minded in their goals.

Informal standards can be organized within two general categories -- proprietary and consortia -- and four classifications:

\section{PROPRIETARY}

When the products or services of one company become widely accepted as "the standard" within a market the result is a proprietary informal standard. There are two ways that such standards emerge:

1. Proprietary De Facto standards. A company strategically positions its products to expand market share and collect royalties by licensing intellectual property rights. Examples: Adobe Postscript, IBM PC Compatible, and Microsoft Windows.

2. End-Result De Facto. Market forces designate one company's product as the standard from among equally effective competitors. Example: VHS video recording. 
This classification includes standards developed by ad hoc groups of suppliers or users, research and development consortia, and patent licensees. These groups work together to develop informal standards or to select those standards that will be given preference within a particular sector or market. Motivations of the sponsors differentiate the two classes of consortia standards:

3. Strategic De Facto. Suppliers, and occasionally users, attempt to establish sufficient critical mass to define the standard or standards in a particular field. Examples include Dolby, Notes Consortium, Bellcore, and the Electronic Commerce Acquisition Team.

4. Ad Hoc Variety Reduction. Traditionally the application of industrial standardization principles has focused on reducing the number of types, sizes, and kinds of parts, materials, and processes to realize cost savings and improve productivity. In some sectors users complain of an overabundance of standards because standards developers are not sufficiently selective, but publish standards for nearly every product offered in the market. To fully realize the potential of standardization through economies of scale, industry consortia have formed to select and harmonize existing standards for preferred use within their industries. The United states Council for Automotive Research (USCAR) is a major consortium with a strategic standardization Board working in this way. other user consortia recognize that many common practices exist within their sectors which could benefit from industry-wide standardization. Most of these practices are documented as internal company standards. Rather than processing these internal standards through the traditional formal standards development process, they prefer to prepare harmonized standards which are intermediate between company standards and formal consensus standards. The Process Industry Practices (PIP) initiative exemplifies this approach.

The developers of informal standards start out with simplified fast-track procedures, but some find that the traditional due process procedures are necessary to accommodate the needs of their members. Others, upon developing a standard, have no mechanism for maintaining it. Some consortia recognize that acceptance of their proposals could be more widespread if their informal standards received a technical review by experts and assurance that the consortium's standards would be integrated into the existing body of formal standards. For these and other reasons, an increasing number of consortia are acting more like traditional standards developers, while others are affiliating with developers of formal standards. VMEbus and the Consortium for Advanced Manufacturing International are ANSI-accredited. The Document Management Alliance is now a task force within the Association for Information and Image Management. USCAR has a working relationship with the SAE. And as consortia mature, many evolve into full service trade associations - the same path that some well known standards developers took in years past.

Initiatives to promote the acceptance of proprietary and consortia-developed informal standards are increasing general awareness of the role of standards. These initiatives are often headlined in financial and trade journals. While traditional standards developers complain that groups developing informal standards are interlopers, many traditional developers are reengineering their procedures to be more responsive to special interests. There are no indications, however, that the activities of non-traditional standards developers will decrease. Marketing experts have adopted standards development as one more essential stratagem they can use to attain their objectives. 
Numerous developers of informal standards have been identified while compiling this directory. Very few, however, have permanent secretariats and fixed addresses, which made communication difficult. Even when they could be contacted, some were reluctant to provide any substantive information about their standardization activities. More than 80 additional developers of informal standards are listed here. Some include telephone contacts. Users of this directory are encouraged to provide information on these or additional groups to NIST using channels described in Section 1.6 of this directory. 


\begin{tabular}{|c|c|}
\hline Full Name & $\begin{array}{l}\text { Short Name or } \\
\text { Acronym }\end{array}$ \\
\hline ACTS MISA Consortium & ACTS MISA \\
\hline Association for Font Information Interchange & AFII \\
\hline Association for Retail Technology standards & ARTS \\
\hline Audio Messaging Interfaces society & AMIS \\
\hline Banking systems vendor Council & BSVC \\
\hline Capital Goods standards Coalition & CGSC \\
\hline \multicolumn{2}{|l|}{ CDPD Forum } \\
\hline \multicolumn{2}{|l|}{ COBOL Foundation } \\
\hline Computer Industry Quality Consortium & CIQC \\
\hline Coalition of Networked Information & CNI \\
\hline Code Division Testbed & CODIT \\
\hline CPI-C Implementers Workshop & CIW \\
\hline Cross Industry Working Group & XIWT \\
\hline Customer support Consortium & $\operatorname{CSC}$ \\
\hline Data Management Interfaces Group & DMIG \\
\hline Desktop Alliance & $\mathrm{DA}$ \\
\hline Desktop Management Interface & DMI \\
\hline Desktop Management Task Force & DMTF \\
\hline Digital Audio Video International Committee & DAVIC \\
\hline Digital Media Distribution Technical Committee & $\mathrm{DMD}-\mathrm{TC}$ \\
\hline Distributed support Information systems & DSIS \\
\hline $\begin{array}{l}\text { Electronic Commerce Acquisition Team } \\
(703) 305-6514\end{array}$ & ECAT \\
\hline Electronic Messaging Association (703) 524-5550 & EMA \\
\hline Embedded Systems Software Environment & ESSE \\
\hline Fiber Channel Association & FCA \\
\hline Fiber Channel systems Initiative & FCSI \\
\hline
\end{tabular}




\begin{tabular}{|c|c|}
\hline Financial Services Technology Consortium & FSTC \\
\hline Food Distribution System Association Dev. Comm. & \\
\hline Frame Relay Forum (415) 578-6980 & FRF \\
\hline \multicolumn{2}{|l|}{ Future Consortium } \\
\hline Geographic Information System Association & GISA \\
\hline Global Messaging Group & GMS \\
\hline Graphics Performance Characterization Committee & GPC \\
\hline Industry Standards Association & ISA \\
\hline Infrared Data Association & $\operatorname{IrDA}$ \\
\hline INSTAC - S/W CALS Standardization & INSTAC \\
\hline Institute for Information storage Technology & IIST \\
\hline Intelligent TV Forum & ITVF \\
\hline Interactive CD-I Author Association & $\begin{array}{l}\text { ICDIA Associa- } \\
\text { tion }\end{array}$ \\
\hline $\begin{array}{l}\text { International Disk Drive Equipment and Materials Associa- } \\
\text { tion (408)720-9380 }\end{array}$ & IDEMA \\
\hline $\begin{array}{l}\text { International Association of Open System Professionals } \\
\text { (408) } 986-8840\end{array}$ & Uni Forum \\
\hline $\begin{array}{l}\text { International Electronic Packaging Society } \\
\text { (708) 260-1044 }\end{array}$ & IEPS \\
\hline $\begin{array}{l}\text { International Society of Hybrid Microelectronics } \\
\text { (703) 758-1066 }\end{array}$ & ISHM \\
\hline Management Integration Consortium & MIC \\
\hline Multimedia CD Consortium & Multimedia CDC \\
\hline National Industrial Information Infrastructure Protocols & NIIIP \\
\hline National Security Telecommunications Advisory Council & NSTAC \\
\hline Notes Consortium & \\
\hline Object Definitions Alliance & ODA \\
\hline Object Management Group (508)820-4300 & OMG \\
\hline OM-1 Consortium & $\mathrm{OM}-1$ \\
\hline Open Firmware Working Group & OFWG \\
\hline Open Geographic Information Systems Consortium & OGISC \\
\hline Open GL Architecture Review Board & Open GL ARB \\
\hline
\end{tabular}




\begin{tabular}{|c|c|}
\hline The Open Group (617) 621-8700 Successor to: & $\begin{array}{l}\text { OSF } \\
\mathrm{X} / \text { Open }\end{array}$ \\
\hline \multicolumn{2}{|l|}{ Open PC Alliance } \\
\hline Open Software Foundation (617)621-8700 & OSF \\
\hline Optical Forming Industry Association & OFIA \\
\hline Optical Storage Trade Association & OSTA \\
\hline Performance Management Working Group & PMWG \\
\hline Personal Digital Assistants Industry Association & PDAIA \\
\hline $\begin{array}{l}\text { Petrotechnical Open Software Corporation } \\
\text { (713) } 784-1880\end{array}$ & POSC \\
\hline $\begin{array}{l}\text { Quarter Inch Cartridge Drive standards, Inc. } \\
\text { (805) } 963-3853\end{array}$ & QIC \\
\hline $\begin{array}{l}\text { Redundant Arrays of Independent Disks Advisory Board (507) } \\
\text { 931-0967 }\end{array}$ & RAID \\
\hline Reuse Library Interoperability Group & RLIG \\
\hline Sales Automation Association & SAA \\
\hline Security and Management Services for Open Networks & SAMSON \\
\hline Serial storage Architecture Industry Association & SSA IA \\
\hline $\begin{array}{l}\text { Service Providers Integrated Requirements for Information } \\
\text { Technology }\end{array}$ & SPIRIT \\
\hline $\begin{array}{l}\text { Shared Multimegabit Data Service Interest Group (415) } \\
962-2590\end{array}$ & SDMS \\
\hline $\begin{array}{l}\text { Small Computer System Integration Association } \\
(507) \text { 931-0967 }\end{array}$ & $\begin{array}{l}\text { SCSI } \\
\text { Association }\end{array}$ \\
\hline SmartCard Forum (813) 286-2339 & \\
\hline Software Quality Association & SQA \\
\hline Stuart Retail Bank Client Server Consortium & SRBCSC \\
\hline Symbologic Customer Support Consortium & $\operatorname{scsc}$ \\
\hline Systems Performance Evaluation Cooperative Forum & SPEC \\
\hline $\begin{array}{l}\text { Telecommunications Information Networking Architecture } \\
\text { Consortium }\end{array}$ & TINA \\
\hline Text software Initiative & TSI \\
\hline Transaction Processing Council & TPC \\
\hline Unixware Technology Group & UTG \\
\hline
\end{tabular}




\begin{tabular}{|l|l|}
\hline $\begin{array}{l}\text { Video Electronics Standards Association } \\
(408) 435-0333\end{array}$ & VESA \\
\hline VMRL+ Alliance & \\
\hline X-Consortium - Industry Carriers Compatibility Forum & X-Consortium \\
\hline
\end{tabular}





\subsection{FEDERAL VOLUNTARY STANDARDS POLICY (OMB CIRCULAR A-119)}

On October 20, 1993, the Office of Management and Budget (OMB) revised and re-issued Circular A-119, entitled "Federal Participation in the Development and Use of Voluntary standards."1 This establishes a policy for all federal executive branch agencies concerning their use of voluntary standards and the participation of federal employees in their development. It sets forth "the policy of the federal government in its procurement and regulatory activities to rely on voluntary standards, both domestic and international, whenever feasible and consistent with law and regulation pursuant to law." Voluntary standards should be adopted and used by federal agencies "in the interests of greater economy and efficiency" and should be given preference over non-mandatory government standards unless use of such voluntary standards would adversely affect performance or cost, reduce competition, or have other significant disadvantages.

Participation by federal agency employees in voluntary standards activities is encouraged when it is "in the public interest and is compatible with agencies missions, authorities, priorities, and budget resources." Such participation should be aimed at contributing to the development of voluntary standards that will eliminate the need to develop and maintain separate government standards.

The Circular requires the coordination of agency participation so that (1) the most effective use is made of agency resources and representatives, and (2) the views expressed by those representatives are in the public interest, and, at minimum, do not conflict with the interests and established views of the agencies. Agencies must establish procedures to ensure that their representatives who participate in voluntary standards activity "will, to the extent possible, ascertain the views of the agency on matters of paramount interest, and will, as a minimum, express views that are not inconsistent or in conflict with established agency views."

The Circular also requires that agencies responsible for developing Government standards review their existing standards at least every five years and cancel those for which adequate and appropriate voluntary standards can be substituted.

The revised Circular provides a policy statement with strengthened administrative guidance to federal agencies on using domestic and international voluntary standards for procurement and regulatory purposes, on further improving participation with private sector organizations to develop such standards and coordinating Executive Branch responsibilities for participation in the development of voluntary standards. Emphasis on improving agency leadership on standards policy issues with agency-wide responsibilities for implementing the Circular are provided with the designation of a senior level agency official to be the "Standards Executive." Provisions for improved agency accountability and coordination, recognition of trade policy objectives, along with wTo standards code obligations in the treatment of international standards by federal agencies are provided. The revision also extends coverage to certain standards related national goals, such as metrication, environmental concerns and energy efficiency. Significant changes in agency administration, adoption, utilization and reporting of standards related activities are required to implement the revised Circular. Responsibilities of the Secretary of Commerce are increased in several areas for Executive Branch implementation of the Circular. 
The Interagency Committee on Standards Policy (ICSP) was established in 1968 to encourage coordination and liaison among federal agencies on matters relating to standards. In 1982, the Secretary of Commerce reconstituted the ICSP to provide the "interagency consultative mechanism to advise the secretary and agency heads in implementing the policy" required by OMB Circular A-119, "Federal Participation in the Development and Use of Voluntary Standards." In August 1994, the Secretary of Commerce approved a new Charter for the ICSP. The new Charter reflected the changes in the revised Circular.

The ICSP is currently composed of representatives of the 14 federal cabinet departments, 11 independent federal agencies, three offices in the Executive office of the President and one legislative branch agency. The National Institute of Standards and Technology (NIST) provides the Chairman and the Secretariat for the ICSP.

Cabinet departments represented on the ICSP include the Departments of: Agriculture; Commerce; Defense; Health and Human Services; Housing and Urban Development; Education; Energy; Interior; Justice; Labor; State; Transportation; Treasure; and Veterans Affairs.

Independent agencies include the: Consumer Product Safety Commission; Environmental Protection Agency; Federal Communications Commission; Federal Emergency Management Agency; Federal Trade Commission; General Services Administration; International Trade Commission; National Aeronautics and Space Administration; National Archives \& Records Administration; National Science Foundation; Nuclear Regulatory Commission; Postal Service; Small Business Administration; and the U.S. Agency for International Development.

Those from the Executive Office of the President include: the office of Management and Budget; the Office of the U.S. Trade Representative; and the office of Consumer Affairs. The U.S. Government Printing Office is represented from the Legislative Branch.

\subsection{FEDERAL GOVERNMENT ORGANIZATIONS}

This section describes more than 90 standards related programs of federal departments, agencies, and other organizational elements, most of which are standards developers. There are 78 entries describing these standardization activities. The entries for some agencies (e.g., NIST, FDA) describe a number of different standards related programs, while others (e.g., Department of Agriculture) prefer a separate entry for each program. It should be noted that some federal standards are voluntary, though the majority are mandatory by reason of being referenced in legislation or regulations, or are invoked in contracts as a condition of sale to Government agencies. Many nongovernment standards are mandated in the same way.

Government organizations were asked to cite the means by which their standards are implemented or promulgated. This is usually accomplished by incorporating the standards in applicable parts of the Code of Federal Regulations (CFR). How the agency usually applies standards is summarized in the paragraph "Application." Authority for an agency's standardization activity is also included, generally a citation of the United states code (U.S.C.), a Public Law (P.I.), or a Part of the CFR. Most organizations have indicated the extent to which they adopt nongovernment standards and participate in government and private sector standards committees. 
The following organizations are listed in this section:

Department of Agriculture

Agricultural Marketing Service . . . . . . . . . . . . . . . 587

Food Safety and Inspection Service . . . . . . . . . . . . . . . . . 589

Foreign Agricultural Service . . . . . . . . . . . . . . . . . . 590

Forest Service . . . . . . . . . . . . . . . . . . . . 592

Grain Inspection, Packers and Stockyards Administration . . . . . . . . 592

Scales and Weighing Branch . . . . . . . . . . . . . . . . 592

Standards and Procedures Branch. . . . . . . . . . . . . . 594

Information Resource Management . . . . . . . . . . . . . . . . . . . . 595

Rural Utilities Service. . . . . . . . . . . . . . . . . . . 597

Department of Commerce

Bureau of Census . . . . . . . . . . . . . . . . . . . . . . 598

Federal Coordinator for Metrology . . . . . . . . . . . . . . . . . . . 599

Industry Functional Advisory Committee

International Trade Administration . . . . . . . . . . . . . . . . . . 601

National Institute of Standards and Technology

Computer Systems Laboratory . . . . . . . . . . . . . . . . . . 602

Technology Services... . . . . . . .. . . . . . . 608

National Marine Fisheries Service. . . . . . . . . . . . . . . . . . . 612

National Oceanic and Atmospheric Administration . . . . . . . . . . . . 614

National Environmental Satellite,

Data, and Information Service . . . . . . . . . . . . 614

National Weather Service . . . . . . . . . . . . . . 615

National Telecommunications and Information Administration . . . . . 616

U.S. Patent and Trademark Office

Office of the Deputy Assistant Commissioner

for Patent Policy and Projects . . . . . . . . . . 6 617

Office of International Patent Documentation . . . . . . . . . 618

Trademark Examining Operation . . . . . . . . . . . . . 619

Congress of the United States

Joint Committee on Printing . . . . . . . . . . . . . . . . . . 620

Consumer Product Safety Commission

Directorate for Engineering Sciences . . . . . . . . . . . . . . . 621

Directorate for Health Sciences . . . . . . . . . . . . . . . . 621

Department of Defense

Defense Information Systems Agency . . . . . . . . . . . . . . . . . 623

Office of the Assistant Secretary of Defense

(Economic Security) . . . . . . . . . . . . . . . 624

Department of Energy

Building Technologies

Building Appliance Division . . . . . . . . . . . . . . . 626

Building Division . . . . . . . . . . . . . . . . . . 627

Defense Programs, Assistant Secretary . . . . . . . . . . . . 629 
Energy Information Administration . . . . . . . . . . . . . . . . . . 631

Environment, Safety, and Health . . . . . . . . . . . . . . . . . . . 632

Technical Standards Program Office . . . . . . . . . . . . . . . . 633

Environmental Protection Agency

Administrator . . . . . . . . . . . . . . . . . . . . . . 635

Executive Office of the President

Office of the U.S. Trade Representative . . . . . . . . . . . . . . . 637

Federal Communications Commission

office of Engineering and Technology . . . . . . . . . . . . . . . . 638

Federal Trade Commission

Bureaus of Competition and Consumer Protection . . . . . . . . . . . . 639

General Services Administration

Information Resources Management . . . . . . . . . . . . . . . . . . . 640

National Archives and Records Administration . . . . . . . . . . . . . 641

Office of Acquisition . . . . . . . . . . . . . . . . . . . . . . . 643

Public Building Service . . . . . . . . . . . . . . . . . . . . . . 645

Health and Human Services

Center for Disease Control . . . . . . . . . . . . . . . . . . . . 646

Food and Drug Administration . . . . . . . . . . . . . . . . . . . . 647

Health Care Financing Administration . . . . . . . . . . . . . . . . 653

Department of Housing and Urban Development

Assistant secretary for Housing -

Federal Housing Commissioner . . . . . . . . . . . . . . . . . 654

Interdepartmental screw Thread Committee (defunct)

Replaced by Defense Industrial Supply Center . . . . . . . . . . . . . 656

Department of the Interior

Mineral Management Service . . . . . . . . . . . . . . . . . . . 657

Federal Geographic Data Committee . . . . . . . . . . . . . . . . . . 658

U.S. Geological Survey . . . . . . . . . . . . . . . . . . . . . . 659

Information Systems Division . . . . . . . . . . . . . . . 659

National Mapping Division . . . . . . . . . . . . . . . . . . 661

Water Resources Division . . . . . . . . . . . . . . . . . . 662

Department of Justice

National Institute of Justice

Technology Assessment Program (see Department of Commerce

National Institute of standards and Technology

Electronics and Electrical Engineering Laboratory

Office of Law Enforcement Standards) . . . . . . . . . . . . . . 664

Department of Labor

Mine Safety and Health Administration . . . . . . . . . . . . . . . . . 664

Occupational Safety and Health Administration . . . . . . . . . . . . . 665

Library of Congress 
Collection Services . . . . . . . . . . . . . . . . . 667

Information Technology Services . . . . . . . . . . . . . . . . . . 671

National Library Service for the

Blind and Physically Handicapped . . . . . . . . . . . . . 672

Photoduplication Services . . . . . . . . . . . . . . . 673

National Aeronautics and Space Administration

Office of the Chief Engineer . . . . . . . . . . . . . . . . . . 6 674

Office of Safety and Mission Assurance . . . . . . . . . . . . . . 675

Office of Space Communications . . . . . . . . . . . . . . . . 676

Nuclear Regulatory Commission

Nuclear Regulatory Research . . . . . . . . . . . . . . . 678

Postal Services, U.S.

Marketing Department . . . . . . . . . . . . . . . . 679

Department of state

U.S. International Telecommunications Advisory

Committee for standardization . . . . . . . . . . . . . . . . 680

Department of Transportation

Federal Aviation Administration . . . . . . . . . . . . . . . . . . 682

Federal Highway Administration . . . . . . . . . . . . . . . 683

Office of Engineering . . . . . . . . . . . . . . . . 683

Office of Environmental Policy . . . . . . . . . . . . . . 685

Office of Motor Carriers . . . . . . . . . . . . . . . . . . 686

Office of Traffic Operations . . . . . . . . . . . . . 687

Maritime Administration

Office of Ship Construction . . . . . . . . . . . . . . . 689

National Highway Traffic Safety Administration

(see Department of Commerce

National Institute of Standards and Technology

Electronics and Electrical Engineering Laboratories

Office of Law Enforcement Standards) . . . . . . . . . . . . . 690

Research and Special Programs Administration

Office of Pipeline Safety, Technology and Regulations . . . . . . 690

United States Coast Guard

office of Marine Safety, Security

and Environmental Protection . . . . . . . . . . . . . 691

Recreational Boating Product Assurance Branch . . . . . . . . . . 692

Department of Treasury

Bureau of Alcohol, Tobacco, and Firearms . . . . . . . . . . . . . . . 694

Internal Revenue Service . . . . . . . . . . . . . . . . . . . . 695

U.S. Customs Service

Office of Regulations and Rulings . . . . . . . . . . . . 696

Office of Laboratories and Scientific Services . . . . . . . . . 697

U.S. Mint . . . . . . . . . . . . . . . . . . . . 698 
U.S. Trade Representative

(see Executive Office of the President) . . . . . . . . . . . . . . . 699

Department of Veterans Affairs

Office of Acquisition and Material Management . . . . . . . . . . . . . 699 
AGRICULTURAL MARKETING SERVICE

Administrator

Room 3071 South Building

P.O. Box 96456

Washington, DC 20090-6456
(202) 720-5115
FAX: (202)
$720-8477$

Authority

Implementation

Agricultural Marketing Service (AMS) carries out standardization activities under the Agricultural Marketing Act of 1946, the Agricultural Marketing Agreement Act of 1937, the U.S. Cotton Standards Act of 1923, the Tobacco Inspection Act of 1935, the Federal seed Act of 1939, and the Egg Products Inspection Act (EPIA).

U.S. grade standards for food and farm products are developed by AMS and available from the agency in hard copy or electronic format. Standards are currently in place for cotton, wool, and mohair; tobacco, live animals, turpentine, fresh fruits and vegetables, processed fruits and vegetables, specialty crops, dairy products, meat, poultry, and poultry products.

The purpose of the standards is to identify the degrees of quality in food and farm products and thereby aid in marketing by establishing the usability or value of these products.

The standards, in most cases, are for voluntary use by industry. There are 30 color grade standards and a leaf grade standards for American Upland cotton, and 7 grade standards for American Pima cotton; 14 standards for dairy products; over 150 standards for fresh fruits, vegetables, nuts, and specialty products; over 150 standards for processed fruits and vegetables, honey, and miscellaneous processed products; 11 standards for meat; 15 standards for live animals and 4 standards for wool and mohair; 5 standards for shell eggs; 9 standards for poultry and rabbits; and 16 standards for tobacco and naval stores. Within each standard, there are a number of grades of quality for the product.

AMS sets standards for agricultural and vegetable seed purity, germination, and variety certification.

Under the EPIA, AMS specifies the conditions under which egg products and "restricted eggs" are handled.

Grading, inspection, or classing services, to certify the quality of products according to the U.S. grade standards, are provided by Department of Agriculture (USDA) to producers, packers, wholesalers or others, on request, and usually for a fee to cover the cost of the service. 
Qualification, Certification, or Calibration

Committee

Activity

Standardization Activities

Availability

Keywords
Businesses that handle shell eggs must register with USDA. They must also destroy eggs that are in any way unsuitable for human consumption. Dirty eggs and eggs with cracked shells but with the contents not leaking, must be shipped only to officially inspected egg products processing plants for proper segregation and processing.

AMS has cooperative agreements with each of the states to regulate interstate commerce for agricultural and vegetable seeds. Under these agreements, the states refer apparent violations of the Federal seed Act interstate provisions to AMS for verification and appropriate action. In addition, AMS cooperates with states that conduct a voluntary seed certification program.

Services to certify the quality of products according to the U.S. grade standards are provided for a fee to cover the cost of the service. The Tobacco Inspection Act requires mandatory inspection of tobacco sold at auction in designated auction markets based on official grades, after a referendum in which two-thirds of the growers supplying an auction market vote approval. Tobacco may also be inspected on a voluntary, fee-for-service basis.

AMS officials participate in committees of trade, technical, and academic organizations -- both national and international --related to AMS commodities and functions as appropriate.

Standardization specialists in each commodity area develop new U.S. grade standards and revise current standards as necessary to promote orderly marketing. Market surveys and other studies are conducted, and proposed standards and revisions are published for public comment before implementation. Specialists also manage the development and coordination of federal food specifications.

Information on the AMS activities described here is available from the AMS, Information Staff, P.O. Box 96456, Room 3510-S, Washington, DC 20090-6456.

food; farm products; agriculture; grading; seed testing; cotton classing; U.S. grade standards; egg products inspection; 
Office of the Administrator

332-E Administration Building

Washington, DC 20250

(202) 447-9113

Authority

Implementation

Application

Qualification, Certification, or Calibration

Committee Activity

Standardization Activities
(1) 21 U.S.C. 601-695, March 4, 1907, the Federal Meat Inspection Act, as amended in 1967, to authorize the examination of animals and meat products used in interstate or foreign commerce, and inspection of slaughter and packing establishments.

(2) 21 U.S.C. 451-469, August 28, 1957, the Poultry Products Inspection Act, as amended in 1968, to provide for the compulsory inspection of poultry and poultry products at slaughter and processing plants.

(3) 7 U.S.C. 1901-1906, the Humane Slaughter Act, to require humane methods of slaughter in federally inspected plants.

9 CFR, III-A and C, Parts 301-335 and 381, Mandatory Meat Inspection and Mandatory Poultry Products Inspection.

Mandatory continuous on-site inspection of domestic meat and poultry. Periodic reviews of foreign country inspection systems eligible to export meat and poultry to the United States.

Standards have been developed to cover the ingredients, methods of processing, and labeling of meat and poultry products; the materials and design of plant facilities and equipment; inspection methods; and chemical compounds permitted in the formulation, packaging or processing of meat and poultry products.

In FY 1988, 154570 labels were approved; 3783 plant blueprints were reviewed; 3861 equipment drawings were reviewed; 11051 packaging materials and compounds were reviewed; and the inspection systems of 29 countries that export products to the United States were reviewed.

Standards are developed by appropriate staffs within the program in consultation with the National Meat and Poultry Inspection Advisory Committee.

The Food Safety and Inspection Service (FSIS), Department of Agriculture (USDA), administers a comprehensive inspection system to ensure that meat and poultry is safe, 
Availability

Keywords wholesome, and accurately labeled. Inspection begins with review of a slaughtering or processing plant's plans for facilities, equipment, and procedures to assure that the plant will have a safe and sanitary operation. Animals are inspected both before and after slaughter. Veterinary supervisors monitor the procedures and work with the inspectors to assure uniformity in the inspection process and to provide expertise in detecting animal diseases. Inspection also includes examination for drug and chemical residues, and inspectors regularly take tissue samples from slaughtered animals and send them to FSIS laboratories. FSIS reviews the procedures, recipes, and labels used to manufacture processed meat and poultry products to assure they will be safe to eat and accurately labeled.

More than 7600 inspectors and veterinarians oversee inspection in 6910 plants nationwide. Scientific testing to support the inspection program is carried out in three field laboratories, augmented by certified state and private laboratories. FSIS compliance officers make over 56000 reviews annually of approximately 10000 meat and poultry product handlers. FSIS regularly reviews the inspection systems operated by foreign countries to ensure they enforce requirements at least equal to those of the U.S. system. Imported products are re-inspected on a sample basis at the port-of entry.

Publications sold by Government Printing Office

inspection; meat; label; review; food; poultry; import;

DEPARTMENT OF AGRICULTURE

FOREIGN AGRICULTURAL SERVICE

Office of the Assistant Administrator

International Trade Policy

14 th and Independence Avenue, SW

Washington, DC 20250

(202) 447-6887

Authority

19 U.S.C. 2542 Trade Agreements Act of 1979-Title IV-Technical Barriers to Trade (Standards) Subtitle B-Functions of Federal Agencies, Sec. 412. Establishment and Operation of Technical Offices. 
Implementation

Committee

Activity

Standardization Activities
7 CFR, Part 2 \& E.O. 1218, Sec. 1-103. Final rule published in the Federal Register Vol. 45, No. 242, December 15, 1980-page 82153 .

The Foreign Agricultural Service (FAS), Department of Agriculture (USDA), Technical office participates in two intra-agricultural committees, the National Agricultural Pesticide Impact Assessment Program (NAPIAP), which is a policy committee, and Technical Advisory Group (TAG), which is an advisory committee to NAPIAP. In addition, the Technical office is represented on the inter- governmental agency Trade Policy staff Committee (TPSC) - Subcommittee on standards. The Technical office is also involved with two nongovernmental committees, the National Agricultural Chemicals Association (NACA) - International Committee and the Association of Official Analytical Chemists (AOAC) committee on laboratory accreditation.

Participated in the development of the World Trade Organization (WTO) Agreement on Technical Barriers to Trade (Standards code) and currently participates in twice-yearly standards code meetings in Geneva. Receives, through the WTO Secretariat and U.S. diplomatic posts in foreign capitals, notifications of proposed foreign mandatory standards and their requirements concerning agricultural products. Publishes proposed standards in Export Briefs (a weekly trade paper published by FAS) and also notifies them in Agnet (a computerized agricultural reporting system of the University of Nebraska). Comments, when appropriate, to other governments, signatories to the Code, on their proposed mandatory standards and related tests or certification systems when their proposals are seen as potential barriers to trade. Assists in representations to foreign governments on standards-related trade policy activities. Provides information to U.S. exporters on existing standards in foreign countries. Provides advice to state and local governments on foreign trade aspects of their activities.

In accordance with provisions of the Trade Agreements Act, 19 committees have been established: ten Agricultural Policy Advisory Committees, and nine Agricultural Technical Advisory Committees for Trade. These committees address trade issues in the areas of cotton, diary, fruits and vegetables, grain and feed, livestock and products, oilseeds and products, poultry and eggs, sweeteners and tropical products, and tobacco and provide advice to Secretary of Agriculture and U.S. Trade Representative on standards-related trade policy activities of the United states. 
Implementation

Application

Committee

Activity

Standardization

Activities

Availability

Keywords
FOREST SERVICE

P.O. Box 96090,

Washington, DC 20090

(703) 453-9400

The United States Department of Agriculture Forest Service (USDA/FS) prepares standards for internal use; it does not promulgate standards for general use and prefers to reference existing voluntary standards.

Application is usually decided by the sponsoring organization. For example, USDA/FS technical input on the strength of wood members was used by ladder manufacturers and was published by the American National standards Institute and the National safety Council. OSHA and CPSC adopt all or parts of these standards.

USDA/FS technical experts participate in organizations including: ALSC, ASTM, AASHTO, ANSI, NFPA, HUD (FHA), FmHA, etc. They participate as technical authorities and represent the general interest category rather than producer or user.

USDA/FS technical experts participate in standards activities as individuals, and occasionally, when required, pay membership dues themselves.

Standards are obtainable through the sponsoring organization (e.g., ASTM, ANSI).

wood; lumber; pulp; paper; glue; lumber grading; strength of wood; wood preservatives; wood adhesives;

DEPARTMENT OF AGRICULTURE

GRAIN INSPECTION, PACKERS AND STOCKYARDS ADMINISTRATION

Scales and Weighing Branch

Room 3414, South Agriculture Building

Washington, DC 20250

(202) 720-3140 FAX: (202) 690-2173

Authority

7 U.S.C. 181-229, Packers and Stockyards Act; 9 CFR 201.71 and 201.72 . 
Subject livestock dealers, market agencies, stockyards, meat packers and poultry dealers are required by regulations promulgated under the authority of the Packers and stockyards Act to install, maintain, and use scales which conform to the specifications, tolerances, and other technical requirements set out in NIST Handbook 44.

Application

Adoption of Nongovernment Standards

Qualification Certification or Calibration

Committee Activity

Standardization Activities

Availability

Keywords
The Scales and Weighing Branch monitors the selection, installation, maintenance, testing and use of livestock, monorail, and vehicle scales operated by subject firms to assure that such devices conform to NIST Handbook 44 requirements. The Branch also participates in the testing of such devices when newly installed and in connection with training and investigative activities.

None

Scale testing agencies must be competent and must use properly calibrated test weights in sufficient amounts to properly test scales in accordance with requirements set out in NIST Handbook 44.

The Grain Inspection, Packers and Stockyards Administration has a participating membership on the Technical Committee on National Type Evaluation, Weighing Industry sector, of the National Conference on Weights and Measures.

The Grain Inspection, Packers and Stockyards Administration is an active participant in the National Training Program of the National Conference on Weights and Measures. In that capacity the agency participates in the development of test procedures and instructional material and furnishes instructors to provide training and certification under the National Training Program.

NIST Handbook 44 is available from the Government Printing Office. Testing and weighing procedure memorandums are available from the Scales and Weighing Branch.

testing; weighing; training; livestock; meat; and poultry; 
Authority

Implementation

Application

Qualification, Certification, or Calibration

Committee Activity
GRAIN INSPECTION, PACKERS AND STOCKYARDS ADMINISTRATION

Standards and Procedures Branch

Room 1094-South Building

Washington, DC 20250

(202) 720-0219

Grain inspection standardization activities are carried out under the U.S. Grain Standards Act (USGSA), as amended (P.L. 94-582) and under the Agricultural Marketing Act of 1946 (AMA), as amended.

Standards for grains are promulgated under 7 CFR, Part 810 . Standards for rice, dry beans, lentils, and dry peas are promulgated under 7 CFR, Part 868 .

Seventeen U.S. Standards are currently in effect. Use of the standards under the USGSA is mandatory for grain, except to Mexico and Canada. Inspections of grains moving in domestic commerce are voluntary. As provided by the AMA, all inspection services (including export) are voluntary on the part of the trade.

The amended U.S. Grain Standards Act requires: (1) mandatory inspection and weighing services at export ports by federal or delegated state agency personnel; and (2) permissive inspection and weighing services at domestic locations by designated state and private agency personnel. The USGSA also requires DOA to supervise all official inspection and weighing activities and, on a request basis, federal personnel perform inspection of rice and related commodities, and provide nationwide appeal inspection services.

The standards and Procedures develops and implements grain inspection procedures to ensure uniformity and reliability.

The Administration participates in the following standards related committees:

-FGIS Advisory Committee

-Codex Committee on Cereals, Pulses and Legumes

- International organization for standardization

- National Conference on Weights and Measures

-NC-151 Committee

-Rice Millers' Association, Grades Committee

-American Dry Pea and Lentil Association, Grades Committee

- National Dry Bean Council, Grades Committee 
-National Grain and Feed Dealers Association,

Grades Committee

- PNW Grain Standards and Quality Committee

-Grain Elevator and Processing Society, Grades

Committee

-National Sunflower Association, Grades Committee

- American Soybean Association, Grades Committee

-American Farm Bureau Federation, Wheat Advisory

Committee

-North American Export Grain Association, Inc.,

Grades Committee

standardization

Activities

Availability

Reywords
Standardization activities aid orderly marketing of grain, oilseeds, rice, and related commodities. This is accomplished through the development, promulgation, and uniform application of new and revised U.S. standards for grain, oilseeds, rice, dry beans, dry peas, and lentils. Activities include establishment, review, and revision of U.S. Grain Standards to reflect the latest inspection techniques and marketing needs. The agency also evaluates instruments and equipment used in the inspection and weighing process to ensure accuracy. In addition, the agency maintains an international monitoring program which interacts with foreign governments and trade teams to exchange information and to respond to complaints concerning quality and quantity of grain shipments.

Copies of the standards are available through the Animal and Plant Health Inspection Service Printing and Distribution, and Mail Service Section, Unit 1, Suite 1A01, 4700 River Road, Riverdale, MD 20737, telephone (301) 734-5524

grain inspection; grain standards; grain weighing; commodity inspection; grain marketing; agricultural grading; food; agriculture;

\section{DEPARTMENT OF AGRICULTURE}

\section{INFORMATION RESOURCES MANAGEMENT}

Planning, Review, and Standards Division

Room 447-W Administration Building

Washington, DC 20250-7600

(202) $447-6330$

PL 89-306 and resulting Federal Information Processing Standards (FIPS PUBS); PL 93-579; PL 96-511; Federal Property and Administrative Services Act of 1949, companion letter of August 14, 1972 from the Administrator of GSA delegating federal telecommunications standards development responsibilities to the Executive Agent of the National Communications system and recently confirmed and amplified by Executive Order 12472 . 
Implementation

Application

Adoption

Qualification, Certification, or Calibration

Committee

Activity

Standardization Activities

Keywords
The Office of Information Resources Management (OIRM) is responsible in USDA for standards that cover information processing management and operations for office automation, data processing, data administration and telecommunications environments, related data and security. The specifications are promulgated in the Departmental Directives system, in regulations, and in the Departmental standards and mandatory procedures which must be followed. Voluntary federal and departmental procedures and guidelines are to be used unless an alternative specification is superior.

The specifications are used in acquisition documents to control products and services brought into the Department's inventory. They apply to all information processing units, resources, and activities in USDA.

The majority of the Departmental standards are incorporated from those specified in the FIPS PUBS of the National Institute for Standards and Technology (NIST). A few are from other standards bodies such as the American National standards Institute (ANSI).

Certification of computer software is required pursuant to the requirements of office of Management and Budget Circular A-71. Certification is required of all sensitive systems. Conformance of products to FIPS PUBS is tested in accordance with tests or procedures developed by NIST or OIRM.

OIRM participates in standardization activities (committees, user workshops, etc.) of the National Institute for Standards and Technology, the United Nations, and the National Communication system.

OIRM coordinates the review of draft FIPS PUBS by

Agriculture agencies, consolidates comments and works with NIST to ensure that standards meet the Department's requirements. New specifications are adopted automatically if they are federal standards and after review if they are procedures or guidelines. OIRM lends assistance to the agencies in developing interim standards to address areas where no formal federal standard exists.

ADP; telecommunications; automation; data management; data administration; computers; information resources management; data processing; standards; 
RURAL UTILITIES SERVICE

Room 4051 South Building

Washington, DC 20250

(202) $720-9540$

WWW: http://www.rurdev.usda.

gov/agency/rus/html/rus_home.html

Authority

Implementation

Application

Adoption of Nongovernment Standards

Qualification, Certification, or Calibration

Committee

Activity

Standardization Activities
7 U.S.C. 901-950b with amendments through October 1988.

Through printed bulletins and lists of accepted materials and equipment.

Staff of the Electric and Telecommunications Divisions work with area offices to maintain and make available to borrowers construction, maintenance, and operating standards and lists of materials accepted as meeting those standards. Various standards making organizations.

RUS incorporates new and revised nongovernment standards into RUS's lists.

Borrowers must submit work plans to RUS defining the proposed construction. RUS does not become directly involved in bidding and letting contracts to manufacturers, but borrowers have the responsibility of using those on approved list.

RUS sits on appropriate committees with IEEE, ANSI, and others with activities which relate directly to electric and telecommunications borrowers.

RUS has issued nearly 400 Bulletins detailing requirements for organizing, financing, designing, constructing, and operating electric generation and distribution systems and telephone facilities. Nearly half of these define technical requirements for equipment, materials, design, testing, safety, and maintenance. The remainder include lists of acceptable materials as well as standards for financial and statistical reports, loan agreements, model contracts and related business matters.

Standards and specifications of national standardizing organizations are utilized to the maximum practicable extent. Where they are not adequate or where they do not exist, RUS prepares standards and specifications to be used by its borrowers which construct and operate rural electric and telephone systems. Standards and specifications are also prepared where it appears that such specifications and standards will result in reduced costs, 
Availability

Formerly

Keywords

DEPARTMENT OF COMMERCE

Comnittee

Activity

Standardization

Activities

Keywords improved materials and equipment, or the more effective use of engineering services. Standards and guides are also prepared which relate to the management and operation of rural electric and telephone systems.

RUS standards are utilized by 2000 rural electric and telephone systems to which loans have been made in 47 states, The Virgin Islands, Guam, Puerto Rico, Saipan, Tinian, and Rota. The standards are also utilized by other organizations in this country and abroad.

Information on RUS standards and copies of most standards are available upon request to the above address.

Rural Electrification Administration

electric power; transmission; distribution; generation; energy; electrical equipment; telephone; communications;

BUREAU OF THE CENSUS

Room 3104, FB 3

Washington, DC 20233

(301) $763-7575$

The Bureau of the Census, Department of Commerce (DOC), participates in pertinent standards committees of the following: American Agricultural Economics Association; American National Standards Institute; Office of Management and Budget, Statistical Policy office, Office of Information and Regulatory Affairs; Department of state, Commission on Cartography; Department of Interior, National Mapping Division, spatial Data Transfer standard Technical Review, Board on Geographic Names.

The Bureau of the Census is active in development of standards and specifications for definition of metropolitan statistical areas, digitizating of geographic information, and statistical economic and geographic definitions.

cartography; metropolitan statistical areas; economic statistics; digital cartography; digital geographics; data; 
Authority

Implementation

Application

Adoption of Nongovernment standards

Committee

Activity

Availability

Keywords
FEDERAL COORDINATOR FOR METEOROLOGY

8455 Colesville Road

Suite 1500

Silver Spring, Maryland 20910

(301) 427-2002

FAX: (301) 427-2007

e-mail: julian_wright_at_ofcm@smtpgate.ssmc.noaa.gov

(1) Section 304 of the Department of Commerce (DOC) Appropriation Act of 1963 .

(2) OMB Circular A-62 dated November 13, 1963 which outlines policies and procedures for the coordination of federal meteorological services.

Meteorological program standards and guidelines are developed within the federal interdepartmental committee structure for meteorological services and supporting research. The guidelines, standards and plans are approved by the Interdepartmental Committee for Meteorological Services and Supporting Research (ICMSSR) for implementation by agencies.

The plans, standards, and guidelines are implemented through procurement specifications, approved interagency plans and procedures, and through cooperative adoption.

Extensive use is made of general standards and guidelines provided by NIST (Federal Information Processing Standards), DOD, ANSI, ISO, World Meteorological Organization (WMO). They are refined to meet the special needs for meteorological operations, services, and supporting research.

The ICMSSR and its subsidiary interagency committees and groups are the developers and approvers of meteorological program plans, standards and guidelines. Members of these groups and of the office of the Federal Coordinator for Meteorology maintain liaison directly and indirectly with other federal and non-federal standards bodies, including international organizations, such as WMO.

Office of the Federal Coordinator for Meteorology.

weather; meteorology; instrumentation; satellites; aviation; space environment; communications; weather reconnaissance; weather radar; solar-terrestrial; data processing; 
Authority

Implementation

Application

Adoption of Nongovernment standards

Qualification Certification or Calibration

Committee Activity

Keywords
INDUSTRY FUNCTIONAL ADVISORY COMMITTEE ON STANDARDS TRADE POLICY MATTERS (IFAC 2)

Trade Advisory Center

14th street and Constitution Avenue NW, Room 2015B

Washington, DC 20230

(202) 482-3681 FAX: (202) 482-5939

IAFC 2 is an advisory committee established under the Trade Act of 1974, as amended by the Trade Agreements Act of 1979 and the Omnibus Trade and Competitiveness Act of 1988, and in accordance with the Federal Advisory Committee Act.

As part of the U.S. Trade Policy Committee structure, IFAC 2 advises the secretary of Commerce, the U.S. Trade Representative, and other government agencies on the negotiation and implementation of trade policy and agreements in the areas of standards and conformity assessment.

IFAC 2 has a membership of 40 individuals from the private sector. Half are users of standards and conformity services and half represent standards developers, and testing or product certification services. The focus of the IFAC 2 is on negotiation and implementation of the Agreement on Technical Barriers to Trade (TBT) of the World Trade Organization (WTO, formerly GATT). IFAC 2 also advises on standards and conformity assessment issues within the North American Free Trade Agreement (NAFTA), AsiaDacific Economic Cooperation (APEC), the Free Trade Area of the Americas (FTAA), and other trade negotiations.

While IFAC has no direct role in adoption of standards, IFAC 2 supports and encourages government adoption of nongovernment standards, in accordance with the principles of the WTO TBT Agreement.

These issues are often included with standards provisions of trade agreements on which IFAC provides advice.

As part of the Trade Policy Committee structure, IFAC 2 coordinates and occasionally meets with representatives of the other IFACs and ISACs (Industry sectoral Advisory Committees).

technical barriers to trade; TBT; conformity assessment; testing; certification; standards; non-tariff trade barriers; trade; business; WTO; standards code; 
INTERNATIONAL TRADE ADMINISTRATION

Office of Multilateral Affairs/WTO Affairs Division

14th street and Constitution Avenue NW., Room 3513

washington, DC 20230

(202) 482-0603

FAX: (202) 482-5939

Authority

Implementation

Application

Committee

Activity

Availability

Keywords
Title IV of the Trade Agreements Acts of 1979 (P.L. 96-39), the U.S. legislation which implemented the GATT Agreement on Technical Barriers to Trade (TBT) for the United states and established rules for federal agencies engaged in standards related activities.

The TBT is implemented in the United states by the Interagency Trade Policy staff Committee, subcommittee on standards. Within the Department of Commerce (DOC), International Trade Administration (ITA) shares responsibility with the National Institute of standards and Technology (NIST) for TBT implementation. ITA is primarily responsible for standards trade policy matters, while NIST has the lead in TBT-related technical and informational activities.

Commerce application of Title IV has centered on three areas: 1) publicity of the TBT's rights and benefits to U.S. exporters, particularly of the TBT's technical information network and notification/comment provisions; 2) raising standards-related trading problems of U.S. business in bilateral negotiations with key trading partners under TBT auspices; and 3) representing U.S. industry's interests in WTO TBT Committee deliberations.

Represents the Commerce Department in the following committees: Committee on Technical Barriers to Trade of the World Trade Organization (WTO); the U.S. Trade Policy staff Committee, Subcommittee on Standards; and the U.S. Industry Functional Advisory Committee (IFAC 2) on standards Trade Policy Matters.

Information to assist U.S. companies in taking advantage of the benefits of the WTO Agreement on Technical Barriers to Trade is available from the WTO Affairs Division.

standards code; technical barriers to trade; non-tariff trade barriers; trade; business; general; WTO; TBT; 
Authority

Implementation

Application

Committee

Activity

Standardization Activities
NATIONAL INSTITUTE OF STANDARDS AND TECHNOLOGY

Computer systems Laboratory (CSL)

Information Systems Architecture Division

Building 820, Room 562

Gaithersburg, Maryland 20899

(301) 975-2816

FAX: (301) 948-6213

e-mail: barbara.blickenstaff@nist.gov

WWW: http://WwW.ncsl.nist.gov

Federal Property and Administrative Services Act of 1949, as amended by the Computer security Act of 1987, Public Law 100.235.

The Computer systems Laboratory (CSL) of the National Institute of Standards and Technology performs computer and related

telecommunications research, develops standards and guidelines for computer systems, and provides technical assistance and advisory services to Federal Government agencies.

CSL's research and standards activities advance the efficient use of computer technology and support the development of off-theshelf, commercial products for computer system users. The Computer security Act specifies CSL's role in protecting sensitive information that is processed in federal computer systems, and designates CSL as the lead agency for standards, guidelines, and technology for the security of unclassified, sensitive information throughout the Federal Government.

CSL supports national and international voluntary standards developing organizations, and broad-based industry and user consortia that complement the voluntary standards process. CSL staff members participate in technical committees of organizations accredited by the American National standards Institute, and other groups to foster the development of standards that will meet federal government requirements for applications portability, for the interoperability of hardware, software and communications systems, for the exchange of information between systems, and for the protection of information from threats of all kinds.

Standards and guidelines that are developed through government/industry cooperative efforts are issued as Federal Information Processing standards Publications (FIPS PUBS) to help federal agencies buy off-the-shelf commercial equipment and systems, and to follow accepted good practices in managing information resources. 
Availability

Keywords

DEPARTMENT OF COMMERCE
FIPS PUBS include standards, guidelines, and program information documents for hardware, software, data, and computer systems operations.

Major areas of focus include high-speed network technologies; wireless communication technologies; multimedia and digital video technologies; internetworking technologies; information security; spoken natural language processing; information retrieval; visual image processing; virtual reality; distributed environments and applications; information technologies management; software methods; and information systems policy.

FIPS PUBS are listed in NIST Publications List 58, which is available from NCSL at the above address. FIPS are available from the National Technical Information Service.

Federal Information Processing Standards; computer systems; computer security; information processing; information technology;

\section{NATIONAL INSTITUTE OF STANDARDS AND TECHNOLOGY}

Electronics and Electrical Engineering Laboratory

Office of Law Enforcement Standards, Bldg. 225, Rm.A323 Gaithersburg, Maryland 20899

(301) 975-2757

FAX: (301) 948-0978

e-mail: higgins@micf.nist.gov

Authority

(1) Title 1, Section 402 (b) of the Omnibus Crime Control and Safe Streets Act of 1968, P.L. 90-351

42 U.S.C. 3701, Justice System Improvement Act of 1979, P.L. $96-157$

The Office of Law Enforcement Standards(OLES) formerly the Law Enforcement Standards Laboratory (LESL), develops standards for the National Institute of Justice (NIJ), and the Federal Bureau of Investigation (FBI) at the Department of Justice, and for the National Highway Traffic Safety Administration (NHTSA) at the Department of Transportation.

The standards developed by OLES are performance-oriented insofar as possible. They are not consensus standards, but are subjected to extensive technical and editorial review within NIST, as well as other government agencies, manufacturers, users, and independent experts. The standards are given a final review by the sponsor (NIJ, NHTSA, or the FBI) and are promulgated by them. 
The NIJ has elected to publish all OLES-developed standards as voluntary national standards. Criminal Justice agencies are encouraged to use the NIJ standards to achieve cost-effective procurement of equipment through competitive bid. In recent years, under a separate NIJ grant, Aspen Systems Corporation has operated a limited equipment testing program through the National Law Enforcement and Corrections Technology Center (NLECTC), formerly the Technology Assessment Program Information Center (TAPIC). The NLECTC contracts with two independent testing laboratories to conduct tests of equipment in accordance with the NIJ standards. Complete test results are then published by NLECTC in a consumer information report series to assist criminal justice agencies in selecting equipment that is suitable for their needs. Test reports published to date include police body armor, hand-held personal/portable transceivers, handcuffs, riot and crash helmets, narcotic test kits, batteries for hand-held transceivers, 12-Gauge shotguns, $9 \mathrm{~mm}$ and 45 caliber revolvers, vehicle tracking devices, body-worn transmitters, and an annual report of police vehicle test results. Subsequent to publication of the initial test report, manufacturers may have their equipment tested to the NIJ standard by either of the two independent testing laboratories, and NLECTC will issue supplemental data sheets for the new products and retest.

In addition to the NLECTC testing program, some manufacturers choose to use the NIJ standards as the benchmark for product design and to certify compliance to the NIJ standards in their equipment specifications.

Prior to 1983, the NHTSA mandated the use of OLES-developed standards for state and local government procurement of evidential breath testers. Commercial products were tested by the U.S. Department of Transportation Systems Center in accordance with OLES-developed standards, and those devices which passed were placed on the NHTSA qualified products list. It is anticipated that all future OLES-developed standards for breath alcohol instruments will be promulgated by NHTSA as voluntary model equipment specifications for use by state and local governments, and not mandated as in the past.

In 1983, the OLES-developed standard for speed measuring radar devices was issued by NHTSA as a voluntary model equipment specification. In that same year, the International Association of Chiefs of Police (IACP) undertook testing of speed measuring radar devices in the same manner as the NIJ equipment testing program and issued a consumer report on the results of those tests. 
Application

Adoption of Nongovernment Standards
The standards that are developed by OLES are developed on a schedule consistent with the priorities of the other-agency sponsors and available funds from those agencies. To ensure that the OLES program is relevant to the needs of the law enforcement community, the NIJ has established, through NLECTC, the Law Enforcement and Corrections Technology Advisory Council (LECTAC), which reviews OLES program plans and recommends research and equipment testing priorities, including the mission of NHTSA.

OLES's primary focus is on helping law enforcement and criminal justice agencies to acquire on a cost-effective basis the high quality resources they need to do their jobs. To accomplish its task, OLES: (1) develops methods for testing equipment performance and for examining evidentiary materials; (2) develops standards for equipment and operating procedures; (3) develops standard reference materials; and, (4) performs other scientific and engineering research as required.

The equipment standards that are developed by OLES are based upon laboratory evaluation of commercially available products to devise precise test methods that can be universally applied by any qualified testing laboratories, and to establish minimum performance requirements for each attribute of an item of equipment that is essential to the manner in which it functions. The OLES-developed standards can serve as design criteria for the manufacturers or as the basis for equipment evaluation. The application of the standards, which are highly technical in nature, is augmented through the publication of technical reports and user guides. Individual jurisdictions may use the standards in their own laboratories to test equipment, have equipment tested on their behalf using the standards, or cite the standards in procurement specifications.

To the extent possible, OLES utilizes pre-existing industrial and trade association standards during the development of standards for NIJ and NHTSA, which may be directly cited or adapted to specialized testing methods in the final standard. Nongovernment standards utilized in the OLES program include those of the American society for Testing and Materials, the American National Standards Institute, the Institute of Electrical and Electronics Engineers, Electronic Industries Association, and the society of Automotive Engineers, among others as appropriate. 
Qualification, Certification, or Calibration

Committee

Activity

Standardization Activities
In those instances when NIJ and NHTSA sponsor the testing of specific items of equipment, OLEs assists in the preparation of the request for proposal from testing laboratories and the evaluation of the resulting bids to tentatively select two independent testing laboratories for each item of equipment. Following the award of the two contracts, OLES, NLECTC/IACP, and members of the National Institute of standards and Technology (NIST) National Voluntary Laboratory Accreditation Program visit the laboratories for an on-site facility investigation and witness the complete testing of one item of equipment.

When the inspection team is satisfied that the laboratory personnel are proficient in testing to the OLES-developed standards, that all test equipment is properly calibrated, maintained and operated, and that appropriate test records are maintained, the NLECTC/IACP classifies the laboratory as a NLECTC/IACP-certified laboratory for that item of equipment. The laboratory is then allowed to proceed with the main-quantity testing. In the event that a laboratory does not demonstrate appropriate testing proficiency or lacks essential facilities during the on-site inspection, the contract is terminated and another laboratory is selected for the testing program. In those instances when the private sector, federal, state or local government agencies wish to apply the OLES-developed standards in their own laboratories, OLES remains available for consultation on the application of the standards. However, certification or accreditation is not provided.

OLES participates in pertinent committees of the American National standards Institute, the American society for Testing and Materials, Electronic Industries Association, and the Institute of Electrical and Electronics Engineers.

The areas of research investigated by OLES include clothing, communication systems, emergency equipment, investigative aids, protective equipment, security systems, vehicles, weapons, and analytical techniques and standard reference materials used by the forensic science community. The composition of OLES projects varies depending upon the priorities of the criminal justice community at any given time and, as necessary, draws upon the resources of both EEEL and NIST divisions external to OLES. 
The NIJ-sponsored activities are part of an overall Law Enforcement and Corrections Standards and Testing Program that includes both the development of standards and other documents and the actual testing of equipment and publication of the test results. The Communication Systems Program has resulted in the development of standards for nearly all items of such systems -transceivers, base stations, control heads, digital transmission systems, and tracking devices, to mention a few. The Weapons and Protective Equipment Program has developed standards for revolvers and automatic pistols, body armor, protective helmets, and tear gas devices. Other studies and standards have centered on emergency vehicle warning systems, police clothing, components of intrusion alarm systems, physical security of door and window assemblies, weapons and explosive detectors, arson accelerant detectors, and narcotic test kits.

In addition, OLES has developed reference collections for use by forensic laboratories of automobile paints and synthetic fibers, and standard reference materials for glass comparisons and DNA profiling.

The overall NHTSA program is limited to the three types of speedmeasuring devices, i.e., conventional radar units, photoradar and lidar.

OLES provides a complete publication list of documents available from the program upon request. This list is updated periodically as new documents are published.

Availability

Keywords
National Technical Information Service; U.S. Government Printing Office; National Criminal Justice Reference Service; National Law Enforcement and Corrections Technology Center; and the office of Law Enforcement Standards.

alarm systems; alcohol countermeasures; ammunition; body armor; breathalyzer; bullets; communications; DNA profiling; electrical; electronic; emergency equipment; firearms; fire protection; forensic science; investigative aids; laser radar; law enforcement; lidar; photoradar; police equipment; protective equipment; radar; security systems; speed enforcement; standard reference materials (SRM); surveillance; traffic safety; vehicles; weapons; 
Authority

Implementation

Application

Qualification, Certification, or Calibration

Committee

Activity

Standardization

Activities
NATIONAL INSTITUTE OF STANDARDS AND TECHNOLOGY

Technology Services (TS)

Gaithersburg, Maryland 20899

(301) 975-4500 FAX:(202) 975-2183

31 stat. 1449 as amended, 64 stat. 371,15 U.S.C. 271-278, P.I. 89-306, P.I. 89-755, and P.L. 94-168.

Voluntary Product Standards (VPS) are developed under Department of Commerce (DOC) procedures (15 CFR, Part 10) current VPS standards pertain to softwood lumber (PS 20-94), wood-based structural use panels (PS 2-92), and construction and industrial plywood (PS 1-95).

Voluntary Product standards are voluntarily used by manufacturers, distributors, purchasers, specifiers, and others in producing, marketing, and specifying products. Some Voluntary Product standards are referenced in local and state building codes and are used in product certification programs.

See program descriptions listed below.

Technology services (TS) coordinates and monitors the National Institute of Standards and Technology (NIST) activities in standards committees. NIST staff members hold more than 1,172 memberships on 819 standards committees of some 80 organizations (national as well as international) involved in standards activities. NIST staff participate in many standards programs as part of the institute's responsibilities for maintaining and advancing national standards of measurement.

The TS Office of standards services (OSS) monitors the Institute's total involvement in private sector standards activities. OSS is the focal point for coordinating standards activities throughout the Department of Commerce, and assists other agencies in implementing federal standards policy as enunciated in OMB Circular A-119. It operates the Interagency Committee on standards Policy and uses that committee to implement the provisions of Circular A-119 in a uniform and effective manner throughout all federal executive branch agencies. The office also serves as the principal point of contact between the federal government and the voluntary standards community. NIST staff persons serve on the boards and councils of many voluntary standards organizations, including ANSI, ASTM, ASHRAE, ITI, IEEE, NFPA, and UL, and thereby have the opportunity to influence national standards policy. 
The Laboratory Accreditation Program operates the National Voluntary Laboratory Accreditation Program (NVLAP), which provides a mechanism for nationally recognizing the competence of testing and calibration laboratories based on evaluation of the technical qualifications and ability of such laboratories to perform specific nationally recognized tests methods in such fields as asbestos fibers and electromagnetic telecommunications and/or to conduct calibrations traceable to national standards. Laboratories must meet ISO/IEC Guide 25 requirements for facilities, equipment, personnel, traceability and quality management systems to be accredited under this program. NVLAP provides evaluation and recognition of testing performance, especially in response to Congressional mandates and requirements of other federal agencies, to domestic and foreign laboratories, state and local governments, and commercial interests. The program also represents U.S. interests in the International Laboratory Accreditation Conference (ILAC) and provides the basis for bilateral agreements with other countries for acceptance of test data produced in U.S. laboratories.

The Global Standards Policy Program provides technical support for the office of the U.S. Trade Representative and the International Trade Administration in negotiations with trading partners; develops policy and planning for implementing the NAFTA and the Free Trade Area of the Americas, as well as for trade with Russia and the NIS, the European Union, the Middle East, and the Asia-Pacific region; participates in DEVCO and UNECE; conducts economic and socio-political analyses of the likely impact of standards and conformity assessment programs on commerce and trade; and operates the National Voluntary Conformity Assessment Systems Evaluation (NVCASE) program.

The Technical Standards Activities Program provides a "technical office for non-agricultural products" to investigate problems related to non-tariff trade barriers; manages U.S. representation and participation in the International Organization of Legal Metrology (OIML), an intergovernmental body concerned with the harmonization of national legal requirements pertaining to measurements in commerce, industry, and public health; provides technical support for domestic and international standardization activities and for U.S. standards experts posted abroad. This program is also responsible for administering the Department of Commerce Voluntary Product Standards Procedures (15 CFR Part 10). 
The Standards Information Program is responsible for providing information on 1) U.S. Voluntary standards, 2) domestic and foreign government regulations and specifications, 3) U.S. certification programs, 4) foreign and international standards, and 5) proposed foreign regulations relating to standards and certification programs which might significantly affect trade. The program operates the National Center for standards and Certification Information (NCSCI) (See Sources of standards and Information), which serves as the U.S. "inquiry point" for the World Trade Organization (WTO) and the North American Free Trade Agreement (NAFTA), as required by law, and the International Organization for standardization's (ISO's) Information Network (ISONET). The Center also participates in meetings of national and international information exchange specialists. The standardization activities of all NIST units are summarized in an annual NIST report which provides statistical and narrative information about the participation of NIST staff in standardization activities.

The Standards Training and Support Program manages the placement in key U.S. embassies, missions or standards organizations of technical experts in standards and conformity assessment. These experts provide technical advice and support to commercial and economic staffs in the identification and resolution of trade issues involving technical barriers. The program also conducts standards related training programs for technical experts from Russia and the NIS, the Americas, the Middle East, and other areas important for U.S. trade.

The Office of Weights and Measures develops recommendations for performance and test requirements for weighing and measuring devices used commercially and develops test methods to be used in evaluating these devices. This office sponsors and provides technical advice for the National Conference on Weights and Measures (a national organization made up of federal, state, and local weights and measures officials and appropriate industry representatives), which promotes uniformity in weights and measures programs through the adoption of model laws, regulations, specifications, and tolerances for weights and measures. 
- The Standards Reference Materials (SRM) Program certifies the chemical composition or physical properties of more than 1200 solids, liquids, and gases. Companies use these SRMs to verify the accuracy of analytical or other measurement methods under development or to calibrate established measurement systems to ensure consistently accurate performance of equipment and operators. The SRM program publishes a catalog that lists all available reference materials, as well as other timely information, offers telephone consultations on SRM uses, and organizes seminars to advise industry on SRM applications.

- The Standards Reference Data Program provides welldocumented numeric data to scientists and engineers for use in technical problem solving, research, and development. These recommended values are based on data extracted from the world's literature, assessed for reliability, and then evaluated to select the preferred value. To increase the usefulness and accessibility of the data, a series of personal computer databases with interactive programs, search routines, and other calculational and graphical software features have been developed and are available from NIST .

- The Calibration Service Program provides more than 500 different services to ensure that manufacturers and other users of precision instruments achieve measurements of The highest possible quality. These services link a customer's precision equipment or in-house standards to national standards. The services, encompass seven major areas: dimensional measurements; mechanical, including flow, acoustic, and ultrasonic; thermodynamics; optical radiation; ionizing radiation; electromagnetics, including direct current, alternating current, radio frequency, and microwave, and time and frequency. The program also publishes a catalog with a complete listing of available services materials as well as other timely information, offers telephone consultations on the use of services and the importance of traceability to national standards, and makes presentations to industry on these issues.

Voluntary Product standards are available from the National Institute of Standards and Technology or the National Technical Information Service. Standard reference materials and standard reference data are available from NIST. 
Formerly

Keywords

DEPARTMENT OF COMMERCE

Authority

Implementation

Application

Adoption of Nongovernment standards
The National Bureau of Standards, Office of Product Standards Policy and Office of the Associate Director for Industry \& Standards.

standards; standard reference materials; standard reference data; reference materials and data; Voluntary Product standards; ILAC; OIML; laboratory accreditation; conformity assessment; GATT; standards information; inquiry point; testing; general; trade; technical barriers to trade; calibration; measurement; traceability;

\section{NATIONAL MARINE FISHERIES SERVICE}

Office of Industry Services, Inspection Services Division 1315 East West Highway, Room 12554 Silver spring, Maryland 20910

(301) 713-2355 FAX: (301) 713-1081

WWW: http://kingfish.ssp.nmfs.gov/iss/issue.html

(1) 7 U.S.C. 1621-1627, Agricultural Marketing Act of 1946, to encourage uniformity and consistency in commercial practices.

(2) 16 U.S.C. 742e, Fish and Wildlife Act of 1956, to promote fair trade standards.

(3) 84 Stat. 2090, Reorganization Plan No. 4, which transferred the National Seafood Inspection Program from the Department of the Interior to the Department of Commerce.

21 voluntary standards are codified as regulations in 50 CFR, Parts 261-267. They establish U.S. Standards for Grades for fish and fishery products.

Inspectors certify, at the request of the seafood processor, that the product meets the criteria established in these standards. The inspection is conducted at the processing facility.

No nongovernment standards have been adopted. 
Qualification, Certification, or Calibration

\section{Committee}

Activity

\section{Standardization}

Activities

Availability

Reywords
To be eligible to use the official Department of Commerce (DOC) grade or identification marks as specified in 50 CFR Part 260.86, the processor must participate in the voluntary National seafood Inspection Program. The marks may appear on the product label and/or the certificate. The processor pays for participation in the Program. Seafood processors that do not participate in the Program may use the U.S. Standards for Grades as guidelines but must not display the official marks.

The following committees of the Codex Alimentarius Commission:

-Fish and Fishery Products

-Food Hygiene

-Food Labeling

- Pesticide Residues

-Methods of Analysis and Sampling

-on Residues of Veterinary Drugs in foods

-Food Import and Export Inspection and Certification Systems

The National Marine Fisheries Service (NMFS) is actively involved in the preparation of U.S. Standards for Grades for seafood products which establish the criteria for the measure of quality of those seafood products (U.S. Grade A, B, and C). The standards currently pertain to various fresh and frozen seafood products. These standards, the use of which is voluntary, are prepared at the request of the seafood processing industry and are available to all interested parties in this country and abroad.

This agency's participation on the various committees of the Codex Alimentarius Commission, specifically the Committee on Fish and Fishery Products, is critical to ensure that the recommended international standards which establish a minimum standard of quality are reflective of this country's commercial practices.

This agency is also responsible for preparing specifications for seafood purchased for USDA's various feeding programs (school children, elderly, needy, American Indians).

National Seafood Inspection Laboratory, National Marine Fisheries Service, P.O. Drawer 1207, Pascagoula, Mississippi 39567-0112.

fish; fishery products; seafood; quality standards; fish quality; seafood specifications; food safety; 
Authority

Implementation

Application

Qualification, Certification, or Calibration

Committee

Activity

Standardization

Activities

Availability
NATIONAL OCEANIC AND ATMOSPHERIC ADMINISTRATION

National Environmental Satellite, Data, and Information Service Data Collection and Direct Broadcast Branch

E/SP21 NOAA/NESDIS

Room 806

5200 Auth Road

Camp Springs, Maryland 20746

(301) 763-8325

15 U.S.C. 3.3, 49 U.S.C. 1483 provides the Secretary of Commerce with the authority to develop an international basic meteorological network.

Regulations on the administration and operation of a Geostationary Orbiting Environmental Satellite Data Collection System (GOES-DCS) is codified at $15 \mathrm{CFR}$, Part 911.

The National Oceanic and Atmospheric Administration (NOAA) GOES Data Collection System utilizes geostationary satellites to collect environmental data from remote locations. Standards on UHF transmitters and related equipment are established to ensure system integrity.

Manufacturers submit plans for in-plant testing of Data Collection Platform Radio sets. If the plans are approved, a NOAA representative visits the manufacturer's testing facility and witnesses the tests. If a representative unit meets all of the established standards a type certificate is issued to the manufacturer.

National Environmental Satellite, Data, and Information Service (NESDIS) participates in the Coordinating Group for Geostationary Meteorological satellites (CGMS) to establish compatible standards for international use. CGMS is sponsored by the World Meteorological Organization (WMO).

Periodic meetings with industry are conducted to review the adequacy and applicability of the standards. Revisions to the existing standards are proposed in response to: technological developments; cost effectiveness considerations; operational difficulties observed within the GOES-DCS; and the need to clarify and improve measurement techniques.

Four standards for self-timed, random reporting, international and interrogated Data Collection Platform Radio sets are available from the address above. 
Keywords

DEPARTMENT OF COMMERCE

satellites; environment; electronic equipment; data processing; aerospace;

\section{NATIONAI OCEANIC AND ATMOSPHERIC ADMINISTRATION}

National Weather Service

Sterling Research \& Development Center

Sensor Test Section

44210 Weather Service Road

sterling, Virginia 20165

(703) 47I-5302

I5 U.S.C. 311 and 313, the original acts establishing the United States weather Bureau. (2) 49 U.S.C. 1463 and Title 8, Section 803, of the Federal Aviation Act of 1958.

Standards for producing weather information are included in the series of the Federal Meteorological Handbooks, Federal Specifications for Meteorological Equipment, and operational Directives from the National Weather service.

Observers are certified by examination and experience and observatories are certified by periodic on-site inspection. Standards for federal specifications are applied by the purchase orders for the equipment, and Operational Directives are applied by on-site inspection of the affected installation.

Excluding those that are produced by intergovernmental agreement within the United Nations, nongovernment generated standards are relatively rare within the field of meteorology. A few such standards produced by organizations such as the American Society for Testing and Materials have been adopted. An effort is now underway to encourage voluntary standards organizations to produce standards for meteorology.

Meteorological observatories are certified if they conform to the performance standards detailed in Federal Meteorological Handbooks, and National Weather Service Operational Directives.

The National Weather service actively participates in the standardization activities of the World Meteorological Organization, the Office of the Federal Coordinator for Meteorological Services and Supporting Research, the American Society for Testing and Materials the International Organization for standardization, and the Range Commanders Council. 
Standardization

Activities

Availability

Keywords

DEPARTMENT OF COMMERCE

Authority

Application
The development of standard methods for producing meteorological observations and measurements and the development and use of standard test methods for meteorological equipment are actively pursued by the National weather service. Most standards are produced within the government and contained within the Federal Meteorological Handbooks and by cooperation with other governments as published by the world Meteorological Organization in its guide to good practice. Nongovernment voluntary standards development organizations, such as the American society for Testing and Materials, have been encouraged to develop standards for use in the field of meteorology, but to date very few such standards exist.

The Federal Meteorological Handbooks are sold by the Government Printing office. Federal specification for equipment and testing are available through the GSA Specification Unit.

meteorology; weather; atmosphere; aviation; climatology; test; environment; instruments;

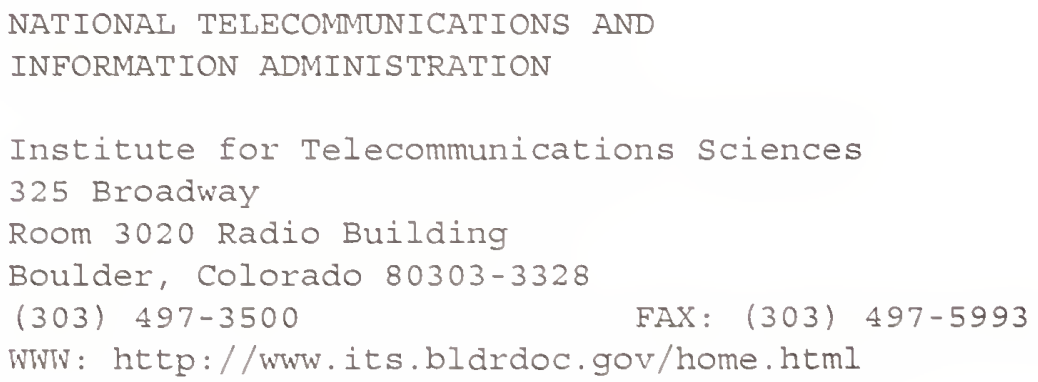

The Institute for Telecommunications sciences (ITS), the research and engineering arm of the National Telecommunications and Information Administration (NTIA), participates and contributes to both national and international standards activities in radio, telecommunications, data transmission, and processing technologies. ITS staff are particularly involved in developing American National standards and Federal Telecommunication Standards and providing leadership and participating in the development and promulgation of international telecommunication standards. 


\section{Comittee}

Activity

\section{Keywords}

DEPARTMENT OF COMMERCE
ITS participates in the development of voluntary

national consensus standards with emphasis on data, voice, and video performance standards, and integrated services digital network (ISDN) standards through the American National Standards Institute (ANSI) committees: Performance and Signal Processing Technical Subcommittee; Services, Architectures, and Signaling Technical Subcommittee; and Systems Engineering, standards Planning and Program Management Technical Subcommittee. ITS participates in the Federal Telecommunications Standards Committee and Chairs HF Radio subcommittee. Internationally, ITS members work to develop Recommendations of the International Telecommunications Union's Telecommunication and Radiocommunication sectors. ITS chairs two U.S. ITU-R Study Groups: Spectrum Utilization and Monitoring. The Institute also chairs a U.S. ITU-T preparatory group: U.S. Study Group B (Switching, Signaling, and ISDN).

radio; telecommunications; data processing;

\section{U.S. PATENT AND TRADEMARK OFFICE}

Office of the Deputy Assistant Commissioner for Patent Policy and Projects

Room 910, Crystal Park Building 2

2121 Crystal Drive

Arlington, Virginia 22202

Mailing Address: Washington, DC 20231

(703) 305-8813

FAX: (703) 305-8825

e-mail: uspto.gov.

WWW: http://WWw.uspto.gov

Authority

(1) 35 U.S.C. 6 authorizes the Commissioner of Patents and Trademarks to "establish regulations, not inconsistent with law."

$$
37 \text { CFR } 1.52(b)
$$

$$
37 \text { CFR } 1.84(b)
$$

Implementation

Manual of Classification, U.S. Patent and Trademark office (USPTO), a looseleaf book containing a list of all the classes and subclasses of inventions in the USPTO classification system.

Application

This classification is used by the USPTO, and any other user of patent information, to classify and retrieve a patent or patent related document in the U.S. Classification system. 
Committee

Activity

Standardization

Activities

Availability

Keywords

DEPARTMENT OF COMMERCE

Implementation

Application

Adoption of

Nongovernment

Standards

Committee

Activity

Standardization

Activities
The Patent and Trademark Office participates in pertinent committees of the World Intellectual Property Organization, Geneva, Switzerland.

Member of Assembly of the Patent cooperation Treaty in order to provide patent application format and units of weights and measures acceptable in all member countries.

Published in "Title 37, Code of Federal Regulations" and "Manual of Patent Examining Procedure," both available from U.S. Government Printing office.

patent applications; paper size; metric system; business; general;

U.S. PATENT AND TRADEMARK OFFICE

Office of International Patent Documentation

Washington, DC 20231

(703) $557-3756$

Subcommittee $\mathrm{H}$ of American National Standards Committee 239 specializes in patent matters and sets guidance standards therefore.

Voluntary adoption

239 meets with representatives of the U.S. Patent and Trademark Office (USPTO) and other related organizations to discuss and set standards to be used by the USPTO on a voluntary basis.

The USPTO actively participates in subcommittee $\mathrm{H}$ of Z39.

Z39 Subcommittee $\mathrm{H}$ (Patent Standards) gives special consideration to the publishing policies and practices of the USPTO in the development of U.S. standards as a result of the position of the USPTO as the primary publisher of U.S. patent literature. 239 subcommittee $\mathrm{H}$ addresses the practices of foreign publishers of patent data and those organizations in the United States who repackage and republish foreign patent data. 
DEPARTMENT OF COMMERCE

Authority

Implementation

Committee

Activity

Standardization Activities
American National Standards Institute

patents; patent standards; business;

\section{U.S. PATENT AND TRADEMARK OFFICE}

Trademark Examining Operation

Office of the Director

2011 Jefferson Davis Highway

Arlington, Virginia 22202

(703) 557-3268

15 U.S.C. 1112, July 15, 1946, Lanham Act Section 30, gives the Commissioner the authority to establish a system of classification of goods and services.

37 CFR 2.85 and Part 6, implement the adoption of the International schedule of classes for goods and services. Classification is the basis for determining the fee which must be paid per application.

U.S. Patent and Trademark Office (USPTO) is a member of the Committee of Experts which is the acting body established by the Nice Agreement. The Committee of Experts meets periodically to revise the International Classification.

The classification of specific goods and services is set forth in the Alphabetical List entitled "International Classification of Goods and Services for Purposes of the Registration of Marks Under the Nice Agreement," published by the World Intellectual Property Organization (WIPO). This classification list contains the name of each class and the basic contents of the class. The Alphabetical List also comprises explanatory notes which serve as guidelines for determining the appropriate International Class for a specific product or service.

The primary purpose of the International Alphabetical List is to provide a written source for determining proper identifications and classifications of goods and services. The classification lists consist of:

(1) a list of classes, together with explanatory notes; and

(2) an alphabetical list of goods and services with an indication of the class into which each of the goods or services falls. 
Availability

Keywords

CONGRESS OF THE UNITED STATES

Authority

Implementation

Application

Standardization Activities
World Intellectual Property Organization, 34 Chemin des Colombettes, 1211 Geneva 20, Switzerland,

UNIPUB, P.O. Box 433, Murray Hill station, New York, New York 10016 .

international classification; Nice Agreement; classification list; trademark classification; business; general;

JOINT COMMITTEE ON PRINTING

818 Hart Senate office Building

Washington, DC 20510-6650

(202) 224-5241

The Joint Committee on Printing (JCP), created by act of August 3 , 1846 (9 stat. 114), is responsible for establishing specification standards for papers used in public printing and binding (44 U.S.C. 509), including Federal Government printing and duplicating procured from the private sector.

The Government Paper Specification standards include approximately 100 individual specifications for writing and printing papers, together with testing information, color standards, and acceptance criteria.

All the Government Paper Specification Standards must be used by all departments of the federal government and their field activities in the preparation of procurement documents for paper stocks and in specifying paper stocks to be used in printing, binding, copying, and duplicating, unless otherwise authorized by the Joint Committee on Printing.

Administered by an Advisory Council on Paper Specifications and its Technical subcommittee, under the chairmanship of the Joint Committee's Staff Director.

Participating agencies include U.S. Government Printing office, General Services Administration, EPA, Treasury, NARA, Federal Environmental Executive and the Department of Defense. Staff participates in relevant activities of ANSI, and the ANSIaccredited CGATS, GCA committees. 
U.S. Government Printing Office, Superintendent of Documents (Order Stock Number 952-001-00000-1; List I.D. Number GPS). Also available: Government Paper Samples (Order Stock Number 021-000$00160-1$ )

paper; colors; office products; printing;

\section{CONSUMER PRODUCT SAFETY COMMISSION}

DIRECTORATE FOR ENGINEERING SCIENCES

Mechanical, Electrical, and Thermal Hazard-Related Standards for Consumer Products

(301) 504-0504

DIRECTORATE FOR HEALTH SCIENCES

Chemical Hazard-Related Standards for Consumer Products (301) 504-0957 FAX: (301) 504-0124

4330 East-West Highway

Bethesda, Maryland 20814

e-mail: info@cpsc.gov

Authority

Implementation

Application
Consumer Product Safety Act (15 U.S.C. 2051 et seq.); Federal Hazardous Substances Act (15 U.S.C. 1261 et seq.); Poison Prevention Packaging Act (15 U.S.C. 1471 et seq.); Flammable Fabrics Act (15 U.S.C. 1191 et seg.); and Refrigerator Safety Act (15 U.S.C. 1211 et seg.).

All standards, regulations and policy issuances are to be found within Title 16, Code of Federal Regulations Chapter II, Commercial Practices, Parts 1000 to end. Information on all Consumer Product Safety Commission (CPSC) mandatory product safety standards is published in the Federal Register in Advance Notices of Proposed Rulemaking, Notices of Proposed Rulemaking, and Final Rules.

The Commission enforces all regulations and standards published in 16 CFR Chapter II, Parts 1000 to end. The Directorate for Compliance and Administrative Litigation is the Commission organization responsible for this activity. This Directorate is located at 4330 East-West Highway, Bethesda, Maryland. Telephone requests for information on regulatory standards enforcement may be obtained by calling (301) 492-6400. This Directorate is also responsible for enforcement activities under section 15 of the Consumer Product Safety Act. Reports of information which reasonably supports the conclusion that a product contains a 
Adoption of Nongovernment Standards

Qualification, Certification, or Calibration

Committee

Activity

Standardization Activities defect which could create a substantial product hazard, as required under section 15 of the Consumer Product Safety Act, should be made by calling (301) 492-6608 with concurrent notification, in writing, to: Division of Corrective Actions, U.S. Consumer Product Safety Commission, Washington, DC 20207.

Amendments to the Consumer Product Safety Act, the Federal Hazardous Substances Act, and the Flammable Fabrics Act enacted by Congress in 1981 encourage reliance on voluntary standards developed by industry or other nongovernmental organizations to reduce risks of injury whenever possible, Sec. 15 U.S.C. 2058, 15 U.S.C. 1262 (f), and 15 U.S.C. $1193(\mathrm{~g})$.

Product certification is specifically required by

Section 14 of the Consumer Product Safety Act (CPSA)

(15 U.S.C. 2063). Manufacturers or private labelers must issue certificates stating that their product meets any applicable consumer product safety standard issued under the CPSA. The Commission may also prescribe testing and labeling requirements by regulation under the authority of section 14 of the CPSA.

CPSC participates in a variety of nongovernment and government standardization committees. For specific information on committees with which the Commission is working contact either the Directorate of Engineering Sciences or the Directorate for Health Sciences.

The U.S. Consumer Product Safety Commission, an independent federal regulatory agency, was officially activated on May 14, 1973, to implement the Consumer Product Safety Act, P.L. 92-573. The Commission's primary goal is to substantially reduce injuries associated with consumer products. The Act granted broad authority to issue and enforce safety standards for more than 10000 consumer products.

The Act specifically excludes certain products from the Commission's jurisdiction. Among the excluded products are foods, drugs, cosmetics, boats, aircraft, motor vehicles, and pesticides, most of which are regulated by other federal agencies.

Amendments to the Consumer Product Safety Act enacted in 1981 encourage the development of voluntary consumer product safety standards by industry. The Commission may adopt voluntary standards issued by nongovernmental organizations as mandatory standards or issue mandatory requirements independently. The Commission may ban products which present an unreasonable risk of injury if no safety standard is feasible. The Directorate for Engineering Sciences and the Directorate for Health Sciences serve as the focal points for standards development within CPSC. 
DEPARTMENT OF DEFENSE

Authority

Implementation

Application

Adoption of Nongovernment standards
U.S. Government Printing office

consumer products; safety; textiles; general;
DEFENSE INFORMATION SYSTEMS AGENCY

Center for standards

Joint Interoperability and Engineering Organization

10701 Parkridge Blvd.

Reston, Virginia 22091-4398

(703) 487-8338

FAX: (703) 735-3575

e-mail: sweetd@cc.ims.disa.mil

WWW: http://WwW.itsi.disa.mil

Title 10, United States Code, Chapter 8, to plan, develop, and support Command, Control, Communications, Computers, and Intelligence (C4I) that serve the National Command Authority (NCA) under all conditions of peace and war. The JIEO Center for Standards acts for DISA as Executive Agent for coordinating the DOD information Technology (IT) Standards Program.

The Center for Standards assists the military services and DOD agencies to identify the need for information technology standards (for information, information transfer, information processing) and to ensure that appropriate standards are available that meet DOD's needs. The center assists the services and agencies in selecting the appropriate standards(i.e., developing the standards profile) for new systems and modernization programs.

The goal is to achieve standards based solutions in DOD C4I systems for interoperability, portability, reusability, efficiency, effectiveness and to make optimal use of commercial standards and products.

The Center promotes, and participates with DOD representatives, in the development and use of international and national nongovernment standards for implementation in DOD C4I systems, achieving economy of cost and schedule. Standards development occurs in nationally recognized voluntary organizations, industry consortia, and international treaty and bilateral and multilateral organizations. Military standards are developed only if the requirements cannot be satisfied by an existing or planned nongovernment standard. Most military standards published under the IT standards Program are profiles of (selecting options and features from) nongovernment standards. 
Qualification, Certification, or Calibration

Committee

Activity

Availability

Keywords

DEPARTMENT OE DEFENSE

Authority

Implementation
The Center supports DOD evaluation of systems with C4I capabilities for satisfaction of interoperability, compatibility, and integration requirements. Specifically, the Center reviews DOD C4I system life cycle acquisition documentation, and standards profiles, for compliance with DOD standards policy. The Center's recommendations, together with other inputs, notably from the DISA Joint Interoperability Test Command (JITC), are processed by the Joint Chiefs of Staff (J6I) and OASD(C3I) leading to requirements and interoperability certification of DOD C4I systems.

The Center provides DOD representatives to many national and international standards bodies including ANSI, IEEE, ISO, ITU, standards consortia such as the OSF (Open Software Foundation), and international treaty, multilateral and bilateral standards bodies, such as found in NATO and in various Pacific Rim arrangements.

On the World wide Web and from the Defense Printing service, Philadelphia, PA.

standards profiles; information technology; information transfer; information processing; communications; command and control; intelligence; C4I; interoperability; portability; reusability;

OFFICE OF THE ASSISTANT SECRETARY OF DEFENSE (ECONOMIC SECURITY)

Standardization Program Division

Suite 1403

5203 Leesburg Pike

Falls Church, Virginia 22041-3466

(703) 681-9340 FAX: (703) 681-7622

WWW: http: //www.acqosd.mil/es/std/stdhome.html

Title 10, U.S. Code, Chapter 145, Cataloging and standardization and implemented by DoD Instruction 50000.2

DoD's standardization program implements 27000 Military Specifications and 1600 Military Standards; it is responsible for 1300 Federal Specifications, 25 Federal standards and 4200 Commercial Item Descriptions. More than 7400 nongovernment standards have been adopted. 
Adoption of Nongovernment standards

Qualification, Certification, or Calibration

\section{Committee}

Activity

\section{Standardization} Activities

\section{Availability}

Department of Defense (DoD) standardization documents are used as procurement documents for all types of equipment and commodities, as well as documents that provide selection criteria for items, equipment, engineering practices, etc., used in new design.

DoD has adopted over 7400 nongovernment standards to be used instead of military documents. These private sector documents were developed by a number of nongovernment standards organization including ASTM, SAE, AIA, UL, and others.

DoD has developed over 1000 Qualified Products Lists and Qualified Manufacturers Lists, which describe products or manufacturing processes that have been examined, tested, and approved as meeting the requirements of applicable specifications.

The Department of Defense participates in numerous intergovernmental and nongovernmental committees to share in the development of both policy and acquisition standardization documents.

The Defense Standardization Program (DSP) is a single, integrated defense-wide program to achieve optimum uniformity among the variety of systems, equipment, materials, engineering practices, operations, and manufacturing processes developed for or used by the DoD. Standards and specifications developed by (or in concert with) nongovernment standards groups are utilized to the maximum extent possible. The adoption of nongovernment standards avoids the preparation of duplicative or overlapping military documents. It is DoD policy to cooperate with the standards organizations operating in other government agencies, as well as, those in the private sector.

Standards and specifications are developed in over 100 offices of the DoD whose addresses are listed in the Standardization Directory, SD-1, which is available from the standardization Document Order Desk, 700 Robbins Avenue, Building 4D, Philadelphia, Pennsylvania 19111-5094.

Military and federal specifications, standards, and handbooks, commercial item descriptions, and adopted nongovernment standards are listed in the DoD Index of Specifications and Standards. Copies of these documents are available from the DoD Single stock Point, IHS, Global, and various other private distributors and libraries. 
Keywords

DEPARTMENT OF ENERGY

Authority

Implementation

Application

Adoption of Nongovernment standards military equipment; industrial equipment; consumer products; materials; parts; food; clothing; packaging; construction; building; aerospace; medical devices; communications; general; defense;

\section{BUILDING TECHNOLOGIES}

Building Appliance Division

Room 1J-018

Washington, DC 20585

(202) 586-0517

42 U.S.C. 6291-6309, the Energy Policy and Conservation Act of 1975 (P.L. 94-163), as amended by the National Energy Conservation Policy Act of 1978 (P.L. 95-619), the National Appliance Energy Conservation Act of 1987 (P.L. 100-12) and the National Appliance Energy Conservation Amendments of 1988 (P.L. 100-357), provides for implementation of energy efficiency test procedures and standards for at least 13 categories of major household appliances.

Test procedures have been established for 13 categories of appliances in 10 CFR Part 430, subpart B. The 13 categories of appliances are: refrigerators, refrigerator-freezers, and freezers; furnaces; central air conditioners and central air conditioning heat pumps; room air conditioners; water heaters; dishwashers; clothes washers; clothes dryers; direct heating equipment; pool heaters; kitchen ranges and ovens; television sets; and fluorescent lamp ballasts. Standards have been established, by legislation, for 12 of the 13 categories of appliances in 10 CFR Part 430, subpart C.

The established test procedures are required, under regulations issued by the Federal Trade Commission (FTC), to be used by manufacturers in the preparation of labels and other representations concerning the energy efficiency of covered products. In addition, the manufacturers certification of compliance with a standards is to be based on manufacturers testing of covered products in accordance with the applicable test procedure. Selective government test may be performed for enforcement purposes.

The established test procedures adopt, by reference, some nongovernment test procedures; including, but not limited to, procedures established by ANSI, ASHRAE, ASTM, and the Association of Home Appliance Manufacturers (AHAM). 
Qualification, Certification, or Calibration

Committee Activity

Standardization Activities

Availability

Keywords

DEPARTMENT OF ENERGY
Consumer product manufacturers are responsible for the application of the established test procedures, although FTC or DOE may perform independent tests to verify manufacturers claims.

The appropriate staff of DOE and The National Institute of standards and Technology (NIST) participate in several relevant committees of ASHRAE and the Air-Conditioning and Refrigeration Institute (ARI).

DOE, with the support of the NIST, is active in the preparation, review, and updating of energy efficiency test procedures for all 13 covered appliances. In addition, DOE in accordance with the law, reviews the standards on a regular basis to determine if updates are justified. With respect to the test procedures, every effort is made to utilize private consensus standards, if appropriate. Federal energy efficiency standards preempt state-established energy efficiency standards. States may apply to DOE for exemptions from this rule.

DOE and U.S. Government Printing Office

energy conservation; energy efficiency; household appliances; buildings; consumer products; energy;

\section{BUILDING TECHNOLOGIES}

Building Division, Office of codes and standards Room $1 \mathrm{~J}-018$

Washington, DC 20585

(202) 586-0517

Title III of the Energy Conservation and Production Act, as amended (42 U.D.C. 6831 et seq.) sets forth four major provisions. First, states are required to consider whether to update the energy efficiency provisions of their residential building codes to meet or exceed the Model Energy Code, 1992 and subsequent revisions to such standard that the secretary makes a determination will improve the energy efficiency of residential buildings. Second, states are required to update provisions of their residential buildings and commercial building codes to meet or exceed the building industry consensus standard 90.1-1989 and 
Implementation

Application

Adoption of Nongovernment Standards

Committee Activity subsequent revisions to such standard that the secretary makes a determination will improve the energy efficiency of commercial buildings. Third, states are required to certify to the secretary that they have accomplished the above actions (extensions are provided for). Fourth, technical assistance and incentive funding are to be provided to the states by the Department to implement the above requirements and to promote building energy efficiency through the use of such codes.

Regarding, federal building energy efficiency standards, the Department is to promulgate standards that meet or exceed the Model Energy code, 1992, in the case of residential buildings, or Standard 90.1-1989, in the case of residential buildings, or standard 90.1-1989, in the case of commercial buildings, and to the extent practicable, use the same format as the appropriate voluntary building energy code. Periodic review and updating is provided for. The existing interim standards are to remain in effect until the new standards become effective. Federal agencies are responsible for implementation and expenditure for construction is dependant on meeting or exceeding the federal standards.

Regarding support for voluntary building energy codes, the Department is required to support the upgrading of the Voluntary building energy codes (such as the Model Energy Code or Standard 90.1) and to participate in the processes for their review and modification.

A draft notice of proposed rulemaking has been prepared for federal commercial and multi-family high rise buildings and is expected to be issued in 1996. A draft notice of proposed rulemaking has been prepared for federal residential low rise buildings and is expected to be issued in 1996.

The head of each federal agency and the Architect of the Capitol are required to adopt procedures necessary to ensure that new federal buildings meet or exceed the federal building energy standards. The head of a federal agency may expend federal funds for the construction of a new federal building only if the building meets or exceeds the appropriate federal building energy standards.

The federal standards reference building industry standards developed by ANSI, ARI, ASTM, ASHRAE, CTI, IES, NEMA, and UL.

DOE staff participate in several relevant committees of ASHRAE, AIA, and IES. 


\section{standardization Activities}

\section{Availability}

Keywords

DEPARTMENT OF ENERGY

Authority

Implementation

Application
DOE staff participate in ASHRAE standing standards

project Committees 90.1 and 90.2; the CABO Model Energy Committee and one and Two Family Dwelling Code Committee; the Building Officials and Code Administrators International (BOCA) National Mechanical and Building Code Activities; the Southern Building Code Congress International (SBCCI) standard Building Code Committee; the International Conference of Building Officials (ICBO) Uniform Mechanical and Building Code Committees; and the emerging International Code Council (ICC) Committees.

Federal codes and standards indicated above are promulgated in the Code of Federal Regulations published by the office of the Federal Register, National Archives and Records Administration. They are also available from the Department.

buildings; energy conservation; energy efficiency; energy;

DEFENSE PROGRAMS, ASSISTANT SECRETARY

DOE, DP-13.1

Washington, DC 20545

(301) $353-3169$

(1) The Atomic Energy Act of 1954

(2) Energy Reorganization Act of 1974

(3) Department of Energy (DOE) Reorganization Act of 1977

The implementation of standards activities for Defense Programs is through the policy statement of the Assistant secretary for Defense Programs (ASDP) dated May 28, 1982, and the individual implementation plans prepared by the DOE field organizations. Responsible program officials also involve the use of standards noted under qualification, certification, or calibration.

Standards are developed and used to support technologies and applications unique to DOE particularly in the Department's defense-related processing and production facilities. Current activities include development of standards for qualifying backup power sources prior to their use in DOE facilities, performing accident analysis of an aircraft crash into a DOE hazardous facility, and preparing safety evaluation reports on the review of DOE nonreactor nuclear facility safety analysis reports. 
standards Qualification, or Calibration

Standardization Activities

Availability

Keywords
DOE-STD-1003-94, Backup Power Sources for DOE Facilities, is a standard that identifies fundamental

criteria, surveillance testing, reporting, and reliability program considerations, which if properly implemented, should improve and maintain capable and reliable backup and emergency power sources (i.e., diesel generators, uninterruptible power supplies, and stationary batteries).

DOE-HDBK-1084-95, DIE Primer on Lead-Acid Storage Batteries, is a handbook that complements the above standard that was prepared and reviewed by the DOE Backup Power Working Group and promulgated by the DOE Office of Environment, Safety and Health. This working group plans to update the handbook in 1996.

Two DOE Specifications for use in purchasing stationary battery systems for use at typical DOE facilities are in a final comment coordination process.

The draft standard for accident analysis of aircraft crashes into DOE hazardous facilities will provide a uniform methodology, input parameter, and major assumptions as well as guidance for consequence calculations and approaches for predicting structural response. This standard will afford the user sufficient information to evaluate and assess the significance of aircraft crash risk on facility safety.

The draft standard entitled Guideline for Review and Approval of Nonreactor Nuclear Facility Safety Analysis Reports will provide the process by which safety analysis reports in DOE should be reviewed and details on the format and content of the safety evaluation report that documents the review and approval process.

The DOE Backup Power Working Group meets twice annually to review best practices and lessons learned, discuss related industry standards, attend training and other presentation sessions, and tour representative backup power sources at DOE sites. The knowledge and experience of the group is documented and disseminated in the form of DOE standards, handbooks, and specifications. Membership includes representatives from most DOE site M\&Os, some DOE HQ, and some DOE field offices.

The above referenced standards were developed and are maintained internal to the Department.

backup power sources; lead-acid storage batteries; uninterruptible power supplies; stationary batteries; accident analysis; aircraft crash; consequence calculation; structural response; nonreactor nuclear facility; safety analysis report; safety evaluation report; 
Office of statistical standards (EI-70)

1000 Independence Avenue, SW

Washington, DC 20585-0670

(202) 426-1068

e-mail: ybishop@eia.doe.gov

WWW : eia.doe.gov

\section{Authority}

\section{Implementation}

\section{Application}

Committee

Activity

Standardization Activities
Both the Federal Energy Administration Act and the Department of Energy Organization Act, which established the Energy Information Administration (EIA) as an independent statistical agency, require that the information collected by the agency be evaluated and assessed internally and that the collection methods used be audited. (See P.L. 93-275 and 95-91).

To evaluate the data and procedures used to collect, process and publish the data, performance standards are needed. A standards program has existed since EIA's inception; however, in 1981 it was reorganized, resulting in the adoption of 19 standards and two orders on model documentation and model archiving.

Standards implementation is monitored by the office of statistical standards (OSS) through the various activities of the office, including the forms clearance process, pre-publication reviews, state-of-the-data reports, quality audits, and documentation reviews of data collection and processing systems.

oss monitors order implementation through reviews of the documentation and model archival packages prior to release, and quality audits.

Oss participates in pertinent committees of the office of Management and Budget (OMB), the American statistical Association, and other statistical organizations.

Thirty standards have been developed covering various aspects of data collection, data processing, forecasting, and dissemination. They are divided into the following groups: models interagency, data systems, data collection, and data presentation. specific standards cover: model acceptances, documentation, and archival; the adoption of Federal Information Processing and OMB standards; standardized codes, abbreviations, and acronyms; contract clauses for data collection and processing; data systems development and documentation; nonresponse handling; respondent contact records; batch entry procedures; edit message handling; 
Availability

Keywords

DEPARTMENT OF ENERGY

Authority

Implementation

Application survey performance statistics; publication of energy statistics, revisions and estimates; data accuracy; graphs; nondisclosure; rounding ; freezing data files; and documentation of public use tapes and diskettes.

These mandatory standards are intended to ensure the quality and consistency of EIA's data and models, increase the efficiency and responsiveness to EIA's data users, and avoid duplication of effort.

These standards will be modified and new ones developed as conditions warrant. The primary focus is on ensuring compliance with the existing standards and providing technical assistance to offices requesting it.

Energy Information Administration, Office of Statistical standards (address above)

statistics; data collection; data processing; data documentation; model documentation; data publication; model forecasting; energy; model acceptance, documentation, archival;

ENVIRONMENT, SAFETY, AND HEALTH

Safety and Quality Assurance

Rm 7A-097

1000 Independence Avenue, SW

Washington, DC 20585

(202) $586-4710$

(1) Atomic Energy Act of 1954, as amended

(2) Energy Reorganization Act of 1974

(3) Department of Energy Organization Act of 1977

Prescribed and recommended Environment, Safety, and Health (ES\&H) standards (approximately 300) are listed in Order DOE 5480.4, Attachments 1,2 and 3 .

Department of Energy (DOE) Headquarters ES\&H program personnel appraise DOE field operations and contractors to evaluate conformance with the prescribed ES\&H standards. DOE field operations personnel also evaluate DOE contractors to ascertain compliance with the standards. As appropriate, recommendations for improved conformance are made and ameliorative actions are implemented. 
Adoption of Nongovernment standards

\author{
Committee \\ Activity \\ standardization \\ Activities
}

Availability

Keywords

DEPARTMENT OF ENERGY
Approximately 65 nongovernment ES\&H standards have been adopted as prescribed standards and approximately 135 nongovernment ES\&H standards have been adopted as recommended standards. These are primarily from ANSI, NFPA, IEEE, and ANS.

American National Standards Institute, American Nuclear Society, and National Fire Protection Association

Adoption of appropriate voluntary standards for use in DOE activities.

U.S. Department of Energy

office of Worker Health and Safety

$\mathrm{EH}-53 / 270 \mathrm{CC}$

19901 Germantown Road

Germantown, MD 20874

environment; safety; health; nuclear; occupational; emergency; fire; transportation; reactor; explosives; energy;

TECHNICAL STANDARDS PROGRAM OFFICE

DOE, EN-31

19901 Germantown Road

Germantown, Maryland 20874

(301) 903-2856

FAX : (301) $903-8693$

e-mail: richard.serbu@hg.doe.gov

WWW: http://apollo.osti.gov/html/techstds/techstds.html

(1) Atomic Energy Act of 1954, as amended

(2) Energy Reorganization Act of 1974

(3) Department of Energy Organization Act of 1977

DOE Order 1300.2A provides for a coordinated DOE-wide standardization program for the development and application of standards; participation in nongovernment standards bodies; and effective management to promote consistent standards application, avoid duplication, share information, and enhance standards availability. DOE has developed 58 technical standards for its unique applications and 34 handbooks to record lessons learned. These are listed in the DOE Standards Index, DOE-TSI-1. 
Adoption of Nongovernment standards

Committee

Activity

standardization Activities

Availability
The focus of DOE's Technical Standards Program is adherence to appropriate nongovernment standards in the design, construction, testing, modification, operation, decommissioning, decontamination, and remediation of DOE's facilities and activities. Standards proven through years of experience and accepted by professional and technical societies are used wherever applicable. No matter how carefully conceived and properly developed, technical standards cannot address all eventualities, therefore, DOE employees and contractors critically assess the standards in use at DOE facilities to ensure that they remain consistent with the latest information arising from operational experience and developments in science and technology. Where standards do not exist or where existing standards do no suffice, appropriate DOE standards are developed and adopted.

DOE has adopted more than 800 nongovernment standards. These are listed in the DOE Standards Index, DOE-TSL-I.

More than 800 DOE and contractor personnel participate in the standardization activities of more than 4000 committees of 64 nongovernment standards organizations.

Development and adoption of technical standards is vested in DOE Field offices. Standards Managers working through Preparing Activities, Adoption Activities, and standing committees of technical experts apply, develop, and maintain the standardization program in their technical areas of responsibility. Overall management and guidance is provided by the DOE Technical Standards Management Committee.

Copies of DOE standards, handbooks, specifications, and technical standards lists (TSLS) are available for DOE employees, DOE contractors, and laboratories from:

Office of Scientific and Technical Information (OSTI)

P.O. BOX 62

Oak Ridge, Tennessee 37831

(423) 576-8401

FAX (423) $576-2865$

Others may obtain copies of these documents from National Technical Information Service, Information Handling Services, and Global.

The TSLS, many DOE standards, and the monthly DOE publication Standards Actions are available on-line at the WWW site listed above. 
products; equipment; processes; materials; systems; construction; maintenance testing; operation; decommissioning; nuclear; safety; environment;

\section{ENVIRONMENTAL PROTECTION AGENCY}

ADMINISTRATOR

401 M Street, SW

Washington, DC 20460
(202) 260-2897
FAX: (202) 260-1847

Authority

Implementation

Application
(1) Clean Air Act, P.L. 88-206

(2) Clean water Act, P.L. 92-500

(3) Comprehensive Environmental Response Compensation and Liability Act (CERCLA), P.L. 96-510

(4) Federal Food, Drug and Cosmetic Act, stat. 1040

(5) Federal Insecticide, Fungicide and Rodenticide Act (FIFRA)， P.I. 92-516

(6) Marine Protection, Research and Sanctuaries Act, P.L. $92-532$

(7) Resource Conservation and Recovery Act (RCRA), P.L. $94-580$

(8) Safe Drinking Water Act, P.L. 93-523

(9) Toxic Substances Control Act (TSCA), P.L. 94-469

(10) Uranium Mill Tailings Radiation Control Act, P.L. 95-604

(11) Plus amendments thereto and other acts not listed

(12) National Environmental Policy Act, (P.L. 91-190)

(13) Noise Control Act, (P.L. 92-574)

(14) Medical Waste Tracking Act, (P.L. 100-582)

(15) Asbestos Hazard Emergency Response Act, (P.I. 99519)

(16) Asbestos Information Act, (P.L. 100-577)

(17) Asbestos School Hazard Abatement Act, (P.L. 98377)

(18) Indoor Radon Abatement Act, (P.L. 100-551)

Environmental Protection Agency (EPA) standards are published in Part 40 of the Code of Federal Regulations ( 40 CFR). Some standards are mandatory, others voluntary. State and local governments usually have the right to impose standards that are more stringent than those EPA sets.

Standards are applied in various ways including individual permits establishing emissions or effluent limits, product registration, state and local implementation plans, direct reporting to EPA, recordkeeping, on-site inspections, voluntary adoption, etc. 
Adoption of Nongovernment standards

Qualification, Certification, or Calibration

Committee Activity

Standardization Activities
$40 \mathrm{CFR}$ refers readers to nongovernmental standards it accepts in lieu of incorporating the standards in the CFR.

EPA samples products and the environment for compliance with its standards. Examples include monitoring motor vehicle emissions, wastewater discharges, new chemicals and pesticides, land fills, ambient air, and drinking water systems. The Agency also reviews manufacturers' requests to label products as "certified to EPA standards."

Advisory Commission on Intergovernmental Relations;

Council on Environmental Quality; Interagency Testing Committee (ITC);

National Air pollution Control Techniques Advisory Committee;

National Drinking Water Advisory Council;

Environmental Committee of the Organization for Economic

Cooperation and Development;

Science Advisory Board;

U.S. Canada International Joint Commission (on air and water); Stratospheric Ozone Protection Advisory Committee;

Volatile Organic Chemical Equipment Leak Rule Negotiated Rule

Making Committee;

Biotechnology Science Advisory Committee;

FIFRA Scientific Advisory Panel;

EPA environmental standards apply to individuals;

businesses; federal, state and local governments; and other organizations. They are intended to ensure clean air and water, safe containment of toxic wastes, protection from excessive radiation, protection of the Nation's waters for fish/wildlife and human use, undue exposure to toxic substances, etc. The following offices are directly involved in standards development and application: Office of Air Radiation, (202)382-7400; Office of Pesticides and Toxic substances, (202)382-2902; Office of Research and Development, (202)382-7676; Office of solid Waste and Emergency Response, (202)382-4610; Office of Water, (202)382-5700. These offices exercise responsibility for standards dealing with water quality, solid and hazardous wastes, pesticides and toxic substances, ambient air, research and development practices, and radiation. The Administrative Procedures Act mandates publication of proposed rules (standards) followed by public comment/ hearings prior to promulgating the rule. Usually, once a standard is set, states and other jurisdictions must submit, by a certain date, implementation plans for meeting these standards or face the alternative of having EPA write and impose its own plan. 
Part 40 of the Code of Federal Regulations, available from the Government Printing office, contains all Agency standards; EPA also publishes both the standards and resulting implementation plans in the Federal Register.

Keywords

environment; air; water; radiation; pollution; toxic substances; hazardous waste; pesticides; chemicals; materials; sanitation;

EXECUTIVE OFFICE OF THE PRESIDENT

OFFICE OF THE U.S. TRADE REPRESENTATIVE

Office of World Trade Organization (WTO) and Multilateral Affairs Room 513

600 Seventeenth Street, NW Washington, DC 20508

(202) 395-3063

FAX: (202) 395-3911

Authority

Implementation

Application

Adoption of Nongovernment standards
Title IV of the Trade Agreements Act of 1979 (P.L. 96-39, July 26, 1979) and the Uruguay Round Agreements Act (PL 103-465) on approval of the Agreements on Technical Barriers to Trade and on the Application of Sanitary and Phytosanitary Measures which sets forth disciplines on standards related activities. USTR does not itself develop standards, test methods or rules of certification.

Through the Trade Policy Committee structure, chaired by the Office of the U.S. Trade Representative (USTR), U.S. Government coordination of the implementation and administration of the WTO Agreements on Technical Barriers to trade and on the application of Sanitary and Phytosanitary measures is achieved. USTR works primarily with the Departments of Agriculture, Commerce, and state in this area.

The U.S. Trade Policy Staff Committee (TPSC) Subcommittee on Standards meets regularly to approve U.S. positions for meetings of the WTO Committees on Technical Barriers to Trade and Sanitary and Phytosanitary Measures. The TPSC also approves positions for bilateral standards related discussions with governments which are WTO signatories.

USTR coordinates with the private sector through an extensive advisory committee structure including, in particular, the Industry Functional Advisory Committee on standards (IFAC 2). The Trade Policy staff Committee (TPSC) Subcommittee on standards is the primary vehicle for coordination of trade policy within the U.S. government. 
Qualification, Certification, or Calibration

Committee

Activity

Keywords

FEDERAL COMMUNICATIONS

Authority

Implementation

Application

Adoption of Nongovernment Standards
USTR coordinates closely with nongovernmental bodies directly and through IFAC 2 .

USTR directly participates in the Board of the American National standards Institute and its International Advisory Committee.

international trade; business; general; WTO; TBT; phytosanitary; sanitary; standards code;

\section{COMMISSION}

OFFICE OF ENGINEERING AND TECHNOLOGY

2000 M street, NW

Suite 480

Washington, DC 20554

(202) 418-2470 FAX: (202) 418-1944

e-mail: rmsmith@fcc.gov

The Communications Act of 1934, as amended (47 U.S.C. 151) established the Federal Communications Commission (FCC) for the purpose of regulating interstate and foreign commerce in communications by wire and radio in the public interest.

The FCC Rules and Regulations are contained in Title 47 Code of Federal Regulations. Relevant standards are located throughout the various rule parts 0 to end. Information on proposed and adopted standards is published in the Federal Register in Notices of Inquiry, Notices of Proposed Rule Making, Report and Orders, and Memorandum Opinion and Orders.

Standards are applied to a wide variety of communications equipment and services. Because there are many different types of standards throughout the FCC rules, various methods are used to enforce the rules or standards. The methods used are: on-site inspections, FCC laboratory testing, review of test data submitted by applicants, and self verification.

The Commission has adopted nongovernment standards and will continue to do so whenever it is in the public interest. These standards are referenced in the appropriate parts of the rules, and in many cases voluntary standards become mandatory standards when referenced in the Rules and Regulations. 
Qualification, certification, or Calibration

Committee

Activity

Standardization

Activities

Availability

Keywords
Applicants wishing to establish a radio station, whether it be broadcast, private, common carrier, or experimental, must submit information showing compliance with FCC Rules. If the requirements (standards) are met, a license is issued. The Commission has issued in excess of 3 million radio licenses. The Commission also has equipment authorization programs and issues approximately 6000 equipment approvals each year.

The Commission participates in pertinent organizations and committees which deal with telecommunications standards. Some of these are: Institute of Electrical and Electronics Engineers, American National Standards Institute, Telecommunications Industry Association, Intelligent Transportation Society of America, International Telecommunication Union, International Special Committee on Radio Interference, Radio Technical Commission for Aeronautics, Radio Technical Commission for Maritime Services, Inter-American Telecommunication Commission, National Marine Electronics Association, Allied Radio Frequency Association, International Maritime Organization, etc.

The Commission participates in international and national standards organizations developing communication systems and equipment. The Commission provides technical analysis and testing of systems and equipment.

Title 47 of the Code of Federal Regulations available from the U.S. Government Printing office.

frequency allocations; radio frequency interference; electromagnetic compatibility; communications; 
Federal Trade Commission Act, S5, 15 U.S.C. S45. Section 5 of the Federal Trade Commission Act declares unfair methods of

competition, and unfair or deceptive acts and practices, in or affecting commerce, to be unlawful.

Adoption of Nongovernment standards

Standardization

Activities

Keywords
In preventing unfair or deceptive acts or practices in commerce, the Federal Trade Commission (FTC) may reference standards in trade regulation rules or guides. For example, the Commission incorporated several nongovernment standards by reference in its rule relating to labeling and advertising of home insulation (R-value rule, 16 CFR, part 460).

The Commission's Bureau of Competition (BC) and Bureau of Consumer Protection (BCP) investigate standards and certification activities that may unreasonably result in a substantial lessening of competition in violation of the Federal Trade Commission Act. One example would be allegations that a standard or a seal of approval program unreasonably excluded innovative products from the marketplace. They would also investigate aliegations that standards or seals of approval are being used deceptively in the sale of products. If the Commission finds reason to believe that the law may have been violated, it may commence a law enforcement action to enjoin such anticompetitive or deceptive activities and to seek such other relief as may be appropriate. The Commission may, under appropriate circumstances: issue advisory opinions as to the legality of standards or certification practices presented for review; participate in relevant interagency or intergovernmental committees; present its views to appropriate legislative, judicial, or industry entities concerning specific standards or certification issues.

antitrust; restraint of trade; anti-competitive practices; competition; unfair methods; innovation; deception; business; general;

GENERAL SERVICES ADMINISTRATION

INFORMATION RESOURCES MANAGEMENT

18th and $F$ Streets, NW

Washington, DC 20405

(202) 566-1180

Authority

1. Public Law 89-306: The Brooks Act

2. Public Law 99-500: The Paperwork Reduction

Reauthorization Act of 1986 
Application

Committee

Activity

Standardization

Activity

Availability

Keywords
The Federal Information Resources Management Regulation (FIRMR) establishes Federal Standards provisions and requirements for the acquisition of ADP and telecommunications resources. The Federal $A D P$ and Telecommunications Standards Index provides terminology to incorporate standards in solicitation documents. It also provides a catalogue of all American National Standards (ANSI), Federal Information Processing Standards (FIPS), and Federal Standards (FED-STD) .

Federal acquisition of $\mathrm{ADP}$ and Telecommunications resources must be in compliance with established Federal Standards provisions of the FIRMR.

The GSA is an active voting member of the $\mathrm{X} 3$ : Information Processing System; ANSI: Standards Committee T1, Telecommunications; Federal Telecommunications Standards Committee; and ANSI Information systems standards Board.

The GSA serves as a focal point for the Government-wide Federal Information Processing and Telecommunications Standards Program. GSA participates directly in the development of federal standards, and develops terminology to incorporate standards in solicitation documents for acquisition and use of $A D P$ and telecommunications resources. GSA provides advice and assistance to federal agencies and private sector personnel on information systems and telecommunications standards.

The Federal ADP and Telecommunications Standards Index is sold by the Government Printing Office.

information processing; telecommunications; terminology;

\section{GENERAL SERVICES ADMINISTRATION}

NATIONAL ARCHIVES AND RECORDS ADMINISTRATION

Policy and IRM Services (PIRM)

Room 4200

8601 Adelphi Road

College Park, MD 20740

(301) 713-6400 FAX: (301) 713-6497

44 U.S.C. 2101 et seq., April 1, 1985, the Archivist of the United States shall provide for the preservation of federal records of continuing value. As provided in 44 U.S.C. chapters 29 and 33, the Archivist of the United States is authorized to establish standards for "the selective retention of records of continuing value" and for the "reproduction of records by photographic or microphotographic processes." 
Standards for managing records of different media are codified in National Archives and Records Administration (NARA) regulations as follows: microfilm records, 36 CFR, Part 1230, subpart C; audiovisual records, 36 CFR, Part 1232; and electronic records, 36 CFR, Part 1234, Subpart C.

Application

Adoption of Nongovernment standards

Qualification, Certification, or Calibration

Committee

Activity

Standardization Activities
NARA requires agencies to produce and maintain microfilm, audiovisual, and electronic records according to production and maintenance standards.

NARA has adopted standards for microfilm and audiovisual records promulgated by the American National Standards Institute (ANSI), International Organization for Standards (ISO), Association for Information and Image Management (AIIM), and the National Fire Protection Association (NFPA).

Agencies are to certify that the permanent microfilm and audiovisual records they produce meet ANSI/AIIM standards and that storage facilities for audiovisual records meet NFPA standards.

NARA participates in the following pertinent standards setting organizations: American Society for Testing and Materials (ASTM) Committee on Binding Adhesives; ASTM Committee D- 6 on Recycled Paper; ANSI/AIIM Committees 20 and 21; Audio Engineering Society Subcommittee (SC) 3 on Audio Preservation and Restoration; ANSI/National Association of Photographic Manufacturers (NAPM) Image Technology (IT) standards Committee 9; ANSI/NAPM IT9-1 Subcommittee on stability of Wet-Processed Silver Images; ANSI/NAPM IT9-2 Subcommittee on stability of Photographic Prints; ANSI/NAPM IT9-2 Subcommittee on storage of Plates, ANSI/NAPM IT9-3 Subcommittee on stability of Colored Images; ANSI/NAPM IT9-5 Subcommittee on stability of Optical and Electronic Media; and NFPA Technical Committee on Records Protection.

In recent years, NARA staff members have participated in the development of voluntary standards, either as members of standards setting committees or as reviewers of drafts of various standards. NARA has adopted five of these voluntary standards: ANSI/NAPM IT9.16-1993, Imaging Media-Photographic Activity Test; ANSI/NAPM IT 9.17-1993, ISO 417, Photography-Determination of Residual Thiosulfate and Other Related Chemicals in Processed Photographic Materials-Methods Using Iodine-Amylose, Methylene Blue, and Silver sulfide. ANSI/NAPM IT9.19-1994, Imaging Media (Film), Thermally Processed silver Microfilm - specifications for Stability; ANSI/NISO/z 39.62-1994, Eye Legible Information on Microfilm Leaders and Trailers and on Containers of Processed Microfilm on Open Reels; and ANSI/AIIM/MS 45-1990, Recommended Practice for Inspection of stored Silver Gelatin Microfilms for Evidence of Deterioration. 
Availability

Keywords

NARA has also prepared guidance for federal agencies regarding the use of Compact Disc-Read Only Memory ( $C D-R O M)$ and optical disk systems to store federal records. The guidance states that CD-ROM files that will be transferred to NARA as permanent records should be in conformance with ISO 9660 standards and the American Standard Code for Information Interchange (ASCII) standard as defined in the Federal Information Processing standard 1-2 (11/14/84). NARA has also revised its regulations on audiovisual records management to include citations to ANSI/ISO and NFPA standards for storage conditions.

NARA's regulations, which may be found in 36 CFR, chapter 12, and which cite NARA's use of voluntary standards, are available from the superintendent of Documents.

permanent records; archives; preservation; micro-graphics; photography; audiovisual records; electronic records; optical disk; magnetic tape; film; paper; data; data exchange;

\section{GENERAL SERVICES ADMINISTRATION}

OFFICE OF ACQUISITION

FSS Acquisition Management Center

Crystal Mall, Building 4

Washington, DC 20406

(703) 305-6930 FAX: (703) 305-6851

Authority

The Federal Standardization Program was developed in compliance with the Federal Property and Administrative Services Act of 1949, 63 STAT. 377, as amended. The program provides for coordination of civil and military standardization functions, so as to avoid unnecessary duplication, pursuant to the Act and in consonance with the Defense Cataloging and Standardization Act (Secs. 24512456, Title 10, U.S.C., superseding P.L. 436).

Implementation

41 CFR 101-29 describes the standardization program under Federal Product Descriptions. The FSS is responsible for 550 Federal Specifications, 35 Federal Standards, and 1450 Commercial Item Descriptions. More than 800 nongovernment standards have been adopted. 
Application

Adoption of Nongovernment Standards

Qualification, Certification, or Calibration

Committee

Activity

Standardization

Activities

Availability
Federal product descriptions shall be used by all federal agencies in the procurement of supplies and services covered by such descriptions, except as provided in 41 CFR 101-29.402 and 41 CFR $101-29.403$.

The General Services Administration has adopted more than 800 nongovernment standards. The majority of these are invoked by reference in the federal specifications, federal standards and commercial item descriptions authored by GSA.

The General Services Administration (GSA) Office of Quality and Contract Administration handles the inspection and testing, as necessary, of supplies procured under GSA contracts. Through the five regional control divisions and the one regional laboratory, this program provides assurance that material supplied is in compliance with contract specifications.

GSA employees participate in a number of standards developing bodies. These organizations include committees of ANSI, ASTM, and SAE.

GSA is responsible for establishing policies and procedures, in coordination with other agencies, for the preparation, coordination, approval, issuance, and maintenance of product descriptions in the federal series.

FSS issues and maintains, on a current status, the Federal standardization Manual. The Manual sets forth operating procedures and applicable definitions used in the development of federal product descriptions.

FSS also promulgates and maintains, on current status, the Index of Federal specifications, Standards, and Commercial Item Descriptions. The Index lists federal product descriptions which have been printed and distributed, including those which are mandatory for use by all federal agencies and identifies the sources from which these documents may be obtained. There are approximately 10000 federal product descriptions in use, of which 75 percent have been assigned to other agencies.

General Services Administration, Federal Supply Service Bureau, Specification Section, suite 8100,470 L'Enfant Plaza, SW, Washington, DC, 20407. 

cial item descriptions; qualified products lists; nongovernment documents; general;

\section{GENERAL SERVICES ADMINISTRATION}

Authority

Implementation

Application

Adoption of Nongovernment standards

Committee Activities

Standardization Activities
PUBLIC BUILDING SERVICE

Eighteenth \& F Streets, NW Room 7313

Washington, DC 20405 (202) 501-0191

The Architectural Barriers Act of August 12, 1968, (Public Law 90480, 1976 amendment, Public Law 94-541)

The General services Administration is required as one of the four standard setting agencies, to "prescribe standards for the design construction, and alteration of buildings lother than residential structures subject to this Act and buildings, structures, and facilities of the Department of Defense and of the United states Postal service subject to this Act) to ensure whenever possible that physically disabled persons will have ready access to, and use of, such buildings.

The General Services Administration, (GSA) issued PBS, PCD, Design Guide 6, GSA Accessibility standard, on October 14, 1980. GSA and the Department of Housing and Urban Development, the Department of Defense, and the United States Postal service jointly published the Uniform Federal Accessibility Standards on August 7, 1984 which sets standards to ensure that certain buildings financed with Federal Funds are so designed and constructed as to be accessible to the physically handicapped.

After passage of the Architectural Barriers Act, GSA adopted "Specifications for Making Building and Facilities Accessible to, and Usable by, the Physically Handicapped" ANSI/CABO A117.1.

GSA is a member of the Architectural and Transportation Barriers Compliance Board and the Council of American Building Officials Committee on Accessability, 1331 F Street, Suite 1000, washington, DC 20004-1111, (202) 272-5434

GSA develops, publishes and updates accessibility standards to ensure that all building designs, constructed, altered, increased by an addition, or leased with federal funds are accessible and usable by disabled individuals. The Administrator also has the authority to waive or modify those standards on a case-by-case basis. 

charge from GSA or the Architectural and Transportation Barriers Compliance Board.

Keywords

building; construction; general; social welfare; access; physically disabled;

HEALTH AND HUMAN SERVICES

CENTER FOR DISEASE CONTROL

National Institute for Occupational Safety and Health Hubert $H$. Humphrey Building 200 Independence Avenue, SW Washington, DC 20201

(202) 401-6997

Authority

Implementation
(1)

29 U.S.C. 651-678, December 29, 1970, Occupational Safety and Health Act (OSH Act), to assure safe and healthful conditions of working men and women; by authorizing enforcement of standards developed under the OSH Act; and for other purposes.

(2) 30 U.S.C. 801, 811, 842 (h), December 30, 1969, Federal Coal Mine Health and Safety Act of 1969, as amended by the Federal Mine Safety and Health Act of 1977, to protect the health and safety of miners.

Recommended Occupational Safety and Health Standards -- developed by the National Institute for Occupational Safety and Health (NIOSH) Division of Education and Development, 4676 Columbia Parkway, Cincinnati, ohio 45202, telephone (513) 684-8302. Approximately 125 nonmandatory standards have been developed in the form of criteria documents dealing with control of toxic substances in the workplace. These criteria documents are submitted by NIOSH as recommendations to the Department of Labor (DOL) for use in the development of mandatory standards by DOL's Occupational Safety and Health Administration and DOL's Mine Safety and Health Administration.

Performance Standard for Respirators -- developed by NIOSH's Division of Safety Research, Testing, and Certification Branch, 944 Chestnut Ridge Road, Morgantown, West Virginia 26505, telephone (504) 923-4595. A mandatory standard under 30 CFR, Part 11 establishes a performance standard and the procedures for testing and certifying personal protective respiratory equipment. 


\section{Application}

Qualification, Certification or Calibration

standardization Activities

Keywords
The Department of Labor is responsible for the promulgation and enforcement of occupational health and safety standards.

NIOSH's Division of Safety Research's Testing and Certification Branch is responsible for testing and certifying personal respiratory protective equipment based upon applications submitted by the manufacturers of such equipment.

NIOSH employees actively participate in voluntary standard development activities of ANSI, ASTM, and American Conference of Governmental Industrial Hygienists (ACGIH).

respiratory protective equipment; toxic substances; workplace standards; safety; public health;

HEALTH AND HUMAN SERVICES

FOOD AND DRUG ADMINISTRATION

Office of Policy HF-23

5600 Fishers Lane

Rockville, Maryland 20857

(301) 827-3344

Authority

Federal Food, Drug, and Cosmetic Act, as amended (21 U.S.C. 321-392)

Public Health Service Act, as amended (42 U.S.C. 262, 263, 263b-263n, and 361), (42 U.S.C. 264 and 13951)

Fair Packaging and Labeling Act (15 U.S.C. 1451-1461)

Federal Import Milk Act (P.L. 69-625)

Tea Importation Act (21 U.S.C. 41-50)

Federal Caustic Poison Act (Note: Section 19 of the Federal Hazardous Substances Act (15 U.S.C. 401) repealed the Federal Caustic Poison Act except for any "dangerous caustic or corrosive substance" as defined by the Federal Caustic Poison Act which is subject to the Federal Food, Drug, and Cosmetic Act and not a "hazardous substance" under the Federal Hazardous Substances Act.) 
Orphan Drug Act (P.L. 97-414)

Drug Price Competition and Patent Term Restoration Act (P.L. 98417)

Drug Exports Amendments Act of 1986 (P.L. 99-660)

Prescription Drug Marketing Act of 1987 (P.L. 100-293)

Anti-Drug Abuse Act of 1988 (P.L. 100-690)

Saccharin study \& Labeling Act

Federal Anti-Tampering Act

The Food and Drug Administration (FDA) Center for Food safety and Applied Nutrition, 200 C street SW., Washington DC 20204, (202) 205-4850, is responsible for:

Color Additives -- Regulations under 21 CFR, Parts 73, 74, and 82 prescribe identity, specifications, and other conditions under which color additives may be safely used in food, drugs, cosmetics, and devices.

Food Additives -- Regulations under 21 CFR, Parts 172-179 prescribe identity, specifications, and other conditions under which food additives may be safely used.

GRAS Substances -- Regulations under 21 CFR, Parts 184 and 186 prescribe identity, specifications, and other conditions under which substances are generally recognized as safe (GRAS) as ingredients added directly or indirectly to human food.

Food Standards -- Regulations under 21 CFR, Parts 131 through 169 prescribe standards of identity, quality, and fill of container for 21 different classes of foods. Most of these are standards of identity which specify the basic composition of the food.

Other Food Regulations - - A number of other miscellaneous mandatory regulations concerning food for human consumption appear under 21 CFR, Subchapters A, B, and L (e.g., general labeling requirements under subpart B of $21 \mathrm{CFR}$, part 1; 
food labeling under 21 CFR, Part 101; 21 CFR Part 104

Nutritional Quality Guidelines for Food; quality standards for foods with no standards of identity under 21 CFR, Part 103; infant formula quality control procedures under 21 CFR, Part 105; Foods for Special Dietary Uses under 21 CFR, Part 105; regulations under the Federal Import Milk Act (21 CFR, Part 1210); and Interstate Conveyance Sanitation (21 CFR, Part 1250); Emergency Permit Control under 21 CFR, Part 108; Unavoidable Contaminants in Foods under $21 \mathrm{CFR}$, Part 110; Good manufacturing Practices in Human Food under 21 CFR, Part 110; Thermally Processed Low-acid foods under 21 CFR, Part 113; Acidified foods under 21 CFR, Part 114; Processing and Bottling of Bottles Drinking Water under 21 CFR, Part 129.

- Cosmetic Regulations -- Regulations under 21 CFR, Parts 701 and 740 prescribe standards for cosmetic labeling.

- Federal Caustic Poison Act -- Regulations under 21 CFR, Part 1230 prescribe labeling requirements, methods of analysis, and other conditions for enforcement of the Federal Caustic Poison Act.

FDA's Center for Drug Evaluation and Research, 1451 Rockville Pike, Rockville, Maryland 20852, (301) 594-6740 and Center for Biologics Evaluation and Research, 1401 Rockville Pike, Rockville, Maryland 20852, (301) 827-0372, develop standards and regulations for:

Biological Products Applicable to the Prevention, Treatment or Cure of Diseases or Injuries of Man --In addition to the regulations at $21 \mathrm{CFR}$ subchapter $\mathrm{C}$ and $\mathrm{D}$ that apply to all products, including biological products, that are applicable to the prevention, treatment or cure of diseases or injuries of man (drug products), mandatory regulations for biological products exist at Subchapter F.

Insulin and Antibiotics -- Regulations under 21 CFR, Parts 429-460 prescribe standards, tests, and methods of assay for insulin and antibiotic drugs. In the near future many of these regulations are expected to be eliminated.

Over-the-Counter (OTC) Drugs -- 21 CFR, Parts 331, 332, 333, $336,338,340,341,344,349$ and 357 prescribe specifications and conditions under which therapeutic categories of OTC drugs are generally recognized as safe and effective. Regulations under 21 CFR Part 310 describe conditions under which certain therapeutic categories of OTC drugs are not generally recognized as safe and effective. 
- Biological Product -- Regulations appear under 21 CFR, Subchapter $\mathrm{F}$ concerning labeling, standards, testing, and other conditions under which bacterial and viral vaccines, toxoids, antitoxins, blood, and blood derivatives, allergenic products, and other biological products can be safely used.

- Control of Communicable Diseases -- Regulations under 21 CFR, Part 1240 concern control of communicable diseases.

FDA's Center for Devices and Radiological Health, Office of Science and Technology, 2094 Gaither Road, Rockville, Maryland 20850, (301) 594-4765, prepares:

Procedures for Performance standards Development -Regulations under $21 \mathrm{CFR}$, Part 861 prescribe the procedures for initiation, development, establishment, amendment, and revocation of performance standards applicable to devices intended for human use.

Device Classification Procedures -- Regulations under 21 CFR, Part 860 prescribe the criteria and procedures governing the classification and reclassification of devices intended for human use into one or more of three regulatory classes: class I (general controls), class II (special controls), and class III (premarket approval).

Device Classification Regulations -- FDA is developing mandatory regulations to classify all medical devices intended for human use into one or more of these three classes depending upon the regulatory controls needed to provide reasonable assurance of their safety and effectiveness. Device classification regulations appear under 21 CFR, Parts 864-892.

Other Device Regulations -- A number of other miscellaneous mandatory device regulations appear under 21 CFR, subchapter $\mathrm{H}$ (e.g., general labeling requirements under 21 CFR, Part 801; exemptions from federal preemption of state and local medical device requirements under $21 \mathrm{CFR}$, Part 808; in vitro diagnostic products for human use under 21 CFR, part 809; investigational device exemptions under 21 CFR, part 812 ; and investigational exemptions for interocular lenses under 21 CFR, Part 813).

Performance Standards for Ionizing Radiation Emitting Products -- Regulations under 21 CFR, Part 1020 prescribe standards to control the emission of radiation from microwave ovens. 
- Performance Standards for Light Emitting Products -Regulations under 21 CFR, Part 1040 prescribe standards to control the emission of radiation from lasers, sunlamps, and other light-emitting products.

- Performance Standards for Sonic, Infrasonic, and Ultrasonic Radiation-Emitting Products - - Regulation under 21 CFR, Part 1050 prescribes standards to control the emission of radiation for ultrasonic therapy products.

- Other Radiological Health Regulations -- A number of other mandatory and nonmandatory regulations appear under 21 CFR, Subchapter J (e.g., general provisions and radiation protection recommendations under 21 CFR, Part 1000; importation of electronic products under 21 CFR, Part 1005; performance standards for electronic products: general under 21 CFR, Part 1010).

FDA's Center for Veterinary Medicine, 7500 Standish Place, Rockville, Maryland 20855, (301) 594-1830, is responsible for:

- Food Additives Permitted in Feed and Drinking Water of Animals -- Approximately 55 mandatory regulations under 21 CFR, Part 573 prescribe identity, specifications, and other conditions under which food additives may be solely used in feed and drinking water of animals.

- New Animal Drugs -- Approximately 650 mandatory regulations under 21 CFR, Parts 520-530 and 558 prescribe identity, specifications, testing, and other conditions for safe use of new animal drugs.

- Other Animal Drugs, Feeds, and Related Products Regulations -- A number of other miscellaneous mandatory regulations concerning animal drugs, feeds, and related products appear under 21 CFR, Subchapter E (e.g., animal food labeling under 21 CFR, Part 501; and tolerances for residues of new animal drugs in food under 21 CFR, Part 556).

To determine that FDA-regulated products are in compliance with statutes, FDA conducts inspections of manufacturing establishments, collects and analyzes domestic samples and import samples, and conducts wharf examinations of products in import channels of trade. Samples collected are analyzed at FDA field and headquarters laboratories. 
Adoption of Nongovernment standards

Qualification, Certification, or Calibration

Committee Activity

standardization Activities
FDA has adopted more than 300 nongovernment standards. The majority of these are ASTM, Association of Official Analytical Chemists (AOAC), Food Chemicals Codex, and American Public Health Association. In addition to these nongovernment standards, 21 U.S.C. $352(\mathrm{~b})$ and $352(\mathrm{~g})$ mandate that FDA use standards in an "official compendium" such as the United States Pharmacopeia.

Color additives (unless the color is specifically exempted) and insulin are batch-certified by FDA prior

to marketing. Many biological products are required by regulation to be tested by FDA prior to release of each lot of product. Well-characterized biological products, once licensed and their manufacturing process validated, are not subject to lot-by-lot release by FDA. With few exceptions (e.g., foods, cosmetics), most FDA-regulated products are subject to preclearance by FDA before they may be marketed.

More than 270 FDA staff members participate with 29 standards organizations in more than 270 standardization activities. For example:

ANSI (13 committees, 16 subcommittees)

ASTM (5 committees, 52 subcommittees)

AAMI (27 committees, 11 subcommittees)

ASME (1 committee, 3 subcommittees)

USP ( 6 subcommittees)

NCCLS (10 committees, 24 subcommittees)

American College of Radiology ( 6 committees)

IEEE (4 committees, 7 subcommittees)

Acoustical Society of America (2 committees)

IEC (4 technical committees, 23 subcommittees)

ISO ( 7 technical committees, 13 subcommittees)

NCCLS (11 committees, 34 subcommittees)

International Organization for Legal Metrology (OIML), U.S.

Technical Advisory Group for SP26

Codex Alimentarius (FAO/WHO) (16 committees)

The broad scope of FDA's involvement in standardization activities is reflected by the programmatic CFR listings above under Implementation and the partial listing under committee Activities. Since May 27, 1975, FDA has regulated and encouraged participation of its employees in outside standard setting activities (the current regulation appears under 21 CFR 10.95). It is FDA policy to use and cite in its regulations nongovernment standards whenever possible and consistent with FDA's statutory mandates to protect the public health. 
Availability

Reywords

HEALTH AND HUMAN SERVICES

Authority

Implementation

Application

Committee

Activity

Standardization

Activities

Availability

Reywords
FDA regulations are published in the Code of Federal Regulations available from the Government Printing office. Each FDA regulation that incorporates by reference test methods or other materials also lists the complete address from which copies may be obtained.

food; food additives; color additives; cosmetics; human drugs; animal drugs; biologics; medical devices; radiation protection; electronic product radiation; safety; public health; consumer products;

\section{HEALTH CARE FINANCING ADMINISTRATION}

7500 Security Boulevard

Baltimore, Maryland 21244-1850

(410) $786-6810$

Titles XVIII and XIX of the Social Security Act.

42 CFR, Chapter 4, Subchapters A through E. Regulations addressing the survey and certification of health care facilities wishing to participate in the Medicare and Medicaid programs.

State survey agencies and Health Care Financing Administration (HCFA) regional offices apply procedures set forth in these regulations in determining a facility's eligibility for certification and in making certification decisions.

HCFA works closely with Association of state and Territorial Health Officials, Association of Health Facility Survey Agencies, and various consumer and industry groups in developing its standards.

HCFA standards apply to the survey and certification of all health care facilities wishing to participate in the Medicare and/or Medicaid programs. Having standard procedures assures national uniformity in approving facilities for Medicare/Medicaid reimbursement.

Standards are available from the Government Printing office and Health Care Financing Administration's Office of Public Affairs.

Medicare; Medicaid; survey and certification; health care providers and suppliers; state survey agencies; health care; facilities management; insurance; 
DEPARTMENT OF HOUSING AND URBAN DEVELOPMENT

ASSISTANT SECRETARY FOR HOUSING - FEDERAL HOUSING COMMISSIONER

Manufactured Housing and Construction Standards Division

451 Seventh street, SW, Room B-133

Washington, DC 20410-8000

(202) 755-7440 FAX: (202) 755-0303

Authority

(1) Minimum Property Standards (MPS) - Sec. 7 (d) of the Department of Housing and Urban Development Act of 1965, 79 stat. $670 ; 42$ U.S.C. 3535 (d); Sec. 211, 52 stat. 23; 12 U.S.C. $1715 \mathrm{~b}$ and 81 stat. $54 ; 5$ U.S.C. $522(\mathrm{a})$.

(2) Technical Suitability of Products Program - Sec. 521 of the National Housing Act was added by Sec. 216 of the Housing and Urban Development Act of 1965, Public Law 89-117.

(3) Manufactured Housing - Section 7(d), Department of Housing and Urban Development Act, 42 U.S.C. 3535(d), Title VI, Housing and Community Development Act of 1974 (42 U.S.C. 5401 ).

Implementation

All standards are codified as regulations and are mandatory. The MPS, which include as supplements product acceptance under Sec. 521 and the Department of Housing and Urban Development (HUD) Building Products Certification Programs, are incorporated by reference in 24 CFR, Part 200 subpart S, Sections 200.925, $200.927,200.929,200.931,200.933,200.935$ with an Appendix. Manufactured Home Construction and Safety standards are in 24 CFR Parts 3280,3282 and 3283 .

Application

Design drawings are reviewed for compliance, and inspectors visit site development and manufacturing facilities for construction or manufacturing compliance. The MPS are only applicable for HUD mortgage or loan insurance and low-rent public housing programs. The Manufactured Home standards are applicable for all manufacture homes which are designed to be used as dwelling units.

Adoption of Nongovernment standards
Nongovernment standards are invoked by reference or adoption whenever possible. There are approximately 500 nongovernment standards referenced in the Minimum Property Standards and supplemental standards issued under the Technical Suitability of Products Program. The Manufactured Housing Program Standards contain 200 nongovernment standards. Principal 
Qualification, Certification, or Calibration

Committee

Activity

Standardization Activities

developers of these standards include the American Society for Testing and Materials (ASTM), American National Standards Institute (ANSI), American Concrete Institute (ACI), American Plywood Association (APA), American Society of Heating, Refrigerating and Air Conditioning Engineers (ASHRAE), and Architectural Aluminum Manufacturers Association (AAMA).

Proponents of new building products or systems submit technical data for analysis under the Technical Suitability of Products Program. Upon a determination of suitability, a Materials Release is issued for products and a Structural Engineering Bulletin for building systems. These documents supplement the MPS, and include these products for national acceptance. Use of Materials Bulletins are issued either as an interim HUD standard for a particular class of like products, such as carpet, or as a means of promulgating a certification program for a product. There are currently Engineering Bulletins, Materials Releases, Use of Materials Bulletins, and 13 Certification Programs in effect.

Under the Manufactured Housing Program all designs, quality assurance manuals, product certifications and listings are approved by design approval agencies, accepted by HUD. All manufactured homes are inspected by in-plant inspection agencies for conformance to the approved design, and federal standards. Average yearly production of manufactured homes is 250000 homes.

HUD encourages industry enforcement and self certification for those materials covered by product standards and Federal

Specifications. It also requires third party certification in conformance with criteria set out in 24 CFR 200.935 for lumber, plywood, carpet, windows, plastic bathtubs, etc.

HUD staff participate in pertinent committees that include the following: ASTM, National Conference of states on Building Codes and standards (NCSBCS), ACI, American Lumber Standards Committee (ALSC), ANSI, ASHRAE, National Academy of Sciences, and National Institute of Building Sciences (NIBS).

The Manufactured Housing and Construction Standards Division writes, updates, revises, and clarifies construction and design standards for HUD-associated residential construction. This activity grew out of the National Housing Act of 1934 and Sec. 7 (d) Department of Housing and Urban Development Act, 42 U.S.C. 3535 (d), Title VI, Housing and Community Development Act of 1974. The Code of Federal Regulations reference is Title 24 Housing and Urban Development. 
Availability

Keywords
The Minimum Property Requirements established the minimum essentials for a property to be considered economically sound security for Federal Housing Administration (FHA) mortgage insurance purposes. They establish and describe those characteristics of a property which will produce continuing utility, livability, durability, marketability, economy of maintenance, safety and healthy environment.

In 1974 the National Mobile Home Construction and Safety Standards Act was enacted by Congress to reduce the number of personal injuries and deaths and the amount of insurance costs and property damage resulting from mobile home accidents and to improve the quality and durability of mobile homes. All mobile manufactured housing built since June 15, 1976 must be in compliance with the requirements of this Act. The standards cover all equipment and installations in the design, construction, fire safety, plumbing, heating, ventilating, and electrical systems of manufactured homes which are designed to be used as dwelling units.

Minimum Property standards are available through HUD field offices. The Manufactured Housing standards are available from HUD, Manufactured Housing and Construction Standards Division at the address above.

manufactured homes; mobile homes; certification; residential; mortgage insurance; building; sanitation; safety; standards; construction;

\section{INTERDEPARTMENTAL SCREW THREAD COMMITTEE (Defunct)}

Replaced by

DEFENSE INDUSTRIAL SUPPLY CENTER

ATTN : DISC-ECF

700 Robbins Avenue

Philadelphia, Pennsylvania 19111

(215) 697-2735

The Defense Industrial Supply Center (DISC) replaced the Interdepartmental screw Thread Committee (ISTC) as preparing activity for the Screw Thread standards for Federal services in 1976. Following this transfer, the National Bureau of Standards Handbook H28, which consisted of 3 volumes of screw thread standards, was converted to a basic cover document, FED-STD-H28, and individually issued sections FED-STD-H28/1, FED-STD-H28/2, ... FED-STD-H28/22. Each section is coordinated with Military Activities, Federal Agencies, and industry associations prior to approval by the General Services Administration. 
DISC works closely with the American National Standards Institute (ANSI) Accredited Committee Bl of the American Society of Mechanical Engineers (ASME) which produces the inch and metric screw thread standards for general use by industry. ANSI/ASME B1 and other industry standards are incorporated into equivalent sections of FED-STD-H28 rather than duplicating industry standards as had been the practice in the old Handbook H28.

fasteners; metric; manufacturing;

\section{DEPARTMENT OF THE INTERIOR}

\section{MINERALS MANAGEMENT SERVICE}

Offshore Rules and Operations Division, Branch of Rules, Orders, and Standards

381 Elden Street

Mail stop 646

Herndon, Virginia 22070

(703) $860-7564$

\section{Authority}

Implementation

Application
The Outer Continental Shelf Lands Act, 43 U.S.C. 1331 et seq., provides for the jurisdiction of the United States over the submerged lands of the Outer Continental Shelf (OCS), authorizes the secretary of the Interior to lease such lands for the development and production of oil and gas, provides for the establishment and enforcement of safety regulations for oil and gas operations, and provides for environmental studies directed towards minimizing the impact of such operations.

Approximately 200 mandatory requirements are codified as regulations in $30 \mathrm{CFR}$, Parts 250, 251, 252, 256, 280, 281, and 282. These regulations are for OCS minerals operations, geological and geophysical explorations, an information program, and for the management of pipeline rights-of-way. The regulations are supplemented by OCS Orders for each of the four OCS Regions.

Inspectors visit offshore operators on the OCS to see that safety requirements are followed. Minerals Management service (MMS) personnel review required reports from lessees to ensure that drilling and production personnel are properly trained, prepared to implement safety contingencies, and that all produced oil gas is properly measured and royalties paid. 
Adoption of

Nongovernment

Standards

Committee

Activity

Standardization

Activities

Availability

Keywords
The MMS currently incorporates by reference 65 nongovernment standards. The majority of these standards were developed by the American Petroleum Institute and the American Society for Testing and Materials.

The MMS participates in pertinent committees of the American Society of Mechanical Engineers, American Petroleum Institute, American Welding Society, American Society of Civil Engineers, American Concrete Institute, American Society for Quality Control, and the American Bureau of Shipping.

The MMS participates in the preparation of the full range of engineering material and operational standards concerning offshore drilling and production of minerals. These standards are used internationally.

MMS Regulations and OCS Orders are sold by Government Printing office and MMS.

offshore minerals exploration; continental shelf; offshore platforms; energy; safety;

DEPARTMENT OF THE INTERIOR

FEDERAL GEOGRAPHIC DATA COMMITTEE

FGDC Secretariat

590 National Center

12201 Sunrise Valley Drive

Reston, Virginia 22092

(703) 648-5752

FAX: (703) 648-5755

Authority

Implementation Activities

Application
Executive Order 12906, calling for the establishment of the National spatial Data Infrastructure (NSDI), requires federal agencies to adhere to applicable FGDC standards when collecting geospatial data, in accordance with responsibilities assigned in OMB Circular No. A-16.

FGDC Subcommittees and Working Groups, charged with coordinating the NDSI by Executive Order 12906, develop standards to support the coordinated development, use, sharing, and dissemination of geospatial data on a national basis.

2 standards, SDTS and Metadata, have been adopted by the FGDC I standard, SDTS, has been adopted as a Federal Information Processing standard (FIPS).

other standards may be submitted for adoption as FIPS, ANSI or ISO standards. 
standardization Activities

Availability

Reywords

DEPARTMENT OF THE INTERIOR
The FGDC has approximately 300 members that participate on subcommittees and working groups. A subset of these members plus additional nonmembers participate in standards development activities. The FGDC Subcommittees and Working Groups review existing standards, propose new or modified standards, and develop, test, and devise implementation strategies for standards. Developed standards relate to the content, classification, documentation, quality, transfer, and collection of geospatial data. They foster the sharing and multi-purpose use of data, avoid wasteful duplication of effort, and promote effective and economical management of our Nations geographic information resources. Standards are developed in cooperation with federal, state, local, and tribal governments, the private and academic sectors, and the international community.

Published and draft standards are available from FGDC at the address above.

National Spatial Data Infrastructure; bathymetric; cadastral; cultural; demographic; geodetic; geologic; transportation; boundaries; soils; vegetation; water; wetlands; hydrography; geospatial; metadata; SDTS;
Authority

Implementation

Application

\section{U.S. GEOLOGICAI SURVEY}

Information Systems Division

Office of Data Administration

806 National Center

Reston, Virginia 22092

(703) $860-6086$

43 U.S.C. 31, March 3, 1879 (USGS Organic Act), establishes the Geological survey basic mission.

A Memorandum of Understanding with the National Institute of standards and Technology (NIST) dated February 1980 gives the U.S. Geological survey (USGS) key agency responsibility for federal digital data standards in the earth sciences (geology, hydrology, cartography, geography).

The USGS Data Standards Committee decides on applicable standards and their priority and establishes work groups to draft such standards, has them reviewed, and forwards them to NIST as proposed Federal Information Processing standards (FIPS). 
Adoption of Nongovernment standards

Committee

Activity

Standardization

Activities

Availability

Keywords
The USGS works with various professional organizations in the development of pertinent standards and uses them as much as possible. The organizations include: the American Public Health Association, American Water Works Association; Water Pollution Control Federation; American Association of Petroleum Geologists; American Society for Testing and Materials; Association of Official Analytical Chemists; Instrument Society of America; International Organization for Standardization; International Electrotechnical Commission; American Commission on stratigraphic Nomenclature.

The USGS participates in pertinent committees of ANSI, ISO, and the U.S. Geographic Names Committee.

A long-term program has been established to develop pertinent standards for data elements and their representation (name, definition, units of measure, digital coding methodology) in the earth sciences. After acceptance by the USGS and Department of the Interior, each standard is published as a USGS circular and sent to NIST as a proposed FIPS. Certain standards proposed as a FIPS are also introduced into the ANSI processes as proposed national standards. The USGS recommends that established standards be used in all new and developing systems. All existing data systems should be modified in accordance with the standards at such time that future redesign or modification to the systems take place. To date, two standards have been accepted at USGS and proposed as FIPS: Codes for the Identification of Hydrologic Units in the United States and the Caribbean Outlying Areas, Geological Survey Circular 878-A, and Specifications for Representation of Geographic Point Locations for Information Interchange, Geological Survey Circular 878-B.

USGS Public Inquiries Offices; the USGS Branch of Distribution, 604 South Pickett Street, Alexandria, Virginia 22304; the USGS Data Administrator.

earth sciences; geology; hydrology; cartography; topography; geography; data processing; 


\section{Authority \\ Implementation}

Application

Committee

Activity

Standardization Activities
U.S. GEOLOGICAL SURVEY

National Mapping Division

office of Technical Management

510 National Center

Reston, Virginia 22092

(703) 648-4566

43 U.S.C. 31, March 3, 1879 (USGS Organic Act)

Memorandum of Understanding, signed February 1980 by the National Institute of Standards and Technology (NIST) and U.S. Geological Survey (USGS), assign to the USGS key agency responsibility for developing and maintaining earth-science data element and representation standards for use in the federal establishment. The National Mapping Division (NMD) develops and maintains digital cartographic data standards which are promulgated by issuance of Technical Instructions when approved for use within the USGS, and by publication as a Federal Information Processing Standard (FIPS) by NIST when approved for use throughout the federal establishment.

Use is mandatory (within the USGS or the federal establishment, depending upon level of approval) for all new and developing systems that utilize data elements and representations described by the standard. All existing data systems will be modified in accordance with the standards when redesign and modifications to the system take place.

The NMD participates in the Federal Interagency Coordinating Committee on Digital Cartography (FICCDC) standards Working Group which is charged with coordinating and promoting activities for exchanging digital spatial data among federal agencies.

The USGS has taken the leadership role in the development of the Spatial Data Transfer standard (SDTS) that will be submitted to NIST for adoption as a FIPS. The SDTS has been produced to meet the need for easy transfer of spatial data from one spatial data handling system to another. It is being promoted throughout the federal community by FICCDC, and once approved as a FIPS, will be used by the federal government to distribute spatial data.

In addition to supporting the development of data exchange standards, the NMD has assembled and published Technical Instructions, including product standards and data users guides that have been developed to govern the collection, archiving, and distribution of USGS digital cartographic data. 
Availability

Keywords
USGS Technical Instructions are available from the Earth science Information Center, U.S. Geological Survey, 507 National Center, Reston, Virginia 22092, phone (703) 860-6045.

cartography; geography; digital spatial data; spatial data transfer standard; data processing; SDTS;

DEPARTMENT OF THE INTERIOR

Authority

Implementation

Application

Adoption of Nongovernment standards
U.S . GEOLOGICAL SURVEY

Water Resources Division

417 National Center

Reston, Virginia 22092

$1-800-426-9000$

WWW: http://WwW. usgs.gov

43 U.S.C. 31, March 3, 1879 (UsGS Organic Act)

U.S. Geological Survey (USGS) guideline documents for the collection and analysis of surface-water, ground-water, and water quality data include:

USGS Bulletin 17B, Guidelines for Determining Flood Flow FrequenCy; USGS Water Supply Paper No. 2175, Measurement and Computation of streamflow: Volume 1. Measurement of stages and Discharge; USGS Circular 878-A, Codes for the Identification of Hydrologic Units in the United states and the Caribbean Outlying Areas; USGS Water Supply Paper 2294, Hydrologic Unit Maps; USGS Techniques of Water-resources Investigation; and National Handbook of Recommended Methods for Water-Data Acquisition.

Standards are voluntarily adopted by the Water Resources Division (WRD). All WRD offices and laboratories are reviewed on a scheduled basis and all quality assurance programs must reference the standards.

Numerous nongovernment standards have been adopted by WRD. There is strong support for the development and use of consensus standards related to water resources data collection and analysis as developed by the International organization for Standardization (ISO), the American Society for Testing and Materials (ASTM), and other groups. 
Committee Activity

\section{Standardization} Activity

\section{Availability}

Reywords
WRD participates in pertinent committees of the following: Interagency Advisory Committee on Water Data, Coordinating Committees of U.S. Geological Survey (USGS) with each of the following federal agencies: National Oceanic and Atmospheric Administration; Bureau of Land Management; and Environmental Protection Agency; and committees for the American Water Resources Association, National Water Well Association, American Society of Civil Engineers, American Public Health Association, ASTM, ISO, and the World Meteorological Organization (WMO) .

The USGS, as part of its implementation of OMB Circular M-92-01, has designated the Office of Water Data Coordination (OWDC) within WRD to identify methods used to acquire water data and to recommend methods for use by federal agencies. The OWDC accomplishes this with the advice and guidance of the IACWD. As of 1989, the IACWD, through OWDC, has published 10 chapters of the National Handbook of Recommended Methods for Water-Data Acquisition. The chapters include recommended methods on: 1 . Surface Water, 2. Groundwater, 3. Sediment, 4. Biological and Microbiological Quality of Water, 5. Chemical and Physical Quality of Water, 6. Soil Water, 7. Drainage-Basin Characteristics, 8. Evaporation and Transpiration, 9. Snow and Ice, 10. Hydrometeorological Observations. Subcommittees of the IACWD periodically review and update the chapters.

WRD is cooperating with EPA, the Navy, and ASTM to accelerate the development of consensus standards for ground-water data collection, reporting, and analysis. WRD also develops standards, methods, and guidelines in the field of hydrology where no standards exist, to assure the reproducibility of analytical results and to give quality assurance to the programs and studies within WRD. WRD participates in the U.S. Geological Survey's interagency Data Standards Committee that identifies standards used within the agency.

Government Printing office, and USGS Water Information Center (1$800-426-9000)$.

hydrology; surface water; ground water; water quality; data processing; public health; 
NATIONAL INSTITUTE OF JUSTICE

Technology Assessment Program

see DEPARTMENT OF COMMERCE

NATIONAL INSTITUTE OF STANDARDS AND TECHNOLOGY

Electronics and Electrical Engineering Laboratory

office of Law Enforcement Standards
DEPARTMENT OF LABOR

Authority

Implementation

Application

Adoption of Nongovernment standards
MINE SAFETY AND HEALTH ADMINISTRATION

Office of Standards, Regulations, and Variances

4015 Wilson Boulevard, Room 627, BT \#3

Arlington, Virginia 22203

(703) 235-1910 FAX: (703) 235-5551

e-mail: psiley@msha.gov

WWW: http://Www.msha.gov

30 U.S.C. 811, November 9, 1977, The Mine Safety and Health Act of 1977, to provide for the health and safety of workers in the mining industry.

Several hundred safety and health regulations are codified in 30 CFR, Chapter I. These requirements include specifications for obtaining approval of certain equipment used in mines, required work practices, and maximum exposure levels to hazardous substances.

Federal inspectors visit mine sites to see that the health and safety standards are followed, and the standards are also applied through voluntary compliance. The standards also establish procedures and requirements for application within the Mine Safety and Health Administration (MSHA). MSHA also tests for approval and certification of certain products for use in potentially explosive underground mine atmospheres.

Whenever practicable MSHA adopts nongovernment standards. The majority of these standards have been developed by the American Conference of Governmental Industrial Hygienists (ACGIH), the American National standards Institute (ANSI), the American Society of Mechanical Engineers (ASME), the National Fire Protection Association (NFPA), and the Society of Automotive Engineers (SAE). 
Qualification, Certification, or Calibration

\section{Committee}

Activity

\section{Standardization Activities}

\section{Availability}

Keywords

DEPARTMENT OF LABOR

Authority

Implementation
Manufacturers of certain equipment for use in underground mines with potentially explosive atmospheres must submit their equipment to MSHA for approval and certification.

MSHA has technical experts who participate on committees of the following: American National standards Institute; American Conference of Governmental Industrial Hygienists; Institute of Electrical and Electronics Engineers; and National Fire Protection Association.

MSHA's standards are directed at improving the occupational safety and health of workers in the mining industry. These standards concern safe work practices, maximum exposure levels to hazardous substandard or potentially harmful conditions, and performance criteria for the design of certain types of mining equipment.

Sold by Government Printing office. Also available on OSHA-MSHA CD-ROM from the Government Printing office and on-line through the Department of Labor bulletin board, and through a loose-leaf service offered by the Bureau of National Affairs, the Mine safety and Health Reporter. Copies of specific standards may also be obtained directly from MSHA.

coal mining; metal and nonmetal mining; underground mines; surface mines; equipment approval for gassy mines; energy; industrial equipment; health care; safety; testing;

\section{OCCUPATIONAL SAFETY AND HEALTH ADMINISTRATION}

Directorate of Safety Standards Programs, N 3605 200 Constitution Avenue NW. Washington, DC 20210
(202) 219-8063
FAX : (202) $219-7477$

Occupational Safety and Health Act of 1970, PL 91-596

29 CFR Part 1910 -- Occupational Safety \& Health Standards for General Industry; 29 CFR Part 1915 -- Occupational Safety \& Health Standards for Shipyard Employments;

29 CFR Part 1917-1918 -- Occupational Safety \& Health Standards for Marine Terminals; Longshoring;

29 CFR Part 1926 -- Construction Safety \& Health Standards;

29 CFR Part 1928 -- Occupational Safety \& Health Standards for Agricultural Employments. 
Application

Adoption of Nongovernment standards

Qualification, Certification, or Calibration

Committee

Activity

Standardization Activities

Inspection of the workplace

American National standards Institute (ANSI)

National Fire Protection Association (NFPA)

Throughout the OSHA standards, there are requirements for certain equipment to be listed, labeled, or approved by nationally recognized testing laboratories.

National Advisory Committee on Occupational Safety and Health Standards Advisory Committee on Construction Safety and Health

American National Standards Institute

National Fire Protection Association

American Society for Testing and Materials

International Labor Organization

The Occupational Safety and Health Administration(OSHA)

develops and enforces occupational safety and health standards to provide protection to the nation's workers on their job. The standards are directed at the various hazards in which workers may be exposed. The purpose of the act is "to assure so far as possible every working man and woman in the nation safe and healthful working conditions and to preserve our human resources." OSHA adopted its initial standards on May 29, 1971 and they consisted of national consensus standards and the federal standards that were already in effect under other Department of Labor administered laws.

OSHA develops and promulgates occupational safety and health standards and issues regulations necessary for assuring compliance with its standards and regulations. The Directorates of Safety Standards Programs and Health Standards Programs have the main responsibility in carrying out these functions. When either of the Directorates determines a need, on the basis of information submitted by interested parties, scientific data from the field, or experience gained under other health and safety laws, the appropriate Directorate will develop new standards, revoke or modify existing standards using one of two procedures available. All regular proposals to promulgate, modify, or revoke an occupational Safety and Health standard using the $6(\mathrm{~b})$ procedure must be published in accordance with Administration Procedures Act (APA) requirements in the Federal Register to afford interested parties an opportunity to comment before the standard becomes effective or is revoked. A temporary emergency standards procedure $\left(6^{\circ}\right.$ procedure) may be used to promulgate standards where the APA procedures are waived. Such a temporary emergency standard must be replaced by a 6 (b) standard within 6 months. 


\section{Availability}

Keywords

LIBRARY OF CONGRESS

In developing new standards or modifying standards, the Directorates of Safety or Health Standards determine whether there is a need for the establishment of a standards advisory committee to assist them in the standards setting function. Once it is determined there is a need for a committee, one is appointed which consists of 5 to 15 members and is composed of representatives of management, labor, state and federal governments and the public. Advisory committee meetings are opened to the public and a transcript is made available for public review.

OSHA standards are contained in Title 29 of the Code of Federal Regulations: (1) General Industry, Part 1910, (2) Maritime, Parts 1915, 1917, and 1918, (3) Construction, Part 1926, and (4) Agriculture, Part 1928.

Publications Office, OSHA, and Government Printing Office

safety; health; environment; electrical equipment; manufacturing; construction; shipyards; agriculture; machinery; business; emergency response;

\section{COLLECTIONS SERVICES}

Washington, DC 20540

(202) 707-5325

Authority

Collection Services (by authority of the Library of Congress Regulation) has as its mission to develop qualitatively the Library's universal collections, which document the history and further the creativity of the American people, and which record and contribute to the advancement of civilizations and knowledge throughout the world; to acquire, organize, provide access to, maintain, secure, and preserve these collections. In achieving this mission, Collections services takes part in the development and implementation of standards governing its technical services activities.

Collections services voluntarily follows OMB Circular A-119 which specifies the use of voluntary standards developed outside the government and participation in the development of voluntary standards as required for office missions. 
Adoption of

Non-Government

standards
The Library of Congress has adopted and applied the following guidelines and publications:

Dewey Decimal Classification: The Library of Congress Decimal Classification Division and Forest Press have agreed to develop and apply the Dewey Decimal Classification at the Library of Congress. The Dewey Decimal Classification schedule is applied on over 100000 catalog records per year at the Library of Congress. sixty thousand sets of the unabridged classification have been sold over the life of the edition (currently the 20th, 1989). Librarians choose to use Library of Congress catalog records or apply the schedule themselves (primarily in public and school libraries).

Anglo-American Cataloging Rules: The standard for descriptive cataloging is developed by the international committee representing national libraries (including the Library of congress for the United states) and the national library associations of Australia, Britain, Canada, and the United States

Library of Congress Rule Interpretations: The second editions (1989) provides a cumulation of all currently valid Library of Congress rule interpretations issued since the Anglo-American Cataloging Rules was published in 1978.

International standard Bibliographic Description: The standard for the part of descriptive cataloging called bibliographic description is developed by the International Federation of Library Associations and Institutions (IFLA), of which the Library of congress is a member. It includes a variety of standard numbers, such as International standard Book Number (ISBN), International standard serial Number (ISSN), etc.

Paris Principles: The quasi-standard for that part of descriptive cataloging called access points, it is a set of guidelines adopted by the International conference on Cataloging Principles held in Paris in 1961.

Library of Congress subject Headings: The twelfth edition (1989) and monthly updates are developed by the subject cataloging Division in Collections services. It includes over 175000 authorized subject headings and subdivisions which are accepted as a library standard of "keywords."

Subject Cataloging Manual: Subject Headings: The third edition (1988) provides guidelines for cataloging as practiced by the subject Cataloging Division of the Library of Congress and explains the rationale for assigning subject headings to specific works. 
Subject Cataloging Manual: Shelflisting: Published in 1987, the manual functions as a practical source for shelflisters and catalogers who wish to create call numbers in the spirit of Library of Congress policy and practice. It also describes the procedures to follow when assigning Cutters.

Library of Congress classification schedules: The 45 separate schedules and updates give an authorized classification scheme for the arrangement of library materials by field of study. The Library of Congress system is used primarily by all university libraries, by some college and junior college libraries, and by some public libraries.

Library of Congress Filing Rules: The rules were developed by the Library of Congress to arrange bibliographic records (or catalog cards) in a basic alphabetical arrangement incorporating logic for application in computer files.

Standards developed by American National Standards Committees Z39, Libraries, Information Science, and Publishing, and X3, Information Processing.

Standards developed by International Organization for standardization (ISO), Technical Committee (TC) 46, Documentation, and TC 97, Computer Information Processing.

The Library of Congress together with the American Library Association develops romanization systems for the major non-Roman alphabet languages. The tables have become the de facto standard of the North American library community.

MARC Formats: The Library of Congress is instrumental in the development of MARC (machine-readable cataloging) formats, which have been adopted as national and international standards. The MARC formats incorporate standards, such as cataloging rules and principles. The formats also include de facto standards for content designators.

Computer Protocols: Assist in establishing library and information community usage profiles. organizations responsible for the guidelines and publications listed above including: 
(1) Subject Analysis Committee, Resources and Technical

Services Division (RTSD), American Library Association (ALA)

(2) Committee on Cataloging: Description and Access, RTSD, ALA

(3) Forest Press Committee

(4) Decimal Classification Editorial Policy Committee

(5) Joint Steering Committee for Revision of Anglo-American Cataloging Rules

(6) NISO, X3, ISO/TC 46, and various related committees and councils

(7) National Institute of Standards and Technology

(8) International Serials Data system (ISDS), including its Governing Board and Directors

(9) Serials Industry Systems Advisory Committee (SISAC)

(10) Book Industry Systems Advisory Committee (BISAC)

(11) Machine-Readable Form of Bibliographic Information Committee (MARBI)

(12) International Federation of Library Associations and Institutions (IFLA)

(13) Linked System Project (LSP) Committees

Standardization Activities
The Library of Congress:

- has principal responsibility for the development of standards for the interchange of bibliographic records (including the format of the data in those records, coded data such as language and country codes, character sets, and works with others on communication protocols);

- acts as the maintenance agency in the United states for the International standard Serial Number standard and cooperates with the maintenance agency in the United States in the use of accurate International Standard Book Numbers;

acts as maintenance agency for information retrieval protocol; 
Availability

Keywords

\section{LIBRARY OF CONGRESS}

is active in developing standards for data in bibliographic records, such as holding statements for serial publications;

formulates official Library of Congress interpretations of cataloging rules; and

- distributes products of standardized cataloging and bibliographic activities in these formats:

catalog cards, MARC tapes, book catalogs, sound recordings, microfiche, and CD-ROMs.

Many of the publications listed above are available from the Library of Congress' Cataloging Distribution Service.

Manual on the Use of the Dewey Decimal Classification: Edition 20 and related publications are sold by Forest Press, 85 Watervliet Avenue, Albany, N.Y.

The Anglo-American Cataloging Rules, 2nd edition are sold by the American Library Association.

Other standards are available from their developers.

Dewey Decimal Classification; library classification; classification; libraries; cataloging; subject headings; thesaurus; language codes; Anglo-American Cataloging Rules; bibliographic control; MARC tapes; catalog cards; bibliographic data formats; ISSN: communication protocols; character sets; information processing ;

\section{INFORMATION TECHNOLOGY SERVICES}

10 First street, SE

Washington, DC 20540

(202) 707-5114

The Library of Congress (LC) pilot program began service operations in 1984, involving all forms of optical disks. A task was established to track the emerging standards in this area, document and identify those areas in which the lack of standards presents problems in information interchange on optical disk, and share findings with other research libraries and related institutions with which the Library would be likely to engage in such information interchange. The library has been represented on the ANSI-accredited standards committee X3B11 on Optical Digital Data Disks since its formation in April 1984 and has participated in international standards developments on the ISO SC 23 committee 
Availability

Keywords

LIBRARY OF CONGRESS

Implementation

Application

\author{
Committee \\ Activity \\ standardization \\ Activities
}

An aperiodic series of reports are planned as well as publication of findings in the open literature.

optical disk; videodisc; digital storage; magneto-optical disks; information processing; optics;

NATIONAL LIBRARY SERVICE FOR THE BLIND AND

PHYSICALLY HANDICAPPED

1291 Taylor street, NW

Washington, DC 20542

(202) 707-5100

(1) Published the guidance document, Published Approved Recommendations on Working Out National standards of Library Service for the Blind, August 1983. This was compiled and adopted by the standards Development Committee, section of Libraries for the Blind, International Federation of Library Associations.

(2) Published the guidance document standards of service for the Library of Congress Network of Libraries for the Blind and Physically Handicapped, revised 1984. This was developed and adopted by the Association of Specialized and Cooperative Library Agencies, a division of the American Library Association.

The recommendations on Working Out National Standards are used by member countries in developing library service to the blind and in promoting international standards of service. The standards of Service are used in evaluating the quality of library service provided by each library in a cooperating network either through self-evaluation or on-site inspections by representatives of the Library of Congress (LC), National Library Service for the Blind and Physically Handicapped (NLSBPH).

American Library Association, Committee on standards.

Reviews and approves proposed and existing standards for continued relevance to the state of library development and service for the blind and physically handicapped. 
On request from Executive Secretariat, Office of the Director, National Library Service for the Blind and Physically Handicapped, at the address above.

Sold by the American Library Association, 50 E. Huron street, Chicago, Illinois 60611.

Reywords

LIBRARY OF CONGRESS

Adoption of Nongovernment standards

Committee Activity

Standardization Activities library service; library networks; blindness; physical handicaps; social welfare;

PHOTODUPLICATION SERVICES

Washington, DC 20540

(202) 707-5650

Photographic standards are specified in various conversion programs for preservation. Bibliographic standards are followed in appropriate divisions to promote more efficient transmission of information. Standards work for permanence of paper for printed library materials is a part of the Library's National Preservation Program.

All new and revised ANSI PHI-5 standards (and those succeeded by IT9) are required for all preservation and conservation work involving photography. ANSI/AIIM standards are used for microphotography. ANSI/NISO standards are adopted for bibliographic and information-related work.

Various staff members serve on American National

Standards (ANSI) committees and subcommittees, especially those dealing with photographic materials in PH1, PH4, and PH5 (some PH1 standards now are designated as IT9), as well as the Association for Information and Image Management (AIIM) which deals with microphotography and micrographics. In addition, staff members have participated in $\mathrm{Z30}$ and $\mathrm{z3} 9$ standards activities, which involves, respectively, library work and publishing practice, and bibliographic description of microforms, serials, and technical reports, plus paper for printed library materials.

As members of the committees listed above, staff members view and vote on the adoption of standards in those areas. Because no standards existed for micrographic reproduction when the Library of Congress had need of such standards, four specifications were developed for the microfilming of newspapers, books and pamphlets, library catalog cards, and manuscripts. The newspaper specification has since become ANSI/AIIM MS111-1987, Recommended Practice for Microfilming Printed Newspapers on $35 \mathrm{~mm}$ Roll Microfilm. 
Availability

Keywords
All Library of Congress microphotographic specifications have been reprinted and are available from the Association for Information and Image Management, 1100 Wayne Avenue, Silver Spring, Maryland 20910 .

reprographics; document reproduction; micrographics; preservation microfilming; photography; information processing;

\section{NATIONAL AERONAUTICS AND SPACE ADMINISTRATION}

\section{Authority \\ Implementation}

Application

Adoption of Nongovernment standards

Qualification, Certification or Calibration
OFFICE OF THE CHIEF ENGINEER

Code AE

NASA Headquarters

Washington, DC 20546-0001

(202) 358-1823

Title 10, USC Chapter 145

Standards and Handbooks are developed as guidance for engineering design, analysis and test for space systems and associated ground support. Standards are developed to enhance commonality and interoperability among performing organizations and to make experience from past programs available for new systems. Documents are issued as NASA Engineering standards.

Standards are available as technical guidance for both internal programs and those carried out under contract for spacecraft, launch systems and associated ground support equipment.

Provisions of the standards are intended to be tailored to meet specific program needs except as specified for safety critical provisions.

Nongovernment standards from organizations such as ASTM, ASME, IEEE, IPC and others frequently cited in program specifications. A process for formal adoption of nongovernment standards is in development

Qualification and certification activities are conducted only for support of internal programs, except that certification is provided for facilities performing flammability and fluid compatibility testing of materials flown on NASA space missions using the test procedures of NASA NHB 8061.1 . 
Committee

Activity

Standardization

Activities

Availability

Keywords
NASA technical experts participate in standards making activities of the Department of Defense; nongovernment standards bodies including ANSI, AIAA, ASME, ASTM, IEEE, IPC, and SAE; and international standards committees of the ISO.

NASA Engineering Standards are developed to enhance comparability and interoperability in system design and to make available experience from previous programs for new design.

Standards are developed in the areas of structural and mechanical design, test requirements, materials and processes, ground support equipment and human factors.

Office of the Chief Engineer at the address above.

spacecraft; space systems; structural design; materials; processes; human factors;

\section{NATIONAL AERONAUTICS AND SPACE ADMINISTRATION}

OFFICE OF SAFETY AND MISSION ASSURANCE

Code Q

NASA Headquarters

Washington, DC 20546

(202) 358-2406

Authority

Implementation

Application

Adoption of Nongovernment Standards
Title 10, USC Chapter 145

NASA Assurance standards (NAS's) are developed by NASA to provide specific guidance for Safety, Reliability, Availability, Maintainability, and Quality Assurance activities. The NAS's are prepared by NASA for use in programs and processes specifically dealing with space flight operations and hardware.

Guidance for application of standards to internal and contracted programs is provided in NASA Policy. Each specific program defines which standards are to be used and how the activity will insure correct implementation of the standards.

NASA has adopted the ISO 9000 series of quality management systems standards as a baseline Quality Management system. NASA efforts continue in the adoption of other nongovernment standards and practices which meet the safety, Reliability and Quality Workmanship requirements for space flight, operations and processes. 
Qualification, Certification or Calibration

Committee

Activity

standardization

Activities

Availability

Keywords
NASA conducts no Qualification, Certification, or Calibration Programs. NASA does perform internal audits of parts manufacturing processes and produces audit reports that are available to the public.

NASA is involved in many industry and interagency standards committees including: space Parts Working Group; Government/Industry Quality Liaison Panel; ISO TC 176 U.S. TAG; and the Electronic Industries Association G-48 Committee.

NASA develops NAS's which address unique requirements for Manned Space Flight systems, facility operations, and workmanship requirements. Safety NAS's address areas such as: Flight and Ground Systems including Ground Pressure systems, Pressure Vessels, and Propulsion Systems. Workmanship NAS's address electronic fabrication and related activities. Software NAS's provide guidance in the development of software and requirements. NASA does not write standards for electronic parts but is an active participant in the Defense Electronics Supply Center, Qualified Manufacturers List (QML) and Qualified Parts List (QPL) certifications. MIL-STD 975, for which NASA is the preparing activity, is used as a section list for NASA Electrical, Electronic and Electromagnetic (EEE) parts. NASA coordinates and uses QML MIL-PRF-38534 Hybrid Circuits, QML MIL-PRF-38535 Microcircuits, and QPL MIL-S-19500 semiconductors, as acceptable references for qualified parts, test and performance data and selection criteria for electronic parts that have been used in NASA programs are available on the Internet.

NASA Assurance standards are available from the Government Printing office and from the NASA Technical Information System. Additional Information on the EEE parts used in NASA programs can be found on the Internet at: http//nppp.jpl.nasa.gov

aerospace; safety; reliability; availability; maintainability; quality assurance; electronic; electrical; electromagnetic; electrical parts;

\section{NATIONAL AERONAUTICS AND SPACE ADMINISTRATION}

OFFICE OF SPACE COMMUNICATIONS

Code OI

NASA Headquarters

Washington, DC 20546-0001

(202) 358-2024 
Authority

Implementation

Application

Adoption of Nongovernment standards

Committee

Activity

Standardization Activities

Availability
NASA Management Instruction 8074.1A, Data Systems Standards: Compliance In Flight Project Development

Data standards for NASA space flight programs are developed through the Consultative Committee for Space Data Systems (CCSDS) by agreement between eight international space agencies to develop space data communication standard recommendations that enable the cross support of satellites by conforming ground terminals.

CCSDS recommendations are implemented through incorporation in development contracts for satellites and ground terminals.

Current Space Communication Protocol Standards (SCPS) efforts within CCSDS based on Internet File Transfer modified for the space communication environment.

CCSDS has three Panels which develop data standards involving space to earth communication, data communication and archiving, and ground terminal communication interfaces. NASA participates in ISO TC 20, SC 13 began in 1990. Thirteen of the current twenty CCSDS recommendations have been adopted as ISO standards. Concentration has been on communication and data handling protocols that enable the cross support of international spacecraft with conforming ground communication and data handling resources of other space agencies. Current work is focused on improving the efficiency in the space to ground communication link and developing international standards for archiving of spacecraft data.

CCSDS was established as an international space data communication standards body in 1982. Adoption of standards into ISO TC $20,5 C 13$ began in 1990. Thirteen of the current twenty CCSDS recommendations have been adopted as ISO standards. Concentration has been on communication and data handling protocols that enable the cross support of international spacecraft with conforming ground communication and data handling resources of other space agencies. Current work is focused on improving the efficiency in the space to ground communication link and developing international standards for archiving of spacecraft data.

CCSDS recommendations are available on-line on the World Wide Web at: http://www.gsfc.nasa.gov/ccsds/ccsds_home.html. They are distributed in hardcopy form by the CCSDS Secretariat through the NASA Office of Space Communications. ISO standards are available from ISO, its national member bodies, and IHS. 
Adoption of Nongovernment standards

Committee Activity

Standardization Activities
NUCLEAR REGULATORY RESEARCH

TWFN, $10 \mathrm{~F} 12$

Washington, DC 20555

(301) 415-6641 FAX: (301) 415-5153

WWW : http://WwW.nrc.gov

Many Nuclear Regulatory Commission (NRC) guides refer to or endorse national standards that are developed by recognized national organizations, e.g., ANSI, ASTM, ASME, often with NRC participation. NRC makes use of a national standard in the regulatory process only after an independent review by the NRC staff and after public comment on NRC's planned use of the standard has been reviewed.

NRC participates on more than 300 interagency, nongovernmental, and international standards committees. The NRC staff is active in national standards programs, particularly with respect to setting priorities. NRC participation derives from a need for national standards to define acceptable ways of implementing the NRC's basic safety regulations. Approximately 200 NRC staff members serve on working groups organized by technical and professional societies.

NRC standards are primarily of two types -- Regulations and Regulatory Guides.

Regulations set forth requirements that must be met by NRC licensees in Title 10, Chapter I, of the code of Federal Regulations. When NRC proposes new or amended regulations, they are normally published in the Federal Register to allow interested persons or organizations time for comment before they are adopted. This is required by the Administrative Procedures Act. Following the public comment period, the regulations are revised, as appropriate, to reflect the comments received. Once adopted by the NRC, they are published in the Federal Register in final form, with the date they became effective. After that publication, rules are codified and included annually in the code of Federal Regulations.

Regulatory Guides are issued to describe and make available to the public such information as methods acceptable to the NRC staff for implementing specific parts of the Commission's regulations, techniques used by the staff in evaluating specific problems or postulated accidents, and data needed by the staff in its review of applications for permits and licenses. Regulatory Guides are 


\section{Reywords}

POSTAL SERVICE, U.S.

not substitutes for regulations, and compliance with them is not required.

The guides are issued in the following ten broad divisions: Power Reactors, Research and Test Reactors, Fuels and Materials Facilities, Environmental and Siting, Materials and Plant Protection, Products, Transportation, Occupational Health, Antitrust and Financial Review, and General. NRC issues the guides for public comment in draft form before an official staff position has been established. Regulatory guides may also be withdrawn when changes make them obsolete.

energy; nuclear; reactors; environment; radiation; safety;

Authority

Implementation

Application

Adoption of Nongovernment Standards
Marketing Department

475 L'Enfant Plaza, SW

Washington, DC 20260-6300

(202) 268-5185

39 U.S.C.: 101, 401, 403, 404, 407, 3001-2, 3621-84

Standards for mail are included in the Domestic Mail Manual and the International Mail Manual, published by the U.S. Postal Service.

Standards for producing letter size and flat size mail which is properly designed and addressed for successful sorting on automated processing equipment are contained in two publications from the U.S. Postal Service; Publication 25, Designing Letter Mail, Publication 28, Postal Addressing Standards, Publication 63, Designing Flat Mail, Publication 353, Designing Reply Mail.

Mail standards are applied by trained postal employees verifying compliance at the point the mail enters Postal Service custody. Trained postal employees also provide information on mail standards to mailers who produce large mailings and to suppliers of mailing materials to the public.

There are no nongovernment generated standards for mail. Standards for international mail generally are produced through agreement according to procedures set by the international postal body, the Universal Postal Union (UPU). standards for domestic mail generally are developed in consultation with the mailing industry body, the Mailers Technical Advisory Committee (MTAC), and may be subject to approval by the independent Postal Rate Commission prior to implementation. Mail standards have a direct relationship to postal rates: standards are used to define mail classes and rates are set according to mail classes. 
Qualification, Certification, or Calibration

\author{
Committee \\ Activities \\ Standardization \\ Activities
}

Availability

Keywords

DEPARTMENT OF STATE

Application
There are no requirements for qualification, certification, or calibration related to mail standards. Assistance in determining compliance with the standards is available through all large city post offices. Requests for assistance and testing on automated equipment should be directed to a postal Mailpiece Design Analyst or Account Representative at those locations.

The U.S. Postal Service participates in UPU and MTAC committees involved in mail standards.

The U.S. Postal Service standardization activities involve the UPU, MTAC, and the Postal Rate Commission.

The Domestic Mail Manual and the International Mail Manual are available as a subscription sold by the Government printing office. Publications 25, 28, 63 and 353 are available, without cost, through all city post offices. Requests for the documents may be directed to any postal marketing representative.

mail; addressing; address format; OCR readability; barcoding; information processing; business; communications; classification;

\section{U.S. INTERNATIONAL TELECOMMUNICATIONS ADVISORY COMMITTEE FOR STANDARDIZATION}

Bureau of Economic and Business Affairs

Office of International Communications and Information Policy

Room 5820 N.S.

2201 C street, NW

washington, DC 20520

$\begin{array}{llll}\text { (202) 647-0197 FAX: (202) 647-7407 } & \end{array}$

Voluntary standards (ITU-T Recommendations formerly CCITT Recommendations) for telecommunications equipments, networks, services and tariffs are issued by the International Telecommunications Union, a specialized agency of the United 
Adoption of Nongovernment Standards

Committee Activity

Standardization Activities
Nations, for use by each nation, according to its needs and laws. The current ITU-T Recommendations (standards) cover more than 60 000 pages through the 1996 ITU-T Plenary cycle being completed in October 1996 at the World Telecommunications standardization Conference, Geneva.

Within the United States, the vast majority of telecommunications standards are produced by industry participants and organizations. Typical of these organizations are AT\&T, MCI Telecommunications, NYNEX, Bell south, the IEEE, TIA, ITI, and ANSI T1 Committee. Twenty-three government agencies participate in these organizations as active players and users.

Industry participants with an interest in telecommunications may join the ITU-T and/or the U.S. ITAC-T National Committee at their own initiative, under the authority of the Department of state which represents the United States as the Telecommunications Administration in the treaty organization - the ITU. They may also petition the FCC for recognition as a Recognized Operating Agency and may choose to join the ITU-T and/or the U.S. National Committee through the Department of State.

The U.S. National Committee Study Groups develop technical, operational and tariff contributions from U.S. industry (both government and private sector) for approval and submission to the ITU-T as U.S. contributions. The U.S. Delegation to the ITU-T is usually chaired by a representative of the Department of state. The chair speaks for the United states at the international sessions and meetings of the ITU-T where the final version of the Recommendations (voluntary standards) are negotiated.

Telecommunications voluntary standards may be initiated by a person or company primarily through one of the U.S. technical committees, such as ANSI T1, CTIA, TIA, etc. (many contributions - mostly non-technical - begin their process directly at the U.S. ITAC-T Study Group level). These contributions are developed to maturity by these bodies, and are submitted for consensus vote in their respective arenas. They are then submitted by a company, committee, or person to the U.S. National Committee for consensus at the United states National Committee level. With consensus, the contribution becomes a U.S. source document for the attention of the appropriate ITU-T Study Group. The nations of the ITU-T will develop the standard further and finally arrive at consensus at an international meeting. The contribution then becomes a ITU-T Recommendation. 


\section{DEPARTMENT OF TRANSPORTATION}

\section{FEDERAL AVIATION ADMINISTRATION}

Flight Standards Service

800 Independence Avenue, SW

washington, DC 20591

(202) 267-8237 FAX: (202) 267-5230

\section{Authority}

Implementation

Standardization Activities
The Federal Aviation Administration (FAA) was created under Title 6 of the Federal Aviation Act of 1958 to provide for the regulation and promotion of civil aviation in such a manner as to best foster its development and safety, and to provide for the safe and efficient use of the airspace by both civil and military aircraft. The Federal Aviation Regulations are promulgated under Title 14 of the Code of Federal Regulations. The first regulation and civil aviation standards originated with the passage of the Air Commerce Act of 1926 .

FAA standards are either regulatory or nonregulatory in nature. Those in the former category are found in the various numbered parts of the Federal Aviation Regulations (FAR's) and, as such, are subject to review in accordance with the Administrative Rulemaking Procedures in which the public participates. Regulatory announcements and Notices of Proposed Rulemaking are published in the Federal Register. The nonregulatory standards generally contained in the FAA Advisory Circulars (AC's) serve principally as the means of providing safety information to the public with respect to aircraft operations or a related aeronautical interest. Nonregulatory circulars also provide the public with guidelines in meeting regulatory requirements.

Regulations and standards are developed and administered by various offices and services within FAA. Flight Standards Service is responsible for most of the regulatory material which includes the certification, operations, and maintenance of aircraft, engines, propellers, and aircraft equipment; licensing of airmen and airman aeromedical standards; for aircraft operational procedures, and the certification of 
schools, repair stations, and parachute lofts; and for airport and air carrier security. The Air Traffic service is responsible for regulations and standards governing airspace utilization, air traffic control and procedures, and for the establishment and installation of navigational facilities. The Associate Administrator for Airports is responsible for regulations and standards concerning airport certification and airport grants; and the Associate Administrator for Policy and International Aviation for aircraft noise standards.

The Federal Aviation Administration periodically publishes a revised Advisory Circular Checklist (ACOO-2) and Status of the Federal Aviation Regulations (ACO0-44) which list current AC's and FAR's. These may be obtained free of charge from the address above. Regulations may be purchased from the Government Printing office.

Reywords

aviation; aircraft; engines; air traffic control; airports; noise; environment; transportation; safety;

\section{DEPARTMENT OF TRANSPORTATION}

Authority

[mplementation

spplication

doption of iongovernment itandards
FEDERAL HIGHWAY ADMINISTRATION

Office of Engineering HNG-1

4007 th street, SW

Washington, DC 20590

(202) $366-4853$

FAX: (202) 366-3713

23 U.S.C. 106, 109, 112, 114, 116, 315 and $402 ; 49$ CFR 1.48 (b) unless otherwise noted Source 43 FR16832, May 7, 1986 unless otherwise noted.

23 CFR Part 625 - Design Standards for Highways

Construction, maintenance, materials, and contracting regulations, standards, and practices are applicable to all federally funded highway projects both on and off the national highway system. Projects may be administered by the Federal Highway Administration, state highway agency, or local governments. Application and compliance of accepted standards and specifications is assured by on-site inspection, process and product reviews and other management techniques.

The Federal Highway Administration actively participates with industry and state highway agency organizations in the development and implementation of highway construction, material, and maintenance standards and 
Committee

Activity

Standardization Activities

Availability

Keywords specifications. Of the 46 publications and references noted in 23 CFR, Part 625, 31 were developed by American Association of State Highway and Transportation Officials (AASHTO); one by the American Welding Society; and three by the Transportation Research Board and the remaining 11 are Federal Highway Administration publications or references.

The Federal Highway Administration is actively involved in industry/state highway agency organizations which develop the national standards cited in the CFR. Committees include both management and technical functions of the American Association of State Highway and Transportation officials, American Society for Testing and Materials, Institute of Traffic Engineers, American Society of Civil Engineers, National Society of Professional Engineers, and American Road and Transportation Builders Association, etc.

The Federal Highway Administration administers the federal-aid highway program and continuity of the national highway network from a third party approach. Although seldom the contracting authority, by serving as the nucleus for the highway industry, the Federal Highway Administration assures reasonable standardization without stymieing creativity and new methods development. This approach allows the state highway agency and local governments the maximum flexibility practical while still attaining national uniformity.

Actual project standards/specifications are developed by each administering agency (state or local) and are reviewed and approved by the Federal Highway Administration. The general guidance provided by the above noted standards is used as a basis for the locally developed standards/specifications.

Federal Highway Administration, Government Printing office, American Association of State Highway and Transportation officials, and local/state highway agencies.

highways; bridges; construction; materials; contracting; traffic control; safety; transportation; 


\section{FEDERAL HIGHWAY ADMINISTRATION}

Office of Environmental Policy 4007 th Street, SW

Washington, DC 20590

(202) 366-2045

Authority

Implementation

Application

Committee

Activity

standardization Activities

Availability
23 U.S.C 109 (I) - The Federal-Aid Highway Act of 1970 requires that noise be considered in the development of new highway projects and that standards for highway noise levels compatible with various land uses be developed and implemented.

The noise standards mandated by 23 U.S.C 109 (I) are codified in 23 CFR, Part 772. The standards provide procedures for noise studies and noise abatement measures to help protect the public health and welfare, supply noise abatement criteria, and establish requirements for information to be given to local officials for use in the planning and design of highways approved pursuant to Title 23, United States Code (U.S.C.).

The standards apply to any proposed federal or federal-aid highway project for the construction of a highway on new location or the physical alteration of an existing highway which significantly changes either the horizontal or vertical alignment or increases the number of through-traffic lanes. They also apply to any proposed federal or federal-aid project for noise abatement on an existing highway.

The Federal Highway Administration participates in pertinent committees of the American Association of state Highway and Transportation Officials, Transportation Research Board, and Society of Automotive Engineers.

The Federal Highway Administration (FHWA) is active in the preparation and implementation of highway traffic noise and construction noise standards for the planning, design, and construction of federal-aid funded highways. These highways are constructed by state and local highway agencies.

The FHWA coordinates the preparation of the standards with the Environmental Protection Agency, other federal agencies, the states, and the public.

Code of Federal Regulations, Title 23, part 772 is available from the Government Printing Office. 
Authority

Implementation
FEDERAL HIGHWAY ADMINISTRATION

Office of Motor Carriers HIA-1

4007 th street, SW

Washington, DC 20590

(202) 366-4039

FAX: (202) 366-3518

Authority to regulate the qualifications and maximum hours of service of employees, the licensing standards for commercial drivers, and safety of operations and equipment is specified in 49 U.S.C. 3102, 3104, and 49 U.S.C. App. 2505, 2701-2716.

Authority to regulate the transportation of hazardous materials is provided by the Hazardous Materials Transportation Act - 49 U.S.C. 1801-1813.

Authority to enforce EPA noise control standards applicable to interstate motor carriers is specified in the Noise Control Act 42 U.S.C. 4917.

Authority to require motor carriers to maintain minimum levels of financial responsibility is specified in 49 U.S.C. 10927 note.

Authority to establish certain federal size limits for commercial motor vehicles is provided by the surface Transportation Act of 1982 - 49 U.S.C. App.2311,2316.

Authority to penalize states that fail to enforce federal weight limits on the Interstate Highway System is specified in 23 U.S.C. 127.

Mandatory regulations are codified in Title 49 and 23 of the Code of Federal Regulations. The rules in Title 49 range from the Federal Motor Carrier safety Regulations (FMCSRs) [Parts 390-399], including the hours of service of drivers [Part 395], to compliance with interstate noise emission standards [Part 325], minimum levels of financial responsibilities [Part 387], and the transportation of hazardous materials [Parts 171-173, 177-178]. They cover interstate motor carriers of passengers and property, as well as their vehicles and drivers.

In addition, Commercial Drivers's License (CDL) standards are codified in 49 C.F.R. Part 383 and apply to states, employers, and all drivers of commercial motor vehicles having a gross vehicle weight rating over 26000 lbs., designed to carry 16 or more persons, or needing placarding for hazardous materials. Unlike 
other Parts of the FMCSRs, the CDL regulations apply without distinction to inter- and intrastate transportation. CDL provisions include a prohibition on multiple licenses; testing and licensing procedures which states and drivers must follow; employer responsibilities; mandatory driver disqualifications for alcohol, drug, and other serious traffic violations and felonies; and a nationwide information clearinghouse on commercial drivers.

Vehicle size and weight regulations and state certification requirements are codified in 23 C.F.R. 657-658. These include regulation of vehicle lengths and widths on the National Network for large trucks (published in Appendix A to Part 658) which consists of the Interstates and other designated federal-aid primary, highways.

Application

Availability

Reywords
Office of Motor Carrier Safety specialists conduct safety and compliance reviews of motor carriers and hazardous materials shippers. They also conduct roadside inspections of vehicles and of drivers' required paperwork. Vehicles and/or drivers not in compliance with the FMCSRs are placed out of service where certain hazards to safety increase the likelihood of an accident.

Office of Motor Carriers transportation specialists review state compliance with the CDL program as well as states' certifications that they are enforcing federal size and weight limits and all state laws on federal-aid highways in the state.

FHWA regulations are available from the Government Printing Office and several private organizations.

commercial motor vehicles; motor carrier; commercial drivers license; hazardous materials; bus; truck; driver qualifications;

FEDERAL HIGHWAY ADMINISTRATION

Office of Traffic Operations

4007 th street, SW

Washington, DC 20590

(202) 366-0411 
Authority

Implementation

Application

Committee

Activity

standardization

Activities
23 U.S.C. 109, Standards, December 20, 1944, the Federal-Aid Highway Act of 1944 .

23 CFR 655, Subpart F, Traffic Control Devices on federal-aid and other streets and highways. A set of national standards have been developed and approved by the Federal Highway Administrator in cooperation with the state highway agencies. These standards are contained in the Manual on Uniform Traffic Control Devices (MUTCD). The Federal Highway Administration will only approve state or other federal agency MUTCDs (or supplements) that are in substantial conformance with the national MUTCD.

The standards contained in the MUTCDs apply to all highways open to public travel.

The MUTCD was developed with cooperation of the:

National Committee on Uniform Traffic Control Devices American Association of State Highway and Transportation Officials Institute of Transportation Engineers

National Committee on Uniform Traffic Laws and Ordinances

National Association of Counties

National Association League of Cities

National Association of Governors' Highway safety Representatives International Association of Chiefs of Police, Inc.

National Electrical Manufacturers Association

American Road and Transportation Builders Association

International Bridge, Tunnel, and Turnpike Association

Existing Highways -- Each state, in cooperation with its political subdivisions, and federal agencies shall have a program which shall include provisions for the systematic upgrading of substandard traffic control devices and for the installation of needed devices to achieve conformity with the MUTCD.

New or Reconstructed Highways -- federal-aid projects for the construction, reconstruction, resurfacing, restoration, or rehabilitation of streets and highways shall not be opened to the public for unrestricted use until all appropriate traffic control devices, either temporary or permanent, are installed and functioning properly. Both temporary and permanent devices shall conform to the MUTCD.

Construction Area Activities - - All traffic control devices installed in construction areas shall conform to the MUTCD. 


\section{DEPARTMENT OF TRANSPORTATION}

Authority

Implementation

Application

Adoption of Nongovernment Standards

Qualification, Certification, or Calibration

Committee

Activity

Standardization Activities
MARITIME ADMINISTRATION

Office of Ship Construction

400 Seventh street, SW

MAR-720, Room 2109

Washington, DC 20590-0001

(202) $366-1800$

The development of guidance specifications for ship construction was first authorized May 20, 1960 by the Federal Maritime Board.

There are three shipbuilding guidance specifications which are for voluntary use: (1) Standards Specifications for Merchant Ship Construction PB 290400; (2) Standards Specifications for Diesel Merchant Ship Construction PB 257261; (3) Standards Specifications for Slow Speed Diesel Merchant Ship Construction. A new publication entitled "Guideline Specifications for Merchant Ship Construction" as well as an Executive summary of it are currently being prepared for publication.

The guidance specifications are for voluntary use by the maritime industry.

Those referred to include: American Society for Testing and Materials (ASTM), American Society of Mechanical Engineers (ASME), Heat Exchange Institute, American Society of Heating, Refrigerating and Air Conditioning Engineers (ASHRAE) and, International Organization for standardization.

None

American Society for Testing and Materials

Active in the preparation of consensus shipbuilding standards through ASTM. 
Availability

Keywords

DEPARTMENT OF TRANSPORTATION
National Technical Information Service, and/or the Maritime Administration

shipbuilding specifications; transportation; merchant ships;

NATIONAL HIGHWAY TRAFFIC SAFETY ADMINISTRATION

SEe DEPARTMENT OF COMMERCE

NATIONAL INSTITUTE OF STANDARDS AND TECHNOLOGY

Electronics and Electrical Engineering Laboratories

office of Law Enforcement Standards

DEPARTMENT OF TRANSPORTATION

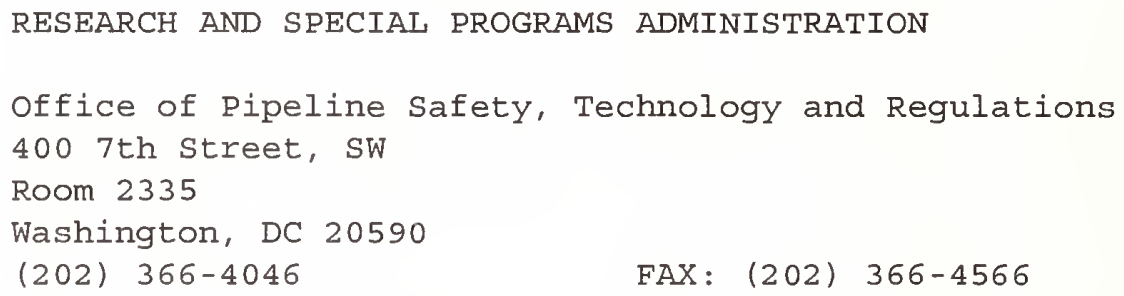

Authority

Implementation
Natural Gas Pipeline Safety Act of 1968 (49 U.S.C. 1671 et seq.)

Hazardous Liquid Pipeline Safety Act of 1979 (49 U.S.C. 2001 et seq.)

Standards for pipelines that carry natural gas or gas that is flammable, toxic, or corrosive are in 49 CFR, Part 192.

Standards for liquefied natural gas (LNG) plants are in 49 CFR, Part 193 .

Standards for interstate pipelines carrying hazardous liquids, such as petroleum, petroleum products, or anhydrous ammonia are in 49 CFR, Part 195.

Regulations to require an anti-drug program for pipeline \& LNG plant employees that perform operation, maintenance and emergencyresponse functions are in 49 CFR, Part 199. 
Application

Adoption of Nongovernment standards

Committee Activity

Standardization Activities

Availability

Reywords

DEPARTMENT OF TRANSPORTATION

UNITED STATES COAST GUARD

Office of Marine Safety, Security and Environmental Protection 2100 second street SW.

Washington, DC 20593-0001

(202) 267-0030

FAX: (202) 267-4816

Maritime shipping laws related to vessels and seamen are codified and enacted into positive law as Subtitle II of Title 46, United States Code, 2101 through 13110.

Mandatory standards for commercial vessel construction and operation, as well as manning and personnel licensing, are codified in 46 and 33 CFR. Program is administered under the direction of the Chief, office of Merchant Marine Safety, U.S. Coast Guard (USCG) 
Application

Adoption of Nongovernment standards

Committee Activity

standardization Activities

Availability

Keywords
Headquarters. A system of district and local port offices (marine safety offices/officers in charge, marine inspection) provide inspection and licensing services to assure compliance with the standards and regulations by shipyards, vessel operators, and merchant mariners.

USCG inspectors periodically inspect commercial, foreign, and domestic vessels to assure compliance.

USCG commercial vessel safety regulations incorporate a wide variety of nongovernment standards by reference.

The Office of Merchant Marine Safety, Security and Environmental Protection participates in those standards developing committees whose standards are used by, or affect, the merchant marine. These include the International Maritime Organization (IMO), ISO, and IEC, as well as the society of Naval Architects and Marine Engineers (SNAME), American Bureau of Shipping (ABS), ASTM, ASME, API, UL, and a dozen other domestic organizations.

USCG commercial vessel safety standards are incorporated into the United States Code of Regulations, Titles 46 and 33. The marine inspection program's regulatory approach includes active participation in voluntary standards programs. By actively participating in voluntary standards, the coast Guard raises issues of public interest and can speak for the public in matters of safety. Also, where industry or owners have not set necessary safety requirements, the Coast Guard can catalyze their development.

Sold by Government Printing office

ship design; safety; environment; hazardous material; marine engineering; naval architecture; inspection; stability; fire protection; merchant marine; transportation;

Recreational Boating Product Assurance Branch (G-NAB-6) Auxiliary, Boating, and Consumer Affairs Division Washington, DC 20593-0001 


\section{Authority}

Implementation

Application

Committee

Activity

Standardization Activities

\section{Availability}

Reywords
Federal Boat Safety Act 1971 (46 U.S.C. 43)

Standards issued to date are in 33 CFR Part 183 and include:

(1) Display of Capacity Information

(2) Safe Loading

(3) Safe Powering

(4) Basic Flotation

(5) Level Flotation

(6) Electrical Systems

(7) Fuel Systems

(8) Ventilation

(9) Start-In-Gear Protection

Boating safety standards are published as mandatory rules in accordance with the Administrative Procedures Act (APA). Final rules become a part of the Code of Federal Regulations. Each proposed rule and each final rule is published in the Federal Register.

Staff members serve on various committees of the American Boat and Yacht Council, Society of Automotive Engineers, National Fire Protection Association, and American Bureau of shipping.

The Auxiliary, Boating, and Consumer Affairs Division is responsible for the development of regulations related to boating safety. The Recreational Boating Product Assurance Branch of the division is responsible for the development of safety standards for recreational boats and associated equipment. Safety standards must be based upon a demonstrated need. This need is frequently related to research involving actual boating safety problem areas. Problem areas are identified from sources such as the Boating Accident Reports, state Accident Reports, Coast Guard District Reports, Defect Notification Reports, and consumer complaints. Specific problems are identified, categorized, and subdivided into specific project areas for standards development.

The volume, 33 CFR Parts 1 to 199, is available from the Superintendent of Documents, U.S. Government Printing Office

recreational; boats; inboard engine; outboard motor; sterndrive unit; environment; safety; 
DEPARTMENT OF THE TREASURY

BUREAU OF ALCOHOL, TOBACCO, AND FIREARMS

National Laboratory Center

1401 Research Boulevard

Rockville, Maryland 20850

(301) 294-0410

Authority

Implementation

and

Application
Availability
Various laws relating to the production, storage, and taxation of alcohol and tobacco products, firearms, and explosives.

Standards have been established by the Bureau of Alcohol, Tobacco and Firearms (ATF) Laboratories, which apply to hydrometers, thermometers, and William's test tubes supplied to the Bureau for testing the alcoholic content of beverages. Although these standards are not usually published, they are supplied to bidders for manufacturing contracts.

In cooperation with various industry segments, ATF prescribes and enforces standards of identity for alcoholic beverages. These standards are established by regulations applicable to all such beverages produced in or imported into the United states. Standards for the various classes of wines are published at 27 CFR, Part 4; those for distilled spirits are published at 27 CFR, Part 5 .

The ATF Laboratories set specifications for ethyl alcohol, denatured alcohol, proprietary solvents, and special industrial solvents. These are incorporated as Federal specifications O-E-760B, issued by the General services Administration. Through regulations issued by BATF at $27 \mathrm{CFR}$, Parts 211 and 212, these specifications are applicable to the production of these products in the United states.

The standards of identity for small cigars, as defined in 26 U.S.C. 5702 and in regulations issued by ATF at 27 CFR, Part 270, are further established by laboratory test procedures set up by the ATF Laboratories. These analytical tests are utilized to enforce these standards for small cigars, as differentiated from cigarettes, upon all such products consumed within the United states.

Additionally, the Bureau sets specifications relating to construction of storerooms for explosive materials. These specifications are published in 27 CFR, Part 181.

National Laboratory Center, ATF. The CFR is available from the Government Printing office 
INTERNAL REVENUE SERVICE

Open Systems Standards (IS:S:A:OS)

Suite 300

1525 Wilson Blvd.

Arlington, Virginia 22209

(703) 235-2820

FAX: (703) 235-2911

e-mail: rick.heroux@ccmail.irs.gov

Authority

Implementation

Adoption of Nongovernment standards

Qualification, Certification, or Calibration
Treasury Directive 87-01 (TD 87-01), Information Standards Program, states that it is the policy of the Department of Treasury to comply with all mandatory Federal Information Processing Standards (FIPS) and Federal Telecommunications Standards (FED-STDS) and other information systems standards and guidelines to the extent they are determined to be cost-effective and appropriate for the intended use.

Within the Internal Revenue Service (IRS) Open Systems Standards is responsible for researching, adopting, and promoting federal standards to ensure portable applications and systems within the IRS. This includes ensuring that the development tools purchased by the agency comply with established FIPS and IRS standards which are manifested in the IRS Open Systems Standards Profile. The IRS Open Systems Standards Profile outlines those technical standards that have been selected for IRS use based upon user requirements. The standards selected must be used by IRS when building or purchasing information systems. These standards are based upon FIPS and de jure standards where possible and follow the National Institute of Standards and Technology (NIST) Application Portability Profile (APP) Service Areas.

The majority of the IRS standards are incorporated from Treasury Directives, FIPS publications, FED-STDs, American National Standards Institute (ANSI), Institute of Electrical and Electronics Engineers (IEEE), International Telecommunications Union (ITU), and other de jure standards. When de jure standards are not mature or do not exist to meet a business requirement, de facto standards have been selected.

Treasury Directive 85-02 Automated Information systems Security and Risk Management Program, establishes the policy with respect to ensuring adequate security for automated information systems, applications, and facilities within the Department of Treasury. This Treasury Directive is intended to fulfill the requirements of Office of Management and Budget (OMB) Circulars A-130 and A-123, and National Security Decision Directive (NSDD) -145 . 
Committee

Activity

Standardization

Activities

Keywords

DEPARTMENT OF THE TREASURY

\section{U.S. CUSTOMS SERVICE}

Office of Regulations and Rulings

International Agreements Staff

1301 Constitution Avenue, NW

Franklin Court Bldg., Suite 4000

Washington, DC 20229

(202) 482-7000

FAX: (202) 482-7042
Authority

Implementation

Application

Committee

Activity
United States accession to the Customs Cooperation Council Convention. Instruments of ratification deposited on November 5 , 1970. United States accession to the Harmonized System Convention, instruments of ratification deposited on october 31 , 1988. The CCC is informally known as the World Customs Organization (WCO).

The Harmonized Tariff Schedule was implemented on January 1, 1989, as a result of the Omnibus Trade and Competitiveness Act of 1988 .

The Harmonized System is applied for the impost of customs duties upon the entry of merchandise into the United states and other countries, and for the collection of international trade data.

The U.S. Customs Service (USCS) serves as chairman of the Inter-agency Advisory Committee on wCO matters, participates on the Trade policy staff Committee and its task force on the Harmonized System, and serves as chairman of the United states delegation of the Harmonized system Committee of the WCO. 


\section{Standardization Activities}

Availability

Keywords
The Harmonized System Committee of the Customs Cooperation Council developed a standardized system of nomenclature for use in international trade. This is essentially a commodity classification system used as a basis for customs tariffs and the foreign-trade statistical systems of the United states and its trading partners. The system is devised such that it is used as a basis for various other international trade facilitation measures, for example, freight tariffs.

A copy of the Harmonized Tariff Schedule of the United States Annotated is available from the United States International Trade Commission, 500 E Street, SW, Washington, DC.

customs; harmonized system; international trade; business;

DEPARTMENT OF THE TREASURY

U.S. CUSTOMS SERVICE

Office of Laboratories and Scientific Services 1301 Constitution Avenue, NW Washington, DC 20229

(202) 927-1060

FAX: (202) 927-2060

e-mail: lab-hq@labhqx31.customs.sprint.com

Authority

Implementation

Application

Adoption of Nongovernment Standards
Title 19, Code of Federal Regulations

Recommended and official laboratory methods are developed and implemented within the U.S. Customs service (USCS) laboratory system for the analysis of imported commodities. Upon request, commodity brochures describing the methods and/or type of instrumentation used by the Customs laboratory, will be issued to the public.

The application of these methods is to meet specific tariff requirements as legislated.

U.S. Customs laboratories most frequently use standards developed by industry groups or other nongovernment organizations such as: AOAC, API, ASTM, ANSI, SAE, etc. 
Qualification, Certification, or Calibration

Committee

Activity

Availability

Keywords

DEPARTMENT OF THE TREASURY

Authority

Implementation

Application
Laboratories and scientific services is involved in the accreditation of private laboratories to perform

testing of merchandise and the approval of commercial gaugers. Currently, gauger approval is provided for animal and vegetable oils, fuel oils, crude oils and organic compounds in bulk and liquid form. Additionally, this office accredits laboratories in the testing of petroleum products for Customs purposes. Additional commodity types will be incorporated into the laboratory accreditation process. We are not involved in the qualification, certification or calibration of methods or standards.

The U.S. Customs laboratory managers and scientists participate in pertinent committees of the American Petroleum Institute, American Society for Testing and Materials, Customs Cooperation Council, American National standards Institute, International Commission for Uniform Methods of Sugar Analysis, Association of official Analytical Chemists, the National Voluntary Laboratory Accreditation Program, and the American Chemical society.

Laboratories and Scientific services, U.S. Customs service.

sampling; laboratory analysis; laboratory methods; customs duties; testing; standards; NASD;
U.S. MINT

Office of Process Control and Quality Assurance Judiciary square Building

633 3rd street, NW

Washington, DC 20220

(202) 874-6160 FAX: (202) 874-6324

31 U.S.C. 317 and 391

The U.S. Mint, Department of the Treasury, develops and administers the technical standards for United states coinage. Nominal diameter and weight standards are established by statute. Deviations allowed in the weight of minor coins are established by 31 U.S.C. 350. Thickness standards and other tolerances are developed by the office of process Control and Quality Assurance, office of the Director.

These standards are only imposed internally on the coin manufacturing processes. However, their importance in the development of coin handling and coin operated equipment so commonly found throughout the nation warrants their publication upon request. 
Availability

Keywords
Written inquiries should be directed to the Director of the Mint, Attention, Office of Process Control and Quality Assurance.

coins; finance;

U.S. TRADE REPRESENTATIVE

see EXECUTIVE OFFICE OF THE PRESIDENT

DEPARTMENT OF VETERANS AFFAIRS

Office of Acquisition and Material Management (92A)

810 Vermont Avenue, NW

Washington, DC 20420

(202) 273-6103 FAX: (202) 273-6225

Authority

Standardization

Activities
Title 38 CFR Chapter I and Title 41 CFR Chapter 8

The standardization activities of the Veterans Administration (VA) are administered by the Safety, Occupational Health, and Fire Protection Division. The Division establishes VA standards as supplements to adopted national standards. Currently there are 26 VA standards including the following 20 product and safety related items:

Carpet Fire-Safety Requirements in Health Care Facilities Automatic Fire Extinguishing Protection

Air Conditioning Systems

Magnetic Door Locks

Liquid Oxygen Walker Units

Trash Containers

Exit Through ICU and CCU

Food Service Equipment and Facilities

Lasers

Pipetting in Hospital Laboratories

Electron Microscopes

Microwave Ovens

Carcinogenic Chemicals

Noise

Bathtubs

Laboratory Safety Equipment-Safety Showers and Eyewashes

Electrical Safety

Prohibition of Using Lead-Based Paint

Storage, Preparation, and Consumption of Food and Beverages by

Employees in Places of Work 
Policy Manual MP-3, Part III lists current standards and is available from the address above.

Keywords

medical devices; air conditioning; consumer products; plumbing; food; safety; noise; 
standards are usually obtained directly from the developing organization, or commercial distributors, or government repositories. A few libraries and standards organizations maintain collections of standards that are open to the public. This section lists distributors of standards in this country and abroad and libraries and information centers.

This information is provided as a service to readers seeking local sources for standards and related materials. It should be emphasized that no endorsement of comprehensiveness, quality, or cost should be inferred, and that potential users must perform their own evaluation.

The following organizations are listed in this section:

American Technical Publishers Ltd . . . . . . . . . . . . . . . 703

ASTM Information Center. . . . . . . . . . . . . . . . 703

Book Supply Bureau . . . . . . . . . . . . . . . . . . . 704

Custom standards services, Inc. . . . . . . . . . . . . . . . 704

Department of Defiense Single Stock Point . . . . . . . . . . . . . 705

DECO - Document Engineering Co. Inc. . . . . . . . . . . . . . . . 706

Document Center . . . . . . . . . . . . . . . . . . 707

Global Engineering Documents . . . . . . . . . . . . . . . . 708

Government Printing Office . . . . . . . . . . . . . . . . . 710

Information Handling Services . . . . . . . . . . . . . . . . . . 711

Information Technology Standards Integrated, Center for standards . . . . . 715

Linda Hall Library . . . . . . . . . . . . . . . . . . . 716

Morgan Technical Library . . . . . . . . . . . . . . . . . 717

National Center for Standards and Certification Information . . . . . . . 718

National Technical Information Service . . . . . . . . . . . . . . 719

Standard Sales Group . . . . . . . . . . . . . . . . . . 720 
27-29 knowl Piece

wilbury Way

Hitchin Herts SG4 OSX

England

Telephone: 01462433678

FAX: 01462433678

Founded: 1980

Type of

Organization

Number of

standards

Types of

standards

Medium

Related

standards

Services
Private for profit

50000 U.S. nongovernment standards and reference books/videos and software.

U.S . NONGOVERNMENT:

ACI American Concrete Institute

IIE Institute of Industrial Engineering

ANSI American National standards Institute

ASTM American Society for Testing \& Materials

ASM ASM International

NACE National Association of Corrosion Engineers

ISA Instrument Society of America

SAE Society of Automotive Engineers

TAPPI Technical Association of the Pulp \& Paper Industry

SME Society of Manufacturing Engineers

Paper, microfiche, CD-ROM.

Individual alphanumeric indexes available.

American Society for Testing and Materials 100 Barr Harbor Drive West Conshohocken, Pennsylvania 19428-2959

(610) 832-9550 FAX: (610) 832-9555

e-mail: sbailey@localastm.org

Founded: 1898

Type of

Organization

Nonprofit

All ASTM. 
Medium

Related

standards

Services

BOOK SUPPLY BUREAU

Type of

Organization

Number of

standards

Types of

standards

Medium

Related

standards

Services

CUSTOM STANDARDS SERVICES, INC.

Gregg Hammerman, President

802 Oakland Avenue

Suite 5

Ann Arbor, Michigan 48104

(800) 699-9277

FAX: (313) 930-9088

e-mail: updates@aol.com

WWW: http: \\ww. well.com\user\css

Founded: 1994

Type of

Organization

Number of

standards
Head Office:

Telephone: 91-4611991, 4634222

Founded: 1972

Private for profit

Issue monthly bulletin about new standards and revisions.
Private for profit

All standards of $35 \mathrm{U} . \mathrm{S}$. nongovernment standards developers. 
Types of

Standards

Medium

Related

Standards

Services
AAMA, AATCC, ABMA, ACI, AF\&PA, AIA, AIIM,

ANSI, API, ARI, ASA, ASCE, ASHRAE, ASME, ASTM, AWPA, AWS, BHMA, BIFMA, California BHFTI, city of Boston Firecodes, CGSB, CSA, EIA/TIA, GANA, GTA, FGMA, HFES, HPVA, ICBO, IEC, IFI, ISO, ISS, LSGA, MPIF, NACE, NEMA, NFPA, NSF, X3/ITI.

Paper, facsimile; eventually full online service.

Custom packages for coverage of federal OSHA and EPA regulations.

Automatic standards updating service at no charge.

DEPARTMENT OF DEFENSE SINGLE STOCK POINT

Type of

organization

Number of

Standards

Types of

Standards
Availability of

Prior Editions

Medium

Indexing
Defense Printing Service Detachment Office 700 Robbins Avenue, Bldg. 4D

Philadelphia, Pennsylvania 19111-5094

(215) 697-2667/2179

FAX: (215) 697-1462

WWW: http://dtic.dla.mil:80/dps-phila/

Government

45000 U.S. Government.

7000 Nongovernment.

15000 other.

U.S. GOVERNMENT:

All military and federal standards, specifications and related documents listed in the Department of Defense Index of Specifications and Standards.

NONGOVERNMENT :

Standards are ONLY provided to DoD Agencies. These are primarily DoD adopted industry standards and specifications such as

Aerospace Industries Association, National Aerospace Standards American National Standards Institute American Society of Mechanical Engineers

American Society for Testing and Materials

American Welding Society

Society of Automotive Engineers

NON-U.S. :

NATO Standardization Agreements

Canceled documents archived by the DODSSP are available in printed format.

Paper, CD-ROM, magnetic tape, and on-line.

The Department of Defense Index of Specifications 
Related

standards

Services and Standards (DODISS) is available in printed book form and CDROM. It is a three part listing: alpha, numeric as well as numeric within Federal Supply Classes.

The printed edition is available from: Government Printing Office, Washington, DC 20402 .

New and/or revised releases of military and federal specifications and standards (including Qualified Products Lists) which are to be listed in the DODISS are available on a subscription basis for a single class or for as many individual classes as the subscriber choose upon payment of a subscription fee per Federal Supply Class.

The Acquisition Streamlining and Standardization Information System (ASSIST) is a relational database system for DoD-wide standardization and acquisition reform management. It links the DODISS, a directory of all activities with an interest in the Defense standardization Program, a directory of all on-going standardization projects, and listings of all active and canceled Data Item Descriptions. Various reports can be developed including lists of referenced documents and specification trees(pyramids). ASSIST is available on-line as well as on CDROM.

DECO - DOCUMENT ENGINEERING CO. INC.

Eric Molinari, President

15210 stagg street

Van Nuys, California 91405-1092

(818) 782-1010 FAX: (818) $782-2374$

e-mail: doceng@doceng.com

WWW: http://www.doceng.com/doceng

Founded: 1958

Type of

organization

Private for profit

Number of

200000 U.S. Government.

Standards

50000 Nongovernment.

Types of

U.S. GOVERNMENT:

Standards
All military and federal standards, specifications and handbooks, QPL's (Qualified Products Lists) and related documents listed in the DOD (Department of Defense) Index. CFR, DESC, DID, FAR, FIPS, NASA. 
Historical

Documents

Medium

Indexing

Related standards

Services

DOCUMENT CENTER

U.S. NONGOVERNMENT :

AA, AGMA, AIA, ANSI*, ASA*, ASME, ASTM*, ASQC, ATA, AWS, EIA, IEEE, IPC, ISA, NEMA*, NFPA, SAE*, UL* .

NON-U.S. :

AECMA*, BSI*, CECC*, CEN, CENELEC, DIN*, IEC*, ISO*, SBAC* .

*Copyright license agreement in place

This is a partial listing of available standards.

Comprehensive DODISS collection dating prior

to 1940. Many industry standards are also

available.

Paper. Limited items available in electronic format.

Indexes are conventional alphanumeric. All indexes are

available in hard copy.

Automatic Updating Service

Library Audits

Military Sheet Form Standards (MS, AN, AND)

Book sets and Updating Service

Claudia Bach, President

1504 Industrial Way, Unit 9

Belmont, California 94002

(415) 591-7600

FAX : (415) 591-7617

e-mail: info@doccenter.com

WWW: http://www.doccenter.com/doccenter

Type of

Private for profit

Organization

Number of

Standards

Types of

Standards

300000 U.S. Government.

100000 U.S. Nongovernment.

50000 Non-U.S. .

U.S. GOVERNMENT:

All military standards and specifications, etc., as

listed in the Department of Defense Index of Specifications and standards. Other military standards (Army, Air Force, Defense

Logistics Agency, DESC, Navy, etc.). Other federal standards

(NASA, FCC, FAA, GSA, etc.).

U.S. NONGOVERNMENT

All ASTM, EIA, ANSI, SAE, AWS, IPC, IEEE, SEMI, NFPA, API, AIIM, ASHRAE, ATA, and others. 
INTERNATIONAL AND FOREIGN:

IEC, ISO, BSI, DIN, VDE, JIS, CSA, EU and others.

OTHER TECHNICAL AND REGULATORY INFORMATION:

GPO Publications, such as the code of Federal

Regulations, etc.

NTIS Publications, such as the FIPS, etc.

Draft standards

Canceled Standards

Availability of

Prior Editions

Medium

Indexing

Related

Standards

Services
Many canceled documents are in stock. Those

not in stock can normally be quoted for price and availability.

Primarily paper, although some microfiched copies

are available. Catalog available to search at no charge on the Internet.

Alphanumeric.

Historical (such as the DoDIss Canceled Documents Index).

Automatic Updating Service.

GLOBAL ENGINEERING DOCUMENTS

A Division of Information Handling Services

Tom Littman, V.P. Operations

15 Inverness Way East

Englewood, Colorado 80112

(303) 792-2181 FAX: (303) 397-7935

Founded: 1968

Type of

Private for profit

Organization

Number of

More than one million new and historical

standards

documents in-stock.

Types of

standards

U.S. GOVERNMENT:

All military and federal standards, and specifi-

cations, handbooks, Commercial Item Descriptions (CID's), Data Item Descriptions (DID's), Qualified Products Lists (QPL's), directives and regulations including Armed Services procurement Regulations/Defense Acquisition Regulations. Also all NATO standards and quality assurance publications, standardization publications of the Army, Navy, and Air Force, and Federal Acquisition Regulations. 
Standards and related publications of the following federal agencies are also stocked: NASA, NIST, Nuclear Regulatory Commission (NRC), DOT, FAA, FCC, GPO, GSA, HUD, OSHA, AND NTIS.

U.S. NON-GOVERNMENT STANDARDS:

ACI American Concrete Institute

$A G A$

AGMA

American Gas Association

AIA

AISC

ANS

ANSI

API

ARI

ARINC

ASA

American Gear Manufacturers Association

American Institute of Architects

American Institute of Steel Construction

American Nuclear Society

American National Standards Institute

American Petroleum Institute

Air Conditioning and Refrigeration Institute

ASHRAE

Aeronautical Radio, Incorporated

Acoustical Society of America

ASHRAE

ASME

American Society of Heating,

Refrigerating

and Air Conditioning Engineers

ASTM

American Society of Mechanical Engineers

American Society for Testing and

Materials

AWS

AWWA

American welding Society

EIA

American Water Works Association

ICBO

Electronic Industries Association

International Conference of Building

Officials

IEEE

Institute of Electrical and Electronics Engineers

IES

Illuminating Engineering Society

IPC

The Institute for Interconnecting and Packaging

Electronic Circuits

ISA

Instrument Society of America

MSS

Manufacturers Standardization society of the Valve and Fittings Industry

NACE

National Association of Corrosion Engineers

NAS

National Aerospace Standards (produced by Aerospace

Industries Association)

NEMA

NFPA

National Electrical Manufacturers Association

NFPA

National Fire Protection Association

National Fluid Power Association

RTCA

SAE

SSPC

TAPPI

UL

Radio Technical Commission for

Aeronautics

Society of Automotive Engineers

Steel Structures Painting Council

Technical Association of the Pulp and Paper Industry

Underwriters Laboratories 


$\begin{array}{ll}\text { INTERNATIONAL AND NON-U.S.: } \\ \text { AFNOR } & \text { Association Francaise De Normalisation } \\ \text { BSI } & \text { British Standards Institution } \\ \text { CCITT } & \text { International Telegraph \& Telephone Consultative } \\ & \text { Committee } \\ \text { CEN } & \text { Comite Europeen de Normalisation } \\ & \text { (European Committee for Standardization) } \\ \text { CENELEC } & \text { Comite Europeen de Normalisation d'Electrotechnique } \\ & \text { (European Committee for Electrotechnical } \\ & \text { Standardization) } \\ \text { CNS } & \text { Chinese National Standards (Republic of China) } \\ \text { CSA } & \text { Canadian Standards Association } \\ \text { DEF } & \text { British Defense Standards } \\ \text { DIN } & \text { Deutsches Institut für Normung } \\ \text { IEC } & \text { International Electrotechnical Commission } \\ \text { EU } & \text { European Union } \\ \text { EN } & \text { Europeen Normalisation } \\ \text { ISO } & \text { International Organization for Standardization } \\ \text { ITU } & \text { International Telecommications Union } \\ \text { JIS } & \text { Japanese Industrial Standards } \\ \text { SAA } & \text { Standards Association of Australia } \\ \text { VDE } & \text { Verband Deutscher Elektrotechniker }\end{array}$

Availability of

Medium

Indexing

Foreign Sales

offices for

U.S. Standards

Related

standards

Services
Global maintains an extensive library of historical

documents, some dating back as far as the 1920's. They also maintain stock on nearly all prior issues of DODISS documents.

Paper.

Global's Product selector is a CD-ROM index listing of over 200000 current documents within their inventory. It provides document number, title, status, as well as pricing on individual documents.

Eastwood, N.S.W., Australia; London, Ontario Canada; Heliopolis, Egypt; Clichy, France; Planegg, Germany; Kowloon, Hong Kong; Tel Aviv, Israel; Mexico City, Mexico; Berkshire, UK. Requests from Central and South America are handled by the Global Information Center, North Miami Beach, Florida.

The Global Standard \& Specification Bulletin provides weekly updates of any new and revised documents.
Superintendent of Documents Washington, DC 20402

(202) 512-1800
FAX: (202) 512-2250 
Type of

organization

Types of standards

Medium
Government

Neither the GPO nor the Superintendent of Documents issues or publishes standards per se. However, as the principal sales agency for Government publications, the superintendent of Documents' inventory of available publications contains hundreds that relate to standards or which contain standards issued by the various Departments and agencies of the Government. A few examples of the publications available are: The Department of Defense Index of Specifications and Standards; Standards for Specifying Construction of Airports; Standard Specifications for Construction of Roads and Bridges on Federal Highway Projects; Government Paper Specifications Standards.

The DOD's Military Specifications and Standards and GSA's Federal Specifications and standards are not available from GPO. Only the indexes for these publications are distributed by GPO. The standards and specifications are available from the DoD Single stock Point and the GSA Specifications Unit, respectively.

Paper.

\section{INFORMATION HANDLING SERVICES}

Michael J. Timbers, Chief Executive Officer, IHS Group

15 Iverness Way East

Englewood, Colorado 80150

(800) 716-3447, ext. 102 (U.S.)

+1 (303) 397-2506 (outside U.S.)

e-mail: info@ihs.com

WWW: http://WwW.ihs.com

Founded: 1959

Private for profit

Type of

Organization

Number of standards
298000 U.S. Government.

83000 U.S. Nongovernment.

24000 International.

144000 Non-U.S. 
Types of Standards

U.S. GOVERNMENT:

All active Military Standards, Specifications and related documents

Federal standards, Specifications and related documents

Military/Federal QPLS

Military Handbooks and Bulletins

MS, AND, ANA, AN Drawings

USAF/NAF Standards

DESC/SMD Drawings

Data Item Descriptions

DoD directives

Naval Instructions and Directives

Commercial Item Descriptions

Joint Army Navy Specs

Federal Construction Regulations and Standards

Federal Aviation Administration Standards

NATO Documents

NASA Documents

Army Documents

Department of Energy Documents

Nuclear Regulatory Commission Regulations and Standards

U.S. NONGOVERNMENT:

Aluminum Association (AA)

American Association of State Highway \& Transportation officials (AASHTO)

American Association of Textile Chemists and Colorists (AATCC)

American Bearing Manufacturers Association (ABMA)

American Bureau of Shipping (ABS)

American Concrete Institute (ACI)

American Gas Association (A.G.A.)

American Gear Manufacturers Association (AGMA)

Asphalt Institute (AI)

Aerospace Industries Association of America, Inc. (AIA [NAS])

American Institute of Architects (AIA)

American Institute of Aeronautics \& Astronautics (AIAA)

American Institute of Chemical Engineers (AIChE)

Association for Information \& Image Management (AIIM)

American Institute of Steel Construction (AISC)

American Iron \& Steel Institute (AISI)

American Nuclear Society (ANS)

American National Standards Institute (ANSI)

American Petroleum Institute (API)

American Railway Engineering Association (AREA)

Air-Conditioning \& Refrigeration Institute (ARI)

Aeronautical Radio, Inc. (ARINC)

Acoustical Society of America (ASA)

The American Society of Agricultural Engineers (ASAE)

American Society of Civil Engineers (ASCE)

American Society of Heating, Refrigerating \& Air-

Conditioning Engineers (ASHRAE)

American Society of Mechanical Engineers (ASME) 
American Society of Nondestructive Testing (ASNT)

American Society for Quality Control (ASQC)

American Society of Sanitary Engineering (ASSE)

American Society for Testing and Materials (ASTM)

American Welding Society (AWS)

American Water Works Association (AWWA)

American Association for Laboratory Accreditation (A2LA)

Builders Hardware Manufacturers Association (BHMA)

Civil Engineering Data (CED)

Compressed Gas Association (CGA)

Cooling Tower Institute (CTI)

Electronic Industries Association (EIA)

General Motors (GM)

Gypsum Association (GA)

Gas Processors Association (GPA)

Insulated Cable Engineers Association (ICEA)

Institute of Electrical \& Electronics Engineers (IEEE)

Illuminating Engineering Society of North America (IESNA)

Industrial Fasteners Institute (IFI)

The Institute for Interconnecting \& Packaging Electronic Circuits (IPC)

ISA - The International Society for Measurement

and Control (ISA)

International Society for Hybrid Microelectronics (ISHM)

Manufacturers standardization Society of the Valve and Fittings

Industry (MSS)

NACE International (NACE)

National Environmental Balancing Bureau (NEBB)

National Electrical Manufacturers Association (NEMA)

National Fire Protection Association (NFPA)

National Fluid Power Association (AFP [A])

National Information Standards Organization (NISO)

NSF International (NSF)

Nondestructive Testing Information Analysis Center (NTIAC)

Pipe Fabrication Institute (PFI)

Plastics Technical Evaluation Center (PLASTEC)

Plastics Pipe Institute (PPI)

Reliability Analysis Center (RAC)

Radio Technical Commission for Aeronautics (RTCA)

Resistance Welder Manufacturers Association (RWMA)

SAE International (SAE)

Semiconductor Equipment \& Materials International (SEMI)

Steel Joist Institute (SJI)

Sheet Metal \& Air Conditioning Contractors' National Association, Inc. (SMACNA)

Society of Motion Picture \& Television Engineers (SMPTE)

Steel structures Painting Council (SSPC)

Technical Association of the Pulp and Paper

Industry (TAPPI) 
Underwriters Laboratories Inc. (UL)

X3 Information Technology (X-3 ITI)

INTERNATIONAL AND REGIONAL:

European Association for Materials of Aerospace

Construction (AECMA)

CENELEC Electronic Components (CECC)

European Committee for Standardization (CEN)

European Committee for Electrotechnical Standardization (CENELEC)

Conference of European Postal and

Telecommunications Administration (CEPT)

European Council (EC)

Electronic Quality Assurance Documents service (EQADS)

European Computer Manufacturers Association (ECMA)

European Telecommunications Standards Institute (ETSI)

International Atomic Energy Agency (IAEA)

International Quality Assessment system for Electronic Components ( IECQ)

European Organization for Civil Aviation

Electronics (EUROCAE)

International Civil Aviation Organization (ICAO)

International Commission on Illumination (CIE)

International Electrotechnical Commission (IEC)

International Organization for Standardization (ISO)

International Telecommunications Union (ITU)

Joint Technical Committee 1 (JTC I) of ISO and IEC

North Atlantic Treaty Organization (NATO)

NON-U.S. :

Association Francaise de Normalisation (AFNOR)

British Standards Institution (BSI)

Civil Aviation Authority (CAA)

Canadian General Standards Board (CGSB)

Chinese National standards - Taiwan (CNS)

Canadian Pulp and Paper Association (CPPA)

Canadian Standards Association (CSA)

Deutsches Institut für Normung e. V. (DIN)

Japanese Industrial standards (JIS)

British Ministry of Defense (MOD UK)

Standards Association of Australia (SAA)

Saudi Arabian Standards organization (SASO)

The Society of British Aerospace Companies (SBAC)

Standards New Zealand (SNZ)

Underwriters' Laboratories of Canada (ULC)

Verein Deutscher Ingenieure (VDI)

Medium

Indexing
Microfilm, microfiche, CD-ROM, magnetic tape, on-line, Internet.

Alphanumeric and by subject in printed indexes. Wordwide standards index on CD-ROM, on-line or Internet allows multilingual searching in English French, German and Spanish. Search by document number, document date, developing organization, keyword, revision status, document type, and other bibliographic 
details. This index also cross-searches to Military Specs and Standards.

Related Standards Services

Foreign Sales

Trade Names
Perinorm, a CD-ROM based index cites all the standards of BSI, AFNOR, DIN, ISO, IEC, CEN/CENELEC, JIS, ASTM, IEEE, UL and standards data from Australia, the Netherlands and Switzerland.

Sales representatives and distributors throughout the U.S. and in over 90 foreign countries.

Extension 99, Hot Specs, VSMF.

\section{INFORMATION TECHNOLOGY STANDARDS INTEGRATED (ITSI), CENTER FOR STANDARDS}

Defense Information Systems Agency

Joint Interoperability Engineering Organization

10701 Parkridge Blvd.

Reston, Virginia 22090

(703) 735-8338

e-mail: helpdesk@itsi.disa.mil

WWw: http://www.itsi.disa.mil

Founded: 1994

Type of

organization

Number of

Standards

Type of

standards
Government

The more than 500 government and nongovernment standards listed in

- Volume 7, Adopted information Technology Standards, of the Technical Architecture for Information Management (TAFIM), and

- Mil-STD-187-700A, Interoperability and Performance Standards for the Defense Information System.

The ITSI Standards Document Library is a database of the most important documents needed to build DoD information systems. It contains policy, guidance, and reference documents, but the bulk of the collection is government and nongovernment standards.

Abstracts are provided for all standards. More than one-third of them are in electronic format available for downloading on-line. However, most nongovernment standards (e.g., ISO, ANSI, IEEE) cannot be downloaded due to copyright restrictions. Sources for these standards are included in the database. 
Medium

Indexing

Related

standards

Services

IINDA HALI IIBRARY
On-line.

In addition to alphanumeric, standards are organized by TAFIM service area and by standards developing organization.

The on-line topic "standards Surveys and Assorted References" provides an up-to-date overview of existing and evolving standards and their relationship to information systems.

The on-line topic "DODEC \EDE Conventions" contain's electronic data interchange conventions for DoD's electronic commerce initiatives.

Mary Moeller, Head of Reference Services

5109 Cherry street

Kansas City, Missouri 64110

(816) $363-4600$

FAX : (816) $926-8790$

e-mail: reference@lhl.lib.mo.us

WWW: http://www.Ihl.lib.mo.us

Founded: 1946

Nonprofit

150000 standards

U.S. GOVERNMENT :

All military and federal specifications, standards and related documents.

U.S. NONGOVERNMENT:

standards of three hundred professional societies and trade associations in the private sector.

American Gas Association - AGA standards

American National standards Institute - ANSI approved engineering standards.

American Society for Testing and Materials - Annual Book of ASTM standards.

American Society of Civil Engineers - ASCE standards

American Society of Mechanical Engineers - ASME Boiler

and Pressure Vessel Code; ASME codes and standards.

Institute of Electrical and Electronics Engineers - IEEE standards. 
National Fire Protection Association - National Fire Codes. Society of Automotive Engineers - SAE Handbook of Ground Vehicle standards; Aerospace standards.

Paper, some microfiche.

Photocopy service.

National Fire Protection Association

1 Batterymarch Park

Quincy, Massachusetts 02269-9101

(617) 984-7445

FAX : (617) $984-7060$

e-mail: library@NFPA.org

WWW: http://www.wpi.edu/nfpe/nfpa.html

Founded: 1945

Type of

Organization

Nonprofit

Types of standards
Availability of Prior Editions

Medium

Indexing

Related

standards

Services
U.S. NONGOVERNMENT:

NFPA National Fire Protection Association

UL Underwriters Laboratories

NON-U.S. :

Partial files on Canadian and UK standards organizations, primarily those standards relating to fire safety.

INTERNATIONAL:

Partial file of standards relating to fire safety from ISO and IEC

Historic files are maintained for the National

Fire Protection Association, 1896-current.

Paper for current files.

Microfiche for historic files.

Indexes are those supplied by issuing body.

Provide photocopies of out-of-print National Fire Protection Association Standards. Authentication services available. 
National Institute of Standards and Technology Bldg. 820, Room 164

Gaithersburg, Maryland 20899

(301) 975-4040

FAX : (301) 926-1559

e-mail: joverman@nist.gov

WWW: http://www.nist.gov

Founded: 1965

Type of

Organization

Types of

standards in

Collection

Medium

Related

standards

Services

Government

UNITED STATES:

Federal agency (technical regulations)

Federal and military standards

Nongovernment

NON-U.S. :

International

Regional

Foreign national

Paper, CD-ROM and microform.
Standards can be viewed from the collection, which is in paper, $C D-R O M$ and microform. Product subject listings are provided in response to inquiries, but copies of standards are not distributed. NCSCI responds to the needs of government, industry and the general public for information on domestic and foreign standards, regulations, certification, and other standards related activities and foreign requests for information on existing U.S. standards and certification information. The objectives are accomplished by: maintaining a microform and hard copy collection of engineering standards and specifications, regulations, certification rules, directories, reference books and special publications; responding to inquiries on the existence, source, and availability of standards and related documents; developing and publishing directories of standards, certification, testing and related information; to the degree possible, responding to trade related queries regarding regulations and other requirements of foreign countries for the export of U.S. manufactured products.

The NCSCI Reference Collection is open to visitors Monday through Friday from $8: 30 \mathrm{a} . \mathrm{m}$. To $5: 00 \mathrm{p} . \mathrm{m}$. 
U.S. Department of Commerce

5285 Port Royal Road

Springfield, Virginia 22161

(703) 487-4650

FAX: (703) 321-8547

$1-800-553-6847$

WWW : http://Www.fedworld.gov

Founded: 1970 (predecessor 1946)

Type of

organization

Types of

standards

Availability of

Prior Editions

Medium

Indexing

Foreign Sales

Offices for

U.S. Standards
Governmental

U.S. GOVERNMENT:

Some military standards

Nuclear

Medical

Environmental

Food and Drug

U.S. NONGOVERNMENT :

American National Standards Institute publications cited in government standards.

Retain all prior editions.

Paper, microfiche, diskette, CD-ROM, on-line, and audiovisual FedWorld ${ }^{\circledR}$.

Government Report Abstracts and Index Journal Published biweekly.

NTIS has distribution agreements in 42 countries including:

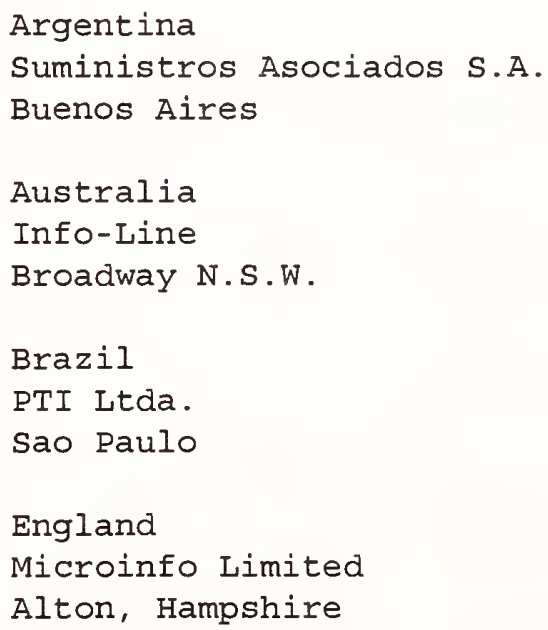




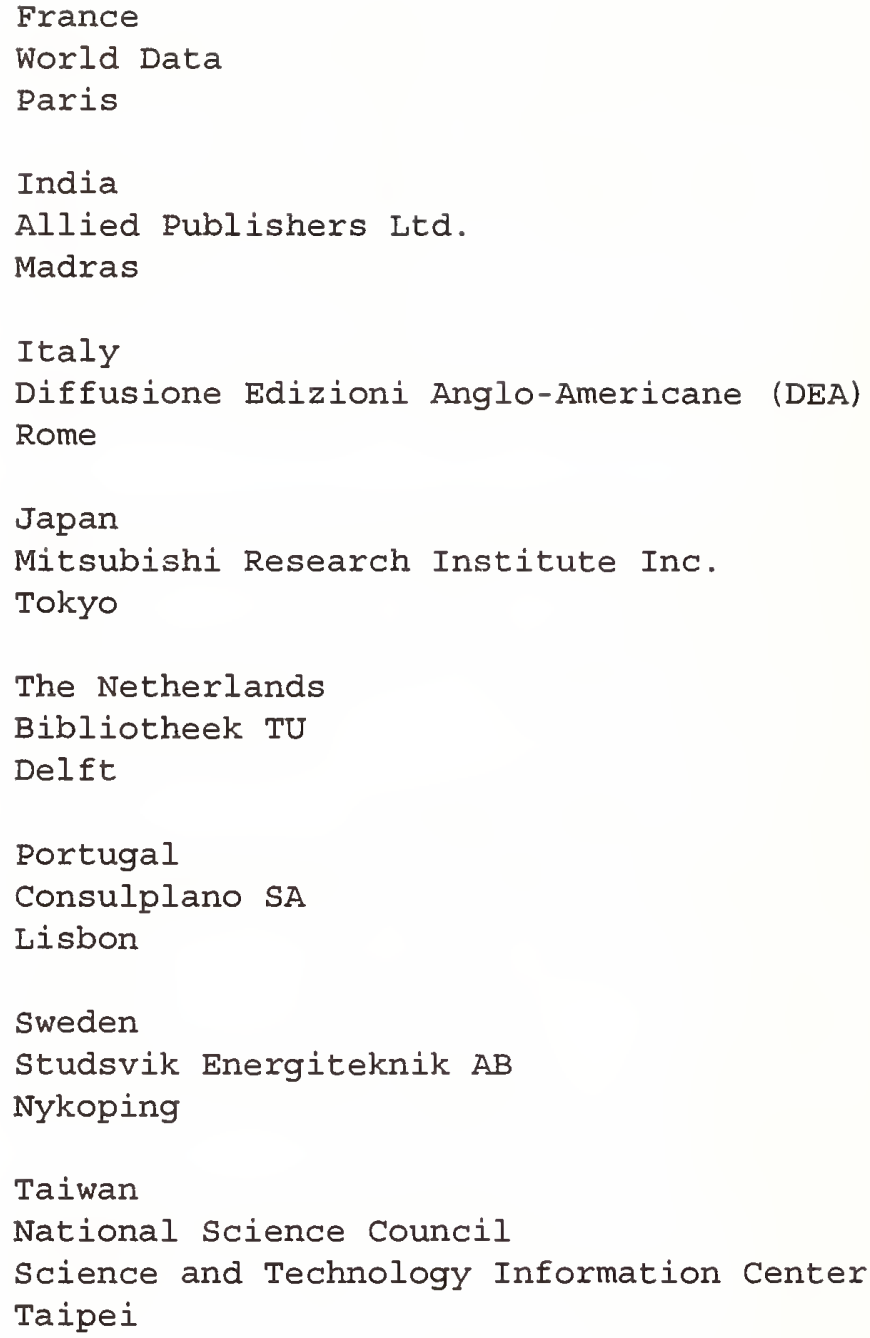

STANDARDS SALES GROUP

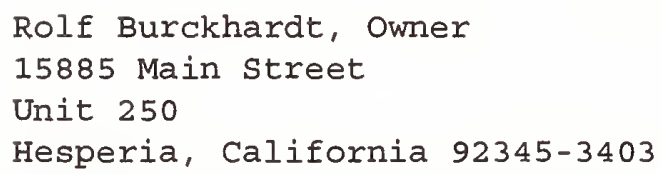


INTERNATIONAL:

CIE, IEC, IMO, ISO, ITU, WHO

NON-U.S. :

EU directives, CEN, CENELEC, CEPT, ETSI, AENOR, AFNOR,

AUSTEL, BABT, BAPT, BGBI, BSI, CEI, CNET, Communications Canada, CSA, DIN, FTZ, FZA, GOST, JIS, MPR, ÖNORM, SA, SASO, VBG, VDE, VDI, Vfg, and others.

OTHER TECHNICAL AND REGULATORY INFORMATION:

Code of Federal Regulations

Draft standards

Foreign laws and regulations

Availability of

Prior Editions

Medium

Indexing

Related

standards

Services
Some withdrawn standards, drafts, and laws.

Paper.

Alphanumeric.

Document Library Monitoring Service.

Automatic Updating Service.

Foreign Technical Document Translations. 


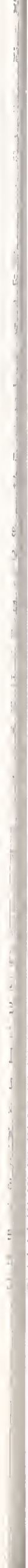




\subsection{SUBJECT INDEX (ORGANIZATIONS BY MAJOR SUBJECTS)}

Government and nongovernment organizations are listed in alphabetic order in their respective sections, and are listed here within forty-three subject categories. These categories were selected after reviewing the keywords of all entries.

Acoustics and Noise Control . . . . . . . . . . . . . . . . . 725

Aerospace and Aviation . . . . . . . . . . . . . . . . . . . 725

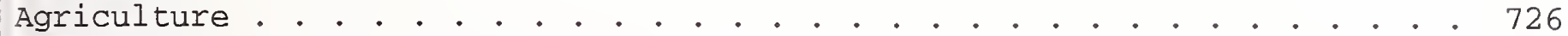

Air-conditioning and Refrigeration . . . . . . . . . . . . . . . . . 726

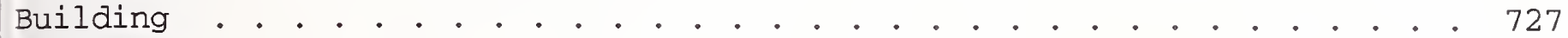

Business, Finance and Insurance . . . . . . . . . . . . . . . . 728

Communications . • . . • • . . • . . . . . . . . . . . . . . . 729

Computers and Information Technology . . . . . . . . . . . . . . . . . 730

Concrete, Masonry, and Ceramic Products . . . . . . . . . . . . . . . . 731

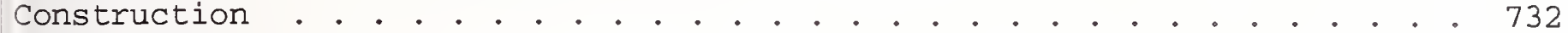

Consumer Products. . . . . . . . . . . . . . . . . . . . . . . 734

Defense . . . . . . . . . . . . . . . . . . . . . . 735

Education . . . . . . . . . . . . . . . . . . . . . . . 735

Electrical and Electronic Equipment . . . . . . . . . . . . . . . . 736

Energy . . . . . . . . . . . . . . . . . . . . . . . . . . 737

Environment . . . . . . . . . . . . . . . . . . . . . . . 737

Facilities Management . . . . . . . . . . . . . . . . . . . . 738

Food and Beverages . . . . . . . . . . . . . . . . . . . . 738

General . . . . . . . . . . • . . . . . . . . . . . . 739

Government Officials . . . . . . . . . . . . . . . . . . . . . 740

Heating, Ventilating and Air Handling . . . . . . . . . . . . . . . . . 740

Industrial Equipment . . . . . . . . . . . . . . . . . . . . . . . . . 741

Instruments and Laboratory Equipment . . . . . . . . . . . . . . . . . 742

Machinery . . . . . . . . . . . . . . . . . . . . . . . 742

Manufacturing . . . . . . . . . . . . . . . . . . . . . . . . . 743

Materials and Finishes . . . . . . . . . . . . . . . . . . . . . 744

Medical and Health Care . . . . . . . . . . . . . . . . . . . . 746

Medical Devices, Equipment and Instruments . . . . . . . . . . . . . . 747

Office Products . . . . . . . . . . . . . . . . . . . . . . . . 748

Optics, Ophthalmic Products and Eye Protection . . . . . . . . . . . . 748

Packaging and Paper . . . . . . . . . . . . . . . . . . . . . . 748

Photography . . . . . . . . . . . . . . . . . . . . . . 749

Plumbing . . . . . . . . . . . . . . . . . . . . . . . . . 749

Public Health. . . . . . . . . . . . . . . . . . . . . . . 750

Quality Assurance and Testing . . . . . . . . . . . . . . . . . 751

Recreation and Sports . . . . . . . . . . . . . . . . . . . 752

Safety, Fire Protection and Public Safety . . . . . . . . . . . . . . . 752

Sanitation . . . . . . . . . . . . . . . . . . . . . . 755

Social Welfare . . . . . . . . . . . . . . . . . . . 755

Textiles and clothing. . . . . . . . . . . . . . . . . . 755

Transportation . . . . . . . . . . . . . . . . . . . . . 756

Wood and Wood Products . . . . . . . . . . . . . . . . . 757 


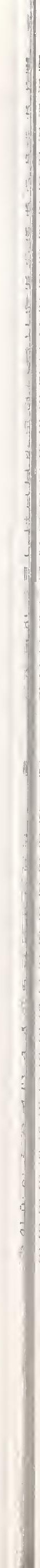




\section{ACOUSTICS AND NOISE CONTROL}

Acoustical Society of America

Air Conditioning and Refrigeration Institute

Air Movement and Control Association

American Association of State Highway and Transportation Officials

American Helicopter Society

American Institute of Physics

American Insurance Services Group

American Society for Testing and Materials

American Speech-Language and Hearing Association

Association of Wall and Ceiling Industries - International

Compressed Air and Gas Institute

Construction Industry Manufacturers Association

Environmental Protection Agency

Federal Aviation Administration (DOT)

Helicopter Association International

Home Ventilating Institute

Inchcape Testing Services

Institute of Environmental sciences

ITA, The International Recording Media Association

Lead Industries Association

National Environmental Balancing Bureau

Outdoor Power Equipment Institute

Sheet Metal and Air Conditioner Contractors National Association

Snowmobile safety and Certification Committee

Society of Automotive Engineers

Veterans Affairs, Department of

\section{AEROSPACE AND AVIATION}

Aeronautical Radio, Inc.

Aerospace Industries Association of America

Air Transport Association of America

Aircraft Owners and Pilots Association

American Helicopter Society

American Institute of Aeronautics and Astronautics

American Society for Testing and Materials

Department of Defense

Federal Aviation Administration (DOT)

Federal Coordinator for Metrology (Commerce)

Flight Safety Foundation

General Aviation Manufacturers Association

Helicopter Association International

National Aeronautics and Space Administration

Radio Technical Commission for Aeronautics

Society of Allied Weight Engineers

Society of Automotive Engineers

Southwest Research Institute

Standards Committee for Hi-Lok, Hi-Tigue, and Hi-Lite Products 
American Association of Cereal Chemists

American Association of Nurserymen

American Society of Agricultural Engineers

American Soybean Association

$A O A C$, International

Association of American Plant Food Control Officials

Association of Official seed Analysts

Association of Official seed Certifying Agencies

Blue Anchor

Corn Refiners Association

Dairy and Food Industries Supply Association

Department of Agriculture

DFA of California

Diamond Walnut Growers

Entomological Society of America

Environmental Industry Association

Equipment Manufacturers Institute

Irrigation Association

Manufacturers Institute

National Association of Photographic Manufacturers

National Bark and Soil Producers Association

National Clay Pot Manufacturers Association

National Coffee Association of the USA

National Cotton Council of America

National Cottonseed Products Association

National Fertilizer Solutions Association

National Institute of Oilseed Products

National Lime Association

National Oilseed Processors Association

Nebraska Power Laboratory

Outdoor Power Equipment Institute

Society of Automotive Engineers

Turfgrass Producers International

United States Hide, Skin and Leather Association

USA Rice Federation

\section{AIR CONDITIONING AND REFRIGERATION}

(Also see Heating, Ventilating and Air Handling)

Air-Conditioning and Refrigeration Institute

Air Conditioning Contractors of America

American Insurance Services Group

American Society of Heating, Refrigerating and Air-conditioning Engineers

Automotive Refrigeration Products Institute

Commercial Refrigeration Manufacturers Association

Inchcape Testing Services

International Institute of Ammonia Refrigeration

International Mobile Air Conditioning Association

Mechanical Contractors Association of America

National Association of Plumbing-Heating-Cooling Contractors

National Environmental Balancing Bureau 
Sheet Metal, and Air Conditioning Contractors National Association Solar Rating and Certification Corporation

Veterans Affairs, Department of

\section{BUIIDING}

(Also see Air-Conditioning; Concrete; Heating; Plumbing; and Wood)

American Architectural Manufacturers Association

American Forest and Paper Association

American Gas Association

American Hardboard Association

American Institute of Architects

American Institute of Steel Construction

American Insurance Services Group

American Laminators Association

American Lighting Association

American Pipe Fittings Association

American Society for Testing and Materials

American Society of Agricultural Engineers

American Society of Civil Engineers

American Society of Mechanical Engineers

American Society of Plumbing Engineers

American Society of Safety Engineers

Asphalt Roofing Manufacturers Association

Associated General Contractors of America

Associated Locksmiths of America

Association of Engineering Geologists

Association of Wall and Ceiling Industries, International

Brick Institute of America

Builders Hardware Manufacturers Association

Building Owners and Management Association International

Building Technologies (DOE)

Ceiling and Interior Systems Construction Association

Concrete Reinforcing steel Institute

Concrete Sawing and Drilling Association

Construction Specifications Institute

Council of American Building Officials

Department of Defense

Door and Hardware Institute

Door Operator and Remote Controls Manufacturers Association

Expanded Shale, Clay and Slate Institute

Factory Mutual Research Corporation

Gas Appliance Manufacturers Association

General Services Administration

Glass Association of North America

Home Automation Association

Housing and Urban Development, Department of

Illuminating Engineering Society of Northern America

Insulated Steel Door Systems Institute

International Association of Electrical Inspectors

International Association of Plumbing and Mechanical Officials

International Cast Polymer Association

International Conference of Building Officials 
Lightning Protection Institute

Manufactured Housing Institute

Marble Institute of America

Metal Building Manufacturers Association

Multi-Housing Laundry Association

National Air Duct Cleaners Association

National Association of Architectural Metal Manufacturers

National Association of Garage Door Manufacturers

National Association of Industrial and office Properties

National Association of store Fixture Manufacturers

National Building Granite Quarries Association

National Concrete Masonry Association

National Conference of States on Building Codes and Standards

National Dimension Manufacturers Association

National Electrical Contractors Association

National Elevator Industry

National Environmental Balancing Bureau

National Fenestration Rating Council

National Institute of Building sciences

National Kitchen and Bath Association

National Lime Association

National Oak Flooring Manufacturers Association

National Roof Deck Contractors Association

National Roofing Contractors Association

National Sash and Door Jobbers Association

National School Supply and Equipment Association

National Wood Window and Door Association

Plumbing and Drainage Institute

Portland Cement Association

Post-Tensioning Institute

Rack Manufacturers Institute

Redwood Inspection Service

Resilient Floor Covering Institute

Screen Manufacturers Association

Sealed Insulating Glass Manufacturers Association

Southern Building Code Congress International

Southern Forest Products Association

Steel Deck Institute

Steel Door Institute

Steel Joist Institute

Steel Window Institute

Tile Council of America

United Lightning Protection Association

water systems Council

Wood Molding and Millwork Producers Association

Woodwork Institute of California

Veterans Affairs, Department of

BUSINESS, FINANCE RND INSURANCE

Accredited Standards Committee X9 - Financial Services

AIM USA

Alliance of American Insurers 
American Association of Advertising Agencies

American Automobile Association

American National Metric Council

American National Standards Institute

American Statistical Association

Association of American Railroads

Association of Records Managers and Administrators

Data Interchange Standards Association

Factory Mutual Research Corporation

Federal Trade Commission

Financial Accounting Foundation

Foreign Agricultural Service (USDA)

Health Care Financing Administration (DHHS)

Industrial Risk Insurers

Institute of Internal Auditors

Internal Revenue Service (Treasury)

International Trade Administration (Commerce)

National Association of Purchasing Management

National Cargo Bureau

National Institute of Standards and Technology (Commerce)

National Insurance Crime Bureau

National Retail Federation

Occupational Safety and Health Administration (Labor)

Project Management Institute

U.S. Council for International Business

U.S. Customs Service (Treasury)

U.S. Mint (Treasury)

U.S. Patent and Trademark office (Commerce)

U.S. Trade Representative, Executive Office of the President

Uniform code Council

\section{COMMUNICATIONS}

Advanced Television Systems Committee

Aeronautical Radio, Incorporated

Air Transport Association of America

Alliance for Telecommunications Industry Solutions

American Association of Advertising Agencies

American Design Drafting Association

American National Standards Institute

Association for Information and Image Management, International

Association for Suppliers of Printing and Publishing Technologies

Association of American Publishers

Association of American Railroads

ATM Forum

Automatic Meter Reading Association

Bellcore

Binding Industries of America

Book Industry Study Group

Book Manufacturers Institute

Corporation for Open Systems International

Data Interchange Standards Association

Department of Defense 
Electronic Media Rating Council

Federal Communications Commission

Federal Coordinator for Meteorology (Commerce)

Graphic Communications Association

Gravure Association of America

Home Automation Association

Information Resources Management (GSA)

Information Technology Industry Council

Institute of Electrical and Electronics Engineers

Insulated Cable Engineers Association

International Communications Industries Association

Internet Society

ITA, The International Recording Media Association

Laser Institute of America

Library Binding Institute

National Association of Broadcasters

National Federation of Abstracting and Information Services

National Information Standards Organization

National Institute of Standards and Technology (Commerce)

National Marine Electronics Association

National Printing Ink Research Institute

National Telecommunications and Information Administration (Commerce)

Network Management Forum

postal Service

Printing Industries of America

Radio Technical Commission for Aeronautics

Radio Technical Commission for Maritime Services

Recording Industry Association of America

Rural Utilities Service (USDA)

Security Industry Association

Semiconductor Equipment and Materials Institute

Society for Technical Communication

Society of Cable Telecommunications Engineers

Society of Motion Picture and Television Engineers

Southwest Research Institute

Telecommunications and Information Standards Directorate (State)

Traffic Audit Bureau

\section{COMPUTERS AND INEORMATION TECHNOLOCY}

Accredited Standards Committee X9 - Financial services

AIM USA

American Association of Motor Vehicle Administrators

American Association of State Highway and Transportation officials

American Congress on Surveying and Mapping

American Design Drafting Association

American Institute for Design and Drafting

American National Standards Institute

American Society for Testing and Materials

American Statistical Association

American Textile Manufacturers Institute

Association for Computing Machinery

Association for Information and Image Management, International 
Association of American Railroads

Association of Records Managers and Administrators

ATM Forum

Automatic Meter Reading Association

Book Industry Study Group

Bureau of the Census (Commerce)

collection Services (Library of Congress)

Construction Specifications Institute

Corporation for Open Systems International

Data Processing Management Association

Electronic Industries Association

Energy Information Administration (DOE)

Federal Coordinator for Meteorology (Commerce)

Geological Survey (Interior)

Graphic Communications Association

Home Automation Association

Information Resources Management (GSA)

Information Technology Industry Council

Information Technology Services (Library of Congress)

Institute of Electrical and Electronics Engineers

Internal Revenue Service (Treasury)

Internet Society

National Archives and Records Administration (GSA)

National Federation of Abstracting and Information Services

National Information Standards Organization

National Institute of Standards and Technology (Commerce)

National Telecommunications and Information Administration (Commerce)

Network Management Forum

Personal Computer Memory Card International Association

Printing Industries of America

Project Management Institute

Radio Technical Commission for Maritime Services

Society for Information Display

Society of Allied Weight Engineers

Special Libraries Association

U.S. Geological Survey (Interior)

U.S. Patent and Trademark office (Commerce)

U.S. Product Data Association

Uniform code Council

VMEBUS International Trade Association

\section{CONCRFTE, MASONRY AND CERAMIC PRODUCTS}

American Concrete Institute

American Concrete Pavement Association

American Concrete Pipe Association

American Concrete Pressure Pipe Association

American Society for Testing and Materials

Association of Engineering Geologists

Brick Institute of America

Concrete Plant Manufacturers Bureau

Concrete Reinforcing steel Institute

Concrete Sawing and Drilling Association 
Expanded Shale, Clay and Slate Institute

International Masonry Institute

Masonry and Concrete Saw Manufacturers Institute

Materials and Methods Standards Association

National Building Granite Quarries Association

National Clay Pipe Institute

National Concrete Masonry Association

National Lime Association

National Terrazzo and Mosaic Association

Portland Cement Association

Post-Tensioning Institute

Precast/Prestressed Concrete Institute

Refractories Institute

Scaffolding, Shoring and Forming Institute

Stucco Manufacturers Association

Technical Ceramics Manufacturers Association

Tile Council of America

Truck Mixer Manufacturers Bureau

wire Reinforcement Institute

CONSTRUCTION

(Also see Concrete, Masonry and Ceramic Products)

Air Conditioning Contractors of America

American Association of State Highway and Transportation Officials

American Fence Association

American Forest and Paper Association

American Hardboard Association

American Institute of Steel Construction

American Institute of Timber construction

American Insurance Services Group

American Iron and Steel Institute

American Laminators Association

American Lumber Standards Committee

American Pipe Fittings Association

American Railway Engineering Association

American Road and Transportation Builders Association

American Society for Testing and Materials

American Society of Civil Engineers

American Society of Mechanical Engineers

American Society of Sanitary Engineering

American Water Works Association

American Wood-Preservers Association

American Wood-Preservers Bureau

Asphalt Emulsion Manufacturers Association

Asphalt Institute

Asphalt Roofing Manufacturers Association

Associated Air Balance Council

Associated General Contractors of America

Association of Asbestos Cement Pipe Producers

Association of Engineering Geologists

Association of Higher Education Facilities Officers

Association of Wall and Ceiling Industries - International 
Building officials and Code Administrators International

Cast Iron Soil Pipe Institute

Chain Link Fence Manufacturers Institute

Compressed Air and Gas Institute

Concrete Plant Manufacturers Bureau

Concrete Sawing and Drilling Association

Construction Industry Manufacturers Association

Construction Specifications Institute

Contractors Pump Bureau

Council of American Building Officials

Department of Defense

Engineered Wood Association

Environmental Industry Association

Factory Mutual Research Corporation

Federal Highway Administration (DOT)

General Services Administration

Gypsum Association

Hardwood Plywood and Veneer Manufacturers Association

Housing and Urban Development, Department of

Institute of Makers of Explosives

International Bridge, Tunnel and Turnpike Association

International Conference of Building Officials

Laborers International Union of North America

Mechanical Contractors Association of America

Metal Building Manufacturers Association

National Association of County Engineers

National Association of Industrial and Office Properties

National Association of Pipe Coating Applicators

National Association of Plumbing-Heating-Cooling Contractors

National Association of Store Fixture Manufacturers

National Building Granite Quarries Association

National Clay Pipe Institute

National Concrete Masonry Association

National Conference of states on Building Codes and standards

National Corrugated Steel Pipe Association

National Electrical Contractors Association

National Lime Association

National Sash and Door Jobbers Association

National Stone Association

National Terrazzo and Mosaic Association

occupational Safety and Health Administration (Labor)

Pipe Line Contractors Association

Plastics Pipe Institute

Portland Cement Association

Post-Tensioning Institute

Powder Actuated Tool Manufacturers Institute

Precast/Prestressed Concrete Institute

Resilient Floor Covering Institute

scaffolding, Shoring and Forming Institute

Sheet Metal and Air Conditioner Contractors National Association

Single Ply Roofing Institute

Southern Building Code Congress International

Steel Tank Institute

Water Pollution Control Federation 
American Furniture Manufacturers Association

American Gas Association

American Insurance Services Group

American Ladder Institute

American National Standards Institute

American Society for Testing and Materials

American Society of Electroplated Plastics

American Textile Manufacturers Institute

Art and Creative Materials Institute

Association of Bedding and Furniture Law officials

Association of Home Appliance Manufacturers

Automatic Meter Reading Association

Building Technologies (DOE)

Bureau of Competition and Consumer Protection (FTC)

Carpet and Rug Institute

Chemical Specialties Manufacturers Association

Color Association of the United States

Consumer Federation of America

Consumer Product Safety Commission

Cookware Manufacturers Association

Cordage Institute

Cosmetic, Toiletry and Fragrance Association

Department of Defense

Electronic Industries Association

Food and Drug Administration (HHS)

Gas Appliance Manufacturers Association

Gas Processors Association

Gemological Institute of America

Hand Tools Institute

Home Automation Association

Inchcape Testing Services

International Fabricare Institute

International sleep Products Association

Jewelers Vigilance Committee

Juvenile Products Manufacturers Association

Manufacturing Jewelers and Silversmiths of America

Metal Ladder Manufacturers Association

Multi-Housing Laundry Association

National Association of Hosiery Manufacturers

National Association of Jewelry Appraisers

National Institute of Infant Services

National Retail Federation

National Safety Council

National Spa and Pool Institute

Outdoor Power Equipment Institute

Resiliant Floor Covering Institute

SGS - United States Testing Company

Snell Memorial Foundation

Tire and Rim Association

Toy Manufacturers of America

Underwriters Laboratories

Vacuum Cleaner Manufacturers Association 
Veterans Affairs, Department of water Quality Association

\section{DEFENSE}

Aerospace Industries Association of America American Defense Preparedness Association

American Helicopter Society

American National Metric Council

American National Standards Institute

American Society for Testing and Materials

Defense Programs (DOE)

Department of Defense

Electronic Industries Association

Helicopter Association International

Institute of Makers of Explosives

Institute of Nuclear Materials Management

Society of Allied Weight Engineers

Society of Automotive Engineers

Society of Naval Architects and Marine Engineers

Sporting Arms and Ammunitions Manufacturers Institute

\section{EDUCATION}

Accrediting Bureau of Health Education Schools Advisory Commission on Textbook Specifications American Academy of Pediatrics

American Association of Psychiatric Services for Children

American Library Association

American National Metric Council

American Optometric Association

American Psychiatric Association

American Psychoanalytic Association

American Public Health Association

American Speech-Language and Hearing Association

Association for Education of the Visually Handicapped

Association of Bedding and Furniture Law Officials

Association of Higher Education Facilities Officers

Book Industry Study Group

Book Manufacturers Institute

FACTS Institute for Research, Standards and Terminology

Hair International

National Association of State Textbook Administrators

National School Supply and Equipment Association

National Standards Educators Association

Special Libraries Association

U.S. Metric Association 
Aeronautical Radio, Incorporated

Air Conditioning and Refrigeration Institute

American Insurance Services Group

American Lighting Association

American Society for Testing and Materials

American Society of Electroplated Plastics

Association of Edison Illuminating Companies

Association of Iron and Steel Engineers

Battery Council International

Certified Ballast Manufacturers

Construction Industry Manufacturers Association

Edison Electric Institute

Electrical Apparatus Service Association

Electrical Generating Systems Association

Electronic Industries Association

Electrostatic Discharge Association

Factory Mutual Research Corporation

Gas Appliance Manufacturers Association

Home Automation Association

Inchcape Testing Services

Institute for Interconnecting and Packaging Electronic circuits Institute of Electrical and Electronics Engineers

Insulated Cable Engineers Association

International Brotherhood of Electrical Workers

International Electrical Testing Association

International Municipal Signal Association

ISA, The International Society for Measurement and Control

Lightning Protection Association

Magnetic Materials Producers Association

National Association of Relay Manufacturers

National Electrical Contractors Association

National Electrical Manufacturers Association

National Marine Electronic Association

occupational Safety and Health Administration (Labor)

Radio Technical Commission for Aeronautics

Radio Technical Commission for Maritime Services

Recreation Vehicle Industry Association

Rural Utilities Service (USDA)

Security Industry Association

Semiconductor Equipment and Materials Institute, International

Small Motors Manufacturers Association

Society of Allied Weight Engineers

Society of Naval Architects and Marine Engineers

Southwest Research Institute

Underwriters Laboratories

United Lightning Protection Association

Variable Resistive Components Institute 
Air Conditioning and Refrigeration Institute

American Gas Association

American Insurance Services Group

American Nuclear Society

American Society for Testing and Materials

American Society of Heating, Refrigerating and Air-Conditioning Engineers

American Society of Mechanical Engineers

Association of Edison Illuminating Companies

Automatic Meter Reading Association

Construction Industry Manufacturers Association

Council of American Building Officials

Department of Energy

Edison Electric Institute

Electrical Generating Systems Association

Gas Appliance Manufacturers Association

Gas Processors Association

Health Physics Society

Heat Exchange Institute

Home Automation Association

Home Ventilating Institute

Institute of Electrical and Electronics Engineers

Institute of Nuclear Materials Management

Insulated Cable Engineers Association

Mine Safety and Health Administration (Labor)

Mineral Management Service (Interior)

National Association of Pipe Coating Applicators

National Conference of states on Building Codes and standards

National Fenestration Rating Council

National Propane Gas Association

Portland Cement Association

Rural Utilities Service (USDA)

Sheet Metal and Air Conditioner Contractors National Association

Solar Rating and Certification Corporation

\section{BNVIRONMENT}

Acoustical Society of America

Aerospace Industries Association of America

Air and Waste Management Association

Air Conditioning and Refrigeration Institute

American Association of state Highway and Transportation officials

American Bus Association

American Conference of Governmental Industrial Hygienists

American Forest and Paper Association

American Industrial Hygiene Association

American Insurance Services Group

American Petroleum Institute

American Society for Testing and Materials

American Society of Agricultural Engineers

American Society of Heating, Refrigerating and Air-Conditioning Engineers

American Society of Mechanical Engineers 
American Society of Safety Engineers

American Textile Manufacturers Institute

$\mathrm{AOAC}$ International

Association of Engineering Geologists

Battery Council International

Construction Industry Manufacturers Association

Environment, Safety and Health (DOE)

Federal Aviation Administration (DOT)

Federal Highway Administration (DOT)

Glass Packaging Institute

Home Automation Association

Industrial Fabrics Association International

Institute of Environmental Sciences

Institute of Nuclear Materials Management

International Fabricare Institute

National Arborist Association

National Association of County Engineers

National Council on Radiation Protection and Measurements

National Environmental Balancing Bureau

National Pest Control Association

NSF International

Nuclear Regulatory Commission

occupational Health (NASA)

occupational Safety and Health Administration (Labor)

Portland Cement Association

Sheet Metal and Air Conditioner Contractors National Association

Steel Tank Institute

Water Pollution Control Federation

Water Quality Association

\section{FACILITIES MANAGEMENT}

Air Conditioning Contractors of America

American Hospital Association

American Petroleum Institute

American Society of Safety Engineers

Association of Higher Education Facilities officers

Building Owners and Managers Association International

Electrical Generating Systems Association

Institute of Environmental Sciences

Multi-Housing Laundry Association

National Association of County Engineers

National Association of Industrial and Office Properties

\section{FOOD AND BEVERAGES}

American Association of Cereal Chemists

American Dairy Products Institute

American Oil Chemists Society

American Society for Enology and Viticulture

American Society of Brewing Chemists

American Spice Trade Association 
AOAC International

Bureau of Alcohol, Tobacco and Firearms (Treasury)

Can Manufacturers Institute

Cookware Manufacturers Association

Corn Refiners Association

Dairy and Food Industries Supply Association

Department of Agriculture

Department of Defense

DFA of California

Diamond Walnut Manufacturers Institute

Distilled Spirits Council of the United States

Food and Drug Administration (HHS)

Food Processing Machinery and Supplies Association

Glass Packaging Institute

Health Care Financing Administration (HHS)

National Association of Photographic Manufacturers

National Automatic Merchandising Association

National Coffee Association of the U.S.A.

National Cottonseed Products Association

National Fisheries Institute

National Food Processors Association

National Institute of Oilseed Products

National Marine Fisheries Service (Commerce)

National Oilseed Processors Association

National Soft Drink Association

SGS, United States Testing Company

Sheet Metal and Air Conditioner Contractors National Association

USA Rice Federation

Veterans Affairs, Department of

Water Quality Association

\section{GENERAL}

American Design Drafting Association

American National Metric Council

American National Standards Institute

American Society for Testing and Materials

American Society of Safety Engineers

American Statistical Association

Association of Records Managers and Administrators

Bureau of Competition and Consumer Protection (FTC)

Color Association of the United States

Consumer Product Safety Commission

Department of Defense

Executive Office of the President

General Services Administration

International Trade Administration (Commerce)

National Institute of Standards and Technology (Commerce)

National Standards Educators Association

SGS - United States Testing Company

Standards Engineering Society

U.S. Metric Association

U.S. Product Data Association 
U.S. Trade Representative, Executive Office of the President

underwriters Laboratory

Uniform code council

\section{GOVERNMENT OFFICIALS}

American Association of Motor Vehicle Administrators

American Association of State Highway and Transportation officials

American Conference of Governmental Industrial Hygienists

AOAC International

Association of American Plant Food Control Officials

Association of Bedding and Furniture Law Officials

Association of Official seed Analysts

Building Officials and Code Administrators International

Council of American Building officials

International Association of Electrical Inspectors

International Association of Plumbing and Mechanical officials

International Conference of Building Officials

National Association of County Engineers

National Association of State Textbook Administrators

National Board of Boiler and Pressure Vessel Inspectors

National Civic League

National Conference of States on Building codes and Standards

National Insurance Crime Bureau

HEATING, VENTIIATING AND AIR HANDLING

Air-Conditioning and Refrigeration Institute

Air conditioning Contractors of America

Air Distribution Institute

Air Movement and Control Association

American Boiler Manufacturers Association

American Conference of Governmental Industrial Hygienists

American Insurance Services Group

American Society of Heating, Refrigerating and Air-Conditioning Engineers

Associated Air Balance Council

Council of American Building Officials

Gas Appliance Manufacturers Association

Heat Exchange Institute

Home Automation Association

Home Ventilating Institute

Hydronics Institute

Institute of Environmental Sciences

Mechanical Contractors Association of America

National Association of Plumbing-Heating-Cooling Contractors

National Certified Pipe Welding Bureau

National Conference of States on Building Codes and standards

National Environmental Balancing Bureau

Recreation Vehicle Industry Association

Sheet Metal, and Air Conditioning Contractors National Association

Solar Rating and Certification Corporation

underwriters Laboratories 
AIM USA

Air Conditioning and Refrigeration Institute

American Boiler Manufacturers Association

American Brush Manufacturers Association

American Gas Association

American Gear Manufacturers Association

American Insurance Services Group

American Ladder Institute

American Petroleum Institute

American Society for Testing and Materials

American Society of Mechanical Engineers

American Vacuum Society

AMT - The Association for Manufacturing Technology

Association of Iron and Steel Engineers

Cleaning Equipment Trade Association

Compressed Air and Gas Institute

Compressed Gas Association

Construction Industry Manufacturers Association

Contractors Pump Bureau

Conveyor Equipment Manufacturers Association

cooling Tower Institute

Cordage Institute

Department of Defense

Ductile Iron Pipe Research Association

Electronic Industries Association

Environmental Industry Association

Expansion Joint Manufacturers Association

Factory Mutual Research Corporation

Fluid Controls Institute

Gas Appliance Manufacturers Association

Hand Tools Institute

Heat Exchange Institute

Hydraulic Institute

Hydronics Institute

Industrial Perforators Association

Industrial Safety Equipment Association

Industrial Truck Association

Institute of Caster Manufacturers

Institute of Clean Air Companies

International Staple, Nail and Tool Association

ISA, The International Society for Measurement and Control

Laser Institute of America

Manufacturers Standardization Society of the Valve and Fittings Industry Masonry and Concrete Saw Manufacturers Institute

Material Handling Industry

Mechanical Power Transmission Association

Metal Ladder Manufacturers Association

Mine Safety and Health Administration (Labor)

Monorail Manufacturers Association

National Association of Chain Manufacturers

National Association of Graphic and Product Identification Manufacturers

National Association of Punch Manufacturers 
National Board of Boiler and Pressure Vessel Inspectors

National Fluid Power Association

National Wood Pallet and Container Association

occupational Safety and Health Administration (Labor)

Optical Product Code Council

Pipe Fabrication Institute

Portable Power Equipment Manufacturers Association

Process Industry Practices Initiative

Rack Manufacturers Institute

Resistance Welder Manufacturers Association

Robotic Industries Association

Rubber Manufacturers Association

scaffolding, Shoring and Forming Institute

Small Motor Manufacturing Association

Steel Plate Fabricators Association

Steel Tank Institute

Sump and Sewage Pump Manufacturers Association

Tubular Exchange Manufacturers Association

Ultrasonic Industry Association

Underwriters Laboratories

Valve Manufacturers Association of America

Water Quality Association

\section{INSTRUMENTS AND LABORATORY EOUIPMENTS}

American Crystallographic Association

American Society for Clinical Laboratory Science

American Society for Testing and Materials

American Society of Electroplated Plastics

American Watchmakers and Clockmakers Institute

Bureau of Alcohol, Tobacco and Firearms (Treasury)

Equipment and Tool Institute

Factory Mutual Research Corporation

Federal Coordinator for Meteorology (Commerce)

Fluid Controls Institute

Institute of Electrical and Electronics Engineers

Inter-Society Color Council

International Centre for Diffraction Data

ISA, The International Society for Measurement and Control

Joint Neurosurgical Committee on Devices and Drugs

Laser Institute of America

National Association of Jewelry Appraisers

National Institute of Standards and Technology (Commerce)

National Oceanic and Atmospheric Administration (Commerce)

Optical Society of America

scale Manufacturers Association

\section{MACHINERY}

American Bearing Manufacturers Association

American Chain Association

American Gear Manufacturers Association 
American Insurance Services Group

American Society for Testing and Materials

American Society of Agricultural Engineers

American Society of Mechanical Engineers

American Textile Machinery Association

AMT - The Association for Manufacturing Technology

Automotive Lift Institute

Baking Industry Sanitation Standards Committee

Compressed Air and Gas Institute

Construction Industry Manufacturers Association

Conveyor Equipment Manufacturers Association

Electrical Apparatus Service Association

Factory Mutual Research Corporation

Fluid Seal Association

Food Processing Machinery and Supplies Association

Forging Industry Association

Friction Materials Standards Institute

Grinding wheel Institute

Hack and Band Saw Manufacturers of America

Mechanical Power Transmission Association

Monorail Manufacturers Association

National Electrical Manufacturers Association

National Fluid Power Association

Nebraska Power Laboratory

Packaging Machinery Manufacturers Institute

Resistance Welder Manufacturers Association

Robotic Industries Association

Semiconductor Equipment and Materials Institute

Small Motors Manufacturers Association

Society of Naval Architects and Marine Engineers

Society of the Plastics Industry

Wood Machinery Manufacturers of America

\section{MANUFACTURING}

Abrasive Grain Association

Adhesives Manufacturers Association

Aerospace Industries Association of America

AIM USA

American Brush Manufacturers Association

American Chain Association

American Insurance Services Group

American Ladder Institute

American Laminators Association

American National Metric Council

American National Standards Institute

American Petroleum Institute

American Society for Testing and Materials

American Society of Electroplated Plastics

American Society of Mechanical Engineers

American Textile Manufacturers Institute

American Welding Society

AMT - The Association for Manufacturing Technology 
Automated Imaging Association

Cast Iron Soil Pipe Institute

Cemented Carbide Producers Association

Certified Automotive Parts Association

Coated Abrasives Manufacturers Institute

Compressed Air and Gas Institute

Concrete Plant Manufacturers Bureau

Consortium For Advanced Manufacturing International

Construction Industry Manufacturers Association

Defense Industrial Supply Center (Interdepartmental Screw Thread Committee)

Diamond Wheel Manufacturers Institute

Factory Mutual Research Corporation

Fluid Controls Institute

Food Processing Machinery and Supplies Association

Grinding wheel Institute

Hack and Band Saw Manufacturers Association of America

Industrial Diamond Association of America

Industrial Fasteners Institute

Industrial Perforators Association

Industrial Safety Equipment Association

Institute of Industrial Engineers

Insulated Cable Engineers Association

International staple, Nail and Tool Association

Laser Institute of America

Marking Device Association

Metal Treating Institute

Monorail Manufacturers Association

National Association of Chain Manufacturers

National Association of Punch Manufacturers

National Certified Pipe Welding Bureau

National Fastener Distributors Association

North American Die Casting Association

occupational Safety and Health Administration (Labor)

Optical Product code Council

Primary Glass Manufacturers Council

Process Industry Practices Initiative

Resistance Welder Manufacturers Association

Robotic Industries Association

Semiconductor Equipment and Materials Institute

Standards Committee for Hi-Lok, Hi-Tigue, and Hi-Lite Products

Steel Plate Fabricators Association

Truck Trailer Manufacturers Association

Tube and Pipe Association, International

Tubular Rivet and Machine Institute

United States Council for Automotive Research

United States Cutting Tool Institute

\section{MATERIAIS AND FINISEES}

(Also see Concrete, Textiles And Wood)

Abrasive Grain Association

Aluminum Association

American Association of state Highway and Transportation Officials 
American Chemical Society

American Concrete Pavement Association

American Electroplaters Society

American Fiber Manufacturers Association

American Foundrymen's Society

American Galvanizers Association

American Hardboard Association

American Iron and Steel Institute

American Laminators Association

American Leather Chemists Association

American National Standards Institute

American Petroleum Institute

American Society for Testing and Materials

American Society of Electroplated Plastics

American Society of Mechanical Engineers

American Textile Manufacturers Institute

American Wire Producers Association

Asbestos Information Association North America

Asphalt Emulsion Manufacturers Association

Asphalt Institute

Association of Nonwoven Fabrics Industry

Association of Wall and Ceiling Industries - International

Brass and Bronze Ingot Manufacturers

Bureau of Alcohol, Tobacco and Firearms (Treasury)

Cemented Carbide Producers Association

Chemical Fabrics and Film Association

Chemical Manufacturers Association

Chemical Specialities Manufacturers Association

Chlorine Institute

Compressed Gas Association

Concrete Plant Manufacturers Bureau

Control Systems Manufacturers Division

Copper Development Association

Cosmetic, Toiletry and Fragrance Association

cotton Warehouse Association of America

Department of Defense

Entomological Society of America

Environmental Protection Agency

Expanded Shale, Clay and Slate Institute

FACTS Institute for Research, Standards, and Terminology

Federal Highway Administration (DOT)

Felt Manufacturers Council of Northern Textile Association

Flat Glass Marketing Association

Forging Industry Association

Friction Materials Standards Institute

Glass Association of North America

Gold Institute

Gypsum Association

Indiana Limestone Institute of America

Industrial Diamond Association of America

Industrial Fabrics Association International

Institute of Makers of Explosives

International Cadmium Association

International Cast Polymer Association 
Jewelers Vigilance Committee

Lead Industries Association

Magnetic Materials Producers Association

Manufacturing Jewelers and Silversmiths of America

Marble Institute of America

Materials and Methods Standards Association

Metal Powder Industries Federation

Metal Treating Institute

NACE International

National Association of Store Fixture Manufacturers

National Building Granite Quarries Association

National Cotton Council

National Lime Association

National Lubricating Grease Institute

National stone Association

North American Die Casting Association

North American Insulation Manufacturers Association

Perlite Institute

Polyurethane Manufacturers Association

Porcelain Enamel Institute

Primary Glass Manufacturers Council

Refractories Institute

Rubber Manufacturers Association

Salt Institute

Semiconductor Equipment and Materials Institute

SGS - United States Testing Company

Silver Institute

Society for Experimental Mechanics

Society of Automotive Engineers

Society of the Plastics Industry

Southern Building Code Congress International

Southwest Research Institute

Steel Founders Society of America

Steel Manufacturers Association

Steel Service Center Institute

Steel Structures Painting Council

Technical Ceramics Manufacturers Association

United States Council for Automotive Research

United States Hide, Skin and Leather Association

Wire Reinforcement Institute

\section{MEDICAL AND HEALTH CARE}

Accrediting Bureau of Health Education Schools

American Academy of Pediatrics

American Alliance for Health, Physical Education, Recreation and Dance

American Association for Respiratory Care

American Association of Poison Control Centers

American Association of Psychiatric Services for children

American College of Surgeons

American Dental Association

American Electroencephalographic Society

American Hospital Association 
American Medical Association

American National Standards Institute

American Occupational Medical Association

American Optometric Association

American Pharmaceutical Association

American Psychiatric Association

American Psychoanalytic Association

American Society for Artificial Internal Organs

American Society for Clinical Laboratory Science

American Society for Testing and Materials

American Society of Anesthesiologists

American Speech-language and Hearing Association

American Thoracic Society

Asbestos Information Association North America

Association for the Advancement of Medical Instrumentation

college of American Pathologists

Compressed Gas Association

Defense Programs (DOE)

Entomological Society of America

Environment, Safety and Health (DOE)

Food and Drug Administration (HHS)

Health Care Financing Administration (HHS)

Health Industry Business Communications Council

Health Industry Manufacturers Association

Helicopter Association International

Institute of Environmental Sciences

Joint Neurosurgical Committee on Devices/Drugs

Mine Safety and Health Administration (Labor)

National Council for Prescription Drug Programs

NCCLS - The Clinical Laboratory Standards Organization

Occupational Health office (NASA)

Orthopedic Surgical Manufacturers Association

Pharmaceutical Research and Manufacturers of America

Prevent Blindness America

U.S. Pharmacopeial Convention

MEDICAL DEVICES, EOUIPMENT AND INSTRUMENTS

American Association for Clinical Chemists American College of Surgeons

American Dental Association

American Electroencephalographic Society

American Insurance Services Group

American Medical Association

American Optometric Association

American Society for Artificial Internal Organs

American Society for Testing and Materials

American Society of Anesthesiologists

American Society of Mechanical Engineers

American Thoracic Society

Association for the Advancement of Medical Instrumentation

Biological stain Commission

Department of Defense 
Food and Drug Administration (HHS)

Health Industry Business Communications Council

Health Industry Manufacturers Association

Institute of Environmental Sciences

Joint Neurosurgical Committee on Devices/Drugs

Laser Institute of America

National Electrical Manufacturers Association

NCCLS - The Clinical Laboratory Standards Organization

Orthopedic Surgical Manufacturers Association

Pharmaceutical Research and Manufacturers of America

Prevent Blindness America

Radiological Society of North America

U.S. Pharmacopeial Convention

Veterans Affairs, Department of

\section{OFFICE PRODUCTS}

American Society for Testing and Materials

Association for Information and Image Management, International

Association of Records Managers and Administrators

Business and Institutional Furniture Manufacturers Association

Human Factors Society

Joint Commission on Printing (Congress of the U.S.)

Marking Device Association

National Association of Graphic and Product Identification Manufacturers Postal Service

Special Libraries Association

\section{OPTICS, OPHTHALMIC PRODUCTS AND EYE PROTECTION}

American Institute of Physics

American Optometric Association

American Society for Testing and Materials

American Society of Safety Engineers

Automated Imaging Association

Industrial Safety Equipment Association

Laser Institute of America

National Association of Manufacturing opticians

optical Laboratories Association

optical Society of America

Prevent Blindness America

\section{PACKAGING AND PAPER}

Adhesives Manufacturers Association

AIM USA

American Forest and Paper Association

American Society for Testing and Materials

Can Manufacturers Institute

Composite Can and Tube Institute

Containerization and Intermodal Institute 
Dairy and Food Industries Supply Association Department of Defense

FACTS Institute for Research, Standards, and Terminology

Fibre Box Association

Flexible Packaging Association

Food Processing Machinery and Supplies Association

Glass Packaging Institute

Gravure Association of America

Joint Commission on Printing (Congress of the U.S.)

National Archives and Records Service (GSA)

National Food Processors Association

National Information Standards Organization

National Soft Drink Association

National Wooden Pallet and Container Association

Optical Product code Council

Packaging Machinery Manufacturers Institute

Paperboard Packaging Council

Postal Service

Pressure Sensitive Tape Council

Printing Industries of America

Steel Shipping Container Institute

Technical Association of the Pulp and Paper Institute

Uniform code Council

\section{PHOTOGRAPHY}

American National Standards Institute

American Society for Photogrammetry and Remote Sensing

Association for Information and Image Management, International

National Archives and Records Service (GSA)

National Association of Photographic Manufacturers

Optical Society of America

Photographic Society of America

Society of Motion Picture and Television Engineers

\section{PLUNBING}

American Pipe Fittings Association

American Society for Testing and Materials

American Society of Electroplated Plastics

American Society of Mechanical Engineers

American Society of Plumbing Engineers

Building Officials and Code Administrators International

Cast Iron Soil Pipe Institute

Council of American Building Officials

Ductile Iron Pipe Research Association

International Association of Plumbing and Mechanical Officials

International Cast Polymer Association

International Conference of Building Officials

Manufacturers Standardization Society of the Valve and Fittings Industry Mechanical Contractors Association of America

National Association of Plumbing-Heating-Cooling Contractors 
National Certified Pipe welding Bureau

National Clay Pipe Institute

National Conference of States on Building codes and standards National Spa and Pool Institute

NSF International

Plastics Pipe Institute

Plumbing and Drainage Institute

Recreation Vehicle Industry Association

Society of Sanitary Engineering

Southern Building Code Congress International

Sump and Sewage Pump Manufacturers Association

Valve Manufacturers Association of America

Veterans Affairs, Department of

water Quality Association

water Systems Council

\section{PUBLIC HEALTH}

Accrediting Bureau of Health Education Schools

American Academy of Pediatrics

American Association of Blood Banks

American Conference of Governmental Industrial Hygienists

American Industrial Hygiene Association

American Medical Association

American Occupational Medical Association

American Optometric Association

American Public Health Association

American Society for Testing and Materials

American Thoracic Society

American Water Works Association

AOAC International

Center for Disease Control (HHS)

Entomological Society of America

Environmental Industry Association

Food and Drug Administration (HHS)

Health Care Financing Administration (HHS)

Health Physics Society

Illuminating Engineering Society of North America

National Association of Plumbing-Heating-Cooling Contractors

National Automatic Merchandising Association

National Institute of Infant Services

National Pest Control Association

NCCLS - The Clinical Laboratory Standards Organization

NSF International

Portable Sanitation Association

Prevent Blindness America

Snell Memorial Foundation

Society of Sanitary Engineering

Textile Rental Services Association of America

U.S. Geological Survey (Interior)

water Quality Association 
ACIL Aerospace Industries Association of America American Association for Clinical Chemistry American Association for Laboratory Accreditation American Association of Textile Chemists and Colorists American Chemical Society American Crystallographic Association American Dairy Products Institute American Hospital Association American Insurance Services Group American Leather Chemists Association American National Standards Institute American oil Chemists Society American Society for Clinical Laboratory Science American Society for Non-Destructive Testing American Society for Quality Control American Society for Testing and Materials American Society of Brewing Chemists American Society of Mechanical Engineers American Statistical Association AOAC International Association of Official seed Analysts Automated Imaging Association Biological Stain Commission Bureau of Alcohol, Tobacco and Firearms (Treasury) College of American Pathologists Construction Industry Manufacturers Association Cosmetic, Toiletry and Fragrance Association Factory Mutual Research Corporation Gemological Institute of America Inchcape Testing Services Institute of Electrical and Electronics Engineers Institute of Environmental Sciences Institute of Nuclear Materials Management Inter-Society Color Council

International Electrical Testing Association Mine Safety and Health Administration (I,abor) National Association of Photographic Manufacturers National Conference of States on Building Codes and Standards National Environmental Balancing Bureau

National Fenestration Rating Council National Fire Protection Association National Institute of Standards and Technology (Commerce) National Oak Flooring Manufacturers Association National Pest Control Association NCCLS - The Clinical Laboratory Standards Organization office of Acquisition (GSA) Portland Cement Association Radio Technical Commission for Aeronautics SGS - United States Testing Company Sheet Metal and Air Conditioner Contractors National Association Society for Experimental Mechanics 
Society of Automotive Engineers

Solar Rating and Certification Corporation

Southwest Research Institute

Toy Manufacturers of America

Underwriters Laboratories

United states Customs Service (Treasury)

\title{
RECREATION AND SPORTS
}

American Alliance for Health, Physical Education, Recreation and Dance American Automobile Association

American Boat and Yacht Council

American Bowling Congress

American Society for Testing and Materials

American Sport Fishing Association

Billiard Congress of America

Color Association of the United States

National Association of Rocketry

National Federation of State High School Associations

National Golf Car Manufacturers Association

National Model Railroad Association

National Rifle Association of America

National Ski Areas Association

Prevent Blindness America

Recreation Vehicle Industry Association

SFI Foundation

Snell Memorial Foundation

Snowmobile safety and Certification Committee

Sporting Arms and Ammunition Manufacturers Institute

Sports Car club of America

U.S. Tennis Court and Track Builders Association

Underwriters Laboratories

United States Coast Guard (DOT)

United States Golf Association

\section{SARTY TITEE PROTECTION AND PUBLIC SAFETY}

\author{
Alliance of American Insurers \\ American Association of Motor Vehicle Administrators \\ American Automobile Association \\ American Boat and Yacht Council \\ American Brush Manufacturers Association \\ American Bureau of Shipping \\ American Bus Association \\ American Conference of Governmental Industrial Hygienists \\ American Fiber Manufacturers Association \\ American Foundrymen's Society \\ American Hospital Association \\ American Hotel and Motel Association \\ American Industrial Hygiene Association \\ American Insurance Services Group \\ American Ladder Institute
}


American National Standards Institute

American Nuclear Society

American Petroleum Institute

American Society for Testing and Materials

American Society of Agricultural Engineers

American Society of Civil Engineers

American Society of Mechanical Engineers

American Society of Safety Engineers

American Textile Machirery Association

American Textile Manufacturers Institute

American welding Society

AOAC International

Art and Creative Materials Institute

Asbestos Information Association North America

Associated Locksmiths of America

Association for the Advancement of Medical Instrumentation

Association of American Railroads

Association of Home Appliance Manufacturers

Building Officials and Code Administrators International

Building Technologies (DOE)

Center for Disease Control (HHS)

Chemical Specialties Manufacturers Association

Chlorine Institute

Coated Abrasives Manufacturers Institute

Compressed Gas Association

Compressed Air and Gas Institute

Concrete Sawing and Drilling Association

Construction Industry Manufacturers Association

Consumer Product Safety Commission

Cordage Institute

Council of American Building Officials

Dairy and Food Industries Supply Association

Department of Transportation

Diamond Wheel Manufacturers Institute

Distilled Spirits Council of the United States

Environment, Safety and Health (DOE)

Factory Mutual Research Corporation

Federal Aviation Administration (DOT)

Federal Highway Administration (DOT)

Flight Safety Foundation

Food and Drug Administration (HHS)

Grinding Wheel Institute

Helicopter Association International

Human Factors Society

Industrial Fabrics Association International

Industrial Safety Equipment Association

Institute of Electrical and Electronics Engineers

Institute of Makers of Explosives

Institute of Nuclear Materials Management

Institute of Transportation Engineers

International Association of Electrical Inspectors

International Association of Plumbing and Mechanical officials

International Conference of Building officials

International Electrical Testing Association 
International Fabricare Institute

International Municipal Signal Association

International sleep Products Association

International Society of Arborculture

Laborers International Union of North America

Laser Institute of America

Lightning Protection Institute

Masonry and Concrete Saw Manufacturers Institute

Mechanical Contractors Association of America

Mine Safety and Health Administration (Labor)

Minerals Management Service (Interior)

National Arborist Association

National Association of Plumbing-Heating-Cooling Contractors

National Board of Boiler and Pressure Vessel Inspectors

National Conference of States on Building Codes and Standards

National Coordinating Council on Emergency Management

National Cotton Council of America

National Council on Radiation Protection and Measurements

National Electrical Manufacturers Association

National Elevator Industry

National Federation of State High School Associations

National Fire Protection Association

National Fire Sprinkler Association

National Institute of Standards and Technology (Commerce)

National Insurance Crime Bureau

National Propane Gas Association

National Rifle Association of America

National Safety Council

National Ski Areas Association

National Spa and Pool Institute

NCCLS - The Clinical Laboratory Standards Organization

Nuclear Regulatory Commission

Occupational Safety and Health Administration (Labor)

Painting and Decorating Contractors of America

Portland Cement Association

Powder Actuated Tool Manufacturers Institute

Prevent Blindness America

Printing and Decorating Contractors of America

Public Buildings Service (GSA)

Radio Technical Commission for Maritime Services

Recreation Vehicle Industry Association

Robotic Industries Association

Scaffolding, Shoring and Forming Institute

Security Industry Association

Sheet Metal and Air Conditioner Contractors National Association

Snell Memorial Foundation

Snowmobile Safety and Certification Committee

Society of Fire Protection Engineers

Society of Naval Architects and Marine Engineers

Southern Building Code Congress International

Sporting Arms and Ammunition Manufacturers Institute

Toy Manufacturers of America

Underwriters Laboratories

United Lightning Protection Association 
Veterans Affairs, Department of

Wood Machinery Manufacturers of America

\section{SANITATION}

American Association of Cereal Chemists

American Dairy Products Institute

American Public Health Association

American Society of Plumbing Engineers

American Water Works Association

AOAC International

Baking Industry Sanitation Standards Committee

Cast Iron Soil Pipe Institute

Dairy and Food Industries Supply Association

Environmental Industry Association

Environmental Protection Agency

Housing and Urban Development, Department of

National Association of Photographic Manufacturers

National Association of Plumbing-Heating-Cooling Contractors

National Automatic Merchandising Association

National Clay Pipe Institute

National Pest Control Association

National Spa and Pool Institute NSF International

Plumbing and Drainage Institute

Portable Sanitation Association

Society of Sanitary Engineering

Textile Rental Services Association of America

Water Pollution Control Federation

Water Quality Association

\section{SOCIAL WELFARE}

American Association of Poison Control Centers

American Association of Psychiatric Services for Children

National Library Service for the Blind and Physically Handicapped (Library

National Safety Council

Prevent Blindness America

Public Buildings Service (GSA)

Snell Memorial Foundation

Standards Engineering Society

United States Council for International Business

\section{TEXTILE AND CLOTHING}

American Association of Textile Chemists and Colorists American Fiber Manufacturers Association American Furniture Manufacturers Association American Society for Testing and Materials American Textile Machinery Association 
American Textile Manufacturers Institute

Association of Nonwoven Fabrics Industry

Chemical Fabrics and Film Association

Color Association of the United States

Consumer Product Safety Commission

Cordage Institute

Department of Defense

Elastic Fabric Manufacturers Council of Northern Textile Association

Felt Manufacturers Council of Northern Textile Association

Industrial Fabrics Association International

Industrial Safety Equipment Association

Institute of Environmental Sciences

International Fabricare Institute

Multi-Housing Laundry Association

National Association of Hosiery Manufacturers

National Cotton Council of America

Secondary Materials and Recycled Textiles

SGS - United States Testing Company

Textile Rental Services Association of America

\section{TRANSPORTATION}

Aeronautical Radio, Incorporated

Aerospace Industries Association of America

Air Transport Association of America

Aircraft Owners and Pilots Association

American Association of Motor Vehicle Administrators

American Association of State Highway and Transportation Officials

American Automobile Association

American Automobile Manufacturers Association of the United States

American Boat and Yacht Council

American Bureau of Shipping

American Bus Association

American Forest and Paper Association

American Helicopter Society

American Institute of Aeronautics and Astronautics

American Petroleum Institute

American Railway Engineering Association

American Road and Transportation Builders Association

American Society for Testing and Materials

American Society of Mechanical Engineers

Asphalt Institute

Association of American Railroads

Automotive Industry Action Group

Automotive Lift Institute

Certified Automotive Parts Association

Compressed Gas Association

Containerization and Intermodal Institute

Department of Transportation

Federal Aviation Administration (DOT)

Federal Highway Administration (DOT)

Flight Safety Foundation

General Aviation Manufacturers Association 
Helicopter Association International

Industrial Fabrics Association International

Institute of Nuclear Materials Management

Institute of Transportation Engineers

International Bridge, Tunnel and Turnpike Association

International Mobile Air Conditioning Association

Maritime Administration (DOT)

National Association of Chain Manufacturers

National Association of County Engineers

National Cargo Bureau

National Institute of Standards and Technology (Commerce)

National Insurance Crime Bureau

National Tire Dealers and Retreaders Association

National Wood Pallet and Container Association

Occupational Safety and Health Administration (Labor)

Railway Tie Association

Recreation Vehicle Industry Association

SFI Foundation

Snell Memorial Foundation

Society of Allied Weight Engineers

Society of Automotive Engineers

Society of Naval Architects and Marine Engineers

Steel Shipping Container Institute

Tire and Rim Association

Truck Trailer Manufacturers Association

Uniform code Council

United States Council for Automotive Research

\section{WOOD AND WOOD BRODUCTS}

Alliance for Telecommunications Industry Solutions

American Forest and Paper Association

American Hardboard Association

American Institute of Timber Construction

American Ladder Institute

American Laminators Association

American Lumber Standards Committee

American Society for Testing and Materials

American Wood-Preservers Association

American wood Preservers Bureau

Architectural Woodwork Institute

Cedar Shake and Shingle Bureau

Engineered Wood Association

FACTS Institute for Research, Standards, and Terminology

Hardwood Plywood and Veneer Manufacturers Association

Housing and Urban Development, Department of

National Association of Store Fixture Manufacturers

National Bark and Soil Producers Association

National Dimension Manufacturers Association

National Oak Flooring Manufacturers Association

National Particleboard Association

National Sash and Door Jobbers Association

National Wood Pallet and Container Association 
National Wood Window and Door Association

Northeastern Lumber Manufacturers Association

Railway Tie Association

Redwood Inspection Service

Southern Cypress Manufacturers Association

Southern Forest Producers Association

Southern Pine Inspection Bureau

Technical Association of the Pulp and Paper Industry

Truss Plate Institute

West Coast Lumber Inspection Bureau

Western wood Products Association

wood Machinery Manufacturers of America

wood Moulding and Millwork Producers Association

Woodwork Institute of California 


\subsection{ACRONYMS AND INITIALS}

This list of acronyms and initials serves to identify organizations, however, there is no exclusivity: there are four NFPA's, three AIA's and other duplications.

AA Aluminum Association

AAA

American Automobile Association

AAAA

American Association of Advertising Agencies

$A A B B$

American Association of Blood Banks

$A A B C$

Associated Air Balance Council

AACC

American Association for Clinical Chemistry

AACC

American Association of Cereal Chemists

$A A C P$

Association of Asbestos Cement Pipe Producers

AAFCO

Association of American Feed Control officials

AAHPERD

AAI American Alliance for Health, Physical Education, Recreation and Dance

AAMA

Alliance of American Insurers

AAMA

AAMI

AAMVA

AAN

AAP

AAP

AAPCC

AAPFCO

American Architectural Manufacturers Association

AAPSC

AAR

AARC

American Automobile Manufacturers Association of the United

States

AASHTO

Association for the Advancement of Medical Instrumentation

American Association of Motor Vehicle Adminstrators

American Association of Nurserymen

American Academy of Pediatrics

Association of American Publishers

American Association of Poison Control Centers

Association of American Plant Food Control officials

American Association of Psychiatric Services for Children

Association of American Railroads

American Association for Respiratory Care

American Association of State Highway and Transportation

officials

AATCC

$A B A$

$A B A$

$A B C$

ABFLO

ABHES

ABMA

ABMA

ABMA

ABS

$A B Y C$

$A C A$

American Association of Textile Chemists and Colorists

American Bus Association

Blue Anchor

American Bowling Congress

Association of Bedding and Furniture Law Officials

Accrediting Bureau of Health Education Schools

American Bearing Manufacturers Association

American Boiler Manufacturers Association

American Brush Manufacturers Association

American Bureau of Shipping

American Boat and Yacht Council

American Chain Association

$A C A$

ACCA

ACGIH

ACI

ACIL

ACM

ACMI

American Crystallographic Association

Air Conditioning Contractors of America

American Conference of Governmental Industrial Hygienists

American Concrete Institute

American Council of Independent Laboratories

Association for Computing Machinery

Art and Creative Materials Institute

ACPA

American Concrete Pavement Association

ACPA

American Concrete Pipe Association 
ACPPA

ACS

ACS

ACSM

ACTS

$A D A$

$A D D A$

$A D I$

$A D P A$

ADPI

AEG

AEIC

AEMA

AER

AES

AESF

AFA

AFMA

AFMA

AFPA

AFS

AGA

AGA

AGA

AGCA

AGMA

AHA

$\mathrm{AHA}$

AHAM

AHEFO

AH\&MA

AHS

AI

AIA

AIA

AIA

AIAA

AIAG

AIAG

$\mathrm{AIA} / \mathrm{NA}$

AIHA

AIIM

AIM

AIP

AISC

AISE

AISG

AISI

AITC

ALA

ALA

ALA

ALA

American Concrete Pressure Pipe Association

American Chemical society

American college of Surgeons

American Congress on Surveying and Mapping

Advisory Commission on Textbook Specifications

American Dental Association

American Design Drafting Association

Air Distribution Institute

American Defense Preparedness Association

American Dairy Products Institute

Association of Engineering Geologists

Association of Edison Illuminating Companies

Asphalt Emulsion Manufacturers Association

Association for Education and Rehabilitation of the Blind and

Visually Impaired

American Electroencephalographic Society

American Electroplaters and Surface Finishers Society

American Fence Association

American Fiber Manufacturers Association

American Furniture Manufacturers Association

American Forest and Paper Association

American Foundrymen's Society

Abrasive Grain Association

American Galvanizers Association

American Gas Association

Associated General Contractors of America

American Gear Manufacturers Association

American Hardboard Association

American Hospital Association

Association of Home Appliance Manufacturers

Association of Higher Education Facilities officers

American Hotel and Motel Association

American Helicopter Society

Asphalt Institute

Aerospace Industries Association of America

American Institute of Architects

Automated Imaging Association

American Institute of Aeronautics and Astronautics

American Insurance Service Group

Automotive Industry Action Group

Asbestos Information Association North America

American Industrial Hygiene Association

Association for Information and Image Management, International AIM USA

American Institute of Physics

American Institute of steel construction

Association of Iron and Steel Engineers

American Insurance Services Group

American Iron and Steel Institute

American Institute of Timber construction

American Laminators Association

American Library Association

American Lighting Association

Associated Locksmiths of America 
ALCA

ALI

ALI

ALSC

AMA

AMA

AMCA

AMRA

AMS

AMT

ANF I

ANMC

ANS

ANSI

$A O A$

$A O A C$

AOCS

AOMA

AOPA

AOSA

AOSCA

APA

APA

APFA

APhA

APHA

API

$A R A$

AREA

ARI

ARINC

ARMA

ARMA

ARPI

ARTBA

ASA

ASA

ASA

ASA

ASAE

ASAIO

ASBC

ASBE

ASC

ASCE

ASCLS

ASEP

ASEV

ASFA

ASHA

ASHRAE

ASME

ASNT

American Leather Chemists Association

American Ladder Institute

Automotive Lift Institute

American Lumber Standards Committee

Adhesives Manufacturers Association

American Medical Association

Air Movement and Control Association

Automatic Meter Reading Association

Agriculture Marketing Service (USDA)

The Association for Manufacturing Technology

Association of Nonwoven Fabrics Industry

American National Metric Council

American Nuclear Society

American National Standards Institute

American optometric Association

AOAC, International

American oil Chemists society

American Occupational Medical Association

Aircraft Owners and Pilots Association

Association of Official seed Analysts

Association of Official seed Certifying Agencies

American Psychiatric Association

American Psychoanalytical Association

American Pipe Fittings Association

American Pharmaceutical Association

American Public Health Association

American Petroleum Institute

Agriculture Retailers Association

American Railway Engineering Association

Air-Conditioning and Refrigeration Institute

Aeronautical Radio, Incorporated

Asphalt Roofing Manufacturers Association

Association of Records Managers and Administrators

Automotive Refrigeration Products Institute

American Road and Transportation Builders Association

Acoustical Society of America

American Society of Anesthesiologists

American Soybean Association

American Statistical Association

American Society of Agricultural Engineers

American Society for Artificial Internal Organs

American Society of Brewing Chemists

American Society of Bakery Engineers

Accredited Standards Committee X9-Financial Services

American Society of Civil Engineers

American Society for Clinical Laboratory Science

American Society of Electroplated Plastics

American Society for Enology and Viticulture

American Sport Fishing Association

American Speech-Language and Hearing Association

American Society of Heating, Refrigerating and Air Conditioning Engineers

American Society of Mechanical Engineers

American Society for Non-Destructive Testing 

Technologies

BT

CABO

CAGI

CAMI

CAMI

CAP

CAPA

CAUS

CBM

CCPA

American Walnut Manufacturers Association

American Wire Producers Association

American Wood-Preservers Association

American Wood Preservers Bureau

American welding Society

American Water Works Association

American Association for Laboratory Accreditation

Bureau of Alcohol, Tobacco, and Firearms (Treasury)

Brass and Bronze Ingot Manufacturers

Bureau of Census (Commerce)

Billiard Congress of America

Battery Council International

Bellcore

Builders Hardware Manufacturers Association

Binding Industries of America

Brick Institute of America

Business and Institutional Furniture Manufacturers

Association

Book Industry study Group

Baking Industry Sanitation standards Committee

Book Manufacturers Institute

Building Officials and code Administrators International

Building Owners and Management Association International

Biological Stain Commission

Building Technologies (DOE)

Council of American Building Officials

Compressed Air and Gas Institute

Coated Abrasives Manufacturers Institute

Consortium for Advanced Manufacturing International

College of American Pathologists

Certified Automotive Parts Association

Color Association of the United States

Certified Ballast Manufacturers

Cemented Carbide Producers Association 
Composite Can and Tube Institute

Copper Development Association

Center for Disease Control (HHS)

Cleaning Equipment Trade Association

Consumer Federation of America

Chemical Fabrics and Film Association

Compressed Gas Association

Chlorine Institute

Cordage Institute

Containerization and Intermodal Institute

Construction Industry Manufacturers Association

Ceiling and Interior Systems Construction Association

Cast Iron Soil Pipe Institute

Chain Link Fence Manufacturers Institute

Chemical Manufacturers Association

Cookware Manufacturers Association

Can Manufacturers Institute

Corporation for Open Systems International

Contractors Pump Bureau

Concrete Plant Manufacturers Bureau

Consumer Product Safety Commission

Corn Refiners Association

Carpet and Rug Institute

Commercial Refrigerator Manufacturers Association

Concrete Reinforcing steel Institute

Collection Services (LC)

CSDA

CSI

Concrete Sawing and Drilling Association

Construction Specifications Institute

CSMA

CSSB

CTFA

CTI

CWAA

DFAC

DFISA

$\mathrm{DHI}$

DIPRA

DISA

DISA

Chemical Specialties Manufacturers Association

Cedar Shake and Shingle Bureau

Cosmetic, Toiletry and Fragrance Association

Cooling Tower Institute

Cotton Warehouse Association of America

DFA of California

Dairy and Food Industries Supply Association

Door and Hardware Institute

Ductile Iron Pipe Research Association

Data Interchange Standards Association

Defense Information Systems Agency (DOD)

DORCMA

$\mathrm{DP}$

DPMA

DSCUS

DWG

DWMI

EASA

EDA

EEI

EFMC

EGSA

EIA

EIA

Door Operator and Remote Controls Manufacturers Association

Defense Program, Assistant Secretary (DOE)

Data Processing Management Association

Distilled Spirits Council of the United States

Diamond Walnut Growers

Diamond Wheel Manufacturers Institute

Electrical Apparatus Service Association

Electrostatic Discharge Association

Edison Electric Institute

Elastic Fabric Manufacturers Council of Northern Textile Association

Electrical Generating Systems Association

Electronic Industries Association

Energy Information Administration (DOE) 
EIA

EJMA

EMI

EMRC

EPA

ESA

ESCSI

$\mathrm{ESH}$

ETI

EWA

FAA

FACTS

FAF

FAS

FBA

FCC

FCI

FCM

FDA

FGDC

FHA

FIA

FMC

FMRC

FMSI

FPA

FPMSA

FS

FSA

FSF

FSIS

FTC

GA

GAA

GAMA

GAMA

GANA

GCA

GI

GIA

GIPSA

GPA

GPI

GWI

HAA

HAI

HBSMAA

HCFA

HEI

HFS

HI

HI

HI

Environmental Industry Association

Expansion Joint Manufacturers Association

Equipment Manufacturers Institute

Electronic Media Rating Council

Environmental Protection Agency

Entomological Society of America

Expanded Shale, Clay and Slate Institute

Environment, Safety, and Health (DOE)

Equipment and Tool Institute

APA The Engineered Wood Association

Federal Aviation Administration (DOT)

FACTS Institute for Research, Standards and Terminology

Financial Accounting Foundation

Foreign Agricultural Service (USDA)

Fibre Box Association

Federal Communications Commission

Fluid Controls Institute

Federal Coordinator for Metrology (Commerce)

Food and Drug Administration (HHS)

Federal Geographic Data Committee (DI)

Federal Highway Administration (DOT)

Forging Industry Association

Felt Manufacturers Council of Northern Textile Association

Factory Mutual Research Corporation

Friction Materials Standards Institute

Flexible Packaging Association

Food Processing Machinery and Supplies Association

Forest Service (USDA)

Fluid Sealing Association

Flight Safety Foundation

Food Safety and Inspection Service (USDA)

Federal Trade Commission

Gypsum Association

Gravure Association of America

Gas Appliance Manufacturers Association

General Aviation Manufacturers Association

Glass Association of North America

Graphic Communications Association

Gold Institute

Gemological Institute of America

Grain Inspection, Packers and Stockyard Administration (USDA)

Gas Processors Association

Glass Packaging Institute

Grinding wheel Institute

Home Automation Association

Helicopter Association International

Hack and Band Saw Manufacturers Association of America

Health Care Financing Administration (HHS)

Heat Exchance Institute

Human Factors Society

Hair International

Hydraulic Institute

Hydronics Institute 
HIBCC HIMA

HLS

HPS

HPVMA

HTI

HUD

HVI

IA

IAEI

IAPMO

IBEW

IBTTA

ICA

ICAC

ICBO

ICC

ICDD

ICEA

ICIA

ICM

ICMA

ICPA

IDAA

IDEA

IEEE

IES

IES

IETA

IFAC

IFAI

IFI

IFI

IIA

IIAR

IIE

IIPEC

ILIA

IMACA

IME

IMI

IMSA

INMM

IPA

IRI

IRM

IRM

IRS

IS

ISA

ISA
Health Industry Business Communications Council

Health Industry Manufacturers Association

Health Level Seven

Health Physics Society

Hardwood Plywood and Veneer Manufacturers Association

Hand Tools Institute

Housing and Urban Development, Department of

Home Ventilating Institute

Irrigation Association

International Association of Electrical Inspectors

International Association of Plumbing and Mechanical

officials

International Brotherhood of Electrical Workers

International Bridge, Tunnel and Turnpike Association

International Cadmium Association

Institute of Clean Air Companies

International Conference of Building officials

Inter-society Color Council

International Centre for Diffraction Data

Insulated Cable Engineers Association

International Communications Industries Association

Institute of Caster Manufacturers

International City Management Association

International Cast Polymer Association

Industrial Diamond Association of America

International District Energy Association

Institute of Electrical and Electronics Engineers

Illuminating Engineering Society of North America

Institute of Environmental Sciences

International Electrical Testing Association

Industry Functional Advisory Committee on Standards Trade Policy Matters (Commerce)

Industrial Fabrics Association International

Industrial Fasteners Institute

International Fabricare Institute

The Institute of Internal Auditors

International Institute of Ammonia Refrigeration

Institute of Industrial Engineers

Institute for Interconnecting and Packaging Electronic

Circuits

Indiana Limestone Institute of America

International Mobile Air Conditioning Association

Institute of Makers of Explosives

International Masonry Institute

International Municipal Signal Association

Institute of Nuclear Materials Management

Industrial Perforators Association

Industrial Risk Insurers

Information Resources Management (GSA)

Information Resource Management (USDA)

Internal Revenue Service (Treasury)

Internet Society

International Society of Arborculture

ISA, the International Society for Measurement and Control 
ISDSI

ISEA

ISNTA

ISPA

ISTA

ITA

ITA

ITA

ITE

ITI

ITS

ITS

JCP

JNCDD

JPMA

JVC

LBI

LIA

LIA

LIUNA

LPI

MA

MBMA

MCAA

MCSMI

$\mathrm{MDA}$

MHI

MHI

MIA

MJSA

MLA

MLMA

MMA

MIPA

MMS

MMSA

MPIF

MPTA

MSHA

MSSVFI

MTI

NAA

NAAMM

NAB

NACE

NACEI

NACHA

NACM

NADCA

NADCA

NAGDM

NAGPIM
Insulated Steel Door Systems Institute

Industrial safety Equipment Association

International staple, Nail and Tool Association

International sleep Products Association

International Safe Transit Association

Industrial Truck Association

International Trade Administration (Commerce)

ITA, The International Recording Media Association

Institute of Transportation Engineers

Information Technology Industry Council

Inchcape Testing Services/ETL Testing Laboratories

Information Technology Services (LC)

Joint Committee on Printing (Congress of the United States)

Joint Neurosurgical Committee on Devices and Drugs

Juvenile Products Manufacturers Association

Jewelers Vigilance Committee

Library Binding Institute

Laser Institute of America

Lead Industries Association

Laborers International Union of North America

Lightning Protection Institute

Maritime Administration (DOT)

Metal Building Manufacturers Association

Mechanical Contractors Association of America

Masonry and Concrete Saw Manufacturers Institute

Marking Device Association

Manufactured Housing Institute

Material Handling Industry

Marble Institute of America

Manufacturing Jewelers and Silversmiths of America

Multi-housing Laundry Association

Metal Ladder Manufacturers Association

Monorail Manufacturers Association

Magnetic Materials Producers Association

Mineral Management Service (DI)

Materials and Methods Standards Association

Metal Powder Industries Federation

Mechanical Power Transmission Association

Mine Safety and Health Administration (DOL)

Manufacturers Standardization Society of the Valve and

Fittings Industry

Metal Treating Institute

National Arborist Association

National Association of Architectural Metal Manufacturer

National Association of Broadcasters

National Association of County Engineers

NACE International

National Automated Clearing House Association

National Association of Chain Manufacturers

National Air Duct Cleaners Association

North American Die Casting Association

National Association of Garage Door Manufacturers

National Association of Graphic and Product Identification Manufacturers 
NAHM

NAIMA

NAIOP

NAJA

NAMA

NAMO

NAPCA

NAPHCC

NAPM

NAPM

NAPM

NAR

NARA

NARM

NASFM

NASTA

NBBPVI

NBGQA

NBSPA

NCA

NCB

NCCA

NCCA

NCCEM

NCCLS

NCL

NCMA

NCPA

NCPDP

NCPI

NCPMA

NCPWB

NCRPM

NCSBCS

NCSPA

NDMA

NEBB

NECA

NEI

NEMA

NFAIS

NFDA

NFI

NFPA

NFPA

NFPA

NFPA

NFRC

NFSA

NFSHSA

NGCMA

NGWA

NHLA
National Association of Hosiery Manufacturers

North American Insulation Manufactures Association

National Association of Industrial and Office Properties

National Association of Jewelry Appraisers

National Automatic Merchandising Association

National Association of Manufacturing Opticians

National Association of Pipe Coating Applicators

National Association of Plumbing-Heating-Cooling Contractors

National Association of Photographic Manufacturers

National Association of Punch Manufacturers

National Association of Purchasing Management

National Association of Rocketry

National Archives and Records Administration (GSA)

National Association of Relay Manufacturers

National Association of Store Fixture Manufacturers

National Association of State Textbook Administrators

National Board of Boiler and Pressure Vessel Inspectors

National Building Granite Quarries Association

National Bark and Soil Producers Association

National Coffee Association of the USA

National Cargo Bureau

National Coil Coaters Association

National Cotton Council of America

National Coordinating council on Emergency Management

NCCLS-The Clinical Laboratory Standards Organization

National Civic League

National Concrete Masonry Association

National Cottonseed Products Association

National council for Prescription Drug Program

National Clay Pipe Institute

National Clay Pot Manufacturers Association

National Certified Pipe Welding Bureau

National Council on Radiation Protection and Measurements

National Conference of States on Building Codes and

Standards

National Corrugated Steel Pipe Association

National Dimension Manufacturers Association

National Environmental Balancing Bureau

National Electrical Contractors Association

National Elevator Industry

National Electrical Manufacturers Association

National Federation of Abstracting and Information Services

National Fastener Distributors Association

National Fisheries Institute

National Fire Protection Association

National Fluid Power Association

National Food Processors Association

National Forest Products Association

National Fenestration Rating Council

National Fire Sprinkler Association

National Federation of State High School Associations

National Golf Car Manufacturers Association

National Ground water Association

National Hardwood Lumber Association 
NHTSA

NIBS

NICB

NIIS

NIJ

NIOP

NISO

NIST

NKBA

NLA

NLGI

NLMA

NLS

NMEA

NMF

NMFS

NMRA

NOAA

NOFMA

NOPA

NPA

NPCA

NPGA

NPIRI

NPL

NRA

NRCA

NRDCA

NRF

NRR

NSA

NSAA

NSC

NSDA

NSDJA

NSEA

NSF

NSPI

NSSEA

NTDRA

NTIA

N'TMA

NWPCA

NWWDA

$\mathrm{OA}$

OAMM

OASD

OCE

OLA

OPCC

OPEI

OSA

National Highway Traffic Safety Administration (DOT)

National Institute of Building sciences

National Insurance Crime Bureau

National Institute of Infant Services

National Institute of Justice (DOJ)

National Institute of Oilseed Products

National Information Standards Organization

National Institute of Standards and Technology (Commerce)

National Kitchen and Bath Association

National Lime Association

National Lubricating Grease Institute

Northeastern Lumber Manufacturers Association

National Library Service for the Blind and Physically

Handicapped (LC)

National Marine Electronics Association

Network Management Forum

National Marine Fisheries Service (Commerce)

National Model Railroad Association

National Oceanic and Atmospheric Administration (Commerce)

National Oak Flooring Manufacturers Association

National Oilseed Processors Association

National Particleboard Association

National Pest Control Association

National Propane Gas Association

National Printing Ink Research Institute

Nebraska Power Laboratory

National Rifle Association of America

National Roofing Contractors Association

National Roof Deck Contractors Association

National Retail Federation

Nuclear Regulatory Research (NRC)

National Stone Association

National Ski Areas Association

National Safety Council

National Soft Drink Association

National Sash and Door Jobbers Association

National Standards Educators Association

NSF International

National spa and Pool Institute

National School Supply and Equipment Association

National Tire Dealers and Retreaders Association

National Telecommunication and Information Administration

(Commerce)

National Terrazzo and Mosaic Association

National Wooden Pallet and Container Association

National Wood Window and Door Association

office of Acquisition (GSA)

Office of Acquisition and Material Management (Veterans)

Office of the Assistant Secretary of Defense (DOD)

Office of Chief Engineer (NASA)

Optical Laboratories Association

Optical Product Code Council

Outdoor Power Equipment Institute

Optical Society of America 
OSC

OSHA

OSMA

OSMA

PATMI

PBA

PBS

PCA

PCMCIA

PDCA

PDI

PEI

PFI

PGMC

PI

PIA

PIPI

PLCA

PMA

PMI

PMMI

PPC

PPCI

PPEMA

PPI

PRMA

PS

PSA

PSA

PSTC

PSUS

PTI

RFCI

RI

RIA

RIAA

RIS

RMA

RMI

RSNA

RSPA

RTA

RTCA

RTCM

RUS

RVIA

RWMA

SAAMI

SAE

SAWE

SBCCI

SBMA

SCCA
Office of Space Communications (NASA)

Occupational Safety and Health Administration (DOL)

office of Safety and Mission Assurance (NASA)

Orthopedic Surgical Manufacturers Association

Powder Actuated Tool Manufacturers Institute

Prevent Blindness America

Public Building Service (GSA)

Portland Cement Association

Personal Computer Memory Card International Association

Painting and Decorating Contractors of America

Plumbing and Drainage Institute

Porcelain Enamel Institute

Pipe Fabrication Institute

Primary Glass Manufacturers Council

Perlite Institute

Printing Industries of America

Process Industry Practices Initiative

Pipe Line Contractors Association

Polyurethane Manufacturers Association

Project Management Institute

Packaging Machinery Manufacturers Institute

Paperboard Packaging Council

Precast/Prestressed Concrete Institute

Portable Power Equipment Manufacturers Association

Plastics Pipe Institute

Pharmaceutical Research and Manufacturers of America

Photoduplication Services (LC)

Photographic Society of America

Portable Sanitation Association

Pressure Sensitive Tape Council

Postal Services, U.S.

Post-Tensioning Institute

Resilient Floor Covering Institute

Refractories Institute

Robotic Industries Association

Recording Industry Association of America

Redwood Inspection Service

Rubber Manufacturers Association

Rack Manufacturers Institute

Radiological Society of North America

Research and Special Programs Administration (DOT)

Railway Tie Association

Radio Technical Commission for Aeronautics

Radio Technical Commission for Maritime Services

Rural Utilities Service (USDA)

Recreation Vehicle Industry Association

Resistance Welder Manufacturers Association

Sporting Arms and Ammunition Manufacturers Institute

Society of Automotive Engineers

Society of Allied Weight Engineers

Southern Building Code Congress International

steel Bar Mills Association

Sports Car Club of America 


\begin{tabular}{|c|c|}
\hline SCHHHP & $\begin{array}{l}\text { Standards Committee for Hi-Lok, Hi-Tigue and Hi-Lite } \\
\text { Products }\end{array}$ \\
\hline SCMA & Southern Cypress Manufacturers Association \\
\hline SCTE & Society of Cable Telecommunications Engineers \\
\hline SDI & Steel Deck Institute \\
\hline SDI & Steel Door Institute \\
\hline SEM & Society for Experimental Mechanics \\
\hline SEMI & Semiconductor Equipment and Materials Institute, International \\
\hline SES & Standards Engineering Society \\
\hline SFI & SFI Foundation Incorporated \\
\hline SFPA & Southern Forest Producers Association \\
\hline SFPE & Society of Fire Protection Engineers \\
\hline SFSA & Steel Founders Society of America \\
\hline SGS & SGS United States Testing Company \\
\hline SI & Salt Institute \\
\hline SI & Silver Institute \\
\hline SIA & Security Industry Association \\
\hline SIA & Ski Industries America \\
\hline SID & Society for Information Display \\
\hline SIGMA & Sealed Insulating Glass Manufacturers Association \\
\hline SJI & Steel Joist Institute \\
\hline SLA & Special Libraries Association \\
\hline SMA & Scale Manufacturers Association \\
\hline SMA & Screen Manufacturers Association \\
\hline SMA & Steel Manufacturers Association \\
\hline SMA & Stucco Manufacturers Association \\
\hline SMACNA & $\begin{array}{l}\text { Sheet Metal and Air Conditioning Contractors National } \\
\text { Association }\end{array}$ \\
\hline SMF & Snell Memorial Foundation \\
\hline SMMA & Small Motor Manufacturers Association \\
\hline SMPTE & Society of Motion Picture and Television Engineers \\
\hline SMRT & Secondary Materials and Recycled Textiles \\
\hline SNAME & Society of Naval Architects and Marine Engineers \\
\hline SOPI & Society of the Plastics Industry \\
\hline SPFA & Steel Plate Fabricators Association \\
\hline SPI & Society of the Plastics Industry \\
\hline SPIB & Southern Pine Inspection Bureau \\
\hline SPRI & Single Ply Roofing Institute \\
\hline SPSC & sleep Products Safety Council \\
\hline SRCC & Solar Rating and Certification Corporation \\
\hline SRI & Southwest Research Institute \\
\hline SSCC & Snowmobile Safety and Certification Committee \\
\hline SSCI & Steel Service Center Institute \\
\hline SSCI & Steel Shipping Container Institute \\
\hline SSE & Society of Sanitary Engineering \\
\hline SSFI & Scaffolding, shoring and Forming Institute \\
\hline SSPC & steel structures Painting council \\
\hline SSPMA & Sump and Sewage Pump Manufacturers Association \\
\hline STC & Society for Technical communication \\
\hline STI & Steel Tank Institute \\
\hline SWI & Steel window Institute \\
\hline $\mathrm{TAB}$ & Traffic Audit Bureau \\
\hline TAPPI & Technical Association of the Pulp and Paper Industry \\
\hline TCA & Tile Council of America \\
\hline
\end{tabular}


TRA

TRMI

TRSA

TSP

TTMA

UCC

UIA

UL

ULPA

USARF

USCAR

USCG

USCIB

USCS

USCTI

USGA

USGS

USHSLA

USITACS

USM

USMA

USP

USPRO

USPT

USTC\&TBA

USTR

VCMA

VITA

VMAA

VRCI

WASTEC

WCLIB

WIC

WMMA

WMMP

WPCF

WQA

WRI

WSC

WWPA
Technical Ceramics Manufacturers Association

Tubular Exchanger Manufacturers Association

Teleconmunications Industry Association

Toy Manufacturers of America

Truck Mixer Manufacturers Bureau

Tube and Pipe Association, International

Truss Plate Institute

Turfgrass Producers International

Tire and Rim Association

Tubular Rivet and Machine Institute

Textile Rental Services Association of America

Technical Standards Program Office (DOE)

Truck Trailer Manufacturers Association

Uniform code Council

Ultrasonic Industry Association

Underwriters Laboratories

United Lightning Protection Association

USA Rice Federation

United States Council for Automotive Research

United States coast Guard (DOT)

United States Council for International Business

U.S. Custom Service (Treasury)

United States Cutting Tool Institute

United States Golf Association

United states Geological Survey (DI)

United States Hide, Skin and Leather Association

United states International Telecommunications Advisory

Committee for Standardization (DOS)

U.S. Mint (Treasury)

United States Metric Association

United States Pharmacopeial Convention

United States Product Data Association

U.S. Patent and Trademark Office (Commerce)

United States Tennis Court and Track Builders Association

U.S. Trade Representative

Vacuum Cleaner Manufacturers Association

VMEBUS International Trade Association

Valve Manufacturers Association of America

Variable Resistive Components Institute

Waste Equipment Technology Association

West Coast Lumber Inspection Bureau

Woodwork Institute of California

Wood Machinery Manufacturers of America

Wood Moulding and Millwork Producers Association

Water Pollution Control Federation

water Quality Association

Wire Reinforcement Institute

Water Systems Council

Western Wood Products Association 


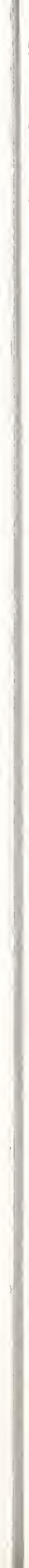




\subsection{FORMER NAMES OF LISTED ORGANIZATIONS}

American Bankers Association

now: Accredited Standards Committee X9

American Council of Independent Laboratories now: ACIL

American Fishing Tackle Manufacturers Association

now: American Sport Fishing Association

American Paper Institute

now: American Forest and Paper Association

American Plywood Association

now: Engineered Wood Association

American Society of Medical Technologists

now: American Society for Clinical Laboratory science

American Society of Sanitary Engineering

now: Society of Sanitary Engineering

American Sod Producers Association

now: Turfgrass Producers International

American walnut Association

now: American Walnut Manufacturers Association

Anti-Friction Bearing Manufacturers Association

now: American Bearing Manufacturers Association

Association of Official Analytical Chemists

now: AOAC International

Association of Physical Plant Administrators of Universities and Colleges now: Association of Higher Education Facilities officers

Automatic Identification Manufacturers

now: AIM USA

Cadmium Council

now: International Cadmium Association

Caster and Floor Truck Manufacturers Association

now: Institute of Caster Manufacturers

Center for Agriculture Equipment

now: Nebraska Power Laboratory

Cleaning Equipment Manufacturers Association

now: Cleaning Equipment Trade Association 
Computer Aided Manufacturing, International

now: Consortium for Advanced Manufacturing International

Computer and Business Equipment Manufacturers Association

now: Information Technology Industry Council

Cultured Marble Institute

now: International Cast Polymer Association

Equipment Manufacturers Institute

now: Environmental Industry Association

ETL Testing Laboratories

now: Inchcape Testing Services/ETL Testing Laboratories

Exchange Carriers Standards Association

now: Alliance For Telecommunications Industry Solutions

Farm and Industrial Equipment Institute

now: Equipment Manufacturers Institute

National Fertilizer Solutions

now: Agricultural Retailers Association

Glass Tempering Association

now: Glass Association of North America

Hardwood Plywood Manufacturers Association

now: Hardwood Plywood and Veneer Manufacturers Association

Industrial Gas cleaning Institute

now: Institute of Clean Air Companies

Instrument Society of America

now: ISA, The International Society for Measurement and Control

International Tape/Disc Association

now: ITA, The International Recording Media Association

International Association of Wiping Cloth Manufacturers now: Secondary Materials and Recycled Textiles

International District Heating and Cooling Association now: International District Energy Association

International Fence Industry Association now: American Fence Association

International Pipe Association now: Tube and Pipe Association, International

Mineral Insulation Manufacturers Association

now: North American Insulation Manufacturers Association 
Motor Vehicle Manufacturers Association

now: American Automobile Manufacturers Association of the United States

National Association of Corrosion Engineers

now: NACE International

National Association of Name Plate Manufacturers

now: National Association of Graphic and Product Identification Manufacturers

National Automobile Theft Bureau

now: National Insurance Crime Bureau

National Committee for Clinical Laboratory Standards

now: NCCL-The Clinical Laboratory Standards Organization

National Forest Products Association

now: American forest and Paper Association

National Retail Merchants Association

now: National Retail Federation

National Sanitation Foundation

now: NSF International

National Solid Wastes Management Associations

now: Environmental Industry Associations

National Water Well Association

now: National Ground Water Association

NMBTA-The Association for Manufacturing Technology

now: AMT-The Association for Manufacturing Technology

Rice Millers Association

now: USA Rice Federation 



\subsection{ORGANIZATIONS NO LONGER INVOLVED IN STANDARDIZATION}

Organizations that had developed standards or were listed in the 1991 Directory and that are

(a) no longer active in standardization;

(b) defunct or merged with another organization;

(c) cannot be located or would not respond.

Abrasive Engineering Society (a)

Aircraft Locknut Manufacturers Association (c)

American Association of Bioanalysts (a)

American Association of Petroleum Geologists (c)

American Feed Industry Association (a)

American Heart Association (c)

American Home Economics Association (c)

American Institute of Chemical Engineers (a)

American Paper Institute (b)

American Paper Machinery Association (a)

American Podiatric Medical Association (a)

American Public Works Association (a)

American Society of Cinematographers (a)

Animal Health International (c)

Archery Manufacturers and Merchants Organization (c)

Architectural Precast Association (c)

Association of Drilled Shaft Contractors (c)

Cellulose Insulation Manufacturers Association (a)

Computer software and Services Industry Association (a)

Decorative Laminate Products (c)

Deep Foundation Institute (c)

Dental Manufacturers of America (a)

Eastern Bird Banding Association (c)

Electronic Data Interchange Association (b)

Federation of Automated Coding Technologies (c)

Federation of Societies for Coatings Technologies (c)

Fertilizer Institute (a)

Fine Hardwood Veneer Association (a)

Grain Elevator and Processing Society (c)

Gummed Industries Association (b)

Hardwood Manufacturers Association (c)

International Cargo Gear Bureau (a)

International City Management Association (c)

International Coalition For Procurement Standards (b)

Investment Casting Institute (c)

Maple Floor Manufacturers Association (b)

Mo-Sai Institute (a)

MTM Association for Standards and Research (c)

Mumps Development Committee (c)

National Accreditation Council for Agencies Serving the Blind and

Visually Handicapped (a)

National Ass. of Hospital Purchasing Materials Management (b)

National Association of State Purchasing Officials (c)

National Burglar and Fire Alarm Association (c)

National Cable Television Association (c) 
National Computer Graphics Association (a)

National Easter Seal Society (c)

National Forest Products Association (b)

National Kerosene Heater Association (c)

National League for Nursing (c)

National office Products Association (a)

National operating Committee for Standards in Athletic Equipment (c)

National Slag Association (c)

National Solid Wastes Management Association (b)

National Wholesale Hardware Association (b)

Photo Chemical Machining Institute (c)

Safety Glazing certification council (c)

SPARC International (c)

Sponge and Chamois Institute (c)

Test Boring Association (c)

Thermal Insulation Manufacturers Association (b)

Tin Research Institute (c)

Trailer Hitch Manufacturers Association (b)

Tube Council of North America (a)

United Shipowners of America (b)

United States Telephone Association (c)

waste Equipment Manufacturers Association (b)

wood and Synthetic Flooring Institute (b)

wood Heating Alliance (a) 


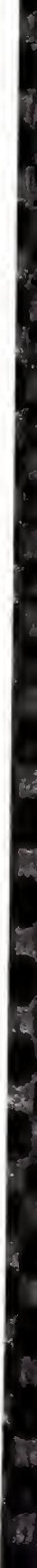





\section{NTST Technical Publications}

\section{Periodical}

Journal of Research of the National Institute of Standards and Technology—Reports NIST research and development in those disciplines of the physical and engineering sciences in which the Institute is active. These include physics, chemistry, engineering, mathematics, and computer sciences. Papers cover a broad range of subjects, with major emphasis on measurement methodology and the basic technology underlying standardization. Also included from time to time are survey articles on topics closely related to the Institute's technical and scientific programs. Issued six times a year.

\section{Nonperiodicals}

Monographs-Major contributions to the technical literature on various subjects related to the Institute's scientific and technical activities.

Handbooks-Recommended codes of engineering and industrial practice (including safety codes) developed in cooperation with interested industries, professional organizations, and regulatory bodies.

Special Publications-Include proceedings of conferences sponsored by NIST, NIST annual reports, and other special publications appropriate to this grouping such as wall charts, pocket cards, and bibliographies.

National Standard Reference Data Series-Provides quantitative data on the physical and chemical properties of materials, compiled from the world's literature and critically evaluated. Developed under a worldwide program coordinated by NIST under the authority of the National Standard Data Act (Public Law 90-396). NOTE: The Journal of Physical and Chemical Reference Data (JPCRD) is published bimonthly for NIST by the American Chemical Society (ACS) and the American Institute of Physics (AIP). Subscriptions, reprints, and supplements are available from ACS, 1155 Sixteenth St., NW, Washington, DC 20056.

Building Science Series-Disseminates technical information developed at the Institute on building materials, components, systems, and whole structures. The series presents research results, test methods, and performance criteria related to the structural and environmental functions and the durability and safety characteristics of building elements and systems.

Technical Notes-Studies or reports which are complete in themselves but restrictive in their treatment of a subject. Analogous to monographs but not so comprehensive in scope or definitive in treatment of the subject area. Often serve as a vehicle for final reports of work performed at NIST under the sponsorship of other government agencies.

Voluntary Product Standards-Developed under procedures published by the Department of Commerce in Part 10, Title 15, of the Code of Federal Regulations. The standards establish nationally recognized requirements for products, and provide all concerned interests with a basis for common understanding of the characteristics of the products. NIST administers this program in support of the efforts of private-sector standardizing organizations.

Order the following NIST publications_FIPS and NISTIRs—-from the National Technical Information Service, Springfield, VA 22161.

Federal Information Processing Standards Publications (FIPS PUB)-Publications in this series collectively constitute the Federal Information Processing Standards Register. The Register serves as the official source of information in the Federal Government regarding standards issued by NIST pursuant to the Federal Property and Administrative Services Act of 1949 as amended, Public Law 89-306 (79 Stat. 1127), and as implemented by Executive Order 11717 (38 FR 12315, dated May 11, 1973) and Part 6 of Title 15 CFR (Code of Federal Regulations).

NIST Interagency Reports (NISTIR)-A special series of interim or final reports on work performed by NIST for outside sponsors (both government and nongovernment). In general, initial distribution is handled by the sponsor; public distribution is by the National Technical Information Service, Springfield, VA 22161, in paper copy or microfiche form. 
